ESCUELA TÉCNICA SUPERIOR DE INGENIEROS INDUSTRIALES

\title{
THE POTENTIAL OF GAS SWITCHING CHEMICAL LOOPING TECHNOLOGY TO ELIMINATE THE ENERGY PENALTY OF $\mathrm{CO}_{2}$ CAPTURE
}

\author{
PhD. THESIS
}

\section{CARLOS RAFAEL ARNAIZ DEL POZO}

Chemical Engineer from Universidad Politécnica de Madrid.

\section{Supervision:}

\section{ÁNGEL JIMÉNEZ ÁLVARO}

PhD. in Industrial Engineering from Universidad Politécnica de Madrid 
"The fool is the precursor to the savior"

C.G. Jung 


\section{Acknowledgement}

Firstly, I would like to thank our laboratory assistant Miguel Parra Bronchalo for his invaluable aid in the elaboration of several of the Figures presented in this Thesis. All of the Figures shown in this document have been done in the Thermodynamics Unit of the Energy Department in ETSII UPM either by Miguel or myself. Also his natural inclination for a coffee break (which he prepared) was very helpful to align the work to be done in the morning.

I am grateful to Paolo Chiesa, Professor from Politecnica de Milano for his contribution in the modelling of the advanced Gas Turbine technologies. These items have been represented rigorously thanks to his expertise and the successful modelling trajectory of the Energy Department of Polimi, whose numerous publications from many authors have been an inspiration and an example to my work. I am still working thoroughly to be on par with their level of quality and excellence, and it has been a privilege to cooperate with Paolo in some of the studies carried out during the GasTech project which are reflected in this document.

Also, I want to show my deep appreciation to Schalk Cloete, Research Scientist from SINTEF, who acted as technical coordinator in the GasTech project and whose passion, professionalism, energy and dedication were extremely contagious. During our discussions, I retrieved the joy for the engineering profession and he triggered and enhanced my research vocation in many occasions, pushing me to explore new frontiers beyond the activities originally within the scope of UPM in the GasTech project. Schalk's vitality and supportive attitude were always balanced with an effective rational and analytical mind-set, which have decisively contributed to many of the good results achieved in this project's work package and to the development of the conceptual modelling framework from which future valuable research output will be extracted.

Last but not least, I would like to express my everlasting gratefulness to Professor Ángel Jiménez Álvaro from ETSII UPM, supervisor of this Thesis. I am obliged to him for entrusting me this project and providing me with unconditional energy and support. Ángel set up the right conditions for success, allowing me to carry out the work with full independence while offering precious guidance when necessary. My desire for frequent technical discussions was always met with fondness while he encouraged my yearning to delve in the science of Thermodynamics, by allowing me to attend his lectures in the advanced course of Physical Chemistry. He also stimulated me to mentor students and propose Thesis subjects for BSc. and MSc. degrees during this period in order to initiate my academic career, while allowing me to assist in the courses of Thermodynamics of the BSc. degree. I remain with the eagerness of delivering to him more results of a higher quality and with the enthusiasm to help enhance the group's research capability in the future.

Finally, I want to use this occasion to be thankful as well to other members of the GasTech project: Shahriar Amini for his management and care and Jan Hendrik Cloete for his support and modelling assistance, alongside the numerous members of the different work packages for our cooperation. I would also like to acknowledge Professor Manuel Valdés del Fresno from ETSII UPM, for his availability and guidance to develop our own gas turbine models. In parallel, it was also a great experience to be side by side and collaborate with the Thermodynamics Unit of the Energy Department from ETSII UPM: Javier Rodriguez Martin, Ignacio López Paniagua, Susana Sánchez Orgaz, Celina González Fernández and Rafael Nieto Carlier, in whose company I have greatly enjoyed spending these last two and a half years. 


\section{Abstract}

The growing concern in global warming caused by greenhouse gas emissions (GHG) has triggered substantial research and technology development efforts to curtail $\mathrm{CO}_{2}$ emissions from fossil fuel power plants, responsible of approximately $25 \%$ of the total $\mathrm{CO}_{2}$ emissions of the global economy. Coal has the highest carbon intensity of the different energy sources for electricity and heat generation and will remain a significant primary energy source in developing countries in the following decades. Compelling energy solutions with carbon capture and storage (CCS) will be a must to meet the global warming targets. Amongst the different solid fuel power generation technologies, Integrated Gasification Combined Cycles (IGCC) have the potential to reach higher efficiencies with a lower environmental impact than Pulverized Coal Boilers (PCB).

Removing the $\mathrm{CO}_{2}$ from exhaust combustion gases in a cost effective manner, with additionally low energy penalty, is a challenge. An alternative pathway to post-combustion $\mathrm{CO}_{2}$ capture is precombustion $\mathrm{CO}_{2}$ capture, where the gaseous fuel undergoes a shift reaction to produce a $\mathrm{H}_{2}$ rich carbon free fuel, while the $\mathrm{CO}_{2}$ is removed with absorbents more efficiently and cost effectively as the $\mathrm{CO}_{2}$ is not diluted in the air stream, typically at a higher partial pressure. This capture technology is well suited for IGCC plants where a gasification unit produces a pressurized syngas fuel. However, the energy penalty relative to an Unabated IGCC plant is still significant. This is a critical issue as a lower thermal efficiency leads to larger coal feed to the plant for a given electricity output increasing simultaneously the specific capital costs and the costs associated with fuel production and transportation.

Chemical Looping Combustion (CLC) appears as a promising technology to minimize the efficiency loss of carbon sequestration. This capture technology mode is also referred to as inherent carbon capture. In CLC, a metal oxygen carrier is exposed alternatively to a gaseous fuel and an air stream in two interconnected fluidized bed reactors. In the fuel reactor, the oxygen carrier is reduced and the products of combustion $\left(\mathrm{CO}_{2}\right.$ and $\left.\mathrm{H}_{2} \mathrm{O}\right)$ are obtained, which after water condensation, a relatively pure $\mathrm{CO}_{2}$ stream ready for compression and storage is delivered. In the air reactor, the exothermic oxidation reaction takes place, thereby heating the air stream to reactor temperature, suitable for power production in a gas turbine. However, the scale up of interconnected fluidized beds at pressurized conditions (required in power cycles) has been slow. Moreover, the complex hydrodynamics of solids transfer from one reactor to another makes the system have very low flexibility in part load operation of the power cycle. To circumvent these challenges, the gas switching (GS) technology was introduced. In this mode of reactor dynamic operation, the oxygen carrier is kept within the reactor volume, and a set of inlet and outlet valves exposes it to oxidant (air) and reduction (fuel) streams. In order to obtain a time constant averaged flow and temperature to the gas turbine for stable operation, a cluster of reactors is needed. The reactors are operated in bubbling fluidization regime as this has several advantages with respect to a fixed packed bed configuration. Alternative to Gas Switching Combustion (GSC), the Gas Switching Oxygen Production (GSOP) technology utilizes an oxygen carrier capable of releasing free oxygen in the reduction stream, which can be effectively utilized as an oxidant stream of a gasification process.

The goal of this Thesis is to determine the potential of gas switching chemical looping technology to eliminate the energy penalty of $\mathrm{CO}_{2}$ capture in IGCC plants, employing GSC and GSOP clusters. The modelling work of this research consists of developing a set of technology blocks that appear in power plant systems based on plausible performances reported in literature and synthesizing different power plant concepts by integrating the technology blocks. The novel power 
plant concepts are benchmarked against and Unabated IGCC plant and a Pre-combustion $\mathrm{CO}_{2}$ capture IGCC plant, the latter representative of an available and deployable CCS technology. In parallel, flexible power plants for $\mathrm{H}_{2}$ and power co-production integrating GSC and membrane reactors using advanced $\mathrm{H}$-class gas turbine technology are developed, together with suitable plant benchmarks with and without CCS, with the purpose of presenting power plant concepts which can balance variable renewable energy (VRE), a critical aspect for the competitiveness of thermal plants in a future with high renewable penetration. With regards to the modelling of GS technology, a dynamic model is developed and connected to the stationary power plant simulation to obtain inlet stream data from it and deliver time-averaged output operating conditions. The 4E analysis methodology is employed to analyse and benchmark the novel plant configurations. 4E stands for Energy, Environmental, Exergy and Economic. Both Energy and Environmental analysis are performed to all of the synthesized plants. Exergy and Economic analysis have been performed to those plants that revealed a higher potential, depending on the project requirements.

It is recognized that substantial technology development is required to reach GS technology deployment. Many material related challenges must be overcome, i.e. the oxygen carrier must have a high mechanical stability and durability through many gas switching reduction and oxidation cycles, achieving a high conversion and preventing any fuel slip through the reduction stage. High temperature valves and filters must be available, to ensure a safe operation of the gas turbine. Furthermore, the reactor temperatures must be maximized in order to attain attractive thermal efficiencies. It is therefore highlighted that this Thesis constitutes and ex-ante assessment of GS technology for CCS, as a forecasting effort of its potential assuming that all technology showstoppers are overcome.

This Thesis is encompassed within the European ACT-GasTech Project (Grant Agreement No 691712) and has received funding from MINECO, Spain (reference PCIN-2017-013). 


\section{Resumen}

La creciente preocupación debida al calentamiento global a causa de los gases de efecto invernadero (GEI) ha causado un incremento considerable de esfuerzos dirigidos a la investigación y al desarrollo de tecnologías para la reducción de emisiones de $\mathrm{CO}_{2}$ en plantas de producción de energía a partir de combustibles fósiles, responsables aproximadamente del 25\% del total de emisiones de $\mathrm{CO}_{2}$ en la economía global. El carbón tiene la mayor intensidad de emisiones de $\mathrm{CO}_{2}$ de las diferentes fuentes de energía disponibles para la generación de electricidad y calor y permanecerá siendo una fuente de energía primaria significativa en las próximas décadas en países en vías de desarrollo. Soluciones energéticas efectivas con captura y almacenamiento de $\mathrm{CO}_{2}$ (CAC) serán un requisito indispensable para alcanzar los objetivos de calentamiento climático. Entre las distintas tecnologías de producción de energía a partir de combustibles sólidos, las centrales de Gasificación Integrada y Ciclo Combinado (GICC) tienen el potencial de alcanzar mayores eficiencias con un impacto medioambiental menor que las calderas de carbón pulverizado (CCP).

Eliminar el $\mathrm{CO}_{2}$ contenido en los gases de combustión de una forma económica y adicionalmente, con baja penalización energética es un desafío. Una alternativa a la captura post-combustión de $\mathrm{CO}_{2}$ es la captura pre-combustión, en la que un combustible gaseoso experimenta una reacción "shift" para producir un combustible rico en $\mathrm{H}_{2}$, mientras que el $\mathrm{CO}_{2}$ es separado mediante absorbente más eficientemente y con un menor coste ya que el $\mathrm{CO}_{2}$ no está diluido en la corriente de aire, y por tanto se halla a una presión parcial mayor. Esta tecnología de captura está bien adecuada a planta GICC en las cuales una unidad de gasificación produce un gas de síntesis presurizado como combustible. Sin embargo, la penalización energética relativa a una planta GICC sin captura sigue siendo sustancial. Este es un factor crítico ya que una menor eficiencia térmica conlleva an un mayor consumo de carbón para una misma generación de electricidad incrementando simultáneamente los costes capitales específicos de la planta así como los costes asociados a la producción y transporte de combustible.

La Combustión por Lazo Químico (CLQ) se presenta como una tecnología prometedora para minimizar la pérdida de eficiencia debida al secuestro de $\mathrm{CO}_{2}$. Esta tecnología de captura también es referida como captura inherente de carbono. En CLQ, un óxido metálico es expuesto alternativamente a un combustible gaseoso y a una corriente de aire en dos reactores de lecho fluidizado interconectados. En el reactor de combustible, el óxido metálico es reducido y se obtienen los productos de combustión que, tras la condensación del agua, permiten lograr una corriente relativamente pura de $\mathrm{CO}_{2}$ para su compresión y almacenamiento. En el reactor de aire, la reacción de oxidación exotérmica tiene lugar, mediante la cual se calienta la corriente de aire hasta la temperatura del reactor, adecuada para la producción de potencia en una turbina de gas. Sin embargo, el desarrollo a gran escala the lechos fluidizados interconectados en condiciones presurizadas (indispensables para los ciclos de potencia) ha sido lenta. Adicionalmente, la compleja hidrodinámica debida al transporte de sólidos de un reactor a otro presenta muy poca flexibilidad cuando el ciclo de potencia opera a cargas parciales. Para evitar estos inconvenientes, surge la tecnología "gas switching" (GS). En este modo de operación dinámica de los reactores, el óxido metálico se mantiene en el volumen de un reactor, y un juego de válvulas de entrada y salida lo exponen a una corriente oxidante (aire) y de reducción (combustible). Para mantener un flujo y temperatura medio constante en el tiempo necesarios para un funcionamiento estable de la turbina, se precisa un "cluster" de reactores, de manera que la adición de las corrientes de salida de cada etapa de los distintos reactores presente un perfil relativamente constante en el tiempo. Los reactores se operan en régimen fluidizado burbujeante, ya que este modo de operación presenta 
numerosas ventajas frente al lecho fijo. Sin embargo, esto ocasiona un mezclado indeseado de las corrientes de salida de oxidación y reducción al cambiar las válvulas que ocasiona una reducción de la captura de $\mathrm{CO}_{2}$ y en la pureza de los gases de salida de reducción. Alternativamente a la tecnología "Gas Switching Combustion" (GSC), se explora también la tecnología "Gas Switching Oxygen Production" (GSOP), que emplea un óxido metálico capaz de liberar oxígeno en la corriente de reducción, que puede ser usado como agente oxidante en un proceso de gasificación.

El objetivo de esta Tesis consiste en determinar el potencial de la tecnología "Gas Switching" de lazo químico para eliminar la penalización energética debida a la captura de $\mathrm{CO}_{2}$ en plantas GICC, empleando clusters GSC y GSOP. El trabajo de modelización de esta investigación consiste en desarrollar una serie de bloques tecnológicos que aparecen en sistemas de generación de potencia basadas en rendimientos razonables obtenidos de la literatura y en sintetizar distintos conceptos de generación de potencia integrando dichos bloques de tecnología. Los conceptos novedosos de plantas son comparados con una planta GICC sin captura y una planta GICC con captura de $\mathrm{CO}_{2}$ mediante pre-combustión, representativa de una tecnología CAC disponible e implementable actualmente. Paralelamente, se desarrollan plantas de potencia flexibles, que coproducen $\mathrm{H}_{2}$ y electricidad integrando tecnología GSC con reactores de membrana y empleando turbinas de gas avanzadas clase $\mathrm{H}$, así como modelos de plantas de referencia análogas, con el propósito de presentar conceptos de plantas térmicas capaces de balancear fuentes de energía renovable variable, un factor crítico para la competitividad de las plantas térmicas en un futuro con una elevada penetración de renovables. Con respecto a la modelización de la tecnología GS, se ha desarrollado un modelo dinámico y se ha conectado a la simulación estacionaria de la planta de potencia, importando los parámetros de las corrientes de entrada y calculando las condiciones de operación promediadas en el tiempo de salida. La metodología de análisis 4E ha sido aplicada para analizar tanto las plantas de referencia como las configuraciones novedosas. 4E se refiere a (análisis) Energético, Emisiones, Exergético y Económico. Tanto el análisis Energético como de emisiones se ha realizado para todas las plantas elaboradas. El análisis Exergético y Económico se han llevado a cabo para aquellas plantas que revelan un mayor potencial, teniendo en cuenta los distintos requisitos del proyecto.

Es apreciable que un desarrollo tecnológico sustancial es todavía necesario para que la tecnología GS se convierta en una realidad. Numerosas dificultades relacionadas con los materiales deben acometerse, por ejemplo, el óxido metálico empleado debe presentar suficiente estabilidad mecánica y durabilidad tras muchos ciclos de oxidación y reducción, alcanzando altas conversiones, evitando el escape de combustible en la etapa de reducción. Válvulas y filtros de alta temperatura deben estar disponibles, asegurando una operación estable de la turbina de gas. Más aún, las temperaturas del reactor deben de ser los más elevadas posibles para obtener eficiencias térmicas competitivas. Por lo tanto se hace énfasis en que esta Tesis constituye una evaluación $e x$ ante de la tecnología GS para CAC, como una herramienta para predecir su potencial, bajo la suposición de que las barreras tecnológicas existentes se han superado.

Esta Tesis se enmarca dentro de Proyecto Europeo ACT-Gas'Tech (Grant Agreement No 691712) y ha recibido financiación por parte de MINECO, España (referencia PCIN-2019-013). 


\section{Content}

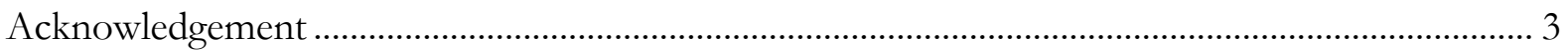

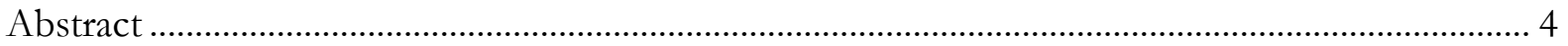

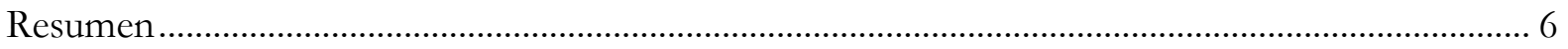

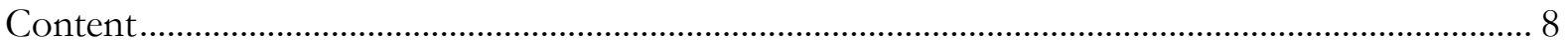

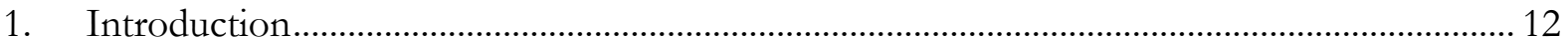

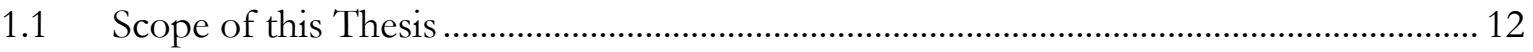

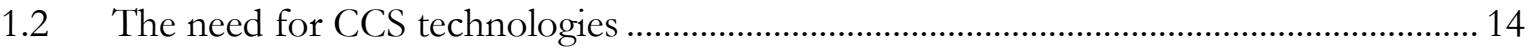

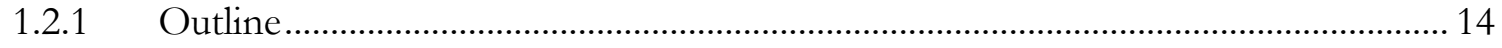

1.2.2 Conventional $\mathrm{CO}_{2}$ Capture Technologies................................................................... 17

1.2.3 Chemical Looping: Inherent Carbon Capture ……...................................................... 22

$1.3 \quad$ Integrated Gasification Combined Cycles (IGCC) …….......................................................... 24

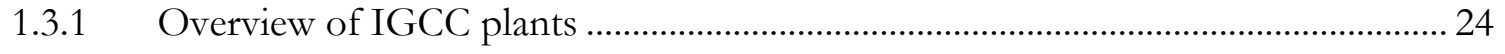

1.3.2 Thermodynamics of Power Generation ........................................................................ 27

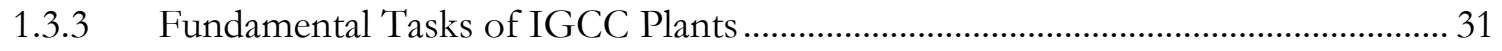

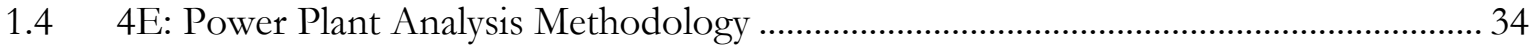

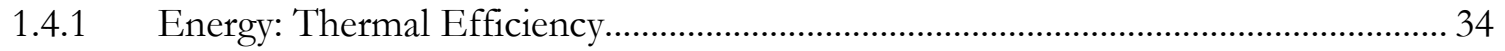

1.4.2 Environmental: $\mathrm{CO}_{2}$ Plant Emissions ……............................................................... 35

1.4.3 Exergy: The Second Law Efficiency …….................................................................... 38

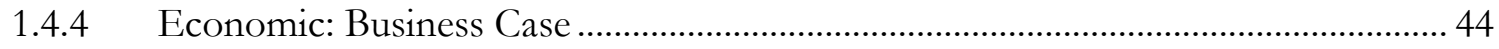

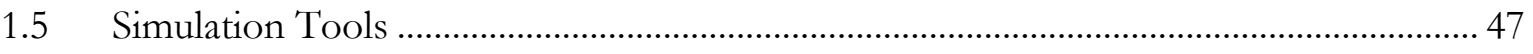

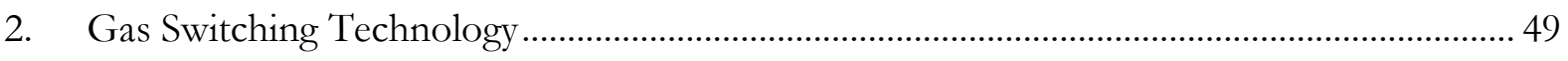

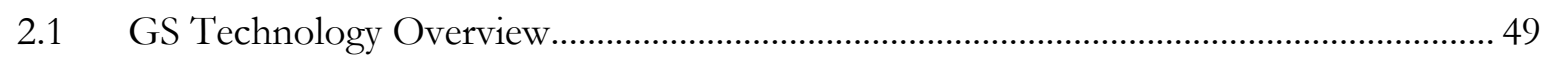

2.2 Dynamic Mass \& Energy Balances to a CSTR ……………………………………............ 52

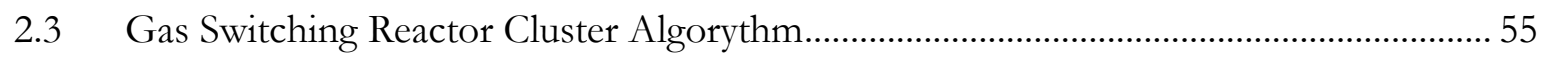

2.3.1 Oxygen Carrier Selection and Reaction Kinetics ........................................................ 58

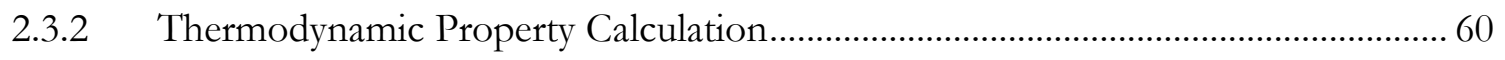

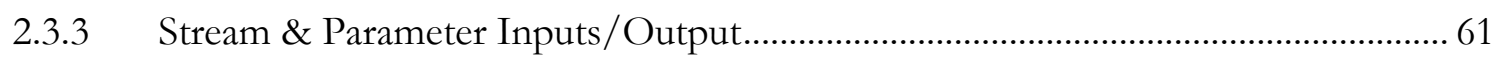

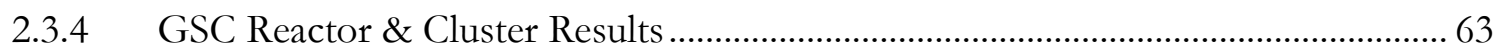

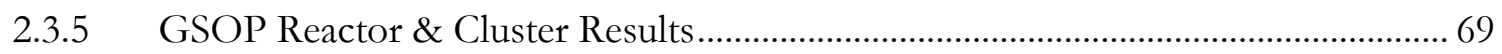

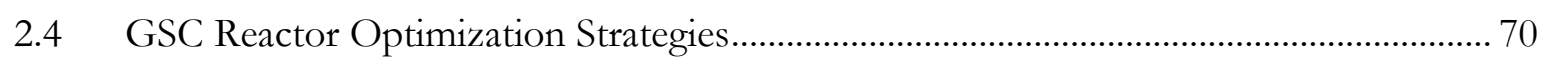

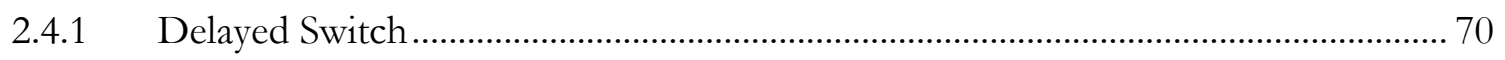

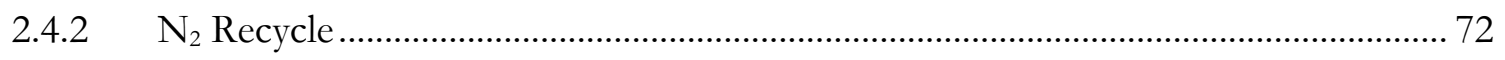

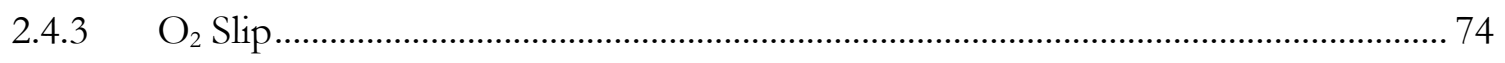

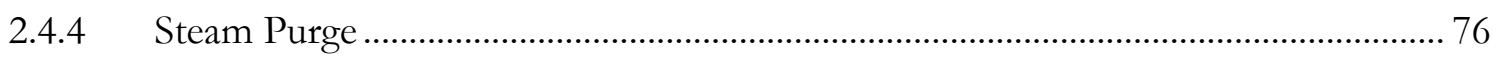




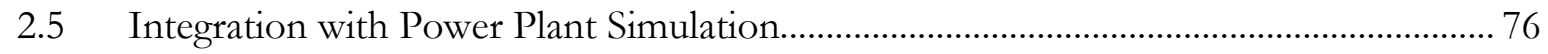

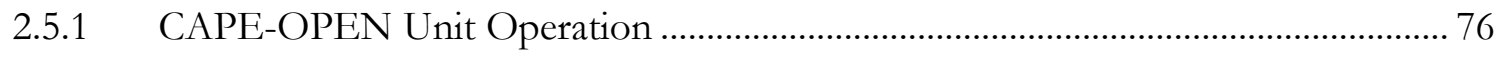

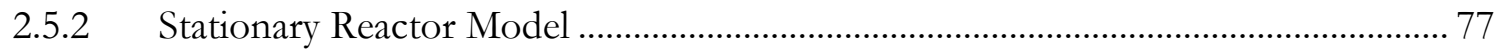

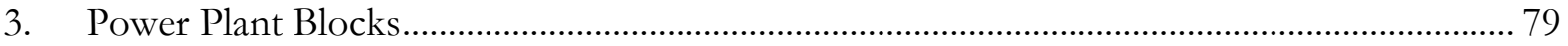

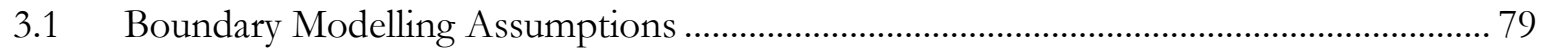

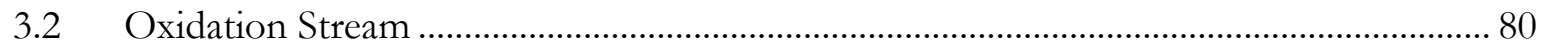

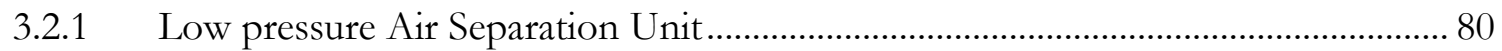

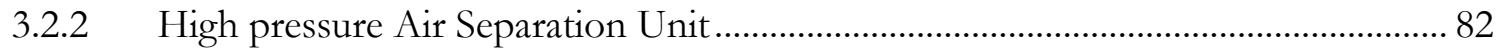

3.2.3 Gas Switching Oxygen Production (GSOP),............................................................... 83

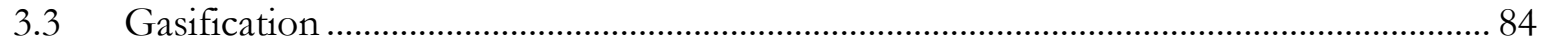

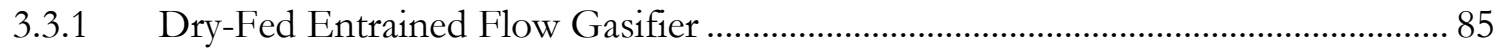

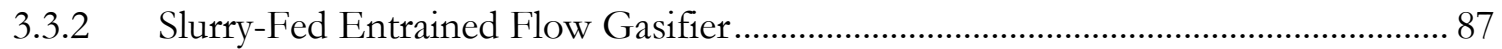

3.3.3 Circulating Fluidized Bed Gasifier ............................................................................... 88

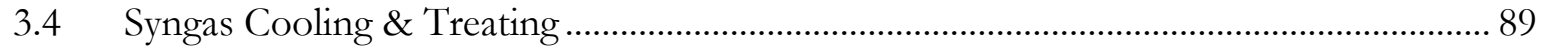

3.4.1 High Temperature Syngas Cooling and Particulate Removal ..................................... 89

3.4.2 Low Temperature Heat Recovery \& Cold Gas Clean-Up .......................................... 91

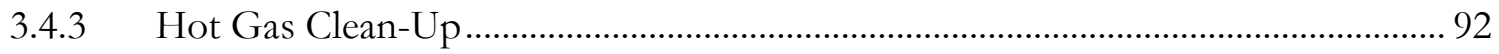

3.4.4 Shift Conversion \& and Heat Recovery ........................................................................ 94

3.4.5 Membrane Assisted Water Gas Shift .......................................................................... 95

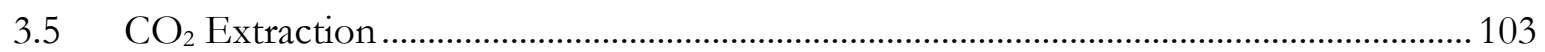

3.5.1 $\quad \mathrm{CO}_{2}$ Physical \& Chemical Absorption..................................................................... 103

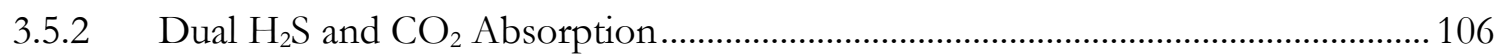

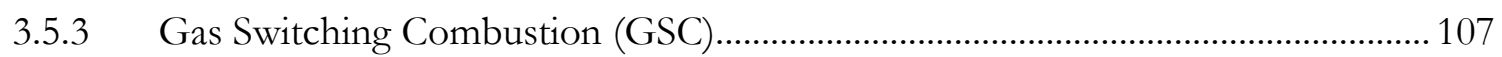

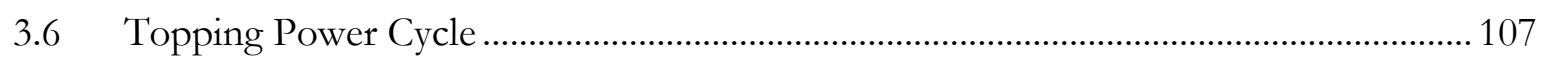

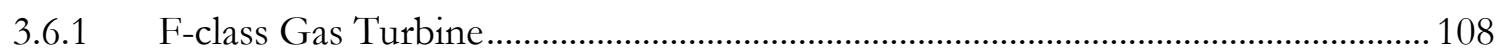

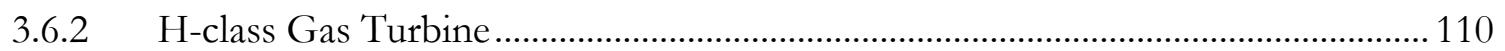

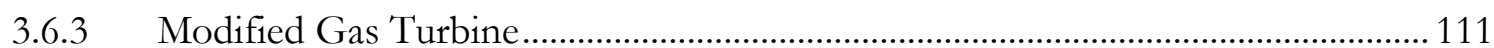

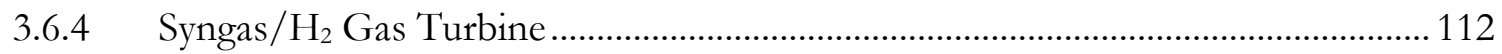

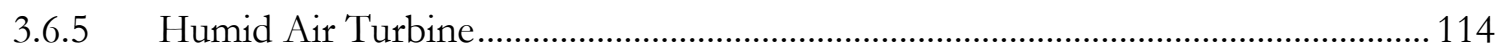

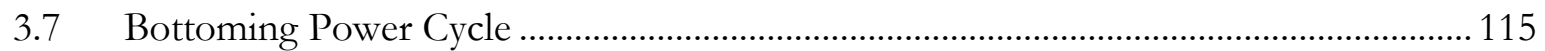

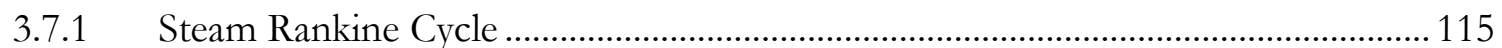

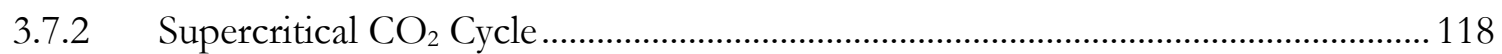

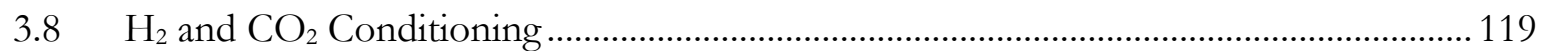

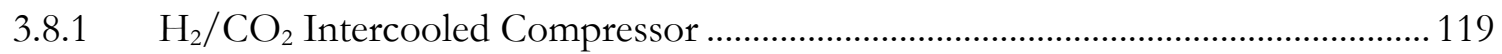

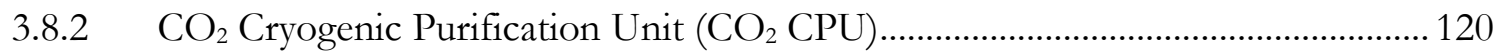


4. Power Plant Concepts.

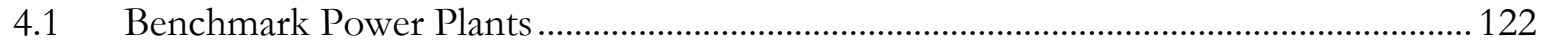

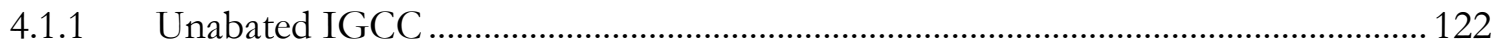

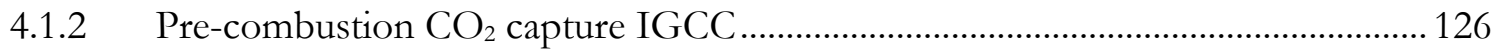

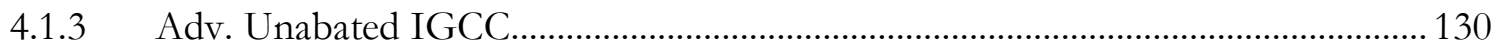

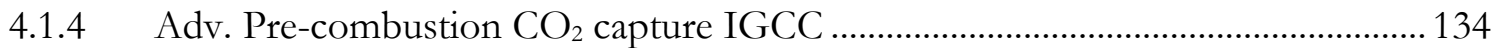

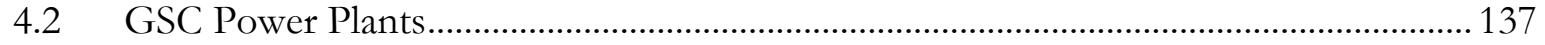

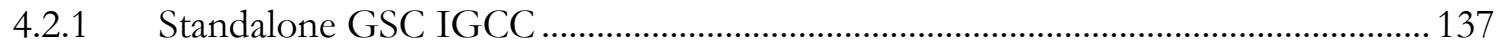

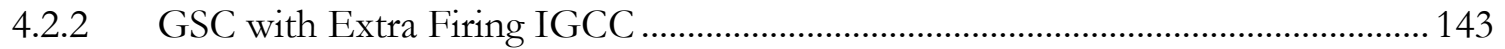

4.2.3 Integrated Gasification GSC-HAT …………........................................................... 147

4.2.4 Adv. GSC-MAWGS IGCC with Shell Gasifier ........................................................ 152

4.2.5 Adv. GSC-MAWGS IGCC with Pregasifier and HTW Gasifier ............................ 158

4.2.6 Adv. GSC-MAWGS IGCC with GE Gasifier ............................................................. 163

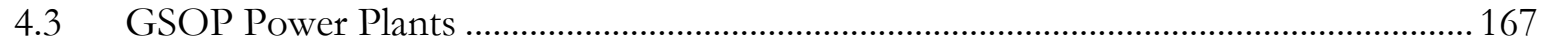

4.3.1 Oxygen Production Pre-Combustion (OPPC) IGCC................................................ 167

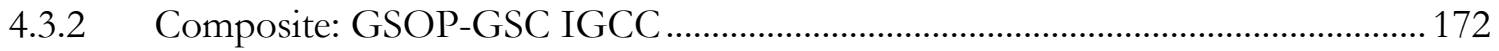

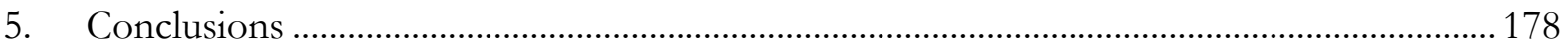

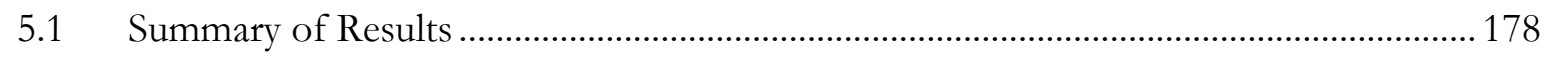

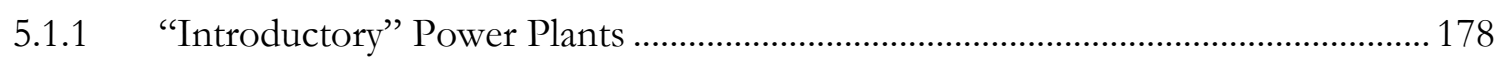

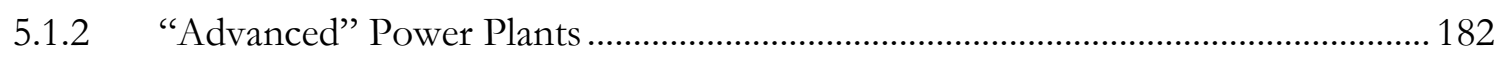

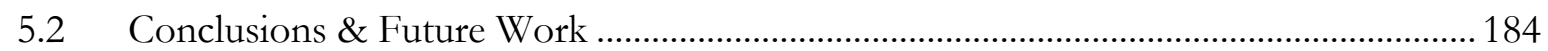

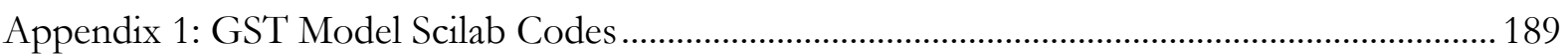

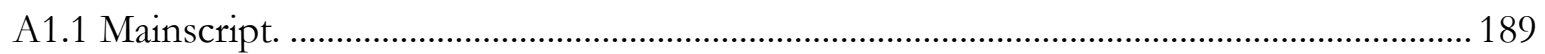

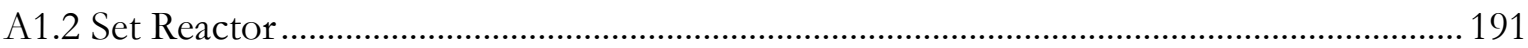

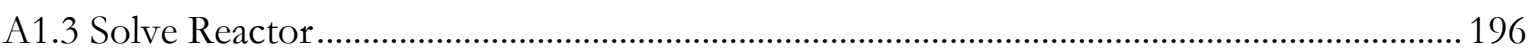

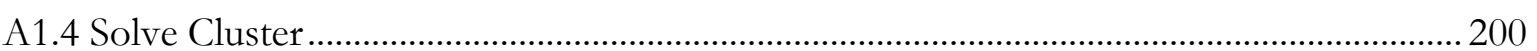

Appendix 2: MAWGS Model \& Auxiliary Scilab Codes.................................................................... 208

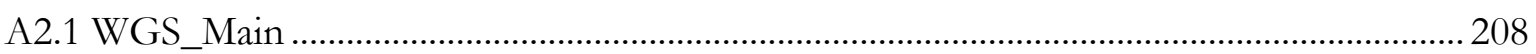

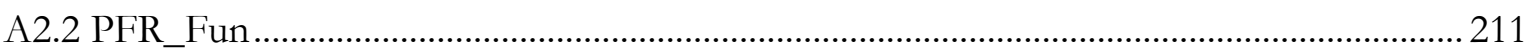

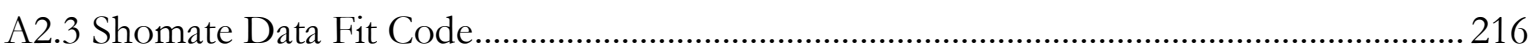

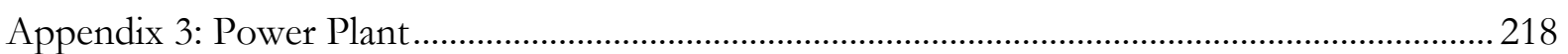

A3.1 Data Sheets for Stationary Operating Points of GSC and GSOP .................................... 218

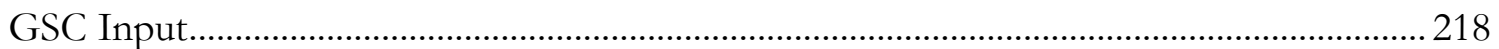

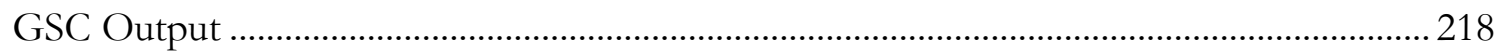

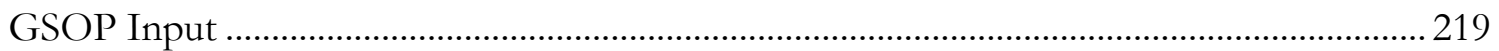




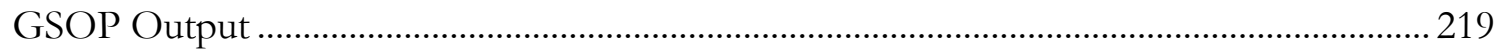

A3.2 Stream Data \& Detailed Schemes for Power Plant Concepts........................................... 220

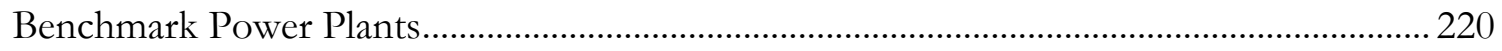

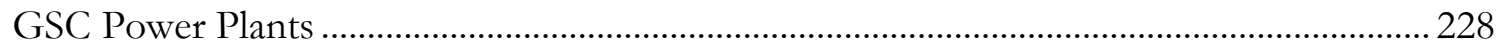

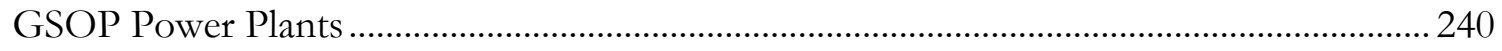

A3.3 Parameters for Economic Evaluation........................................................................................ 244

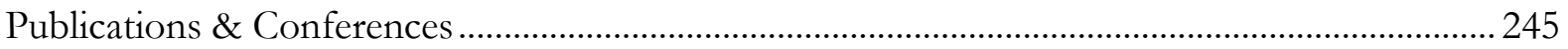

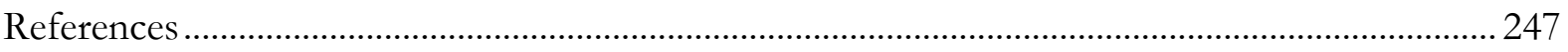

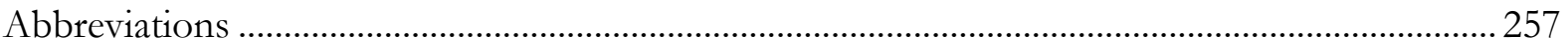

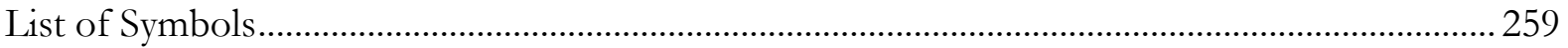

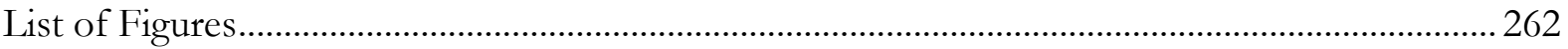

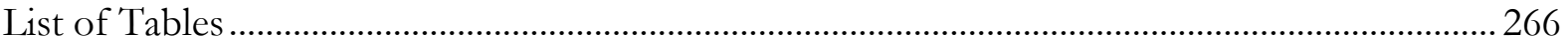




\section{Chapter 1}

\section{Introduction}

In this Chapter the scope of the thesis is defined within the framework of the research project GasTech. An outline of existing CCS deployable technologies is presented as well as the concept of chemical looping for inherent $\mathrm{CO}_{2}$ capture. The Chapter ends offering a comprehensive view of the methodology employed for the evaluation of different power plant concepts as well as describing the simulation tool employed.

\subsection{Scope of this Thesis}

The present Thesis is encompassed within the Accelerating Carbon Technologies (ACT) project GaSTech (Grant Agreement No. 691712), which consists of the demonstration of gas switching technology for accelerated scale-up of pressurized chemical looping applications. This project is cofounded by the European Commission under the Horizon 2020 programme. Gas switching technology provides several advantages relative to chemical looping concepts when applied to power generation or hydrogen production with inherent $\mathrm{CO}_{2}$ capture, since this processes typically require elevated pressures to operate efficiently, underlining the simplicity and scalability of gas switching standalone units compared to interconnected chemical looping reactors. Four gas switching technologies are studied in this project: combustion, reforming, water splitting \& oxygen production.

The project scope spans from material development and lab-scale reactor demonstration to largescale process techno-economic evaluations, involving different research and business partners. Table 1 shows the project components and partners based on Work Packages (WP):

Table 1 Gas'Tech work distribution ${ }^{1}$

\begin{tabular}{|c|c|c|c|}
\hline WP N & WP Title & Lead & Participants \\
\hline WP1 & Material selection, testing \& manufacturing & ETH & ESAM \\
\hline WP2 & $\begin{array}{c}\text { Demonstration of pressurized GSC,GSR,GSWS and } \\
\text { GSOP operation }\end{array}$ & SINTEF & NTNU \\
\hline WP3 & $\begin{array}{c}\text { Large-scale process simulation of gas switching } \\
\text { technology }\end{array}$ & NTNU & $\begin{array}{c}\text { UPM } \\
\text { SINTEF } \\
\text { NTNU }\end{array}$ \\
\hline WP4 & Economic assessments of gas switching technology & UBB & ESAM \\
\hline WP5 & Business case & HAYAT & All \\
\hline WP6 & Management and dissemination & SINTEF & All \\
\hline
\end{tabular}

SINTEF: Stiftelsen SINTEF

NTNU: Norwegian University of Science and Technology

ETH: ETH Zürich

ESAM: Euro Support Advanced Materials B.V.

UBB: Universitatea Babes-Bolyai

UPM: Universidad Politénica de Madrid

HAYAT: Hayat 
UPM's role in the GaSTech project originally consisted of evaluating configurations involving exclusively Gas Switching Oxygen Production (GSOP), introducing the reactor input data provided by SINTEF in stationary process simulations. It soon became apparent that, given the preliminary laboratory work with regards to oxygen carrier material feasibility, only combustion and reforming showed technical viability. In view of this, UPM took the initiative to develop also concepts involving Gas Switching Combustion (GSC) for power generation. The data exchange between SINTEF and UPM was initially performed through excel files: the averaged reactor conditions were delivered once the stream data was provided. For concepts which have many recycle streams or heat exchange between streams upstream and downstream the GSC cluster this proved to be a cumbersome and tedious procedure to converge the power plant simulation. For this reason, and in order to deliver an output with more completeness, UPM has developed its own Gas Switching transient model in Scilab and has successfully coupled it to the stationary process simulator, with a high degree of flexibility to select different oxygen carrier materials and modes of operation of the cluster. UPM's transient GS model has been thoroughly validated with the Matlab code developed at SINTEF, enabling a fast, reliable and independent convergence of the power plants. A detailed description of the transient model is provided in Chapter 2. The mass and energy balances and adequate parameters for unit sizing of several promising concepts were delivered to WP4 (UBB). Figure 1 shows a schematic that represents the work flow between the project partners involved in the techno-economic assessment of large scale processes employing GS technology (WP 3\&4). Chapter 3 will present, based on the fundamental task categorization proposed in section 1.3 of the present Chapter, the different power plant sub-processes giving a brief theoretical background and key modelling assumptions taken. Chapter 4 will present the different power plant models proposed through the integration of the different technology blocks, showing the main results as the key performance indicators of the plants based on the analysis methodology described in section 1.4. Two sets of power plant models are developed: 1) "Introductory" plants using a reference F-class gas turbine and 2) "Advanced" plants employing $\mathrm{H}$-class gas turbines design for $\mathrm{H}_{2}$ and electricity co-production. Finally, Chapter 5 will provide a summary of the main outcomes of the research and outline the future research work as continuation of the GasTech project. 


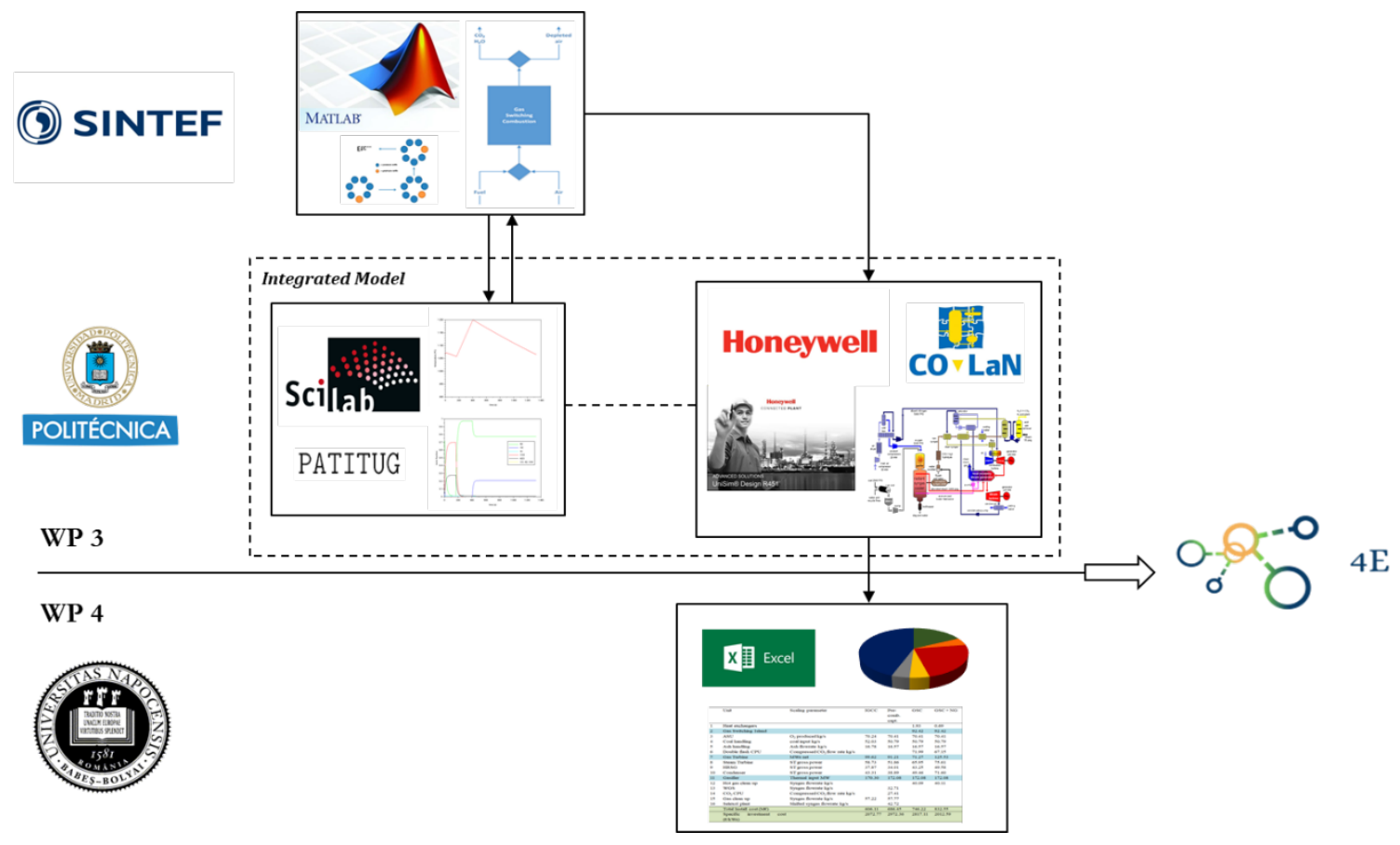

Figure 1 Work flow between WP3 and WP4

To summarize in a few lines, this Thesis will focus on process design and simulation of different power plants from solid fuels with GSC and GSOP clusters, using Integrated Gasification Combined Cycle (IGCC) plants as a baseline. The novel plants will be benchmarked employing the 4E analysis against reference gasification plants for electricity production: an Unabated IGCC plant and a pre-combustion $\mathrm{CO}_{2}$ capture IGCC plant. An important focus will be made on the development of concepts that can operate flexibly, with $\mathrm{H}_{2}$ co-production as an energy storage vector. Besides and integrated model between GS technology and IGCC stationary simulation, an important outcome of this project is a collection of modelling blocks of the different power plant sections which can be used in future for academic purposes or alternatively, as building blocks to synthesize power generation, chemical or cryogenic systems in other research projects within the Energy Department of the Escuela Técnica Superior de Ingenieros Industriales (ETSII, UPM).

\subsection{The need for CCS technologies}

\subsubsection{Outline}

There is generalized scientific consensus on the fact that human activity has an effect on climate, and that anthropogenic emissions of greenhouse gases (GHG), to a large extent consisting of $\mathrm{CO}_{2}$ as shown in Figure 3, are at its peak. As a result, a rise in the global average temperature has been observed in the last decades, as illustrated in Figure 2. Currently, the social cost of $\mathrm{CO}_{2}$ has been estimated at approximately $50 \$$ /ton and, although this figure it does not include all the economic effects and scientific concerns, it suggest already that the adverse impact of increased carbon is not negligible, demanding action and commitment from many levels of society and policymakers. 


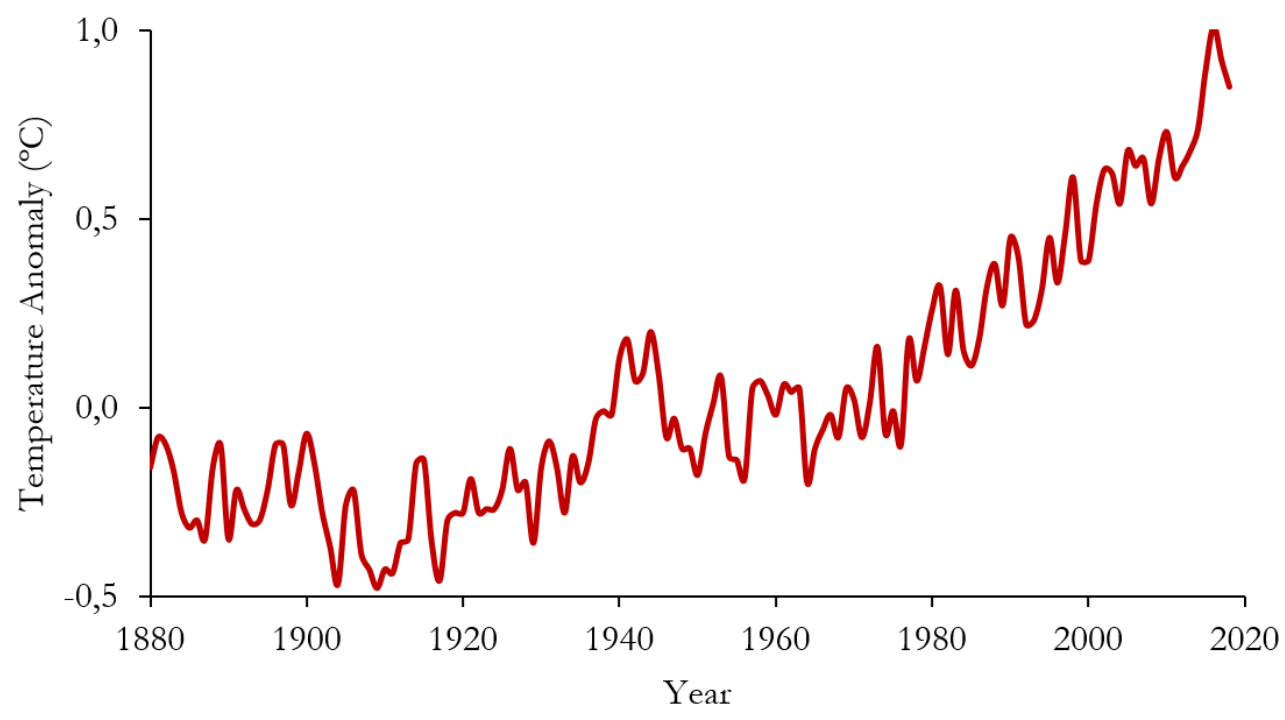

Figure 2 Global surface (land-ocean) temperature relative to 1951-1980 average values [1]

However, the cumulative emissions of $\mathrm{CO}_{2}$ will affect decisively the global mean surface warming for the rest of the century. This will have severe consequences for human and natural systems, and will cause bigger impacts on those areas that present lower levels of development. In order to limit climate change, anthropogenic emissions must be mitigated. Substantial emission reductions over the next decades will improve the prospects and reduce the risks, minimizing the likelihood of irreversible impacts.

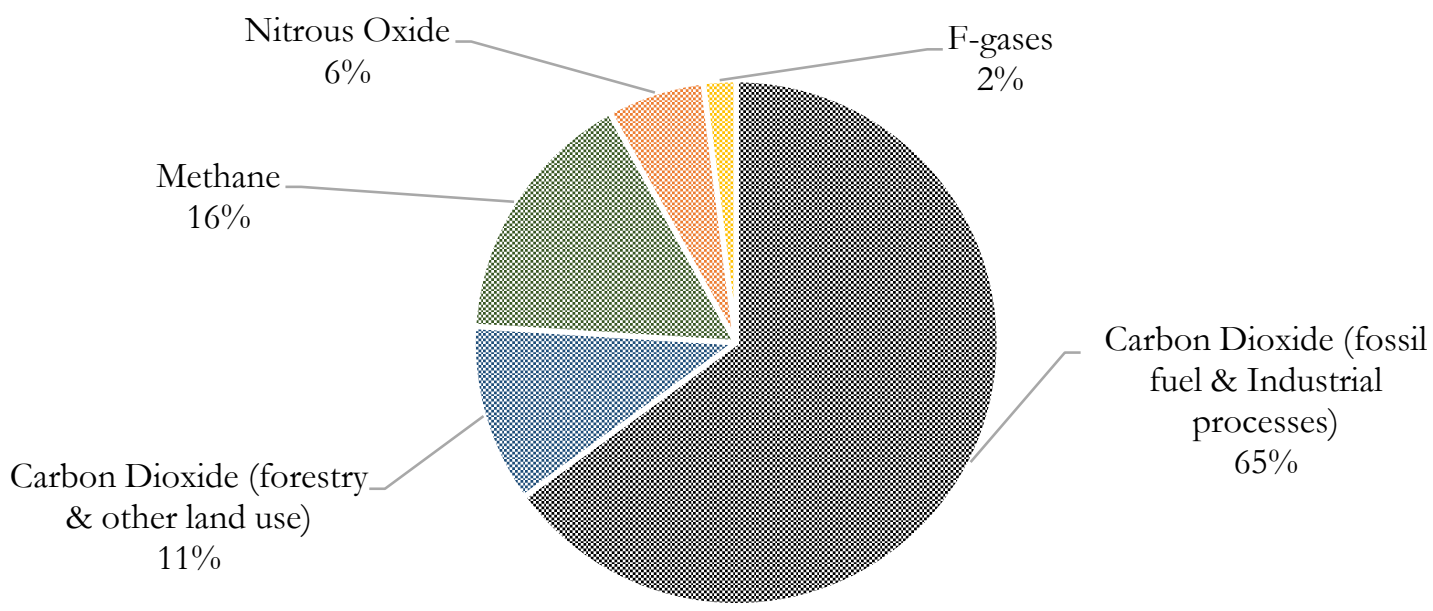

Figure 3 Global greenhouse gas emissions by gas in 2010 [2]

The mitigation pathways are diverse, posing substantial economic, social and institutional challenges, which have led up to now to a small pace of the different deployment strategies. The scenarios that show high probability of limiting global warming below $2^{\circ} \mathrm{C}$ relative to preindustrial levels are characterized by a GHG emission reduction of $40-70 \%$ by the year 2050 , compared to 2010, and emission levels near zero (or below) by 2100. Without new efforts to reduce GHG emissions beyond the current policies, the growth of emissions taking place nowadays will lead to a global mean surface temperature increase of $3,7^{\circ} \mathrm{C}-4,8^{\circ} \mathrm{C}$ by 2100 , driven by global economic and demographic growth. The energy sector will be key to achieving the global warming objectives, with a large focus on efficiency improvement and renewable energy production. 
However, the deployment of Carbon Capture and Storage (CCS) technology will still be necessary since there are numerous developing economies which cannot give up the use of fossil fuels such as coal (e.g. China, India, and South Africa) in the short-mid-term. Furthermore, CCS will have a relevant role to play to ensure sustainable energy supply in an electricity market with a high penetration of renewables that can result in supply intermittencies. CCS will also substantially reduce emissions from carbon intensive industries such as steel or cement, which in combination with the energy production sector represent the largest portion of the global GHG emissions, as shown in Figure 4. Finally, CCS has some attractive advantages in the thermal power plants with fossil fuels, as this technology can be retrofitted to existing facilities, which typically have long operating lifetimes.

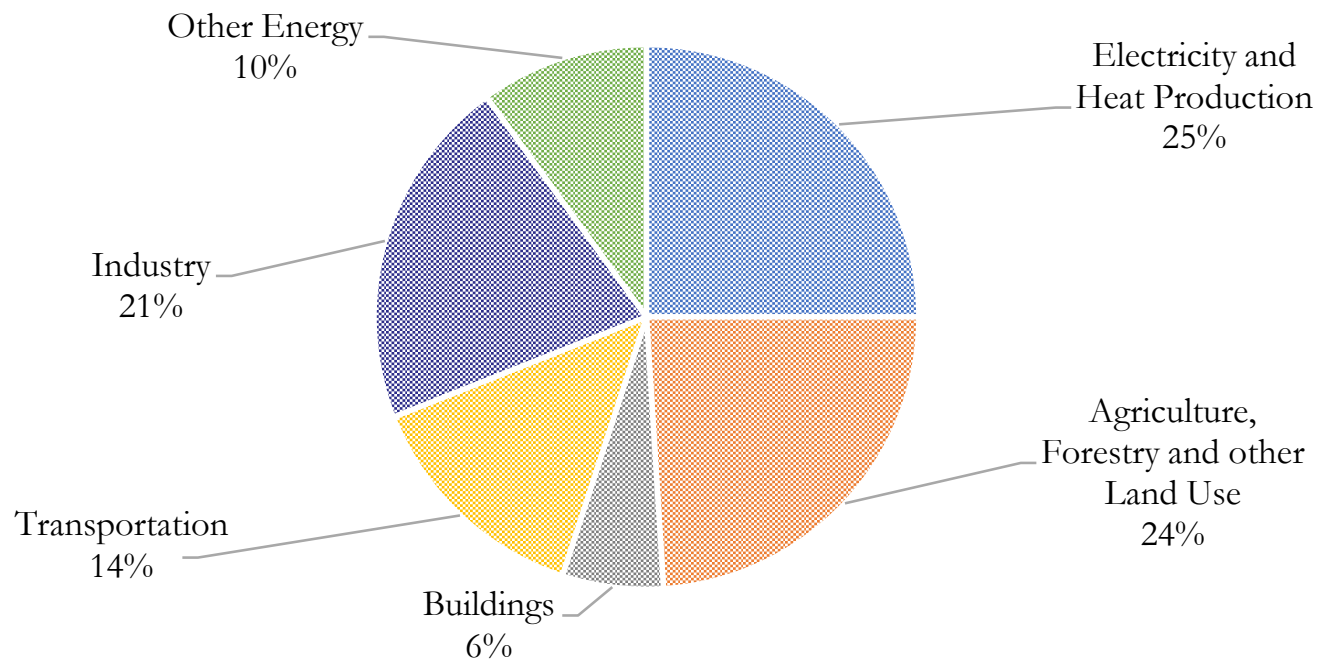

Figure 4 Global emissions by economic sector in 2010 [2]

In such sustainable development scenario of global warming "well below" $2^{\circ} \mathrm{C}$ a, [3] forecasts a $\mathrm{CO}_{2}$ price of $20 € /$ ton in 2020 , increasing to $100 € /$ ton by 2030 and reaching $140 € /$ ton in advanced economies by the year 2040, with developing economies implementing novel schemes to limit $\mathrm{CO}_{2}$ emissions. This fast rise of $\mathrm{CO}_{2}$ prices will trigger industrial interest in CCS, and new fossil fuel based power plants with CCS will be able to compete in the market, with the capability of achieving carbon negative power generation when utilizing biomass feedstocks. The GHG emissions lifecycle data of the different primary energy sources for power production is presented in Figure 5. 
- All values in $\mathrm{kgCO} 2 \mathrm{eq} / \mathrm{MWh}$

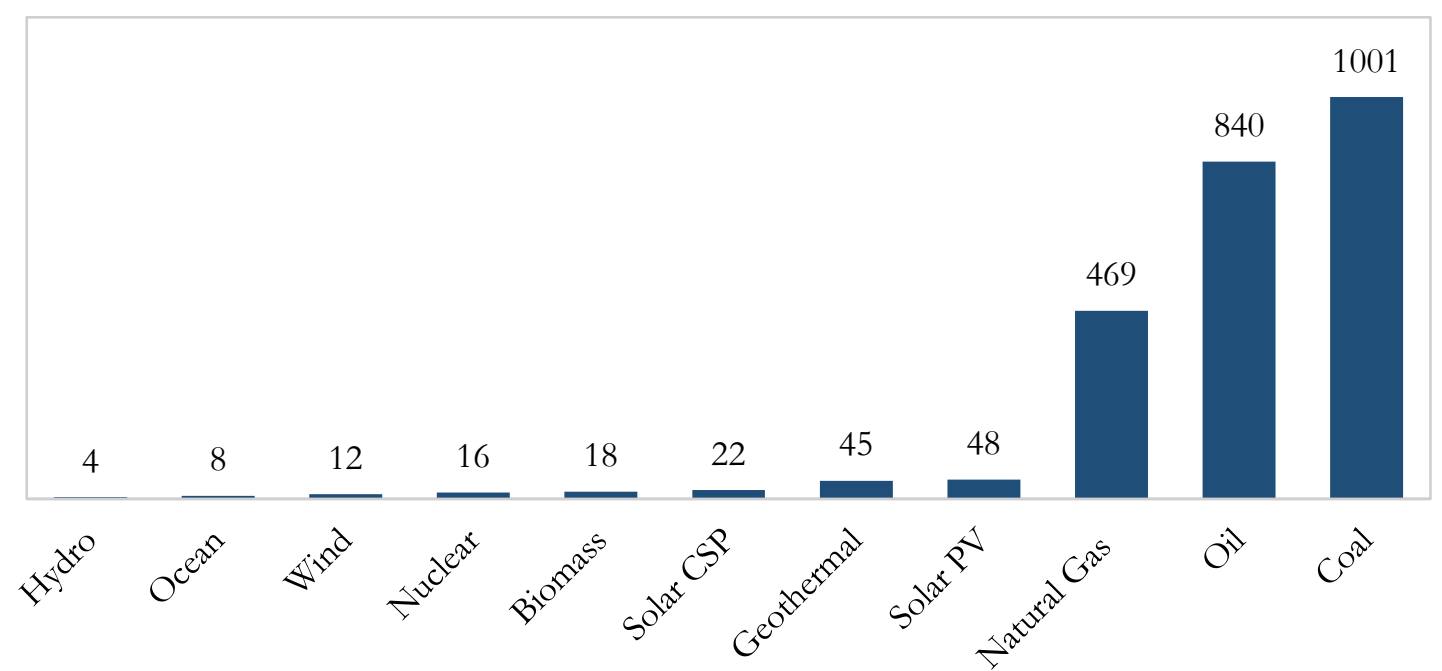

Figure 5 Carbon intensity of different sources for electricity generation [2]

Evidently, fossil fuels have the highest carbon intensity, led by coal. Coal presents a low capital investment to generate energy, but the combined expansion of renewable sources (wind and solar) with increasing $\mathrm{CO}_{2}$ prices are beginning to present a significant negative influence on coal investment returns [4]. Still, thermal power plants (primarily coal fuelled) will still outcompete clean energy production in the developing world, and will be prioritized over climate change policies in developing economies. As stated before, CCS will become attractive when a sufficient $\mathrm{CO}_{2}$ emissions price is adopted, with an initial focus on retrofit of existing plants. Next generation CCS power plants will become a reality by 2040, offering higher flexibility, lower energy penalties and $\mathrm{CO}_{2}$ avoidance costs [5], and therefore the conceptual design and evaluation of these plants will be the focus of the following chapters.

\subsubsection{Conventional $\mathrm{CO}_{2}$ Capture Technologies}

\section{Post-combustion $\mathrm{CO}_{2}$ Capture}

The initial steps to carbon emission mitigation in fossil fuel power generation plants will be the retrofitting with CCS technology based on post-combustion capture. In existing thermal plants, the combustion of a fuel (be it natural gas or coal) takes place with a large stream of air, which provides the oxygen for combustion, significantly above the stoichiometric requirements. This results in an exhaust $\mathrm{CO}_{2}$-diluted output stream from the power plant. Recovering this $\mathrm{CO}_{2}$ efficiently and cost effectively is a challenge; the benchmark technology to retrieve the $\mathrm{CO}_{2}$ from the plant exhaust consists of an absorption- desorption process using methyl-ethanol amine (MEA). Research and development effort has lately focused on the development of more advanced solvents, sorbents and membranes for the separation, and hybrid technologies are being investigated. In this short introduction, the main considerations for a post combustion capture system based on absorption are detailed, based on the outcomes of the reference study [6]. A basic block flow diagram is presented in Figure 6, for typical coal and natural gas fired power plants. The blocks contained in the dashed line are particular of each specific fuel, while the remaining elements are common to both plants. 


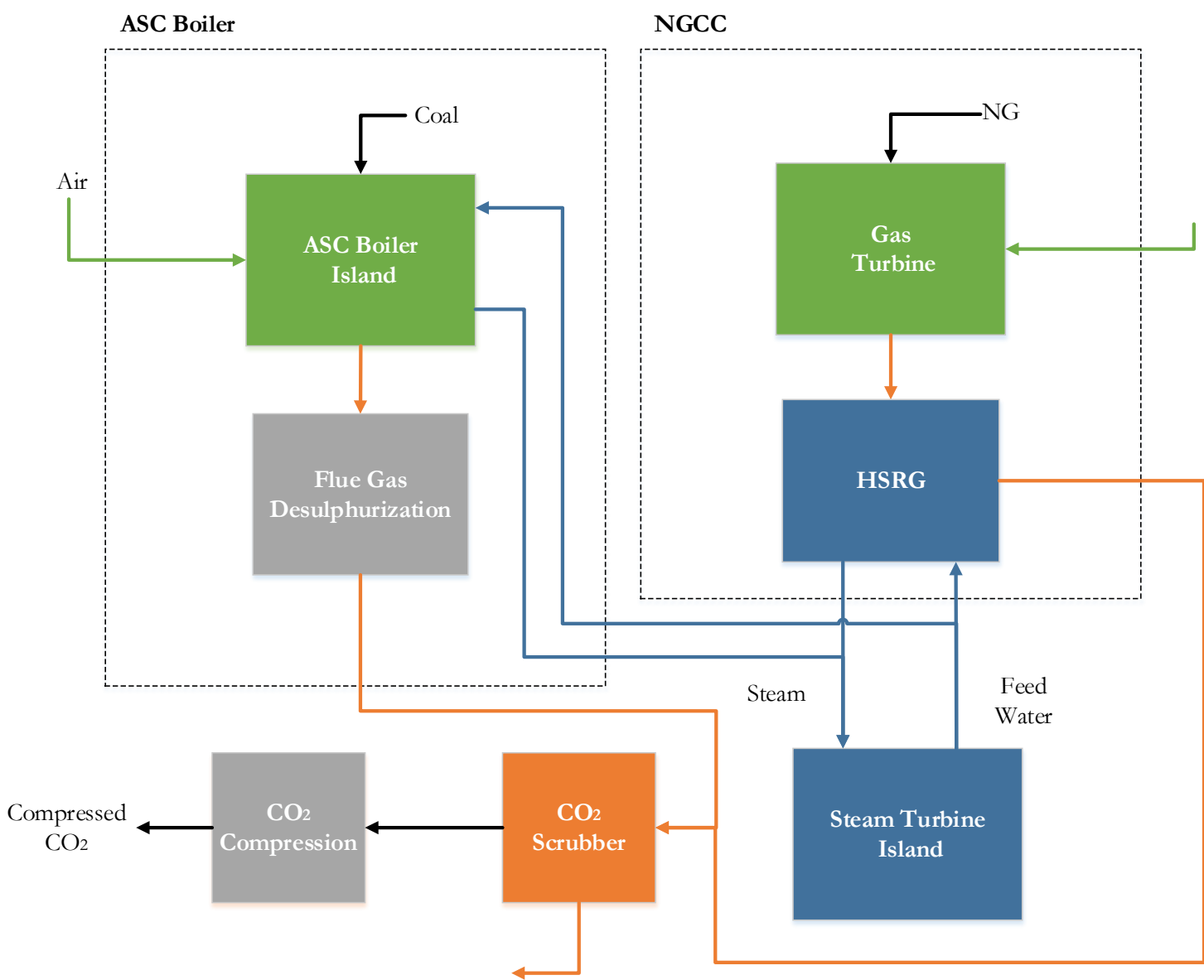

Figure 6 Block flow diagram of post-combustion $\mathrm{CO}_{2}$ capture plants for solid and gaseous fuels

A chemical solvent is used because the boiler flue gas or gas turbine exhaust (depending the type of power plant) is typically at about atmospheric pressure, with a resulting low $\mathrm{CO}_{2}$ partial pressure. The solvent reacts with the $\mathrm{CO}_{2}$, thereby improving the absorption capability, relative to that that would be achieved with a physical solvent. The main inconvenient of using a chemical solvent, is that it requires heat for the regeneration in a stripper column at close to ambient pressure. This regeneration duty is usually provided by low pressure steam extracted from the steam power cycle. A schematic of the absorption-desorption set up is given in Figure 7: 


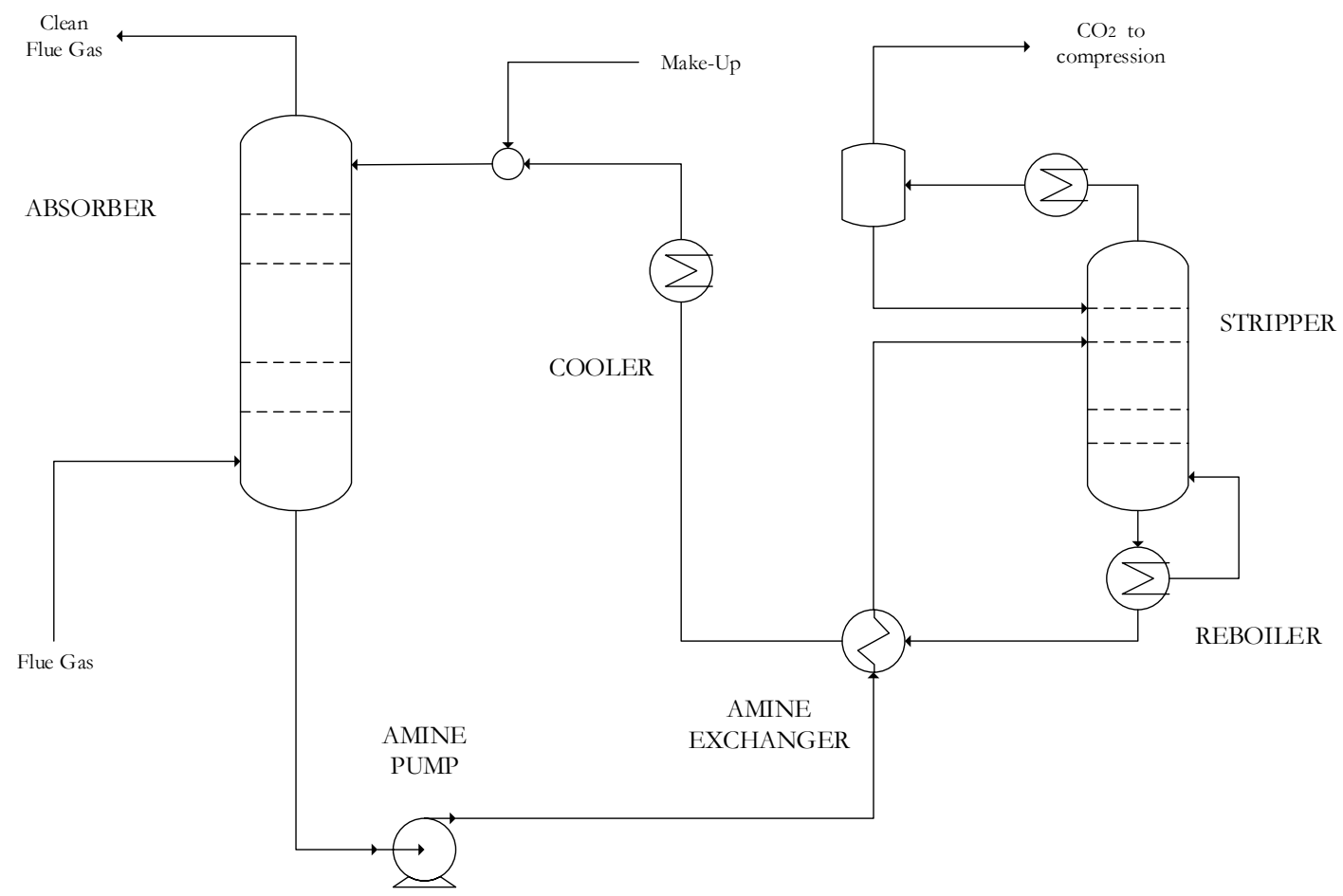

Figure 7 Absorption-desorption process for post-combustion $\mathrm{CO}_{2}$ capture

For an MEA solvent, the steam regeneration conditions are typically at around $135^{\circ} \mathrm{C}$ and 3 bar. The flue gas composition in a post-combustion capture plant for an Advanced Supercritical Coal (ASC) boiler delivering approximately $800 \mathrm{MW}$ gross output is approximately $14 \% \mathrm{~mol}$, whereas for a Natural Gas Combined Cycle (NGCC) power plant of comparable output it has a composition of only $4 \% \mathrm{~mol} \mathrm{CO}_{2}$. Since a non-negligible amount of steam must be extracted from the steam turbine for solvent regeneration, the power output of the steam cycle is reduced. Furthermore, an air fan with a substantial auxiliary consumption must be introduced to overcome the pressure losses caused by the additional flue gas cooler after the boiler/HSRG and the absorption column, while some additional power must be supplied to the recirculating pumps between the absorber and the stripper. Finally, the near pure $\mathrm{CO}_{2}$ stream is obtained at the stripper column tops at ambient pressure. An intercooled compression train and a supercritical pump are used to reach the $\mathrm{CO}_{2}$ delivery pressure (typically around $150 \mathrm{bar}$ ), with a high power requirement. All these items contribute to an important energy penalty relative to the plants without capture, as illustrated in Table 2 for both types of plants without and with a capture rate of approximately $90 \%$ of $\mathrm{CO}_{2}$.

Table 2 Thermal efficiencies for power plants without capture and post-combustion $\mathrm{CO}_{2}$ capture with MEA [6]

\begin{tabular}{|c|c|c|}
\hline Plant / Item & $\begin{array}{c}\text { Net Electric Efficiency } \\
\text { (no capture) } \%\end{array}$ & $\begin{array}{c}\text { Net Electric Efficiency } \\
\text { (CCS with MEA) } \%\end{array}$ \\
\hline NGCC & 58,3 & 49,9 \\
\hline ASC Boiler & 45,5 & 33,4 \\
\hline
\end{tabular}

\section{Pre-combustion $\mathrm{CO}_{2}$ capture}

The large energy penalties reflected in Table 2 opened the pathway to research different capture strategies. Pre-combustion capture consists of a partial oxidation of the primary fuel with oxygen and/or steam to produce a syngas, a gaseous fuel consisting primarily of carbon monoxide (CO) 
and hydrogen $\left(\mathrm{H}_{2}\right)$. The $\mathrm{CO}$ present in this stream is reacted with steam to deliver a $\mathrm{H}_{2}$ rich fuel with $\mathrm{CO}_{2}$ through the Water Gas Shift (WGS) reaction. A detailed description of pre-combustion capture process for power generation can be found in [7].

$$
\mathrm{CO}+\mathrm{H}_{2} \mathrm{O} \rightarrow \mathrm{H}_{2}+\mathrm{CO}_{2} \quad \Delta H^{0}=-41 \mathrm{~kJ} \mathrm{~mol}^{-1} \quad \text { Eq. } 1
$$

The 'shift conversion' is followed by a $\mathrm{CO}_{2}$ separation stage. The concentration of $\mathrm{CO}_{2}$ on a dry basis is typically between $15-60 \% \mathrm{~mol}$ and the stream has a total pressure in the range of 20-70 bar. Thus, the $\mathrm{CO}_{2}$ separation and subsequent compression is less energy intensive than the postcombustion process. However, the generation of the oxidant stream in an air separation unit (ASU) for partial oxidation of natural gas or gasification of coal and the additional steam requirement of the WGS reaction (and steam reforming in case of natural gas) balance out the reduced energy requirements.

The main steps for pre-combustion capture processes can be summarized in 1) $\mathrm{O}_{2}$ generation 2) syngas production 3) $\mathrm{CO}_{2}$ separation \& compression and 4) power island. These are represented in Figure 8 for power plants using natural gas and coal as fuels (dashed lines indicate plant components inherent to each specific fuel). This diagram foreshadows the power plant configuration that will be the subject of analysis in subsequent chapters: the Pre-combustion $\mathrm{CO}_{2}$ capture Integrated Gasification Combined Cycle (IGCC) power plant. In the case of natural gas as primary fuel, the typical configuration consists of a Steam Methane Reforming (SMR) unit, carried out at approximately $900^{\circ} \mathrm{C}$, or an autothermal reforming heat exchanger unit where the heat for reforming is produced from combustion of part of the $\mathrm{H}_{2}$ rich fuel. For solid fuels (coal, biomass, oil residues etc.), syngas is produced through gasification technology and an elaborate gas clean up section to eliminate particulates, sulphur and other contaminants. The common WGS unit usually consists of two catalyst beds with the bulk conversion taking place in the first adiabatic reactor: the mildly exothermic reaction favours the equilibrium to the products of Eq. 1 at low temperatures, therefore an interstage cooler helps to achieve very high conversions in the second bed. When the syngas contains sulphur, a sour shift catalyst is used [8]. This is typically the preferred case for IGCC plants, as the feed desulphurization at low temperatures and reheating prior to the combustion chamber results in a significant efficiency loss. 


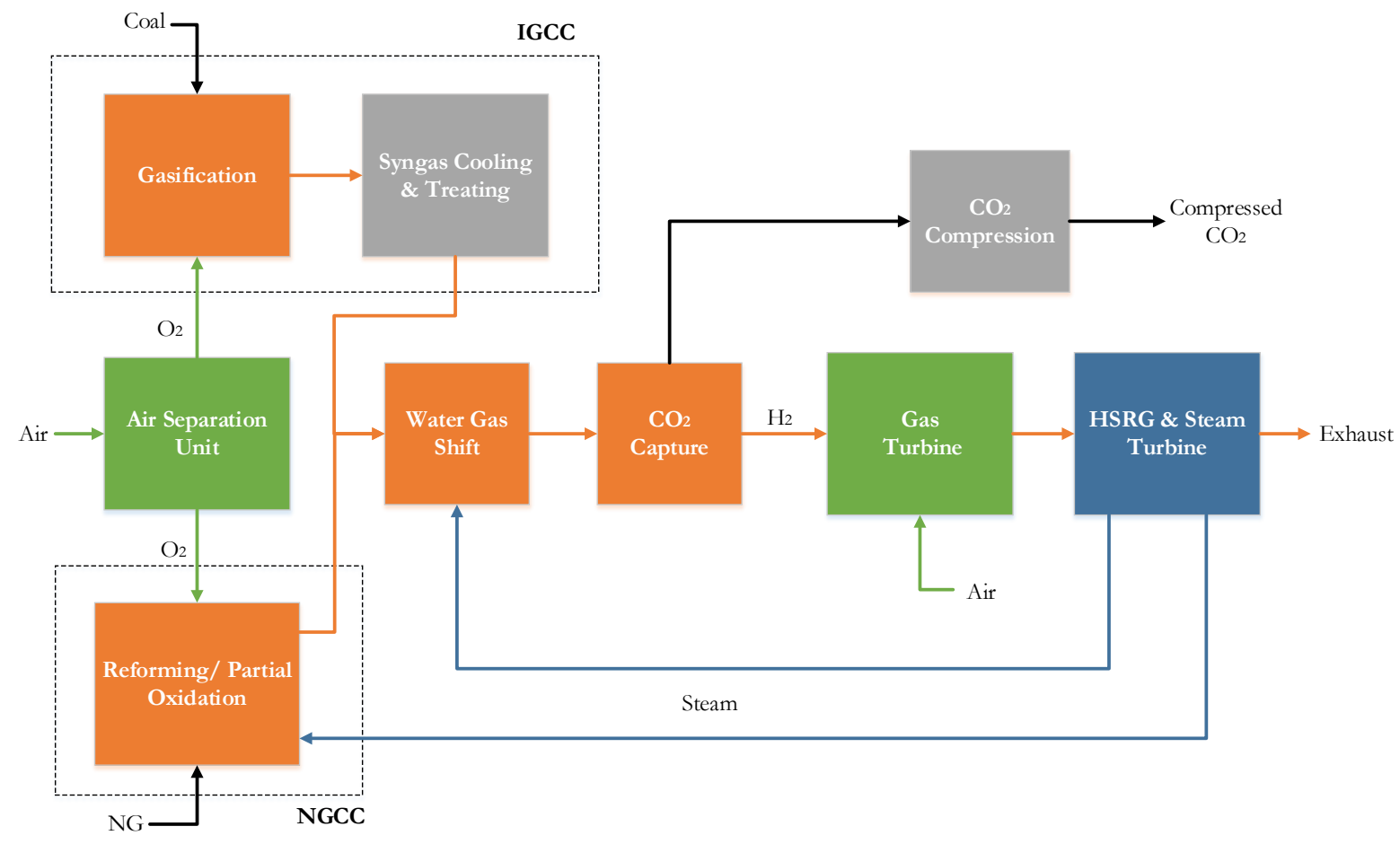

Figure 8 Block flow diagram of pre-combustion $\mathrm{CO}_{2}$ capture plants for gaseous and solid fuels

A large excess of steam is used in the WGS reactors for several reasons. Firstly, it drives the equilibrium to a high conversion of the $\mathrm{CO}$, while limiting the adiabatic temperature rise. Finally, a large steam to $\mathrm{CO}$ ratio in the feed prevents undesired side reactions like methanation which damage the catalyst.

Due to the high partial pressure of $\mathrm{CO}_{2}$ in the product stream of an IGCC syngas, produced by gasification, a physical solvent is usually employed to remove it from the $\mathrm{H}_{2}$ fuel, which results in higher efficiencies as low energy is required for solvent regeneration as opposed to chemical absorption. There are many separation technologies available, with the flexibility to retrieve $\mathrm{CO}_{2}$ and $\mathrm{H}_{2} \mathrm{~S}$ separately, with usual capture rates of up to $90 \%$. The resulting thermal efficiency penalization for these type of plants with CCS, which are currently commercially available, is typically in the range of 7 to $12 \%$-points. For natural gas, several economic assessments [9] reveal that pre-combustion $\mathrm{CO}_{2}$ capture is less attractive than post-combustion capture, with similar and even higher efficiency penalties. A relevant concern related to power producing systems with precombustion $\mathrm{CO}_{2}$ capture is the specific adaptations that must be implemented in gas turbine technology for secure operation with $\mathrm{H}_{2}$ rich fuels [10].

\section{Oxy-combustion $\mathrm{CO}_{2}$ capture}

A completely different approach for $\mathrm{CO}_{2}$ capture consist of using this component as working fluid in a semi closed power cycle. This eliminates entirely the disadvantage of diluted $\mathrm{CO}_{2}$ contained in the exhaust gases that employ air in an open cycle, as the flue gases mainly consist of $\mathrm{H}_{2} \mathrm{O}$ and $\mathrm{CO}_{2}$. To achieve this, an air separation must be used to deliver an almost pure $\mathrm{O}_{2}$ stream to carry out the combustion, and an adequate recirculation and recompression of the $\mathrm{CO}_{2}$ must be implemented to control the temperatures attained in the power cycle. Since the component characteristics are different from air, the optimal pressure ratios employed $\mathrm{CO}_{2}$ cycles with gas turbines is around $40 \mathrm{bar}$, requiring a redesign of the axial compressor and expander. Also, the 
$\mathrm{CO}_{2}$ combustors are currently experiencing technology development to reach commercial availability. If the $\mathrm{O}_{2}$ purity is not sufficiently high, a purification step must me included prior to the compression of $\mathrm{CO}_{2}$ to meet the transport and storage specifications [11]. The oxy-combustion principle can be applied to a wide variety of plants using gaseous (NGCC) and solid (ASC boiler, IGCC) fuels, with the common element of an energy consuming system (typically an ASU) to provide a pure oxidant stream. The bottoming steam cycle may be replaced by a regenerative heat exchanger (Allam cycle). [12] provides a detailed technical and economic analysis of the different oxy-combustion configurations. A simplified schematic is given in Figure 9 for a semi closed oxycombustion IGCC plant.

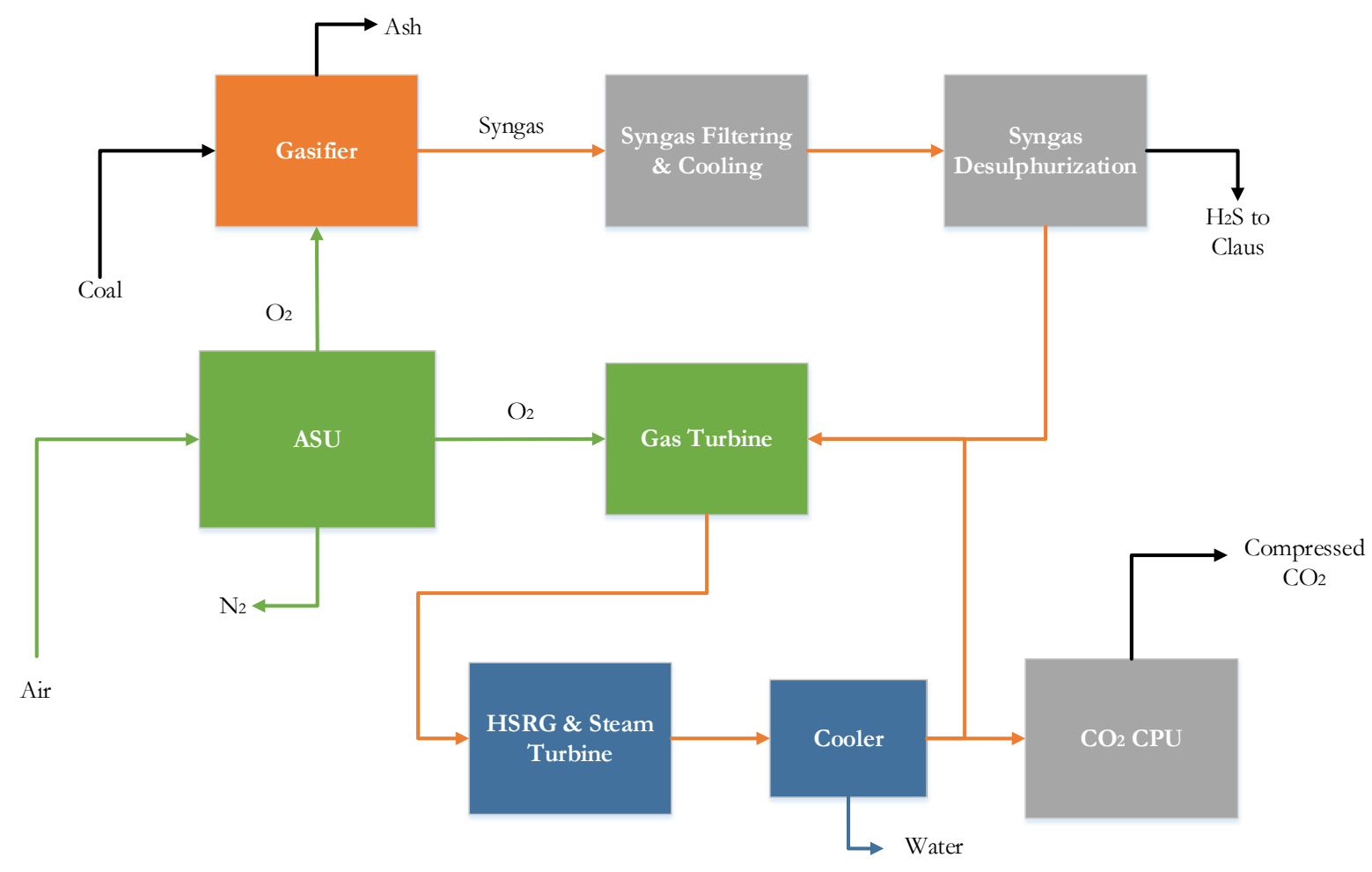

Figure 9 Block flow diagram of an oxy-combustion $\mathrm{CO}_{2}$ capture IGCC plant

For plants using coal as primary energy fuel with gasification, the oxy-combustion process has a slightly lower thermal efficiency than the pre-combustion $\mathrm{CO}_{2}$ capture plant and substantially higher capital costs. Despite this, oxy-combustion gasification plants allow to introduce the benefits of hot gas desulphurization, which is not useful for pre-combustion plants, as the syngas must be cooled for $\mathrm{CO}_{2}$ removal. This can allow a comparatively improved thermal efficiency of around $2 \%$-points [13]. In any case, the thermodynamic efficiency of the ASU and $\mathrm{CO}_{2} \mathrm{CPU}$ critically affect the overall erformance of the oxy-combustion cycle, to a greater extent than in precombustion capture. For ASC coal boilers and NGCC's, oxy-combustion capture technologies show more competitive economic potential with respect to post-combustion capture processes, with similar efficiency penalties and lower attainable specific emissions. Finally, from an environmental point of view, oxy-combustion cycles completely eliminate the problem of $\mathrm{NOx}$ formation.

\subsubsection{Chemical Looping: Inherent Carbon Capture}

An effective strategy to reduce the energy penalty of $\mathrm{CO}_{2}$ capture in fossil fuel plants known as Chemical Looping Combustion (CLC) was proposed by [14]. The basic concept of CLC consists 
of isolating the combustion reaction of the fuel from the air stream used in the power cycle. In this way, an inherent carbon separation prevents $\mathrm{CO}_{2}$ dilution in the exhaust gases, and almost a pure stream with the products of combustion is obtained ready for compression and storage after water knock out. The means by which the necessary oxygen molecules are delivered to combust the fuel is a metal oxygen carrier. The metal carrier is reduced in the fuel reactor and then transported back to an air reactor where it is re-oxidized, heating the air stream as a result of the exothermic nature of the reaction. The set up consists of interconnected fluidized bed reactors as depicted in Figure 10:

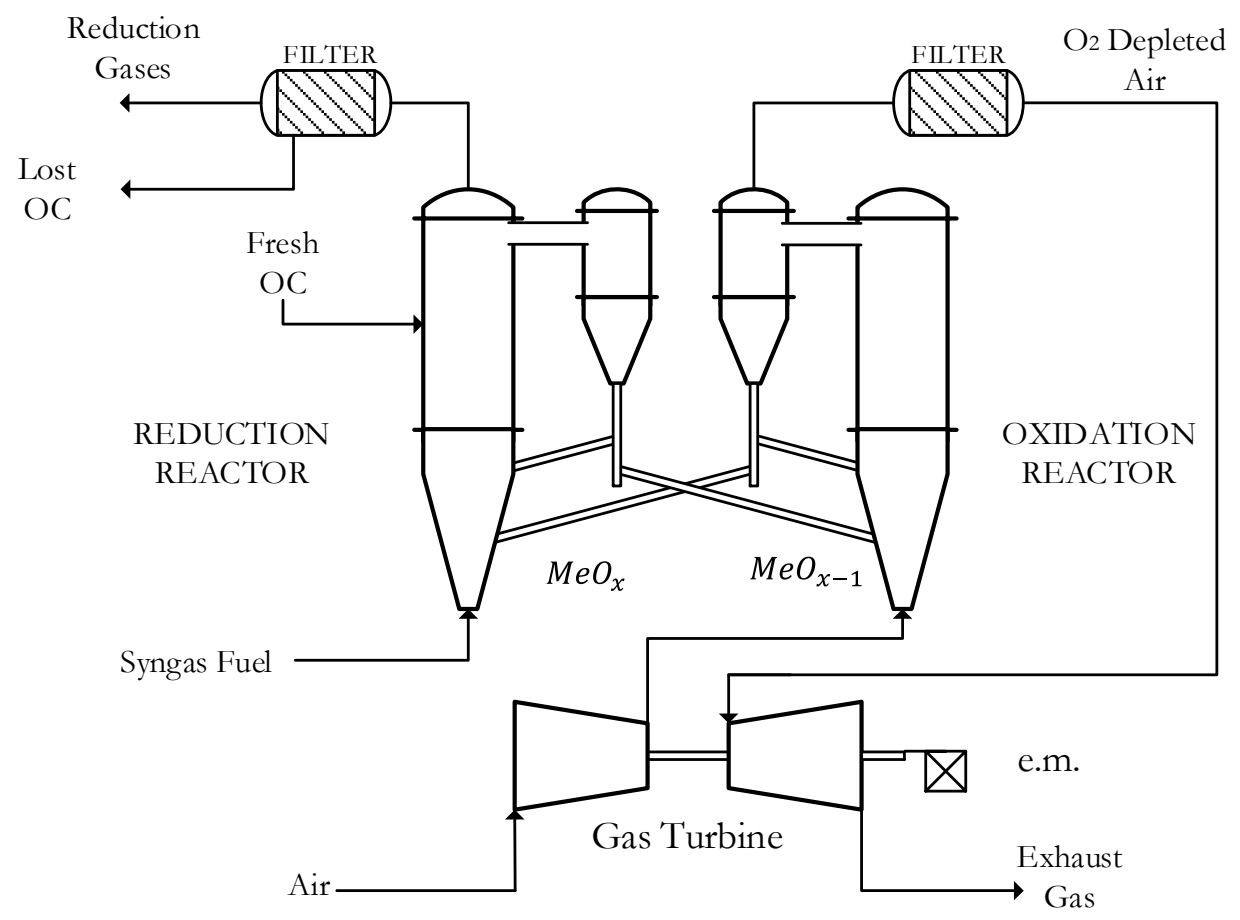

Figure 10 Basic gas-fuelled CLC layout with interconnected fluidized beds

CLC has no intrinsic energy penalty (beyond the auxiliary consumption of $\mathrm{CO}_{2}$ compression) when operated at atmospheric pressures. However, for gaseous fuels indirect Rankine cycles result in very low efficiencies compared to configurations using a Brayton (topping) cycle followed by a Rankine (bottoming) cycle to retrieve energy from the exhaust gas, achieving higher working fluid hot temperatures [15]. These cycles however must operate at pressurized and sufficiently high temperature conditions (typically around 20 bar and $1200^{\circ} \mathrm{C}$ or higher) to attain attractive efficiencies.

To operate at elevated pressure poses a significant challenge for the reactor system, with the need of a very careful control of the circulation of solids across the two reactors due to the complex hydrodynamics, which has led to a very slow progress of CLC scale up. In the 15 years, only one study of gas fuelled CLC has been completed [16], with reactor pressure of only 5 bar. Furthermore, it must be ensured that an appropriate oxygen carrier inventory in each reactor is achieved to attain maximum conversion, maintaining the system thermally balanced with the right amount of energy transfer. CLC dual fluidized systems have therefore relatively low flexibilities to different compressor air feed rates resulting from part load operation of the power cycle. Finally, a pressurized operation also helps to reduce the $\mathrm{CO}_{2}$ compression requirements downstream the reduction reactor. An extensive review of CLC systems using fluidized beds is given in [17]. The aspect of flexibility will become of paramount importance in new generation fossil fuel plants with 
CCS, as the ability to balance variable renewables will result in a key feature to their competitiveness.

Solid-fuelled CLC has been proposed to avoid pressurized operation and has shown more promising results in terms of scale-up, but introducing a solid fuel to the reactor creates new challenges such as fuel slip, the need of a carbon stripper unit to avoid char presence in the air reactor and also requires a very low cost oxygen carrier with acceptable active lifetime. Chemical Looping Combustion of solid fuels requires a high solid fuel conversion but also a high gas conversion, while attaining acceptable $\mathrm{CO}_{2}$ capture. This becomes a challenge when the syngas released from the char particles is generated through all the reactor volume, (i.e. also in the upper region of the reduction reactor), and achieving complete conversion of the gases is problematic. To circumvent this issue, chemical looping with oxygen uncoupling (CLOU) is proposed, where the oxygen carrier releases free oxygen in the fuel reactor to achieve complete gas combustion [18].

Overall, although solid fuelled CLC presents some advantages and similarities to well-known circulating fluidized bed combustion of coal, it is uncertain whether oxygen carrier materials will be available at reasonable costs, and in the scale up of the fuel reactor system to achieve high performances is still needed. $\mathrm{CO}_{2}$ capture may be hindered due to char reaching the air reactor caused by the solids circulation, unless a carbon stripper to separate the unconverted char from the oxygen carrier is introduced between the air and fuel reactors, thus incurring in additional costs. However, due to the intrinsically high efficiencies of solid-fired CLC process with theoretically $100 \%$ capture efficiencies, the $\mathrm{CO}_{2}$ avoidance costs have been estimated to be as low as $10 € /$ ton [19]. These configurations have been demonstrated at laboratory and small pilot scales [20], but have encountered substantial operational issues arising from the interconnected reactor design, making pressurized operation of CLC a challenging endeavour.

An intrinsic advantage of CLC systems is that the gaseous outlet from the oxidation reactor is completely free of SOx (as there is no direct contact with the fuel) and also there are also no NOx compounds due to the flameless combustion. Any sulphur or nitrogen combustion product is obtained in the reduction gases of the fuel reactor system, which are more easily separated downstream because of the smaller stream flow rate.

The challenge remains, therefore, in the development of strategies that will allows us to reap the advantages of CLC systems, without incurring in the intrinsic drawbacks of scale up under pressurization and flexibility for power modulation. With this purpose, the Gas Switching (GS) reactor concept has been proposed [21], and will be thoroughly developed in Chapter 2 .

\subsection{Integrated Gasification Combined Cycles (IGCC)}

\subsubsection{Overview of IGCC plants}

Gasification is usually related to power generation, however, it has several more applications. For instance, if the syngas product from gasification is shifted to reach the desired $\mathrm{H}_{2} / \mathrm{CO}$ ratio it can be later employed to synthesize or methanol (2:1) [22], a building block of the petrochemical industry. If the syngas is completely shifted to $\mathrm{H}_{2}$, ammonia [23], which is the base chemical for fertilizer production, can be manufactured through reaction with pure $\mathrm{N}_{2}$. Another interesting application is the generation of high molecular weight hydrocarbons through the Fischer-Tropsch synthesis [24], which usually requires a $\mathrm{H}_{2} / \mathrm{CO}$ ratio slightly above 2:1. The variety of feedstock/product possibilities involving gasification are summarized in Figure 11: 


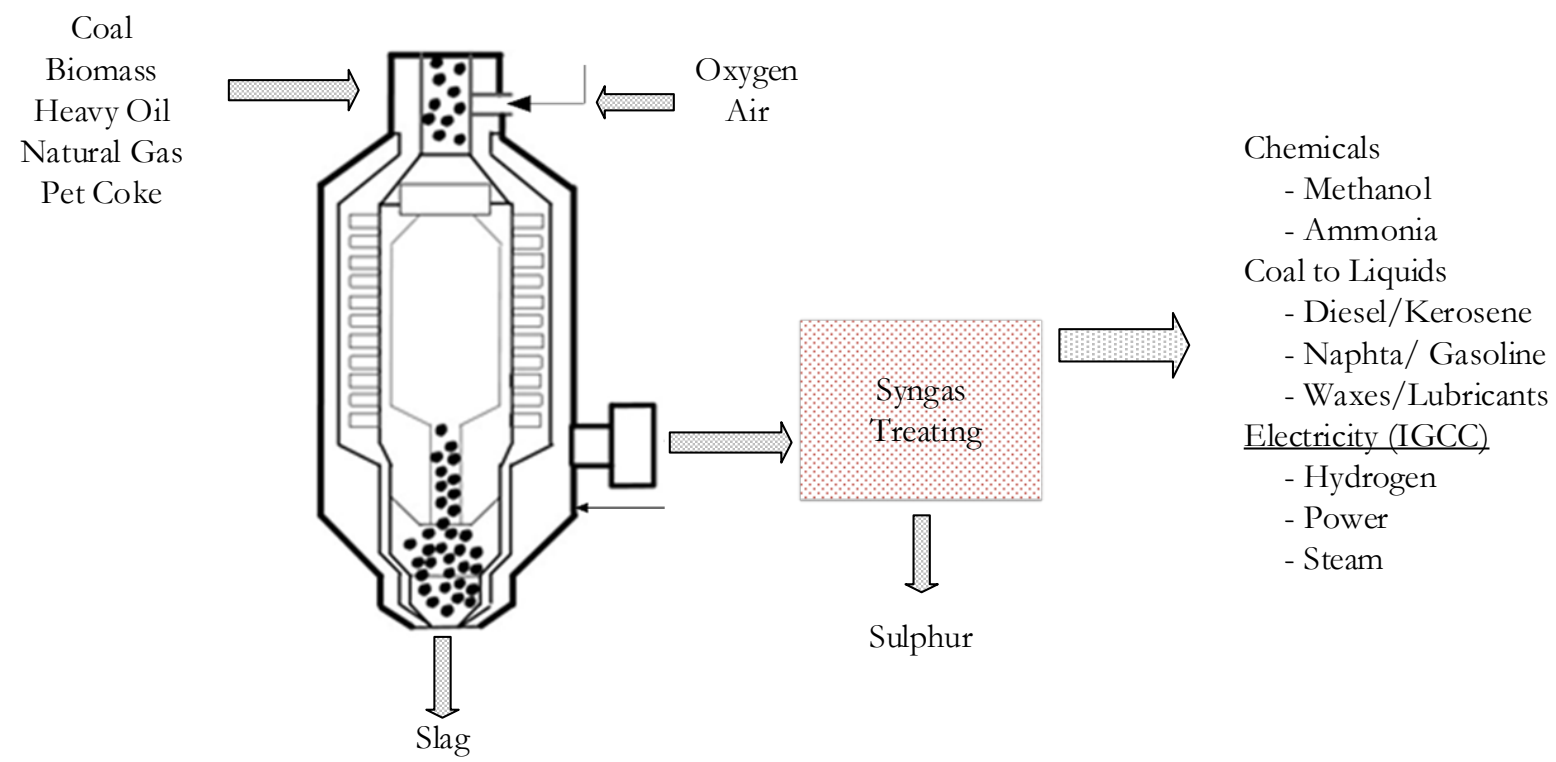

Figure 11 Applications of gasification

Nonetheless, the focus of this work will be in electricity generation through gasification of a solid fuel feedstock. The fuel gas generated in a gasification process is cleaned from contaminants and fed to a gas turbine combustor with compressed air and expanded in the turbine to produce electricity through a generator. The hot flue gases from the GT are routed to a steam generator; the steam is expanded in a steam turbine to generate more electrical power. The basic layout of an IGCC plant without $\mathrm{CO}_{2}$ abatement is depicted in Figure 12, where the pure $\mathrm{O}_{2}$ supplied to the gasifier is usually generated in an Air Separation Unit (ASU):

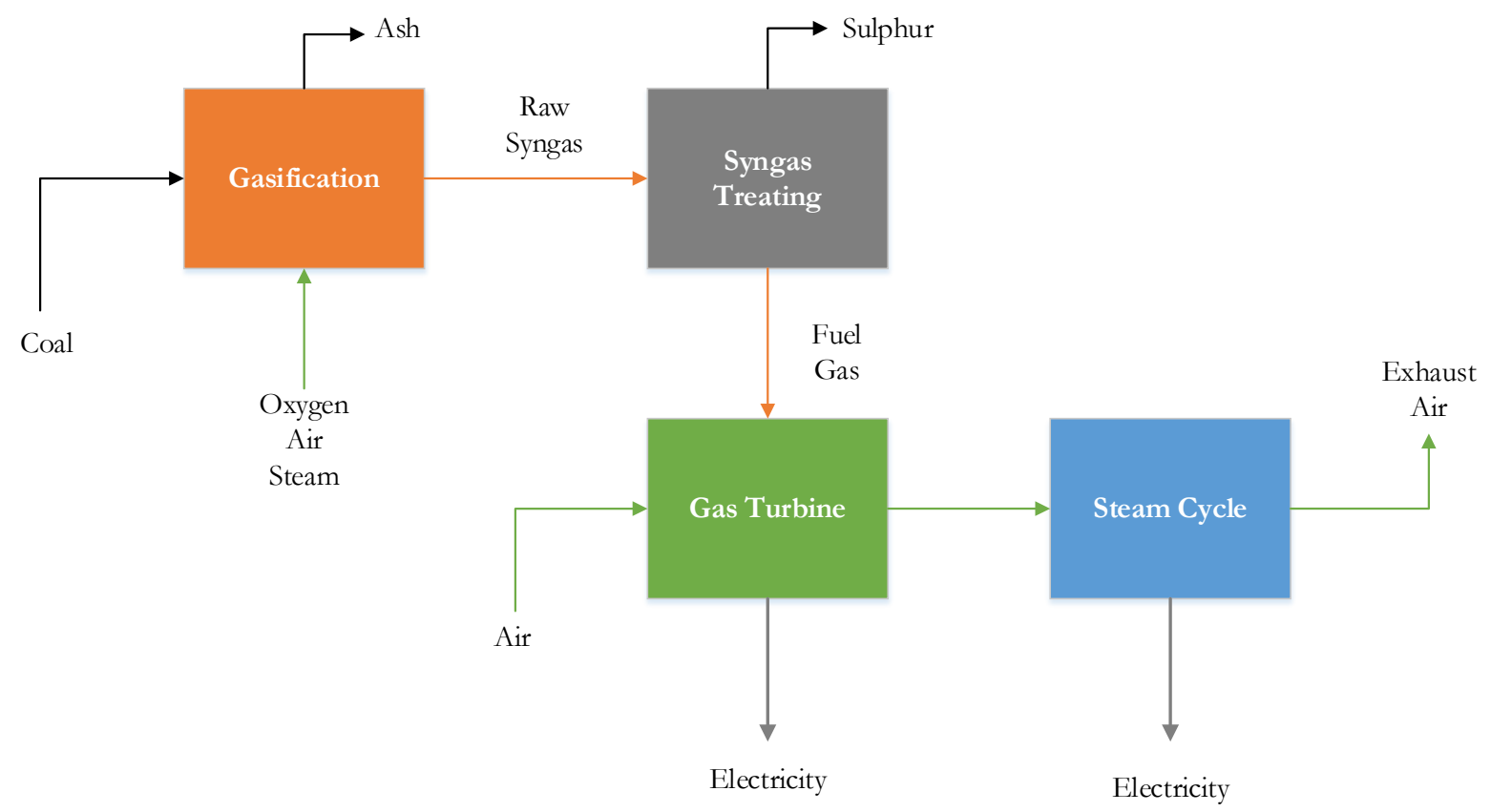

Figure 12 Main IGCC plant components

The syngas treating section usually involves the cooling of syngas to low temperatures and the elimination of particulate material entrained by the raw syngas from the gasifier through syngas 
filtration and scrubbing. Other harmful contaminants besides sulphur derived substances $\left(\mathrm{H}_{2} \mathrm{~S}\right.$, COS) are hydrogen chloride (HCL) and ammonia $\left(\mathrm{NH}_{3}\right)$, which are eliminated downstream typically with absorption units. Gasification offers a relevant alternative relative to direct combustion technologies to convert solid carbonaceous feedstocks such as coal, biomass or waste material into electricity. IGCC can be more efficient than PCB technology by utilizing the combined cycle (Brayton + Rankine), comparatively reaching higher temperatures in the process of electricity generation and thus achieving higher thermodynamic efficiencies, as outlined in section 1.3.2. Furthermore, IGCC presents several environmental advantages compared to traditional coal boilers, as described in section 1.4.2, mainly due to the fact that the syngas fuel is cleaned before it's combustion in the gas turbine, where the components are found concentrated and pressurized. In addition to this, in IGCC power plans the water consumption is reduced because comparatively less heat is rejected in the steam cycle condenser, thereby reducing the water make-up requirements of the cooling water tower (as it is lost by evaporation). Some of the major examples of IGCC plants which have been commercialized are listed in Table 3:

Table 3 Commercial IGCC plants [25]

\begin{tabular}{|c|c|c|c|}
\hline Name & $\begin{array}{c}\text { Electricity } \\
\text { Output }\end{array}$ & Start up & Gasification \\
\hline $\begin{array}{c}\text { Tampa Electric, Polk } \\
\text { County }\end{array}$ & $250 \mathrm{MW}$ & 1996 & GE Gasifier \\
\hline $\begin{array}{c}\text { Wabash, West Terre } \\
\text { Haute }\end{array}$ & $265 \mathrm{MW}$ & 1995 & $\begin{array}{c}\text { CB\&I E-Gas } \\
\text { Gasifier }\end{array}$ \\
\hline Nuon, Buggenum & $250 \mathrm{MW}$ & Start-up in 1994, shutdown in 2013 & Shell Gasifier \\
\hline Elcogas, Puertollano & $300 \mathrm{MW}$ & Start-up in 1997, shutdown in 2016 & Prenflo Gasifier \\
\hline $\begin{array}{c}\text { Edwardsport IGCC } \\
\text { Station, Indiana }\end{array}$ & $618 \mathrm{MW}$ & Commercial operations in 2013 & GE Gasifier \\
\hline $\begin{array}{c}\text { Nakoso IGCC, Japan } \\
\text { Experimental demo start-up 2007, } \\
\text { commercial operations in 2013 }\end{array}$ & MHI Gasifier \\
\hline
\end{tabular}

Nevertheless, IGCC has encountered several challenges to establish itself as a commercial power production technology. The high specific costs are the most important deterrent to reach IGCC acceptance. Compared to PCB and NGCC, IGCC capital costs are high, and require more development and have higher design costs due to the large process complexity. Finally, the availability of the plants is a critical factor to ensure its competitiveness, since the pioneering plants built in the 90's in Europe and the US experienced several problems during the initial years of operation. Despite this, future advances in several of the plant key sections will provide a higher efficiency, reduced capital cost and life cycle costs and improved availability. These technology enhancements are:

- Advanced Gas Turbines: Capable of firing $\mathrm{H}_{2}$ /Syngas with equivalent firing temperatures to natural gas GT. The technological developments are incorporated to the GT specifically designed to run on a $\mathrm{H}_{2}$-rich fuel without the need of derating, incorporating improved blade cooling technology. The advanced GT will produce more electric power more efficiently, increasing the coal input and benefiting from economies of scale to reduce specific capital costs.

- Warm (Hot) Gas Clean Up: This technology replaces the low temperature absorption units for syngas contaminant removal, carrying out these tasks at high temperatures and avoiding the efficiency losses related to cooling and reheating of the fuel [26]. 
- Ion Transport membranes (ITM): the ITM based oxygen production unit can replace a conventional ASU. The auxiliary consumption is overall similar to that of the ASU, given that the products are needed at pressurized conditions $\left(\mathrm{O}_{2}\right.$ at gasification pressures and $\mathrm{N}_{2}$ at the combustor pressure for the fuel). However, ITM has the potential to reduce the cost of a highly capital intensive section.

- Hydrogen Membrane: This is applicable to pre-combustion $\mathrm{CO}_{2}$ capture schemes where syngas is shifted to $\mathrm{H}_{2}$. This allows the elimination of Selexol absorption units using a Palladium based membrane [27]. Efficiency benefits arise due to a smaller auxiliary consumption of the $\mathrm{CO}_{2}$ compression unit.

Amongst the technological advances described above, the Advanced Gas Turbines are included in all the power plant models with syngas and/or $\mathrm{H}_{2}$ firing, by adjusting the features of a reference F-class turbine designed to operate with natural gas [6]. In plants with chemical looping, the warm (or hot) gas clean up (HGCU) was also introduced. The membrane for $\mathrm{H}_{2}$ separation with some water gas shift catalyst to carry out the CO conversion simultaneously is extensively studied in detail with the aim of boosting the efficiency of plants with chemical looping plants, which are limited by low reactor temperatures. Also, a set of benchmark models (with and without CCS) using highly efficiency H-class turbines [28] and HGCU were developed. These issues will be presented in more detail in Chapter 4.

\subsubsection{Thermodynamics of Power Generation}

The attractiveness of IGCC plants has been justified from an efficiency point of view, arising from the higher combustion temperatures reached in the power cycle relative to coal boiler technologies. This section aims to provide a conceptual understanding of the thermodynamic cycles employed in the IGCC plant, starting from fundamental principles. The theoretical background presented here is a summary of the academic material shown in the subjects of Thermodynamics and Thermal Machines [29].

The first Principle of Thermodynamics applied to a physical system reveals that the transfer of energy in the forms and of heat and work, reaching and starting from equilibrium states, that is, states in which the macroscopic variables of the system do not change in time, corresponds to the change of a function of state known as Internal Energy U. If this system does not only exchange energy with its surroundings but it also exchanges mass with it, the system is referred to as an open system. The generalized form of the 1st Principle applied to an open system undergoing a nonstationary thermodynamic process is formulated in Eq. 2, where $U_{j}^{\prime}$ represents the total internal energy of system $\mathrm{j}, \dot{Q}_{j}$ is the heat flux across the boundary of the system $\mathrm{j}, \dot{W}_{j}$ is the work flux and $h_{i, j}^{\prime}$ represents the specific enthalpy of stream i entering or leaving system $\mathrm{j}$, with its corresponding mass flow rate $\dot{m}_{i, j}$. The superscript indicates that potential and kinetic energies are accounted for in the variables of state appearing in Eq. 2. The internal energy is a state function which only depends on the current equilibrium state of the system, defined by its state variables. A state function is independent of the thermodynamic processes undergone to arrive at a certain state. The functions of state have the mathematical advantage that they can be treated as potentials (which behave as total or exact differentials fulfilling the Schwarz relationship), and therefore the solving of the partial differential equations that arise from thermodynamic processes is relatively fast and straightforward.

$$
\frac{\partial U_{j}^{\prime}}{\partial t}=\dot{Q}_{j}-\dot{W}_{j}+\sum_{i} h_{i, j}^{\prime} \dot{m}_{i, j}
$$


Already in the XIX century, a French engineer with the name of Sadi Carnot made a philosophical dissertation [30], with no mathematical formulae, on the capacity of a thermal machine operating in a thermodynamic cycle to produce useful work from heat produced from burning a fuel. He determined the thermodynamic transformations taking place in an ideal thermal machine that would deliver the maximum amount of work to establish a reference for the improvement of the efficiency of existing steam machines. Setting the fundamentals of the Second Principle of Thermodynamics, later formulated mathematically by Clausius, he came to the conclusion that such ideal machine's efficiency would be only dependant on the temperature at which the heat was absorbed by the machine, and the temperature at which the remnant heat, that which was not transformed into work, was released. This is expressed mathematically by means of Eq. 3 . Conceptually, a hot temperature reservoir symbolized the combustion chamber where the fuel was burned, while a cold temperature reservoir represented the ambient, to which the "excess heat" was thrown. The conceptual representation of this thermal machine is depicted in Figure 13:

$$
\eta_{C}=\frac{W}{Q}=\frac{Q-Q_{0}}{Q}=1-\frac{Q_{0}}{Q}=1-\frac{T_{0}}{T} \quad \text { Eq. } 3
$$

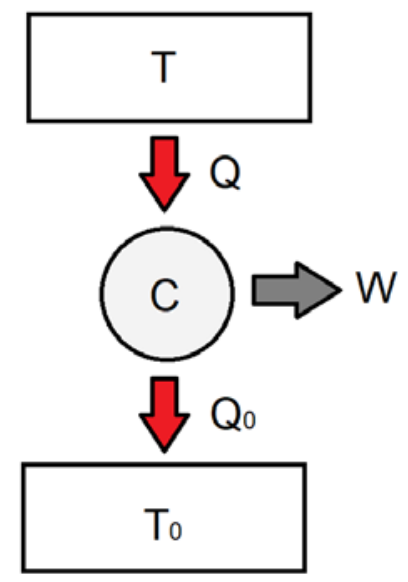

Figure 13 Schematic of a bi-thermal machine

The formulation of the Second Principle of Thermodynamics can be often seen from the perspective of these thermal machines and, as stated by Clausius, it says that "it is not possible to build a thermal machine which operates in a thermodynamic cycle capable of absorbing heat from a hot reservoir and transforming it entirely into work". At least a portion of the absorbed heat must be released to a cold reservoir (typically at ambient conditions). It is noteworthy to mention that the statement refers to a machine undergoing a thermodynamic cycle, meaning that at the sequence of thermodynamic process taking place within the thermal machine always results indefectibly in the initial thermodynamic state at which such sequence of thermodynamic transformations began. The usefulness of the $2^{\text {nd }}$ Principle resides in its ability to quantify the degree of irreversibility taking place in a thermodynamic process, giving a quantitative understanding of the quality of the energy exchanged in a system. However, the mathematical formulation of this is accessible without the need of recurring to bi-thermal machines, albeit being a less intuitive pathway. Constantin Carathéodory employed the Pfaffian differential equations [31] as the mathematical axiomatic base to present entropy $S$ as a state function, through an integrating factor: $1 / \mathrm{T}$ for the differential form of the internal energy, such that it had the useful properties (for PDE solving) of the exact differentials. The application of the entropy balance to an open system $\mathrm{j}$ in the most generalized form is presented in Eq. 4. This balance allows a fast calculation 
of the energy that is spoiled due to irreversibility. In fact, when the thermodynamic process undergone by the system is adiabatic, this spoiled energy actually coincides with the function of state. In other words, for a process to be isentropic it must be adiabatic and reversible.

$$
\frac{\partial S_{j}}{\partial t}=\int \frac{d \dot{Q}_{j}}{T}+\dot{\sigma}_{j}+\sum_{i} s_{i, j} \dot{m}_{i, j}
$$

The IGCC power plants that are the subject of this study are composed of several interconnected open systems exchanging energy, in the forms of heat and work, and mass, as process flow streams. In the case of a system operating under stationary conditions, the variables of state remain constant in time, thus facilitating the balance calculations. The boundary of the system can be selected at will, incorporating within it as many process units or plant subsections as it is convenient.

The fundamental principle of the thermal machine composed of many systems is the supply of heat from the combustion of a fossil fuel to obtain electrical power from it. The design of the real thermal machine is conceived such that the thermodynamic cycle that it undergoes mimics as closely as possible the ideal Carnot cycle which yields the highest efficiency. Two main cycles are considered:

- A Brayton cycle is an open thermal machine with internal combustion, using an air stream as working fluid which is used to combust the fuel. The essential systems which compose this machine are an adiabatic compressor, a combustion chamber and a gas expander. A simple layout of the machines is given in Figure 14 (above)

- A Rankine cycle is a closed thermal machine with external combustion (i.e. the fuel is not mixed with the working fluid). Its basic design consists of a water pump, a boiler (evaporator), steam turbine and a condenser unit. A schematic of the cycle is provided in Figure 14 (below)
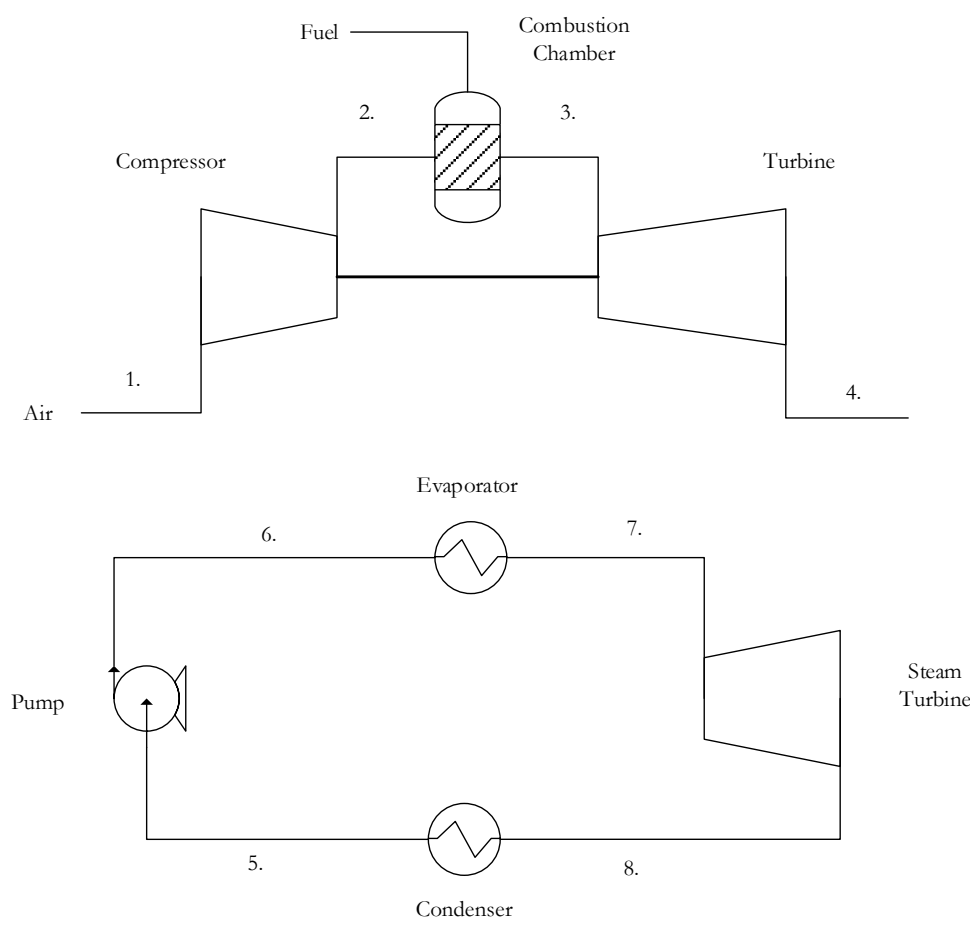

Figure 14 Brayton Cycle (above) and Rankine cycle (below) 
Although the Brayton (topping) cycle is an open system in which composition changes occur due to the chemical combustion of the fuel, it can also be viewed as an approximation to a closed system where the exhaust gas stream is cooled down with the working fluid of the Rankine (bottoming) cycle, as shown in Figure 15:

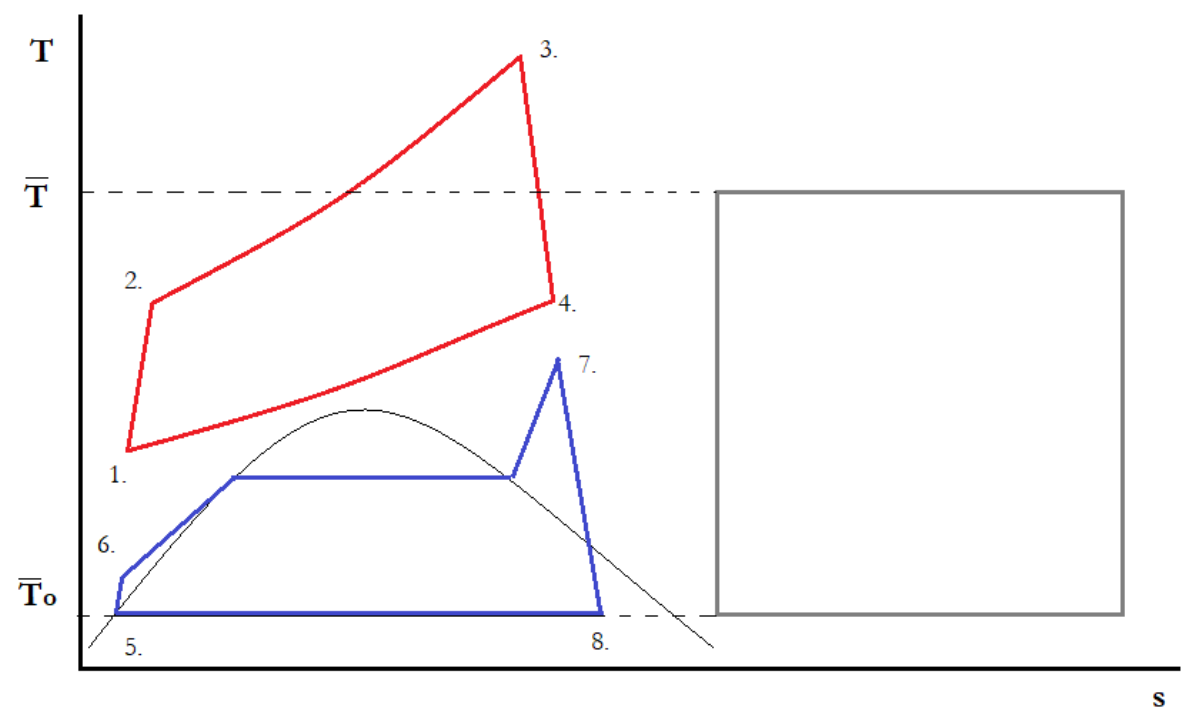

Figure 15 T-s diagram of a Brayton (topping) and Rankine (bottoming) combined cycle and comparison to an ideal Carnot cycle (right)

It is noted that in the real cycle, the component efficiencies of the adiabatic processes $(1-2,3-4,5-$ 6 and 7-8) are lower than 1 and therefore the transformations are not isentropic. For simplicity, the process with absorption and release of heat has been represented at constant pressure. Finally, it should be mentioned that for the case of a plant with gasification of a solid fuel, where an initial partial oxidation is needed to reach a gaseous fuel suitable for a GT, a certain fraction of the fuel heating value will be only retrieved (at best) in the bottoming cycle: $1-\varphi$, (as opposed to a natural gas fired combined cycle, where all the fuel is added directly to the combustion chamber). The overall efficiency of the cycle can be approximated by using Eq. 5:

$$
\eta_{t o t}=\eta_{B} \varphi+\eta_{R}\left(1-\eta_{B} \varphi\right)
$$

Where, $\eta_{B}$ and $\eta_{R}$ correspond to the Brayton and Rankine overall efficiencies of conversion of heat into work. The term $\varphi$ will be later defined more rigorously as the cold gas efficiency and it corresponds to the fraction of heating value in the syngas gasification product relative to the solid feedstock. It is worthwhile noticing that a high $\varphi$ is desirable to maximize the overall performance of the plant, as shown in Figure 16 for different pairs of Brayton and Rankine efficiencies: 


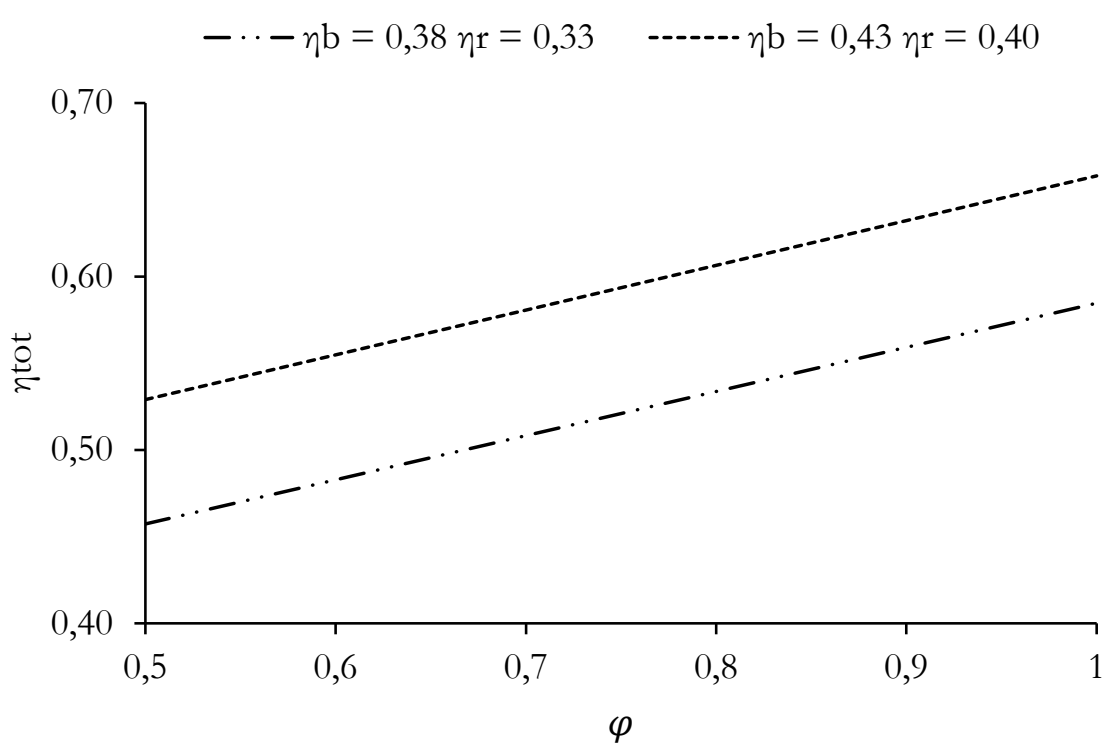

Figure 16 Overall efficiency as a function of $\varphi$

Also important to highlight is the fact that the auxiliary duties for the gasification plant must still be accounted for, which will bring the overall net efficiencies of IGCC plants typically below $50 \%$, even for cases with a high value of $\varphi$.

\subsubsection{Fundamental Tasks of IGCC Plants}

In section 1.3.1, a brief outline of the main constituents of an IGCC plant was given. When incorporating CCS technologies or considering other process topologies relative to the combined cycle, the complexity of the plant substantially increases. In the present section, a rational categorization of the fundamental tasks involved in electricity production through gasification with CCS is presented. This classification will aid to identify the different technology blocks available to perform these fundamental tasks and present them in a structured way. Although such blocks have different levels of technological maturity at present, it is noted that they will all likely be a commercial reality by the time gas switching technology becomes deployed. Therefore, gas switching elements have the longest time horizon and the demonstration and de-risking of these units determine the feasibility of the power plants presented in this work.

Figure 17 presents the technology blocks categorized by the elemental task performed in the power plant. Not all elemental tasks are necessarily performed in every power plant concept (i.e. the IGCC unabated model does not have the $\mathrm{CO}_{2}$ extraction and $\mathrm{CO}_{2}$ conditioning steps). The fundamental tasks are as follows:

1. Oxidant stream: This task consists of the generation of an oxidant stream which can be employed to gasify coal to obtain a syngas fuel suitable for power production in a gas turbine. The most commonly known method of obtaining a purified oxygen stream is an Air Separation Unit (ASU) which requires a substantial auxiliary power. Alternative to an ASU, this work investigates the possibility of employing a GSOP reactor cluster to generate the oxidant stream. A more detailed analysis of the process units involved in this step is given in section 3.2.

2. Gasification of Coal: Coal is partially oxidized with the oxidant stream to generate a syngas fuel. Key to the efficiency of the plant is the amount of heating value that remains in the syngas stream relative to the coal heat input $\varphi$. A fluidized bed gasifier 
and two entrained flow gasifier models have been developed. Further details of the technologies investigated for this step and the associated process models are detailed in section 3.3 .

3. Syngas Cooling $\&$ Treating: a fraction of heating value of coal after gasification is present as sensible heat in the syngas stream. This heat can be retrieved for power production in the bottoming cycle by raising steam. However, the raw syngas contains several contaminant species (sulphur, chlorides, ammonia, heavy metals and entrained particulates) that must be removed prior to the power producing units, to avoid harmful emissions to the environment. In some concepts, syngas is further reacted with steam to obtain a $\mathrm{H}_{2}$ rich fuel which, after $\mathrm{CO}_{2}$ removal, which can be combusted with air avoiding carbonaceous emissions. In section 3.4, the different methods for heat recovery/cooling, contaminant removal and syngas conversion are detailed.

4. $\mathbf{C O}_{2}$ Extraction: This task consists of the removal of the $\mathrm{CO}_{2}$ species from the fuel stream. Absorption technologies are typically employed for this purpose and are particularly favoured from and efficiency and capital cost perspective. Alternatively, GSC presents an opportunity for inherent carbon capture, where the combustion of fuel takes place decoupled from the air stream. Section 3.5 describes the fundamental background of these technologies and the modelling assumptions employed.

5. Topping Cycle: This task relates to the turbomachinery employed to obtain electrical work from a high temperature source (i.e. combustion of the syngas fuel). Different simplified gas turbine models are considered. Section 3.6 gives an overview of the primary assumptions taken for these units.

6. Bottoming Cycle: The exhaust air stream released from the topping cycle still contains sensible heat that can be converted to useful work and maximize plant efficiency by means of a bottoming unit. Typically, this consists of a steam turbine with different heat recovery units, but incipient efficient and compact power cycles such as s- $\mathrm{CO}_{2}$ are investigated, as detailed in section 3.7.

7. $\mathbf{H}_{2} / \mathbf{C O}_{2}$ conditioning: this step consists of reaching the purity and pressure specifications that are required for $\mathrm{H}_{2} / \mathrm{CO}_{2}$ transport and storage from the extraction point in the process. The different pathways to achieve this are described in section 3.8 . 


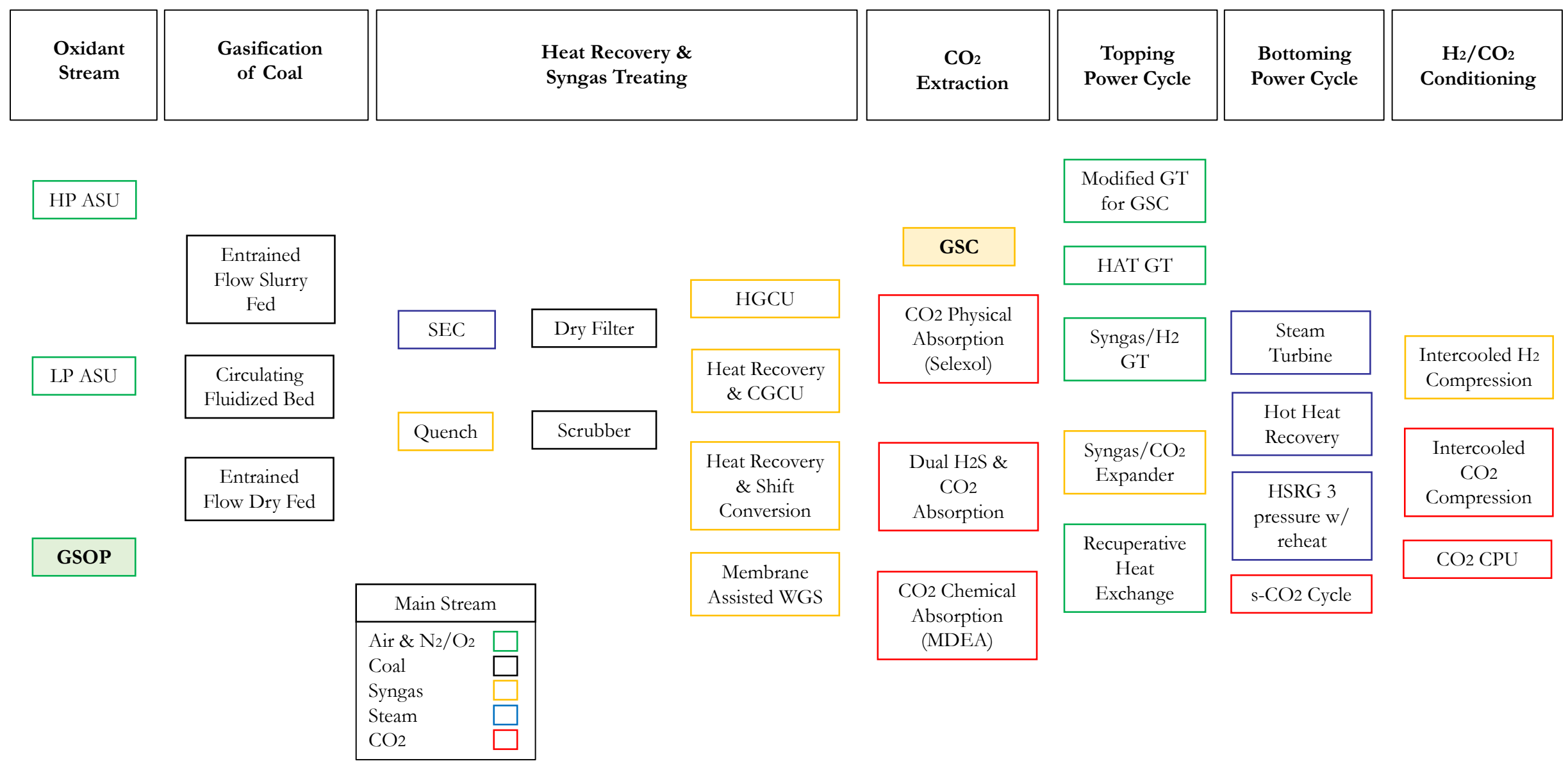

Figure 17 Technology blocks based on fundamental tasks 
This assessment will firstly present a background of the technology blocks depicted above, classified by the fundamental task, providing the modelling assumptions taken in each case and offering a comprehensive view of the key parameters governing the performance of each block.

\subsection{E: Power Plant Analysis Methodology}

The following section provides the framework to evaluate the different power plant concepts that are developed in this work. The $4 \mathrm{E}$ analysis is a comprehensive method to evaluate different power plant systems and the determination of the key performance indicators is detailed. 4E stands for Energy, Environmental, Exergy and Economic. The main performance indicators and corresponding symbols/abbreviations are listed in Table 4:

Table 4 Summary of plant key performance indicators

\begin{tabular}{|c|c|c|}
\hline Item & Key Performance Indicator & Symbol/Abbreviation \\
\hline \multirow{2}{*}{ Energy } & Net Thermal Efficiency & $\eta_{t}^{w}$ \\
& $\mathrm{H}_{2}$ Efficiency & $\eta_{t}^{H_{2}} / \eta_{t, e q}^{H_{2}}$ \\
\hline \multirow{4}{*}{ Environmental } & $\mathrm{CO}_{2}$ Capture & - \\
& Specific Emissions & $E_{\mathrm{CO}_{2}}$ \\
& $\mathrm{CO}_{2}$ Avoidance & $A_{\mathrm{CO}_{2}}$ \\
& SPECCA Index & $S P E C C A$ \\
\hline \multirow{2}{*}{ Exergy } & Exergy Efficiency & $\xi$ \\
& Exergy Breakdown & - \\
\hline \multirow{3}{*}{ Economic } & Specific Investment & $S I$ \\
& Levelized Cost of Electricity & $L C O E$ \\
& $\mathrm{CO}_{2}$ Avoidance Cost & $C O C A$ \\
\hline
\end{tabular}

\subsubsection{Energy: Thermal Efficiency}

Each power plant is presented with a detailed breakdown of the power consumers/generators within the plant. The IGCC based power plants studied can be represented schematically as a series of energy and material streams crossing a defined boundary as shown in Figure 18.

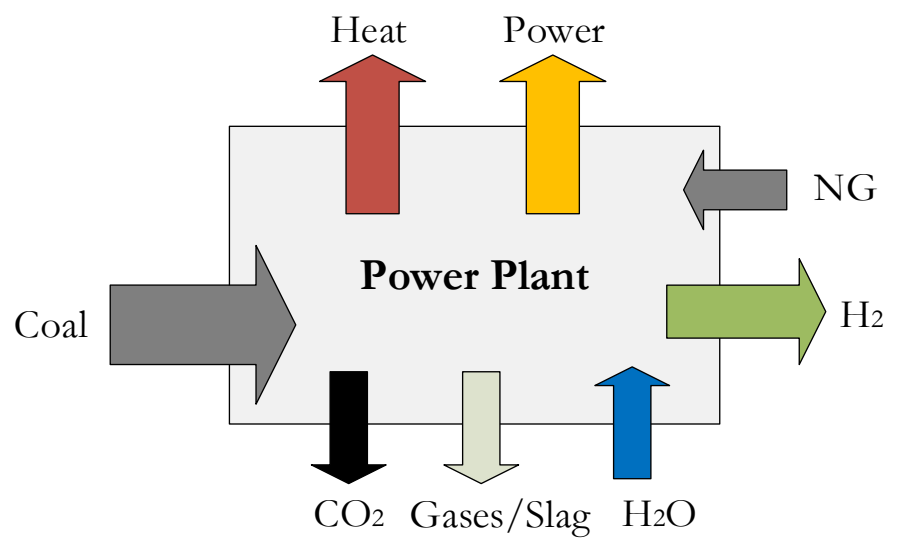

Figure 18 Basic diagram of a power plant

The net thermal efficiency of the plant is defined as the net power output divided by the total heat input (on LHV basis) as described in Eq. 6: 


$$
\eta_{t}^{w}=\frac{\dot{W}_{\text {net }}}{\dot{m}_{\text {coal }} L H V}
$$

Eq. 6

The net power output of the plant is calculated as the sum of all the power generation systems minus the sum of power consumers. All power plant models subsystems show consistency from the 1st principle of Thermodynamics, and therefore all the heating value contained in the original fuel transformed into heat released to the ambient, high temperature material stream leaving the plant boundary and electrical power. Therefore, the power plant models run under assumed stationary conditions, with no accumulation term of the total internal energy, given by Eq. 2 .

Alternatively to electricity generation, some of the power plants in this work are able to operate flexibly to produce $\mathrm{H}_{2}$ as an energy storage vector, at time when the electricity prices are low, in such a way that these plants can balance variable renewable energy. Thus, the $\mathrm{H}_{2}$ efficiency and equivalent $\mathrm{H}_{2}$ efficiency are defined as shown in Eq. 7 \& Eq. 8 respectively. The latter assumes that the minimum electricity load of the plant with $\mathrm{H}_{2}$ production is produced at the corresponding efficiency of a reference plant producing only power.

$$
\begin{gathered}
\eta_{t}^{H_{2}}=\frac{\dot{m}_{\mathrm{H}_{2}} L H V_{\mathrm{H}_{2}}}{\dot{m}_{\text {coal }} L H V_{\text {coal }}} \\
\eta_{t, e q}^{H_{2}}=\frac{\dot{m}_{\mathrm{H}_{2}} L H V_{\mathrm{H}_{2}}}{\dot{m}_{\text {coal }} L H V_{\text {coal }}-\frac{\dot{W}_{\text {net }}}{\eta_{t, r e f}}}
\end{gathered}
$$

Some studies report efficiency values based on the higher heating value (HHV). These results comparatively below the efficiencies based on LHV because the latter assumes that the latent heat of vaporization of water is not recovered. This may cause slight incongruences for hybrid plants where fuels with different $\mathrm{H}_{2}$ compositions are used or in systems where the heat of vaporization of the water present in the combustion product is to some extent transformed to electricity, underlying the 1 st Law efficiency limitations to compare different energy systems (for instance those with CHP). In any case, it is important to clarify that the convention that is used here is based on LHV, following the approach recommended in [6]. In parallel to this, the gross electric efficiencies (taking into account the plant generators are also given. This parameter to provide a reference of the amount of heat input to the plant that must be invested in satisfying the plant internal electricity demand.

\subsubsection{Environmental: $\mathrm{CO}_{2}$ Plant Emissions}

Environmental emissions caused by coal fired power plants are of diverse nature. The focus of this evaluation is on carbonaceous emissions, but a brief discussion is presented here regarding sulphur and $\mathrm{N}_{2}$ derived emissions in IGCC power plants. Coal is a fuel which, depending on its origin, has a non-negligible amount of sulphur in it. When combusted with air, it forms sulphur dioxide $\left(\mathrm{SO}_{2}\right)$ and if emitted to the atmosphere in high concentrations, it can pose a hazardous threat to the surroundings. In IGCC plants, the sulphur is transformed primarily to hydrogen sulphide $\left(\mathrm{H}_{2} \mathrm{~S}\right)$ in the gasification process. This species is highly toxic, but it can be removed from the syngas quite effectively, usually but not exclusively with low temperature absorption, preventing the downstream combustion and the resulting SOx emissions. This feature allows IGCC plants to be presented as a cleaner technology than widespread pulverized coal (PC) boilers, with a lower capacity to control sulphur emissions. For this latter power plant type, Wet Gas Desulphurization Units (WGDU) must be employed to reduce SOx components from the 
combustion gases to acceptable levels [32], but with a substantial effect on the economics. This technology typically consists of gas scrubbing with a limestone sorbent, to obtain sulphuric acid, which can be later sold as a plant by-product. These wet scrubbers can achieve $\mathrm{SO}_{2}$ removal efficiencies above 99\%. In IGCC plants, where the sulphur and different contaminants are concentrated in the syngas stream recent developments in treating technologies avoid the cooling of the syngas to ambient temperature, thus avoiding the resulting efficiency loss, and carry out the gas desulphurization at elevated temperatures [33]. In the present work, the SOx emissions are not explicitly calculated as the auxiliary systems (Claus unit, Scrubbers) are not modelled and it is assumed that $100 \%$ of the sulphur contaminants $\left(\mathrm{H}_{2} \mathrm{~S}\right.$ primarily) is completely removed from the process stream.

On the other hand, $\mathrm{NOx}$ (nitride oxide, $\mathrm{NO}$, and Nitrogen dioxide, $\mathrm{NO}_{2}$ ) emissions arise when burning a fuel due to the high temperatures that are reached during the combustion process. These contaminants contribute to the formation of ozone which causes health issues in human beings and contribute to the formation of acid rains which has negative environmental impacts. For natural gas fired power plants, NOx emissions are controlled to levels below $25 \mathrm{ppm}$ through the use of Lean Premix Technology burners. IGCC power plant use a syngas fuel in the GT, with a heating value substantially smaller than that of natural gas. This results in an increased fuel flow rate for a fixed heat input. Furthermore, when compared to methane, $\mathrm{H}_{2}$ has a higher flame speed and broader flammability limits, precluding the use of lean premixed combustors from $\mathrm{NOx}$ control. Instead, diffusion burners with massive steam and $\mathrm{N}_{2}$ dilution are adopted [34]. In these burners, the stoichiometric flame temperature is representative of the actual flame temperature, which is related to the NOx formation rate, as shown in [35].

In the present study, for the plants where elevated Combustor Outlet Temperature (COT) is achieved using conventional gas turbine technology, the rate of dilution with $\mathrm{N}_{2}$ and steam through direct fuel injection and syngas saturation was set so as to achieve an SFT of $2200 \mathrm{~K}$ with the corresponding air feed delivered by the compressor. Despite the succinct quantification made in this study, an optimistic statement with regards to $\mathrm{SOx}, \mathrm{NOx}$ and particulate emissions can be made for IGCC plants, relative to other coal technologies as outlined in Figure 20:

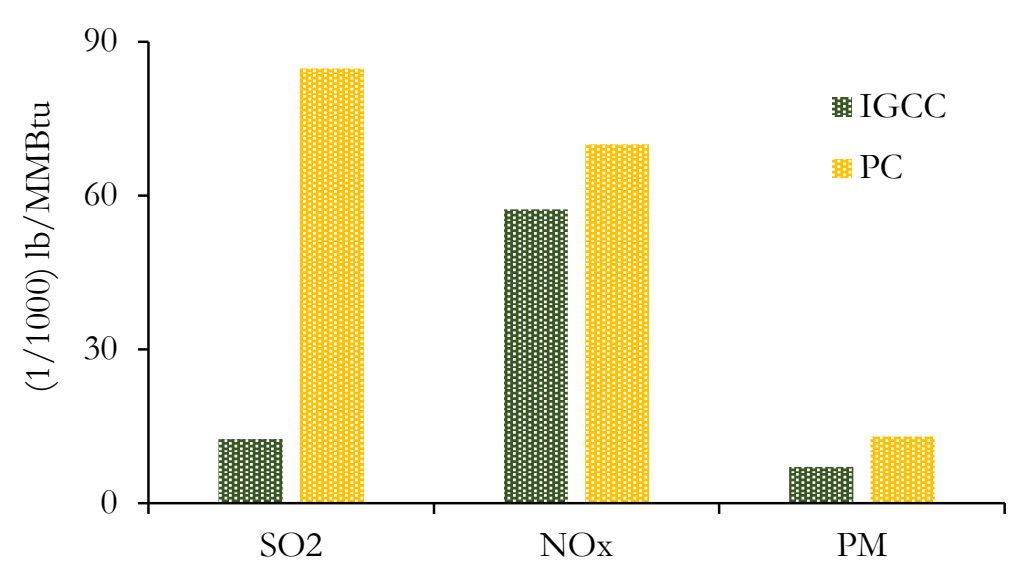

Figure 19 Average emissions: sulphur dioxide $\left(\mathrm{SO}_{2}\right)$, nitrogen oxides (NOx) and particulate matter (PM) by technology [36]

It must be mentioned that relative to existing combustion technology, future power plants with chemical looping combustion are exempt of any NOx emissions thanks to the flameless combustion taking place with the oxygen carrier material in the air and fuel reactors. This is yet 
another positive environmental impact (besides $\mathrm{CO}_{2}$ sequestration) that this technology will present. Furthermore, if some sulphur components remain entrained in the fuel used in a CLC unit, the hazardous contaminant will remain in the concentrated reduction gases stream potentially allowing $\mathrm{SO}_{2}$ and $\mathrm{CO}_{2}$ co-capture or, alternatively the possibility to employ $\mathrm{SO}_{2}$ scrubbers more efficiently and cost effectively with this pressurized stream, which has a reduced flow rate after cooling and water knock out (relative to a boiler or gas turbine exhaust). The power cycle will experience some efficiency gains by allowing to feed high temperature syngas to the CLC unit and by utilizing the heat of combustion of sulphur components, but it must be ensured that the oxygen carrier employed is sulphur resistant [37] at the concentrations present in the syngas.

A marked focus of this study is on $\mathrm{CO}_{2}$ emissions, as this pollutant is massively emitted in thermal fossil fuel power plants. Its quantity is strictly related to 1) the amount of fuel that is used up to produce electricity and 2) the carbon intensity of the fuel. In other words, the power plant efficiency has a decisive contribution when comparing the $\mathrm{CO}_{2}$ emissions from different plants. Specific emissions $E_{\mathrm{CO}_{2}}$, represented as the $\mathrm{CO}_{2}$ intensity divided by the plant net power output (expressed henceforward in $\mathrm{kg}$ of $\mathrm{CO}_{2} / \mathrm{MWh}$ ) is the adequate metric to compare different power plants. The capture ratio of the plant with CCS gives an understanding of the overall $\mathrm{CO}_{2}$ capture efficiency that the different process strategies implemented to avoid $\mathrm{CO}_{2}$ emissions deliver. However, if such plant will potentially substitute an Unabated technology, the $\mathrm{CO}_{2}$ avoidance $A_{\mathrm{CO}_{2}}$ of the plant with CCS will be lower than its capture rate since electricity is produced more efficiently (requiring less fuel heat input per MW of electricity output and therefore generating less $\mathrm{CO}_{2}$ ). This idea is clearly depicted in Figure 21:

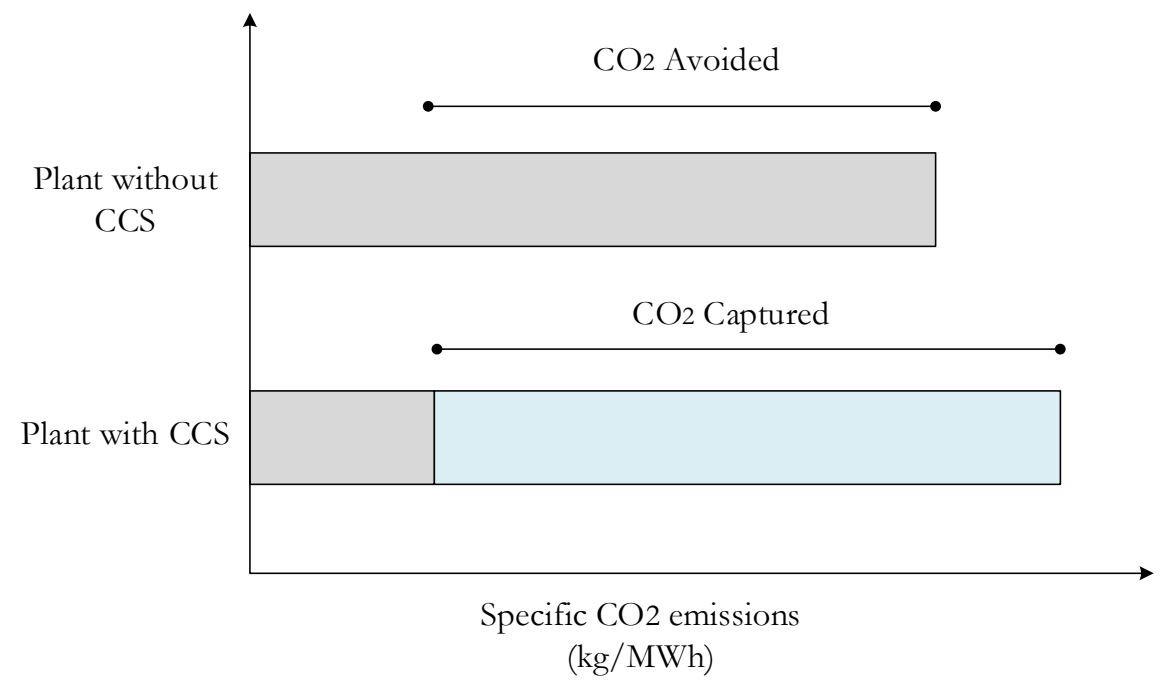

Figure 20 Schematic comparison of $\mathrm{CO}_{2}$ emissions for power plants with and without CCS

The $\mathrm{CO}_{2}$ avoidance can therefore be determined with the specific emissions of both plants as shown in Eq. 9. Finally, the Specific Primary Energy Consumption of $\mathrm{CO}_{2}$ Avoided (SPECCA), allows to quantify the primary energy (as fuel heat input) that is invested in removing the $\mathrm{CO}_{2}$ and delivering it at a certain specified conditions of pressure and temperature to the plant battery limits. It is measured in $\mathrm{MJ} / \mathrm{kgCO}_{2}$ and calculated through Eq. 10:

$$
A_{\mathrm{CO}_{2}}=\frac{E_{\mathrm{CO}_{2}, \mathrm{Ref}}-E_{\mathrm{CO}_{2}, \mathrm{CCS}}}{E_{\mathrm{CO}_{2} \mathrm{Ref}}}
$$




$$
S P E C C A=3600 \frac{\frac{1}{\eta_{t, C C S}}-\frac{1}{\eta_{t, R e f}}}{E_{C_{2}, \text { Ref }}-E_{C_{2}, C C S}}
$$

\subsubsection{Exergy: The Second Law Efficiency}

Although thermal efficiency is a common indicator to evaluate a power system it is lacking in the sense that it does not provide a rational measure of the plant performance, since not all the $\mathrm{kJ}$ contained in the fuel heating value can be fully converted into work in virtue of the 2 nd Principle of Thermodynamics, as anticipated in section 1.3.2. The extent to which heat can be transformed into work is illustrated Figure 21 (left), assuming an ambient temperature of $25^{\circ} \mathrm{C}$. It shows that for a given amount of heat to be equivalent to work, it must be released at an infinite temperature (Carnot value of 1). This of course, is not technologically possible but it does indicate that a more efficient conversion of a fuel to electricity will take place the higher the temperature attained in the thermodynamic power cycle. It is also evident that the ideal Carnot efficiency increases more steeply for lower heat absorption (averaged) temperatures, while the efficiency gains at higher absorption temperature values become milder. Also interesting, but less directly related to power generation, is the fact that the Carnot factor of heat released or absorbed from a reservoir at cryogenic temperatures can be higher than unity, revealing that the quality of heat in these conditions can be even higher than the electrical input required to operate between the ambient and the cold reservoir temperature. This insight will be of relevance when dealing with cold units such as the Air Separation Unit (ASU) or Cryogenic Purification Unit (CPU) for $\mathrm{CO}_{2}$.
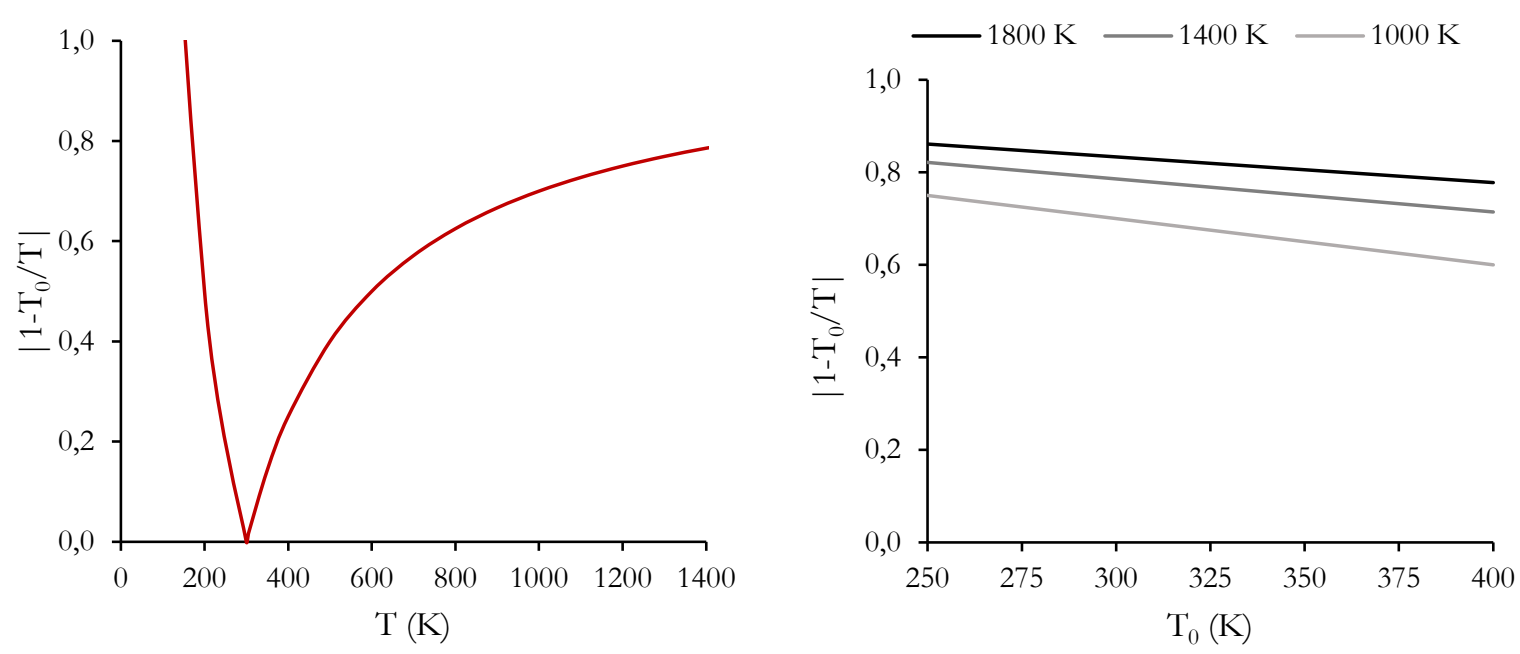

Figure 21 Carnot efficiency as a function of hot temperature $(\mathrm{T})$ for heat rejection temperature T0 $=300 \mathrm{~K}$ (left) and heat rejection temperature $\left(\mathrm{T}_{0}\right)$ for different hot temperature $(\mathrm{T})$ values (right)

Alternatively, the question arises of what is the dependency of the maximum electrical output that can be obtained from heat for a changing environment temperature. This evaluation is shown in Figure 21 (right) for several high temperature values. In actual practice, the cold temperature will be limited to that which is achievable with the assumed heat rejection system, typically a cooling water tower.

The fundamental framework for exergy analysis is presented in detail in [29]. In the analysis of energy systems, it is valuable to know what the maximum capacity of a given system to produce 
useful work is. Useful work refers to that which can be derived from a system interacting only with the environment, which is usually considered as the inert state, as shown in Figure 23.

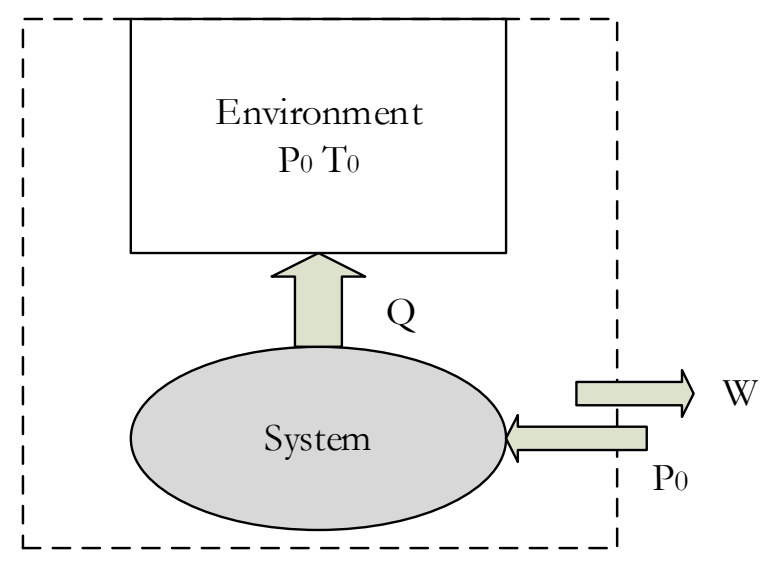

Figure 22 Closed system interacting only with an environment at $\mathrm{P}_{0}$ and $\mathrm{T}_{0}$

For a closed system, this work can be determined through a function of state named Exergy (B), which, by derivation from the internal energy and entropy balances applied to a closed system, results in Eq. 11:

$$
\Delta B_{j}^{\prime}=-W_{u s e f u l}^{\max }=\Delta U_{j}^{\prime}-T_{0} \Delta S_{j}+P_{0} \Delta V_{j}
$$

Where $T_{0}$ and $P_{0}$ are the temperature and pressure at ambient condition. If the inert state is defined correctly, the absolute value of this state function is always positive. However, most of the systems that appear in power plants are open, with multiple material and energy stream crossing the boundaries of each system. For this reason, Eq. 11 is extended using the balances presented in Eq. $2 \&$ Eq. 4, yielding a general expression for the exergy balance to an open system:

$$
\frac{d B_{j}^{\prime}}{d t}=\int \dot{Q}_{j}\left(1-\frac{T_{0}}{T}\right)-\left(\dot{W}_{j}-P_{0} \frac{d V_{j}}{d t}\right)-\dot{I}_{j}+\sum_{i} e_{i, j}^{\prime} \dot{m}_{i, j}
$$

It is noteworthy to examine the physical meaning of each of the terms in Eq. 12:

$\dot{Q}_{j}\left(1-\frac{T_{0}}{T}\right)$ : Exergy content of heat (Carnot efficiency) when the physical system is encountered at the same temperature. Otherwise, integration to the system must be applied for each differential of heat transferred at every given temperature.

$\left(\dot{W}_{j}-P_{0} \frac{d V_{j}}{d t}\right)$ : Exergy content of work, acknowledging that the system does not produce any useful work when it expands against the environment pressure $\mathrm{P}_{0}$.

$\dot{I}_{j}=T_{0} \sigma_{j}$ : Exergy destruction, which represents the energy losses that are accountable for internal irreversibilities within the system.

$e^{\prime}{ }_{i, j}$ : Exergy flow of stream i, which is defined by Eq. 13.

In most process involving power and chemicals production, the process units operate under stationary conditions, and the variation of the total exergy of the system $\mathrm{j}$ can be considered constant in time. Furthermore, these are typically rigid systems with no change in volume either. Thus, under assumed stationary operation, the accumulation term equals to zero (Total exergy $B_{j}{ }_{j}$ remains constant) and no deformable parts are encountered in the process (constant volume $V_{j}$ ). 
Therefore, the exergy destruction term $\dot{I}_{j}$ can be determined when the work $\dot{W}_{j}$ and heat flows $\dot{Q}_{j}$ alongside the specific exergy flow for stream i entering or leaving system $\mathrm{j}, e_{i, j}{ }_{i, j}$ are known. The exergy flow terms are calculated with Eq. 13 and Eq. 14:

$$
\begin{gathered}
e_{i}^{\prime}=e_{C h}+e_{P h}+e_{p}+e_{c} \\
e_{p h}=h_{i}-T_{0} s_{i}-\left(h_{0}-T_{0} s_{0}\right)
\end{gathered}
$$

Usually, changes in kinetic $e_{c}$ and potential $e_{c}$ energy can be considered negligible. The calculation of the physical exergy flow $e_{p h}$ is immediate by accessing the specific enthalpies and entropies of a stream. This term represents the maximum useful work which can be retrieved from a stream through ideal technological devices, interacting only against the environment because of pressure and temperature imbalances relative to the environmental inert state.

Chemical exergy is the work needed to reversibly synthetize a certain substance at ambient pressure and temperature withdrawing from the environment (through ideal membranes) the stoichiometric amounts of reference substances, bringing them to $\mathrm{P}_{0}$ and $\mathrm{T}_{0}$ (by means of ideal compression devices), reacting these substances at $\mathrm{T}_{0}$ and $\mathrm{P}_{0}$ and finally releasing the reference by-products to the environment at the same chemical potential as in the environment (with ideal membranes and expanders). The reference substances are usually present in the atmosphere and the environment composition must be predefined beforehand in order to carry out exergy calculations.

The negative definition can be conceived were the chemical exergy corresponds to the negative value of the state functions which measures a devaluation reaction following the process described earlier in a reverse way to obtain the reactants and release the products from and to the environment. Such disposition is represented in Figure 23 for the synthesis of a pure component (methane), where the stoichiometric reactants $\left(\mathrm{O}_{2}\right)$ and products $\left(\mathrm{H}_{2} \mathrm{O}\right.$ and $\left.\mathrm{CO}_{2}\right)$ appear:

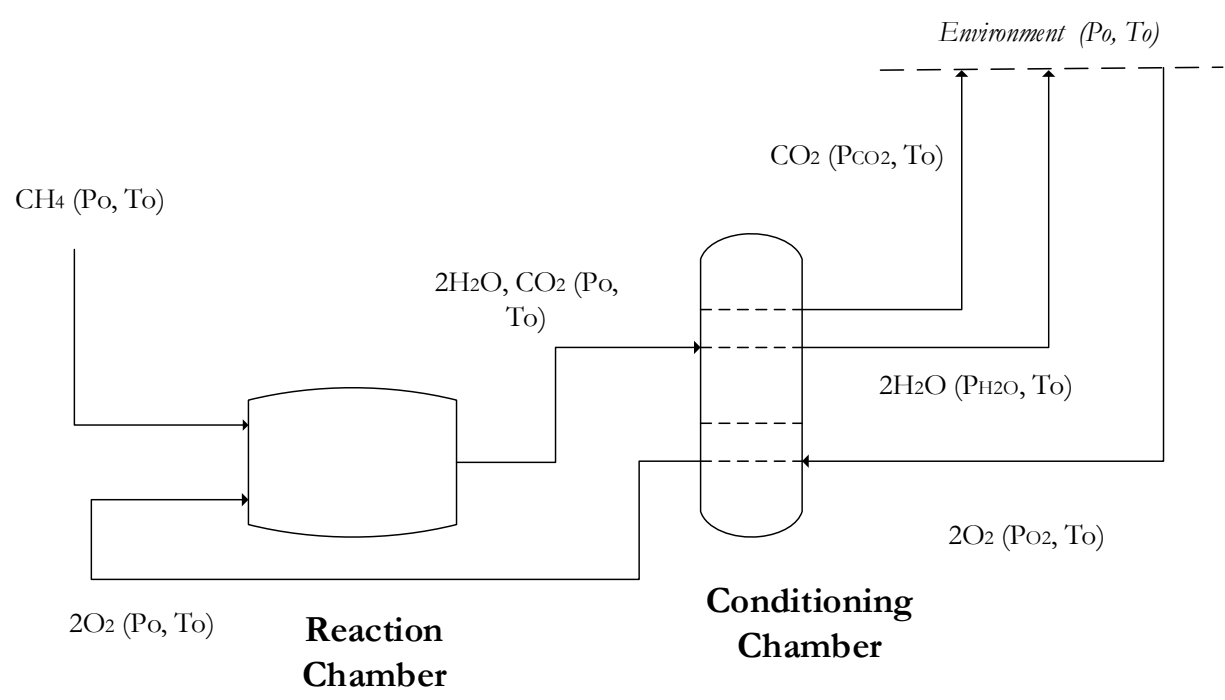

Figure 23 Chemical exergy process for methane

The maximum work that can be withdrawn from the reaction chamber, considering that the reaction takes place at constant temperature and pressure, corresponds to the standard Gibbs free energy of reaction (Eq. 15), at reference conditions $\mathrm{T}_{0}$ and $\mathrm{P}_{0}$. Such values can be accessible through thermochemical tables [29], but require a correction when their reference does not coincide with the values assumed for the inert state. 


$$
w_{R C}=-\Delta G_{r}^{o}
$$

Eq. 15

On the other hand, the work required/obtained for the reactants / products to reach the reaction chamber through the conditioning chamber correspond to the change in chemical potential between the environmental state and the inlet conditions to the reaction chamber (Eq. 16). Since the reference pressure is usually $1 \mathrm{~atm}$ or $1 \mathrm{bar}$ it can be assumed that the chemical potential can be determined directly with the substance partial pressure, meaning that the environment behaves like an ideal gas mixture.

$$
w_{C C}=\sum v_{k}^{d}\left(\mu_{k}\left(T_{0}, P_{0}\right)-\mu_{k}\left(T_{0}, P_{k}\right)\right)=\sum R T_{0} \ln \left(\frac{P_{0}}{P_{k}}\right)^{v_{k}^{d}} \quad \text { Eq. } 16
$$

Finally, it should be mentioned that process streams in the processes evaluated are usually not pure components but rather a mixture of different substances. Some of these substances can undergo other chemical devaluation reactions $\left(\mathrm{H}_{2}\right.$ or $\left.\mathrm{CO}\right)$ or they may be substances present in the environment at a different chemical potential $\left(\mathrm{N}_{2}\right)$. In this cases, a separation chamber Figure 25 must deliver the pure components prior to entering the system represented in Figure 24 for the particular case methane. The work required to reversibly separate such mixture corresponds to the molar Gibbs free energy of mixing, determined with the molar fractions of each component and the chemical potentials in the mixture and in pure form Eq. 17

$$
w_{S C}=g^{M}=\sum x_{k}\left(\bar{\mu}_{k}-\mu_{k}^{\square}\right)
$$

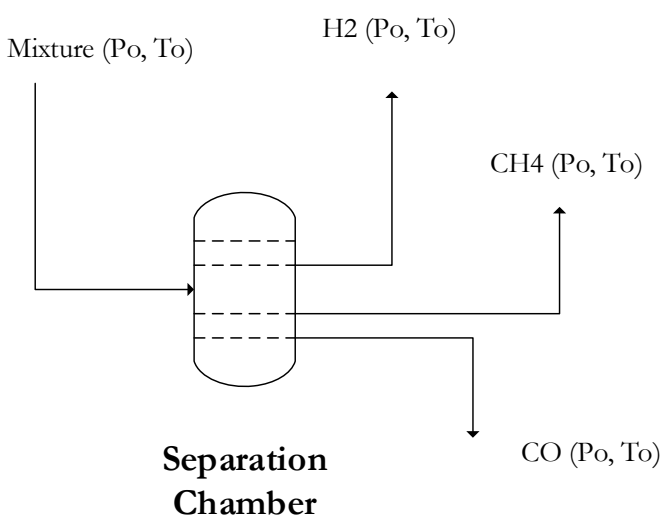

Figure 24 Diagram of a reversible separation chamber

If the ideal gas mixture assumption is not applicable, a mixing rule to determine this work must be available.

Given the numerous streams and systems and different mixtures that occur in process systems modelling of power plants, the calculation of all these thermodynamic properties can be quite tedious, even when the thermochemical tables for the Gibbs free energy of reaction are available and the gases can be assumed to behave as ideal gas mixtures. Furthermore, if the reference of the Gibbs free energy of reaction does not coincide with the inert state assumed, a correction effort must be performed as well. In this study, a short-cut method was employed to determine both physical and chemical exergy flow of a mixture stream by means of an auxiliary process tool, represented in Figure 25. 


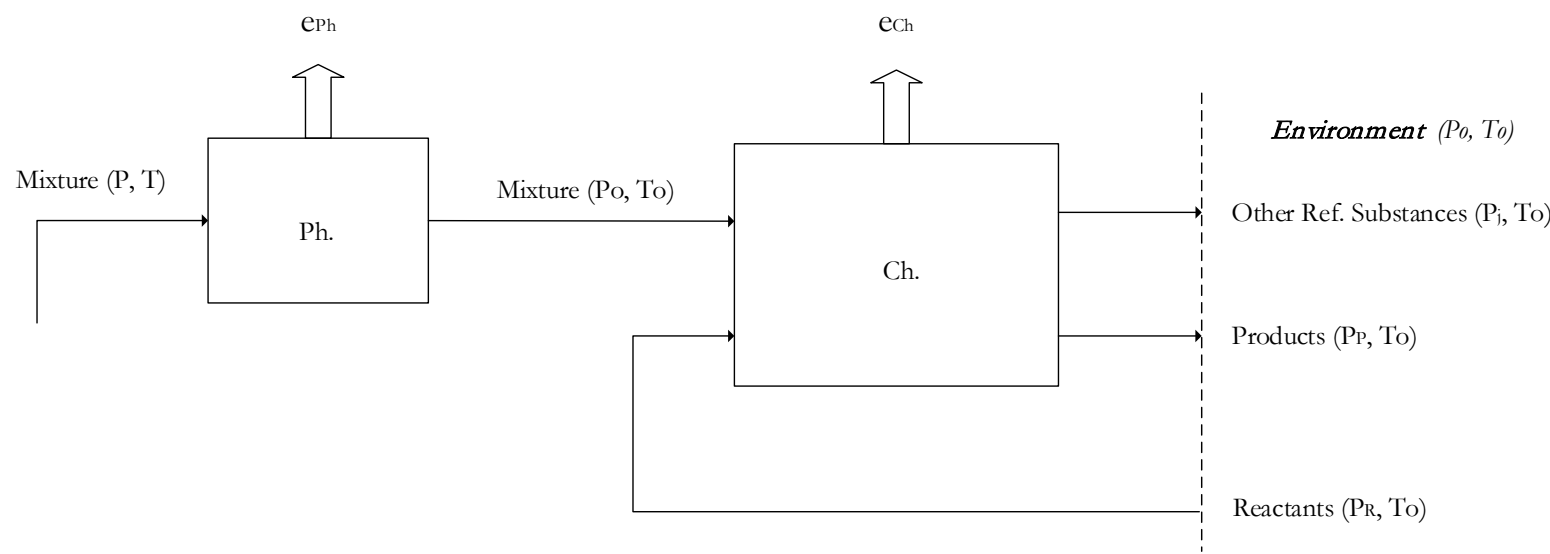

Figure 25 Modelling tool diagram for the determination of the total exergy flow of a mixture

The determination of the total exergy flow is accomplished by coupling this auxiliary model to the process flowsheet. For the model to calculate the exergy flow of a stream, several inputs must be specified:

- Stream conditions (flow, temperature pressure \& composition)

- Definition of Inert Thermomechanical State $\left(\mathrm{P}_{0}=1,01325\right.$ bar and $\left.\mathrm{T}_{0}=298,15 \mathrm{~K}\right)$

- Dry Air composition

- Relative Humidity $(\mathrm{RH}=60 \%)$

- Thermodynamic property method for enthalpy and entropy calculation. (this is the same as the original process model to which the stream mixture belongs)

The model takes the species of a given mixture at temperature $\mathrm{T}$ and pressure $\mathrm{P}$ and delivers substances (which are found in the reference environment defined above) to the environment at the same chemical potential in which these components are found, fulfilling the definition of chemical exergy. In order to do this, the tool performs the following tasks:

1. Expansion and cooling of the mixture from $\mathrm{T}$ and $\mathrm{P}$ to the reference thermomechanical inert values $\mathrm{T}_{0}, \mathrm{P}_{0}$ by means of an expander and a cooler. In this way the physical exergy is determined.

2. Separation of the mixture in its pure components (whereby the Gibbs free energy of mixing represents the minimum work input to achieve that separation) by using component splitters and coolers.

3. Devaluation reaction of each species to attain reference substances $\left(\mathrm{CO}_{2}, \mathrm{H}_{2} \mathrm{O}, \mathrm{SO}_{2}\right)$ at $\mathrm{P}_{0}$ and $\mathrm{T}_{0}$. The stoichiometry of the devaluation reaction is known and is implemented for species present in natural gas and syngas, in such a way that the required $\mathrm{O}_{2}$ is withdrawn from the environment to carry out the these reactions. The stoichiometric coefficients for the combustion of $\mathrm{CO}, \mathrm{H}_{2}, \mathrm{C} 1-\mathrm{C} 8$ and $\mathrm{H}_{2} \mathrm{~S}$ are available through a spreadsheet unit.

4. Release of the reference substances at the same chemical potential at which they are found in the environment by means of ideal expansion and cooling devices. The environment is assumed an ideal gas mixture, and therefore the chemical potential of each species is determined by their partial pressure. The composition of the reference environment consists of the characteristics detailed earlier and the dry air composition 
is given in Table 5. A relative humidity $(\mathrm{RH})$ of $60 \%$ is assumed to fix the molar fraction of water in the mixture.

Table 5 Dry air composition

\begin{tabular}{|c|c|}
\hline Component & mole fraction \\
\hline $\mathrm{N}_{2}$ & 0,7808 \\
\hline $\mathrm{O}_{2}$ & 0,2095 \\
\hline $\mathrm{Ar}$ & 0,0093 \\
\hline $\mathrm{CO}_{2}$ & 0,0004 \\
\hline $\mathrm{SO}_{2}$ & $0,1 \mathrm{PPM}$ \\
\hline
\end{tabular}

The model also accounts for the possibility of mixtures with a composition imbalance with respect to the environment but which do not undergo any devaluation reaction (e.g. streams of pure $\mathrm{O}_{2}$ or $\mathrm{N}_{2}$ ). Overall, given the specifications of the mixture stream, the total (physical and chemical) exergy flow can be determined as shown in Eq. 18, where the specific exergy flows in each term can be directly calculated through Eq. 14, with the subscripts, referring to the mixture (mix), reference reactants $(r)$, reference products $(\mathrm{p})$ and other reference substances (ref) present in the mixture respectively. It is noted that such calculation purposefully fulfils the definition of chemical exergy.

$$
e_{t, m i x}=\frac{1}{n_{m i x}}\left(n_{m i x} e_{p h, m i x}+\sum n_{k, r} e_{k, r}-\sum n_{k, p} e_{k, p}-\sum n_{k, r e f} e_{k, r e f}\right) \quad \text { Eq. } 18
$$

When applying the exergy balance (Eq. 12) to the power plant systems and a heat loss or heat rejection to the environment occurs in a given process unit, it is assumed that the heat term in Eq. 12 is grouped with the exergy destruction term, as an overall exergy loss. This is a plausible assumption as no useful work can be retrieved from the heat rejected at low temperatures such as in a steam condenser unit. Likewise, when some minor mass or heat stream leaves a given system, the exergy contained in it is considered in the overall exergy destruction term assuming that no useful effect can be delivered by such streams.

The exergy efficiency is defined as the useful effect obtained from the power plant relative to the total exergy input. The useful effect is usually considered as the net electricity produced by the plant or alternatively, the $\mathrm{H}_{2}$ exergy can be used as the main power plant product. Furthermore, the pure $\mathrm{CO}_{2}$ stream obtained from the CCS plants can also be accounted for together with any potential steam export from the plant, as beneficial by-products from the plant boundary. Alternatively, the summation of all the exergy destruction terms in each system $j$ and the total exergy flow leaving the power plant can also be used to determine the exergy efficiency (when only net electricity is considered), as shown in Eq. 19. Furthermore, with the exergy balance the specific losses associated to each power plant block $\dot{I}_{j}$ are identified. In this way, it is possible to dedicate optimization efforts to the sections with greatest exergy destruction in order to reach an improved plant performance. In the present assessment, the exergy breakdown is shown for several of the plants presented, and where applicable, suitable improvement strategies are suggested. It is not the scope of this study to elaborate an exergetic optimization based on cost performance parameters, as the $\mathrm{n}^{\circ}$ of subsystems is substantial and the precision of the economic estimations at the current technology readiness level is relatively low. However, it is an insightful tool to provide visibility and understanding of why the foreseen energy penalty reductions occur, and to propose improved process line-ups based on the insights provided by the exergy analysis study. 


$$
\xi=\frac{\dot{W}_{\text {net }}+\dot{E}_{\mathrm{H}_{2}}}{\dot{E}_{\text {coal }}}=1-\frac{\sum \dot{I}_{j}+\sum \dot{E}_{\text {out }}}{\dot{E}_{\text {coal }}} \quad \xi^{\prime}=\frac{\dot{W}_{\text {net }}+\dot{E}_{\mathrm{H}_{2}}+\dot{E}_{\mathrm{CO}_{2}}+\dot{E}_{\text {Steam }}}{\dot{E}_{\text {coal }}}
$$

Finally, the exergy of solid species (i.e. coal and slag leaving the gasification system) was accounted for by using a correlation provided by [38], and presented in Eq. 20 it was assumed that the chemical exergy of the ash components was negligible compared to the organic matter.

$$
\begin{gathered}
e^{0}{ }_{\text {solid }}=(L H V+2442 w) \varphi_{\text {dry }}+9417 s \\
\varphi_{\text {dry }}=1,044+\frac{h}{c} 0,1882+\frac{o}{c} 0,0610+\frac{n}{c} 0,0404
\end{gathered}
$$

Where $\mathrm{w}, \mathrm{s}, \mathrm{h}, \mathrm{c}, \mathrm{o} \& \mathrm{n}$ are the coal mass fraction of water, elemental sulphur, hydrogen, carbon, oxygen and nitrogen respectively.

Exergy Analysis is a powerful tool that provides a comprehensive and holistic understanding of any system (chemical or energetic). Sankey diagrams help visualize the exergy flows across the plant and have been performed to several of the introductory concepts investigated.

\subsubsection{Economic: Business Case}

The promising efficiency benefits of GS technology implemented for decarbonization of thermal power plants must be assessed from an economic point of view to determine the overall benefits, together with suitable sensitivity studies of several uncertain parameters (fuels costs, GS cluster costs, oxygen carrier lifetime etc.). Furthermore, a comparison of the economic metrics including $\mathrm{CO}_{2}$ taxes relative to other energy sources (nuclear, solar, wind etc.) is useful to assess the competitiveness of the proposed energy solutions. The cost of CCS is closely related to the energy penalty that is incurred upon, and it is expected that these costs will tend to decrease when such penalty is minimized.

The capital costs of the plants were estimated using the values presented in [6], using a scaling factor as shown in Eq. 21, where $C_{0}$ and $Q_{0}$ are the reference cost and the capacity of each unit, and are updated using a CEPCI (Chemical Engineering Plant Cost Index) factor of 2018 [39]. The reference costs, capacities and scaling exponents $M$ used for the economic assessment are given in the Appendix in Table 101 \& Table 102.

$$
C=C_{0} *\left(\frac{Q}{Q_{0}}\right)^{M}
$$

Eq. 21

The total investment cost is determined following the assumptions provided in Table 6 . A process contingency of 30\% was included for the GSC cluster as this technology presents a low level of maturity. Furthermore, the relatively high owner's costs and project contingency applied reflect the high technological uncertainty related to IGCC power plants. The specific cost results from dividing the total overnight cost by the net power output, as shown in Eq. 22:

$$
S I=\frac{T O C}{\dot{W}_{n e t}}
$$

Table 6 Total cost calculation methodology

\begin{tabular}{|c|c|}
\hline Component & Definition \\
\hline Total install cost (TIC) & Install cost of each process unit \\
\hline
\end{tabular}




\begin{tabular}{|c|c|}
\hline Process contingency (PS) & $\begin{array}{c}30 \% \text { of TIC for GSC } \\
10 \% \text { of TIC for HGCU }\end{array}$ \\
\hline $\begin{array}{c}\text { Engineering procurement and construction } \\
\text { costs (EPCC) }\end{array}$ & $14 \%$ of (TIC + PS) \\
\hline Project contingency (PT) & $18 \%$ of (TIC + PS + EPCC) \\
\hline Total plant costs (TPC) & TIC + PS + EPCC + PT \\
\hline Owners cost & $12 \%$ of TPC \\
\hline Total overnight costs (TOC) & TPC + Owners costs \\
\hline
\end{tabular}

With regards to fixed and variable maintenance and operating costs (O\&M), Table 7 summarizes the main assumptions taken in the economic assessment. For all the cases, the oxygen carrier replacement period is two years, and the economic parameters of this item are the same for GSC and GSOP clusters. For the case of combustion, the NiO oxygen carrier described in section 2.3.1 is used. Finally, the maintenance cost are determined based on the gross power output of the plant.

Table 7 Fixed and variable operating and maintenance cost assumptions

\begin{tabular}{|c|c|c|}
\hline \multicolumn{3}{|c|}{ Fixed O\&M costs } \\
\hline Operating labour & \multicolumn{2}{|c|}{ *Included in maintenance } \\
\hline Maintenance and administrative costs & 56 & $€ / \mathrm{kW} /$ year \\
\hline Cost of coal & 2,5 & $€ / G J$ LHV \\
\hline Cost of ash disposal [40] & 9,73 & $€ / \mathrm{t}$ \\
\hline Cost of NG & 6,5 & $€ / G J$ LHV \\
\hline \multicolumn{3}{|c|}{ Variable $O \& M$ costs } \\
\hline Process water costs & 6 & $€ / \mathrm{t}$ \\
\hline Cooling water make up costs & 0,325 & $€ / t$ \\
\hline \multicolumn{3}{|c|}{ Catalyst replacement } \\
\hline Oxygen carrier [41] & 12500 & $€ / \mathrm{t}$ \\
\hline SelexolTM replacement & 5000 & $€ / \mathrm{t}$ \\
\hline \multicolumn{3}{|c|}{$\mathrm{CO}_{2}$ costs } \\
\hline Transport and storage & 10 & $€ / \mathrm{t}$ \\
\hline \multicolumn{3}{|c|}{ Chemicals } \\
\hline Cooling water chemical treatment & 0,0025 & $€ / \mathrm{m}^{3}$ \\
\hline Process water chemical treatment & 45000 & $€ /$ month \\
\hline Oxygen carrier lifetime & 2 & years \\
\hline Membrane lifetime & 5 & years \\
\hline
\end{tabular}

The Levelized Cost of Electricity (LCOE) is defined as the electricity price at which the Net Present Value (NPV) of the plant at the end it's economic lifetime becomes zero. To calculate this parameter, the Annual Cash Flow (ACF) from the plant's construction (assumed over 4 years for the plants with CCS) and an operating lifetime (25 years) is actualized yearly with the discount rate $\mathrm{i}$, as shown in Eq. 23. The ACF of a year is the result of adding the revenues from electricity sales and the expenditures from fuel, O\&M costs and capital, as expressed in Eq. 24. The main assumptions for this analysis are given in Table 8: 
Table 8 Assumptions for cash flow analysis

\begin{tabular}{|c|c|}
\hline Item & Value \\
\hline Economic lifetime* & 25 years \\
\hline Discount rate & $8 \%$ \\
\hline Construction period & 4 years \\
\hline Capacity factor $(\phi)$ & $85 \%$ \\
\hline First year capacity factor & $65 \%$ \\
\hline
\end{tabular}

On the other hand, the cost of $\mathrm{CO}_{2}$ avoidance (COCA) is calculated with Eq. 25, where the LCOE and the specific emissions of the plant $E_{\mathrm{CO}_{2}}$ are used of a plant with CCS and a reference plant are used.

$$
\begin{gathered}
N P V=\sum_{t=0}^{n} \frac{A C F_{t}}{(1+i)^{t}} \\
A C F_{t}=\phi * L C O E * W_{e}^{y}-C_{C A P E X}-C_{F O M}-C_{V O M} \\
\operatorname{COCA}\left(\frac{€}{t C O_{2}}\right)=1000 * \frac{L C O E_{C C S}-L C O E_{r e f}}{E_{C O_{2}, r e f}-E_{C O_{2}, C C S}}
\end{gathered}
$$

COCA can be calculated with different reference plants, because there are a variety of thermal power plants without $\mathrm{CO}_{2}$ capture that the novel designs can replace. For instance the IGCC unabated reference will determine the $\mathrm{COCA}_{\mathrm{IGCC}}$. Alternatively, the supercritical pulverized coal plant, with an assumed LCOE of 55,7 €/MWh and specific emissions of 763,0 $\mathrm{kg} \mathrm{CO} / \mathrm{MWh} \mathrm{[6]}$ can be used as well to determine the COCA $\mathrm{SCPC}_{\text {. }}$

A final remark is made here on the calculation of the GS reactor cost. This component cost was estimated assuming a wall structure as the one presented in Figure 27, where a Ni based alloy is used in the inner wall to withstand the high temperature and corrosive atmosphere, followed by a layer of $\sim 0,5 \mathrm{~m}$ thickness (to achieve an outer wall temperature of $80^{\circ} \mathrm{C}$ ) and an external carbon steel shell to withstand the operating pressures. The reactors were sized assuming a fluidization velocity of $0,5-1 \mathrm{~m} / \mathrm{s}$ and an aspect ratio of 2 . This will lead to a bubbling fluidization regime when using $150 \mu \mathrm{m}$ particles, based on [42]. Since the reactivity of the oxygen carrier is high at the operating temperatures, the reactor height was not a limitation. The cost of the vessels was calculated using correlations from [43], while the cost of the high temperature valves and filters are included following an approach detailed in [44]. 


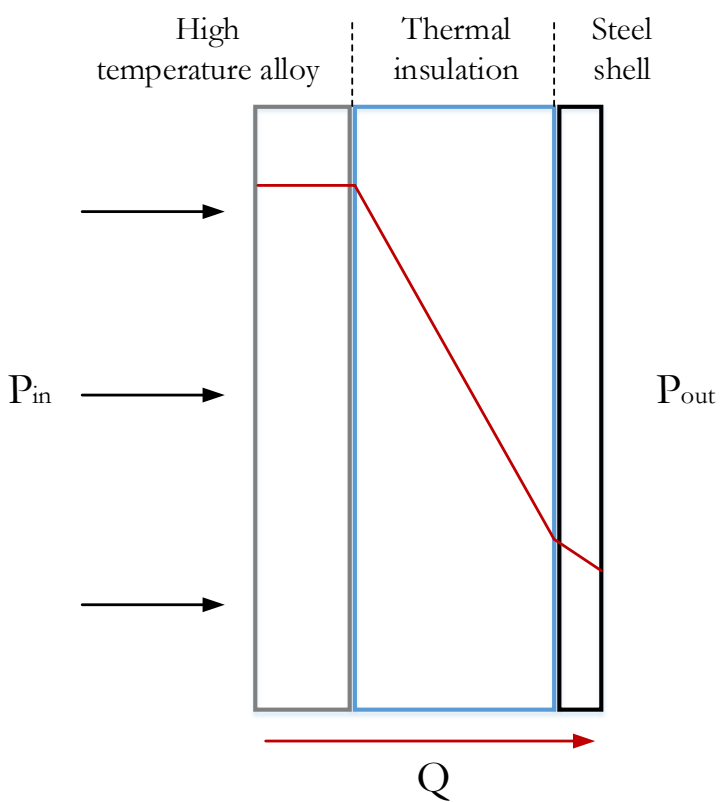

Figure 26 Reactor wall structure and temperature profile

\subsection{Simulation Tools}

The development of models as a means of representation of physical process is an essential characteristic of innovative action in industry. There is a wide variety of process modelling tools available to represent and predict the performance of different integrated engineering systems. The functionality ranges from a basic design stationary simulation to optimization and economic evaluation. In the chemical industry, Aspen Plus [45] is a plant simulation solution of widespread acceptance. Other process engineering softwares are ProII [46] or CHEMCAD [47], or open source simulators such as DWSIM and COCO. A competitive alternative to these which grants free academic licenses to universities and research organizations is Unisim Design from Honeywell [48], which offers a powerful tool to create robust and realistic process simulations. The high degree of flexibility and user friendly interface to achieve fast results, with an intuitive user interface suitable for process synthesis made this last option the preferred choice.

The process simulators described above have a sequential modular approach, where the process units are solved in sequence, once the feed streams are specified. If the flowsheet contains several recycle streams, the sequential solution of each unit operation is performed through "tear streams" in which initial values are assigned until convergence is reached. This solving approach has low flexibility but is more robust than equation oriented solvers. It allows a rigorous solving of the mass and energy equations for several unit operations in a continuous (stationary) process. It also provides some data required for the sizing of the equipment. For this purpose, the softwares contain a set of packages to determine different physical properties required for the execution of the simulation. The model library of the software tool usually comprises a set of models with predefined constitutive equations (equilibrium, reaction rates etc.). In this way, it is relatively straightforward to specify the model and to correctly satisfy the degrees of freedom of each unit operation. The architecture of the stationary modelling tool is described in Figure 27: 


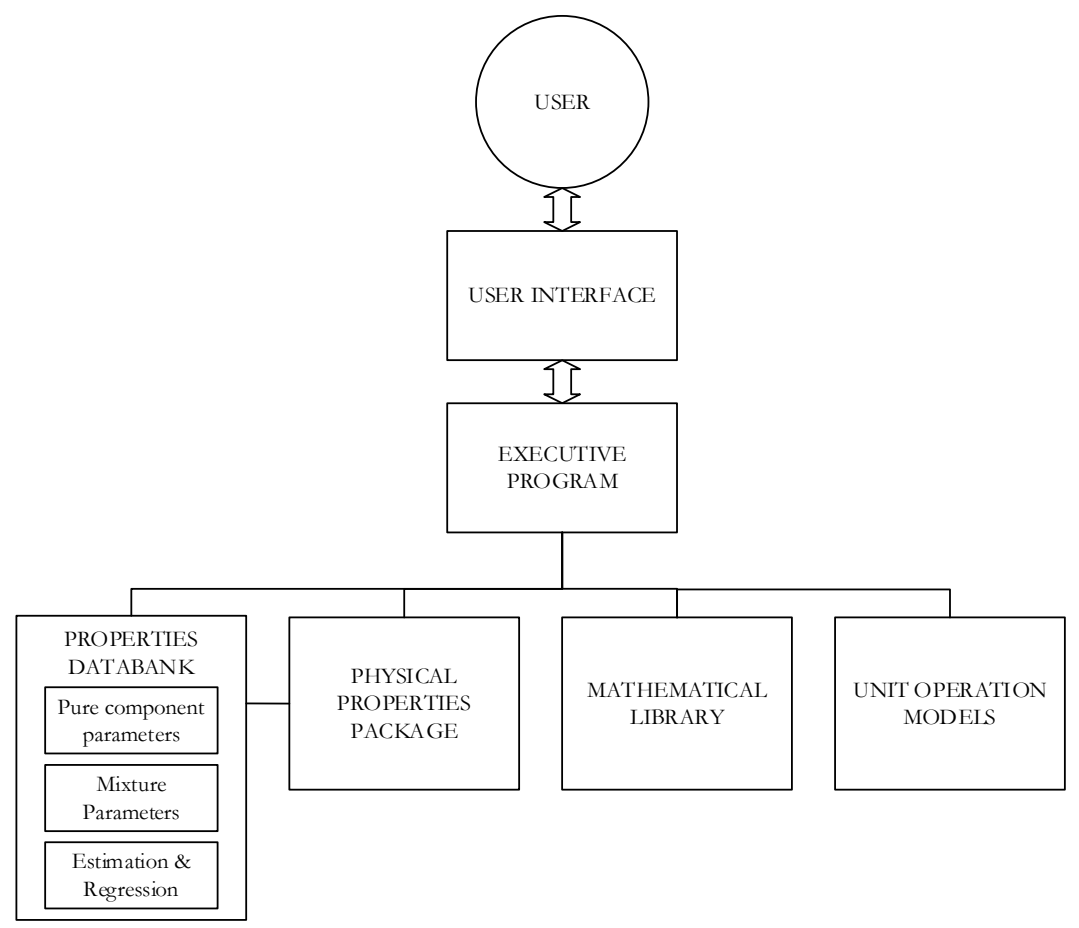

Figure 27 Software architecture for modelling and simulation

Alternative to the stationary flowsheet simulation, dynamic models for the GS clusters must be solved. Other process units which are not modelled as a grouped system (i.e. there is a change in properties alongside a particular dimension of the unit operation) require a more complex modelization. Softwares which are suitable for such purposes are Matlab or GPROMS. Scilab [49] is an open source program with the same basic functionality as Matlab. Since a Thermodynamic database for property calculation (Patitug) from the Energy Department is coded in Scilab, this latter modelling tool was selected.

The preferred solving approach for dynamic simulation is indeed equation oriented solvers, in which all existing units in a model are solved simultaneously, updating the unknown variables. It is more flexible for modelling purposes than the modular sequential softwares, but it can be less robust, while a correct problem initialization is critical. The equations and variables of the model compose a large system of non-linear equations, and the required $\mathrm{n}^{\circ}$ of specifications to attain zero degrees of freedom for its solving must be inputted. The representation of the dynamic results is effectively performed with plotting functions. The solver has built-in tool to deal with stiffness problems when solving the algebraic differential equations, which is caused when very fast and very slow phenomena appear simultaneously in a chemical/energy system. The initialization of the GS clusters is relatively straightforward to specify in this case. The challenge was to achieve the same conditions at the end of the reactor cycle, which required numerous iterations, and increased the computational effort substantially. However, the effective coding and set-up of the model resulted in simulation runs of up to 30 min for most of the cases.

Finally, it is mentioned here that the outcomes of the dynamic simulation are coupled to the stationary process flowsheet by means of CAPE-OPEN unit operation, as described in more detail in section 2.5.1. 


\section{Chapter 2}

\section{Gas Switching Technology}

In this chapter, the basics of the gas switching concepts is presented, the fundamental mass and energy balances and primary assumptions are later detailed and comprehensive cases for the gas switching cluster for combustion are shown, to provide insights on the methodology and optimization strategies applied for the cases which are later integrated in a stationary power plant flowsheet.

\subsection{GS Technology Overview}

As anticipated in the previous chapter, the gas switching reactor operation consists of a set of inlet and outlet valves which alter the feed and product streams to and from a reactor. In this way, a single reactor operates dynamically through a whole cycle of reduction and oxidation, with the total time length of the cycle being imposed by 1st) the oxygen carrier degree of conversion specified in the reduction and 2nd) the relative amount of reactors operating in oxidation vs. reduction at any instant of time. Figure 28 shows a simple schematic of the CLC mechanism using interconnected fluidized beds and a gas switching reactor concept of a reactor cluster operating under fluidized conditions.

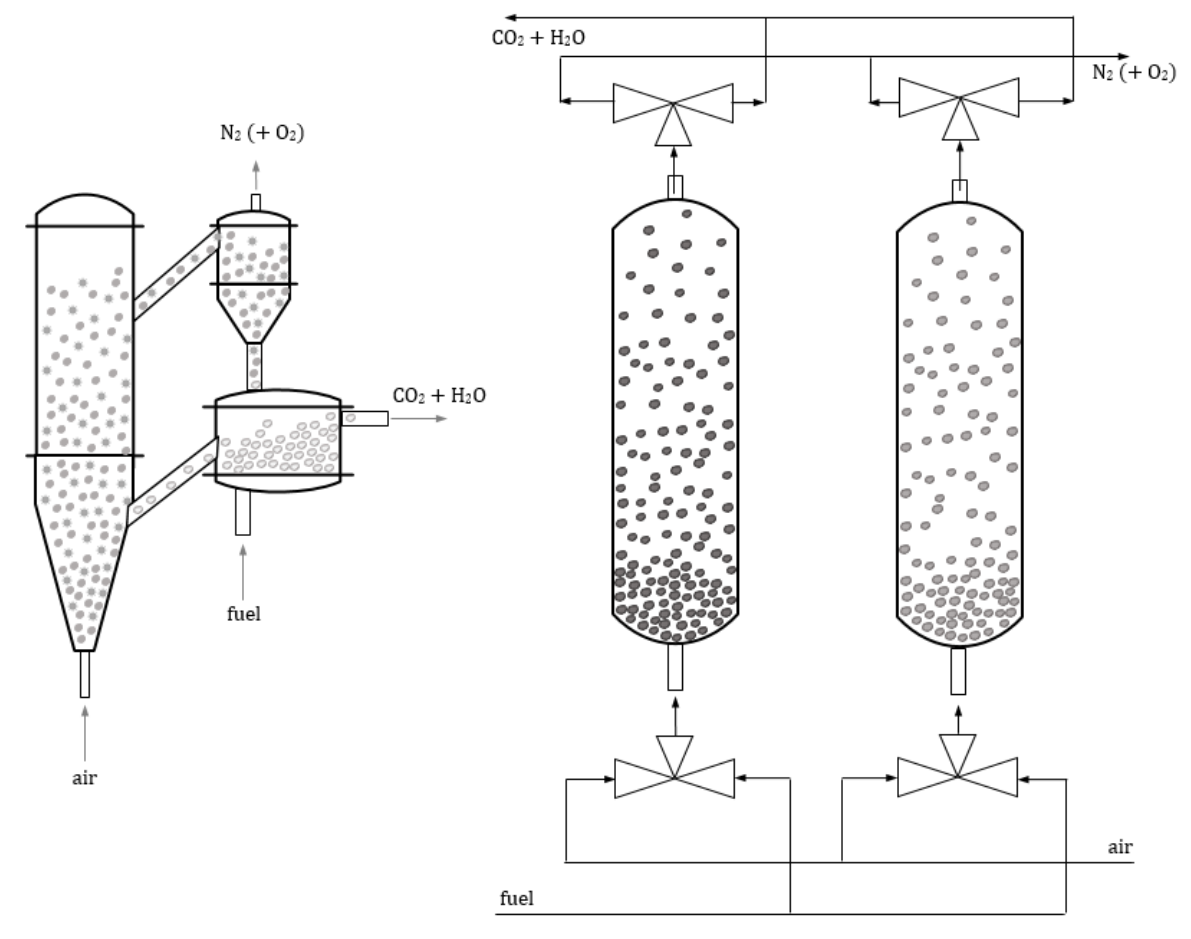

Figure 28 CLC system with interconnected fluidized beds vs. gas switching concept

The outlet products of each reactor (for each stage) from a cluster (each of them simultaneously operating in a reduction/oxidation cycle) are then mixed adiabatically and two main outlet flows are obtained from the cluster, with characteristics which vary depending on the GS technology, but typically consists of: a reduction gases stream with the products of combustion of the fuel and 
an $\mathrm{O}_{2}$ depleted air stream. While the fuel and air flow delivered to the GS cluster are typically constant in time, because of the transient nature of the GS operation, the mixed product flows of the show a cyclic variation in terms of flow, temperature and composition, as the oxygen subtracted from the oxidation reactors is being added to the product stream of the reduction reactors at every instant of time. Since the valves switching alter the chemical reactions taking place inside the reactors by exposing the oxygen carrier contained in it to different feeds, the need to circulate the solid material from one reactor to another is eliminated. Figure 29 shows a schematic of a GS cluster operation designed to achieve near steady state products as per one reduction reactor, which ensures that the time of oxidation is longer than the reduction, resulting in similar fuel and air flow rates from each reactor. A large number of reactors is desirable as the increasing $\mathrm{n}^{\mathrm{o}}$ of outlet streams that are mixed downstream will minimize the property fluctuations (flow rate, temperature) achieving a more stable operation of the power cycle couplet to the GS system.

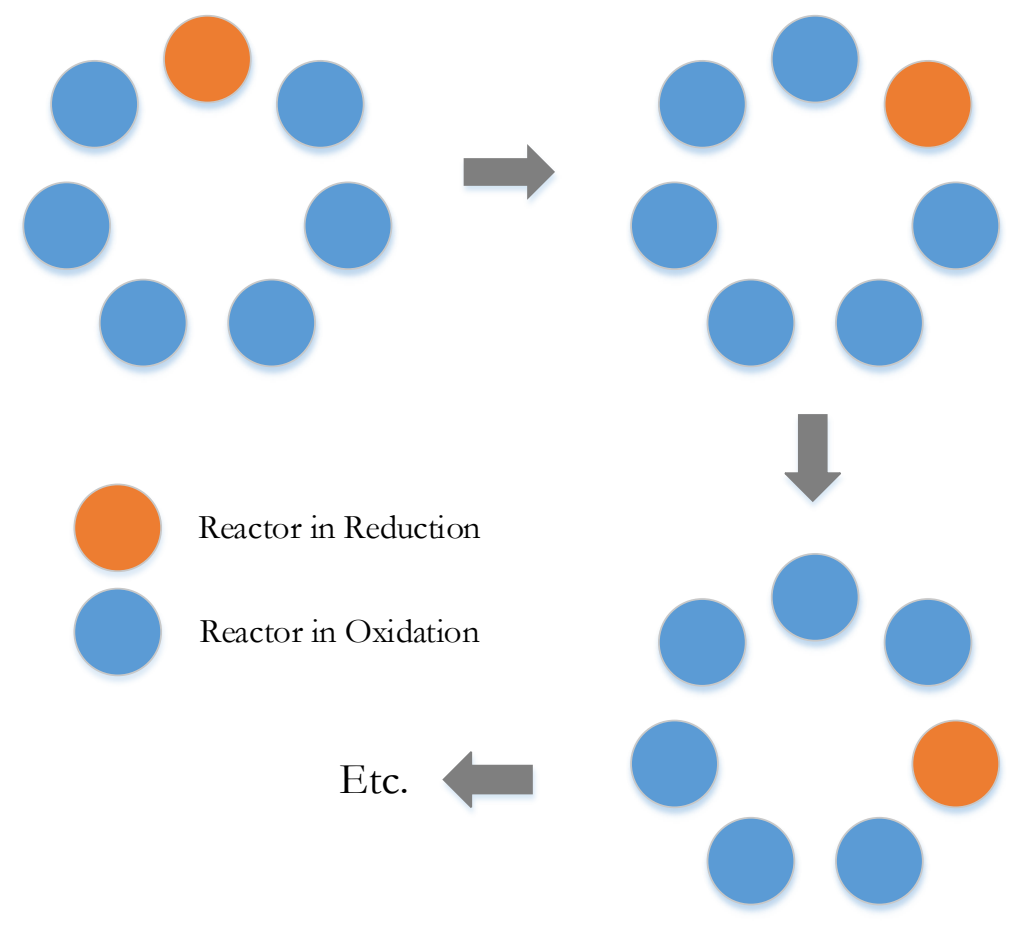

Figure 29 Illustration of the gas switching cluster operation concept

The switching mode of operation for CLC systems was first proposed by [50] for packed bed conditions, with promising experimental results at lab-scale operation with reduced process complexity at high pressure and achieving heat integration between the reactor stages. Nonetheless, several drawbacks of packed bed reactor configuration are present, mostly related to the stability and reactivity of the materials of the pelletized oxygen carriers. Furthermore, temperature gradients across the reactor length occur as the reaction front advances. In the bottom of the reactor where the gaseous fuel is fed, the solid material will be cooled down, reducing the reactivity in the subsequent stage and consequently not attaining a complete conversion of the fuel. The use of highly reactive oxygen carriers at low temperature at the bottom of the bed reactor or several heat management strategies [51] can palliate this effect, but at the cost of some process efficiency and $\mathrm{N}_{2}$ stream requirements for reactor purging (potentially above that delivered by an ASU in an IGCC plant) for the latter.

Besides these issues, the gas switching concept has substantial potential to increase thermal efficiency while reducing capital costs of accelerated scale up. Because of this, GS technology has 
been evaluated experimentally using bubbling fluidized bed reactors [21], where the excellent mixing under fluidization operation avoids the axial temperature gradients and localized hot reaction areas in the reactors encountered in packed beds. From a material perspective, cheaper oxygen carrier from the mineral ore can be used in the beds, allowing for a continuous replenishment of the deactivated material. Bubbling fluidization also achieves lower pressure drops and higher attainable gaseous feeds with good heat integration, while delivering two steady state outlet product streams that can be used downstream in a thermodynamic cycle for power generation. However, this increased $n^{\circ}$ of reactors affect the total investment cost of the power plant.

From a technology perspective, important showstoppers for these concepts are still present, namely, high temperature outlet valves to deliver the reactor outlet flows, and high temperature filters which prevent the entrained particulate materials from reaching the turbomachinery components must be available. Learnings from coal combustion technology in the field of ceramic filters shown in [52], or the devices described in [53] for fluidized bed combustion syngas filtering can be incorporated in future studies to enhance the technical feasibility of GS concepts. With regards to valves, [54] offers devices for extreme temperature service of up to $1200^{\circ} \mathrm{C}$, but only a low pressure operation. In any case, these items together with the oxygen carrier reactivity remain as the technical uncertainties of the present study, and all process evaluations are performed assuming that they will be supplied by manufacturers by the time the GS based concepts become deployed at a large scale. The gas switching concept can be applied to different chemical looping process such as combustion, reforming water splitting and oxygen production. A brief schematic of the four chemical looping processes is given in Figure 30:
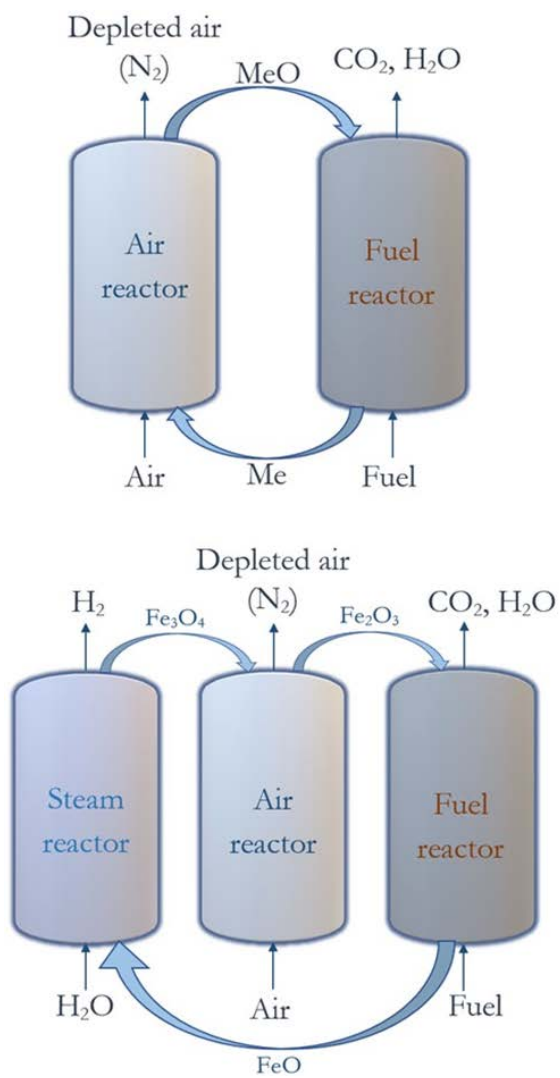
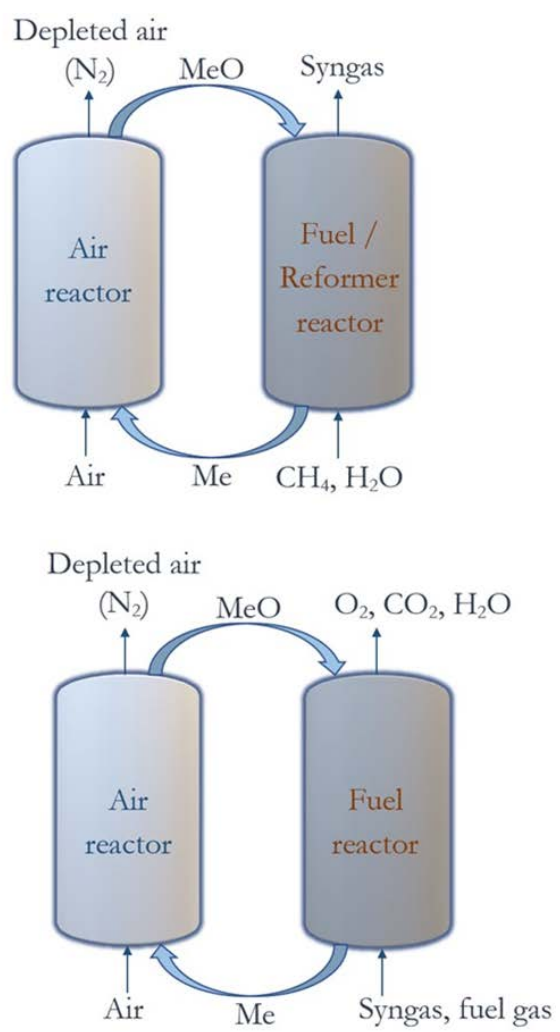

Figure 30 Different chemical looping concepts: combustion (top left) reforming (top right), water splitting (bottom left) and oxygen production (bottom right) 
In the reforming process (GSR), a natural gas fuel is converted to a syngas stream, as opposed to a complete fuel conversion occurring in combustion. The syngas produced can be later employed as feedstock for flexible $\mathrm{H}_{2}$ production in a WGS unit or electricity in a combined cycle [55]. In the water splitting process, an additional steam stage is used to obtain $\mathrm{H}_{2}$, while attaining full conversion of the fuel in the reduction reactor using an iron oxide oxygen carrier. Finally, the oxygen production utilizes an oxygen carrier capable of releasing free oxygen in the reduction reactor, which can later be used as an oxidant stream for instance, in a gasification unit. Within the framework of the GasTech project, UPM will investigate the modelling and integration of Gas Switching Combustion (GSC) and Gas Switching Oxygen Production (GSOP) in large scale IGCC power plants. Because of the big uncertainty related to the GSOP oxygen carrier, a wide temperature range of reactor operation has been considered in the process configurations proposed, acknowledging that substantial development for the oxygen carrier must still be undergone, and the simplified kinetic model based the $\mathrm{O}_{2}$ equilibrium fraction, which was determined through a thermogravimetric analysis for a particular formulation reported in [56]. With regards to material selection, testing and manufacturing of the CLC carrier in the GasTech project, highly reactive candidates with a high cyclic stability and proven production methods have been achieved, therefore substantial more focus has been put on the development of power production concepts that use GSC for inherent carbon capture. GSWS has shown unfortunately no realistic prospects due to agglomeration and coke deposition on the carrier. Finally, GSR concepts have been extensively covered by the research efforts in SINTEF.

\subsection{Dynamic Mass \& Energy Balances to a CSTR}

The energy and mass balance discussed in section Eq. 2 is applied to a reactor shown in Figure 31 Dynamic reactor and different control volumes. The variables of state, that is, the number of moles, energy, entropy etc. vary in time. The reactor has a feed stream (in) and a product stream (out). The objective is to determine all state variables of the reactor and product stream characteristics over a period of time.

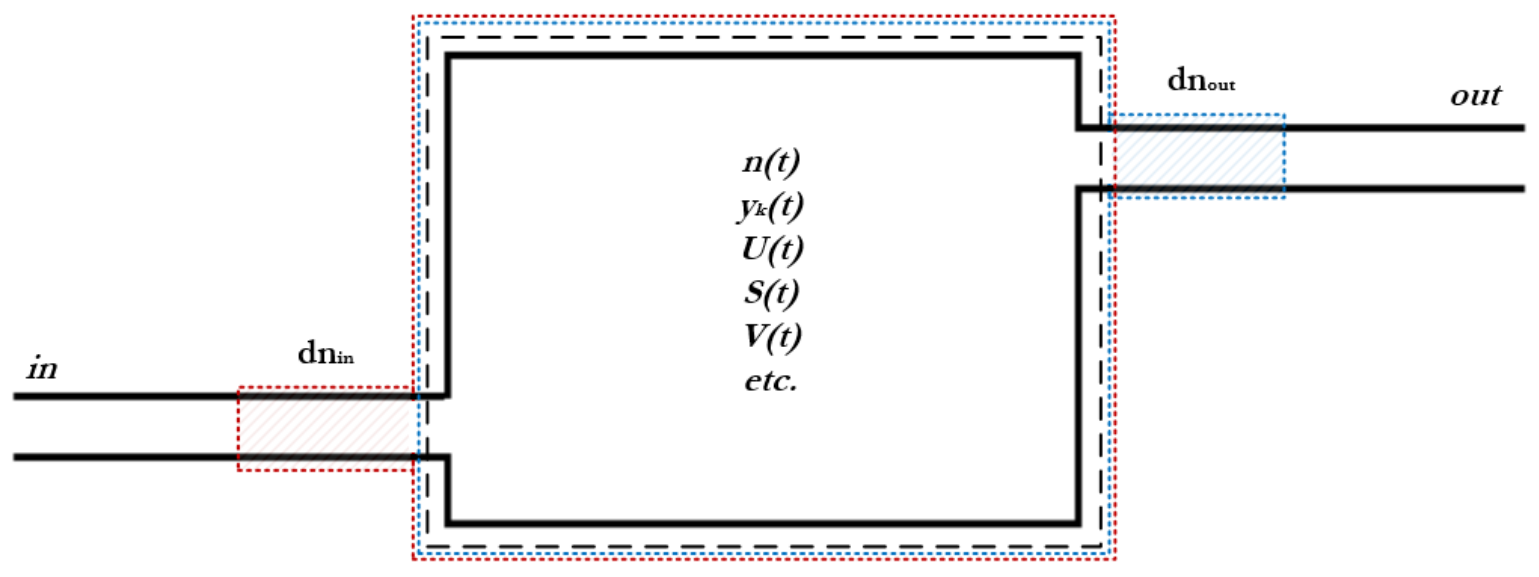

Closed System at $t+d t$

Closed System at $t$

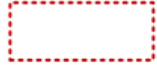

i --1

Open System

Figure 31 Dynamic reactor and different control volumes 
It is considered that, at any given instant $t$, the system behaves as a closed system with control volume represented by the red dotted line. On the other hand, in an infinitely close time $t+d t$, the closed system is now defined by the control volume represented as the blue dotted line. The mass balance conservation of each species $\mathrm{k}$ contained in the reactor, provided that $\xi_{\mathrm{r}}$ is the degree of advance of the reaction $r$, applied to the closed system (CS) between instants $t$ and $t+d t$, undergoing $\mathrm{R}$ chemical reactions, results in Eq. 26:

$$
n_{k}(t+d t)^{c s}=n_{k}(t)^{c s}+\sum_{r=1}^{R} v_{r, k} \xi_{r}
$$

The molar flow differential of each species can be expressed using the molar flow rate and molar fractions of the gas phase $y_{i, k}$ for each stream $\mathrm{i}$ as shown in Eq. 27:

$$
d n_{i, k}=F_{i} y_{i, k} d t
$$

In this way, the balance can be re-written as shown in Eq. 28:

$$
\begin{gathered}
n_{k}(t+d t)+F_{\text {out }} y_{\text {out }, k} d t=n_{k}(t)+F_{\text {in }} y_{\text {in }, k} d t+\sum_{r=1}^{R} v_{r, k} \xi_{r} \\
\frac{d n_{k}}{d t}=\dot{n}_{k}=F_{\text {in }} y_{\text {in }, k}+F_{\text {out }} y_{\text {out }, k}+\sum_{r=1}^{R} v_{r, k} \xi_{r}
\end{gathered}
$$

On the other hand, the energy balance can be applied to the closed system (CS) between $t$ and $t+$ $\mathrm{dt}$, as shown in Eq. 29, with

$$
\begin{gathered}
U(t+d t)^{C S}=U(t)^{C S}+d Q^{C S}-d W^{C S} \\
d Q^{C S}=d Q \\
d W^{C S}=d W+P_{\text {in }} v_{\text {in }} d n_{\text {in }}-P_{\text {out }} v_{\text {out }} d n_{\text {out }}
\end{gathered}
$$

The balance to the open system then results in Eq. 29, following the previous notation and taking into account the definition of specific enthalpy for stream $\mathrm{i}$, as $h_{i}=u_{i}+P_{i} v_{i}$ :

$$
\begin{gathered}
U(t+d t)+u_{\text {out }} d n_{\text {out }}=U(t)+u_{\text {in }} d n_{\text {in }}+d Q-d W-P_{\text {in }} v_{\text {in }} d n_{\text {in }}+P_{\text {out }} v_{\text {out }} d n_{\text {out }} \\
\frac{d U}{d t}=\dot{U}=\dot{Q}-\dot{W}+F_{\text {in }} h_{\text {in }}-F_{\text {out }} h_{\text {out }}
\end{gathered}
$$

Which is a particular case of Eq. 2 for a system with only one feed and one product stream.

The above equations apply to any system with changes in its state properties in time. In the case of a Continuous Stirred Tank Reactor (CSTR), the primary hypothesis is that all mass and thermal diffusive effects occur sufficiently fast in time that the whole reactor volume has reached at any given instant thermodynamic equilibrium [57]. In the surroundings of the point in the reactor where a stream is fed, there might exist local temperature and composition gradients but these are considered to be very small with respect to the total reactor volume. It therefore follows that any product stream leaving the reactor must be at the same conditions (defined by its composition, temperature and pressure) as the whole reactor volume. Therefore, any state variable of this outlet stream can be rewritten without the subscript out. 
Although fluidized bed reactors are complex systems and rigorous models involve much more refined assumptions, these systems can be reasonably represented with the CSTR model based on the excellent mixing properties encountered in industrial-scale fluidized beds, in practice reaching thermal and chemical equilibrium. Thermal equilibrium is justified for the GS clusters because the small particle sizes (around $100 \mu \mathrm{m}$ ) ensure extremely fast fluid-particle heat transfer. On the other hand, it is assumed that a sufficiently reactive oxygen carrier is employed, eliminating the possibility of fuel slip, and that the reduction of the carrier does not proceed to a very high conversion, running into potential issues of reaction rate limitations.

The total volume of the CSTR reactor will not change in time, and if additionally the pressure remains constant (which can be achieved by controlling the reactor outlet flow), the state variables of the reactor $\dot{U}$ and $\dot{H}$ are interchangeable. The variation of total enthalpy of the reactor can be expressed as the contribution of each species k, as presented in Eq. 31:

$$
\begin{gathered}
\dot{H}=\sum_{k} \dot{n}_{k} h_{k}+\sum_{k} n_{k} \dot{h}_{k} \\
\dot{h}_{k}=\left(\frac{\partial h_{k}}{\partial T}\right)_{P} \dot{T}=c_{p, k} \dot{T}
\end{gathered}
$$

Eq. 31

The energy balance, making use of the CSTR hypothesis and making this last transformation results in Eq. 32:

$$
\sum_{k} \dot{n}_{k} h_{k}+\sum_{k} n_{k} c_{p, k} \dot{T}=\dot{Q}-\dot{W}+F_{\text {in }} h_{\text {in }}-F_{\text {out }} h
$$

To solve the energy balance and obtain the temperature profile in a certain length of time one must eliminate from Eq. 32 the term $F_{\text {out }}$, which has not been yet determined. The process that is considered here is that the reaction takes place adiabatically, without any work exchange between the system and its surroundings, and the specific enthalpy of each of the substances in the reactor are taken coherently assigning to it the normal enthalpy of formation at $298.15 \mathrm{~K}$ as a reference. In this way, the substitution of the molar balance for each species in the energy balance results in Eq. 33. Identifying each of the elements of both sides of the equation, the term $F_{\text {out }}$ disappears and considering that $\sum_{r=1}^{R} v_{r, k} h_{k}=\Delta H_{r, T}$ :

$$
\begin{gathered}
{\left[\sum_{k}\left(F_{\text {in }} y_{\text {in }, k}+F_{\text {out }} y_{k}+\sum_{r=1}^{R} v_{r, k} \dot{\xi}_{r}\right) h_{k}+n_{k} c_{p, k} \dot{T}\right]=F_{\text {in }} h_{\text {in }}-F_{\text {out }} h} \\
\sum_{k} n_{k} c_{p, k} \dot{T}=-F_{\text {in }} \sum_{k} y_{\text {in }, k}\left(h_{k}-h_{\text {in }, k}\right)+\sum_{r=1}^{R} \xi_{r}\left(-\Delta H_{r, T}\right) \\
\frac{d T}{d t}=\frac{-F_{\text {in }} \sum_{k} y_{\text {in }, k} \int_{T_{\text {in }}}^{T} c_{p, k} d T+\sum_{r=1}^{R} \xi_{r}\left(-\Delta H_{r, T}\right)}{\sum_{k} n_{k} c_{p, k}}
\end{gathered}
$$

The energy balance is now solved if the degree of each reaction $\xi_{r}$ is known. Establishing a rate of reaction between the oxygen carrier material and gaseous species, taking into account the stoichiometry, will determine the degree of advance of each reaction. Once Eq. 33 is known, the total outlet flow required for isobaric operation (which was a requisite of the mathematical formulation developed to solve this balance) can be calculated at each time instant. With this 
information, the molar species in the reactor, and therefore in the product stream, can be determined as well. To explicitly calculate $F_{\text {out }}$ use of the thermal equation of state must be made, considering that the total reaction volume remains constant in time, as reflected in Eq. 34. In the present analysis, it is assumed that the gases are relatively well described with the ideal gas equation of state, and that the mixture behaves as an ideal gas mixture, thus with no volume or enthalpy of mixing [29]. This is a reasonable assumption due to the high temperature encountered in the GS clusters and the relatively low pressures.

$$
\begin{gathered}
V=\sum_{k} n_{k} v_{k} \\
\dot{V}=\sum_{k}\left(\dot{n}_{k} v_{k}+n_{k} \dot{v}_{k}\right)=\sum_{k}\left(\dot{n}_{k} v_{k}+n_{k}\left(\frac{\partial v_{k}}{\partial T}\right)_{P} \dot{T}\right)=0
\end{gathered}
$$

Now, with the ideal gas assumption, $v_{k}=R T / P,\left(\frac{\partial v_{k}}{\partial T}\right)_{P}=R / P$ and $n_{k}=y_{k} \frac{P V}{R T}$. By substitution of $\dot{n}_{k}$ with the right hand side of (Eq. 28), $F_{\text {out }}$ results in Eq. 35:

$$
F_{\text {out }}=F_{\text {in }}+\sum_{R}^{k \in \text { gases }} v_{k, r} \xi_{r}+\frac{P V_{\text {gas }}}{R T^{2}} \dot{T}
$$

Where only the gaseous volume of the reactor and the degree of advance of the gaseous reactions are taken into account (as the solids permanently remain in the reaction volume).

To summarize, the dynamic mass and energy balances applied to a CSTR with heterogenous reactions taking place can be solved. The total number of differential equations are $\mathrm{C}+1$, with $\mathrm{C}$ being the total number of chemical components in the mixture (gases and solids), corresponding to each the species $n_{k}$ and the temperature $\mathrm{T}$ of the reactor. Also, an algebraic equation to determine the total molar outlet flow must be solved. The key assumptions are a CSTR behaviour of the reactor (perfect mixing that leads to the same composition and temperature in the while reactor volume) operating adiabatically at constant volume and pressure, using the ideal gas equation of state and requiring a kinetic model to determine the rates of reaction for each species (solid or gas).

\subsection{Gas Switching Reactor Cluster Algorythm}

In the previous section, the fundamental mathematical representation of the gas switching reactor has been formally presented. However, the solving of these equations requires an involved modelling procedure, which will be developed and exemplified in the following pages. The modelling tool employed for this purpose is Scilab 6.0.2, a software for numerical analysis which allows to build an equation oriented model to represent a physical system, as discussed in section 1.5 .

The basic outline of the algorithm for the resolution of a Gas Switching Technology (GST) cluster is given in Figure 32, where the connectivity of the transient model with the stationary power plant is reflected. The algorithm is shown for the particular case of Gas Switching Combustion (GSC), where a maximum temperature of the oxidation stage is assumed and achieved through manipulation of the total air inlet flow rate. The solver has the flexibility to provide operating points of different GS technologies, and has been adapted to determine GSOP performance as 
well. Several updates on the code and appropriate addition of stoichiometry and chemical reaction kinetics would allow the calculation of GSR clusters.

In summary, the oxygen carrier is selected in the Mainscript file, which unequivocally determines the reaction stoichiometry matrix and the formulation of the oxygen carrier. Several heat management strategies are available for an optimized reactor operation, which will be discussed later. By introducing the dimensions of the reactor cluster (height and volume) and assuming a solids volume fraction during fluidization, the solid contents of the reactor are determined. The $\mathrm{n}^{\circ}$ of reactors operating in oxidation and reduction during a cycle is set to achieve similar fluidization velocities in the reactors and similar molar outlet flows. The product streams of each reactor stage are then mixed and delivered either to the power cycle (oxidation stage outlet) or to a heat recovery unit and downstream water condensation and $\mathrm{CO}_{2}$ purification and compression (reduction stage outlet).

The GS technology is then selected: either GSC or GSOP. The model reads from an auxiliary function the data regarding the fuel composition and temperature, as well as the inlet air temperature. These values can be manually introduced in case the model is run standalone, or directly imported from the stationary process simulation of the power plant through a CAPEOPEN unit operation. As mentioned before for the case of the GSC, the initial reactor temperature and the total air flow rate are iterative variables. With specified initial values, the function fsolve solves a set of nonlinear equations to determine the air flow rate which achieves the maximum reactor temperature allowable and the initial reactor temperature value that coincides with the value obtained at the end cycle (authothermal cycle). These nonlinear equations are the dynamic mass and energy balances of the CSTR reactor explained in section 2.2, which are calculated using the function odestiff. To determine the time length of each reduction stage, an oxygen carrier conversion is assumed, defined as the ratio of reduced oxygen carrier species divided by the total moles of solids in the reactor. The oxidation time length is a multiple of the reduction time, based on the relative $\mathrm{n}^{\circ}$ of reactors assumed for each stage, in such a way that the whole reactor volume is utilized through an entire time cycle. Since the inlet flow to the oxidation stage (air) is higher than that of the reduction stage, the $\mathrm{n}^{\circ}$ of oxidation reactors are a multiple of the $\mathrm{n}^{\circ}$ of reduction reactors.

Once the initial reactor temperature and specified maximum allowable reactor temperature are simultaneously converged, the solver exits the ode loop. Depending on the ratio of reduction/oxidation reactors specified, the outlet flows at every time instant of the cluster are determined. The solver has the flexibility to specify any ratio of stage reactors and calculate outlet streams accordingly. The average values of temperature and species molar flows are determined using a simple the trapezoidal rule between two points of the cluster at any given instant to integrate the whole cycle length. The averaged total and individual species molar flow and temperatures along the reactor cycle for each stage are delivered to the process flowsheet for stationary simulation. Further details of the GST code can be found in the Appendix. 
Honeywell GAS SWITCHING DYNAMIC SOLVER ALGORITHM \& INTEGRATION WITH
SATIONARY PROCESS SIMULATOR

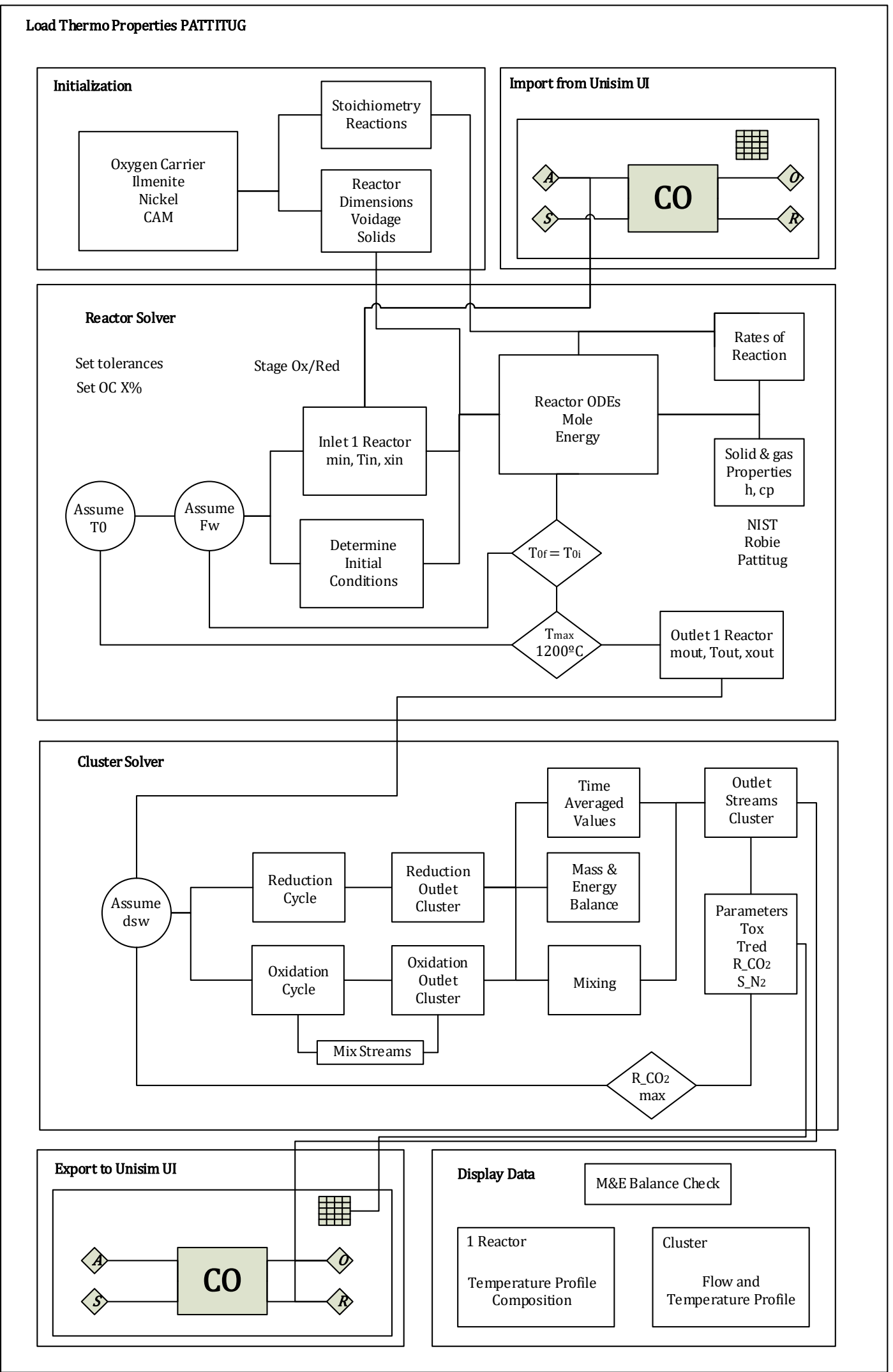

Figure 32 GST algorithm 
With the values for the reactor initial temperature and air flow rate are converged, the solver determines the molar and temperature profile of one reactor in the cycle time length. The outlet molar flows of the gaseous species are also determined by re-evaluation of the differential equation at the final values of initial temperature and air flow rate.

The cluster is then solved. The species molar outlet flow of each reactor is determined with a time phasing between each reactor calculated by dividing the total time length by the total $\mathrm{n}^{\circ}$ of reactors of the cluster. If the reduction or oxidation stage consist of more than one reactor (which is always the case for oxidation), the outlet flows of each reactor must be added at each time instant. The mixing of the flows requires an internal enthalpy balance with an iterative procedure to calculate the outlet stream temperature of the mixing which satisfies this energy balance. The solver tool makes use of the function convergeh in Patitug, which returns the temperature of a given mixture at a certain pressure and specific enthalpy). A matrix with the mixed outlet species flow streams at each time of the cycle length is obtained. The time averaged compositions, temperature and flow rates are delivered to the stationary power plant simulation through the processing data tool. The recovery of $\mathrm{CO}_{2}$ in the reduction stream and the $\mathrm{N}_{2}$ slip from the oxidation stage are also calculated. A check on the global mass and energy balance is performed, with relative errors below $0,1 \%$ for the mass balance and an absolute value error below than 0,5 MW for the energy balance. If the model is run standalone, the results are represented with the plot function. The composition and temperature profile of a single reactor is shown as well as temperature and non-dimensionless mass flow rate of the cluster oxidation and reduction outlets. These plots allow to ensure that the stream that is routed to the gas turbine does not experience excessive fluctuations in time that would hamper and deteriorate the lifetime of the turbomachinery components.

\subsubsection{Oxygen Carrier Selection and Reaction Kinetics}

The formulation of the oxygen carrier depends of the application: either GSC or GSOP. For GSC operation, two oxygen carriers have been evaluated. Ilmenite $\left(\mathrm{Fe}_{2} \mathrm{O}_{3} / \mathrm{FeO}\right)$ and Nickel Oxide $(\mathrm{NiO} / \mathrm{Ni})$ present good prospects as $\mathrm{OC}$ in terms of mechanical stability and reactivity. In the latest power plant assessments, Nickel Oxide was the preferred choice due to its larger oxygen carrier capacity and proven when fluidized under high temperatures [58], despite its toxicity. Development efforts should be carried out to manufacture appropiate oxygen carriers with good performances at high temperature and with no effect on health.

The carrier is fully oxidized at the beginning of the reduction stage. The reduction stage time is set to achieve a specified oxygen carrier (OC) conversion. The lower the assumed conversion, the lower time of reduction and the frequency of valve switching increases, thereby reducing the capture performance of the cluster and the purity of the reduced outlet stream. On the other hand, a low OC conversion results in a smaller variation of the temperature across the cycle which, given a maximum reactor temperature taken as $1200^{\circ} \mathrm{C}$, increases the average outlet temperature of the reduction and oxidation stages, resulting in an improved thermal performance of the power cycle. On the other hand, when the OC conversion is high and the duration of the cycle is long, a higher capture rate and purity of the reduction gases stream can be obtained at the cost of lower average outlet temperature, and thus, thermodynamic efficiency.

The heterogeneous reaction stoichiometry and rates for the oxidation (Eq. 39) and reduction (Eq. Eq. 36, Eq. 37 \& Eq. 38) of Ilmenite $\left(\mathrm{Fe}_{2} \mathrm{O}_{3} / \mathrm{FeO}\right)$ are as shown in Table 9, considering the combustible species present in syngas from coal gasification and no hydrocarbon molecules other than methane: 
Table 9 Heterogeneous reactions and kinetic rates for Ilmenite oxygen carrier

$$
\begin{array}{ccc}
\mathrm{CH}_{4}+4 \mathrm{Fe}_{2} \mathrm{O}_{3} \rightarrow 8 \mathrm{FeO}+\mathrm{CO}_{2}+2 \mathrm{H}_{2} \mathrm{O} & R_{\mathrm{CH} 4}=\frac{1}{\tau} n_{\mathrm{CH}_{4}} n_{\mathrm{Fe}_{2} \mathrm{O}_{3}} & \text { Eq. } 36 \\
\mathrm{H}_{2}+\mathrm{Fe}_{2} \mathrm{O}_{3} \rightarrow 2 \mathrm{FeO}+\mathrm{H}_{2} \mathrm{O} & R_{\mathrm{H}_{2}}=\frac{1}{\tau} n_{\mathrm{H}_{2}} n_{\mathrm{Fe}_{2} \mathrm{O}_{3}}
\end{array}
$$

For the oxygen carrier $\mathrm{NiO} / \mathrm{Ni}$, the reduction (Eq. 40, Eq. 41 \& Eq. 42) and oxidation (Eq. 43) reaction rates are given below in Table 10:

Table 10 Heterogeneous reactions and kinetic rates for Nickel Oxide oxygen carrier

$$
\begin{array}{ccc}
\mathrm{CH}_{4}+4 \mathrm{NiO} \rightarrow 4 \mathrm{Ni}+\mathrm{CO}_{2}+2 \mathrm{H}_{2} \mathrm{O} & R_{\mathrm{CH}_{4}}=\frac{1}{\tau} n_{\mathrm{CH}_{4}} n_{\mathrm{NiO}} \\
\mathrm{H}_{2}+\mathrm{NiO} \rightarrow \mathrm{Ni}+\mathrm{H}_{2} \mathrm{O} & R_{\mathrm{H}_{2}}=\frac{1}{\tau} n_{\mathrm{H}_{2}} n_{\mathrm{NiO}}
\end{array}
$$

Finally, the GSOP oxygen carrier is based on $\mathrm{Cu}$ - $\mathrm{Mn}$ - and $\mathrm{Co}$ - oxides [59] with many different potential formulations to operate in a wide range of temperatures. For the present work, $\mathrm{Ca}_{2} \mathrm{AlMnO}_{5.5}$ is considered, henceforward referred to as $\mathrm{CAM}_{\mathrm{ox}}$ and $\mathrm{CAM}_{\text {red }}$ for the oxidized and reduced species respectively. The heterogeneous reduction and oxidation reactions taking place are shown in Table 11:

Table 11 Heterogeneous reactions and kinetic rates for CAM oxygen carrier

$$
\begin{aligned}
& \mathrm{CH}_{4}+8 \mathrm{Ca}_{2} \mathrm{AlMnO}_{5.5} \rightarrow 8 \mathrm{Ca}_{2} \mathrm{AlMnO}_{5}+\mathrm{CO}_{2}+2 \mathrm{H}_{2} \mathrm{OR}_{\mathrm{CH} 4}=\frac{1}{\tau} n_{\mathrm{CH}_{4}} n_{\mathrm{Ca}_{2} \mathrm{AlMnO}_{5.5}} \quad \text { Eq. } 44 \\
& \mathrm{H}_{2}+\mathrm{Ca}_{2} \mathrm{AlMnO}_{5.5} \rightarrow \mathrm{Ca}_{2} \mathrm{AlMnO}_{5}+\mathrm{H}_{2} \mathrm{O} \quad \mathrm{R}_{\mathrm{H} 2}=\frac{1}{\tau} n_{\mathrm{H}_{2}} n_{\mathrm{Ca}_{2} \mathrm{AlMnO}} \mathrm{Al}_{5.5} \quad \text { Eq. } 45 \\
& \mathrm{CO}+\mathrm{NiO} \rightarrow \mathrm{Ca}_{2} \mathrm{AlMnO}_{5}+\mathrm{CO}_{2} \quad R_{\mathrm{H} 2}=\frac{1}{\tau} n_{\mathrm{CO} n_{\mathrm{Ca}_{2}} \mathrm{AlMnO}_{5.5}} \quad \text { Eq. } 46 \\
& \mathrm{O}_{2}+\mathrm{Ca}_{2} \mathrm{AlMnO}_{5} \leftrightarrow \mathrm{Ca}_{2} \mathrm{AlMnO}_{5.5} \quad R_{\mathrm{H} 2}=\frac{1}{\tau}\left(y_{\mathrm{O}_{2}}-y_{\mathrm{O}_{2} \text { eq }}\right) n_{g a s} n_{\mathrm{Ca}_{2} \mathrm{AlMnO}} \quad \text { Eq. } 47
\end{aligned}
$$


To determine the equilibrium oxygen mole fraction $y_{\mathrm{O}_{2}}$ eq , an equation from a thermogravimetric analysis (TGA) is used in [56], as shown in Eq. 48. In this way the rate of reaction approaches zero when the oxygen partial pressure is close to the equilibrium value. Such expression is a result of applying the Vant'Hoff equation to the $\mathrm{O}_{2}$ release reaction, which assumes that the enthalpy of reaction is constant with temperature:

$$
y_{O_{2} e q}=\frac{1}{P} e^{\left(\frac{-91000}{R}\left(\frac{1}{T}-\frac{1}{T_{\text {ref }}}\right)\right)}
$$

In the experiment carried out in [56], the oxidation enthalpy corresponds to $-91 \mathrm{~kJ} / \mathrm{mol}$ with a reference temperature of $720^{\circ} \mathrm{C}$ at an oxygen partial pressure of 1 bar. However, since oxygen carriers which release free oxygen are in a very early stage of development, the studies presented in this work seek to determine the optimal reactor operating temperature, and the $\mathrm{T}_{\text {ref }}$ value in Eq. 48 was adjusted conveniently to match the equilibrium conversion required. It should be noted that different oxygen carrier material will need to be developed to enable such operation. Indeed, the oxygen production concept is of a theorical nature, and oxygen carriers with suitable thermodynamic properties have not been developed up to date. Such lengthy development timeframe stirred the efforts of the GasTech project towards the development of the oxygen carrier materials for the other gas switching concepts, primarily involving combustion and reforming.

The properties of the oxygen carrier with respect to density, support material and fraction of active material for GSC are provided in [60]. On the other hand, for the GSOP carrier, the composition described in [56] was adopted. Table 12 summarizes the carrier formulation and main properties used in the transient model for each carrier:

Table 12 Property summary of the different oxygen carriers employed

\begin{tabular}{|c|c|c|c|c|c|c|}
\hline $\begin{array}{c}\text { Oxygen } \\
\text { Carrier }\end{array}$ & $\begin{array}{c}\text { GS } \\
\text { Operation }\end{array}$ & $\begin{array}{c}\text { Oxidized } \\
\text { Form }\end{array}$ & $\begin{array}{c}\text { Reduced } \\
\text { Form }\end{array}$ & $\begin{array}{c}\text { Support } \\
\text { Material }\end{array}$ & $\begin{array}{c}\text { Active } \\
\text { Content } \\
\mathbf{( \% )} \boldsymbol{~}\end{array}$ & $\begin{array}{c}\text { Density } \\
\mathbf{( k g} / \mathbf{m}^{3} \mathbf{)}\end{array}$ \\
\hline Ilmenite & GSC & $\mathrm{Fe}_{2} \mathrm{O}_{3}$ & $\mathrm{FeO}$ & $\mathrm{TiO}_{2}$ & 33 & 3446 \\
\hline Nickel & GSC & $\mathrm{NiO}$ & $\mathrm{Ni}$ & $\mathrm{Al}_{2} \mathrm{O}_{3}$ & 40 & 4000 \\
\hline $\mathrm{CAM}$ & GSOP & $\mathrm{Ca}_{2} \mathrm{AlMnO}_{5.5}$ & $\mathrm{Ca}_{2} \mathrm{AlMnO}_{5}$ & $\mathrm{Ca}_{2} \mathrm{AlMnO}_{5}$ & 75 & 3000 \\
\hline
\end{tabular}

\subsubsection{Thermodynamic Property Calculation}

As anticipated in section 2.2, the solving of the balance equations requires the knowledge of several physical properties of the different gaseous and solid species contained in the reactor volume, namely the specific heat capacity and the specific enthalpy. The hypothesis of ideal gas behaviour was earlier justified, and therefore all physical properties are exclusively temperature dependent. To calculate the specific heat and enthalpy of solid species, coefficients of the Shomate equation from [61] are coded in an auxiliary function. When no data was available for a species in the aforementioned database, such as the case of $\mathrm{NiO}$, the table data in [62] is adjusted with the function leastsq to the coefficients of the Shomate equation, which is detailed in Eq. 49, Eq. 50 \& Eq. 51 for the calculation of specific heat $c_{p}^{\circ}$ in $\mathrm{J} / \mathrm{molK}$, specific enthalpy $h^{\circ}$ in $\mathrm{kJ} / \mathrm{mol}$ and specific 
entropy $s^{\circ}$ in $\mathrm{J} / \mathrm{molK}$ (the latter not required in the model calculations) using $t$ as the temperature in $\mathrm{K}$ divided by 1000 .

$$
\begin{gathered}
c_{p}^{\circ}=A+B t+C t^{2}+D t^{3}+\frac{E}{t^{2}} \\
h^{\circ}-h_{298,15}^{\circ}=A t+\frac{B t^{2}}{2}+\frac{C t^{3}}{3}+\frac{D t^{4}}{4}-\frac{E}{t}+F-H \\
s^{\circ}=A \cdot \ln (t)+B t+\frac{C t^{2}}{2}+\frac{D t^{3}}{3}-\frac{E}{2 t^{2}}+G
\end{gathered}
$$

To determine the enthalpy or specific heat capacity of a gaseous stream, defined by the molar flows of each component, temperature and pressure; the model makes use of the built-in functions in Patitug, an in-house thermodynamic database from the Thermodynamics' Unit in the Energy Department, which includes all relevant thermodynamic properties for several pure species with the flexibility to calculate functions of state such as enthalpy, entropy, exergy etc. The subroutines can efficiently determine the enthalpy of a pure component, and thereof that of a mixture if it can be considered an ideal gas mixture. The temperature dependency of the property calculation tools both for solids and gases ensures that the precise enthalpy of reaction (that taking place at a given temperature) is evaluated at each time instant within the reaction volume, as an improvement relative to other literature models [63] where a constant enthalpy of reaction (typically taken at standard conditions) is assumed over a wide range of temperatures. This results in a more accurate representation of the reactor profiles and the determination of averaged stationary outputs with more precision. The specific heat capacity of pure gaseous substances is on the other hand reliably calculated with coefficients obtained from [64].

\subsubsection{Stream \& Parameter Inputs/Output}

\begin{tabular}{|c|c|}
\hline In & Out \\
\hline $\begin{array}{c}\text { Fuel composition, flow, temperature \& } \\
\text { Pressure }\end{array}$ & $\begin{array}{l}\text { Reduction stage time-averaged flow, } \\
\text { composition and temperature }\end{array}$ \\
\hline Air composition, temperature $\&$ pressure & $\begin{array}{l}\text { Oxidation stage time-averaged flow, } \\
\text { composition and temperature }\end{array}$ \\
\hline $\mathrm{N}^{\circ}$ of reduction reactors & $\begin{array}{l}\mathrm{CO}_{2} \text { recovery (with respect to the total } \\
\text { generated) }\end{array}$ \\
\hline $\mathrm{N}^{\mathrm{o}}$ of oxidation reactors & $\begin{array}{l}\mathrm{N}_{2} \text { slip (slip to reduction stage with } \\
\text { respect to total at inlet) }\end{array}$ \\
\hline Reactor diameter \& height & $\begin{array}{c}\text { Calculated fluidization velocity for each } \\
\text { stage/reactor }\end{array}$ \\
\hline Oxygen carrier specified conversion & $\begin{array}{l}\text { Inlet air flow rate \& initial rector } \\
\text { temperature }\end{array}$ \\
\hline
\end{tabular}

The input/output parameters from the transient model are listed in Table 13:

Table 13 Input/output parameters from transient reactor simulation

By tuning the $\mathrm{n}^{\mathrm{o}}$ of oxidation and reduction reactors the target fluidization velocity of each stage is achieved. Furthermore, it is ensured that the dimensionless mass flow rate of the oxidation stage variations does not surpass $2 \%$. A typical syngas composition obtained from the power plant 
simulations, for a Shell gasifier and Hot Gas Clean Up technology is shown in Figure 33. This stream characteristics are used henceforward in this chapter to exemplify the performance of the GSC cluster. The inlet composition to the oxidation stage corresponds to that of air at ISO conditions, $\left(15^{\circ} \mathrm{C}\right.$ and $60 \%$ relative humidity), and the inlet conditions corresponding to the pressure ratio of an F-class GT and an assumed compressor outlet temperature of $430^{\circ} \mathrm{C}$.

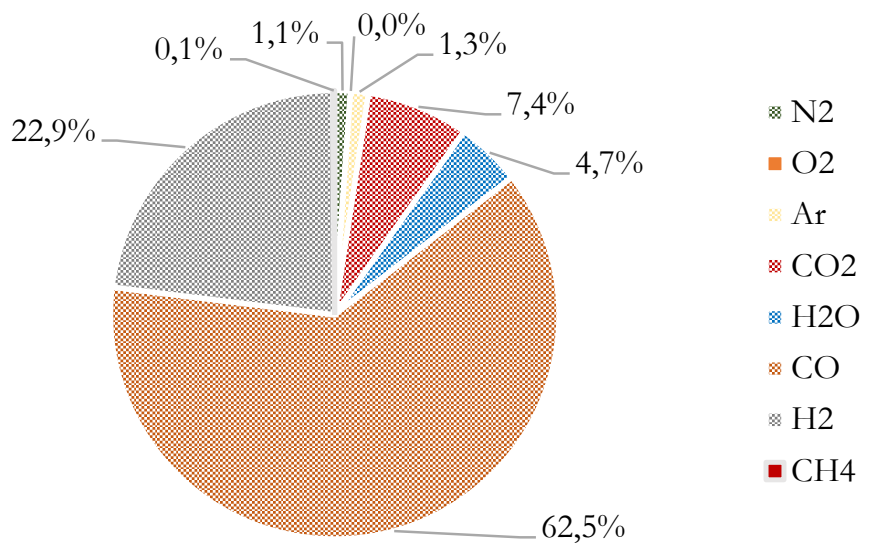

Figure 33 Syngas composition to GSC reduction stage

The syngas flow rate is $67.43 \mathrm{~kg} / \mathrm{s}$ at $400^{\circ} \mathrm{C}$ and the operating cluster pressure is $18.16 \mathrm{bar}$. The transient reactor assumes a constant pressure operation but an adequate pressure drop is used in the stationary reactor model linked to the power plant described in section 2.5. The reactor dimensions used for these cases were $12 \mathrm{~m}$ height and $6 \mathrm{~m}$ diameter, with 6 reactors operating in oxidation for 1 in reduction. For the cases employed in the power plant models described in the Chapter 4, the ratio of reactors in reduction and oxidation as well as the dimensions are adjusted accordingly to meet the fluidization requirements and operational stability of the downstream power units.

With regards to the output parameters used to determine and evaluate the performance of the cluster from an emissions perspective, the $\mathrm{CO}_{2}$ recovery ratio and $\mathrm{N}_{2}$ slip are defined by Eq. 52 and Eq. 53 respectively:

$$
\begin{gathered}
R_{C O_{2}}=\frac{f_{C O_{2}}^{R E D}}{f_{C O_{2}, \text { ideal }}^{R E D}}=100 \cdot\left(\frac{f_{C O_{2}}^{R E D}}{f_{C O_{2}}^{R E D}+f_{C O_{2}}^{O X}-f_{C O_{2}}^{\text {air }}}\right) \\
S_{N_{2}}=\frac{f_{N_{2}, \text { ideal }}^{O X}-f_{N_{2}}^{O X}}{f_{N_{2}, \text { ideal }}^{O X}}=100 \cdot\left(1-\frac{f_{N_{2}}^{O X}}{f_{N_{2}}^{O X}+f_{N_{2}}^{R E D}-f_{N_{2}}^{s g}}\right)
\end{gathered}
$$

With RED and OX refers to oxidation and reduction stage averaged outlets, air being the total feed flow to the oxidation stage reactors and fuel the equivalent to the reduction stage reactors of the cluster. The averaged species molar flows and temperature of the cluster product streams (RED \& OX) are calculated as the integral of the instantaneous stage outlet (after mixing the product of each reactor in the stage) throughout the entire cycle length, as illustrated by Eq. 54 for a given generic variable $\mathrm{Z}$ (which may be individual molar flows, temperature, enthalpy etc.). A trapezoidal approximation for finite element integration is used. 


$$
\bar{Z}=\frac{\int_{0}^{t_{c y c l e}} Z(t) d t}{\int_{0}^{t_{c y c l e}} d t}
$$

On the other hand, the approximated fluidization velocities for each reactor stage are determined with the total volumetric molar flow inlets to each stage (denoted as $\mathrm{F}_{\mathrm{sg}}$ and $\mathrm{F}_{\text {air }}$ ), the average stage temperature and the total cross-sectional area of each stage, as shown in Eq. 55 \& Eq. 56, with $\mathrm{n}_{\mathrm{RED}}$ and $\mathrm{n}_{\mathrm{OX}}$ as the total $\mathrm{n}^{\circ}$ of reactors in each stage.

$$
\begin{array}{ll}
u_{f}^{R E D}=\frac{F_{s g} R T^{R E D}}{P} \frac{4}{n_{R E D} \pi D_{R}^{2}} & \text { Eq. } 55 \\
u_{f}^{O X}=\frac{F_{\text {air }} R T^{O X}}{P} \frac{4}{n_{O X} \pi D_{R}^{2}} & \text { Eq. } 56
\end{array}
$$

\subsubsection{GSC Reactor \& Cluster Results}

When the GST code is run in a standalone simulation, with the input parameters listed previously introduced for Gas Switching Combustion operation, a series of graphical outputs are attained when the solver converges. For the case where Ilmenite is used with a specified oxygen carrier utilization of $20 \%$, a .csv file corresponding to Case 1 is created with the results shown in Table 14 is obtained:

Table 14 Case 1 cluster results

\begin{tabular}{|c|c|}
\hline GSC & Ilmenite \\
\hline OC $(\%)$ & 20,0 \\
\hline Tox $\left({ }^{\circ} \mathrm{C}\right)$ & 1176,4 \\
\hline Tred $\left({ }^{\circ} \mathrm{C}\right)$ & 1157,3 \\
\hline $\mathrm{R}_{\mathrm{CO} 2}(\%)$ & 74,4 \\
\hline $\mathrm{S}_{\mathrm{N} 2}(\%)$ & 3,0 \\
\hline Air flow $(\mathrm{kg} / \mathrm{s})$ & 708,0 \\
\hline Reactors $(\mathrm{red}-\mathrm{oxi})$ & $1-6$ \\
\hline $\mathrm{uf}_{\text {ox }}(\mathrm{m} / \mathrm{s})$ & 0,96 \\
\hline $\mathrm{uf}_{\mathrm{red}}(\mathrm{m} / \mathrm{s})$ & 0,68 \\
\hline Ox. flow $(\mathrm{kg} / \mathrm{s})$ & 677,8 \\
\hline Red. flow $(\mathrm{kg} / \mathrm{s})$ & 97,6 \\
\hline
\end{tabular}

For illustration, the $\mathrm{O}_{2}$ depleted air stream and reduction gases composition is presented in Figure 34. Despite the relatively high temperatures of the product streams of the cluster, which will allow to reach an attractive thermodynamic efficiency, the capture performance is rather weak, with a large amount of $\mathrm{CO}_{2}$ transferred to the oxidation outlet and $\mathrm{N}_{2}$ from the air stream in the reduction gases stream.

A better capture performance and a higher purity of the $\mathrm{CO}_{2}$ stream can be achieved if the reduction stage time is increased by means of specifying a higher oxygen carrier utilization. In this way, the frequency in which the valves for a single reactor are switched from oxidation to reduction and vice versa is reduced, minimizing the amount of undesired mixing between outlet streams. This is what has been done for Case 2, with Ilmenite as oxygen carrier and a $40 \%$ oxygen carrier utilization. The results of this model run are given in Table 15. 

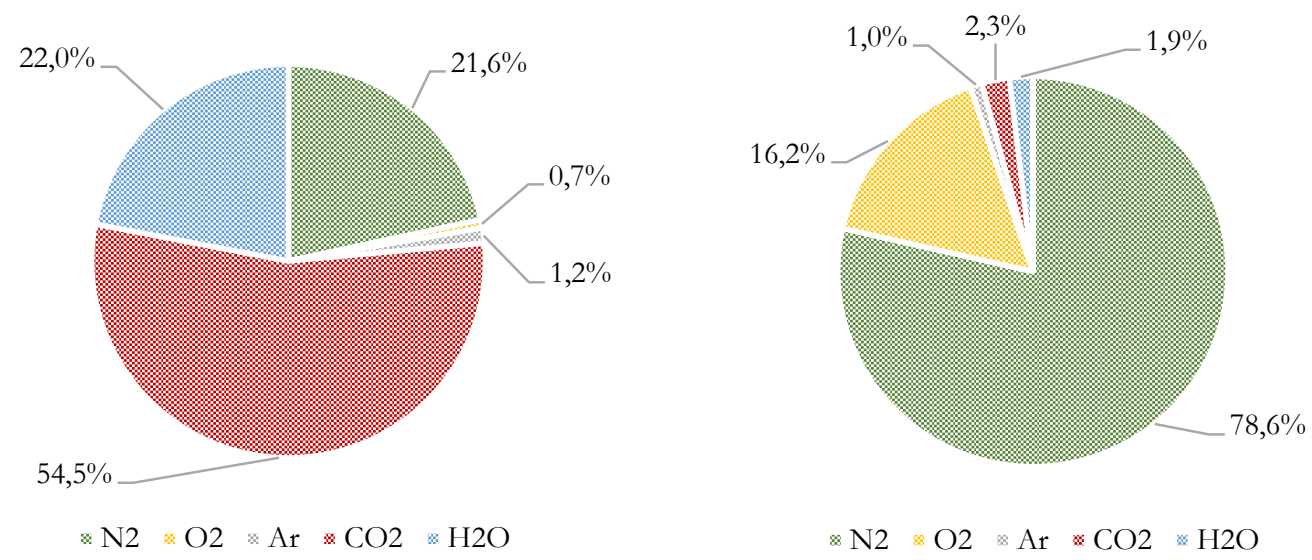

Figure 34 Time averaged outlet reduction (left) and oxidation (right) compositions of GSC cluster for Case 1

Because of the larger reduction time, and consequently total cycle length, the average stage outlet temperatures are reduced with respect to Case 1. Since the same available heat input is used to heat up the product streams to lower (average) temperatures, the total air flow rate calculated is increased.

Table 15 Case 2 cluster results

\begin{tabular}{|c|c|}
\hline GSC & Ilmenite \\
\hline OC $(\%)$ & 40 \\
\hline Tox $\left({ }^{\circ} \mathrm{C}\right)$ & 1154,4 \\
\hline Tred $\left({ }^{\circ} \mathrm{C}\right)$ & 1113,1 \\
\hline $\mathrm{R}_{\mathrm{CO} 2}(\%)$ & 85,8 \\
\hline $\mathrm{S}_{\mathrm{N} 2}(\%)$ & 1,63 \\
\hline Air flow $(\mathrm{kg} / \mathrm{s})$ & 737,9 \\
\hline Reactors $(\mathrm{red}-\mathrm{oxi})$ & $1-6$ \\
\hline $\mathrm{uf}_{\text {ox }}(\mathrm{m} / \mathrm{s})$ & 0,99 \\
\hline $\mathrm{uf}_{\text {red }}(\mathrm{m} / \mathrm{s})$ & 0,66 \\
\hline Ox. flow $(\mathrm{kg} / \mathrm{s})$ & 703,2 \\
\hline Red. flow $(\mathrm{kg} / \mathrm{s})$ & 102,1 \\
\hline
\end{tabular}

A more clear understanding of the cycle evolution is attained when looking at the reactor temperature profile for these two cases, where the same temperature at the beginning of the reduction and end of the oxidation is achieved, and the maximum reactor temperature reached is $1200^{\circ} \mathrm{C}$, revealing a good solver convergence. 


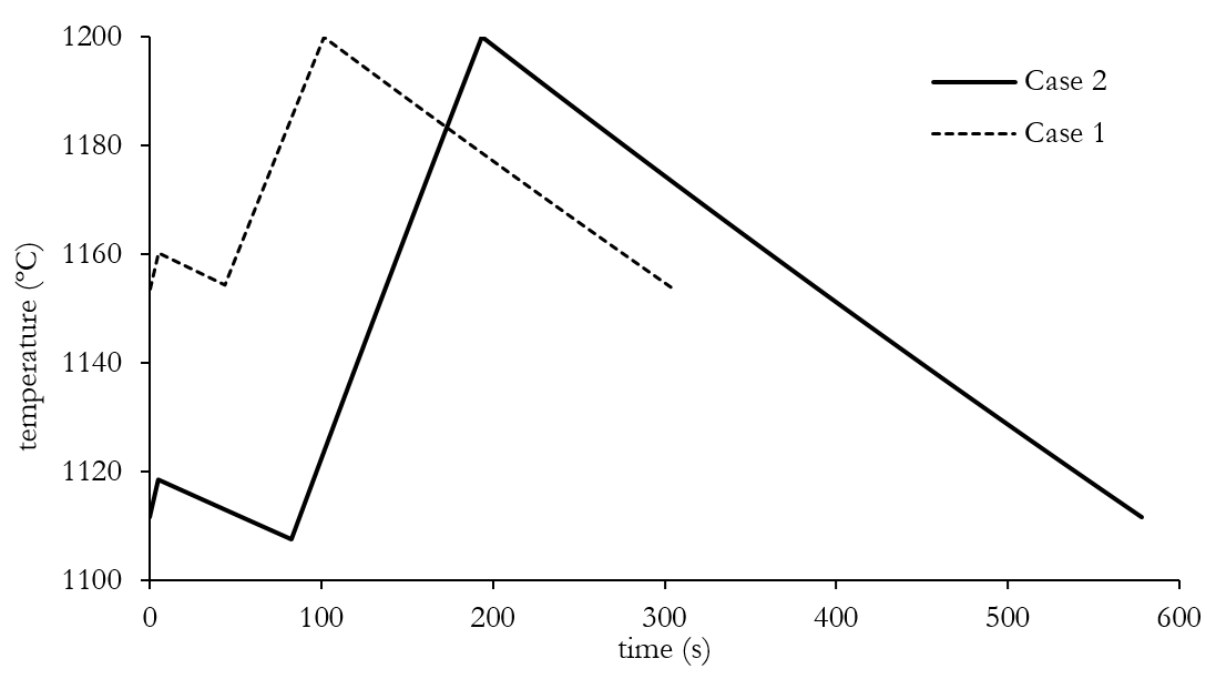

Figure 35 Temperature profile of a reactor cycle for Case 1 (dashed line) \& Case 2 (solid line)

At the beginning of the reactor, a small temperature increase is observed due to the presence of $\mathrm{O}_{2}$ within the reactor volume (present due to the earlier oxidation stage). The model reduces the oxygen carrier and simultaneously the reduced solids species is oxidized by the remaining $\mathrm{O}_{2}$ moles within the reactor. Once all $\mathrm{O}_{2}$ has disappeared, the reduction reactions of Ilmenite are not exothermic enough to heat up the reactor contents, and the net effect is a cool down of the reactor volume because of the low temperature fuel feed flow. For Case 2, the transition (valve switch) to oxidation stage occurs at a later time and, as the oxygen in the air oxidizes the oxygen carrier (highly exothermically), the reactor heats up. This heating effect lasts until the reduced oxygen carrier species disappears, coincidentally at the point where the reactor reaches the highest allowable temperature, after which it begins to cool down due to the low temperature air inlet and that full carrier oxidation has been achieved. Again, because the oxidation stage proceeds for a longer time (total cycle length of 578s for Case 2 vs 305 s for Case 1 ), the reactor cools down more relative to Case 1 , thereby achieving lower average cluster temperature outlets. The evaluation of the composition profile for each of the stages is also explanatory with regards to the chemical transformations of the gaseous and solid species taking place in each stage. Figure 36 shows this composition profile for Case 2.

In the reduction stage the prevalent gaseous species in the reactor corresponds to the products of combustion, namely $\mathrm{CO}_{2}$ and $\mathrm{H}_{2} \mathrm{O}$. It is noted that at any instant in time, the molar outlet compositions from a reactor corresponds to the reactor composition in virtue of the CSTR assumption of ideal mixing. It is thus straightforward to see the undesired mixing phenomena where a substantial amount of $\mathrm{N}_{2}$ is still present when the reduction stage has already proceeded for a considerable amount of time and likewise, the $\mathrm{CO}_{2}$ is still persist within the reactor volume at a later time after the valve switch, reducing the capture rate of the system. On the other hand, when looking at the composition in the oxidation stage it is noted at the beginning, only $\mathrm{N}_{2}$ is produced. This is due to the fact that all available $\mathrm{O}_{2}$ is being consumed in the oxidation of the oxygen carrier. When the reduced metallic compound is fully converted, the reaction can no longer proceed and therefore the profile shows a composition which exactly corresponding to the air is feed. The combustible components present in the syngas fuel $\left(\mathrm{H}_{2}, \mathrm{CO}\right.$ and $\left.\mathrm{CH}_{4}\right)$ are not shown in Figure 36 given that the fast reaction kinetics prevent any accumulation of these components in the reactor. 


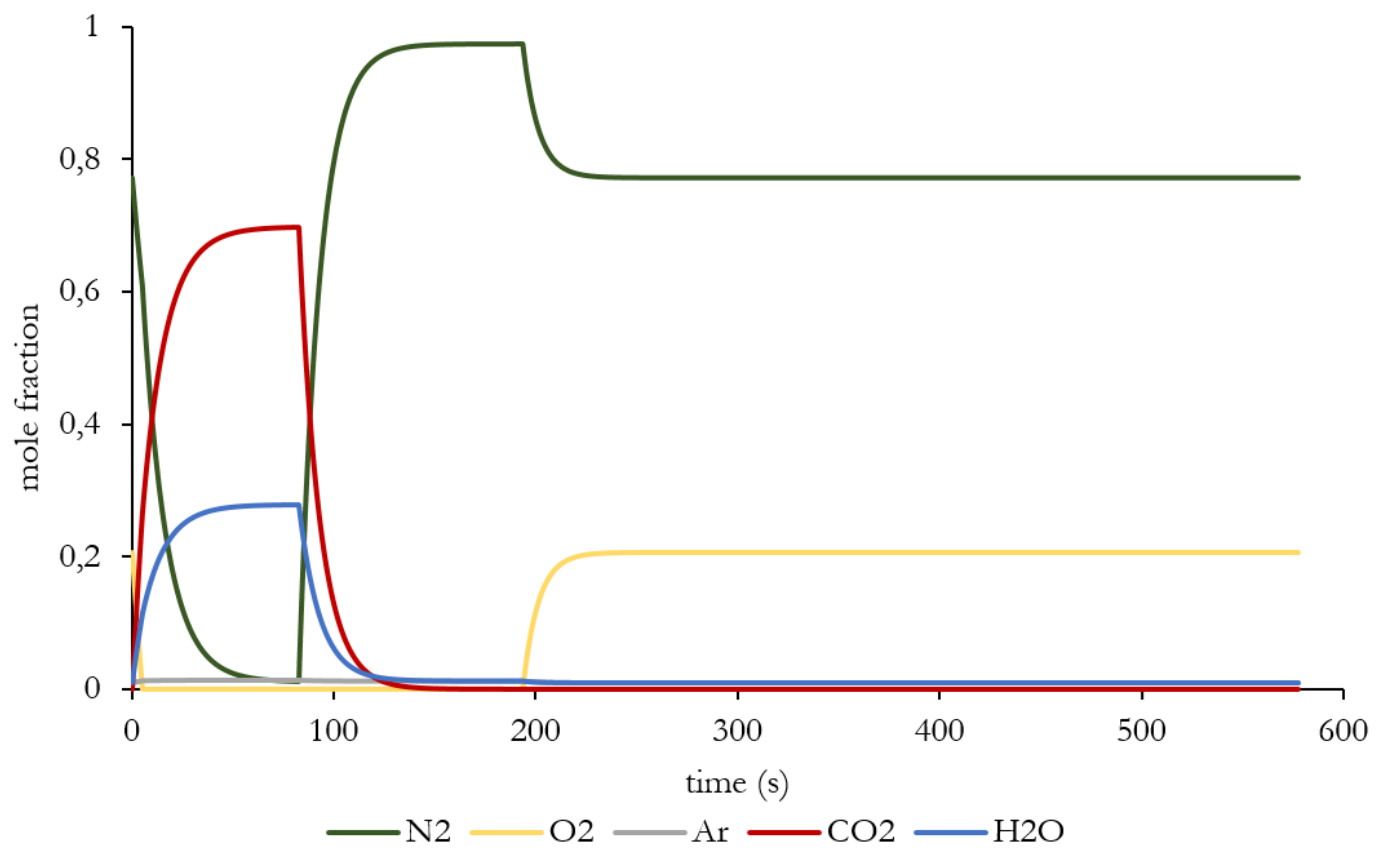

Figure 36 Reactor composition profile through a cycle for Case 2

Case 2 therefore reaches a better compromise between high outlet temperatures desirable for power cycle efficiency and relatively high degree of capture rate. It is important however to check the fluctuations with respect to average values of the stream products for each stage of the cluster, that are later going to be fed to sensible technology components such as gas turbines. In particular, the temperature variations must be relatively small to avoid excessive thermal fatigue (which can reduce the life time of costly components) and the dimensionless mass flow rate (Eq. 57) must be kept constant for a given turbine inlet nozzle area $S_{T}$. Otherwise, the mechanical integrity of systems such as turbine bearings can be compromised. Furthermore, excessive flow rate variations can lead to unstable compressor operation [63].

$$
\begin{gathered}
\dot{m}_{R}=\frac{\dot{m} \sqrt{T}}{\kappa P S_{T}} \\
\kappa=\sqrt{\frac{\gamma}{R_{g}}\left(\frac{2}{\gamma+1}\right)^{\frac{\gamma+1}{\gamma-1}}}
\end{gathered}
$$

For these reasons, Figure 38 and Figure 39 show the instantaneous cluster temperature and dimensionless mass flow rate average variation of the oxidations stage outlet for Case 2 respectively, as a pre-emptive check that these conditions are met. 


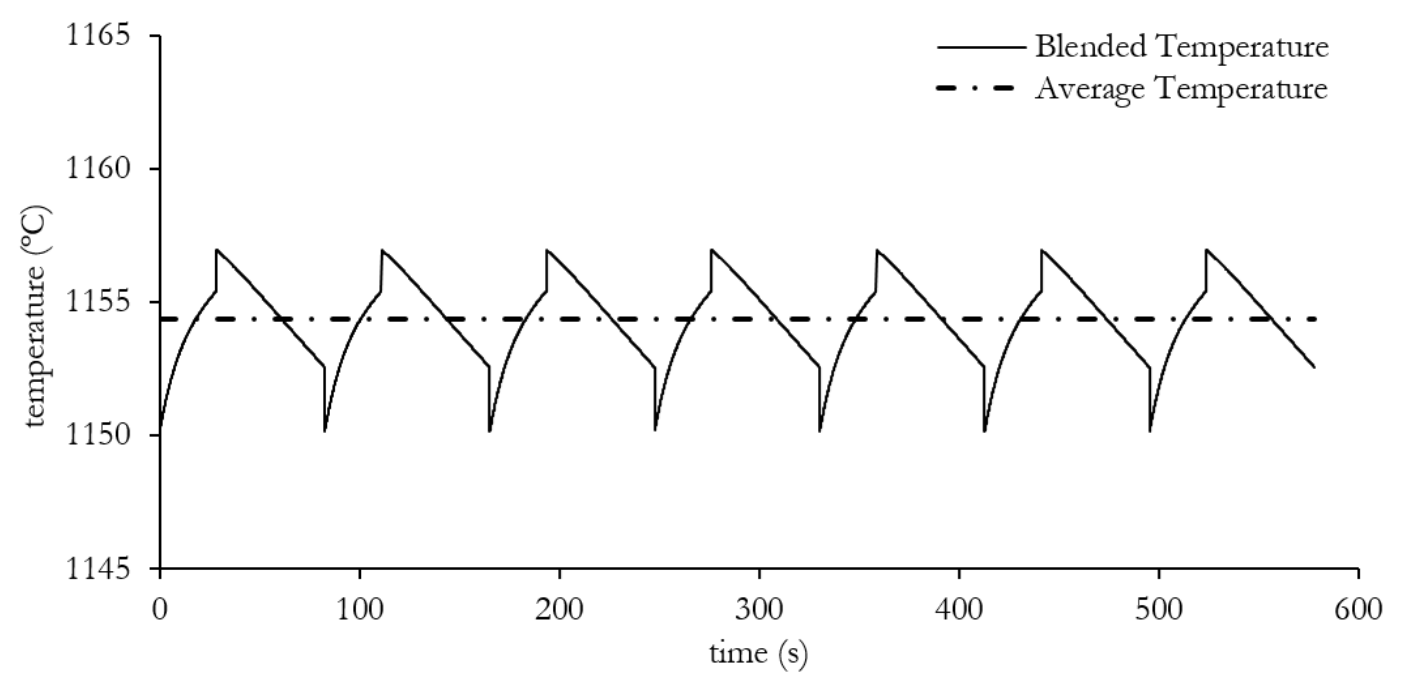

Figure 37 Blended and average temperature of the oxidation stage outlet for Case 2

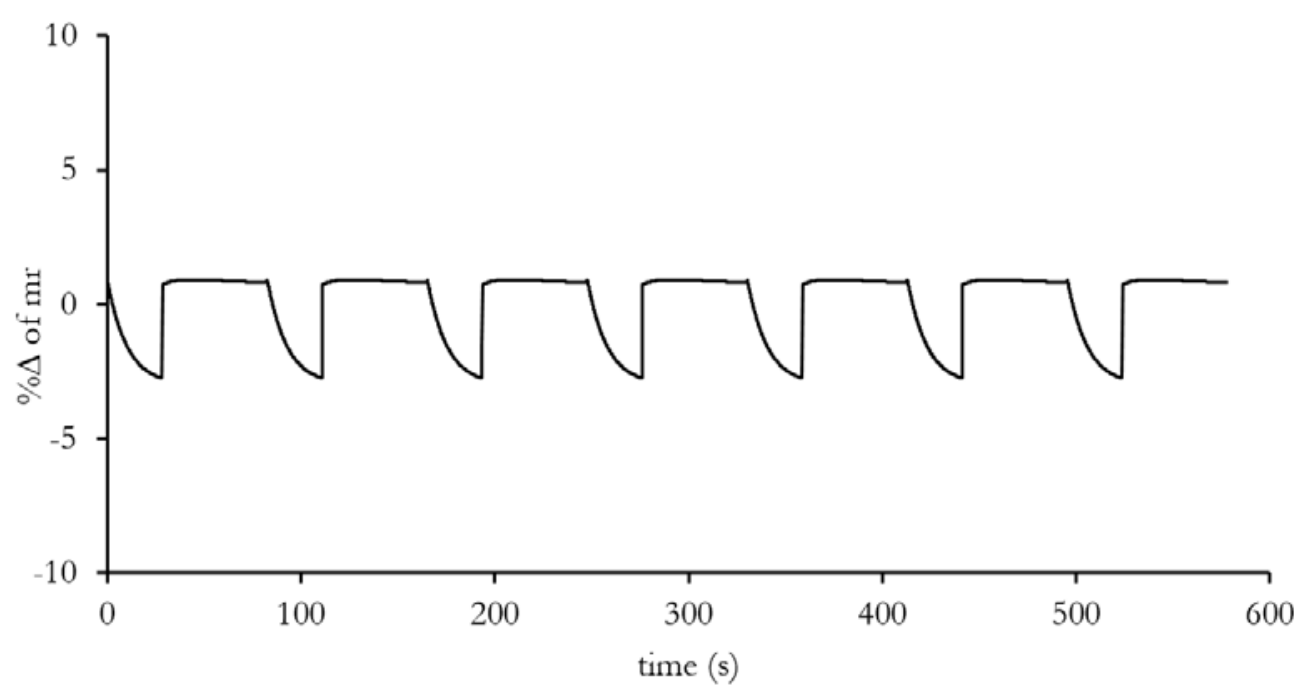

Figure 38 Dimensionless mass flow variation of the oxidation stage outlet with respect to average value for Case 2

At this point a new evaluation: Case 3, is performed but using Nickel as oxygen carrier instead of Ilmenite, to investigate its advantages related to a higher oxygen carrying capacity [20]. An oxygen carrier conversion of $20 \%$ is specified, and the cluster results obtained are given in Table 16:

Table 16 Case 3 cluster results

\begin{tabular}{|c|c|}
\hline GSC & Nickel \\
\hline OC $(\%)$ & 20,0 \\
\hline Tox $\left({ }^{\circ} \mathrm{C}\right)$ & 1098,4 \\
\hline Tred $\left({ }^{\circ} \mathrm{C}\right)$ & 1015,4 \\
\hline $\mathrm{R}_{\mathrm{CO} 2}(\%)$ & 92,99 \\
\hline $\mathrm{S}_{\mathrm{N} 2}(\%)$ & 0,74 \\
\hline Air flow $(\mathrm{kg} / \mathrm{s})$ & 818,7 \\
\hline Reactors $(\mathrm{red}-\mathrm{ox})$ & $1-6$ \\
\hline $\mathrm{uf}_{\text {ox }}(\mathrm{m} / \mathrm{s})$ & 1,05 \\
\hline $\mathrm{uf}_{\text {red }}(\mathrm{m} / \mathrm{s})$ & 0,61 \\
\hline Ox. flow $(\mathrm{kg} / \mathrm{s})$ & 781,0 \\
\hline Red. flow $(\mathrm{kg} / \mathrm{s})$ & 105,2 \\
\hline
\end{tabular}


Compared to Case 1, it can be seen that the average outlet temperatures are significantly lower, resulting in a higher air flow rate to the reactors, but on the other hand, a very high capture rate and low $\mathrm{N}_{2}$ slip is attained. With regards to the temperature profile, important differences can be noted as shown in Figure 39. In the first place, the reduction stage shows that the reactor contents are being heated, i.e. the reduction is sufficiently exothermic to warm the cold fuel feed. For the same degree of oxygen carrier conversion, the cycle length is almost twice with respect to Ilmenite, which explains the lower mixing degree.

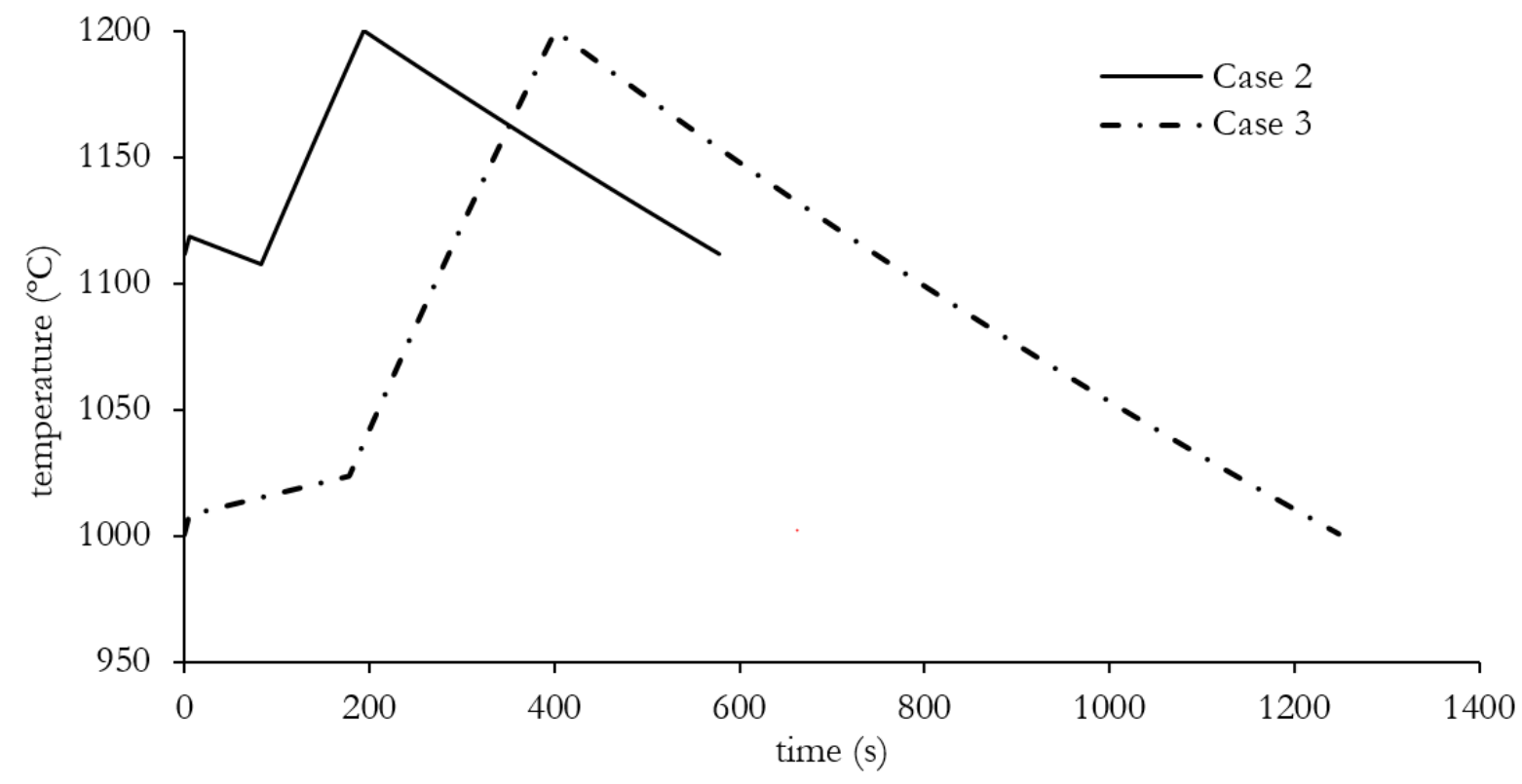

Figure 39 Temperature profile of a reactor cycle for Case 2 (solid line) and Case 3 (dashed line)

To accurately assess the potential operational advantage of one carrier over the other, the oxygen carrier utilization of the Nickel based carrier was modified to reach the same average oxidation temperature as in Case 2 (Tox $=1154,4^{\circ} \mathrm{C}$, Ilmenite with $40 \%$ OC utilization). The value reached for Nickel was of $9.35 \%$ OC utilization. This can reasonably be translated to a constant attainable thermal efficiency of the power cycle utilizing the oxidation stage products for each case. The performance comparison in terms of $\mathrm{CO}_{2}$ capture with constant average oxidation outlet temperature for each carrier is given in Figure 40:

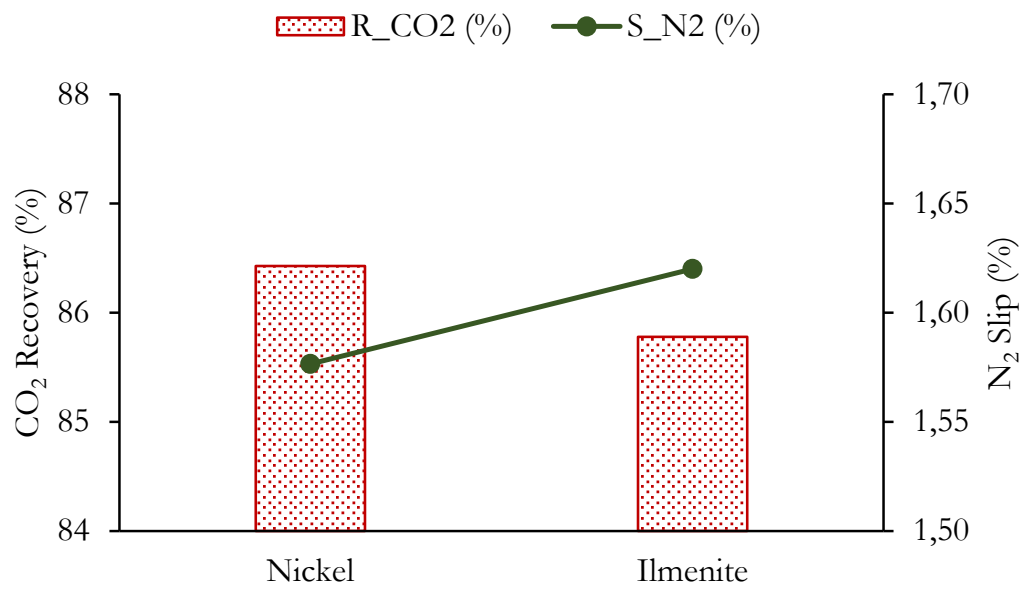

Figure $40 \mathrm{CO}_{2}$ capture performance of Nickel and Ilmenite for the same oxidation stage temperature (as Case 2) 
Figure 40 For cases were heat management strategies are employed to increase the average outlet temperatures for high oxygen carrier utilization, Nickel shows a more attractive performance than Ilmenite, as it allows to eliminate in some occasions a costly purification unit for the $\mathrm{CO}_{2}$ stream due to the lower degree of $\mathrm{N}_{2}$ ingress in the reduction gases stream, reaching acceptable $\mathrm{CO}_{2}$ purities for transport and storage. The lower frequency between valve switching for this carrier, due to longer reduction stage times, also contributes to reduce the operational complexity of the cluster.

\subsubsection{GSOP Reactor \& Cluster Results}

An illustrative simulation run with the oxygen carrier being the CAM material, capable of releasing $\mathrm{O}_{2}$ in the reduction gases stream, is presented in this section, were syngas from a High Temperature Winkler (HTW) gasifier with steam from the bottoming cycle is fed to the reduction stage. The syngas composition is represented in Figure 41, where a larger portion of $\mathrm{CO}_{2}$ and $\mathrm{H}_{2} \mathrm{O}$ are present, due to the lower purity of the oxidant stream delivered to the gasification. The ratio of syngas $/ \mathrm{H}_{2} \mathrm{O}$ sweep in the feed is 1 .

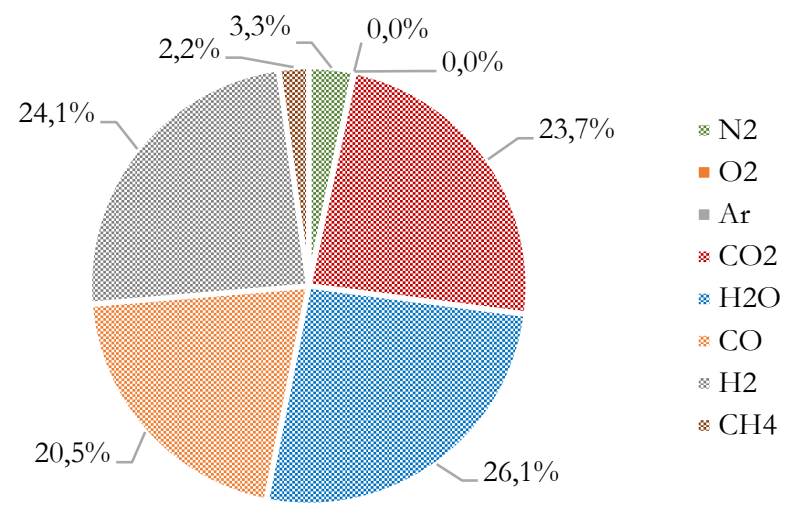

Figure 41 Syngas composition fed to GSOP reduction stage

To converge this cluster operation, it must be ensured that the initial reactor temperature is the same as the value obtained at the end of the cycle (identically as in the GSC operation), and that the $\mathrm{n}^{\circ}$ moles of reduced oxygen carrier are the same at the beginning of the reduction stage and at the end of the oxidation. The GSOP reactor temperature profiles and compositions are given in Figure 42 and Figure 43 respectively, for a target outlet temperature of approximately $700^{\circ} \mathrm{C}$ 


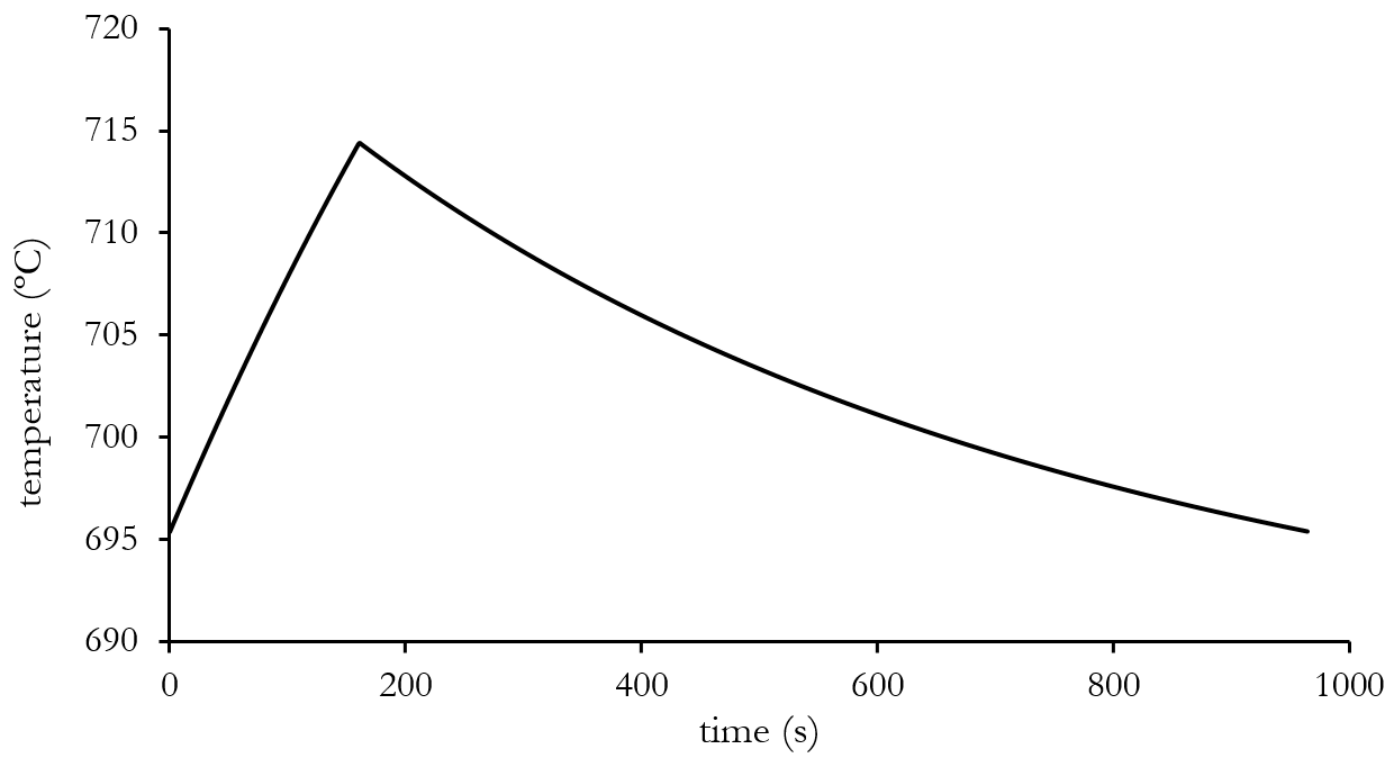

Figure 42 Reactor temperature profile for GSOP case

The reactor $\mathrm{O}_{2}$ mole fraction is permanently in equilibrium conditions (due to the fast kinetics imposed) and it can be seen that the highest $\mathrm{O}_{2}$ fraction is reached at the temperature peak of the cycle.

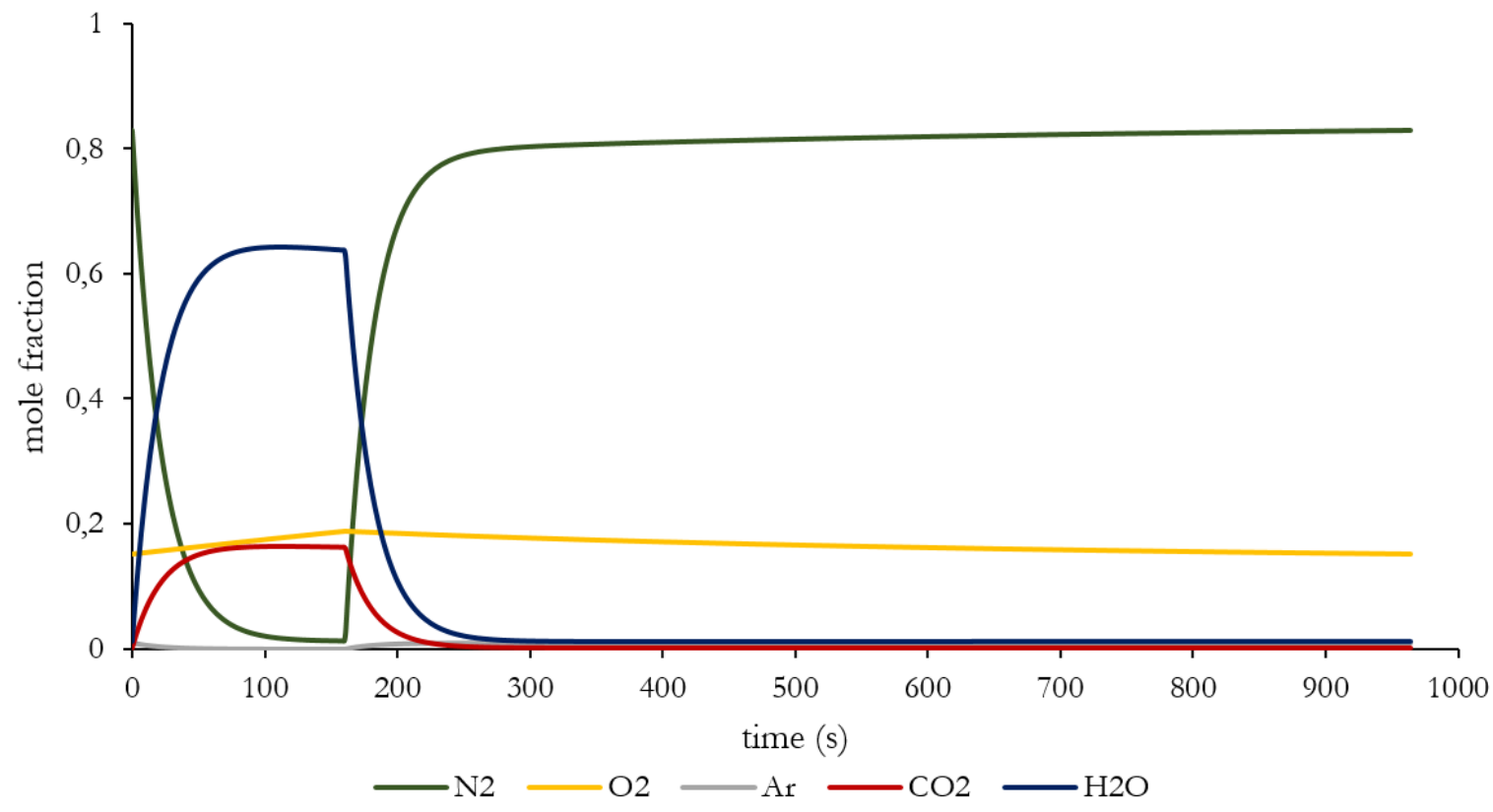

Figure 43 Reaction composition profile for GSOP case

\subsection{GSC Reactor Optimization Strategies}

Once the essential insights of a GS cluster for combustion have been presented, the different optimization strategies focused on improving the capture performance and increasing the outlet average temperatures are discussed.

\subsubsection{Delayed Switch}

The capture ratio of the cluster can be substantially improved if the valve switching of the product streams takes place with a time delay with respect to the feed switch. This effectively means that 
when the average reduction and oxidation molar flow rates are calculated by integrating the reactor profile, the starting integration point for each stage outlet will begin at the beginning of the stage time plus a small time phase of delayed valve switch. This concept is illustrated in Figure 44 for Case 2 for the first 300s of the cycle, where only the molar composition profile for $\mathrm{N}_{2}$ and $\mathrm{CO}_{2}$ are plotted for better visibility, and where the end of the reduction stage time is indicated (tred $=82.6 \mathrm{~s}$ ), i.e. feed valve switch occurs, as well as the delayed point in time $(+8 \mathrm{~s})$ for outlet valve switching for both stage products.

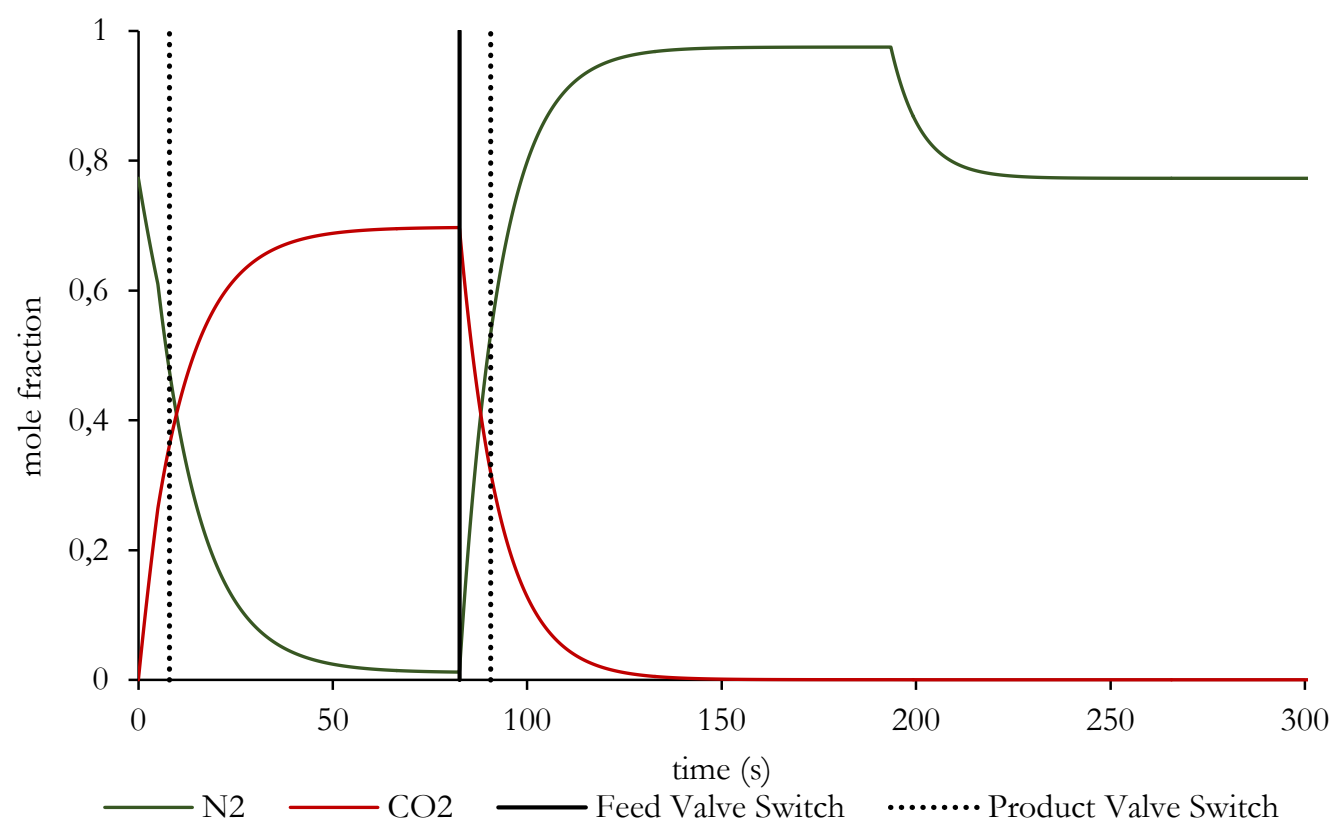

Figure 44 Delayed switch for Case 2 with feed valve switch (at 0s and 82.6s) and product valve switch (at 8s and $90.6 \mathrm{~s})$

This optimal time must be determined iteratively, and the delayed switch time that achieves the highest $\mathrm{CO}_{2}$ recovery, which may slightly vary with respect to the lowest $\mathrm{N}_{2}$ slip, was targeted. Shows the $\mathrm{CO}_{2}$ recovery and $\mathrm{N}_{2}$ slip for different delayed switch times, which reveals that this optimization strategy can be very effective to lower the $\mathrm{CO}_{2}$ emissions of the plant, in particular reaching 5\%points higher $\mathrm{CO}_{2}$ recovery with respect to the case without delayed valve switch. 


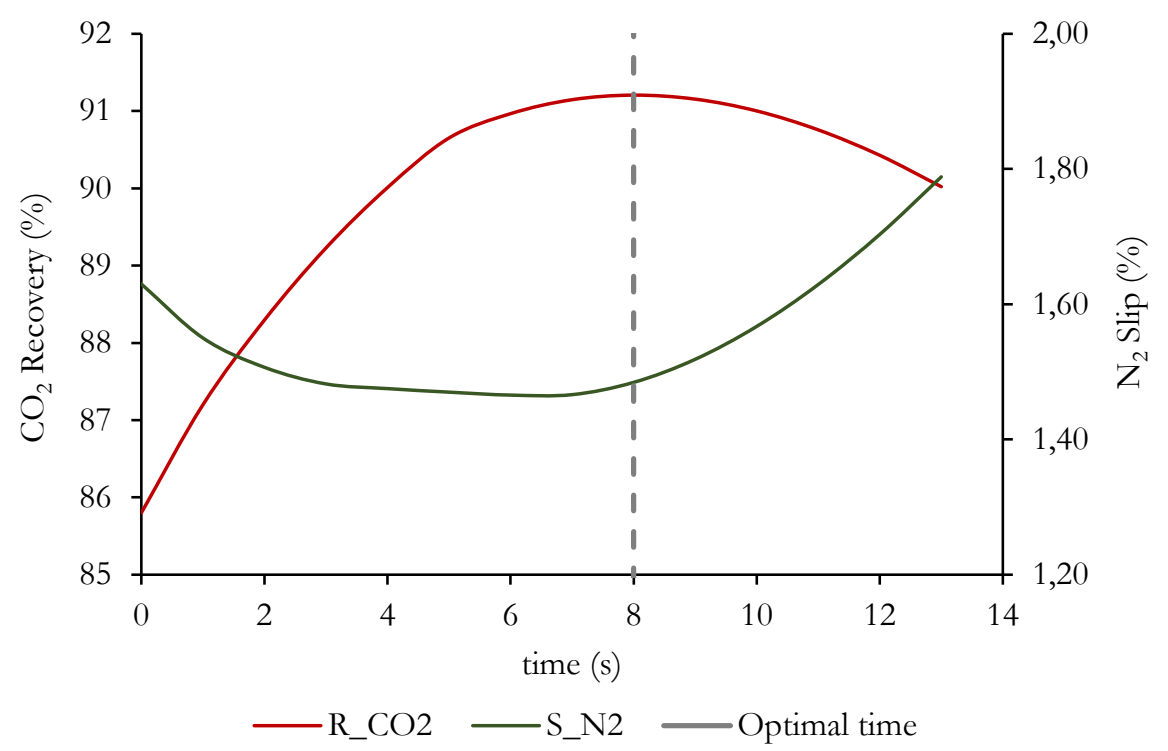

Figure $45 \mathrm{CO}_{2}$ Recovery and $\mathrm{N}_{2}$ Slip in \% for different delayed switch times for Case 2

It is noteworthy to mention that, in order to successfully implement the delayed switch strategy, it is mandatory to achieve similar molar outlet flows in each reactor. Otherwise, the if large changes in flows occur when switching from reduction to oxidation or vice versa, the blended stream of the delayed gas output fed downstream to a GT will present excessive fluctuations for a stable operation.

\subsection{2 $\quad \mathrm{N}_{2}$ Recycle}

Because of the larger oxygen available in the air stream than the strictly required for complete carrier oxidation, the temperature profiles shown earlier reveal a reactor cooling after a certain oxidation stage time has passed. As described before, the longer the stage time the more reactor cooling takes place and consequently, the lower average oxidation stage temperature is attained, which is detrimental for thermodynamic efficiency.

A pathway to simultaneously run the cycle at a high oxygen carrier conversion (i.e. longer cycle time) that results in a high degree of carbon capture (lower valve switch frequency and better operability) whilst achieving a high average oxidation temperature (resulting in high thermal efficiency) is to modify the $\mathrm{O}_{2}$ mole fraction of the air feed in such a way that the oxygen carrier oxidation reaction takes place throughout the whole oxidation time length. To achieve this, the exhaust stream of the heat recovery system after GT expansion is further cooled down to ambient temperature and partly recirculated to the GT compressor inlet, in such a way that the fraction of $\mathrm{O}_{2}$ at the GSC cluster inlet is reduced to a desired level.

This strategy implies modifications to the GT and can only be applied when no extra firing after the GSC (for instance with $\mathrm{H}_{2}$ or a low carbon intensive fuel like $\mathrm{CH}_{4}$ ) is carried out, as there is no remaining $\mathrm{O}_{2}$ after the oxidation stage to accomplish this. A small excess of $\mathrm{O}_{2}$ must be allowed in the oxidation feed in order to prevent a reactor operation where the oxygen carrier does not become totally oxidized at the end of the cycle. Two runs, Case 4 and Case 5 with the two different oxygen carriers were done for comparison. The cluster results for these cases are given in Table 17 grouped together to highlight the better performance of the Nickel carrier in terms of capture rate for the same degree of OC utilization, achieving very similar averaged stage outlet temperatures. 
Table 17 Case 4 (left) and Case 5 (right) cluster results

\begin{tabular}{|c|c|c|}
\hline GSC & Ilmenite & Nickel \\
\hline OC $(\%)$ & 70 & 70 \\
\hline Tox $\left({ }^{\circ} \mathrm{C}\right)$ & 1189,6 & 1185,2 \\
\hline Tred $\left({ }^{\circ} \mathrm{C}\right)$ & 1189,0 & 1185,0 \\
\hline $\mathrm{R}_{\mathrm{CO} 2}(\%)$ & $\mathbf{9 1 , 8 6}$ & $\mathbf{9 8 , 5 6}$ \\
\hline $\mathrm{S}_{\mathrm{N} 2}(\%)$ & 0,97 & 0,20 \\
\hline Air flow $(\mathrm{kg} / \mathrm{s})$ & 681,9 & 686,8 \\
\hline Reactors $(\mathrm{red}-\mathrm{ox})$ & $1-6$ & $1-6$ \\
\hline $\mathrm{uf}_{\text {ox }}(\mathrm{m} / \mathrm{s})$ & 0,95 & 0,96 \\
\hline $\mathrm{uf}_{\text {red }}(\mathrm{m} / \mathrm{s})$ & 0,70 & 0,70 \\
\hline Ox. flow $(\mathrm{kg} / \mathrm{s})$ & 643,9 & 646,6 \\
\hline Red. flow $(\mathrm{kg} / \mathrm{s})$ & 105,4 & 107,6 \\
\hline
\end{tabular}

This higher $\mathrm{CO}_{2}$ recovery in the reduction stream of approximately $6.7 \%$-points can be explained due to the longer cycle time (959.6s vs 4252s for Case 4 and Case 5 respectively). When looking at the reactor temperature profiles in Figure 46, the higher "exothermicity" of the reduction stage relative to the oxidation for the Nickel oxygen carrier (Case \%) results in an overall heating of the reactor for the reduction and cooling for the oxidation, whereas for Ilmenite (Case 4), the tendency is reversed, and in the reduction stage the reactor cools down while in the oxidation it heats up. For each reactor stage, a trade-off exists between the cooling effect of the lower temperature feed and the exothermal conversion of the oxygen carrier exists, and depending on the characteristics and flows of these fuel and air feeds the behaviour of the reactor can be different for the same OC.

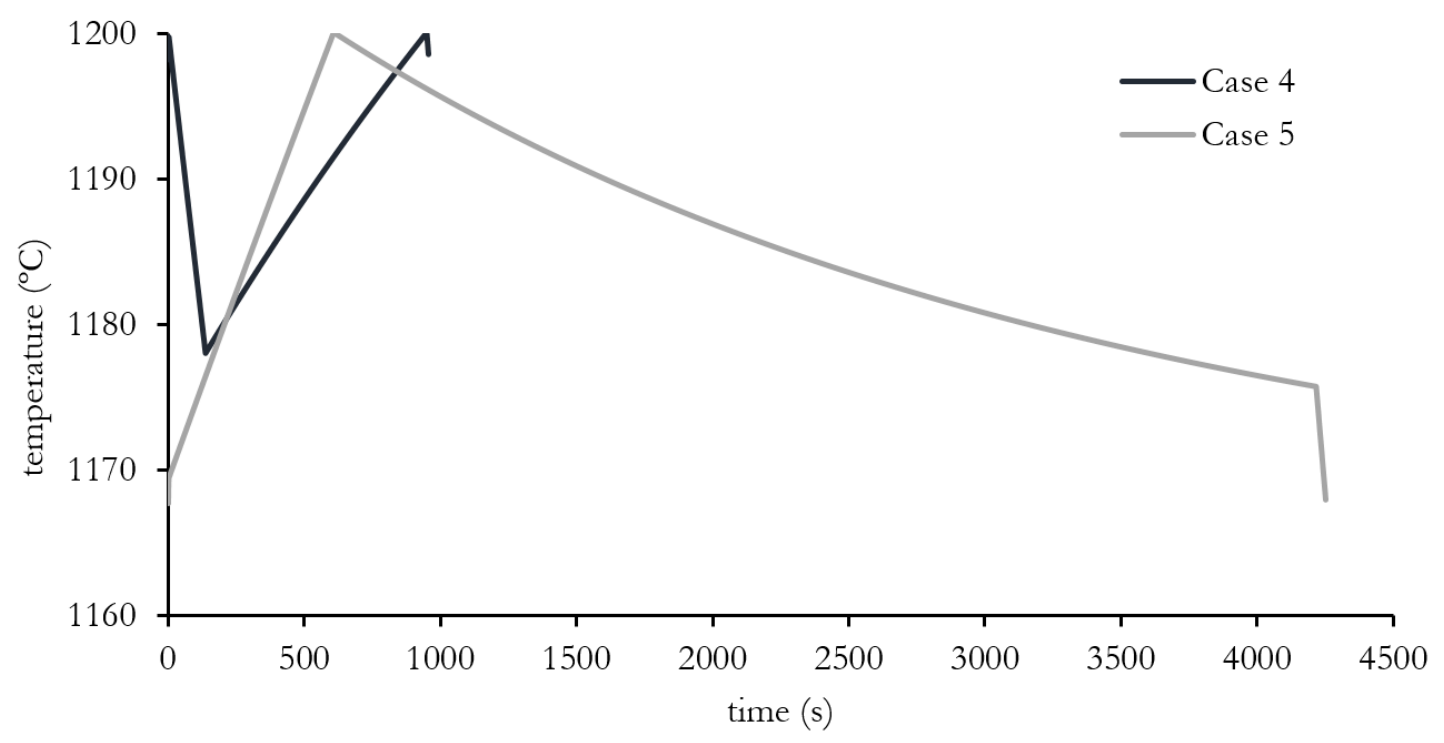

Figure 46 Reactor temperature profile for Case 4 (black line) and Case 5 (grey line) with $\mathrm{N}_{2}$ recycle

A careful look at the composition profile in Figure 47 will show that the reactor gaseous phase is close to $100 \% \mathrm{~N}_{2}$ throughout almost the whole oxidation stage length. 


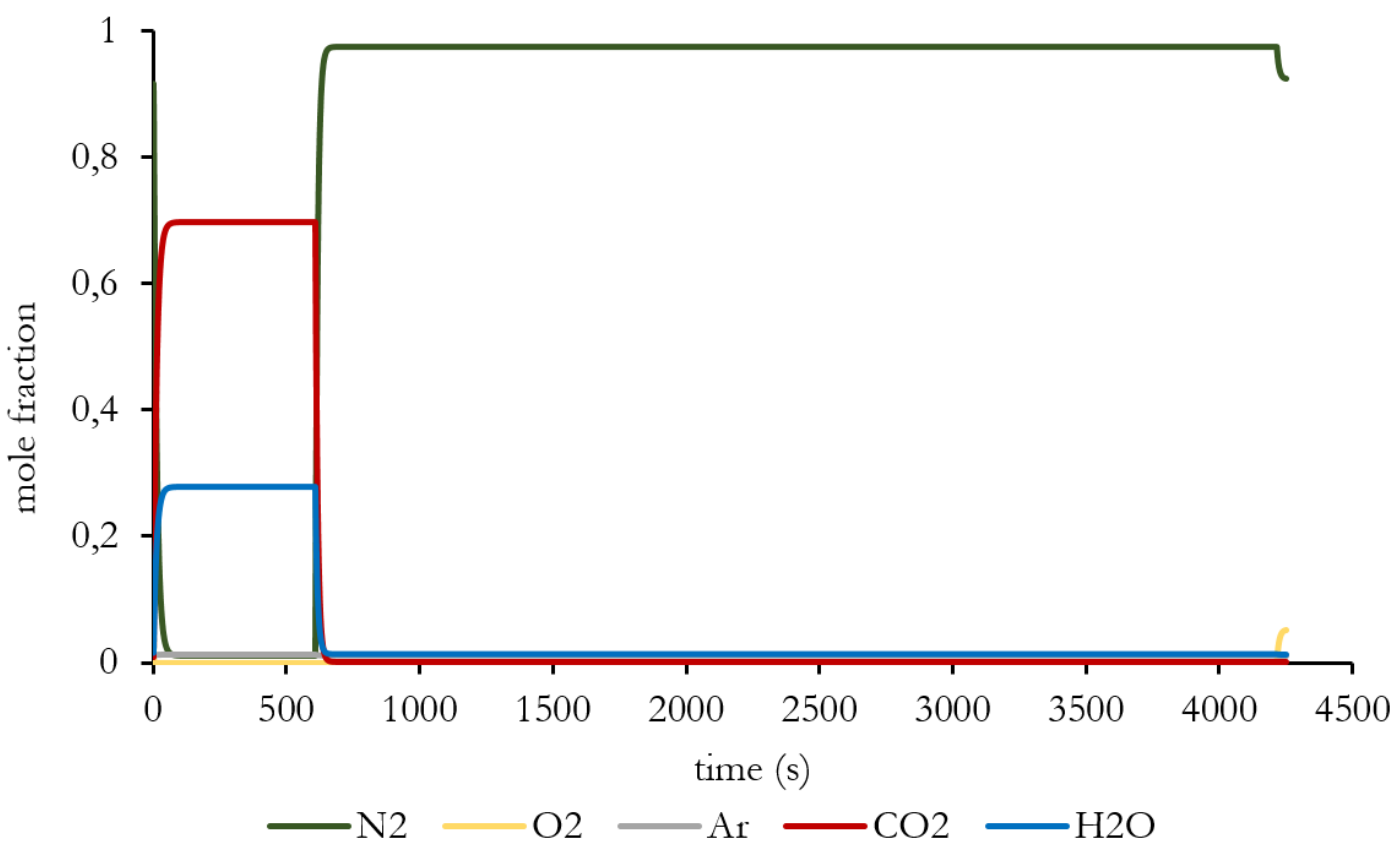

Figure 47 Composition profile for Case 5 with $\mathrm{N}_{2}$ recycle

Again, combustible species do not accumulate in the reactor as they react very fast with the oxygen carrier. The implementation of this heat management strategy requires an iterative procedure with the stationary power plant model to converge the inlet $\mathrm{N}_{2}$ stream composition and temperature after the compressor. The reactor model can be converged in standalone mode tuning the excess of $\mathrm{O}_{2}$ relative to the stochiometrically required to oxidize all the reduced carrier after the reduction stage.

\subsection{3 $\quad \mathrm{O}_{2}$ Slip}

Alternative to the $\mathrm{N}_{2}$ recycle strategy, to achieve a sequential conversion of the oxygen carrier throughout the whole oxidation time length, the $\mathrm{O}_{2}$ slip strategy has been proposed [65]. In practice, this method allows to "freeze" a certain quantity of the $\mathrm{O}_{2}$, allowing it to pass through the fluidized bed behaving like an inert. This concentrated air injection can replicate the effect observed for $\mathrm{N}_{2}$ recycle, and is coded in the model by specifying a certain maximum degree of $\mathrm{O}_{2}$ conversion in the model by tuning the kinetic rate, limiting it through a hypothetical oxygen equilibrium conversion in a similar way as the GSOP kinetics are modelled.

Although this reactor design constitutes an important design challenge in which gas solid/contact must be reduced, experimental results carried out in [65] show promising results.

Table 18 Case 6 (Ilmenite) and Case 7(Nickel) cluster results

\begin{tabular}{|c|c|c|}
\hline GSC & Ilmenite & Nickel \\
\hline $\mathrm{OC}(\%)$ & 70 & 70 \\
\hline Tox $\left({ }^{\circ} \mathrm{C}\right)$ & 1187,1 & 1182,1 \\
\hline Tred $\left({ }^{\circ} \mathrm{C}\right)$ & 1189,3 & 1184,7 \\
\hline $\mathrm{R}_{\mathrm{CO} 2}(\%)$ & 92,10 & 98,26 \\
\hline $\mathrm{S}_{\mathrm{N} 2}(\%)$ & 1,11 & 0,26 \\
\hline Air flow $(\mathrm{kg} / \mathrm{s})$ & 692,2 & 697,5 \\
\hline Reactors $(\mathrm{red}-\mathrm{ox})$ & $1-6$ & $1-6$ \\
\hline $\mathrm{uf}_{\mathrm{ox}}(\mathrm{m} / \mathrm{s})$ & 0,95 & 0,95 \\
\hline $\mathrm{uf}_{\text {red }}(\mathrm{m} / \mathrm{s})$ & 0,70 & 0,70 \\
\hline
\end{tabular}




\begin{tabular}{|c|c|c|}
\hline Ox. flow $(\mathrm{kg} / \mathrm{s})$ & 655,0 & 657,7 \\
\hline Red. flow $(\mathrm{kg} / \mathrm{s})$ & 105,9 & 107,5 \\
\hline
\end{tabular}

Case 6 and Case 7 with Ilmenite and Nickel as oxygen carriers respectively, employing the " $\mathrm{O}_{2}$ Slip" heat management strategy (or concentrated air injection) is summarized in Table 18. Again the better capture performance of the Nickel oxygen carrier compared to Ilmenite with respect to $\mathrm{CO}_{2}$ capture is observed.

The temperature profile for this heat management strategy given in Figure 48 results almost identical to the $\mathrm{N}_{2}$ recycle case, with a small decrease at the beginning of the oxidation stage (Case 7) which is caused by the fact that during a short time interval the $\mathrm{O}_{2}$ mole fraction in the reactor is below the minimum $\mathrm{O}_{2}$ fraction specified above which the oxidation reaction of the carrier takes place. The average outlet temperatures are slightly below the $\mathrm{N}_{2}$ recycle strategy (Case 5).

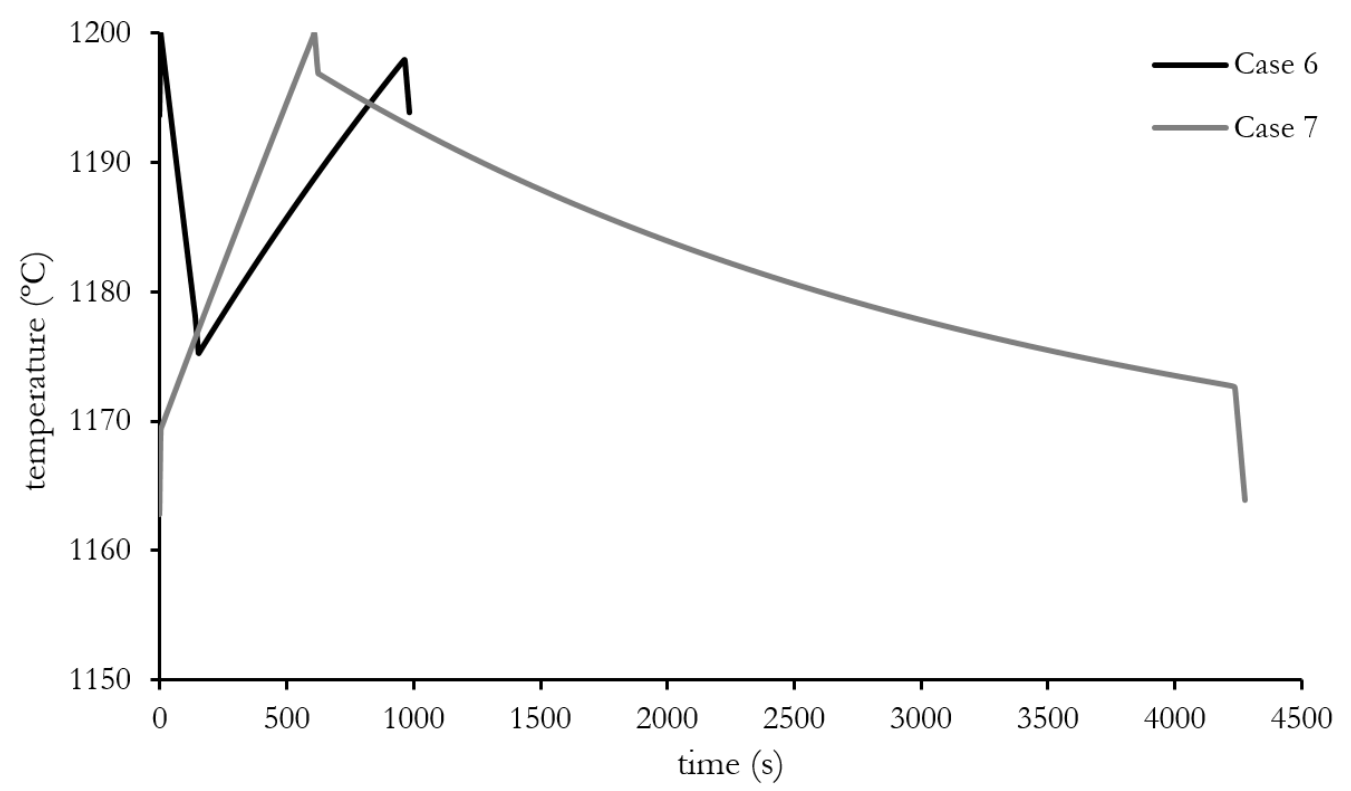

Figure 48 Reactor temperature profile for Case 6 and Case 7 with $\mathrm{O}_{2}$ slip

A sharp temperature drop is observed at the end of the oxidation stage corresponding to the full oxidation of the carrier. The cool down results from the low temperature air feed and the lack of any exothermic reaction. At the end of the reduction stage a slight cooling occurs because the oxygen concentration has not reached the required level to react with the carrier. On the other hand it can be appreciated that a significant fraction of $\mathrm{O}_{2}$ (below that present in the air feed stream) during the oxidation stage does not react, as shown in Figure 49 


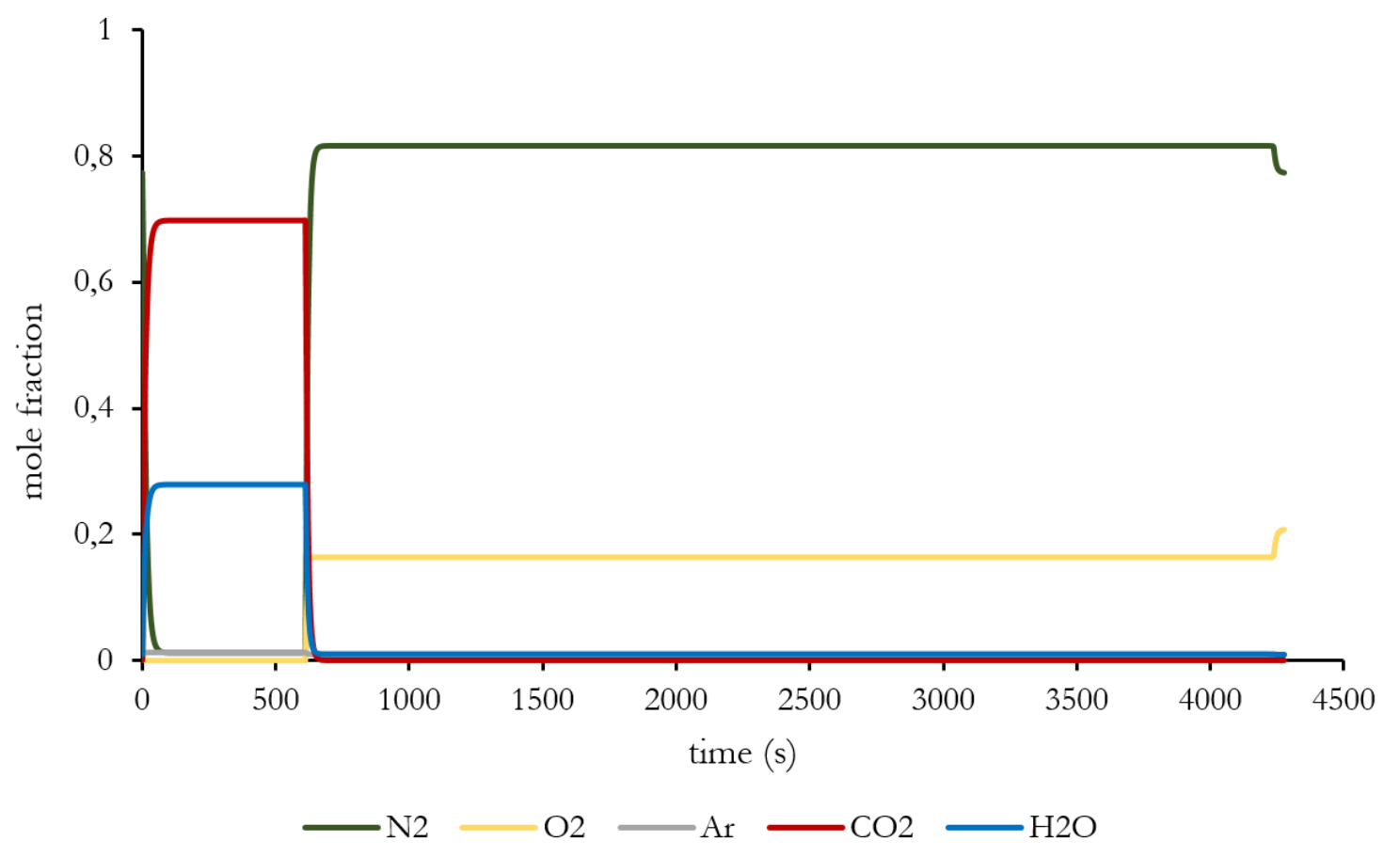

Figure 49 Reactor composition profile for Case 7 with $\mathrm{O}_{2}$ slip

Due to the high degree of technical uncertainty for this heat management strategy, the $\mathrm{N}_{2}$ recycle option is usually preferred. However, the $\mathrm{O}_{2}$ slip allows to implement an extra firing chamber to heat the GSC oxidation stage outlet above temperatures

\subsubsection{Steam Purge}

Previous literature studies [63] also suggest the possibility of using a purge stream of steam from the bottoming cycle between stages. Although the capture rate is substantially improved, an important energy penalty is incurred upon by steam extraction that would otherwise be efficiently used to produce power in the steam turbine. Also, the use of steam purging results in a considerable increase of the $\mathrm{n}^{\circ}$ of reactors and associated costs, and therefore this strategy was not implemented in the model developed by UPM.

\subsection{Integration with Power Plant Simulation}

In this section the information transfer between the transient GS cluster model in Scilab and the stationary power plant simulation in Unisim Design R451 is presented. The simplified cluster model for the stationary process flowsheet is also introduced.

\subsubsection{CAPE-OPEN Unit Operation}

A Computer-Aided Process Engineering Open software (CAPE OPEN) allows to connect different process simulations and modelling environments through easy 'plug \& play' interoperability [66]. An auxiliary code is developed within the CAPE OPEN unit operation in the process flowsheet to invoke the code from Scilab and retrieve the cluster results. The unit operation is defined in the process flowsheet as a CO standard available in Unisim Design R451. In the auxiliary code, the feed and product ports are specified. This ports provide the CO executive interface a standardized view of a material or energy stream, which can be later used in external platform for calculations, or export the predefined outputs to the main simulator. Additionally, parameter values can be exchanged between interfaces. Figure 50 shows a schematic of the interface operation the two simulation platforms employed. 

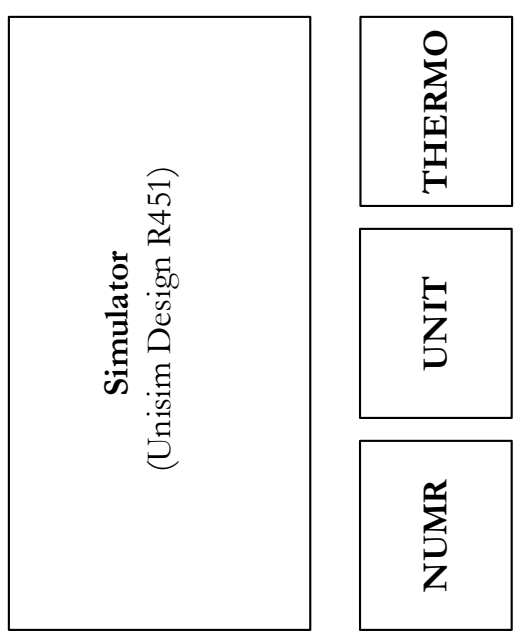

Material Objects

to ports

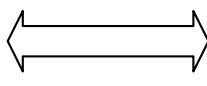

Parameter

Transfer

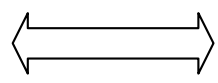

EO Unit operations

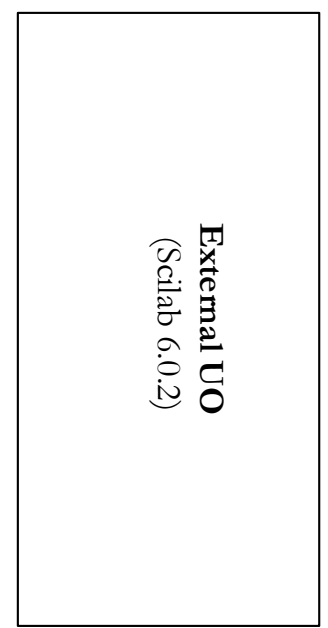

Figure 50 Schematic of the CAPE OPEN Interface

\subsubsection{Stationary Reactor Model}

A basic reactor model designed to represent the cluster behaviour in the stationary power plant flowsheet was developed. The unit consists of ideal reactor, separators and heat exchanger units, in which the averaged temperature values delivered by the transient reactor model are specified. Depending on the particular power plant configuration, the air flow rate is manipulated to reach a certain oxidation outlet temperature, while the heat transferred from the spontaneous reaction of the fuel with the stoichiometric fraction of $\mathrm{O}_{2}$ extracted from the air steam is adjusted to reach the required reduction stage outlet temperature. The fractions of the flow splitters from the reactor outlet are tuned to reach the required degree of $\mathrm{CO}_{2}$ recovery and $\mathrm{N}_{2}$ slip. For the power plants with GSOP clusters, the specification of the oxygen molar differences between outlet streams obtained from the transient model is introduced as well, to determine the fraction of $\mathrm{O}_{2}$ withdrawn from the stationary air stream. A schematic of this concept is depicted in Figure 51.

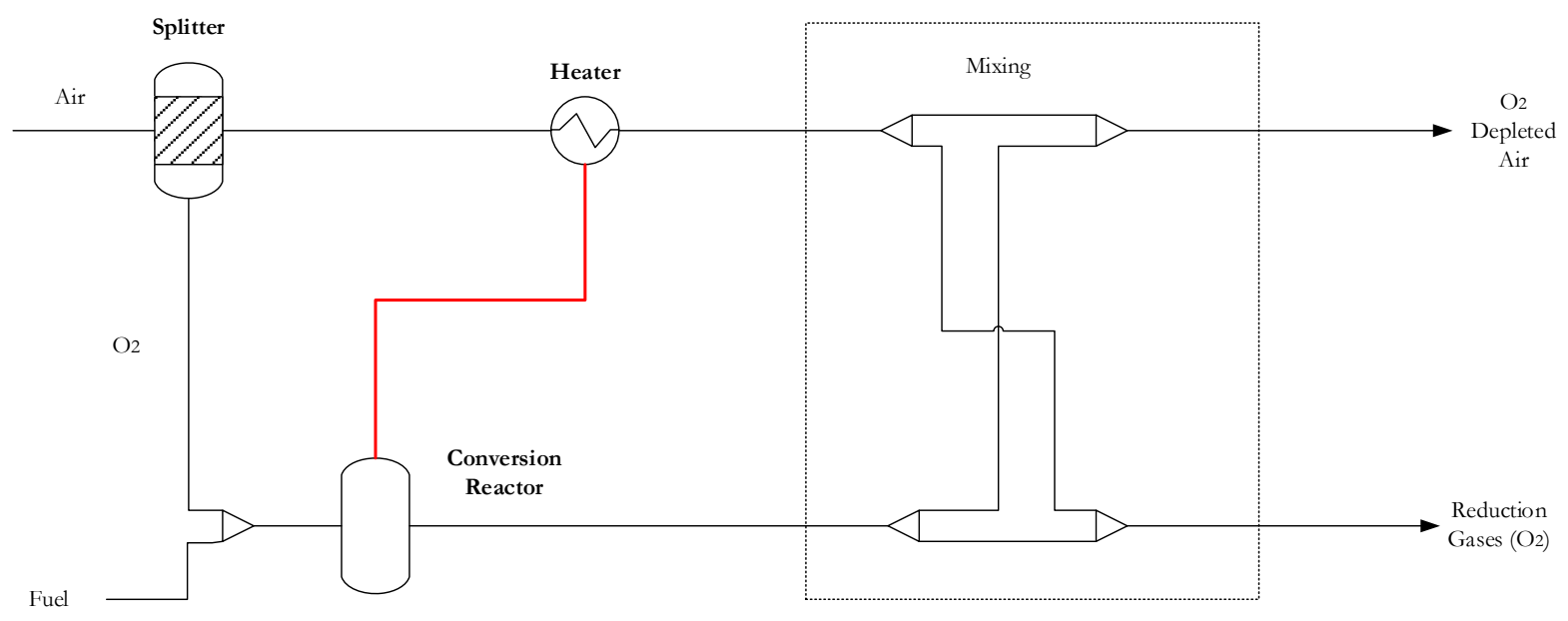

Figure 51 Simplified cluster model for the stationary flowsheet

The model achieves 100\% fuel conversion in line with the assumption of the high reactivity of the oxygen carrier. It is also considered that the reactors are sufficiently well insulated that heat losses to the exterior are negligible. Figure 52 shows a schematic with the parameter values that are exchanged between the interfaces for the case of combustion: 


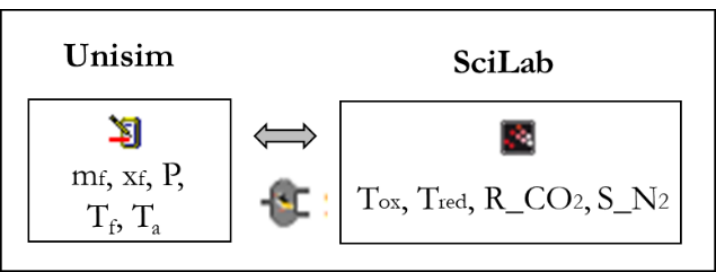

Figure 52 Schematic of parameter and material transfer between Scilab and Unisim simulation platforms

In this way, although the different platforms use different thermodynamic models, the stationary power plant preserves the original property package for the stationary process calculation, and allows a better controllability of the flowsheet by deactivating the transient reactor unit operation.

Alternative to the integrated model for Gas Switching power plants, the preliminary models were converged through information exchange with the Matlab model for GS clusters developed at NTNU. The parameters to describe the cluster behaviour were essentially the same, with slight differences on the definition. The spreadsheet templates were the input/output parameters were exchanged are provided in the Appendix. 


\section{Chapter 3}

\section{Power Plant Blocks}

In this Chapter, the different technology blocks arranged based on the fundamental task presented in section 1.3.3 are presented. The models pretend to represent the actual performance of the process elements that configure the systems encountered in IGCC power plants. The main modelling assumptions are provided for each of the blocks.

\subsection{Boundary Modelling Assumptions}

Two sets of power plant models with consistent modelling approaches have been elaborated. The "introductory" plants correspond to more conservative assumptions regarding the gas turbine, using a generic F-class machine, and employing the current available technology for the benchmark plants in terms of syngas treating. The "advanced" plants employ H-class GT and include HGCU for syngas treating also for the reference technologies. The steam cycle has several notable differences in terms of component efficiencies and pressure drops, given the different sources used to develop the models, but are accurately described in section 3.7.1.

Douglas Premium Bituminous coal was employed as feedstock in the power plants modelled. This low sulphur coal has a LHV value of $25170 \mathrm{~kJ} / \mathrm{kg}$ and a composition as detailed in Table 19. For concepts employing natural gas as fuel, or for GT model calibration, the NG composition is detailed in Table 20. The property estimation tool from UniSim predicts a somewhat lower heating value, which was corrected by introducing an offset of $181 \mathrm{~kJ} / \mathrm{kg}$. It is noted that although the models employ this coal feedstock as a basis, the plants designed in these work have the potential to operate with any organic carbonaceous fuel such as biomass. The evaluation of feedstocks with a different compositions should be attended case by case, with special attention on the impact in the gasification section which, as it was shown in 1.3.1, plays a vital role in the combined cycle efficiency.

Table 19 Douglas Premium Coal feedstock characteristics

\begin{tabular}{|c|c|}
\hline Element & \% weight \\
\hline $\mathrm{C}$ & 66,52 \\
\hline $\mathrm{H}$ & 3,78 \\
\hline $\mathrm{O}$ & 5,46 \\
\hline $\mathrm{N}$ & 1,56 \\
\hline $\mathrm{S}$ & 0,52 \\
\hline Moisture & 8,00 \\
\hline Ash & 14,15 \\
\hline Fixed Carbon & 54,93 \\
\hline Volatile Matter & 22,91 \\
\hline Thermal properties \\
\hline LHV $(\mathrm{MJ} / \mathrm{kg})$ & 25,17 \\
\hline HHV $(\mathrm{MJ} / \mathrm{kg})$ & 25,98 \\
\hline
\end{tabular}


Table 20 Natural gas feedstock characteristics

\begin{tabular}{|c|c|}
\hline Element & \%omol \\
\hline $\mathrm{N}_{2}$ & 0,89 \\
\hline $\mathrm{CO}_{2}$ & 2,0 \\
\hline $\mathrm{C} 1$ & 89,0 \\
\hline $\mathrm{C} 2$ & 7,0 \\
\hline $\mathrm{C} 3$ & 1,0 \\
\hline $\mathrm{nC} 4$ & 0,5 \\
\hline $\mathrm{iC} 4$ & 0,5 \\
\hline $\mathrm{nC} 5$ & 0,05 \\
\hline $\mathrm{iC} 5$ & 0,05 \\
\hline Thermal properties \\
\hline $\mathrm{LHV}(\mathrm{kJ} / \mathrm{kg})$ & 46497,6 \\
\hline
\end{tabular}

The process flowsheet simulator allows to select from a wide variety of thermodynamic property packages. For air and its components, syngas and $\mathrm{CO}_{2}$ containing streams, the Peng Robinson (PR) EOS [67] is used because of its applicability in the wide range of temperatures and pressures encountered in the power plant (from $-190^{\circ} \mathrm{C}$ in the cryogenic ASU to $>1400^{\circ} \mathrm{C}$ of the GT combustor and gasification, and from atmospheric conditions at compressor inlet to supercritical pressures after the $\mathrm{CO}_{2}$ pump)

For water and steam, ASME (American Society of Mechanical Engineers) steam tables (integrated in the software thermodynamic library) are used [68]. This is generally the working fluid of the bottoming cycle. When a water stream is mixed with air, syngas etc., and a property package transition block to PR EOS is used performing flash calculation at equal enthalpy and pressure.

For the amine absorption system (MDEA), a third party property package DRBAMINE was used. Honeywell kindly provided us a license for this package to employ in our evaluations. For the physical absorption system (Selexol), a Henry model with coefficients from [69] was employed to accurately predict the solubility of the different components present in the Syngas. In both cases, the vapour phase was modelled with Peng Robinson EOS.

The transient reactor simulations from SINTEF, modelled with Matlab, assume Ideal Gas behaviour, an assumption which is justifiable provided the high temperatures and relatively low pressures encountered in these units. The Scilab code also assumes ideal gas for property calculation, but is capable of determining the heat of reaction accurately at any given temperature, improving the predictability of the reactor temperature profiles and consequently, the average stage temperatures.

\subsection{Oxidation Stream}

\subsubsection{Low pressure Air Separation Unit}

The low pressure air separation unit (LP-ASU) refers to a cryogenic process which is used to separate the components of air, where the main elements are represented in Figure 53, based on the configurations studied in [70]. The system cools down in the main cryogenic heat exchanger (MCHE) a compressed air feed stream with the products to very low temperatures. A portion of the air is compressed to high pressures in the booster air compressor (BAC) and is fed after expansion as a reflux of the high pressure column (HPC), operating at around 6 bar, where a partial 
separation is reached. The medium pressure air is fed at a low stage of the HPC. The purified bottoms are at around $34 \% \mathrm{O}_{2}$ purity, while the tops consists of almost pure $\mathrm{N}_{2}$.

$\mathrm{N}_{2}$ and $\mathrm{O}_{2}$ have a boiling point of 77 and $90 \mathrm{~K}$ respectively at 1 bar. The process makes use of the different volatilities of the components at different pressures to enhance the separation with low compression duty requirements. For instance, at a pressure of $6 \mathrm{bar}, \mathrm{N}_{2}$ boils at $95 \mathrm{~K}$, and can be condensed by boiling an $\mathrm{O}_{2}$ stream at 1 bar. This is the aim of the condenser-reboiler unit, whose temperature profile is given in Figure 54 (right). The $\mathrm{N}_{2}$ reflux to the HPC is set to achieve the required $\mathrm{N}_{2}$ purity while the operating pressures (defined by the main air compressor (MAC) ensure a narrow temperature pinch in this exchanger.

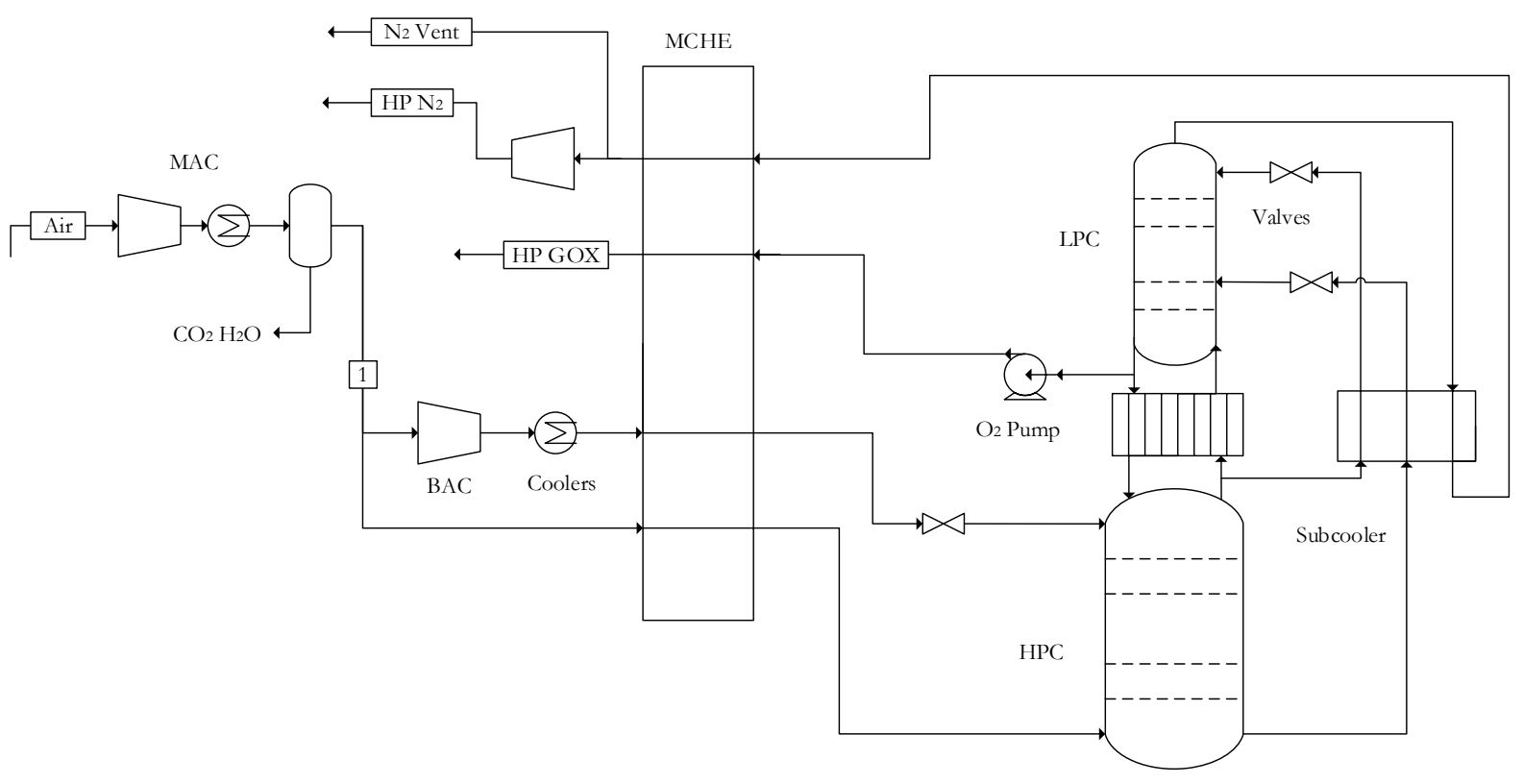

Figure 53 Schematic of an ASU

The HPC bottoms are fed after subcooling to the low pressure column (LPC), where an almost complete separation of the components is achieved. The $\mathrm{O}_{2}$ molar purity attained at the bottom of the LPC is $95 \%$. This oxygen stream is pumped in a cryogenic pump to the pressure values required by the gasification unit and sent to the main exchanger. The pure $\mathrm{N}_{2}$ (tops from the LPC) are also routed to the MCHE to provide cold to the incoming feeds streams. The narrow temperature approaches shown in Figure 54 (left) reveal an optimal design of this unit. If $\mathrm{N}_{2}$ is required in the power plat for fuel dilution, an intercooled compressor is used to reach the combustor pressure level. 

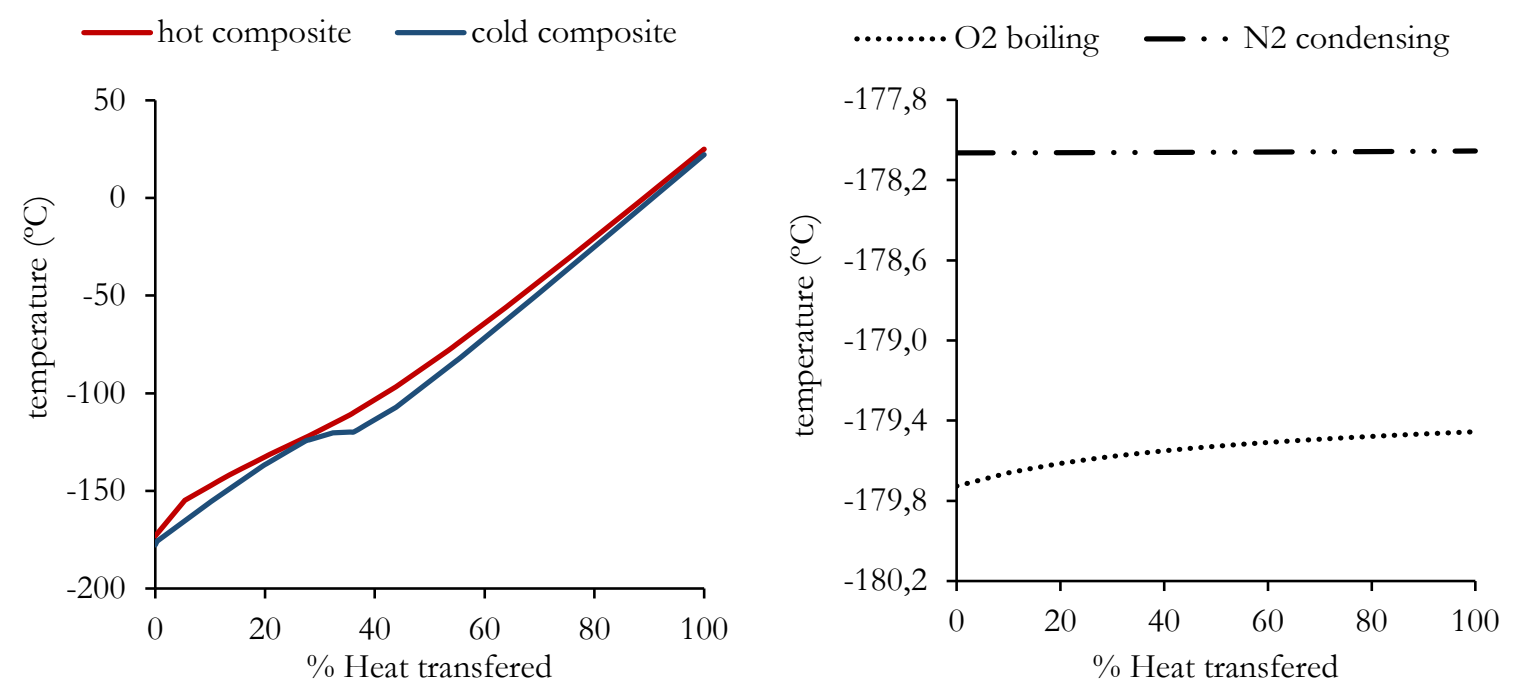

Figure 54 Temperature profile in the MCHE (left) and condenser reboiler (right)

The key modelling assumptions for the ASU are given in Table 21. Both MAC and BAC are comprised of two intercooled stages.

Table 21 Modelling assumptions for the LP-ASU

\begin{tabular}{|c|c|c|}
\hline Equipment/Item & Value & Units \\
\hline Main Air Compressor Polytropic Efficiency & 89 & $\%$ \\
\hline Booster Air Compressor Polytropic Efficiency & 87 & $\%$ \\
\hline $\mathrm{N}_{2}$ Compressor Polytropic Efficiency & 83 & $\%$ \\
\hline Cryogenic Pump Isentropic Efficiency & 80 & $\%$ \\
\hline HPC Equilibrium Trays & 50 & - \\
\hline LPC Equilibrium Trays & 40 & - \\
\hline Reboiler-Condenser MITA & 1,5 & ${ }^{\circ} \mathrm{C}$ \\
\hline MCHE MITA & 2 & ${ }^{\circ} \mathrm{C}$ \\
\hline Process Stream Temperature & 25 & ${ }^{\circ} \mathrm{C}$ \\
\hline Oxygen Purity & $95-98$ & $\%$ \\
\hline Oxygen Pressure (Shell) & 48 & $\mathrm{bar}$ \\
\hline Oxygen Pump Efficiency & 80 & $\%$ \\
\hline Exchanger Pressure Losses / side & 10 & $\mathrm{kPa}$ \\
\hline Intercooler Pressure Loss & 10 & $\mathrm{kPa}$ \\
\hline
\end{tabular}

The specific power consumption for oxygen production in a Shell gasification plant resulted in $355.0 \mathrm{kWh} / \mathrm{tonO}_{2}$, which is around $10 \%$ higher than the values reported in $[71,72]$ for a $\mathrm{LP}$ configuration designed with a better heat integration using three distillation columns (325 $\mathrm{kWh} /$ ton $\mathrm{O}_{2}$ ). These results match well with what is predicted in [73]. For the introductory plants, this is the auxiliary consumption used, assuming a more simple ASU configuration. The $\mathrm{N}_{2}$ compression duty (if required) was determined independently, with several (2-3) intercooled stages each with a polytropic efficiency of $82 \%$.

\subsubsection{High pressure Air Separation Unit}

A high pressure air separation unit (HP-ASU) is convenient when the ASU is partially or totally integrated in the GT, whereby the GT compressor delivers a portion (the case have been done 
with $50 \%$ integration as suggested in [6]) of the air intake after an expansion to ASU pressures and heat recovery. The high pressure operation requires an extra stage in the MAC, while the HPC column operates at 10 bar and the LPC at 3 bar. This allows to obtain pressurized N2 at approximately 2.7 bar, which significantly reduces the compression duty (relative to a LP-ASU product at $1.2 \mathrm{bar}$ ) when this stream is used for fuel dilution to avoid NOx emissions. The partial integration of the GT compressor with the ASU will also help to reach a compressor operating point closer to the nominal design point [74], preventing surge. [75] makes a thorough assessment of the optimal degree of integration of several ASU configuration in a pre-combustion $\mathrm{CO}_{2}$ capture IGCC plant, concluding that low levels of integration are desirable. In any case, the "introductory" models adopt the assumption that the compressors are able to cope with the increased fuel flow rate through IGV closing operation or machine re-design, reaching the nominal design pressure ratio and component efficiencies, as detailed in 3.6.3.

\subsubsection{Gas Switching Oxygen Production (GSOP)}

The use of a GSOP reactor cluster has been presented as an effective alternative to an ASU. The energy required for separation is provided through thermal energy in the syngas feed to the reduction stage. Two ensure sufficient oxygen in the reduction outlet, steam or a mixture of $\mathrm{CO}_{2}$ and $\mathrm{H}_{2} \mathrm{O}$ are also fed together with the syngas. Alternatively a compressed air by pass to the reduction outlet is possible. Air is fed to the oxidation stage, which delivers a depleted air stream at the studied temperature range of $700-900^{\circ} \mathrm{C}$. The high temperature reduction gases outlet can be effectively used as gasification agent. Because the $\mathrm{O}_{2}$ concentration in the product stream is around $20 \% \mathrm{~mol}$, the preferred gasification choice coupled to a GSOP cluster has been the High Temperature Winkler (HTW) gasifier, which is described in more detail in 3.3.3, because it operates at low temperature, reaching high syngas conversion efficiencies.

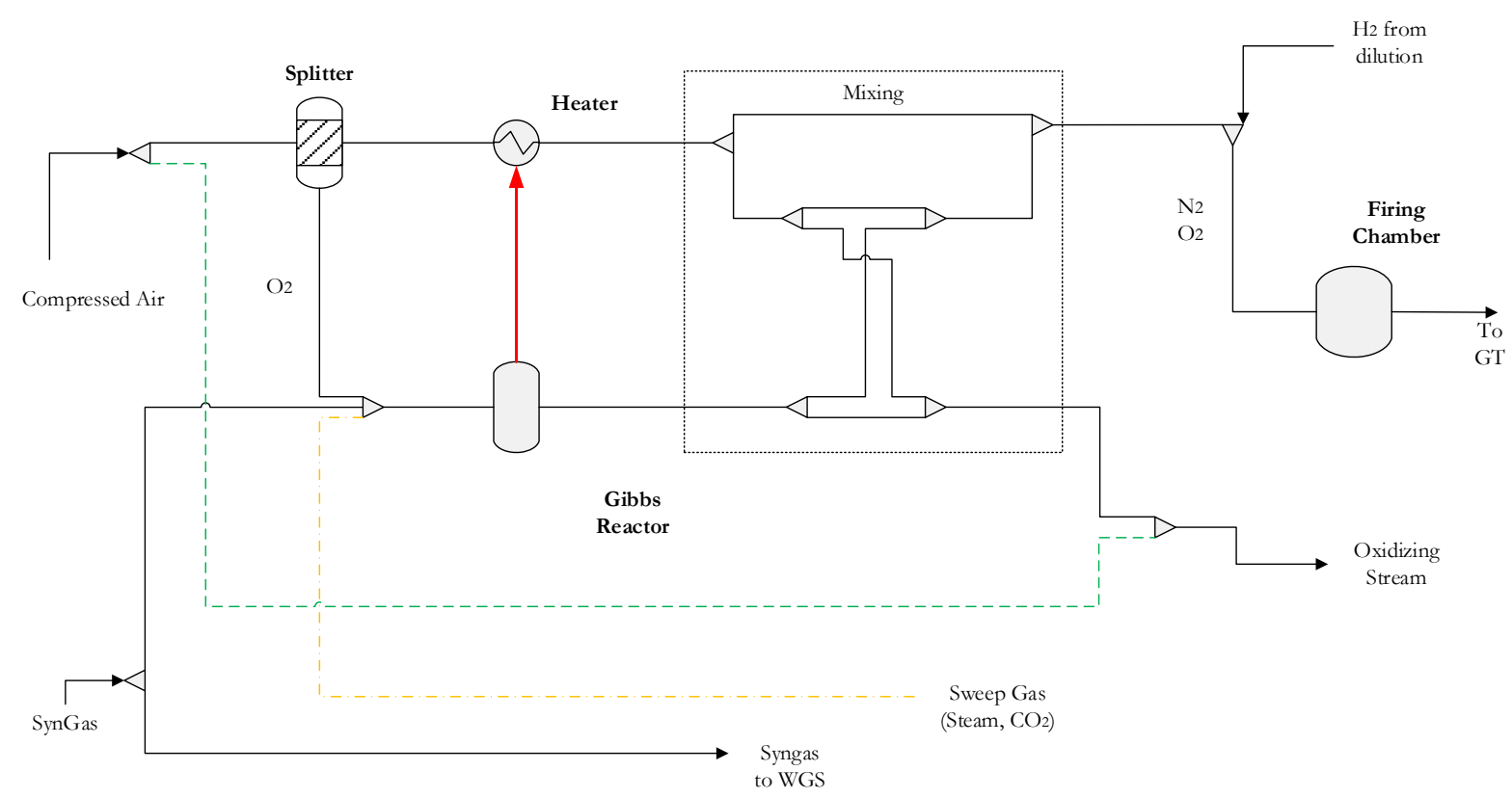

Figure 55 Schematic of the stationary model for a GSOP cluster

The GSOP reactor cluster is represented in the stationary process model by means ideal reactors, heaters and component splitters similarly to the GSC presented in section 2.5.2. The parameters to fix the operating point of the GSOP are the average outlet oxidation and reduction temperatures, the degree of mixing and the oxygen production represented by the $\mathrm{O}_{2}$ 
concentration difference between oxidation and reduction outlets. Figure 55 shows the process flow diagram with different possibilities to integrate the cluster with the gasification island (dotted lines) and with an extra firing chamber after the GSOP. A fixed pressure drop of 0,8 bar was assumed in all cases.

\subsection{Gasification}

Gasification is a well-known technology in which a solid fuel is converted to gas by means of a partial oxidation reaction with air, pure $\mathrm{O}_{2}$, steam and/or $\mathrm{CO}_{2}$. The assumptions for the modelling of gasification systems have been based primarily on [76], where a detailed description of the fundamental background and technological features is provided. For plant design purposes, three characteristic technologies applied in power generation and demonstrated on a large IGCC scale have been developed. It is acknowledged that other gasifiers are available in the market, which can lead to efficiency gains relative to the options presented. The study aims to address the suitability of these characteristic technologies in the different power plant configurations. Other applications of gasification are briefly discussed in section 1.3.1. In this section, a brief overview of the available technologies is given.

Fundamentally, gasification is the conversion through partial oxidation of a solid fossil fuel into a gas, which is easier to manage. Neglecting the heterogeneous nature of the coal feedstock for the purposes of the example, when a mole of elemental carbon is gasified to carbon monoxide (CO), more than $70 \%$ of the original heating value remains in the gaseous product. In the gasification systems considered here, full carbon conversion is desirable. The reaction mixture is composed of solid carbon, $\mathrm{CO}, \mathrm{CO}_{2}, \mathrm{H}_{2}, \mathrm{H}_{2} \mathrm{O}$ and $\mathrm{CH}_{4}$. The gasification equilibrium can be represented with three heterogenous reactions and a homogenous reaction, provided complete $\mathrm{O}_{2}$ consumption in the combustion reactions. The gas phase equilibrium reactions correspond to the WGS reaction described in Eq. 1, and the remaining are listed below:

\begin{tabular}{|c|c|c|c|}
\hline Combustion & $\begin{aligned} \mathrm{C}+{ }_{2}^{1} \mathrm{O}_{2} & \rightarrow \mathrm{CO} \\
\mathrm{CO}+{ }_{2}^{1} \mathrm{O}_{2} & \rightarrow \mathrm{CO}_{2} \\
\mathrm{H}_{2}+{ }_{2}^{1} \mathrm{O}_{2} & \rightarrow \mathrm{H}_{2} \mathrm{O}\end{aligned}$ & $\begin{array}{c}\Delta H^{\circ}=-111 \mathrm{~kJ} / \mathrm{mol} \\
\Delta H^{\circ}=-283 \mathrm{~kJ} / \mathrm{mol} \\
\Delta H^{\circ}=-242 \mathrm{~kJ} / \mathrm{mol}\end{array}$ & Eq. 58 \\
\hline Bouduard & $\mathrm{C}+\mathrm{CO}_{2} \leftrightarrow 2 \mathrm{CO}$ & $\Delta H^{\circ}=172 \mathrm{~kJ} / \mathrm{mol}$ & Eq. 59 \\
\hline Water Gas Reaction & $\mathrm{C}+\mathrm{H}_{2} \mathrm{O} \leftrightarrow \mathrm{CO}+\mathrm{H}_{2}$ & $\Delta H^{\circ}=131 \mathrm{~kJ} / \mathrm{mol}$ & Eq. 60 \\
\hline Methanation & $\mathrm{C}+2 \mathrm{H}_{2} \leftrightarrow \mathrm{CH}_{4}$ & $\Delta H^{\circ}=-75 \mathrm{~kJ} / \mathrm{mol}$ & Eq. 61 \\
\hline
\end{tabular}

A key performance indicator of gasification are the Cold Gas Efficiency (CGE) which was already introduced in section 1.3.2 as $\varphi$, and is accurately expressed in Eq. 62 for a coal feedstock. CGE represents the fraction of the original fuel heating value that is preserved in the product syngas.

$$
\varphi[\%]=100 \frac{m_{\text {syngas }} L H V_{\text {syngas }}}{m_{\text {coal }} L H V_{\text {coal }}} \quad \text { Eq. } 62
$$

It should be highlighted, that in terms of power applications, high CGE efficiency (for instance due to a large methane formation) is generally desirable, whereas for chemical production purposes, this may not be the case. In parallel to CGE, the fixed carbon conversion defined in Eq. 63 is a measure of the degree of fuel conversion that provides a complete overview of the gasification efficiency.

$$
X_{c}[\%]=100\left(1-\frac{C_{\text {slag }}}{C_{\text {coal }}}\right)
$$


There are three categories of gasification systems, which are summarized in Table 22 , attending to the characteristic properties.

Table 22 Gasification process characteristics [77]

\begin{tabular}{|c|c|c|c|}
\hline Category & Moving Bed & Fluidized Bed & Entrained Flow \\
\hline Ash conditions & Dry ash/slag & $\begin{array}{c}\text { Dry ash } / \\
\text { agglomerating }\end{array}$ & Slag \\
\hline Oxygen demand & Low & Medium & High \\
\hline Gas temperature & $425-625^{\circ} \mathrm{C}$ & $900-1050^{\circ} \mathrm{C}$ & $1200-1600^{\circ} \mathrm{C}$ \\
\hline Typical process & Lurgi, BGL & HTW, CFB, U-gas & $\begin{array}{c}\text { GE, Shell, E-Gas, } \\
\text { Siemens, MHI }\end{array}$ \\
\hline Other characteristics & $\begin{array}{c}\text { Hydrocarbons } \\
\text { in gas }\end{array}$ & $\begin{array}{c}\text { Low carbon } \\
\text { conversion }\end{array}$ & $\begin{array}{c}\text { High carbon } \\
\text { conversion }\end{array}$ \\
\hline
\end{tabular}

Moving bed gasifiers operate by contacting a downward flow of solid fuel against an upward $\mathrm{O}_{2} /$ Steam blast. Due to the low operating temperature, high molecular weight hydrocarbons and tars are formed in these gasifiers and they typically present high values of CGE.

Fluidized beds present very good mixing properties, and require operating temperatures below the ash softening point to ensure good fluidization behaviour. Because of the residence time distribution of the solid particles in the reactor volume, carbon conversion is limited. Fluidized bed gasifier have moderately high CGE and a substantial amount of methane is present in the syngas product, which can reduce the carbon capture efficiency in power plant schemes with CCS.

All of the successfully commercialized technologies for IGCC at large scale are entrained flow gasifiers because of their large acceptability for different feedstocks and reliability. They operate with co-current feeding of fuel and gasification agent (blast) with a very low residence time. The feedstock is milled to a small particle size to maximize the heat and mass transfer in the gas phase. To reach acceptable conversions, very high temperatures are required, and therefore these gasifiers have a high oxygen demand and operate above the ash melting point (slagging). The liquid ash flows downwards the gasifier and is collected in a water bath. An efficient recovery of the sensible heat contained in the syngas (around 20\% of the fuel heat input) can be performed through different means, as discussed in section 3.4.1.

\subsubsection{Dry-Fed Entrained Flow Gasifier}

Coal loading can be realized using a pneumatic system, known as lock hoppers, using a transport gas (typically $\mathrm{N}_{2}$ or $\mathrm{CO}_{2}$ ) to pressurize through several discrete stages the solid fuel and feed it to the gasification reactor at high pressure. This is the case of the Shell gasification process, schematically represented in Figure 56. The coal feedstock and pure $\mathrm{O}_{2}$ from an ASU are fed upwards. Due to the high reaction temperature, the ash melts and flows downwards across the membrane wall. The gasifier wall is refrigerated with IP steam through the membrane wall, eliminating the need of refractory lining and associated durability issues. The syngas is cooled with recirculated cold syngas and producing HP steam in a Syngas Effluent Cooler (SEC). Gasification temperatures are above $1400^{\circ} \mathrm{C}$ and CGE surpass $80 \%$. Coal must be fed with a low moisture content ( $2 \% \mathrm{w}$.) to ensure reasonable $\mathrm{O}_{2}$ consumption and coal drying is performed using a slip stream of clean syngas. Operating pressure of the Shell process is between 30-50bar, and it is limited by the lock hoppering system which requires higher and higher transport gas mass flow at elevated pressures. 


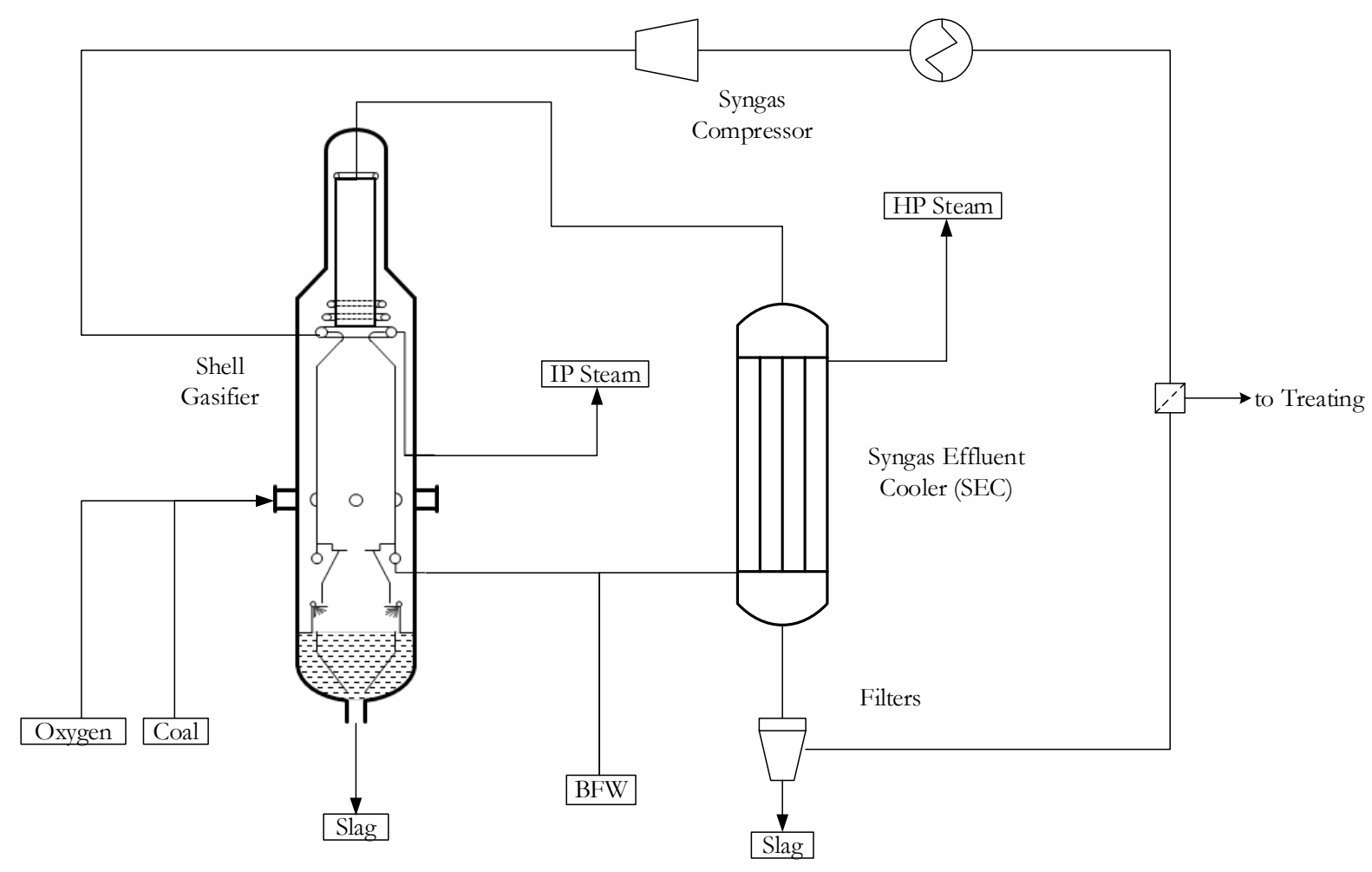

Figure 56 Shell gasification process

Shell gasification is the reference technology used to develop the benchmarks and many of the plants incorporating GS technology. The main modelling assumptions for this unit have been taken from $[6,71]$ and are summarized in Table 23:

Table 23 Shell gasification modelling assumptions

\begin{tabular}{|c|c|c|}
\hline Item & Value & Units \\
\hline Moderator (steam) to dry coal ratio & 0,09 & $\mathrm{~kg} / \mathrm{kg}$ \\
\hline Oxygen to dry coal ratio & 0,873 & $\mathrm{~kg} / \mathrm{kg}$ \\
\hline Moisture in coal after drying & 2 & $\%$ \\
\hline Syngas for coal drying \%LHV & 0,9 & $\%$ \\
\hline Fixed carbon conversion & 99,3 & $\%$ \\
\hline Gasifier operating pressure & 44 & $\mathrm{bar}$ \\
\hline Steam moderator pressure & 54 & $\mathrm{bar}$ \\
\hline $\mathrm{O}_{2}$ heater temperature & 180 & ${ }^{\circ} \mathrm{C}$ \\
\hline Heat loss as \%LHV & 0,7 & $\%$ \\
\hline Heat to membrane wall as $\%$ LHV & 2 & $\%$ \\
\hline Coal Milling \& Handling & 100 & $\mathrm{~kJ} / \mathrm{kg}$ coal \\
\hline Ash Handling & 50 & $\mathrm{~kJ} / \mathrm{kg}$ ash \\
\hline \multicolumn{2}{|c|}{$\mathrm{CO}_{2}$ coal loading } \\
\hline $\mathrm{CO}_{2} \mathrm{HP} / \mathrm{HHP}$ pressure & $56 / 88$ & $\mathrm{bar}$ \\
\hline $\mathrm{CO}_{2}$ temperature & 80 & ${ }^{\circ} \mathrm{C}$ \\
\hline $\mathrm{CO}_{2}$ to dry coal ratio & 0,83 & $\mathrm{~kg} / \mathrm{kg}$ \\
\hline Vented gas & 10 & $\%$ \\
\hline \multicolumn{2}{|c|}{$N_{2}$ coal loading } \\
\hline $\mathrm{N}_{2} \mathrm{HP} / \mathrm{HHP}$ pressure & 88 & $\mathrm{bar}$ \\
\hline $\mathrm{N}_{2}$ temperature & 80 & ${ }^{\circ} \mathrm{C}$ \\
\hline $\mathrm{N}_{2}$ to dry coal ratio & 0,28 & $\mathrm{~kg} / \mathrm{kg}$ \\
\hline
\end{tabular}




\subsubsection{Slurry-Fed Entrained Flow Gasifier}

Alternatively to costly dry feeding through lock hopper systems, coal mixed with water can be pumped to higher pressures (up to $80 \mathrm{bar}$ ) in a slurry feed gasification. The $\%$ of solids in the slurry can vary depending on the feedstock characteristics. $\mathrm{O}_{2}$ demand is higher and CGE is lower than in entrained-flow dry fed gasifiers because of the need to evaporate and heat the water to the gasification temperature, which also results in a higher degree of complete combustion of the fuel. On the other hand, the larger presence of water shifts the WGS reaction to the products side, resulting in a higher $\mathrm{H}_{2} / \mathrm{CO}$ ratio in the syngas product. A brief schematic of the GE gasification technology is presented in Figure 57:

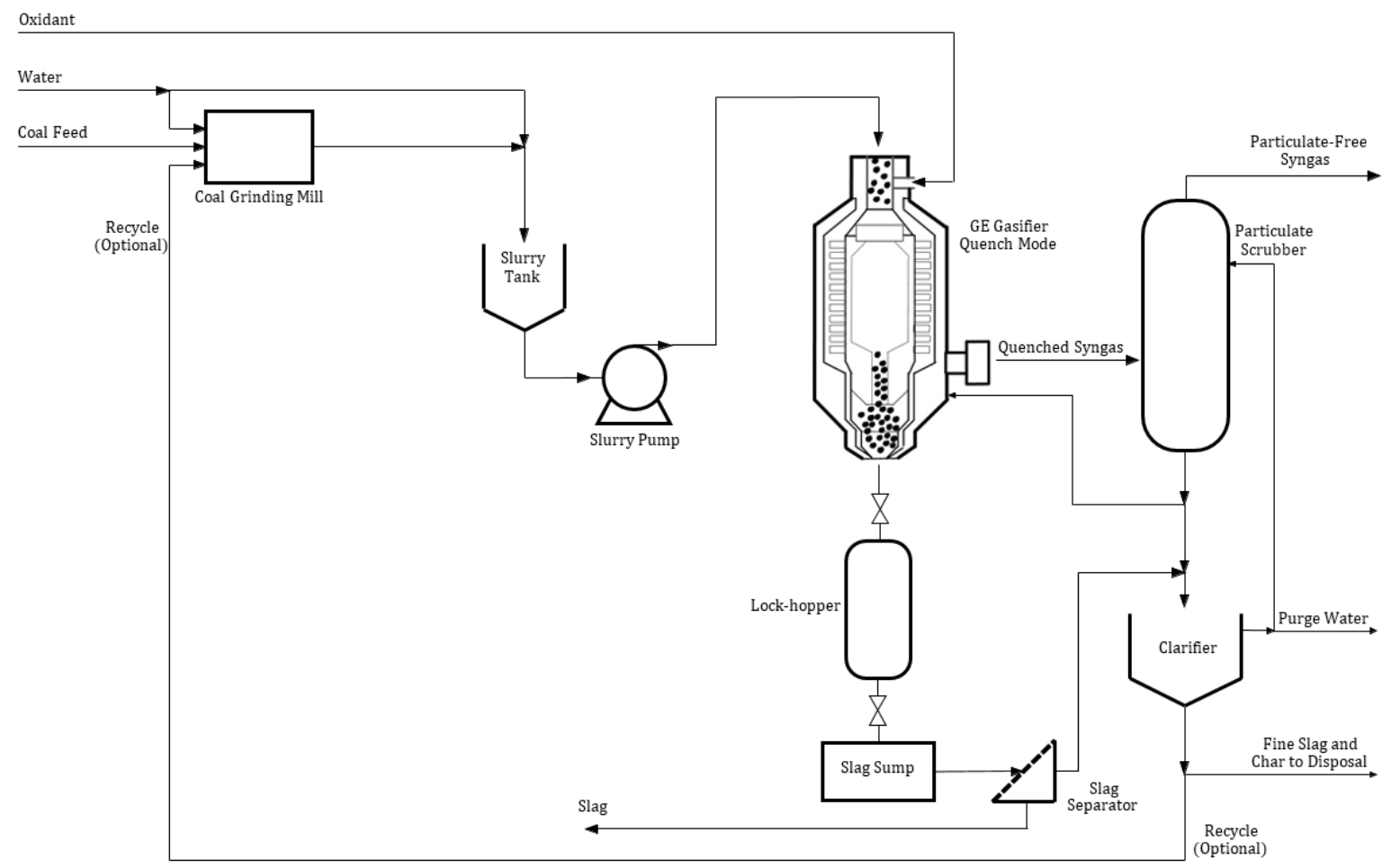

Figure 57 GE gasification system with full water quench and syngas scrubber

Coal water slurry preheating with heat excess from other power plant sections proves to be very beneficial to reduce $\mathrm{O}_{2}$ consumption and increase CGE [76]. A reference GE gasifier is modelled based on the performances given in $[36,78]$ and summarized in Table 24. GE gasification achieves also a small reduction of $\mathrm{CO}_{2}$ emissions as the avoidance of lock hoppers eliminates the need of a transport gas and associated venting during coal loading.

Table 24 GE gasification modelling assumptions

\begin{tabular}{|c|c|c|}
\hline Equipment/Item & Value & Units \\
\hline Oxygen to coal ratio (a,r) & 0,884 & $\mathrm{~kg} / \mathrm{kg}$ \\
\hline Reference CGE/Gasification temperature & $75 / 1300$ & $\% /{ }^{\circ} \mathrm{C}$ \\
\hline Fixed Carbon Conversion & 99,0 & $\%$ \\
\hline Coal-water slurry \%w, of solids & 65 & $\%$ \\
\hline Slurry water Temperature & 60 & ${ }^{\circ} \mathrm{C}$ \\
\hline Heat Loss as \%LHV & 0,5 & $\%$ \\
\hline Gasifier Operating Pressure & 80 & $\mathrm{bar}$ \\
\hline Other Gasification Auxiliaries \\
\hline
\end{tabular}




\begin{tabular}{|c|c|c|}
\hline Coal Milling \& Handling & 100 & $\mathrm{~kJ} / \mathrm{kg}$ coal \\
\hline Ash Handling & 50 & $\mathrm{~kJ} / \mathrm{kg}$ ash \\
\hline Oxygen to Gasifier Temperature & 180 & ${ }^{\circ} \mathrm{C}$ \\
\hline
\end{tabular}

\subsubsection{Circulating Fluidized Bed Gasifier}

The Hot Temperature Winkler (HTW) gasifier presented in Figure 58 is a fluidized bed gasifier with dry coal feeding systems, and are operated either with air or pure oxygen. HTW gasifiers have a high degree of feedstock flexibility, and more importantly, have a large flexibility in terms of capacity and turndown ratio, ideally suited for integration with GSOP technology. Furthermore, the low operating temperatures (around $800-1000^{\circ} \mathrm{C}$, below the ash slagging temperatures) result in a low $\mathrm{O}_{2}$ consumption and high CGE, which are beneficial from a power production perspective, particularly when low rank coal is fed. Operating pressures are up to $30 \mathrm{bar}$. HTW gasification has been demonstrated on a pilot plant scale and for chemical production process, but there are no large scale IGCC facilities built. The gasification temperatures are high enough that no hydrocarbons other than methane are produced in the syngas product [79]. Methane, with a high heating value improves CGE, but can result in undesirable carbon slip in CCS plants using absorption as a $\mathrm{CO}_{2}$ removal mechanism [80]. Due to the uneven residence time of the coal particles in the gasification volume, the carbon conversion is limited, which makes ash disposal more costly.

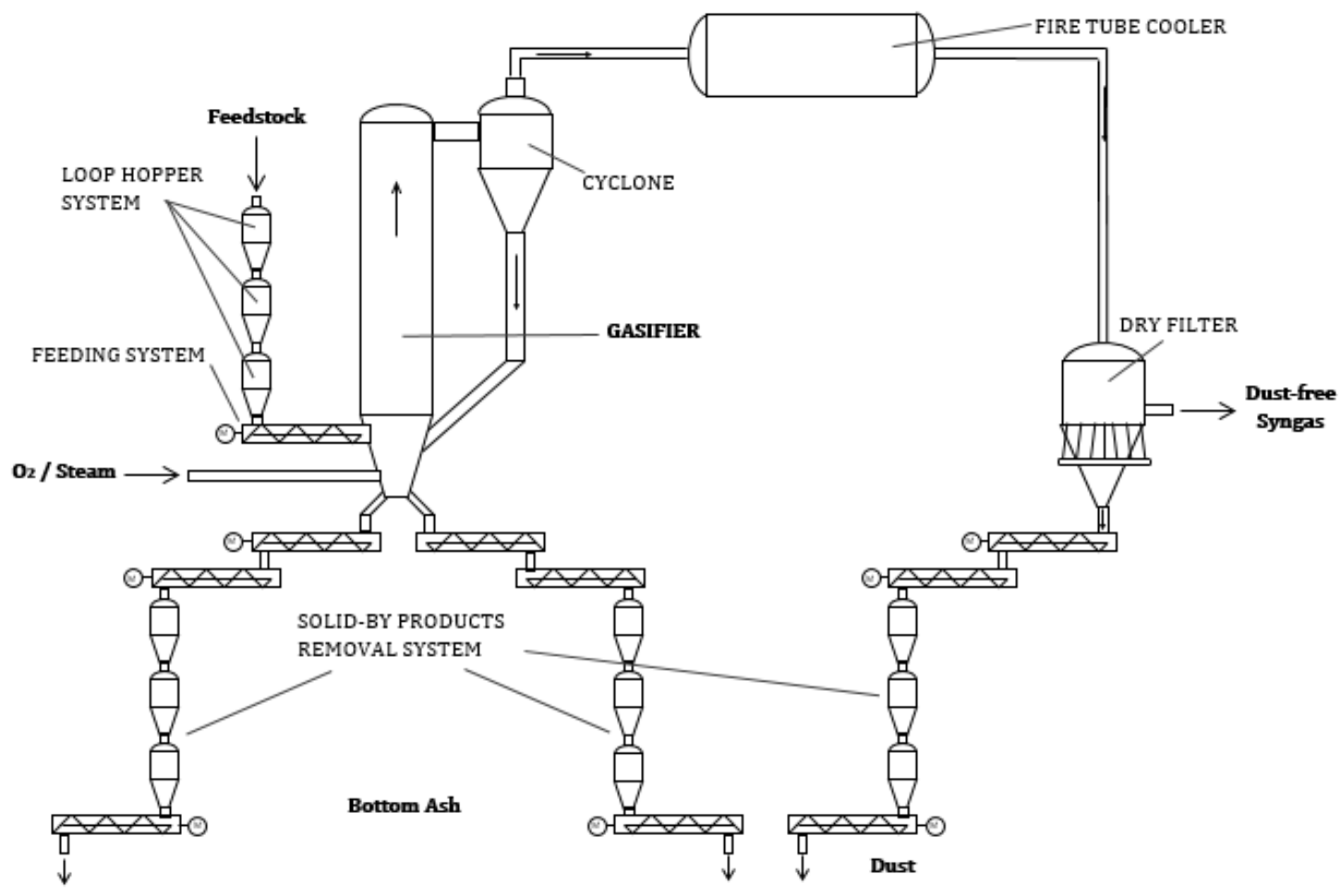

Figure 58 HTW gasification process

The main modelling assumptions taken to represent this gasification technology are summarized in Table 25, and are similar to the ones employed in [56]:

Table 25 HTW Winkler modelling assumptions

\begin{tabular}{|c|c|c|}
\hline Item & Value & Units \\
\hline Freeboard temperature & 900 & ${ }^{\circ} \mathrm{C}$ \\
\hline
\end{tabular}




\begin{tabular}{|c|c|c|}
\hline \%w. $\mathrm{CO}_{2}$ for coal loading & 15 & $\%$ \\
\hline \% LHV $\mathrm{CH}_{4}$ in syngas & 11,3 & $\%$ \\
\hline Oxidizer overpressure & 50 & $\mathrm{kPa}$ \\
\hline HP steam superheat & 450 & ${ }^{\circ} \mathrm{C}$ \\
\hline Fixed carbon conversion & 97,0 & $\%$ \\
\hline \%w. vented $\mathrm{CO}_{2}$ in lock hoppers & 10 & $\%$ \\
\hline Coal milling \& handling & 40 & $\mathrm{MJ} / \mathrm{kg}$ coal \\
\hline Ash handling & 200 & $\mathrm{MJ} / \mathrm{kg}$ ash \\
\hline
\end{tabular}

\subsection{Syngas Cooling \& Treating}

As anticipated in section 1.3.3, the syngas cooling and treating correspond to the series of unit operations that take place from the gasification raw syngas stream product to the delivery of a suitable fuel to the GT. These treating steps also include the syngas conversion units and dilution requirements to reach adequate combustion free of $\mathrm{NOx}, \mathrm{SOx}$ and eventually $\mathrm{CO}_{2}$.

\subsubsection{High Temperature Syngas Cooling and Particulate Removal}

Due to the high temperature of the gasification process and the presence of environmentally hazardous components in the raw syngas stream, it is not possible to directly combust it with air in the GT.

Syngas outlet temperatures from the entrained flow gasifiers described in the earlier section can be in the range of $1200-1600^{\circ} \mathrm{C}$. As anticipated from the diagrams in the previous sections, each gasification technology usually has a standardized cooling system, but there is room for flexibility as shown in Figure 60. The degree to which each of the potential cooling concepts are applied to each of the gasification technologies studied in this work varies. Because of the high capital expenditure of radiant coolers [81] concept B was not applied, but it is outlined here to show the diversity of options. Concept $\mathrm{C}$ is generally used in most of the plants, corresponding to the entrained flow Shell gasification technology with gas quench and syngas effluent coolers followed by dry solids filtration with candle filters and, optionally, a syngas water scrubber (for concepts without HGCU). Concept A corresponds to a full water quench that can be applied to slurry or dry fed entrained flow gasifiers. Syngas cooling employing a total quench can result on around 3$4 \%$-points of efficiency loss, but a significant lower capital expenditure. Finally, concept D is a particular case employed in one of the advanced plants to compromise between capital costs and efficient heat recovery for a slurry fed entrained flow gasification system. The configurations evaluated in this work are inspired in [82]. It should be mentioned, that a chemical type of quench exists consisting of carrying out partial coal oxidation in a first gasification stage and then partially feeding the coal slurry to a second stage to quench (through endothermic gasification reaction) the product stream from the first stage. This gasification cooling concept is applied in the CB\&I Egas slurry fed entrained flow gasifier [36], and reaches improved efficiencies compared to the GE gasification process albeit at higher capital costs. This gasification process however has not been investigated in this work and is left for future evaluations. 


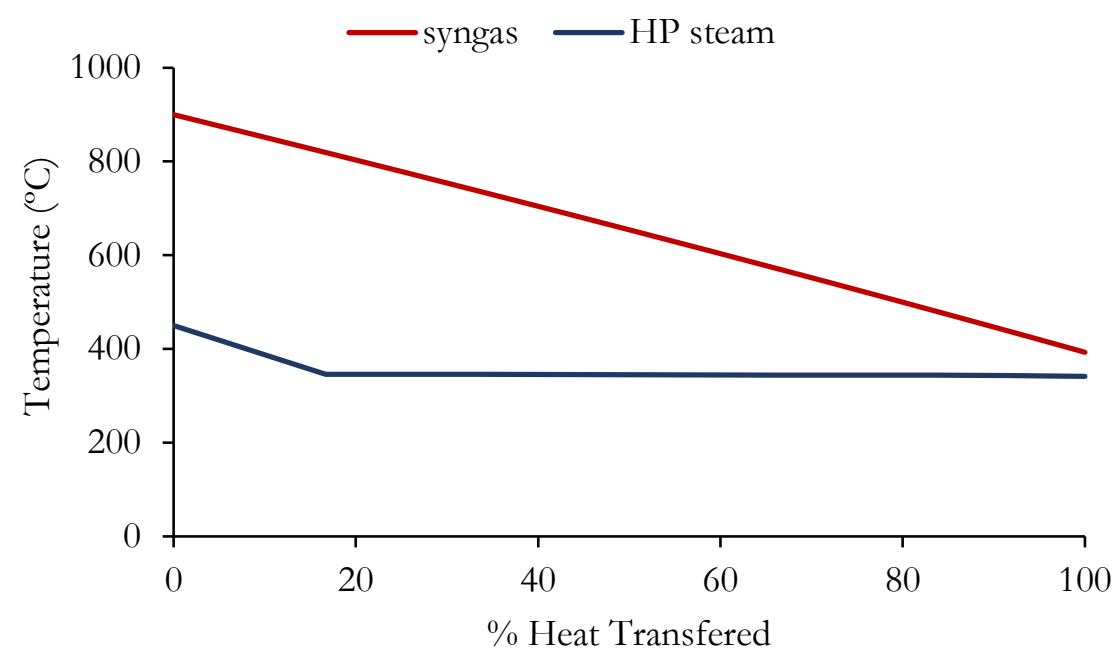

Figure 59 Temperature profile of a syngas effluent cooler (SEC)

On the other hand, for process concepts using gasification below the ash melting point (HTW gasifier), the cooling of syngas is performed with a conventional syngas effluent cooler, whose temperature profile is given in Figure 59 for illustration. For all cases, the steam superheat temperature was limited to $450^{\circ} \mathrm{C}$ to avoid the undesired phenomena of 'metal dusting' [83]. A syngas cooler by heat recuperation of a clean fuel stream is used for one of the advanced HTW concepts.

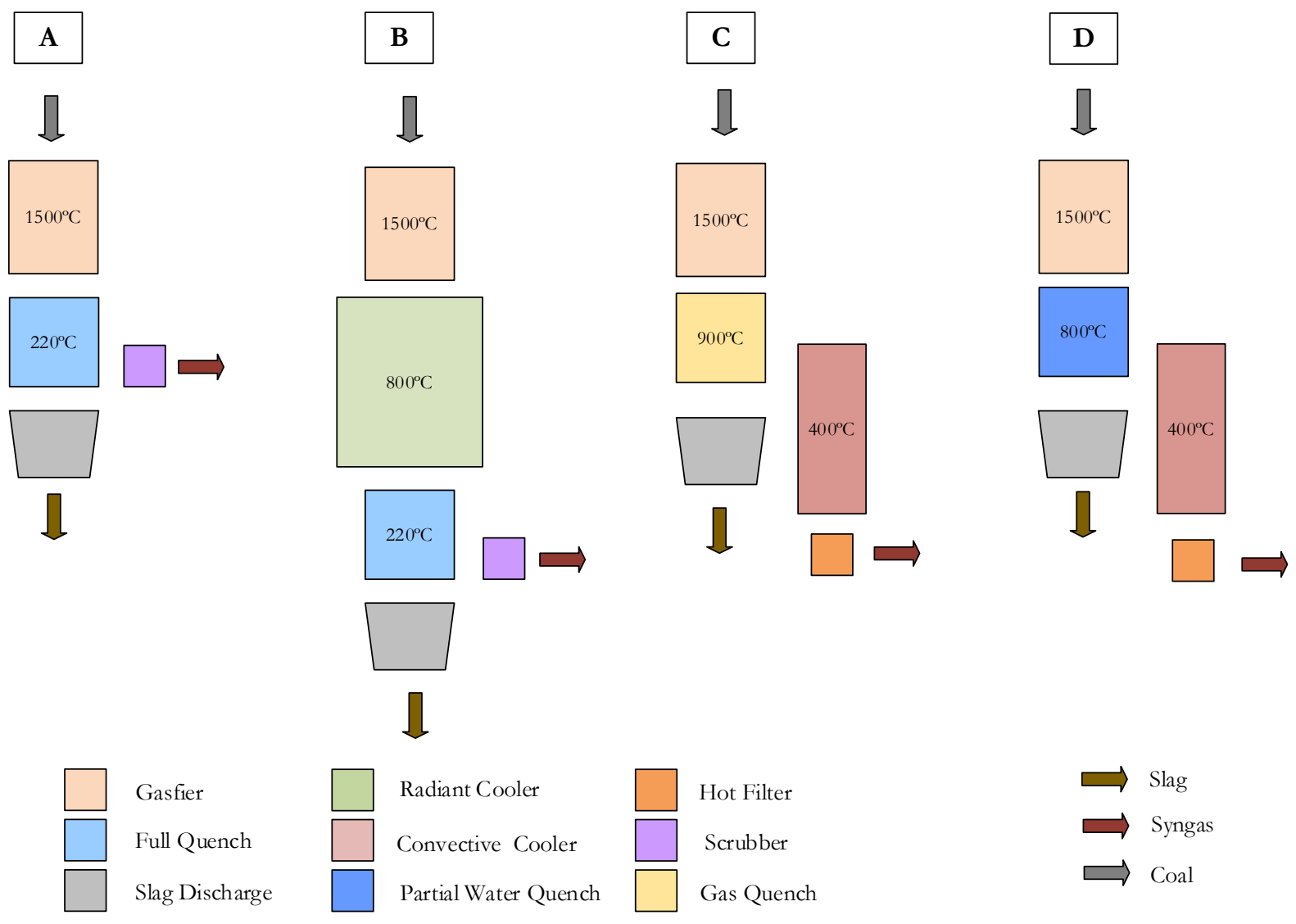

Figure 60 Syngas cooling designs. Temperature values are approximate 
A short mention is made here to particulate removal using either water scrubbers (simulated as an equilibrium column of 1-2 stages) with gas outlet saturated with water. This unit operation removes entrained particles from the gasifier and also eliminates chlorides and ammonia. It often proceeded or replaced (depending on the final application) by a hot gas ceramic filter. The model predicts no solids entrainment from gasification, therefore the filters have been represented by imposing a reasonable pressure drop.

\subsubsection{Low Temperature Heat Recovery \& Cold Gas Clean-Up}

The low temperature heat recovery (LTHR) section employed for syngas cooling for downstream contaminant removal at ambient temperatures consists of a network of heat exchangers and unit operations as described in Figure 61:

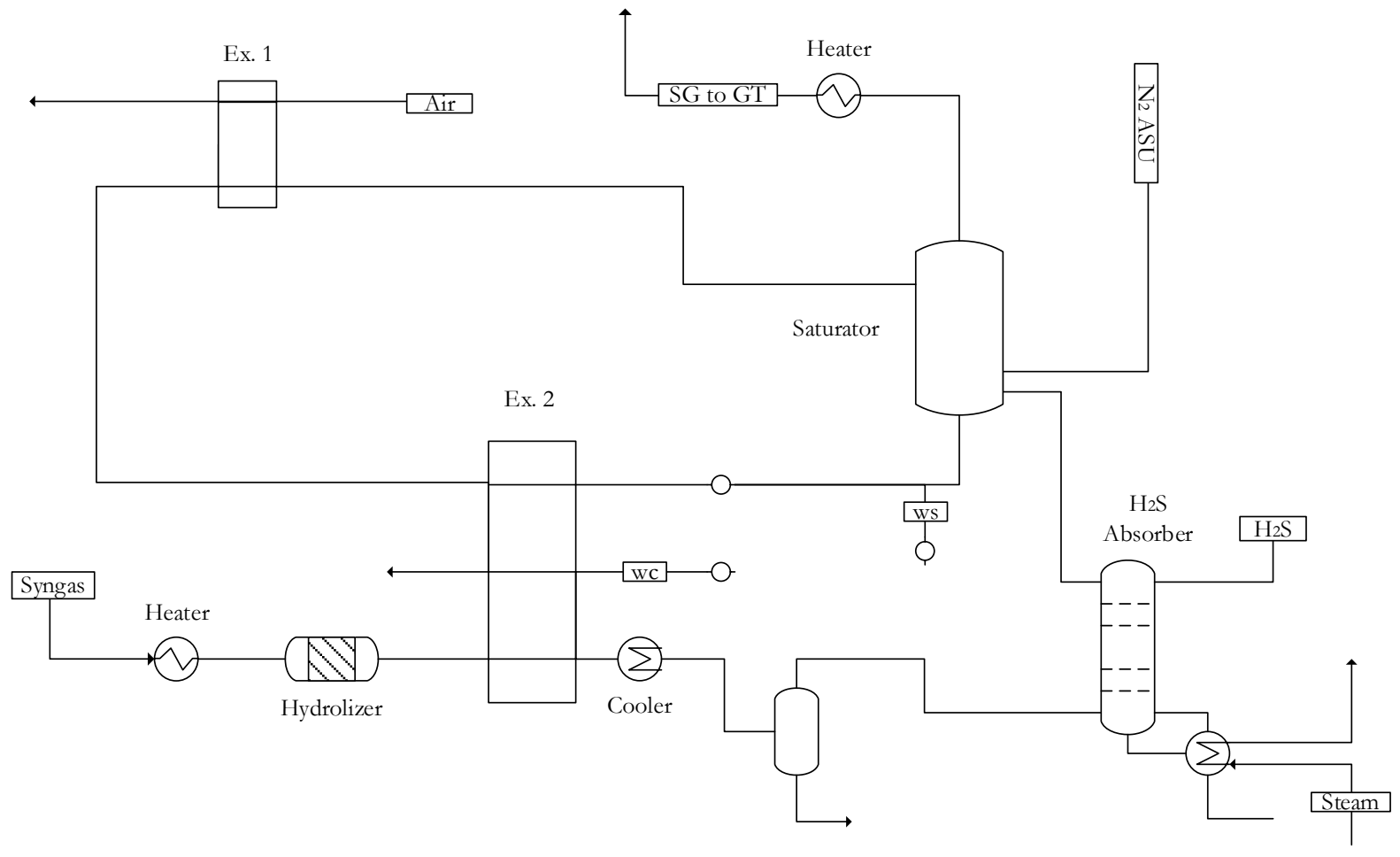

Figure 61 LTHR section with $\mathrm{H}_{2} \mathrm{~S}$ removal and syngas saturator

Syngas after the scrubbing section is slightly heated with hot water to $180^{\circ} \mathrm{C}$ and traces of COS are converted to $\mathrm{H}_{2} \mathrm{~S}$ in the hydrolyser. Hot water and for the scrubber (not shown) and saturator are generated in the multistream heat exchanger. After a final cooling to ambient temperatures $\left(30^{\circ} \mathrm{C}\right)$ and water knock out, the $\mathrm{H}_{2} \mathrm{~S}$ is removed in an absorption column. The steam consumption in the absorber reboiler and auxiliary duty required for $\mathrm{H}_{2} \mathrm{~S}$ treating (downstream Claus and SCOT units which are not modelled) is estimated as $20.95 \mathrm{MJ}$ th $/ \mathrm{kgH}_{2} \mathrm{~S}$ and $1.93 \mathrm{MJe} / \mathrm{kgH}_{2} \mathrm{~S}$ respectively. These values correspond to desulphurization with a Selexol sorbent, and are taken from [63]. The saturator unit humidifies the clean syngas stream and after further heating with hot water to $200^{\circ} \mathrm{C}$ the fuel is routed to the GT combustor. This clean up setup is primarily used in the benchmark unabated IGCC power plant as the GS plants operate under the assumption that HGCU (described in section 3.4.3) will be implemented to all power plants with the resulting efficiency gains. The $\mathrm{N}_{2}$ stream from the ASU is used to dilute the syngas to limit the stoichiometric flame temperature in the GT combustor. This section is also integrated with the ASU when some air cooling is required to provide more hot water to the saturator. 


\subsubsection{Hot Gas Clean-Up}

Hot Gas Clean-Up refers to a series of unit operations which remove entrained particulate material from the syngas stream after gasification, sulphur species present such as $\mathrm{H}_{2} \mathrm{~S}$ and COS and other harmful contaminants such as $\mathrm{NH}_{3}$ and $\mathrm{HCl}$. The particulates are removed using candle filters, consisting of porous ceramic material which operates between $300-500^{\circ} \mathrm{C}$. A conservative maximum temperature of $400^{\circ} \mathrm{C}$ was assumed for dry solids filtration, and was represented in the models specifying a small pressure drop in the raw syngas and a small pressurized $\mathrm{CO}_{2} / \mathrm{N}_{2}$ injection addition for purging. This is a relatively low temperature operation of the downstream desulphurization unit compared to the evaluation performed in [26], justified by the fact that lower temperatures minimize material and corrosion problems. It is challenging to remove multiple contaminants (including trace elements such as mercury) at high temperatures, and different sorbents in a one-step capture process are used [84].

The proposed models for HGCU are two: A simplified model using a component splitter to remove the contaminant species at constant temperature. This is a quick calculation tool used in some of the introductory power plant models, with minimal impact in the process efficiency, since the concentration of the sulphur species is relatively small. There is a small difference in the resulting syngas composition $\left(\mathrm{H}_{2} \mathrm{O}\right)$ and higher syngas cooling temperature is achieved relative to the more detailed model described subsequently.

Such model consists of a configuration with $\mathrm{H}_{2} \mathrm{~S}$ adsorption and desorption stages using $\mathrm{ZnO}$, a species which shows the highest potential for this application due to its favourable thermodynamics [85]. The sorbent regeneration is also taken into account in the calculations. The model calculates the syngas inlet temperature required (imposed by the cooling devices upstream) which yields a clean syngas stream at $400^{\circ} \mathrm{C}$ (assumed treating temperature). The model determines the solids circulation rate to satisfy the mass and energy balances between the fluidized bed adsorber and regenerator. Also the amount of $\mathrm{N}_{2}$ from the ASU added to the regeneration stream is selected to reach low $\mathrm{O}_{2}$ concentration values, preventing the undesired formation of zinc sulphate. In summary, the chemical reactions taking place in the adsorption and regeneration bed are shown in Eq. 64 \& Eq. 65 respectively:

$$
\begin{array}{ll}
\mathrm{ZnO}+\mathrm{H}_{2} \mathrm{~S} \rightarrow \mathrm{ZnS}+\mathrm{H}_{2} \mathrm{O} & \text { Eq. } 64 \\
\mathrm{ZnS}+\frac{3}{2} \mathrm{O}_{2} \rightarrow \mathrm{ZnO}+\mathrm{SO}_{2} & \text { Eq. } 65
\end{array}
$$

The process configuration consists of an interconnected fluidized bed set-up as presented in Figure 62. Non-sulphur species are removed analogously to the simplified HGCU model. Given the low concentration of these components, the effect in terms of energy balance is negligible. For a specified clean syngas temperature, the macro mass and energy balance are performed to each of the beds assuming total sulphur removal in the adsorption step and a specified regeneration conversion. 


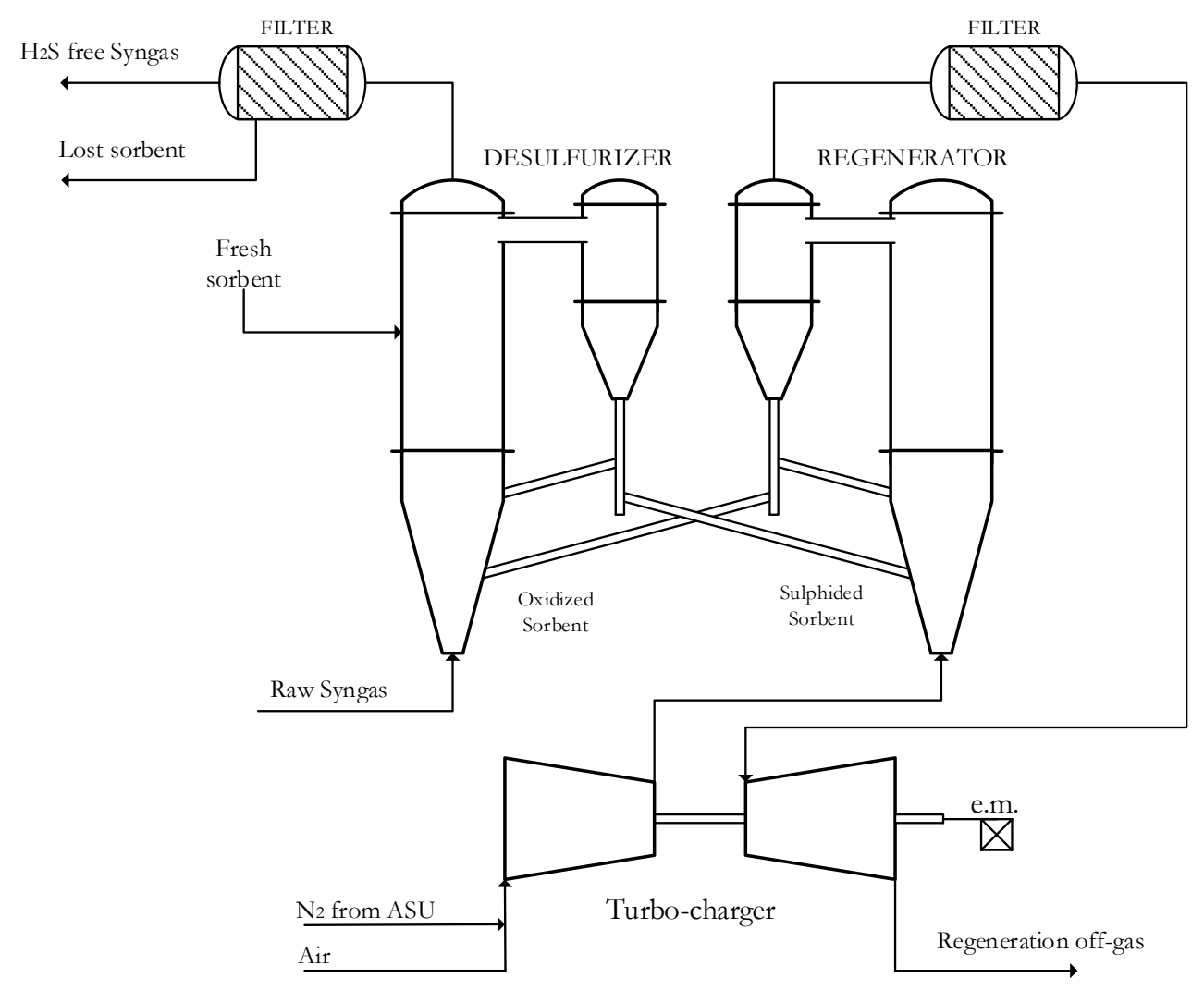

Figure 62 Schematic of HGCU process with sorbent regeneration

Applied to the adsorption and the regenerator beds, the energy balance assuming adiabatic stationary operation results in Eq. 66 \& Eq. 67 :

$$
\begin{array}{rlr}
h_{\text {raw }} \dot{m}_{\text {raw }}+ & h_{O S} \dot{m}_{O S}+h_{f S} \dot{m}_{f S}=h_{\text {clean }} \dot{m}_{\text {clean }}+h_{S S} \dot{m}_{S S}+h_{l S} \dot{m}_{l S} & \text { Eq. } 66 \\
h_{O x} \dot{m}_{O x}+h_{S S} \dot{m}_{S S} & =h_{N_{2}} \dot{m}_{N_{2}}+h_{O S} \dot{m}_{O S} & \text { Eq. } 67
\end{array}
$$

Given that the regenerator operates with a restraint in $\mathrm{O}_{2}$, an assumed mass flow rate of the solid oxidant species is used to iteratively determine the specific enthalpy of the syngas stream entering the adsorption bed $h_{\text {raw }}$. With a known composition and pressure, the actual inlet temperature is directly determined with the equation of state from the stationary process model. The amount of $\mathrm{H}_{2} \mathrm{~S}$ present in the syngas sets the regeneration stream input to the plant to close the balance in the regenerator. The main modelling assumptions used in this section are summarized in Table 26.

Table 26 Modelling assumptions for HGCU

\begin{tabular}{|c|c|c|}
\hline Item & Value & Units \\
\hline Adsorption temperature & 400 & ${ }^{\circ} \mathrm{C}$ \\
\hline Regeneration temperature & 750 & ${ }^{\circ} \mathrm{C}$ \\
\hline Filter pressure drop & 5 & $\%$ \\
\hline Auxiliary consumption & 5,34 & $\mathrm{MJe} / \mathrm{kgH}_{2} \mathrm{~S}$ \\
\hline Fresh sorbent $\mathrm{ZnO} / \mathrm{TiO}_{2}$ ratio & 1 & - \\
\hline ZnS/ZnO ratio ex. regenerator & 0,1 & - \\
\hline Compressor polytropic efficiency & 90 & $\%$ \\
\hline Expander polytropic efficiency & 89 & $\%$ \\
\hline Compander mechanical efficiency & 99 & $\%$ \\
\hline $\mathrm{O}_{2}$ mol fraction in regeneration stream & 2 & $\%$ \\
\hline
\end{tabular}


The specific enthalpies of the solid species are determined through a 2 nd order polynomial regression of the data retrieved from [62]. The turbocharger auxiliary consumption is also determined; since the regenerator operates at a relatively high temperature, the overall consumption is small. The off gas stream is routed to a Wet Gas Desulphurization Unit (WGDU), modelled as a component splitter, in which $\mathrm{SO}_{2}$ is removed from the vented gas stream dissolved in water. For power plant concepts which do not have an ASU to provide pure $\mathrm{N}_{2}$ to dilute the regeneration stream, a partial recirculation to the turbocharger is performed after a cooling step. This is depicted in Figure 63:

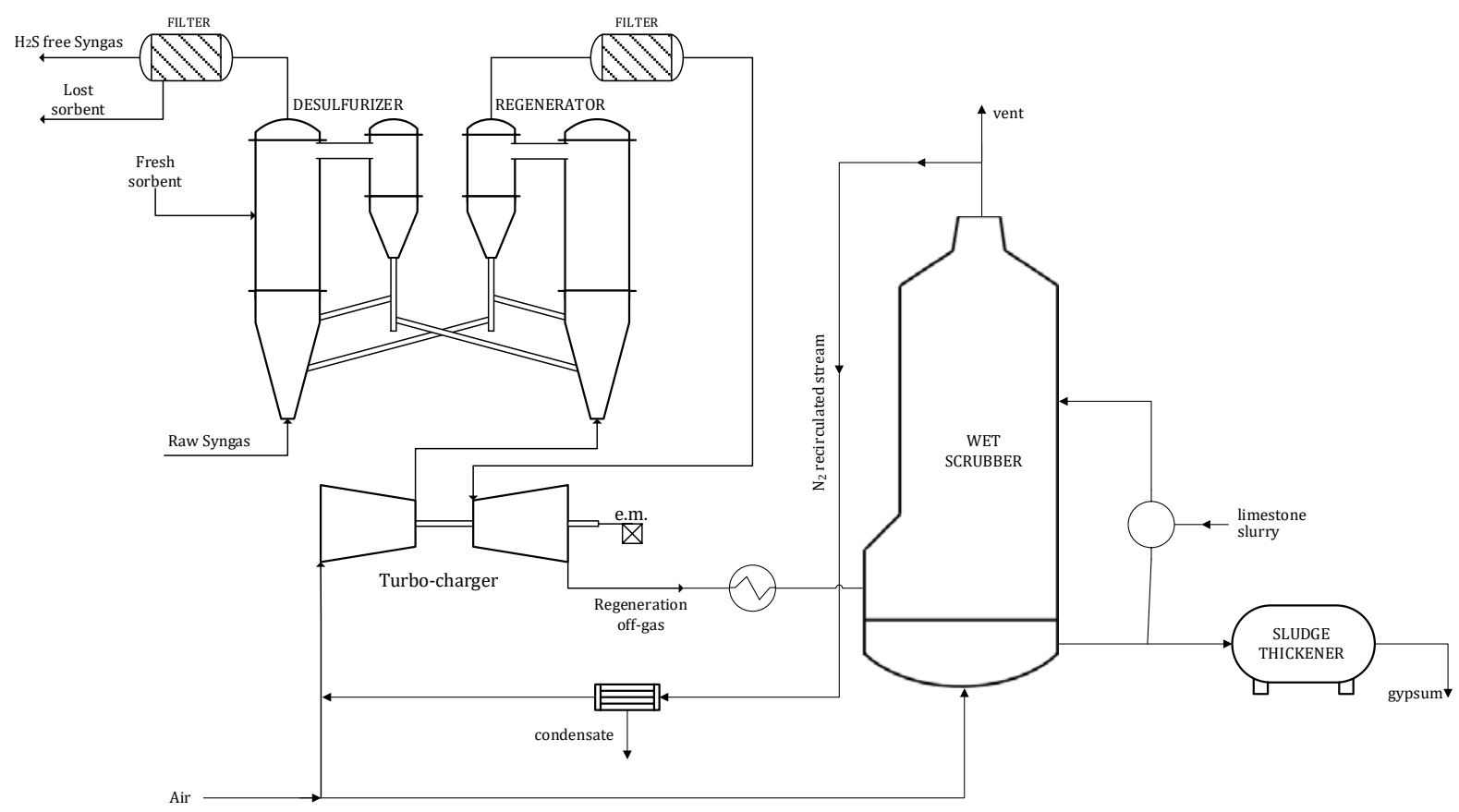

Figure $63 \mathrm{HGCU}$ with off gas recirculation to the regenerator

\subsubsection{Shift Conversion \& and Heat Recovery}

In plants with pre-combustion $\mathrm{CO}_{2}$ capture an essential step consists of the shifting of the syngas to create $\mathrm{a}_{2}$ rich fuel which can be burnt in the gas turbine combustor free of any carbon emissions [7]. The traditional pre-combustion train consists of two adiabatic reactors in which $\mathrm{CO}$ reacts with steam following Eq. 1 to produce $\mathrm{H}_{2}$ and $\mathrm{CO}_{2}$. The WGS reaction is exothermic, and equilibrium to the products side of the reaction is favoured at low temperatures. For this reason, the bulk CO conversion is reached in the first packed bed reactor (High Temperature Shift or HTS) with a sharp adiabatic temperature rise, and after an interstage cooling generating steam for the bottoming cycle, higher overall conversions are attained in the second reactor (Low Temperature Shift or HTS). A key feature of the shift conversion unit is the high steam requirement at the reactor inlet, which is provided by extracting some IP steam from the steam turbine HP stage outlet. The steam to CO ratio must be high enough to ensure that no catalyst carbiding and subsequent methanation occurs due to the high temperature rise. In this work, all models assume a steam to $\mathrm{CO}$ ratio of 1,9 on a molar basis, consistent to the values reported in [6]. The HTS inlet temperatures were fixed at a value between $250-300^{\circ} \mathrm{C}$ and the LTS feed was at $200^{\circ} \mathrm{C}$. A pressure drop of approximately 1 bar was specified for each bed. A temperature pinch of $10^{\circ} \mathrm{C}$ was assumed in the heat recovery network. 
The product stream consists primarily of $\mathrm{CO}_{2}$, remaining unconverted $\mathrm{CO}, \mathrm{H}_{2}$ and excess of steam. The stream is cooled down in a series of recuperative heat exchangers which generate hot water for the saturator and the upstream evaporator. A limited amount of heat can be extracted, and the remaining is rejected to the ambient to reach the absorption temperature of $25-30^{\circ} \mathrm{C}$. A unit as the ones described in 3.5 is used to remove $\mathrm{CO}_{2}$ while the $\mathrm{H}_{2}$ product gas (around $90 \% \mathrm{~mol}$ ) is routed back to the shift unit were a saturator (modelled with 1-3 ideal equilibrium stages) increases the moisture content and is further heated to the required fuel temperature. The $\mathrm{N}_{2}$ from the ASU is also introduced in the saturator to increase the water content, thereby allowing a safe combustion of the fuel with low NOx formation. A brief schematic of the shift unit is given in Figure 64:

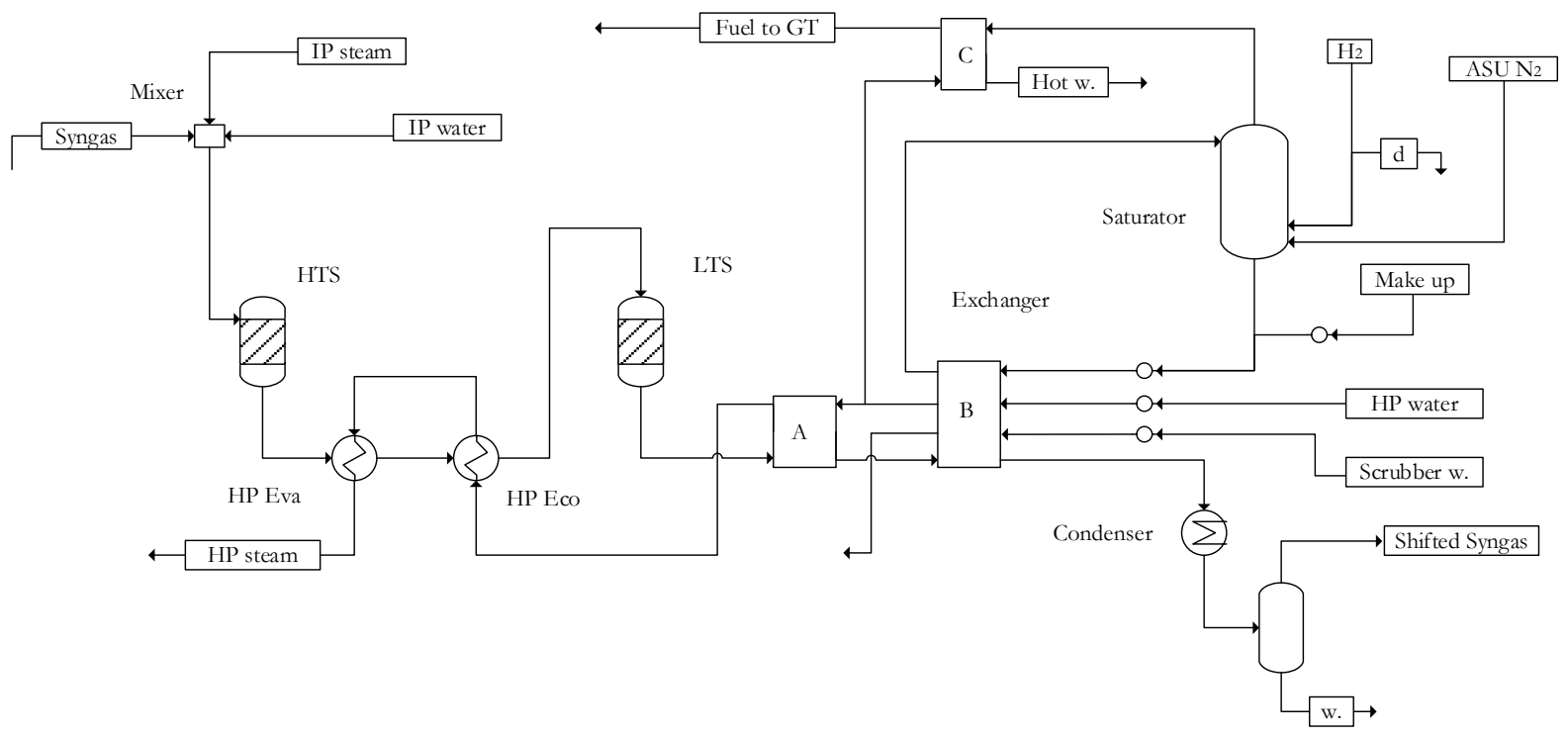

Figure 64 Schematic of the WGS unit with saturator and heat recovery units

The integration in the process flowsheet has subtle differences depending on each power plant concept, but essentially all contain the elements described in above.

\subsubsection{Membrane Assisted Water Gas Shift}

The WGS reaction (Eq. 1) is employed to transform the carbon intensive fuel delivered by a coal gasifier to a $\mathrm{H}_{2}$ rich fuel which can be burnt in a gas turbine avoiding an exhaust flow containing a diluted amount of $\mathrm{CO}_{2}$. WGS imposes an energy penalty as the reaction is exothermic, degrading the fuel at a relatively low temperature. Further cooling of the syngas after shift for $\mathrm{CO}_{2}$ removal with absorption as explained in section 3.5.1 increases the energy loss and removes water when condensed.

In order to prevent this loss, the Membrane Assisted Water Gas Shift (MAWGS) reactor can be employed. This consists of a packed bed reactor with a Palladium-based membrane [86] which selectively removes $\mathrm{H}_{2}$ from the reaction medium. $\mathrm{N}_{2}$ from the ASU or steam can be used as sweep gas in the permeate to increase the diffusion of $\mathrm{H}_{2}$ through the membrane, by reducing its partial pressure in the permeate stream. Alternatively, steam from the bottoming cycle at different pressure levels can be employed, although this strategy imposes a large energy penalty. Since a product of the reaction is removed and the sweep gas provides refrigeration to the exothermic reaction, the overall conversion of the bed is increased, compared to an adiabatic packed bed reactor operation described in the previous section. Alternatively, the permeate side can be operated at low pressures with no sweep gas, to obtain a pure $\mathrm{H}_{2}$ stream. The high mechanical integrity of the membrane allows it to withstand high pressure gradients. However, this results in 
an extra power consumption needed to pressurize the $\mathrm{H}_{2}$ product to fuel delivery pressures in case it is used in a GT combustor.

\section{MAWGS Model Description}

The reactor concept proposed to model the MAWGS is a plug flow reactor with heat effects and product diffusion. To determine outlet conditions of the reactor products the conservation of energy and mass equations are used applied to a differential of reactor height (or catalyst weight) as shown in Figure 65. The balances are applied to the section of the membrane between $\mathrm{z}$ and $\mathrm{z}+\Delta \mathrm{z}$, considering that a membrane heat resistance, resulting in a permeate and retentate stream at different temperatures for each reactor section. Since the kinetic expressions are expressed as a function of catalyst mass, the catalyst density \& weight fraction and bed voidage must be used to express the balances in terms of each differential of height.

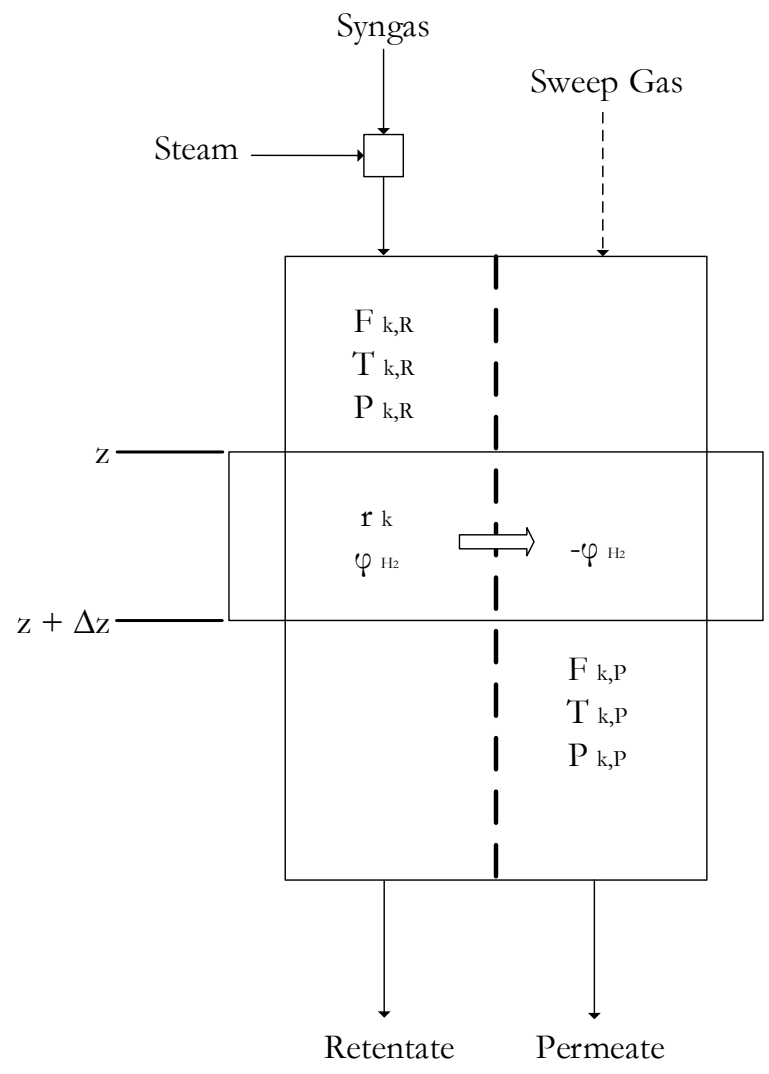

Figure 65 Plug flow reactor with membrane

The following equations show the steps undergone to perform the mass and energy balance in generalized form assuming the reactor operates under stationary conditions. They are applied to the retentate (syngas) and permeate (sweep gas \& $\mathrm{H}_{2}$ ) section, considering that the sweep gas is fed countercurrently to the syngas (contrary to what is shown in Figure 56). Applying the first principle to a differential of tube reactor volume (Eq. 2) under stationary conditions using molar flows of species $f_{k}$ results in Eq. 68:

$$
0=\dot{Q}^{\prime} \Delta z+\left.\sum h_{k} f_{k}\right|_{z}-\left.\sum h_{k} f_{k}\right|_{z+\Delta z}
$$

The heat flux per unit of length $\dot{Q}^{\prime}$ is calculated as shown below, using the expression for the heat flux $\dot{Q}^{\prime \prime}$ and surface to volume relation: 


$$
\begin{gathered}
\dot{Q}=\dot{Q}^{\prime \prime} d A=\dot{Q}^{\prime \prime} d A * \frac{d V}{d V}=U\left(T_{P}-T_{R}\right) \frac{\pi h d_{t}}{\frac{\pi h d_{t}^{2}}{4}} d V=U\left(T_{P}-T_{R}\right) \frac{4}{d_{t}} d V=\dot{Q}^{\prime \prime \prime} d V \\
\dot{Q}^{\prime}=U\left(T_{P}-T_{R}\right) \frac{4}{d_{t}} \frac{\pi d_{t}^{2}}{4}=U\left(T_{P}-T_{R}\right) \pi d_{t}
\end{gathered}
$$

Where $T_{P}$ and $T_{R}$ are the sweep gas (permeate $\mathrm{P}$ ) and reaction (retentate $\mathrm{R}$ ) section temperatures at each point, while $d_{t}$ is the outer tube diameter and $\mathrm{h}$ is the total tube length. A particular case of adiabatic membrane (with an overall heat transfer coefficient $U=0$ ) can be considered. If the heat resistance is assumed negligible, then the same temperature is attained at each side, which will tend to cool down the reaction section faster increasing the CO conversion (due to the exothermic nature of the WGS reaction). If we develop the balance expression and particularize for each section, changing the sign of the heat transfer for the permeate side we reach Eq. 69:

$$
\begin{aligned}
\dot{Q}^{\prime}=\frac{\partial \sum h_{k} f_{k}}{\partial z} & =\sum h_{k} \frac{\partial f_{k}}{\partial z}+\sum f_{k} \frac{\partial h_{k}}{\partial z}=\sum h_{k} \frac{\partial f_{k}}{\partial z}+\sum f_{k} c_{p, k} \frac{\partial T}{\partial z} \\
\frac{\partial T_{R}}{\partial z} & =\frac{-\sum h_{k, R} \frac{\partial f_{k, R}}{\partial z}+U \pi d_{t}\left(T_{P}-T_{R}\right)}{\sum f_{k, R} c_{p k, R}} \\
\frac{\partial T_{P}}{\partial z} & =\frac{-\sum h_{k, P} \frac{\partial f_{k, P}}{\partial z}+U \pi d_{t}\left(T_{P}-T_{R}\right)}{\sum f_{k, P} c_{p k, P}}
\end{aligned}
$$

To determine the term $\frac{\partial f_{k}}{\partial z}$, the molar balances in steady state must be applied to permeate and retentate sections. For that purpose, the rates of diffusion and reaction must be expressed in their corresponding units. Analogously to heat flux, the diffusion flux $\phi_{k}^{\prime \prime}$ can be expressed as:

$$
\phi_{k}=\phi_{k}^{\prime \prime} d A=\phi_{k}^{\prime \prime} d A * \frac{d V}{d V}=\phi_{k}^{\prime \prime} \frac{4}{d_{t}} d V
$$

An expression for $\phi_{k}^{\prime \prime}$ can be found in [87] for a Pd-based membrane. It is applicable to $\mathrm{H}_{2}$, which is the only component that diffuses (Eq. 70). Infinite perm-selectivity of the membrane is an acceptable assumption which has been validated expermientally [88].

$$
\begin{gathered}
\phi_{k}^{\prime \prime}=\frac{P_{0}}{t_{m}} e^{\left(\frac{-E_{a}}{R T}\right)}\left(P_{k, R}^{0.74}-P_{k, P}^{0.74}\right) \\
P_{0}=4,24 * 10^{-10} \frac{\mathrm{mol}}{\mathrm{ms} \mathrm{Pa} a^{0.74}} t_{m}=5 * 10^{-6} \mathrm{~m} E_{a}=5180 \frac{\mathrm{J}}{\mathrm{mol}}
\end{gathered}
$$

On the other hand, the reaction rate can be determined using the values given in [89] for the power law exponents, as a function of the partial pressure of the components and their stoichiometric coefficients $v_{k}$ as shown in Eq. 71:

$$
\begin{gathered}
r_{k}=v_{k} k P_{C O}^{a} P_{C O 2}^{b} P_{H 2}^{c} P_{H 2 O}^{d}\left(1-\frac{P_{H_{2}} P_{C O_{2}}}{K_{e q, W G S} P_{C O} P_{H_{2} O}}\right) \\
k=A_{0} e^{\left(\frac{-E_{a}}{R_{g} T}\right)}
\end{gathered}
$$




$$
A_{0}=10^{2,845} \mathrm{~mol} \mathrm{~s}^{-1} \mathrm{~g}^{-1} \mathrm{kPa}^{-(a+b+c+d)} E_{a}=-111 \mathrm{~kJ} / \mathrm{mol}
$$

The equilibrium constant is temperature dependent (pressure does not influence the equilibrium as there is no mole variation in the chemical reaction) and are obtained from Eq. 72 [90]:

$$
\ln K_{e q, W G S}=\frac{4577,8}{T}-4,33
$$

The rate of reaction is given in $\mathrm{mol} / \mathrm{s}$ per $\mathrm{g}$ of catalyst, and is applicable for an iron based high temperature shift catalyst. The rate of reaction is expressed per unit of reactor volume, considering the membrane density $\rho_{s}$, catalyst weight fraction $w_{c}$ and tube voidage $\varepsilon$ as shown:

$$
r_{k}^{\prime \prime \prime}=r_{k} \rho_{s} w_{c}(1-\varepsilon)
$$

Consequently, the stationary mass balance (no mass accumulation) for component $k$ results:

$$
\begin{gathered}
0=\frac{\pi d_{t}^{2}}{4} \Delta z\left(r_{k} \rho_{s} w_{c}(1-\varepsilon)-\frac{4}{d_{t}} \phi_{k}^{\prime \prime}\right)+\left.f_{k}\right|_{z}-\left.f_{k}\right|_{z+\Delta z} \\
\frac{\partial f_{k}}{\partial z}=r_{k} \rho_{s} w_{c}(1-\varepsilon) \frac{\pi d_{t}^{2}}{4}-\pi d_{t} \phi_{k}^{\prime \prime}
\end{gathered}
$$

Particularized to each section, considering that no reaction takes place in the permeate side, yields Eq. 73, which corresponds to the molar flow variations of each component per unit of reactor length required to solve the energy balance:

$$
\begin{gathered}
\frac{\partial f_{k, R}}{\partial z}=r_{k, R} \rho_{s} w_{c}(1-\varepsilon) \frac{\pi d_{t}^{2}}{4}-\pi d_{t} \phi_{k, R}^{\prime \prime} \\
\frac{\partial f_{k, P}}{\partial z}=-\pi d_{t} \phi_{k, R}^{\prime \prime}
\end{gathered}
$$

Other reaction kinetics can be used to model the WGS reaction, but caution should be taken to adapt the balance equations with the corresponding units. When the sweep gas (permeate) is introduced in the reactor co-currently, the opposite sign of the terms $\frac{\partial f_{k, P}}{\partial z}$ and $\dot{Q}^{\prime}$ must be taken when applying the balance equations, since the subsequent section contains a smaller flow rate of the diffused species. The reactor model has also implemented the possibility of considering the steam methane reaction (SMR) when this component is present. However, because of the low operating temperatures (Maximum membrane temperature set to $600^{\circ} \mathrm{C}$ ) and the endothermicity of steam reforming, this reaction is shifted towards methane reactant. It is assumed that the reaction proceeds to equilibrium [91], determined with Eq. 74 and calculated with the partial pressure of the respective reaction components.

$$
\ln K_{e q, S M R}=\frac{-26830}{T}+30,114
$$

The major modelling assumptions for the MAWGS are detailed in Table 27:

Table 27 MAWGS reactor modelling assumptions

\begin{tabular}{|c|c|c|}
\hline Item & Value & Units \\
\hline Membrane heat transfer coefficient & 200 & $\mathrm{~W} / \mathrm{m}^{2} \mathrm{~K}$ \\
\hline $\mathrm{N}^{\circ}$ of tubes & 6000 & - \\
\hline
\end{tabular}




\begin{tabular}{|c|c|c|}
\hline Tube height & 10 & $\mathrm{~m}$ \\
\hline Tube diameter & 0,05 & $\mathrm{~m}$ \\
\hline Retentate side $\Delta \mathrm{P}$ & 200 & $\mathrm{kPa}$ \\
\hline Permeate side $\Delta \mathrm{P}$ & 20 & $\mathrm{kPa}$ \\
\hline Membrane void fraction & 0,5 & - \\
\hline Membrane density & 5240 & $\mathrm{~kg} / \mathrm{m}^{3}$ \\
\hline Catalyst weight fraction & 50 & $\%$ \\
\hline Maximum membrane temperature & 600 & ${ }^{\circ} \mathrm{C}$ \\
\hline
\end{tabular}

\section{Model Implementation in Scilab}

To obtain the output molar flows of the MA-WGS reactor a code in Scilab has been developed. The solver must solve the mass and energy differential equations derived previously. A matrix vector is used where the first 16 rows correspond to the molar flows (in mol/s) of each of the components $\left(\mathrm{N}_{2} \mathrm{O}_{2} \mathrm{Ar} \mathrm{CO}_{2} \mathrm{H}_{2} \mathrm{O} \mathrm{CO} \mathrm{H} \mathrm{CH}_{4}\right)$ through the reactor length for the permeate and retentate streams. Rows 17 and 18 contain the respective temperatures, and rows 19 and 20 are the tube side pressures. A linear pressure drop is assumed to simplify calculations although a more detailed pressure drop correlation to obtain an accurate profile can be derived from the Ergun equation as shown in [57]; it does not alter substantially the results as the equilibrium is not pressure dependant and the absolute pressures are very high relative to the pressure drops assumed. A slight difference will be noted in the diffusion flux, but the improvement of the model in this direction is left for future work.

The differential equations require an initial boundary condition, at the beginning of the reactor (tube) length. When the reaction stream flows counter currently to the sweep gas, it is necessary to assume the outlet conditions of the sweep gas stream. In particular, the sweep gas (permeate) outlet temperature, pressure and hydrogen molar flow rate in that stream must be assumed. The remaining molar flows of the rest of species do not change with respect to the inlet, and can be set to the original values. The code must iterate in such a way that the boundary conditions assumed for the ODE yield an inlet temperature (considered at the reactor length) of this stream equal to that provided by the stationary process simulation. Furthermore, the $\mathrm{H}_{2}$ molar flow at the sweep gas inlet must be zero, as there is no presence of this component in the $\mathrm{N}_{2}$ delivered by the ASU or the steam used as sweep gas. The differential equations must be solved iteratively to reach the solution, which can cause significant convergence issues when the initial assumptions are very far away from the final solution.

Analogously to the GS transient model described in section 2.3, the MAWGS model in Scilab is coupled to the stationary process flowsheet in UniSim. The reactor dimensions can also be controlled from the stationary process flowsheet. The ideal gas assumptions within the Scilab code cause energy balance errors of less than $0.2 \%$ with respect to the enthalpy balance predicted by UniSim using Peng Robinson EOS.

The structure of the code is as follows: after loading workspace \& properties in WGS_main script, the console runs PFR_fun function, which calculates the difference between the specified values of sweep gas inlet and those obtained from solving the stiff ODE of the PFR_dif function, and solved iteratively with the function fsolve until the differences become zero. The ODE is solved providing an updated feed stream as boundary condition by means of the function feeds. Within the ODE, the diffusion and reaction rates are calculated with the function rates, which require the 
vector of molar flows, temperatures and pressures at each reactor length. The complete code is provided in

The model has flexibility to operate counter or co-currently, to deactivate the membrane at a specified reactor section, inhibit the chemical reaction or eliminate heat transfer effects at choice of the user. Operation of the reactor with cocurrent stream feeding is numerically more manageable. A correct design, operation and optimization of the reactor is a required step to integrate it in the stationary power plant model with appealing results both from an electric efficiency point of view and from a $\mathrm{H}_{2}$ production perspective, minimizing the membrane area for such purposes, resulting in a lower cost.

\section{Model Reactor Profiles}

In this section, a brief illustration of the model profiles is given. A detailed description of the integration of this unit with the IGCC power cycle is provided in the power plant concepts presented in section 4.2. Although it is acknowledged that this particular unit operation could be the subject of a very extensive study, only two cases are presented corresponding to the power plant models shown in sections 4.2.4 and 4.2.6:

- Case A: Operation with no sweep gas and a syngas composition from a Shell gasifier, with a pressure of 39,9 bar at MAWGS inlet, using 6000 membrane tubes and Permeate pressure fixed at 3 bar.

- Case B: A case where $\mathrm{N}_{2}$ from the ASU at 37 bar is used as sweep gas with a syngas obtained from a GE gasifier with water quench at 73,2 bar, using 3000 membrane tubes.

Operation with cocurrent sweep gas is discarded as it allows to extract less $\mathrm{H}_{2}$ relative to the countercurrent mode. The temperature and partial pressure reactor section profiles for Case $\mathrm{A}$ are presented in Figure 66. The composition profile and the cumulative $\%$ of $\mathrm{H}_{2}$ flow at each reactor with respect to the total outlet is given in Figure 67:

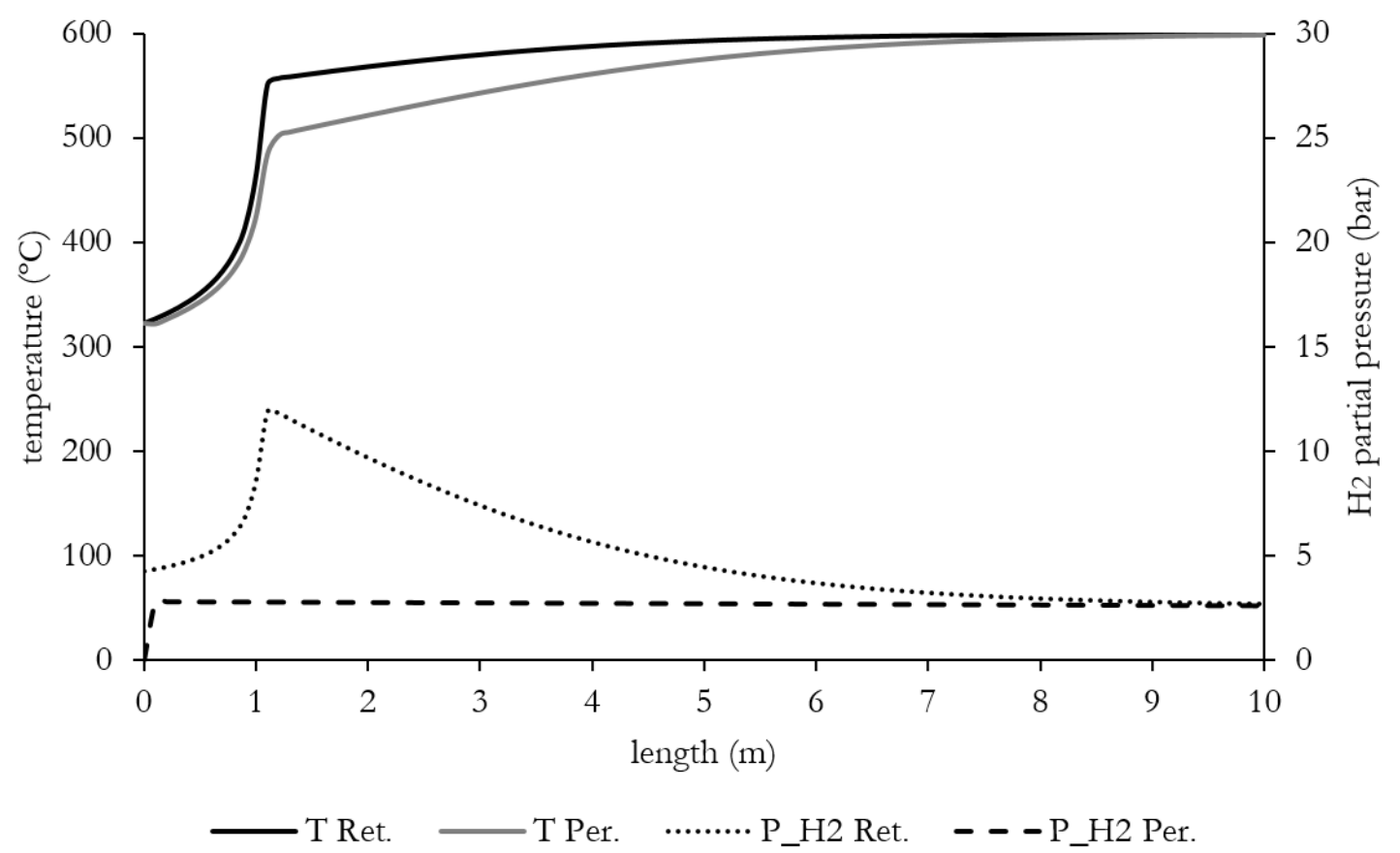

Figure 66 MAWGS reactor temperature and pressure profile for Case A 
Notably, due to the fixed permeate pressure operation, the $\mathrm{H}_{2}$ partial pressure remains constant. The retentate $\mathrm{H}_{2}$ partial pressure increases substantially at the beginning of the tube due to the exothermic reaction proceeding very rapidly, and equalizes to the permeate value as the CO species is spent and $\mathrm{H}_{2}$ diffuses. The temperatures reach the maximum allowable value quite rapidly, which suggests that in actual practice an adiabatic bed will be placed beforehand for bulk conversion followed by the membrane doped with catalyst for $\mathrm{H}_{2}$ extraction, to avoid potential issues that such temperature gradient would cause on the mechanical stability of the membrane. The composition profile shows that $90 \%$ of the $\mathrm{H}_{2}$ flow rate is achieved at $60 \%$ of the reactor length, manifesting the relevance of the partial pressure as a driving force for $\mathrm{H}_{2}$ diffusion.

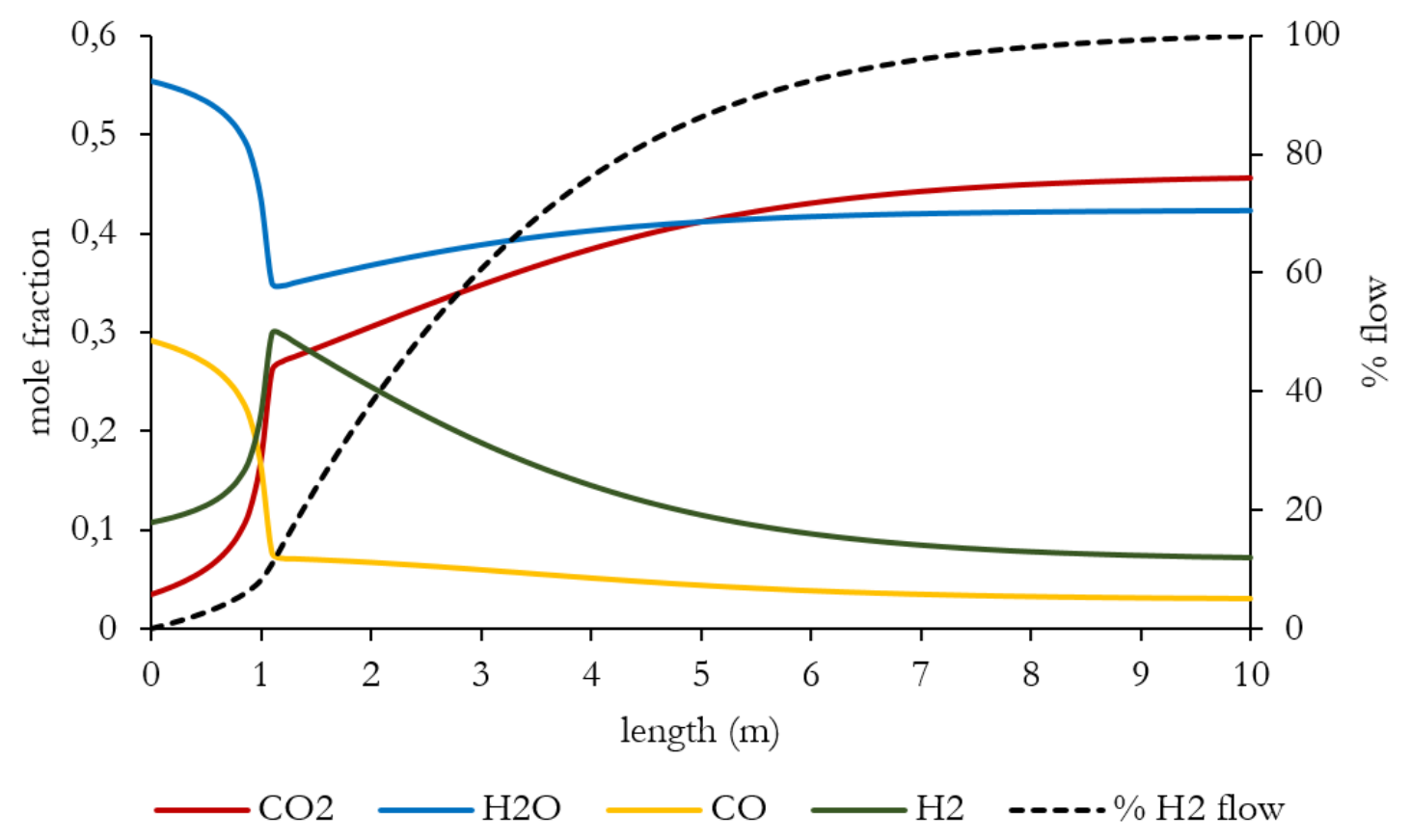

Figure 67 MAWGS reactor composition profile for Case A

For Case B, the temperature and pressure profiles shown in Figure 68 reveal the attractiveness of using a pressurized $\mathrm{N}_{2}$ sweep gas stream. The high pressure on both sides results in a high driving force for $\mathrm{H}_{2}$ diffusion, allowing a higher reaction rate across the reactor length. Furthermore, the cold sweep gas refrigerates the reactor boosting the CO conversion. It can be seen that at the end of the reactor the $\mathrm{H}_{2}$ mole fraction also drops to very low levels, extracting most of the syngas heating value in the permeate stream, as shown in Figure 69. The $\mathrm{H}_{2}$ permeation is uniform across the reactor length, and the maximum temperature is only reached locally.

On the downside, the $\mathrm{H}_{2}$ outlet is not obtained pure, so it cannot be sold as a product, but could potentially be used as fuel for a GT. Since the fuel is already diluted to a great extent in $\mathrm{N}_{2}$, this combustion won't cause high emission of $\mathrm{NOx}$ in a diffusive flame combustor. Alternatively, steam could be used as a sweep gas medium to retrieve pure pressurized $\mathrm{H}_{2}$ after condensation, but this would impose a substantial efficiency penalty in the bottoming cycle from which the stream is extracted. 


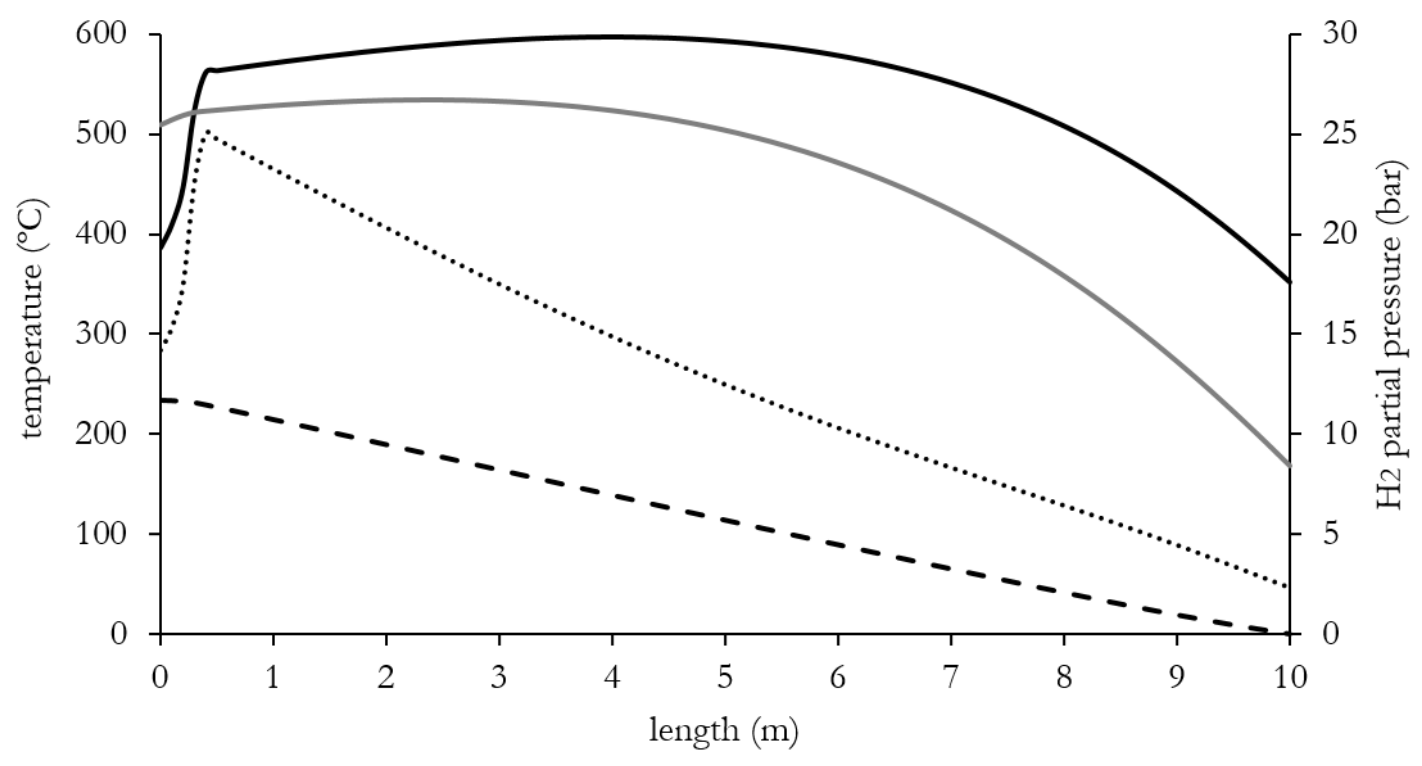

- T Ret. $\longrightarrow$ T Per.

P_H2 Ret. - - - P_H2 Per.

Figure 68 MAWGS temperature and pressure profile for Case B

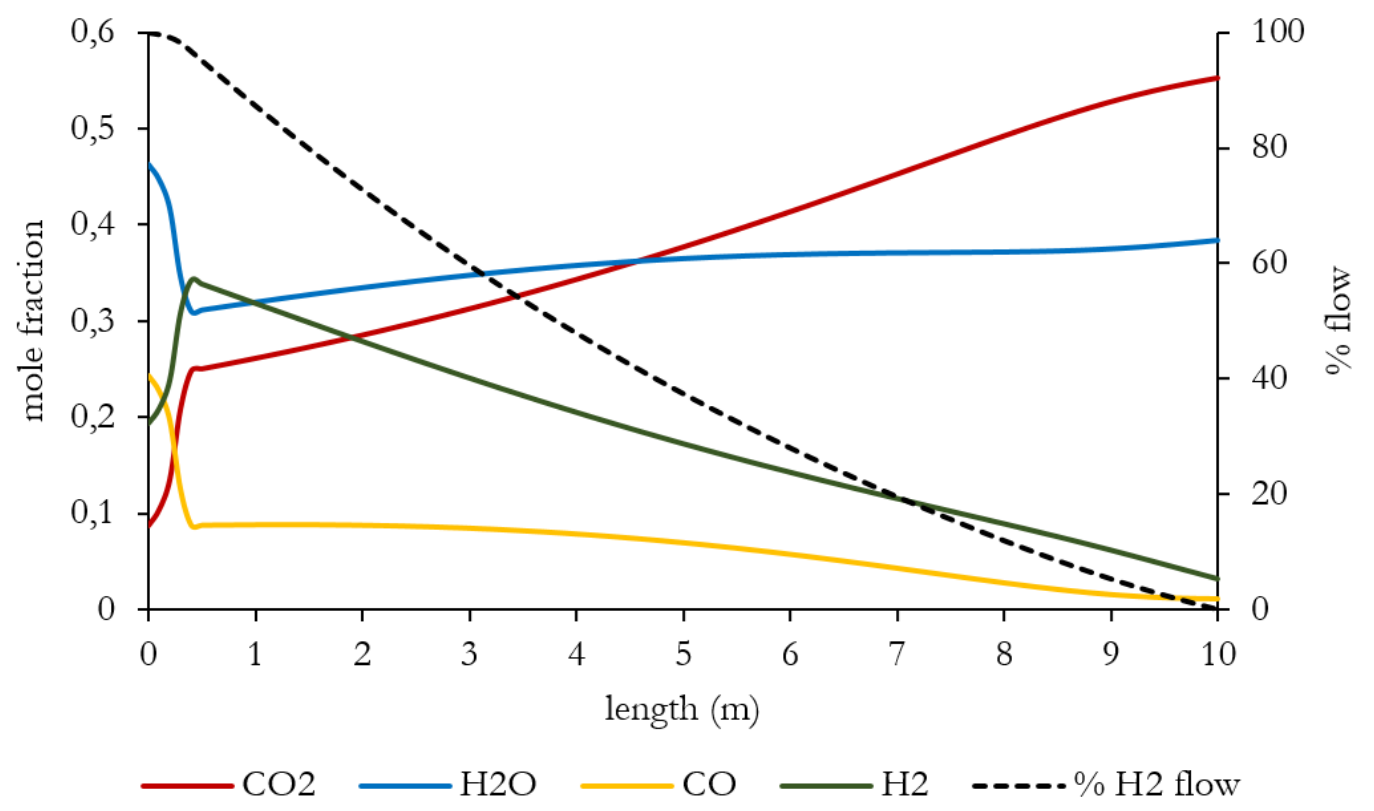

Figure 69 MAWGS composition profile for Case B

Without delving excessively into the particularities of each case (for instance Case B syngas has a higher $\mathrm{H}_{2} / \mathrm{CO}$ ratio as it is a slurry feed gasification system), an insightful conclusion can be extracted from Figure 70 regarding the $\mathrm{H}_{2}$ recovery and CO conversion of Case $\mathrm{B}$ relative to Case A for half the reactor surface. This results already foreshadows the attractiveness of the very high in the slurry fed gasificaiton system to mazxmize heating value retrieval in the form of $\mathrm{H}_{2}$ in the membrane reactors. 


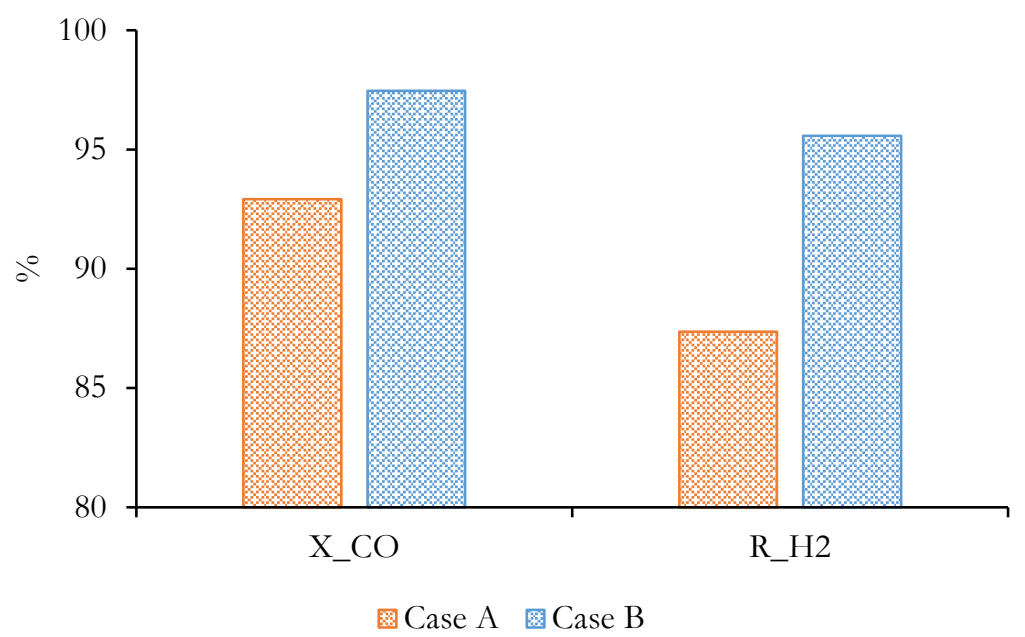

Figure $70 \mathrm{CO}$ conversion and $\mathrm{H}_{2}$ Recovery of the MAWGS for Case A and Case B

\section{5 $\mathrm{CO}_{2}$ Extraction}

In this section, a brief description is provided of the standard $\mathrm{CO}_{2}$ removal technologies using physical and chemical solvents. When the partial pressure of $\mathrm{CO}_{2}$ is high, the solvent regeneration duty of the physical solvents will be preferred. Finally, a thorough description of the process employed to selectively remove $\mathrm{CO}_{2}$ and $\mathrm{H}_{2} \mathrm{~S}$ selectively and simultaneously is provided.

\subsection{1 $\quad \mathrm{CO}_{2}$ Physical \& Chemical Absorption}

The reference physical solvent employed for $\mathrm{CO}_{2}$ removal is Selexol, an acid gas removal solvent which is made up of dimethyl ethers and polyethylene glycol. Secondly, the reference chemical solvent unit is Methyl-diethanoleamine (MDEA), a tertiary amine which reacts with the protons generated by the $\mathrm{CO}_{2}$ species (hydrolysis) when it dissolves in the solution (even at low partial pressures) allowing a higher capture degree relative to only physical absorption.

\section{Selexol Absorption Unit}

The basic Selexol unit treating desulphurized syngas consists of an absorption tower simulated with 10 equilibrium stages to determine the solvent circulation duty, fixing the solvent flow rate at a point where a certain fraction of the $\mathrm{CO}_{2}$ is captured (typically $90 \%$ ) or alternatively a certain methane recovery in the clean syngas stream. The loading capacity of the solvent is determined with the Henry's law, which can be approximated to a linear dependency between the solute partial pressure and the degree of solvent loading. An appropriate estimation of the Henry constants is mandatory to reflect an accurate performance. In Unisim, such constants are implemented following a Van't Hoff approximation with two parameters for each component $\mathrm{k}$ as described in Eq. 75:

$$
\ln K_{k}=A_{k}+\frac{B_{k}}{T}=C+\left(\frac{-\Delta H_{r}}{R T}\right)
$$$$
\text { Eq. } 75
$$

The values for A and B for several species are shown in Table 28, and were taken from [69], where it is revealed that these parameter values match the experimental results much better than the Unisim default model. The Peng Robinson equation of state is still used to determine the fugacity of each component in the vapour phase, whereas that of the liquid phase results from applying $f_{k}^{L}=K_{k} x_{k}$, where $x_{k}$ is the molar fraction in the liquid phase. 
Table 28 Henry's Constant parameters for different components

\begin{tabular}{|c|c|c|}
\hline Component & $\mathbf{A}_{\mathbf{k}}$ & $\mathbf{B}_{\mathbf{k}}$ \\
\hline $\mathrm{CO}_{2}$ & 13,828 & $-1720,0$ \\
\hline $\mathrm{H}_{2} \mathrm{~S}$ & 13,678 & $-2297,2$ \\
\hline $\mathrm{H}_{2}$ & 12,402 & 0 \\
\hline $\mathrm{CH}_{4}$ & 16,531 & $-1720,0$ \\
\hline $\mathrm{CO}$ & 17,403 & $-1720,0$ \\
\hline $\mathrm{N}_{2}$ & 17,740 & $-1720,0$ \\
\hline
\end{tabular}

Once the loaded solvent exists the bottom of the absorber, it is regenerated in a series of flash vessels, as depicted in Figure 71. The pressure levels are selected to minimize the compression duty while simultaneously retrieve combustible species that have been partially absorbed $\left(\mathrm{CO}, \mathrm{H}_{2}\right.$ and $\mathrm{CH}_{4}$ ). The entrainment of these components is relatively small, since methane has one tenth of the solubility relative to $\mathrm{CO}_{2}$. However, due to the large solvent flow, the total amount can become significant.

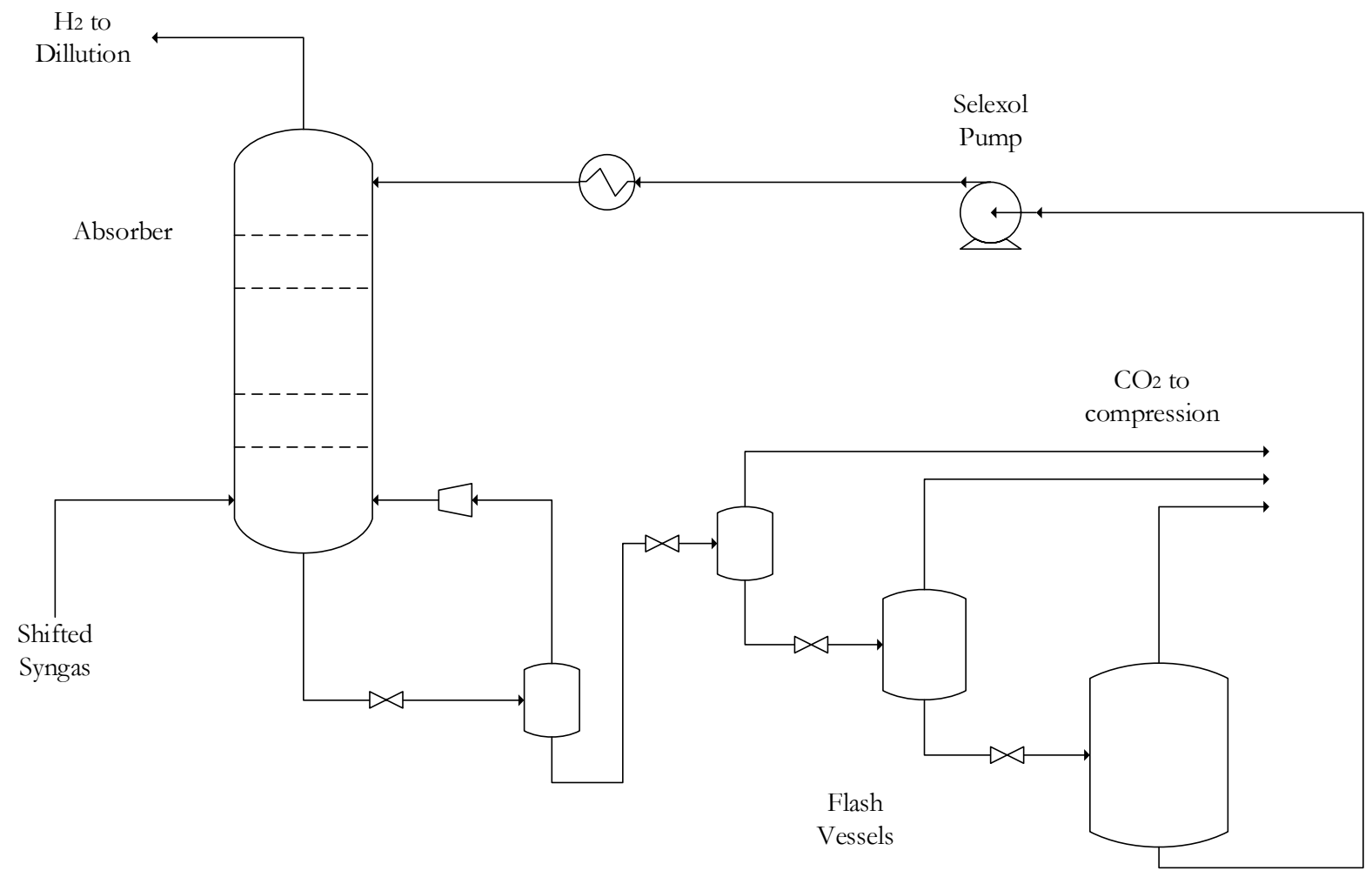

Figure 71 Schematic of a Selexol absorption unit

A key advantage of this technology is that no energy in the form of steam is required for solvent regeneration. Potentially, the capture efficiency can be improved if refrigeration is used at the cost of higher auxiliary consumption.

\section{MDEA Absorption unit}

Alternative to the Selexol plant, when the partial pressure of $\mathrm{CO}_{2}$ in the syngas becomes too low, an amine chemical solvent is employed. MDEA is useful as a bulk $\mathrm{CO}_{2}$ removal solvent and has the lowest regeneration duty requirements with respect to other amines (MEA, DEA), which allows to minimize the energy penalty. The absorption model is a simplification assuming theorical 
equilibrium stages using a DRB Amine thermodynamic property package from Unisim to determine the different chemical reactions taking place in the amine species using 12 equivalent trays in the absorber and imposing a stage efficiency of 35\% as specified in [92]. It is acknowledged that detail mass and energy transfer calculations should be done to realistically determine the actual column height, but the current approach is sufficient to determine the energy consumption (electrical and thermal), which resulted in similar values to the literature references. The process flow sheet is similar to the configuration discussed in [93], and is depicted in Figure 69:

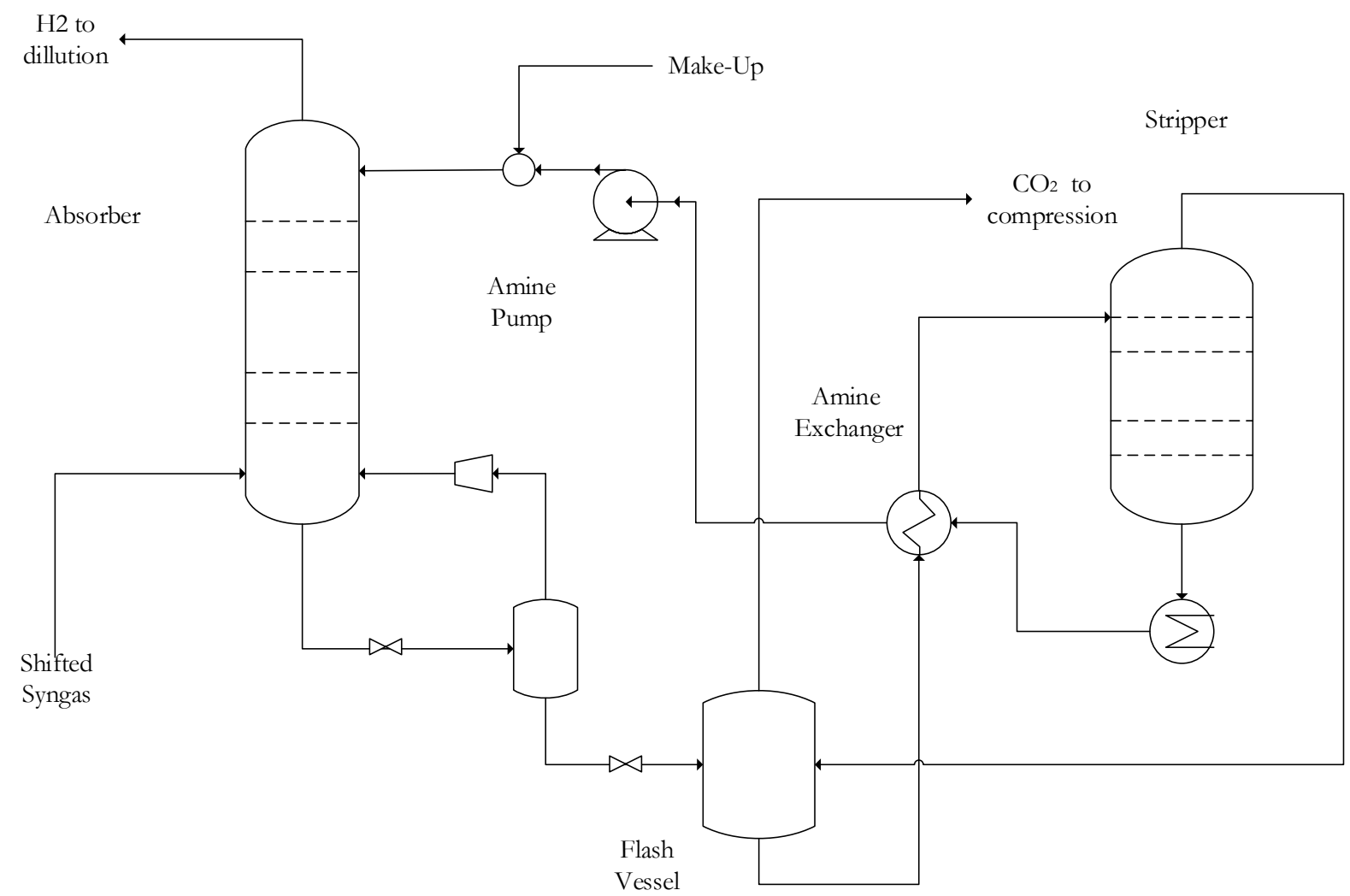

Figure 72 Amine (MDEA) absorption process

The main modelling assumptions used in the process unit above are summarized in Table 29:

Table 29 Modelling assumptions for MDEA absorption unit

\begin{tabular}{|c|c|c|}
\hline Equipment/Item & Value & Units \\
\hline Lean Amine Loading & 1 & $\%$ \\
\hline Equilibrium Stages & 12 & - \\
\hline Stage Efficiency & 35 & $\%$ \\
\hline Amine Exchanger Pinch & 5 & ${ }^{\circ} \mathrm{C}$ \\
\hline Absorber Pressure Drop & 0,5 & bar \\
\hline Stripper Pressure & 1,25 & bar \\
\hline Steam Pressure & 1,8 & bar \\
\hline Solvent \%w, MDEA & 50 & $\%$ \\
\hline Solvent Pump Isentropic Efficiency & 80 & $\%$ \\
\hline
\end{tabular}

The flow of solvent was adjusted to reach a reference value of $95 \% \mathrm{CO}_{2}$ capture from the syngas stream. Absorption with MDEA was only implemented in one of the power plants as an alternative to physical absorption capture. 


\subsubsection{Dual $\mathrm{H}_{2} \mathrm{~S}$ and $\mathrm{CO}_{2}$ Absorption}

For power plant concepts where hydrogen sulphide is not removed prior to $\mathrm{CO}_{2}$ extraction (such as in plants with a sour WGS), a dual stage sequential $\mathrm{H}_{2} \mathrm{~S} / \mathrm{CO}_{2}$ removal process is designed suing Selexol as absorbent. The process line-up [69] entails substantial complexity and the main objective is to determine the auxiliary consumption of solvent pumping/ recycle compressors and the thermal steam demand for solvent regeneration in the $\mathrm{H}_{2} \mathrm{~S}$ stripper unit. A schematic of the process flowsheet developed in Unisim is provided in Figure 73:

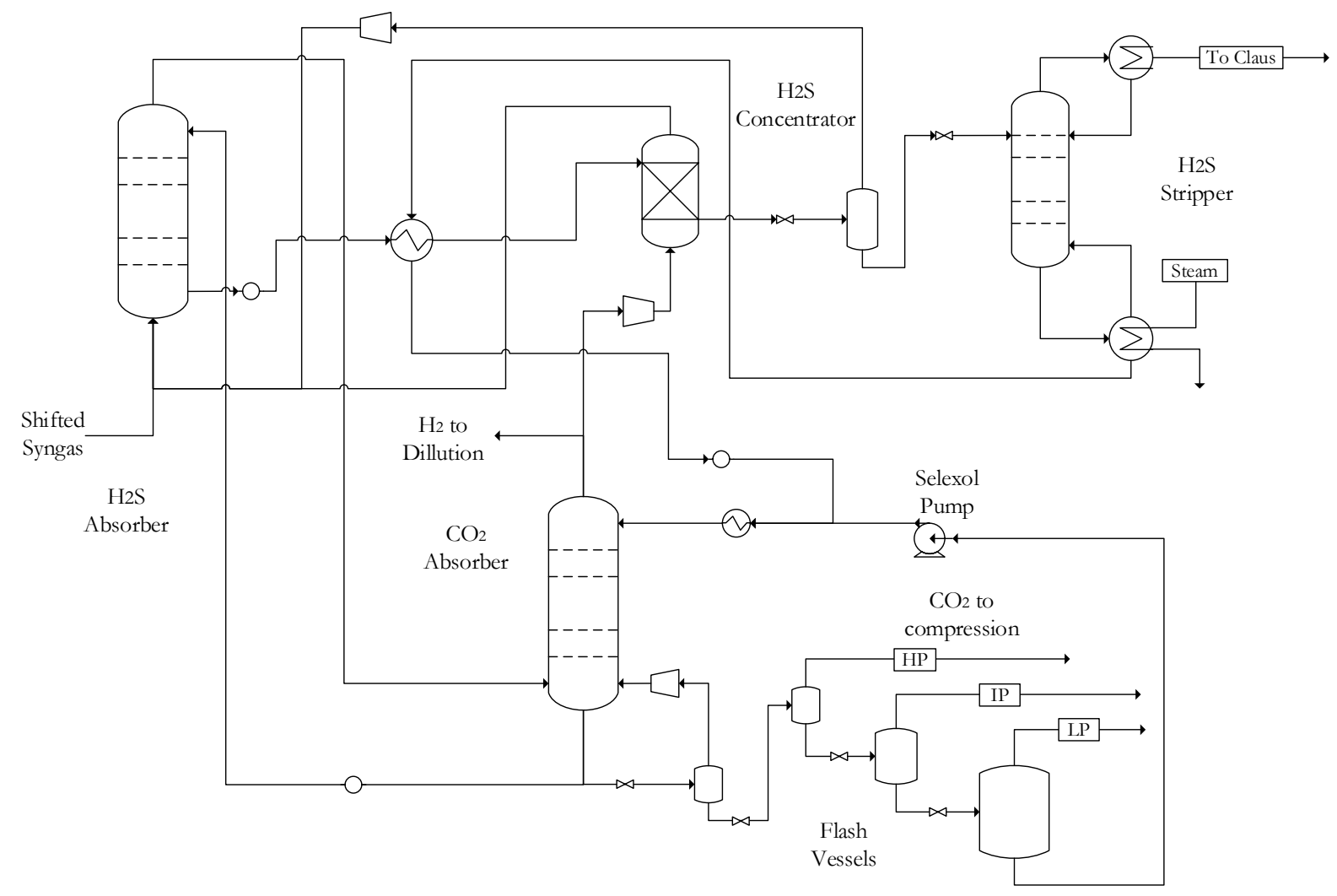

Figure 73 Dual $\mathrm{H}_{2} \mathrm{~S} / \mathrm{CO}_{2}$ Selexol absorption unit

The main process assumptions are given in Table 30, and are also applied to the $\mathrm{CO}_{2}$ standalone absorption unit described in the previous section where required.

Table 30 Modelling assumptions of the Selexol unit

\begin{tabular}{|c|c|c|}
\hline Equipment/Item & Value & Units \\
\hline Absorber temperature & 25 & ${ }^{\circ} \mathrm{C}$ \\
\hline$\%$ Syngas to $\mathrm{H}_{2} \mathrm{~S}$ concentrator & 20 & $\%$ \\
\hline$\%$ mol $\mathrm{H}_{2} \mathrm{~S}$ to Claus unit & $>25$ & $\%$ \\
\hline $\mathrm{H}_{2} \mathrm{~S}$ in $\mathrm{CO}_{2}$ compressed & $<20$ & $\mathrm{ppm}$ \\
\hline Recycle compressors isentropic efficiency & 80 & $\%$ \\
\hline Lean $-\mathrm{H}_{2} \mathrm{~S}$ laden solvent exchanger pinch & 5 & ${ }^{\circ} \mathrm{C}$ \\
\hline Pressure levels HP/MP/LP & $6 / 2,5 / 1$ & $\mathrm{bar}$ \\
\hline Solvent pump isentropic efficiency & 80 & $\%$ \\
\hline
\end{tabular}

The Claus sulphur recovery unit is not modelled in this assessment. 


\subsubsection{Gas Switching Combustion (GSC)}

Alternatively to the absorption technologies described earlier (which also required a prelaminar syngas shifting step), a GSC cluster can be employed to extract the $\mathrm{CO}_{2}$ species during the combustion of the syngas fuel. This has been earlier referred to as inherent carbon capture. The stationary process unit to represent an averaged performance of the GSC cluster cycle was already presented in section 2.5.2. In Figure 74, different integration possibilities are also presented with the objective of showing the flexibility opportunities that the GSC can present. Namely, the reduction gases outlet can be used in a recuperator to transfer the heat to the incoming air (or fuel streams) by means of a recuperator. Alternatively this stream can be expanded in a reduction gases expander. On the other hand, the $\mathrm{O}_{2}$ depleted air stream outlet can be routed to an extra firing chamber where the addition of some natural gas (or syngas bypass) fuel can allow to reach higher TIT to maximize thermodynamic efficiency.

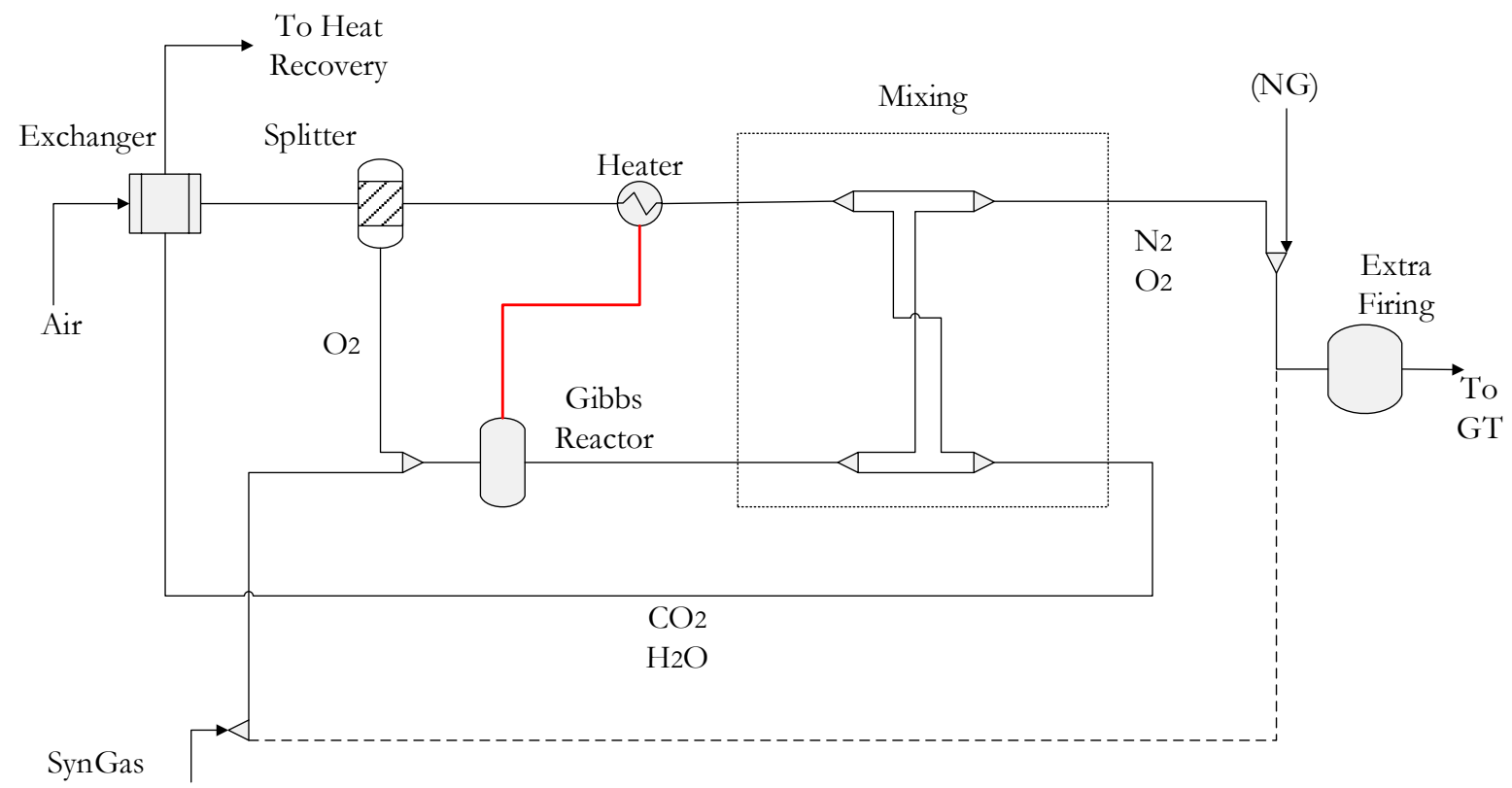

Figure 74 GSC with reduction gases heat recovery and/or extra firing chamber

The process parameters employed to simulate the heat exchange recuperator elements are a 20 $30^{\circ} \mathrm{C}$ minimum temperature approach and a relatively low pressure drop of approximately $1 \%$. Resulting heat exchanger effectiveness were approximately $90 \%$, while the absolute pressure drops assumed ranged between $10-20 \mathrm{kPa}$. Due to the high GSC temperatures, adequate construction materials must be employed for these units [94]. No radiation effects were considered in any of the models.

\subsection{Topping Power Cycle}

The topping cycle refers to the thermodynamic cycle whereby electricity is produced from burning a fuel at high temperature, typically following the Brayton cycle described in section 1.3.2, which uses air as working fluid. In this section, the characteristics of the reference natural gas turbines are presented, with a description of how they have been adapted to run with a syngas $/ \mathrm{H}_{2}$ fuel, and the modelling simplifications undertaken.

To evaluate power plant process concepts, two generic gas turbine models representative of different technology levels have been used. The F-class machine is illustrative of a heavy duty GT with many operating hours and well established in the power market. It can be considered as a 
"proven" technology, provided that adaptations for optimal and efficient operation with fuels different to natural gas must still be carried out. Typical combined cycle efficiencies reach $58 \%$ on a lower heating value basis. On the other hand the H-class GTs are highly efficient machines with comparatively bigger net power outputs operating at higher temperatures and gas throughputs, resulting in combined cycle efficiencies surpassing $60 \%$.

\subsubsection{F-class Gas Turbine}

The standard F-class turbine described in [6] is the baseline for the topping power cycle performance of the introductory plants. A natural gas fired model was calibrated in Unisim to meet the specifications of this turbomachine, which are described in Table 31 and are consistent for advanced turbine technology parameters given in [28].

Table 31 F-class GT reference values

\begin{tabular}{|c|c|c|}
\hline Item & Value & Units \\
\hline COT & 1440 & ${ }^{\circ} \mathrm{C}$ \\
\hline TIT & 1360 & ${ }^{\circ} \mathrm{C}$ \\
\hline TOT & 603,0 & ${ }^{\circ} \mathrm{C}$ \\
\hline Open Cycle efficiency & 39,0 & $\%$ \\
\hline Pressure Ratio & 18,1 & - \\
\hline Net power output & 280 & MW \\
\hline
\end{tabular}

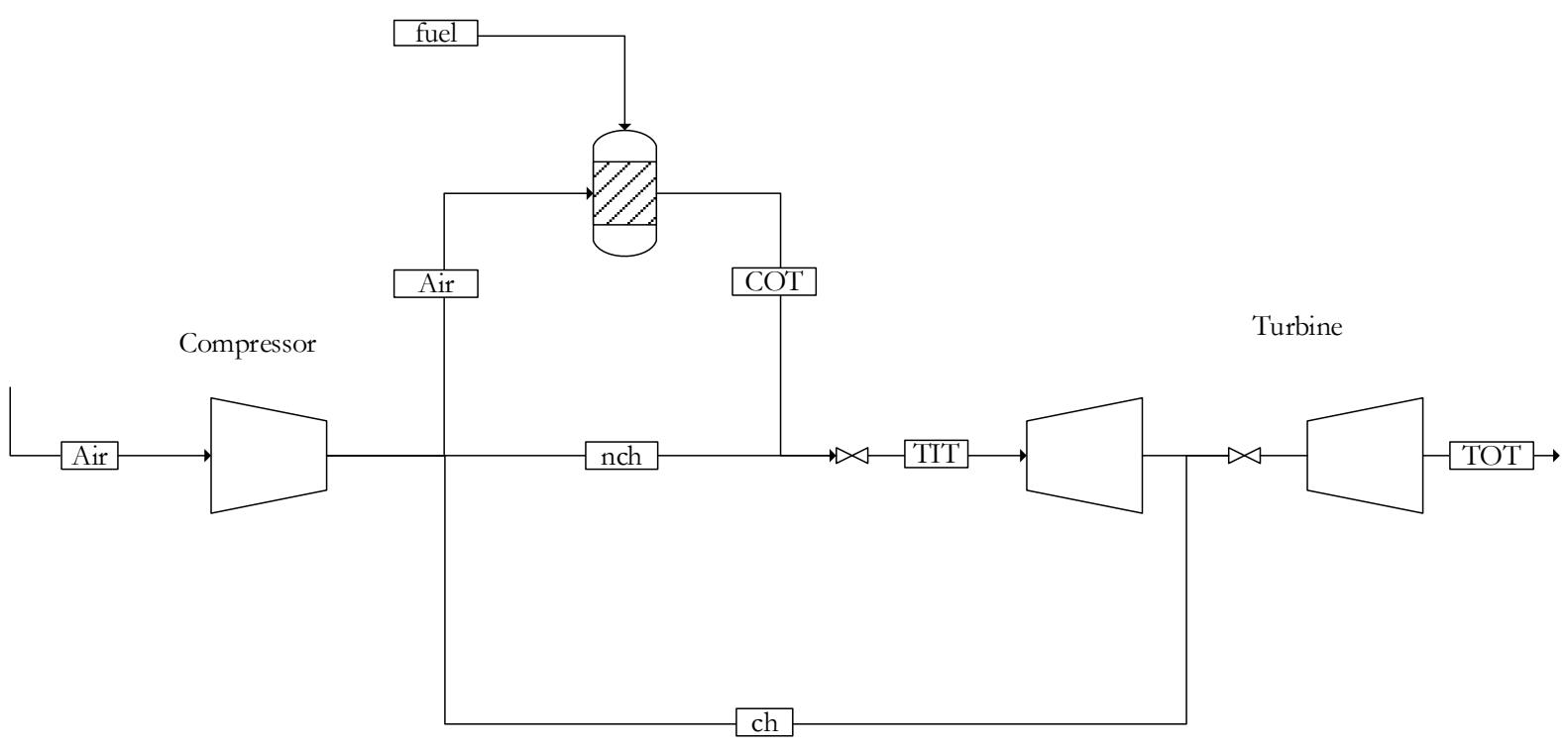

Figure 75 Reference GT model with cooling flows

The process model flow diagram used for the GT is depicted in Figure 75. There are several degrees of freedom that are specified in the simplified model to reach the operating values that are listed in Table 31. These are summarized in Table 32. The total air flow is set to reach the required COT, while the non-chargeable (stator) cooling air is manipulated to reach the specified TIT. On the other hand, the chargeable (rotor) cooling air is set to achieve the TOT, and finally the total natural gas heat input is varied to reach the GT net power output of $280 \mathrm{MW}$. The turbomachinery component polytropic efficiencies are adjusted to reach the required open cycle efficiency. 
Table 32 Specified model assumptions of reference NG GT

\begin{tabular}{|c|c|c|}
\hline Item & Value & Units \\
\hline Mechanical efficiency & 99,86 & $\%$ \\
\hline Generator efficiency & 98,70 & $\%$ \\
\hline Combustor pressure drop & 3 & $\%$ \\
\hline Air filter pressure drop & 1 & $\%$ \\
\hline Discharge overpressure in open cycle & 1 & $\mathrm{kPa}$ \\
\hline Expansion stages & 3 & - \\
\hline Fuel temperature & 200 & ${ }^{\circ} \mathrm{C}$ \\
\hline Stator blade temperature & 850 & ${ }^{\circ} \mathrm{C}$ \\
\hline Rotor blade temperature & 825 & ${ }^{\circ} \mathrm{C}$ \\
\hline
\end{tabular}

The results of the model calibration of the nominal design point are summarized in Table 33. Usually, the gas turbine (expander) is operated under choked conditions in the first nozzle, with the dimensionless mass flow rate being constant and defined previously by Eq. 57 . The specific work of the GT is defined as the net duty delivered per kg of compressed air.

Table 33 Reference GT model calibration results

\begin{tabular}{|c|c|c|}
\hline Item & Value & Units \\
\hline Compressor polytropic efficiency & 91,0 & $\%$ \\
\hline Expander polytropic efficiency & 87,0 & $\%$ \\
\hline Air flow intake & 655,2 & $\mathrm{~kg} / \mathrm{s}$ \\
\hline Chargeable cooling air (ch.) & 61,0 & $\mathrm{~kg} / \mathrm{s}$ \\
\hline Non-chargeable cooling air (nch.) & 53,4 & $\mathrm{~kg} / \mathrm{s}$ \\
\hline Specific work & 427,3 & $\mathrm{~kJ} / \mathrm{kg}$ \\
\hline TIT ISO & 1283 & ${ }^{\circ} \mathrm{C}$ \\
\hline cooling air/combustion gases & 19,4 & $\%$ \\
\hline $\mathrm{m}_{\mathrm{R}}$ & 10,47 & - \\
\hline $\mathrm{b}_{\mathrm{s}}$ & 0,08541 & - \\
\hline $\mathrm{b}_{\mathrm{r}}$ & 0,07145 & - \\
\hline
\end{tabular}

A cooling flow model is in place if it is required to recalculate the cooling flows to stator and rotor for a different hot gas composition (while maintaining the same cooling technology). This cooling flow model is based on the work done in [95], but amplified to predict to a reasonable extent the different cooling flows (to stator: $\dot{m}_{s}$ and to rotor: $\dot{m}_{r}$ ), using the technology parameters $b_{s} \& b_{r}$

$$
\begin{aligned}
& \frac{\dot{m}_{s} \bar{c}_{p, s}}{\dot{m}_{g} \bar{c}_{p, g}}=b_{s} \frac{\left(T_{g, i}-T_{b l, s}\right)}{\left(T_{b l, s}-T_{s, i}\right)} \\
& \frac{\dot{m}_{r} \bar{c}_{p, r}}{\dot{m}_{g} \bar{c}_{p, g}}=b_{r} \frac{\left(T_{g, i}-T_{b l, r}\right)}{\left(T_{b l, r}-T_{r, i}\right)}
\end{aligned}
$$

Where $\bar{c}_{p}$ is the average specific heat capacity of the stream between the inlet temperature to the stage $T_{g, i} T_{s, i}$ and $T_{r, i}$ (for hot gas or coolant streams respectively) and the maximum allowable blade temperature $T_{b l}$ (either stator or rotor). The rotor cooling flow (chargeable) is introduced after $1 / 3$ of the total expansion has taken place, while the coolant temperature is the same as the compressor discharge temperature and the hot gas temperature at the stator inlet corresponds to 
the TOT, whereas as to the rotor it is the TIT. The pressure drop losses that occur due to mixing of hot gas and coolant streams are determined with Eq. 68, using $\mathrm{k}$ as 0.07 , as recommended in [96] and $\varphi$ is the ratio between coolants to hot gas mass flow rate.

$$
\frac{\Delta p}{p}=k \varphi
$$

For off design operation of the compressor, a parametric compressor curve from Thermoflex [97] is introduced to re-adjust the pressure ratio to the required value, as show in Figure 76 . This is a typical problem when dealing with higher volumetric flow fuels with a lower calorific value than natural gas (such as syngas), where the reduced air intake requires an increase of the pressure ratio and/or a decrease of the COT. The pertinent variations take place to operate the turbine at the same dimensionless mass flow rate in the expander as in the nominal design operation and within the surge margin of the compressor [74]. For this to happen, both the COT must decrease and the pressure ration must increase.

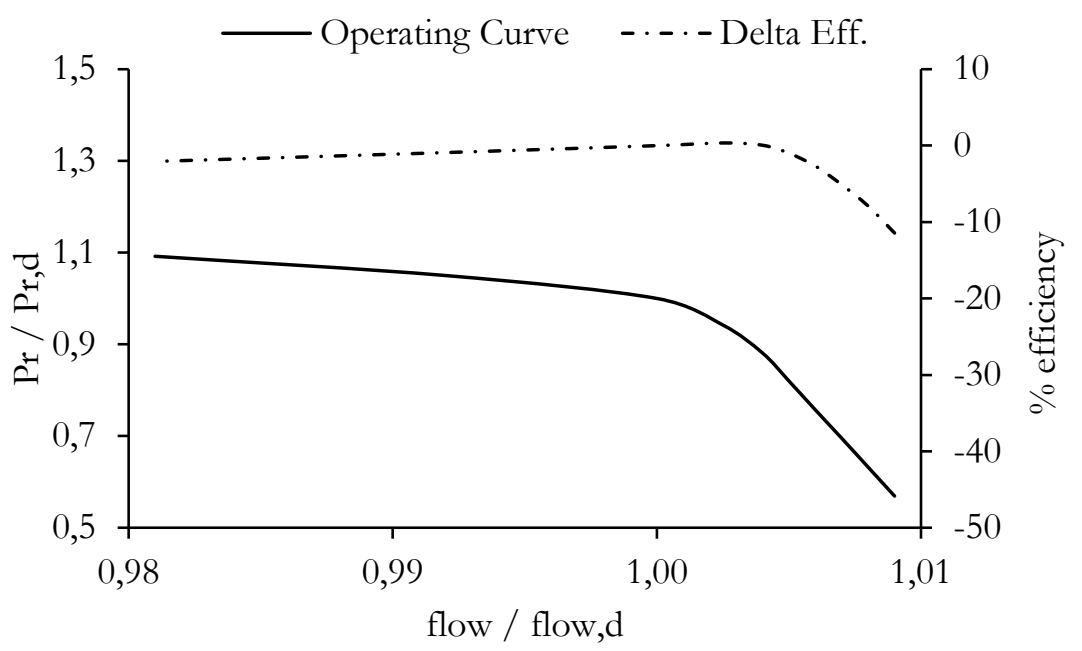

Figure 76 Compressor operating curve with efficiency and pressure ratio changes at different inlet flows. Design point is indicated with $\mathrm{d}$

\subsubsection{H-class Gas Turbine}

The H-class GT used to model the "advanced" power plants in this assessment is representative of the technology described in [28] for these machines. The H-class GT has a substantially higher net power output than the F-class counterpart and is capable of reaching higher combustion temperatures thanks to an improved blade cooling technology with thermal barrier coatings using advanced materials and film blade cooling. The main characteristics of the $\mathrm{H}$-class turbine for a reference natural gas fired case are provided in Table 30.

Table 34 H-class GT reference values

\begin{tabular}{|c|c|c|}
\hline Item & Value & Units \\
\hline COT & 1648 & ${ }^{\circ} \mathrm{C}$ \\
\hline TIT & 1550 & ${ }^{\circ} \mathrm{C}$ \\
\hline TOT & 641 & ${ }^{\circ} \mathrm{C}$ \\
\hline Simple cycle efficiency & 43,0 & $\%$ \\
\hline Pressure ratio & 23,6 & - \\
\hline Rated Power & 520 & $\mathrm{MW}$ \\
\hline
\end{tabular}


The H-class turbine has also been modelled in Unisim based on these reference values for a natural gas fired operation, with an additional cooling flow stream representative of the stage cooling after the first rotor and stator, and considering that the expander has 4 stages. The simulation of the gas turbine in the power plants using H-class technology was performed by Paolo Chiesa from Politecnica di Milano, and the tool developed in Unisim was only used for verification. The GS code employed in the Energy Department from that institution has been extensively used in previous research works and can accurately predict GT performance [34, 98].

\subsubsection{Modified Gas Turbine}

The GT coupled to a GSC cluster has very different operating characteristics with respect to the reference GT described in the previous section, since the cluster operating temperature is limited to a maximum of $1200^{\circ} \mathrm{C}$. Given the same fuel heat input and pressure ratio, this lower equivalent combustor outlet temperature will result in a comparatively higher mass flow rate across the GT. On the other hand, because of the lower temperatures across the first expansion stages, the cooling flow requirements will be substantially lower. In order to capture these effects to an appropriate extent, a modified gas turbine model using stator cooling and neglecting rotor cooling was elaborated, based on correlations from [96]. This assumption is acceptable provided the significantly lower temperatures across the expansion path. The model preserves the same component polytropic efficiencies shown obtained from the calibration in Table 29, and the applicable modelling assumptions described in Table 28. Figure 77 presents a schematic of the main elements of a GT integrated to a GSC cluster.

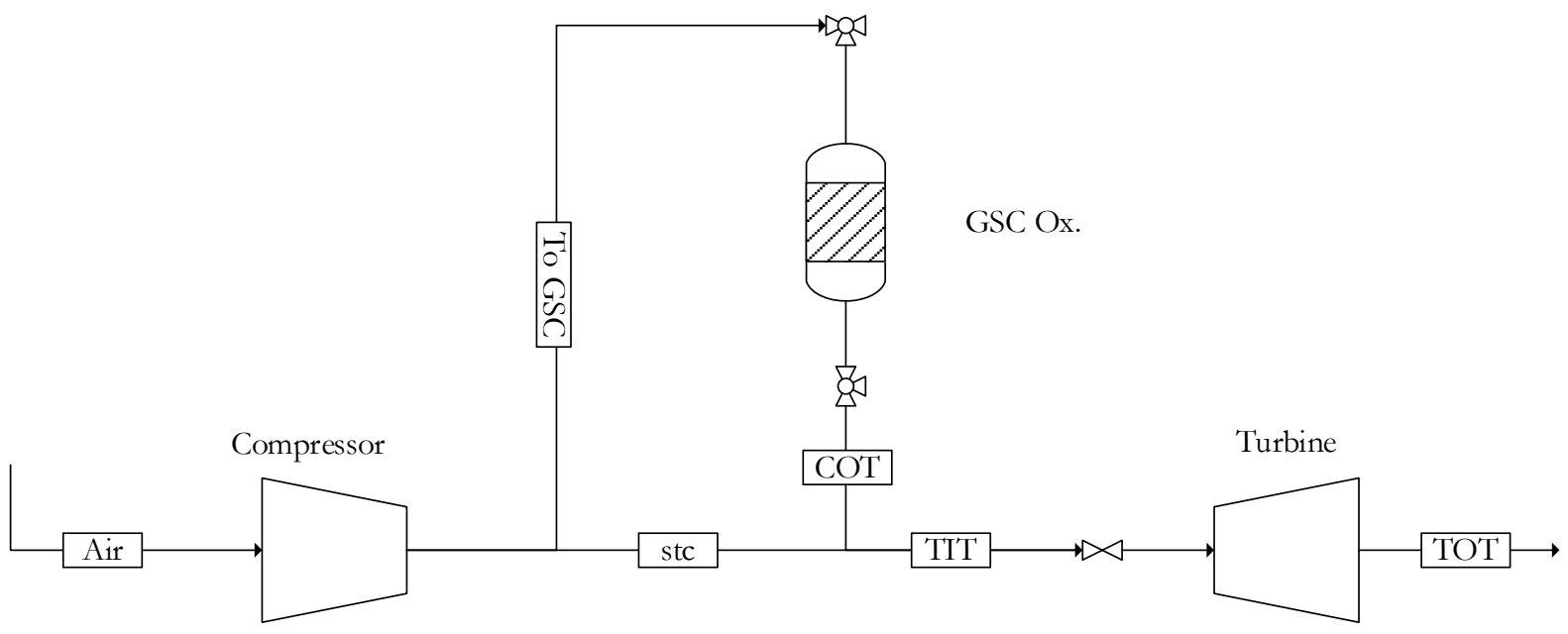

Figure 77 GT model integrated with GSC cluster

The expression employed to determine the stator cooling flow in this model is taken from [96] and shown in Eq. 78 , using $\mathrm{K}=0.05$. The blade maximum allowable temperature $T_{b l}$ was as assumed at a value of $850^{\circ} \mathrm{C}$.

$$
\varphi=K \frac{T_{g}-T_{b l}}{T_{b l}-T_{c}}
$$

The GT is also operated at the same pressure ratio as the reference natural gas fired GT, since this parameter has relatively a small impact on the combined cycle efficiency over a wide range (as shown in [71]) and the steam cycle was operated at constant pressure levels. 


\subsubsection{Syngas $/ \mathrm{H}_{2}$ Gas Turbine}

The reference F-class turbine is operated using syngas fuel or $\mathrm{H}_{2}$ (with $\mathrm{N}_{2}$ or steam added for appropriate dilution) using diffusive flame combustors, due to the challenges of using premixed combustors, typical of natural gas fired applications [34]. In particular, since more air than stoichiometric is fed in premixed combustors, it is troublesome to maintain flame stability due to the higher flame speed of $\mathrm{H}_{2}$ and the larger flammability limits (relative to methane).

The main concern when burning $\mathrm{H}_{2}$ / syngas is the increase of NOx emissions, directly related to the stoichiometric flame temperature (SFT), given the fact that $\mathrm{H}_{2}$ and $\mathrm{CO}$ have a higher adiabatic flame temperature and higher reactivity than $\mathrm{CH}_{4}$. Diffusive flame combustors (with close to stoichiometric air feed in the combustion zone) are used by burning a fuel which has been diluted with $\mathrm{N}_{2}$ or steam. The degree of dilution with steam or $\mathrm{N}_{2}$ in diffusion burners is fixed to obtain an SFT in the range of 2200-2300K, which is representative of NOx emissions [99]. The consequences of fuel dillution for the plant and the GT are several:

- If $\mathrm{N}_{2}$ is used because it is available from the ASU, a dedicated compressor to reach the required fuel pressures is necessary. This intercooled stage compression is somewhat less efficient than the adiabatic GT compressor (considering that the approximately the same amount of air would be compressed if the fuel were not diluted). If steam is used, extraction from the bottoming cycle has an important energy penalty due to flashing and mixing with the fuel, and steam injection to the topping cycle produces power less efficiently than direct expansion in the steam turbine. The interconnection between the process units also results in process constraints that lead to a decreased operational flexibility and availability.

- Operating the turbine with a syngas $/ \mathrm{H}_{2}$ fuel results in a decreased air intake in the compressor (for choked expander operation) relative to natural gas that must be compensated by increasing the pressure ratio and/or reducing the COT (consequently TIT) to restore the operating point within the compressor operating map surge margin. Use if IGV can allow to an extent to operate with reduced volumetric air intake with low performance penalties. Alternatively, to compensate the reduced air demand, the ASU can be partially integrated with the GT compressor in such a way that typically $50 \%$ of the ASU air demand is provided from the GT unit (higher integration values can result in a large decrease in availability and reliability).

- Thermodynamically, an increased concentration of water in the combustion products results in an increased enthalpy drop upon expansion, which may require the addition of an extra expansion stage. On the other hand, a larger water (and $\mathrm{CO}_{2}$ ) presence increases the heat transfer coefficient of the hot gas path which results in a higher cooling air requirement to keep the blade temperature profile similar to the natural gas fired case. As a consequence, this results not only in a faster thermal barrier coating degradation but effectively in a lower TIT, needed to maintain the material integrity of the blade, which results in a decreased thermodynamic efficiency.

The approach followed to evaluate the performance of the GT using $\mathrm{H}_{2} /$ Syngas (for instance in "introductory" benchmark plants) was the following, based on previous simplifying assumptions used in literature studies [71, 100] under the "advanced" GT scenario where sufficient technological developments have taken place to allow low heating value fuel's combustion in the GT: 
1. The compressor operating point is adjusted by regulating the air intake. The nominal pressure ratio and efficiencies are preserved. This assumes that IGV operation or compressor reengineering has taken place. Despite this, 50\% ASU air integration for some plants was still performed to make these assumptions more plausible. Nominal operation by compressor air intake regulation is also assumed for cases with a GS cluster coupled to an extra firing chamber, where the extraction of $\mathrm{O}_{2}$ moles from the air stream in the GSC should also influence the compressor-turbine matching for a machine which was not conveniently adapted. The fuel dilution is accomplished in all plants with $\mathrm{N}_{2}$ if available. The syngas after contaminant removal is firstly saturated with water to make use of the low temperature heat in the syngas cooling system as described in sections 3.4.2 and 3.4.4. The higher moisture content of the fuel reduces therefore the integration requirements with the ASU.

2. The blade cooling technology elements have been developed to allow GT operation at the reference COT and TIT. In that sense, the stator cooling flow is resultant from the imposed operating temperatures and the rotor cooling flow is calculated by maintaining the same coolant to hot gas fraction as in the natural gas fired reference turbine. Given the relatively low blade metal temperatures, COT and TIT which are representative of the Fclass GT compared to the improved performances of material coatings and high operating temperatures of the most modern GT, this extra demand for syngas $/ \mathrm{H}_{2}$ operation considering the deployability timeframe for the GS clusters and other technological step outs (such as membrane reactors and high temperature desulphurization) that are considered to be realized.

Finally, Figure 78 illustrates the various integration opportunities of the gas turbine using $\mathrm{H} 2 /$ Syngas as fuel regarding the generation of a hot gas stream for expansion, the different fuel dilution options and other system's integration potential such as GSC and natural gas extra firing.

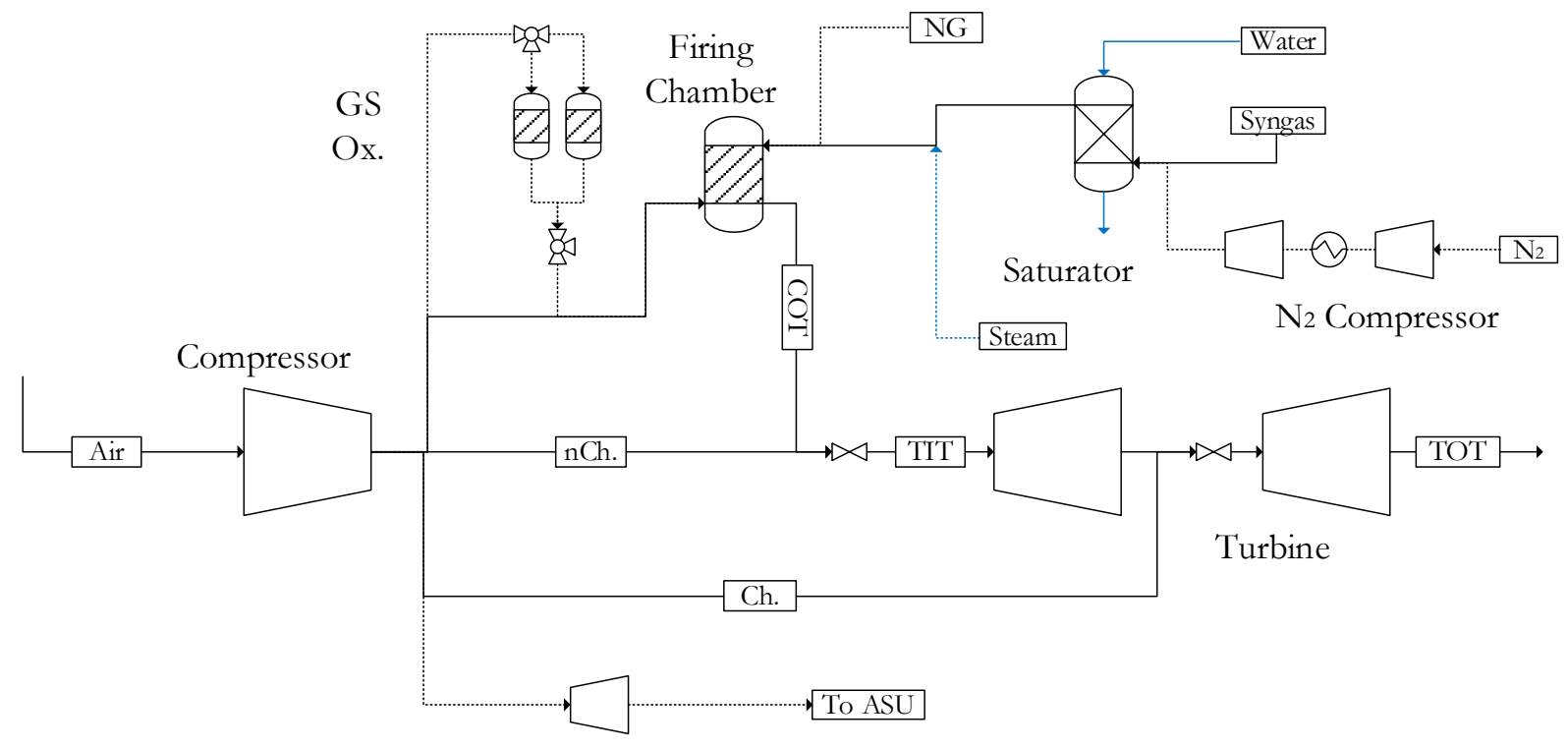

Air Expander

Figure 78 Block flow diagram of the Syngas $/ \mathrm{H}_{2}$ fired gas turbine. Blue lines indicate water/steam streams. Dotted lines indicate potential integration options 


\subsubsection{Humid Air Turbine}

An interesting application that has received substantial research attention in the last decades is the humid air turbine (HAT) as an alternative to the bulky elements of the bottoming steam cycle. Indeed, in this configuration, based in the process configuration described in [101, 102] amongst others, the mass flow rate across the expansion turbine is increased using a saturator. The compression is performed in two intercooled stages, generating hot water for the saturator unit. The expanded gas in the turbine is cooled down in a recuperator, heating up the saturator gaseous outlet. Further heat is removed from the expanded stream by generating more hot water in an economizer. This cycle (in particular with sequential combustion) achieves efficiencies which are potentially above than in a conventional combined cycle configuration [103]. For the simple configuration though, the HAT cycle cannot compete with the efficiencies reached in large combined cycle power plants. Successful commercialization of this technology has not taken place up to date, although several studies indicate its high potential in the medium size power market [102, 104]]. HAT cycle have a better efficiency when operating under part load, with a lower environmental footprint in terms of NOx emissions due to the large amount of water in the air stream. In terms of costs, the reheated cycle can result in up approximately $30 \%$ lower electricity costs for a $40 \mathrm{MW}$ power output cycle. A schematic of the HAT cycle is depicted in Figure 79.

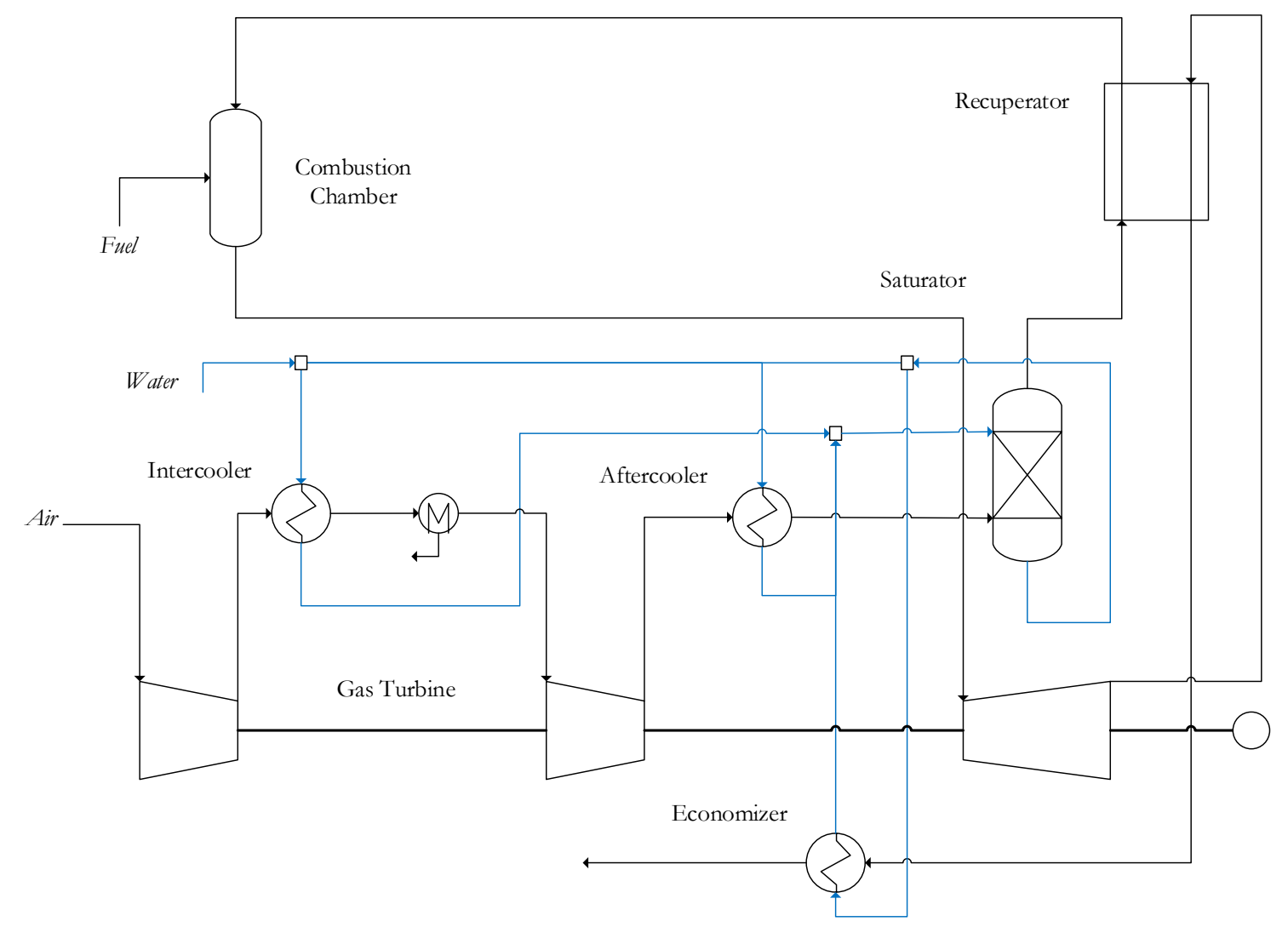

Figure 79 HAT cycle configuration. Blue lines indicate water streams

The implementation of the HAT cycle coupled to a GSC cluster is a study that was performed using the modelling assumptions detailed in Table 35. The heat exchanger pressure drops and temperature approaches, as well as saturator design have optimistic values with respect to some literature sources such as [104].This will results in a higher capital expenditure that would erode to an extent the foreseen cost reduction benefits of HAT cycles relative to combined cycles. The degree of air humidification is consistent with [105] for the operating pressures considered. 
Table 35 Modelling assumptions of the HAT cycle

\begin{tabular}{|c|c|c|}
\hline \multicolumn{2}{|c|}{ Turbomachinery } \\
\hline Equipment/Item & Value & Units \\
\hline Compressor stage polytropic efficiency & 90 & $\%$ \\
\hline Gas turbine polytropic efficiency & 89 & $\%$ \\
\hline Pressure ratio & 10 & - \\
\hline Expander Polytropic efficiency & 87 & $\%$ \\
\hline Mechanical efficiency & 99,86 & $\%$ \\
\hline Generator efficiency & 98,7 & $\%$ \\
\hline Gas turbine auxiliaries & 0,35 & $\%$ net \\
\hline Heat Recovery \& Cooling & & \\
\hline Equipment/Item & Value & Units \\
\hline Cooled stream temperatures & 10 & ${ }^{\circ} \mathrm{C}$ \\
\hline Recuperator MITA & 15 & ${ }^{\circ} \mathrm{C}$ \\
\hline Saturator pressure drop & 30 & ${ }^{\circ} \mathrm{C}$ \\
\hline Intercooler / aftercooler / economizer MITA & 20 & ${ }^{\circ} \mathrm{C}$ \\
\hline Intercooler / aftercooler / economizer LMTD & 20 & $\mathrm{kPa}$ \\
\hline Recuperator pressure drop/side & 10 & $\mathrm{kPa}$ \\
\hline Intercooler / aftercooler gas pressure drop & 10 & $\mathrm{kPa}$ \\
\hline Intercooler condenser gas pressure drop & 5 & $\mathrm{kPa}$ \\
\hline Cooling auxiliaries & 3 & $\mathrm{kPa}$ \\
\hline Reduction Gases / economizer \& condensers pressure drop & 0,008 & $\mathrm{MWe} / \mathrm{MWth}$ \\
\hline
\end{tabular}

A more detailed description of the integration with GSC clusters is given in section 4.2.3.

\subsection{Bottoming Power Cycle}

In this section, a set of unit operations which take heat from the GT exhaust stream and transform it to electricity is described. In all the power plants presented in Chapter 4, use is made of the standardized Rankine steam cycle with three pressure levels and reheat as a baseline technology. The modelling assumptions for this indirect heat engine are thoroughly described in the present section.

\subsubsection{Steam Rankine Cycle}

The steam cycle configuration employed in this work consists of a three pressure level Heat Recovery Steam Generator (HSRG) with intermediate pressure (IP) reheat to which the exhaust gases from the gas turbine are fed. This configuration is the most efficient from an exergetic point of view of all the steam cycle configurations currently available [106]. Steam raised in this unit is sent to a steam turbine consisting of three stages and finally routed to a steam condenser operating at vacuum. The large pressure ratio in the LP turbine stage allows to maximize work output from the enthalpy of the steam. The IP steam reheat improves the thermodynamic efficiency of the process by effectively elevating the mean temperature of heat addition (which mimic more closely to the Carnot cycle). Furthermore, the high enthalpy value obtained after reheat results in low moisture fractions (approximately 10\% in the outlet stream) in the last stages of the LP turbine, minimizing efficiency losses.

The condenser, with an absolute pressure in the order of mbar, consists of multiple tubes refrigerated by water from a cooling water tower. Its pressure is therefore set by the ambient water temperature plus the temperature approach of the cooling water circuit, temperature rise of the 
cooling water and pinch in the condenser. The cycle operating parameters are taken mostly from [6] and detailed in Table 36. An intermediate pressure drop between the latter reference and [107] for the exchangers was assumed, resulting in a slightly smaller water pumping duty.

Table 36 Steam cycle modelling assumptions for introductory and advanced plants

\begin{tabular}{|c|c|c|c|}
\hline \multicolumn{4}{|c|}{ Steam Turbine \& Condenser } \\
\hline \multirow{2}{*}{ Equipment/Item } & \multicolumn{2}{|c|}{ Value } & \multirow{2}{*}{ Units } \\
\hline & Intro. & Adv. & \\
\hline Steam HP/IP/LP Stage Isentropic Efficiency & $92 / 94 / 88$ & $90,3 / 92,0 / 87,7$ & $\%$ \\
\hline Condensing Pressure & 0,048 & 0,04 & bar \\
\hline Turbine Mechanical Efficiency & 99,6 & 99,6 & $\%$ \\
\hline Generator Efficiency & 98,7 & 98,7 & $\%$ \\
\hline Water Pumps Adiabatic Efficiency & 80 & 80 & $\%$ \\
\hline Power for Heat Rejection & 0,008 & 0,008 & MJe/MJth \\
\hline \multicolumn{4}{|c|}{ Heat Recovery Steam Generators } \\
\hline \multirow{2}{*}{ Equipment/Item } & \multicolumn{2}{|c|}{ Value } & \multirow{2}{*}{ Units } \\
\hline & Intro. & Adv. & \\
\hline HP/IP/LP Pressure Levels (at ST/at Eva.) & $144 / 36 / 4$ & $185 / 43 / 6$ & bar \\
\hline Gas-Gas Temperature Minimum Approach & 20 & 20 & ${ }^{\circ} \mathrm{C}$ \\
\hline LP/IP/HP Pinch Point & 10 & $10 / 10 / 9$ & ${ }^{\circ} \mathrm{C}$ \\
\hline LP/ IP/ HP Approach Point & 5 & $9 / 9 /-$ & ${ }^{\circ} \mathrm{C}$ \\
\hline Maximum SH/RH Steam Temperature & 565 & 600 & ${ }^{\circ} \mathrm{C}$ \\
\hline LP Superheat Temperature & Sat. & 300 & ${ }^{\circ} \mathrm{C}$ \\
\hline Minimum Stack Outlet Temperature & 90 & 90 & ${ }^{\circ} \mathrm{C}$ \\
\hline Eco $\Delta \mathrm{P} / \mathrm{LP}$ Eco+Eva $\Delta \mathrm{P} / \mathrm{P}$ & 3 & 25 & $\%$ \\
\hline Eva $\Delta \mathrm{P} / \mathrm{IP} \& \mathrm{HP}$ Eco+Eva $\Delta \mathrm{P} / \mathrm{P}$ & 4 & 15 & $\%$ \\
\hline Superheater Pressure Loss & 5 & 8 & $\%$ \\
\hline HRSG Air Pressure Loss & 3 & 3 & $\mathrm{kPa}$ \\
\hline HRSG Heat Loss & 0,7 & 0,7 & $\%$ heat \\
\hline
\end{tabular}

The heat recovery exchanger network of the HSRG in the introductory plants is inspired in the configurations given in $[108,109]$, where a partial extraction from the LP stage turbine is used to establish a feedwater temperature of $60^{\circ} \mathrm{C}$ in the deaerator tank. This temperature is required to eliminate more effectively condensed gases from the water and to prevent excessively low temperatures in the HSRG gas exhaust stream that could ultimately lead to the condensation and localized corrosion due to the presence of traces of sulphur components. The HSRG are usually designed with a certain subcooling in the economizer section to avoid evaporation of the fluid in these exchangers, which can be problematic from an operational point of view. 


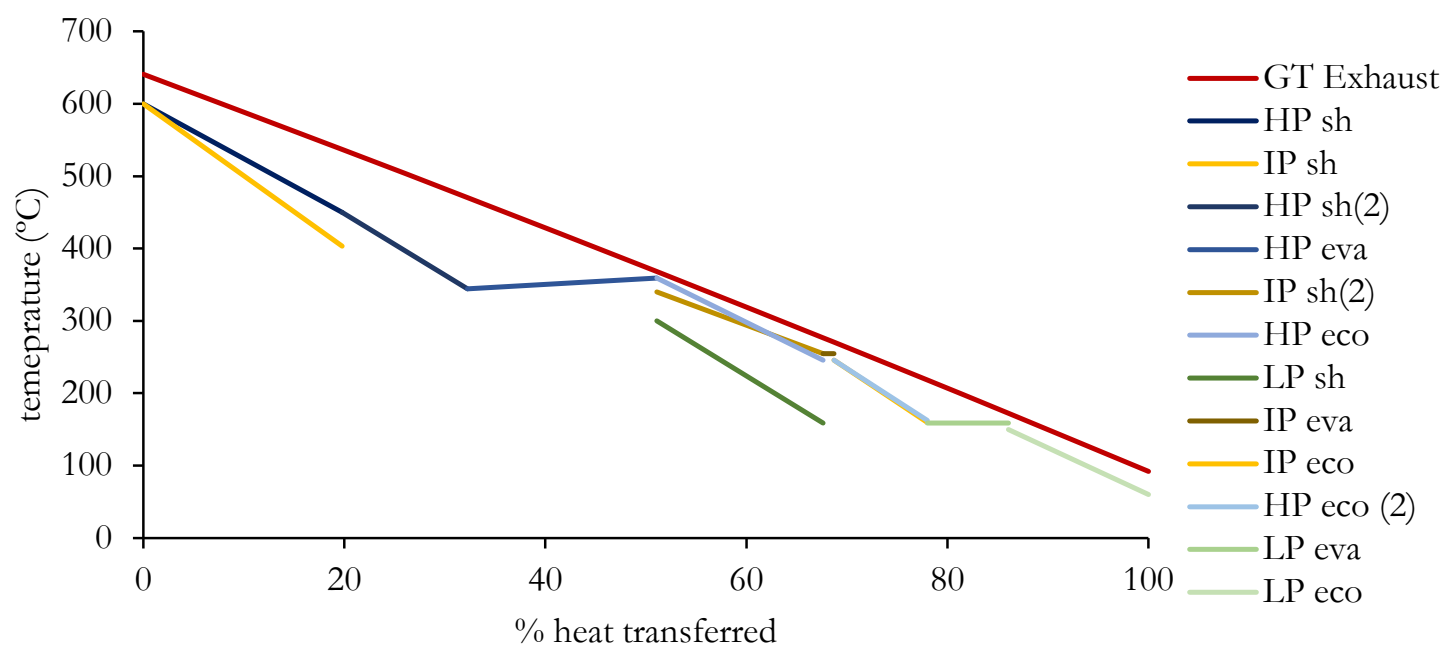

Figure 80 Heat temperature profile of a NGCC base case

On the other hand, an alternative configuration with a different water tempering strategy and heat exchanger network was utilized for the advanced power plant concepts based on the internal communication with Paolo Chiesa from Politecnica di Milano. In particular, the HP evaporator is a once through exchanger with no recirculation drum. Further process assumptions for these plants are also given in Table 36. A schematic of this steam cycle for a natural gas combined cycle plant is presented in Figure 81, while the heat temperature profile of the HSRG for a NGCC base case is given in Figure 80. It is noted how the phase change at constant temperature at the different pressure levels prevents a flat temperature profile that would result in the least exergy destruction.

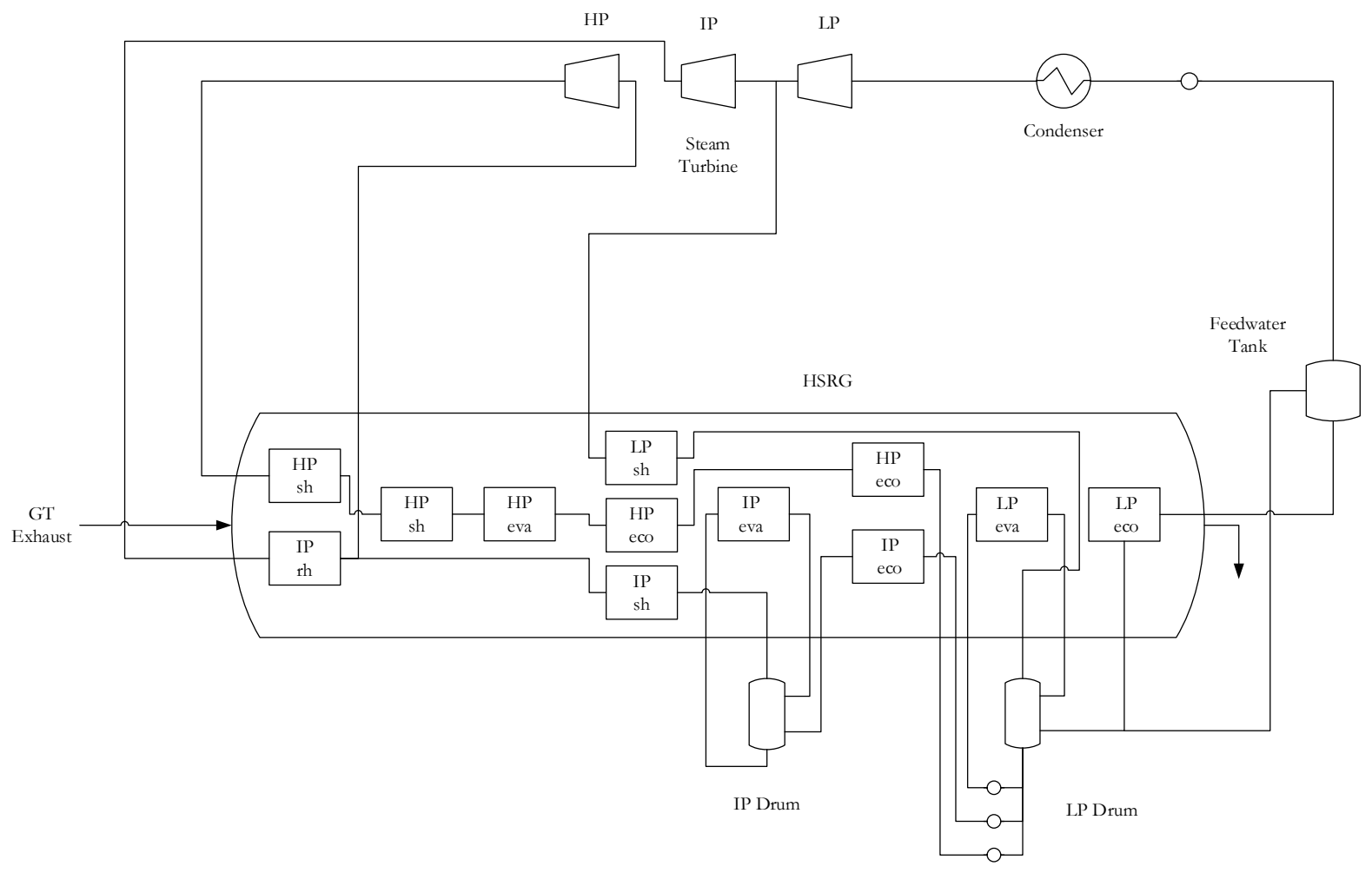

Figure 81 Steam cycle configuration for advanced power plants

When integrating the steam cycle with the heat recovery systems in a gasification plant (syngas effluent coolers etc.) it is noted that the large hot water demand required to feed these systems is 
so large that on some occasions it is not possible to pinch the HP evaporator in the main HSRG. In this cases with large HP steam production in the SEC, the large reheating duty of IP steam can also eliminate the generation of steam in the IP evaporator. Integration of this cycle in the IGCC power plant may have case to case differences to satisfy different model constraints, but the essential structure and assumptions described in this section remain unaltered. Nonetheless, this can result in different heat temperature profiles than the one shown in Figure 68, and more importantly, overall steam cycle performance relative to a NGCC base case.

\subsubsection{Supercritical $\mathrm{CO}_{2}$ Cycle}

Alternative to traditional Steam Rankine cycles for exhaust heat recovery applications, an alternative option using supercritical $\mathrm{CO}_{2}$ as working fluid was attempted. When using this fluid at such pressure conditions, there is no phase change across the heat recovery network, reducing thereby the exergy losses. On the other hand, upon expansion in the $\mathrm{CO}_{2}$ turbine, the exhaust stream must be cooled down to ambient levels before recompression in the $\mathrm{CO}_{2}$ pump. The $\mathrm{CO}_{2}$ cooler does not operate in the two phase region as in a steam condenser, resulting in a wider temperature gap in this the heat rejection unit and consequently a higher exergy destruction in this section. An outline of the s- $\mathrm{CO}_{2}$ cycle evaluated is provided in Figure 82, with modelling assumptions taken from [110].

The s- $\mathrm{CO}_{2}$ cycle integration in IGCC plants with the syngas effluent coolers from the gasification island proved to be challenging, due to the limited pressures and temperatures attainable in the latter. Furthermore, the natural gas fired case with s- $\mathrm{CO}_{2}$ gave lower efficiencies than the NGCC with a bottoming cycle consisting of a steam Rankine cycle with three pressure levels and reheat, similarly to what was reported in [111]. For these reasons, s- $\mathrm{CO}_{2}$ was not introduced in the designs presented in Chapter 5, but it is presented here acknowledging the potential advantages from a capital cost perspective and availability of this working fluid in plants with CCS, in the case that the syngas cooling can be decoupled from the bottoming cycle. Future conceivable designs with a syngas total water quench could be a promising concept to implement s- $\mathrm{CO}_{2}$ cycles, with the aim of reducing capital cost and improving operability. 


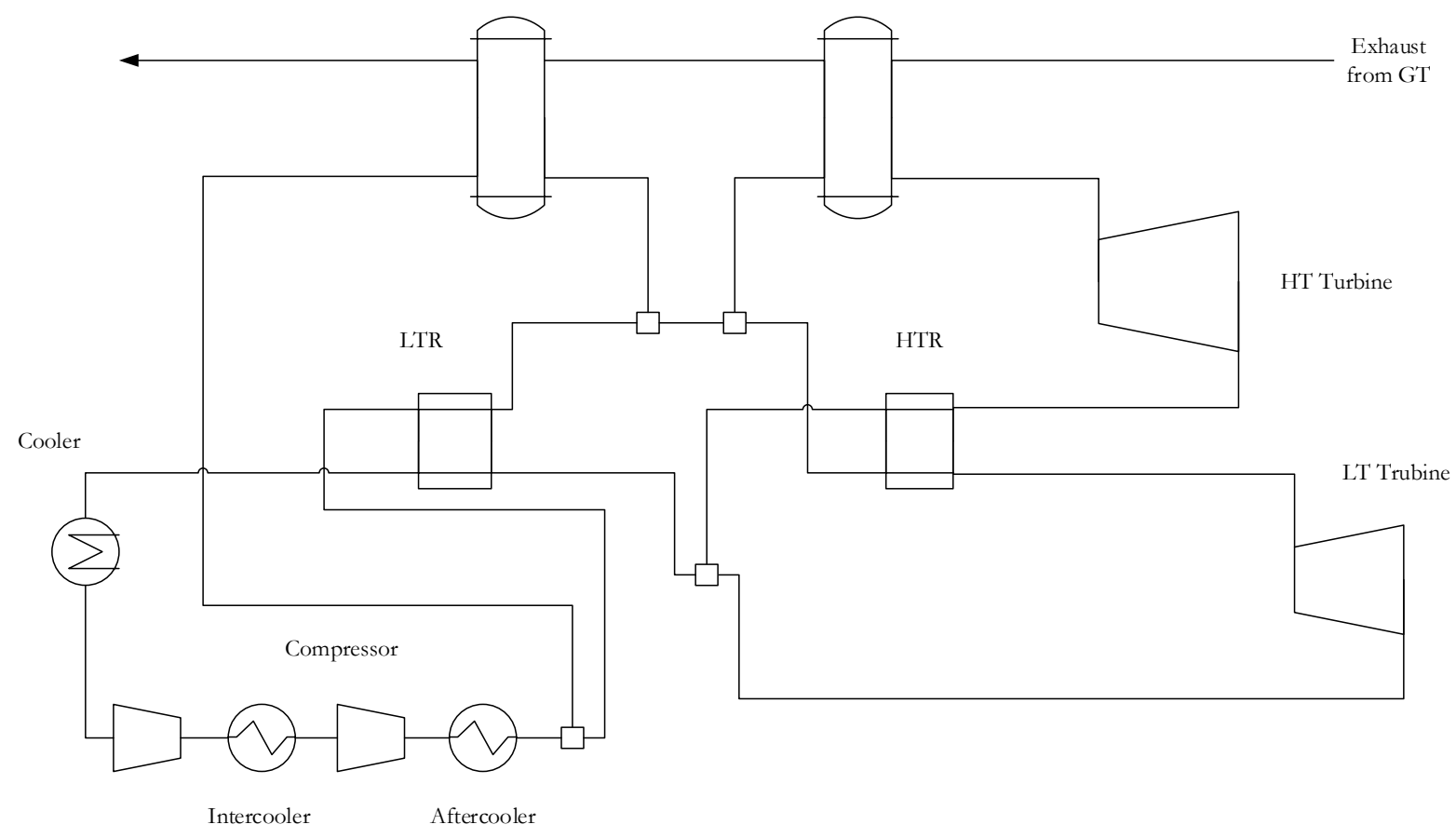

Figure 82 Supercritical $\mathrm{CO}_{2}$ cycle

\section{8 $\mathrm{H}_{2}$ and $\mathrm{CO}_{2}$ Conditioning}

The final step for plants with CCS consists of conditioning the $\mathrm{CO}_{2}$ stream obtained from the power cycles and treating units to the transport and storage specifications shown in Table 37:

Table $37 \mathrm{CO}_{2}$ purity specifications

\begin{tabular}{|c|c|}
\hline Source/Species & $\begin{array}{c}{[6]} \\
\text { (fraction by volume) }\end{array}$ \\
\hline $\mathrm{CO}_{2}$ & $>90 \%$ \\
\hline $\mathrm{N}_{2}$ & $<4 \%$ \\
\hline $\mathrm{O}_{2}$ & $<100 \mathrm{ppm}$ \\
\hline $\mathrm{Ar}$ & $<4 \%$ \\
\hline $\mathrm{H}_{2} \mathrm{O}$ & $<500 \mathrm{ppm}$ \\
\hline $\mathrm{SOx}$ & $<100 \mathrm{ppm}$ \\
\hline $\mathrm{NOx}_{\mathrm{H}}$ & $<100 \mathrm{ppm}$ \\
\hline $\mathrm{H}_{2} \mathrm{~S}$ & $<2 \% \mathrm{ppm}$ \\
\hline $\mathrm{CH}_{4}$ & $<0.2 \%$ \\
\hline $\mathrm{CO}$ & $<4 \%$ \\
\hline $\mathrm{H}_{2}$ & $<\%$ \\
\hline
\end{tabular}

$* \sum x_{i}<4 \%$ vol. $=$ Total content of non-condensable gases

If the $\mathrm{CO}_{2}$ stream removed from the process meets the purity levels specified above, it can be sent directly to a $\mathrm{CO}_{2}$ compression unit described in section. 3.8.1. Alternatively, a line up which can reduce the $\%$ of lower boiling point substances is presented in section 3.8.2.

\subsection{1 $\mathrm{H}_{2} / \mathrm{CO}_{2}$ Intercooled Compressor}

The compression system utilized to deliver $\mathrm{H}_{2}$ and or $\mathrm{CO}_{2}$ at the required pressure consists of an intercooled compressor of several stages and optionally a supercritical pump (for $\mathrm{CO}_{2}$ ). The $\mathrm{n}^{\circ}$ of intercooled stages depends on the total pressure ratio, and has been selected to limit the adiabatic temperature rise per stage to a maximum of $120^{\circ} \mathrm{C}$. The pressure ratio of each stage is optimized 
to obtain the minimum overall consumption. Occasionally, when the $\mathrm{CO}_{2}$ purity of the GSC is acceptable, a three stage compressor is directly used in the GSC plant, avoiding the $\mathrm{CO}_{2} \mathrm{CPU}$ unit discussed in the next section. An illustrative schematic of a five stage intercooled $\mathrm{CO}_{2}$ compressor coupled to a Selexol plant is provided in Figure 71, where the $\mathrm{CO}_{2}$ intake takes place at different pressure levels.

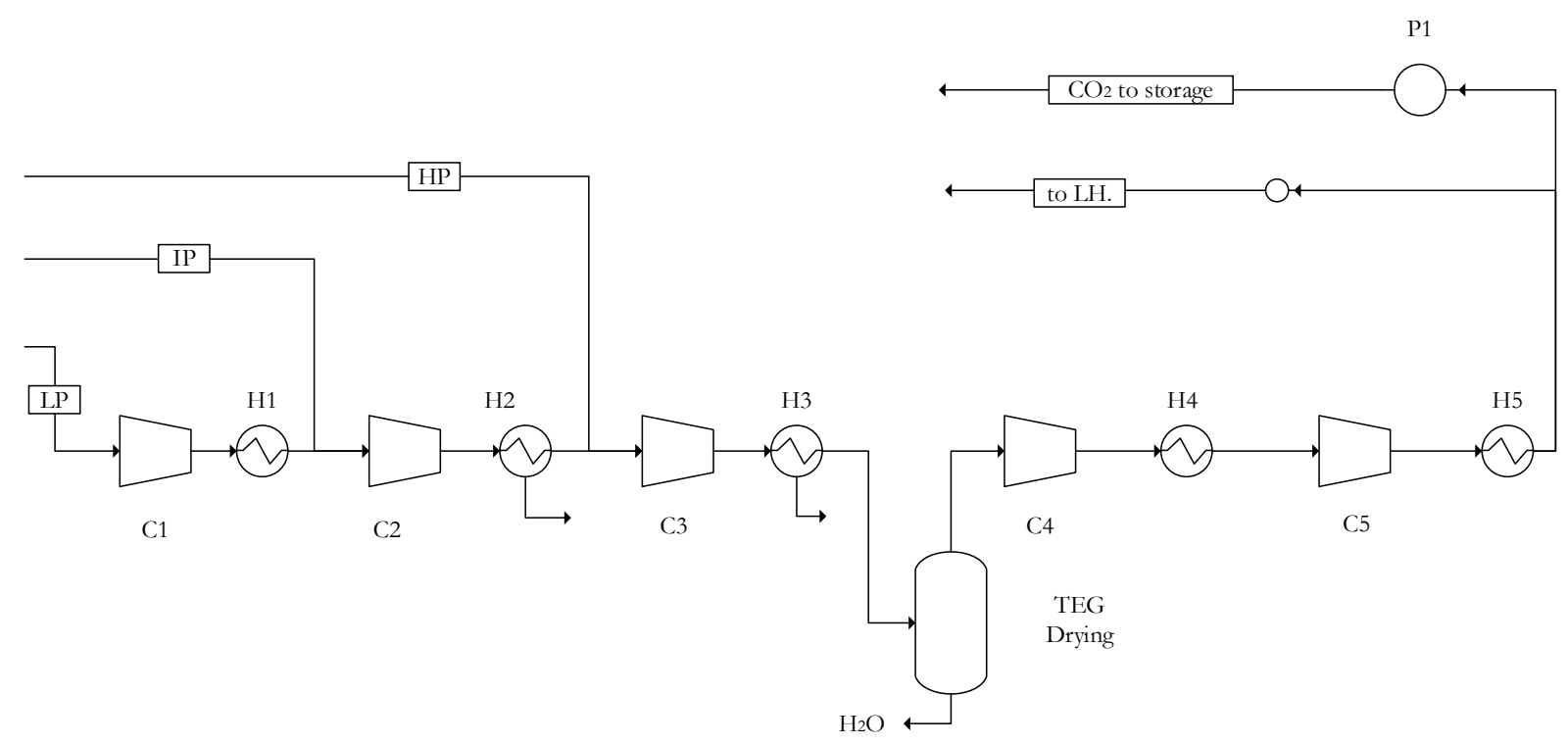

Figure $83 \mathrm{CO}_{2}$ compression unit

A summary of the main modelling assumptions considered for these units is provided in Table 38:

Table 38 Modelling assumptions of a $\mathrm{CO}_{2} / \mathrm{H}_{2}$ compression unit

\begin{tabular}{|c|c|c|}
\hline Item & Value & Units \\
\hline $\mathrm{CO}_{2}$ compression polytropic efficiency & 82 & $\%$ \\
\hline $\mathrm{CO}_{2}$ Pump isentropic efficiency & 80 & $\%$ \\
\hline $\mathrm{H}_{2}$ compression polytropic efficiency & 85 & $\%$ \\
\hline Intercooler pressure drop & $5-20$ & $\mathrm{kPa}$ \\
\hline Process streams cooled to & 25 & ${ }^{\circ} \mathrm{C}$ \\
\hline
\end{tabular}

The $\mathrm{H}_{2}$ delivery pressure was set to 150 bar, consistently to the values suggested in [112].

\subsection{2 $\mathrm{CO}_{2}$ Cryogenic Purification Unit $\left(\mathrm{CO}_{2} \mathrm{CPU}\right)$}

Because of the undesired mixing with the air stream from the oxidation stage outlet in the GSC, the purity of the reduction stage outlet after water removal is not $100 \% \mathrm{CO}_{2}$. Some $\mathrm{Ar}$ and $\mathrm{N}_{2}$ is also present from the ASU, as the oxidant stream in the gasifier is only at $95 \% \mathrm{~mol} \mathrm{O}_{2}$ purity.

To reach the purity levels required, a $\mathrm{CO}_{2}$ purification unit $\left(\mathrm{CO}_{2} \mathrm{CPU}\right)$ is employed. The simplest configuration which results in the lowest capital expenditure and auxiliary power demand consist of a two flash vessel configuration as the one depicted in Figure 84, which has been applied previously to Oxy-combustion and fuel-cell based power plants [113, 114], but using expanders in the gaseous streams to deliver more refrigeration to the cold boxes. A triethylene glycol drying step which eliminates $\mathrm{H}_{2} \mathrm{O}$ simulated as a component splitter is also included at a pressure between 15-25 bar for all cases (prior to the cryogenic exchangers). 


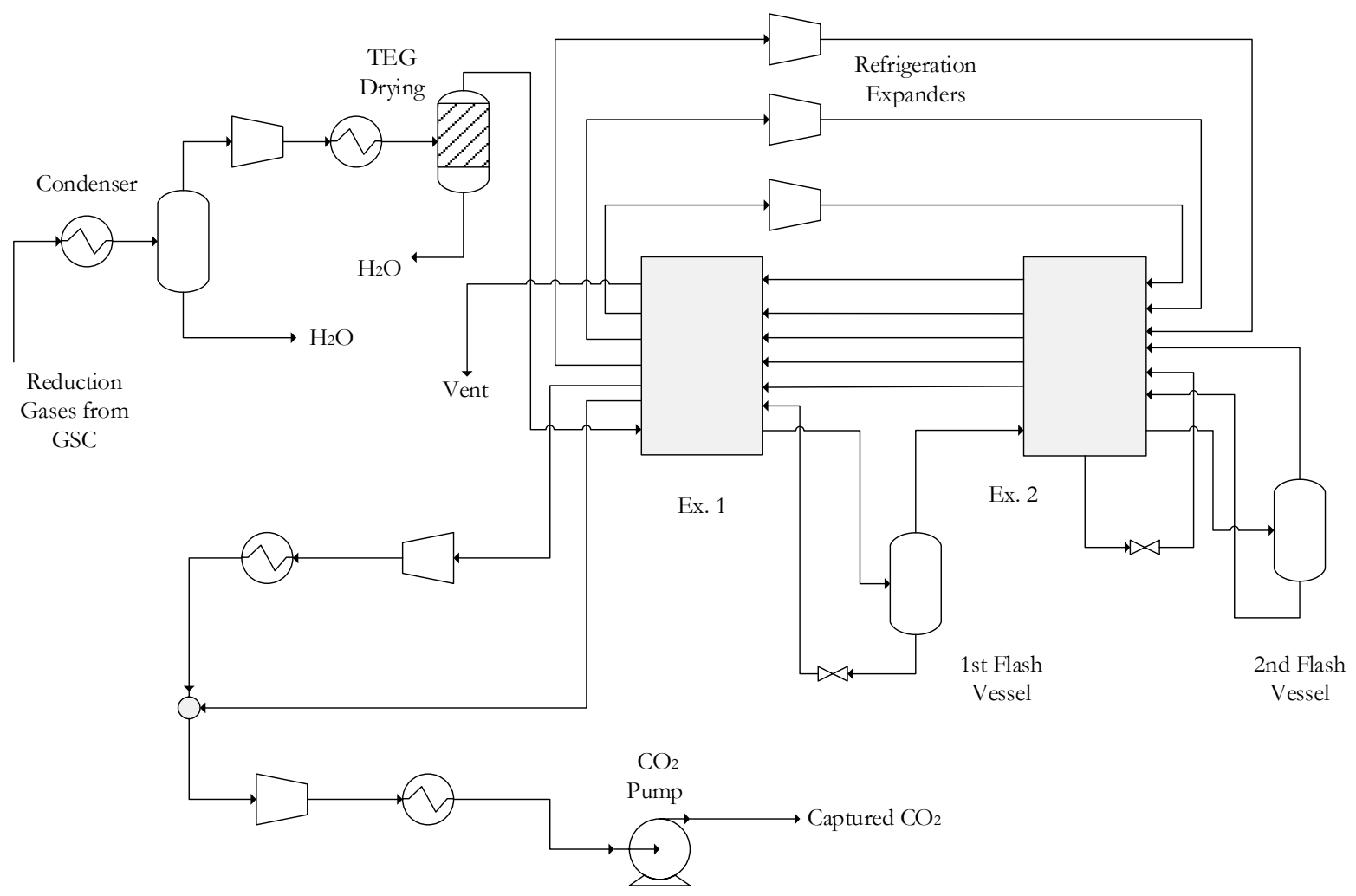

Figure 84 Schematic of the $\mathrm{CO}_{2} \mathrm{CPU}$

The modelling assumptions for this technology block, consistent to literature values, are provided in Table 39. A different degree of integration between the gasifier and the CPU unit can occur, depending on the $\mathrm{CO}_{2}$ demand for coal loading in the lock hoppers. The portion of $\mathrm{CO}_{2}$ that is not vented during coal loading is recycled to the CPU unit thereby increasing the auxiliary consumption of this unit.

Table 39 Modelling assumptions of the $\mathrm{CO}_{2} \mathrm{CPU}$

\begin{tabular}{|c|c|c|}
\hline Equipment/Item & Value & Units \\
\hline Compression stages & 3 & - \\
\hline Intercooler pressure drop & 10 & $\mathrm{kPa}$ \\
\hline Process stream temperature after heat rejection & 25 & ${ }^{\circ} \mathrm{C}$ \\
\hline Exchanger minimum temperature approach & 2 & ${ }^{\circ} \mathrm{C}$ \\
\hline Exchanger pressure loss / side & 10 & $\mathrm{kPa}$ \\
\hline Compressor stage isentropic efficiency & 80 & $\%$ \\
\hline Expander stage isentropic efficiency & 85 & $\%$ \\
\hline Minimum cold stream temperature & -56 & ${ }^{\circ} \mathrm{C}$ \\
\hline Flash vessels temperatures HT/LT & $-25 /-53$ & ${ }^{\circ} \mathrm{C}$ \\
\hline Mechanical driver efficiency & 95 & $\%$ \\
\hline Electrical generator efficiency & 90 & $\%$ \\
\hline $\mathrm{CO}_{2}$ pump isentropic efficiency & 80 & $\%$ \\
\hline & & \\
\hline
\end{tabular}

The auxiliary electrical consumption of the drying units were neglected for all plants. 


\section{Chapter 4}

\section{Power Plant Concepts}

In this Chapter, the power plant configurations that have been elaborated are presented following the analysis methodology presented in section 1.4. The benchmark plants with and without CCS are initially presented, followed by the power generation concepts with GSC and finally two plants including a GSOP cluster are also discussed.

\subsection{Benchmark Power Plants}

\subsubsection{Unabated IGCC}

The reference IGCC plant without $\mathrm{CO}_{2}$ capture is based on the configuration shown in [6] and [100]. Coal is loaded with $\mathrm{N}_{2}$ from the ASU into a Shell gasifier. A high pressure ASU 50\% integrated with the GT compressor and fully integrated in the product $\left(\mathrm{N}_{2}\right)$ side for syngas dillution delivers the oxidant stream. The gasification has a CGE of around $81 \%$. After syngas quench with recirculated cold syngas and further cooling raising HP steam in the SEC, candle filters and a scrubber remove remaining particulate material, before the COS hydrolysis reactor and low temperature heat recovery. $\mathrm{H}_{2} \mathrm{~S}$ is removed in the AGRU unit and then mixed with compressed $\mathrm{N}_{2}$ from the ASU, after which it is fed to a saturator unit to increase its moisture content and reduce the flame temperature. The results shown below assume that full product $\mathrm{N}_{2}$ integration with the ASU is possible withough negatively affecting the GT compressor performance nor design point (i.e. pressure ratio), as explained in section 3.6.4.

The diluted syngas is combusted in the F-class GT combustor, producing electricity upon expansion in the turbine. The turbine outlet is routed to the HSRG of the steam cycle where steam is raised at different pressure levels to produce extra work in the steam turbine. Because of the large amount of HP steam produced in the cooling of raw syngas form the gasifier and consequent superheating and reheating requirements in the bottoming cycle HSRG, almost no IP steam is produced in the the IP drum. Figure 85 shows a block flow diagram of the Unabated IGCC plant with the main components, while a detailed schematic and stream summary are given in the Appendix in Figure 139 and Table 89 respectively. 


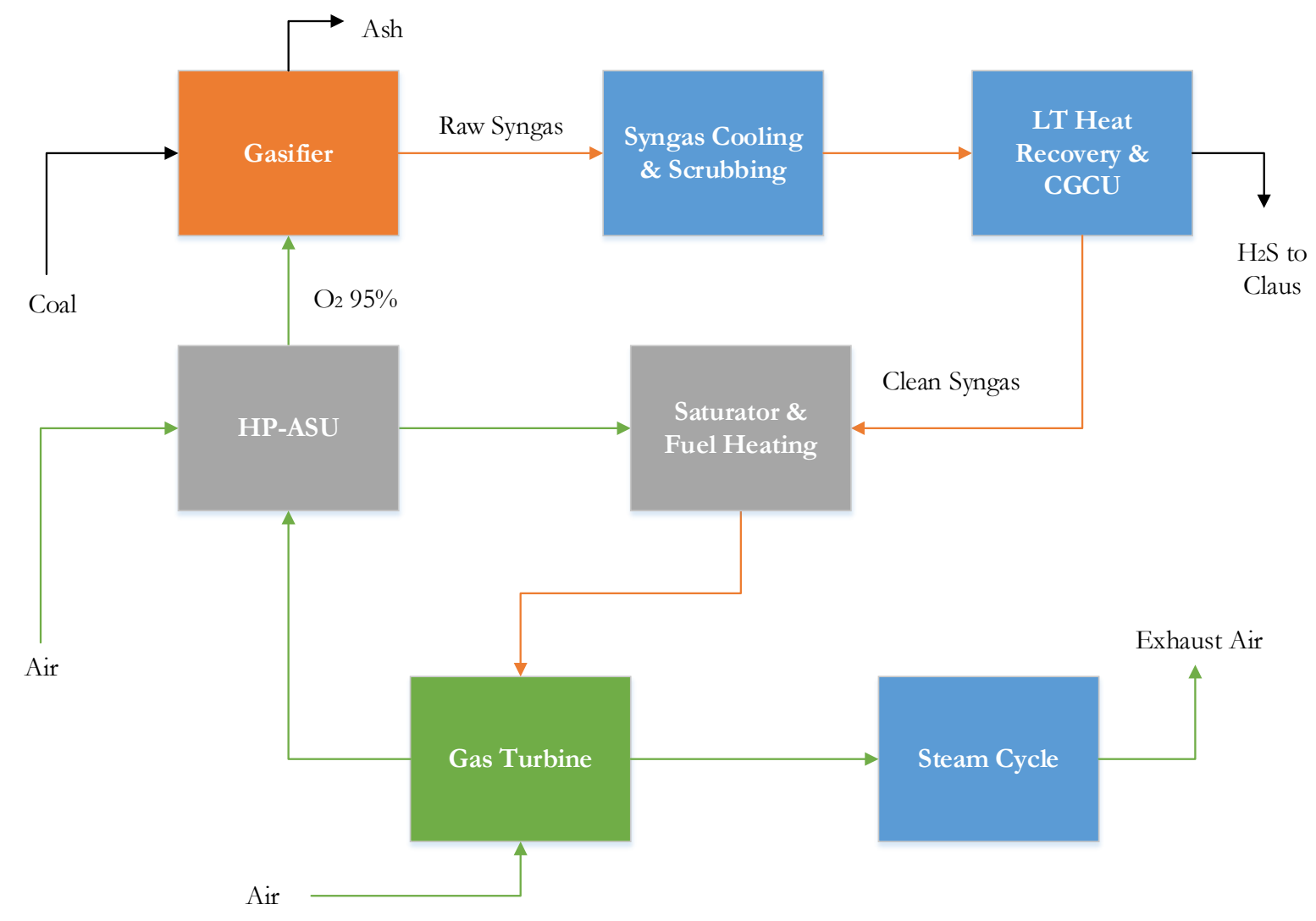

Figure 85 Block flow diagram of the Unabated IGCC power plant

Energy

The Unabated IGCC power plant energy breakdown in provided in Table 40. Due to the lack of carbon capture, the auxiliary consumption for this plant is relatively low, primarily consisting of the electrical work required for air separation and product $\mathrm{N}_{2}$ compression.

Table 40 Energy breakdown of the Unabated IGCC plant

\begin{tabular}{|c|c|}
\hline \multicolumn{2}{|c|}{ Power-heat balance } \\
\hline Coal input (MW) & 854,0 \\
\hline Compressor (MW) & 222,8 \\
\hline Turbine (MW) & 504,7 \\
\hline GT net (MW) & 277,8 \\
\hline Air expander (MW) & 5,5 \\
\hline Steam cycle net (MW) & 189,5 \\
\hline Condenser (MW) & 244,8 \\
\hline Power plant auxiliaries & \\
\hline GT auxiliaries (MW) & 1,0 \\
\hline ASU (MW) & 26,3 \\
\hline N $_{2}$ compression (MW) & 28,0 \\
\hline Coal milling (MW) & 1,7 \\
\hline Ash handling (MW) & 0,5 \\
\hline Syngas recycle blower (MW) & 1,1 \\
\hline Syngas treating (MW) & 1,2 \\
\hline Water pumps (MW) & 2,7 \\
\hline Heat rejection (MW) & 2,1 \\
\hline Balance of plant (MW) & 1,3 \\
\hline
\end{tabular}




\begin{tabular}{|c|c|}
\hline \multicolumn{2}{|c|}{ Global balance } \\
\hline Total auxiliaries (MW) & 66,0 \\
\hline Gross plant (MW) & 472,8 \\
\hline Net plant (MW) & 406,8 \\
\hline Total heat input (MW) & 854,0 \\
\hline Gross efficiency (\%LHV) & 55,4 \\
\hline Net efficiency (\%LHV) & 47,6 \\
\hline
\end{tabular}

The efficiency results are slightly above those provided in [6] due to the assumption that all available $\mathrm{N}_{2}$ can be inserted into the GT (which makes use of a slightly pressurized stream), and a somewhat lower rotor cooling requirements in the present model than when accounting for the composition change in the syngas. It is mentioned here that when the GT takes into account changes in the compressor operating point and increased blade cooling flows (keeping the stator and rotor maximum temperatures at $850^{\circ} \mathrm{C}$ and $825^{\circ} \mathrm{C}$ respectively), the thermal efficiency of the Unabated IGCC plant drops approximately $2 \%$-points, with a TIT reduction to $1312^{\circ} \mathrm{C}$, when the $\mathrm{N}_{2}$ addition is done only to reach an SFT of $2250 \mathrm{~K}$. These results coincide with the values reported in [71], although no ASU integration is presented in that particular model. A rigorous study on the effect of syngas firing in GT designed to run with natural gas is given in [74].

\section{Environmental}

The Unabated IGCC plant presents no $\mathrm{CO}_{2}$ capture technology. The primary $\mathrm{CO}_{2}$ emissions source is naturally occurring in the GT exhaust steam due to the combustion of syngas in the combustor. The Unabated IGCC plant presents a specific emissions value of $726,8 \mathrm{~kg} \mathrm{CO}_{2} / \mathrm{MWh}$ of net electricity. This reference value of $\mathrm{CO}_{2}$ intensity together with the net thermal efficiency shown in Table 40 will be employed as the reference values in the determination of SPECCA index of the introductory plants. The amount of $\mathrm{CO}_{2}$ generated per unit of coal feed resulted in 2.42 $\mathrm{kg} / \mathrm{kg}$. In terms of NOx emissions, it is expected that this plant will perform substantially well as the SFT can be lowered to up to $2167 \mathrm{~K}$, provided that the GT compressor can cope with the added flow rate to the combustor.

\section{Exergy}

The exergy analysis performed to the Unabated IGCC plant shows the relative loss contribution of each plant system, grouped into different blocks for simplicity and shown in Figure 86 in percent. In this case, the useful effect corresponds only to the net electrical output from the plant. The absolute exergy breakdown and the process units or streams accounted for in each block are given in Table 41.

Table 41 Total exergy breakdown per system of the Unabated IGCC plant

\begin{tabular}{|c|c|c|}
\hline Block & Item & Exergy Loss(MW) \\
\hline \multirow{3}{*}{ Gasification island } & ASU & 17,9 \\
\cline { 2 - 3 } & Air expander \& cooling & 3,8 \\
\cline { 2 - 3 } & $\mathrm{N}_{2}$ compression & 7,0 \\
\cline { 2 - 3 } & Shell gasifier & 130,3 \\
\hline \multirow{3}{*}{ Syngas cooling \& treating } & 15,9 \\
\cline { 2 - 3 } & SEC & 15,5 \\
\cline { 2 - 3 } & Scrubbing, LTHR \& CGCU & 13,9 \\
\cline { 2 - 3 } & Saturator \& fuel heating & 18,1 \\
\hline \multirow{3}{*}{ Gas turbine } & Compressor & 165,9 \\
\cline { 2 - 3 } & Combustor & 33,2 \\
\cline { 2 - 3 } & Turbine & 19,3 \\
\hline Steam cycle & HSRG & \\
\hline
\end{tabular}




\begin{tabular}{|c|c|c|}
\hline \multirow{2}{*}{ Exergy out } & Condenser cooling \& pumps & 9,2 \\
\cline { 2 - 3 } & Steam turbine & 17,1 \\
\hline & Slag & 5,3 \\
\cline { 2 - 3 } & Stack gases & 28,7 \\
\hline Misc. & Other $\left(\mathrm{H}_{2} \mathrm{~S}\right.$, water $)$ & 5,8 \\
\hline Useful effect & $\mathrm{BoP}_{1}$ & 1,28 \\
\hline & $\mathrm{W}_{\text {net }}$ & 406,9 \\
\hline
\end{tabular}

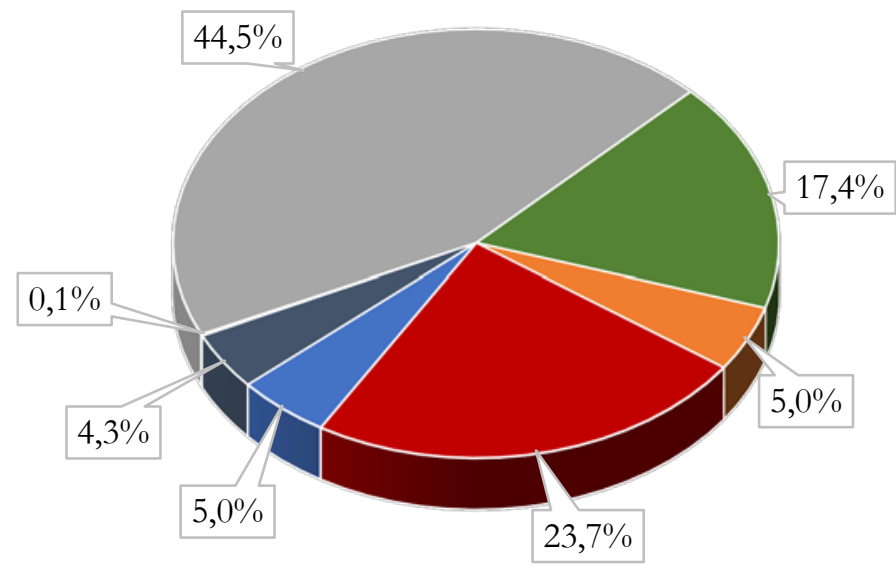

- Gasification island

- Syngas cooling \& treating

- Gas turbine

- Steam cycle

- Exergy out

- Misc.

- Useful effect

Figure 86 Exergy breakdown in \% for the Unabated IGCC power plant

The greatest exergy loss contributors are the combustion chamber of the GT and the gasification unit, where the chemical degradation of the fuel occurs. This result emphasizes the large impact that the chemical exergy flow has on the total flow exergy. On the other hand, due to the lower exergy of the heat used to produce electricity in the steam cycle relative to the topping cycle, the exergy loss contribution is relatively low in the former. And notably, even though the heat rejected in the condenser is large, as shown in Table 38, the exergy destruction term is approximately 1\%point of the total exergy input.

\section{Economic}

The economic results for the Unabated IGCC plant are summarized in Table 42, while Figure 87 and Figure 88 show the distribution of the total installed cost and LCOE build up per item respectively:

Table 42 Economic results for the Unabated IGCC power plant

\begin{tabular}{|c|c|}
\hline Item & Value \\
\hline$S I(€ / \mathrm{kW})$ & 2244,7 \\
\hline $\operatorname{LCOE}(€ / \mathrm{MWh})$ & 61,2 \\
\hline $\mathrm{COCA}\left(€ / \operatorname{ton} \mathrm{CO}_{2}\right)$ & - \\
\hline
\end{tabular}

The cost distribution shows that the gasification island (gasifier, syngas treating \& ASU etc.) contribute to more than half of the total installed cost, underlying the adequateness of the assumption taken for a higher degree of flexibility for the gas turbine design in the introductory plants. The total installed cost for this plant (TIC) amounted to 605,9 M€. 


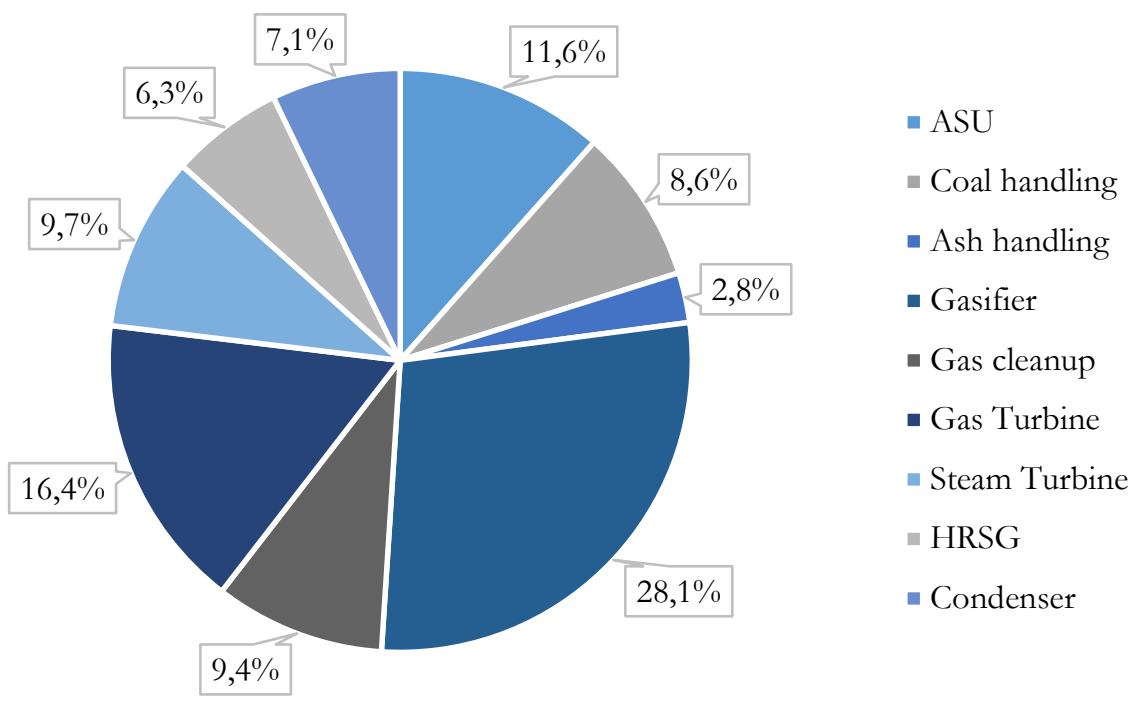

Figure 87 TIC distribution for the Unabated IGCC power plant

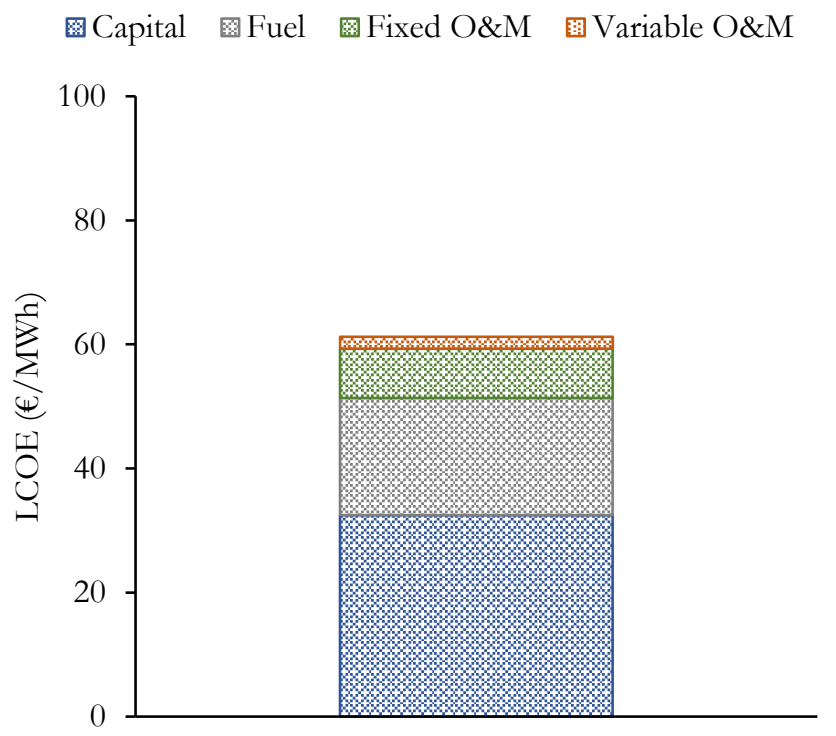

Figure 88 LCOE build-up for the Unabated IGCC power plant

\subsubsection{Pre-combustion $\mathrm{CO}_{2}$ capture IGCC}

The Pre-combustion $\mathrm{CO}_{2}$ capture plant consist of a Shell gasification unit where coal is loaded with captures $\mathrm{CO}_{2}$ and oxygen is delivered by a LP-ASU unit. No integration with GT compressor is advised for pre-combustion plants, to maximize reliability [75]. The syngas is cooled and scrubbed with water to remove particulate material and then sent to a sour WGS unit where, after IP steam addition from the HP stage steam turbine outlet, it is shifted to $\mathrm{CO}_{2}$ and $\mathrm{H}_{2}$. After low temperature heat removal and cooling to ambient temperatures, the shifted syngas stream is routed to a selective $\mathrm{H}_{2} \mathrm{~S} / \mathrm{CO}_{2}$ Selexol absorption unit. The rich syngas outlet is sent back to the WGS unit, mixed with $\mathrm{N}_{2}$ from the ASU for NOx control and saturated with water before being heated to $200^{\circ} \mathrm{C}$ and finally combusted with air in the GT. The $\mathrm{CO}_{2}$ removed with the Selexol is sequentially compressed and pumped to 150 bar after dehydration. The exhaust heat from the GT is partially recovered and transformed to electricity in the steam cycle adequately integrated with the syngas cooling exchangers. A block flow diagram of the pre-combustion $\mathrm{CO}_{2}$ capture IGCC 
plant is given in Figure 89, while a detailed diagram with stream summary is provided in Figure 140 and Table 93 in the Appendix.

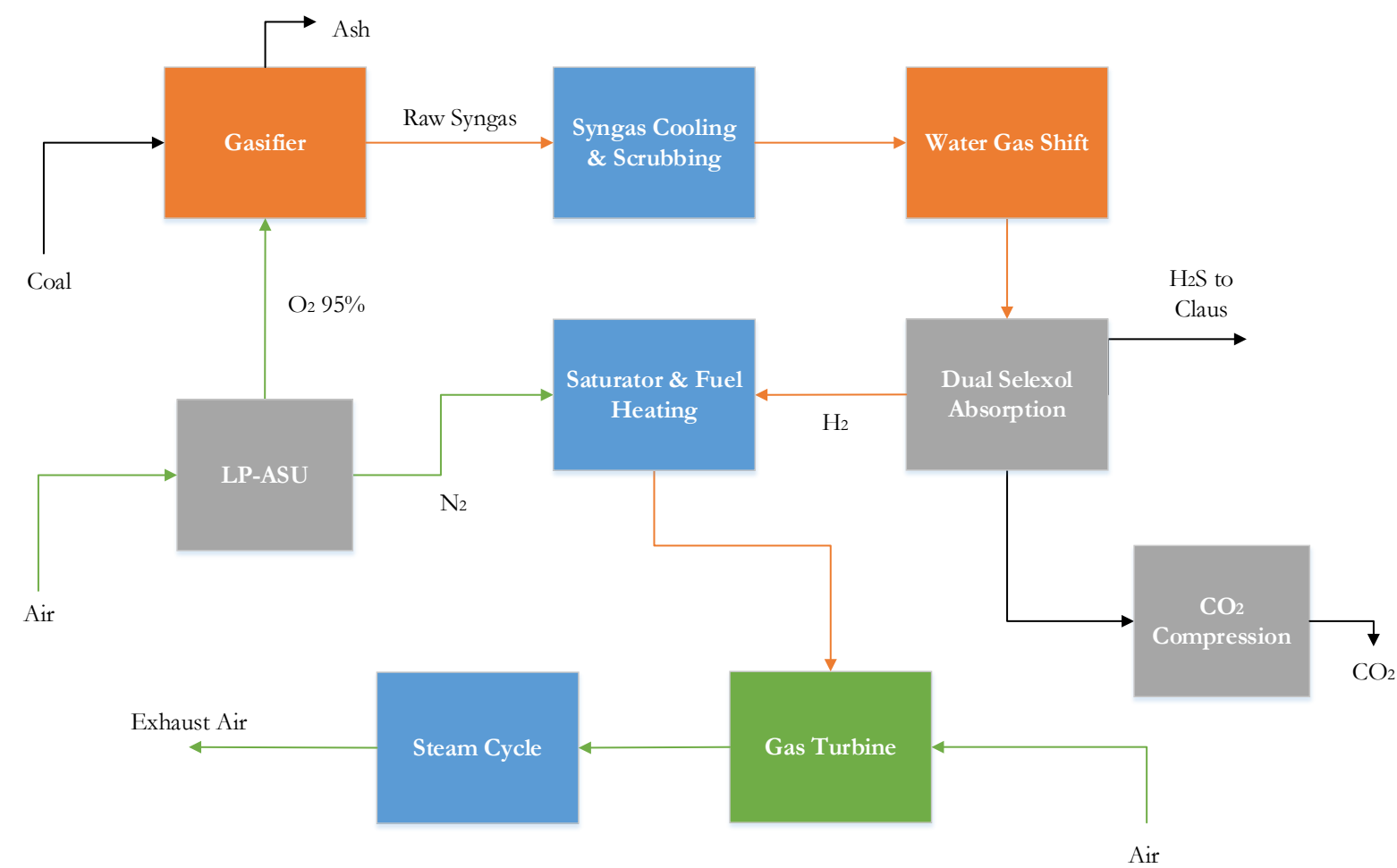

Figure 89 Block flow diagram of the Pre-combustion $\mathrm{CO}_{2}$ capture IGCC plant

Energy

The energy breakdown of the Pre-combustion $\mathrm{CO}_{2}$ capture IGCC plant is shown in Table 43. It can be seen that the gross efficiency for this concept is substantially lower than in the Unabated case due to the fuel degradation and steam consumption that take place in the WGS unit. The energy penalty of $\mathrm{CO}_{2}$ capture is around $9 \%$-points, with only $\mathrm{CO}_{2}$ compression resulting in approximately 2,7\%-points efficiency loss. The major sources of auxiliary consumption are once again the standalone ASU and $\mathrm{N}_{2}$ compression requirement for syngas dilution.

Table 43 Energy breakdown of the Pre-combustion $\mathrm{CO}_{2}$ capture IGCC power plant

\begin{tabular}{|c|c|}
\hline \multicolumn{2}{|c|}{ Power-heat balance } \\
\hline Coal heat input (MW) & 854,0 \\
\hline Compressor (MW) & 191,9 \\
\hline Turbine (MW) & 467,6 \\
\hline GT net (MW) & 271,7 \\
\hline Steam cycle net (MW) & 157,8 \\
\hline Condenser (MW) & 182,4 \\
\hline Power plant auxiliaries \\
\hline GT auxiliaries (MW) & 1,0 \\
\hline ASU (MW) & 36,8 \\
\hline $\mathrm{N}_{2}$ compression (MW) & 23,7 \\
\hline Coal milling (MW) & 1,7 \\
\hline Ash handling (MW) & 0,5 \\
\hline Syngas recycle blower (MW) & 1,2 \\
\hline Selexol plant (AGRU) (MW) & 11,7 \\
\hline $\mathrm{CO}_{2}$ compression(MW) & 23,6 \\
\hline
\end{tabular}




\begin{tabular}{|c|c|}
\hline Water pumps (MW) & 3,1 \\
\hline Heat rejection (MW) & 2,3 \\
\hline Balance of plant (MW) & 1,3 \\
\hline Global balance \\
\hline Total auxiliaries (MW) & 106,8 \\
\hline Gross plant (MW) & 429,5 \\
\hline Net plant (MW) & 322,7 \\
\hline Total heat input (MW) & 854,0 \\
\hline Gross efficiency (\%LHV) & 50,3 \\
\hline Net efficiency (\%LHV) & 37,8 \\
\hline
\end{tabular}

Again, the efficiency of the plant results slightly above its counterpart in [6] due to the more optimistic assumptions regarding the GT operation and to an extent, a lower auxiliary consumption predicted by the Selexol plant. Due to steam extraction for WGS, the heat rejection in the condenser and steam cycle output become smaller.

\section{Environmental}

In terms of $\mathrm{CO}_{2}$ emissions the plant is designed to achieve a capture rate of approximately $90 \%$. This is achieved by controlling the absorption capability of the Selexol unit. With respect to the NOx emissions the $\mathrm{N}_{2}$ flow rate to the saturator was fixed to reach a conservative SFT of $2200 \mathrm{~K}$.

Table $44 \mathrm{CO}_{2}$ emissions performance of the pre-combustion $\mathrm{CO}_{2}$ capture IGCC power plant

\begin{tabular}{|c|c|}
\hline Item & Value \\
\hline $\mathrm{CO}_{2}$ Emissions $\left(\mathrm{kgCO}_{2} / \mathrm{MWh}\right)$ & 86,4 \\
\hline $\mathrm{CO}_{2}$ Capture $(\%)$ & 90,6 \\
\hline $\mathrm{CO}_{2}$ Avoidance $(\%)$ & 88,1 \\
\hline SPECCA $\left(\mathrm{MJ} / \mathrm{kgCO}_{2}\right)$ & 3,078 \\
\hline
\end{tabular}

\section{Exergy}

An analogous exergy analysis to the one shown for the Unabated IGCC plant was performed for the pre-combustion $\mathrm{CO}_{2}$ capture plant. Figure 90 shows the exergy distribution following the same block categorization while Table 45 provided the absolute contribution of each block subsystem:

Table 45 Total exergy breakdown for the Pre-combustion $\mathrm{CO}_{2}$ capture IGCC power plant

\begin{tabular}{|c|c|c|}
\hline Block & Item & Exergy (MW) \\
\hline \multirow{3}{*}{ Gasification island } & ASU & 23,7 \\
\cline { 2 - 3 } & $\mathrm{N}_{2}$ Compression & 6,5 \\
\cline { 2 - 3 } Syngas cooling \& treating & Shell Gasifier & 129,4 \\
\hline & SEC & 16,2 \\
\cline { 2 - 3 } & Scrubber \& WGS & 44,4 \\
\cline { 2 - 3 } & AGRU (Selexol) & 19,3 \\
\cline { 2 - 3 } & Saturator \& Fuel Heating & 14,6 \\
\hline \multirow{3}{*}{ Gas turbine } & Compressor & 16,2 \\
\hline \multirow{3}{*}{ Steam cycle } & Combustor & 163,0 \\
& Turbine & 31,4 \\
\hline & HSRG & 13,2 \\
\hline $\mathrm{CO}_{2}$ Compression & Condenser Cooling \& Pumps & 7,8 \\
\hline Exergy out & $\mathrm{CO}_{2}$ Compression & 14,3 \\
\cline { 2 - 3 } & Slag & 10,3 \\
\hline
\end{tabular}




\begin{tabular}{|c|c|c|}
\hline \multirow{2}{*}{} & $\mathrm{CO}_{2}$ Captured & 51,4 \\
\cline { 2 - 3 } & Stack Gases & 20,1 \\
\cline { 2 - 3 } & Other $\left(\mathrm{H}_{2} \mathrm{~S}\right.$, water $)$ & 5,7 \\
\hline Misc. & BoP & 1,3 \\
\hline Useful effect & Wnet & 322,7 \\
\hline
\end{tabular}

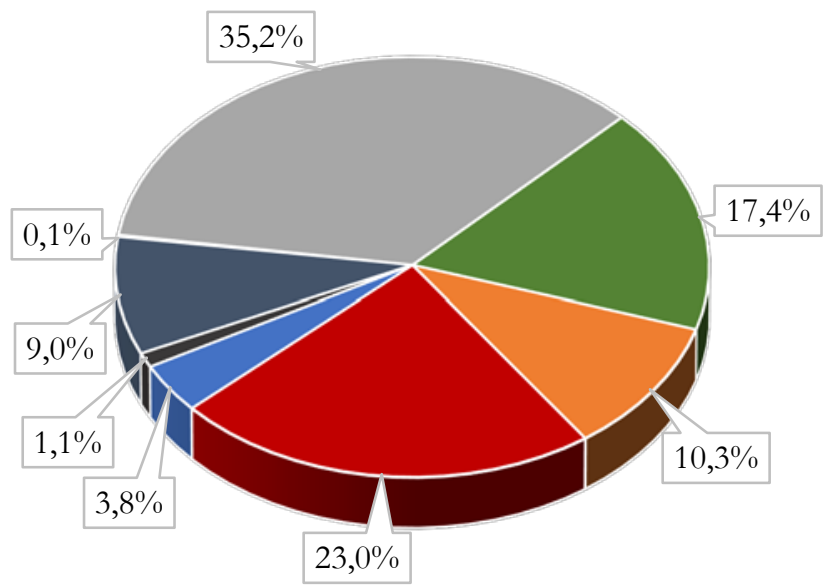

- Gasification island

- Syngas cooling \& treating

- Gas turbine

- Steam cycle

- CO2 Compression

- Exergy out

- Misc.

- Useful effect

Figure 90 Exergy breakdown in \% of the pre-combustion $\mathrm{CO}_{2}$ capture IGCC power plant

The portion corresponding to syngas cooling and treating has notoriously increased due to the added WGS step, while the exergy that leaves the plant is now larger in virtue of the pure $\mathrm{CO}_{2}$ stream output, relative to the Unabated IGCC plant.

\section{Economic}

The economic results for the Pre-combustion $\mathrm{CO}_{2}$ capture IGCC power plant are summarized in Table 46, while Figure 91 shows the contribution of different plant elements to the TIC, which amounts to 679,6 M€, and Figure 92 provides the breakdown of the LCOE in capital, operating and fuel costs.

Table 46 Economic results for the Pre-combustion $\mathrm{CO}_{2}$ capture IGCC power plant

\begin{tabular}{|c|c|}
\hline Item & Value \\
\hline$S I(€ / \mathrm{kW})$ & 3178,0 \\
\hline $\operatorname{LCOE}(€ / \mathrm{MWh})$ & 92,7 \\
\hline $\operatorname{COCA}_{I G C C}(€ /$ tonCO 2$)$ & 41,2 \\
\hline$C O C A_{S C P C}(€ /$ tonCO 2$)$ & 54,7 \\
\hline
\end{tabular}

Relative to the Unabated IGCC power plant, the present model with CCS reveals an increase of $31,5 € / \mathrm{MWh}(51,5 \%$ higher $)$ in the cost of electricity, while the investment per $\mathrm{kW}$ of net electricity output increased by $933,3 €(29,4 \%$ rise $)$, which manifests the disadvantages of added CAPEX for $\mathrm{CO}_{2}$ capture and lower electricity sales (less electricity production) for the fixed fuel consumption assumed. 


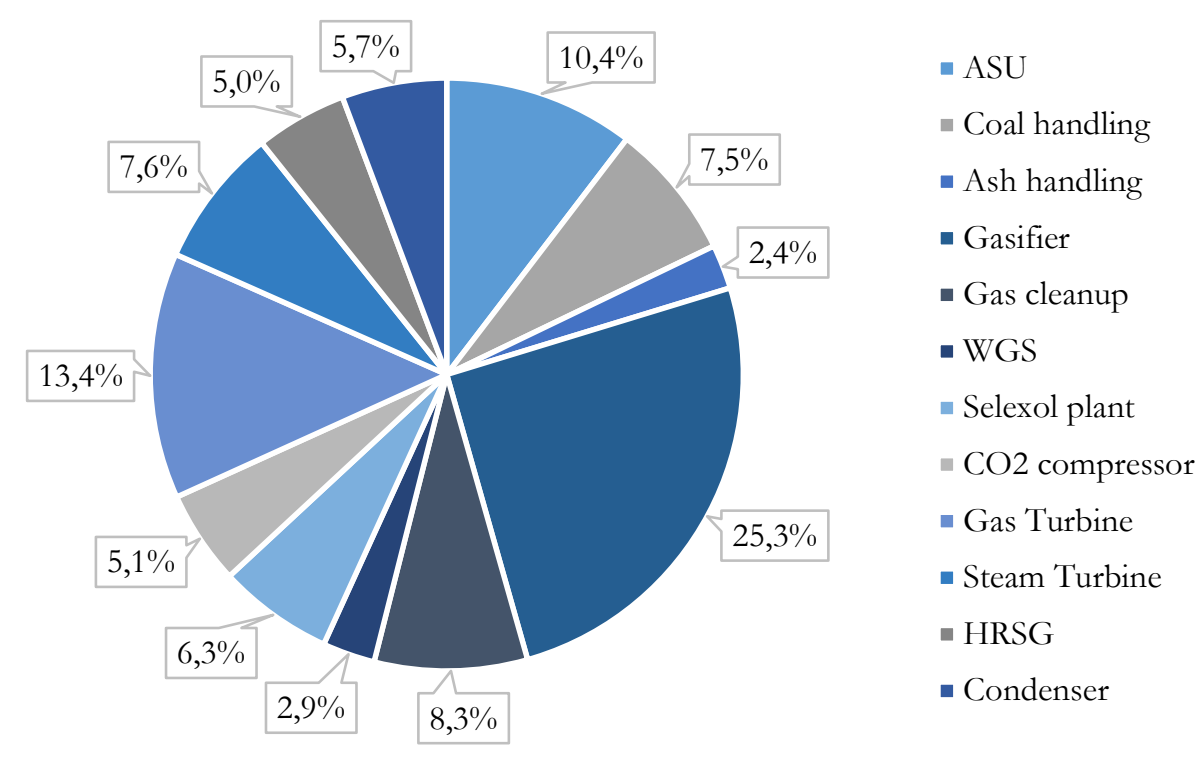

Figure 91 TIC distribution for the Pre-combustion $\mathrm{CO}_{2}$ capture IGCC power plant

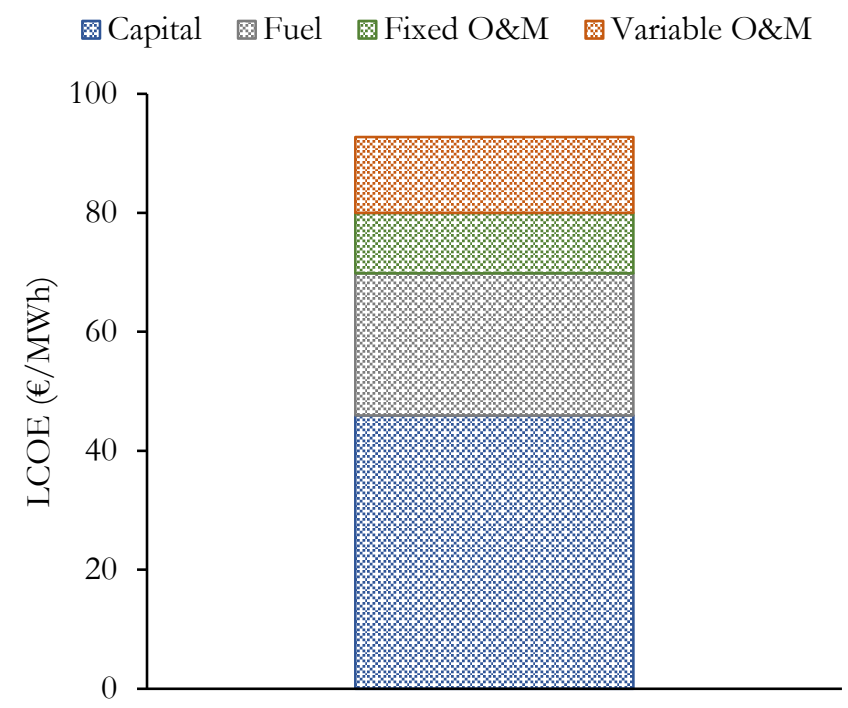

Figure 92 LCOE build up for the Pre-combustion $\mathrm{CO}_{2}$ capture IGCC power plant

\subsubsection{Adv. Unabated IGCC}

The Advanced Unabated IGCC power plant consists of the same element as its earlier counterpart but incorporates the benefits of HGCU and employed the modern H-class turbines. The coal input to the "advanced" plants is selected to meet the syngas fuel requirements of the GT based on the nozzle area for the given air flow rate imposed by the GT model. The GT was simulated by Paolo Chiesa from Politecnica di Milano, provided the syngas composition and the ratio of compressed air diverted to the ASU, which was 50\% integrated with the GT compressor. Since the fuel temperature after desulphurization is substantially higher than when using an ambient temperature clean up set up, the resulting SFT upon combustion is higher, thereby increasing notably the NOx emissions, as was reflected in [115]. A block flow diagram of this plant is given in Figure 93, where a colour code also indicates the elements that are added to the Advanced Precombustion $\mathrm{CO}_{2}$ capture IGCC power plant described in section 4.1.4. A detailed schematic and corresponding stream summary table can be found in Figure 141 and Table 91 in the Appendix. 


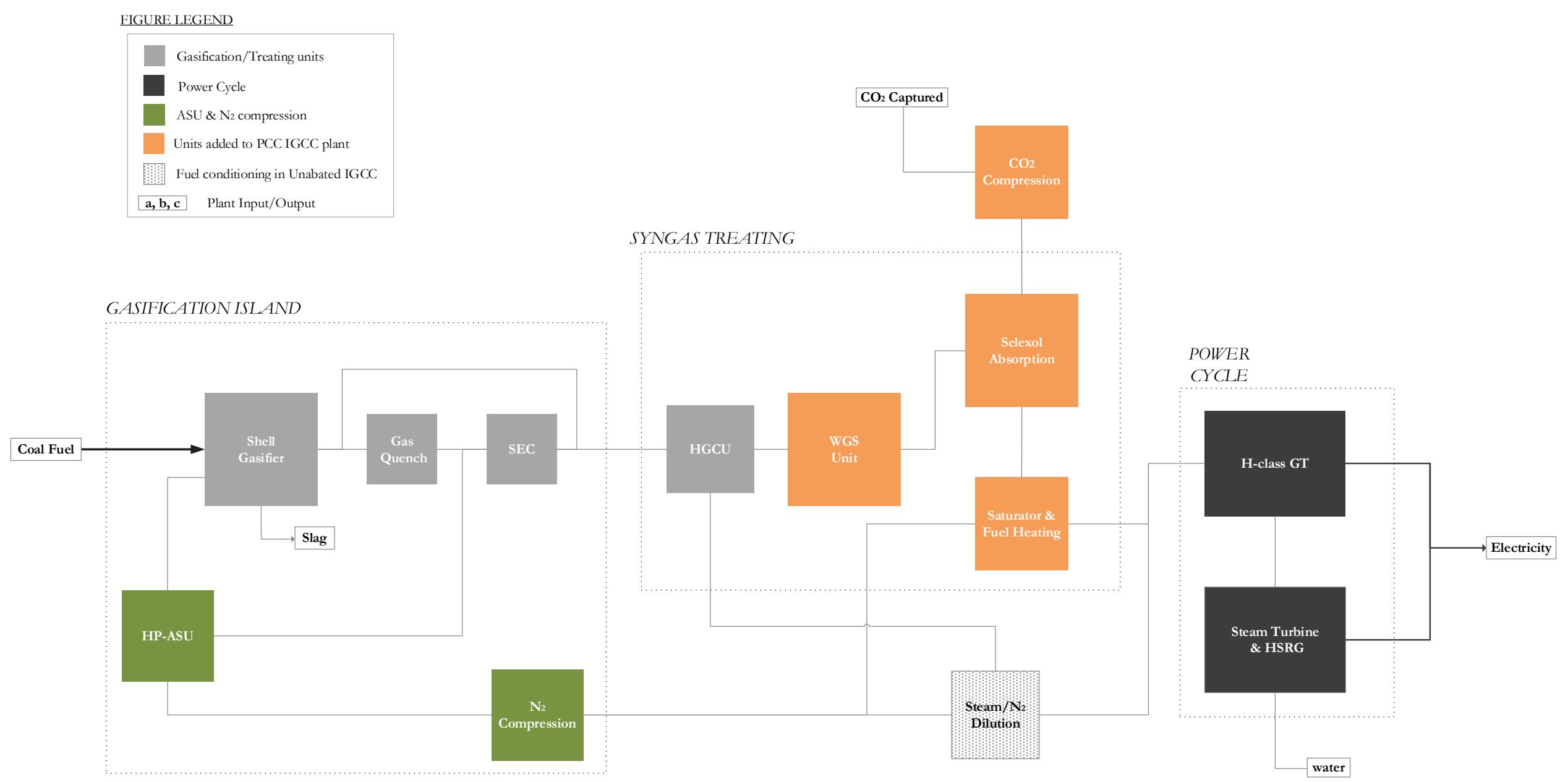

Figure 93 Block flow diagram of the Advanced Unabated and Pre-combustion $\mathrm{CO}_{2}$ capture IGCC power plants 


\section{Energy}

The energy breakdown of the Advanced Unabated IGCC power plant is provided in Table 47 Energy breakdown for the Advanced Unabated IGCC power plant . The use of advanced GT technology and HGCU results in an efficiency improvement of around 4\%-points. It is noted that the efficiency benefits of HGCU are not fully obtained as approximately $13 \%$ of HP stage steam turbine outlet is extracted to dilute the syngas (together with the $\mathrm{N}_{2}$ from the ASU) to reach an SFT of $2200 K$.

Table 47 Energy breakdown for the Advanced Unabated IGCC power plant

\begin{tabular}{|c|c|}
\hline \multicolumn{2}{|c|}{ Gasification \& treating } \\
\hline Coal (as received) (kg/s) & 60,95 \\
\hline Heat input to plant (MW) & 1534,1 \\
\hline Coal milling (MW) & 3,0 \\
\hline Ash handling (MW) & 0,9 \\
\hline Syngas recycle compressor (MW) & 2,3 \\
\hline HGCU aux. (MW) & 1,8 \\
\hline HGCU compander (MW) & 4,1 \\
\hline ASU (MW) & 47,4 \\
\hline N $_{2}$ compression (MW) & 52,0 \\
\hline Expander air (MW) & 15,5 \\
\hline & \\
\hline Power cycle & 561,0 \\
\hline GT net (MW) & 2,2 \\
\hline GT aux. (MW) & 333,1 \\
\hline Steam net (MW) & 6,3 \\
\hline Pumps (MW) & 3,3 \\
\hline Heat rejection( (MW) & 2,3 \\
\hline BoP (MW) & \\
\hline Global balance & 1534,1 \\
\hline Heat input (MW) & 913,6 \\
\hline Gross power (MW) & 792,1 \\
\hline Net power (MW) & 121,5 \\
\hline Total auxiliaries (MW) & 59,6 \\
\hline Gross efficiency (\%) & 51,6 \\
\hline Net efficiency (\%) & \\
\hline & \\
\hline & \\
\hline & \\
\hline & \\
\hline & \\
\hline & \\
\hline & \\
\hline & \\
\hline
\end{tabular}

\section{Environmental}

The plant without capture showed an efficiency improvement which results in a reduction of specific emissions relative to the Unabated IGCC model using F-class turbines, as observed in Figure 94. The specific emissions for the Advanced plant amount to $670,9 \mathrm{~kg} \mathrm{CO} / \mathrm{MWh}$. 


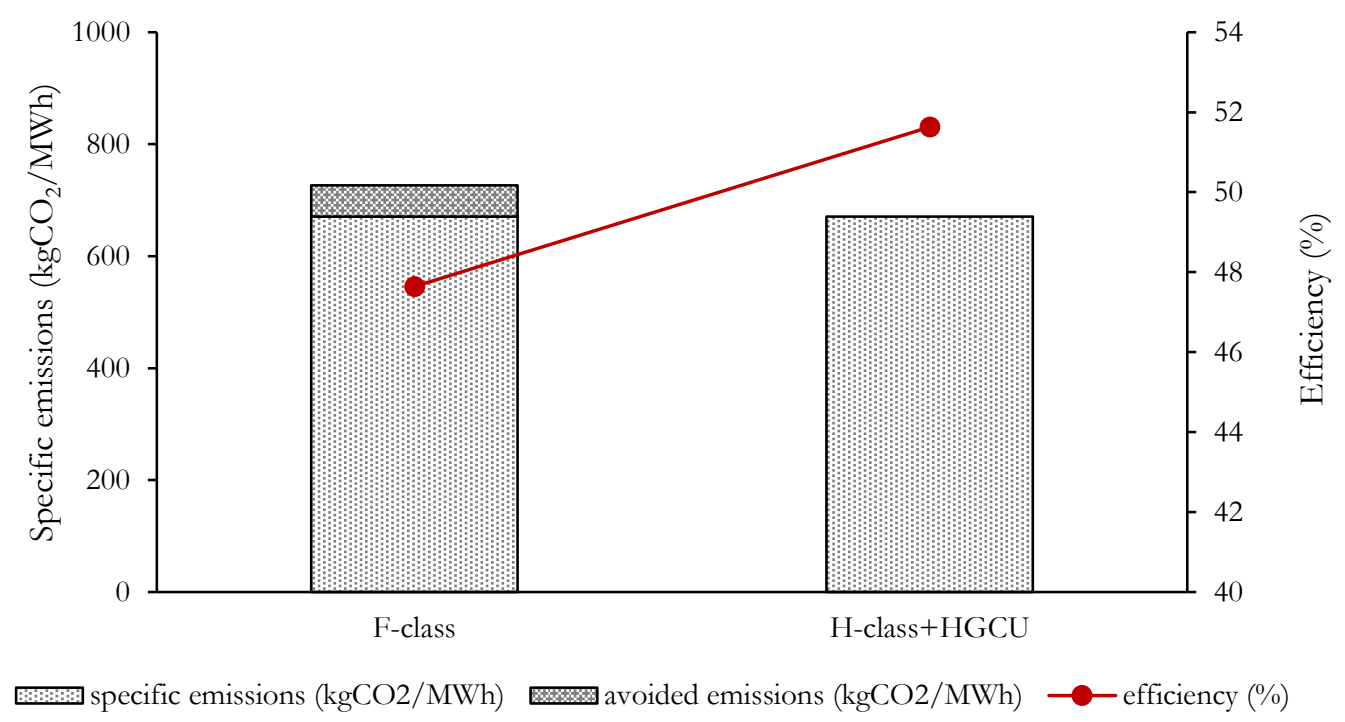

Figure 94 Specific emissions and efficiency comparison between Unabated IGCC benchmarks

\section{Exergy}

For the advanced plants, the exergy study was limited to the calculation of the exergy efficiency based on the definitions provided in section 1.4.3. Table 48 summarizes the global exergy balance:

Table 48 Exergy results for the Advanced Unabated IGCC power plant

\begin{tabular}{|c|c|}
\hline Item & Value \\
\hline Total exergy input (MW) & 1642,3 \\
\hline $\mathrm{CO}_{2}$ captured exergy $(\mathrm{MW})$ & 0,0 \\
\hline $\mathrm{W}_{\text {net }}(\mathrm{MW})$ & 792,1 \\
\hline Exergy lost \& destroyed (MW) & 850,2 \\
\hline$\xi(\%)$ & 48,2 \\
\hline$\xi^{\prime}(\%)$ & 48,2 \\
\hline
\end{tabular}

\section{Economic}

The economic results of the Unabated IGCC plant with advanced GT technology and HGCU are summarized in Table 49:

Table 49 Economic results for Adv. Unabated IGCC power plant

\begin{tabular}{|c|c|}
\hline Item & Value \\
\hline$S I(€ / \mathrm{kW})$ & 2117,9 \\
\hline $\operatorname{LCOE}(€ / \mathrm{MWh})$ & 56,4 \\
\hline $\mathrm{COCA}\left(€ /\right.$ tonCO $\left.\mathrm{CO}_{2}\right)$ & - \\
\hline
\end{tabular}

These results highlight a specific cost reduction of $126,8 € / \mathrm{kW}$ with respect to the previous Unabated IGCC plant (5,7\% less), ultimately leading to $4,8 € / \mathrm{MWh}$ decrease in the cost of electricity (7,9\% reduction). The electricity cost decomposition per item is presented in Figure 96, while Figure 95 shows the cost distribution of the installed cost, where it is highlighted again the large contribution of the gasification island units. The total installed cost added up to $1113,5 \mathrm{M} €$ for this plant. 


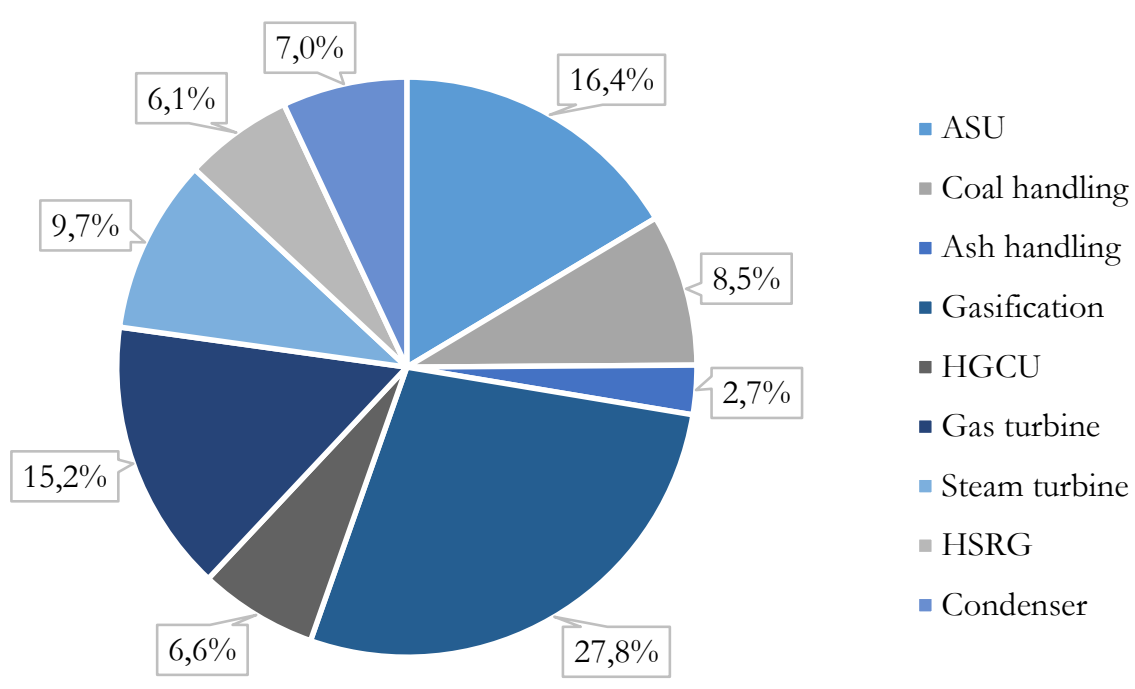

Figure 95 TIC distribution of the Adv. Unabated IGCC power plant

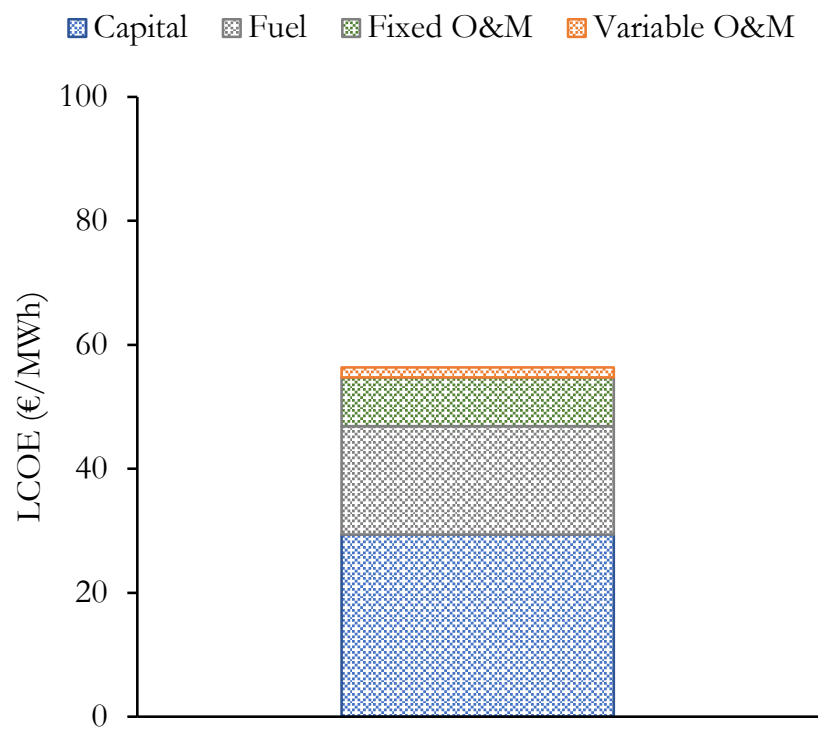

Figure 96 LCOE build-up for the Adv. Unabated IGCC power plant

It is noteworthy to emphasize that the relative contribution of the fuel costs for this plant are approximately $26 \%$ of the total LCOE; a value which somewhat below $(31 \%)$ to the one obtained for the "Introductory" Unabated IGCC power plant. This underlines the higher efficiency of the advanced plant. The economies of scale for the "Advanced" plants are accounted for using a scale up factor of 1 in the economic cost estimations, where due to the large heat rate demand of the GT, two gasification units will be required to deliver sufficient syngas fuel to the machines.

\subsubsection{Adv. Pre-combustion $\mathrm{CO}_{2}$ capture IGCC}

The pre-combustion $\mathrm{CO}_{2}$ capture plant configuration is illustrated in Figure 93, where a WGS unit, A Selexol plant and a $\mathrm{CO}_{2}$ compressor is integrated after gasification. Although previous designs with pre-combustion capture employ a LP-ASU, the current model allows full $\mathrm{N}_{2}$ integration with the GT and is designed for base-load electricity production. A Detailed schematic and stream summary of the plant can be found in Figure 142 and Table 92 in the Appendix. 
Energy

As with the introductory benchmark, pre-combustion capture presents a substantial energy penalty with respect to the Unabated IGCC plant. The main energy and duty outputs are summarized in Table 50.

Table 50 Energy breakdown for the Advance Pre-combustion $\mathrm{CO}_{2}$ capture IGCC power plant

\begin{tabular}{|c|c|}
\hline \multicolumn{2}{|c|}{ Gasification \& treating } \\
\hline Coal (as received) $(\mathrm{kg} / \mathrm{s})$ & 71,31 \\
\hline Heat input (MW) & 1794,9 \\
\hline Coal milling (MW) & 3,6 \\
\hline Ash handling (MW) & 1,0 \\
\hline Syngas recycle compressor (MW) & 2,8 \\
\hline HGCU aux. (MW) & 2,1 \\
\hline HGCU compander (MW) & 4,7 \\
\hline ASU (MW) & 55,5 \\
\hline $\mathrm{N}_{2}$ compression (MW) & 61,1 \\
\hline Expander air (MW) & 18,1 \\
\hline Selexol plant (MW) & 20,7 \\
\hline \multicolumn{2}{|l|}{ Power cycle } \\
\hline GT net (MW) & 585,3 \\
\hline GT aux. (MW) & 2,2 \\
\hline Steam net (MW) & 347,3 \\
\hline Pumps (MW) & 7,4 \\
\hline Heat rejection ( (MW) & 3,9 \\
\hline BoP (MW) & 2,7 \\
\hline $\mathrm{CO}_{2}$ compression \& pump (MW) & 40,7 \\
\hline \multicolumn{2}{|c|}{ Global balance } \\
\hline Heat input (MW) & 1794,9 \\
\hline Gross power (MW) & 955,5 \\
\hline Net power (MW) & 751,8 \\
\hline Total auxiliaries (MW) & 203,6 \\
\hline Gross efficiency $(\%)$ & 53,2 \\
\hline Net efficiency $(\%)$ & 41,9 \\
\hline
\end{tabular}

\section{Environmental}

The Selexol plant is designed to remove approximately $92 \%$ of the $\mathrm{CO}_{2}$ contained in the shifted syngas, resulting in an overall capture and voidance which are reflected in Table 51.

Table $51 \mathrm{CO}_{2}$ emissions performance of the Advanced Pre-combustion $\mathrm{CO}_{2}$ capture IGCC power plant

\begin{tabular}{|c|c|}
\hline Item & Value \\
\hline Specific Emissions $\left(\mathrm{kgCO}_{2} / \mathrm{MWh}\right)$ & 70,6 \\
\hline Capture Ratio $(\%)$ & 91,5 \\
\hline $\mathrm{CO}_{2}$ Avoidance $(\%)$ & 89,5 \\
\hline SPECCA $\left(\mathrm{MJ} / \mathrm{kgCO}_{2}\right)$ & 2,70 \\
\hline
\end{tabular}

It should be said that if the pre-combustion plant was designed for $\mathrm{H}_{2}$ coproduction, a Pressure Swing Absorption (PSA) unit would be needed to reach the required product purity, increasing plant capital costs and preventing the efficiency benefits arising from ASU integration. Moreover, 
the PSA-off gas with should be managed effectively (smaller GT to generate some electricity) that could result in a lower capture rate and therefore much higher emissions.

\section{Exergy}

The global exergy balances applied to the Advance Pre-combustion $\mathrm{CO}_{2}$ capture plant are summarized in Table 52:

Table 52 Exergy balance for the Advance Pre-combustion $\mathrm{CO}_{2}$ capture IGCC power plant

\begin{tabular}{|c|c|}
\hline Item & Value \\
\hline Total exergy input (MW) & 1921,4 \\
\hline $\mathrm{CO}_{2}$ captured exergy (MW) & 107,6 \\
\hline $\mathrm{W}_{\text {net }}(\mathrm{MW})$ & 751,8 \\
\hline Exergy lost \& destroyed (MW) & 1062,0 \\
\hline$\xi(\%)$ & 39,1 \\
\hline$\xi^{\prime}(\%)$ & 44,7 \\
\hline
\end{tabular}

It can be noted that when the exergy of the captured $\mathrm{CO}_{2}$ is taken into account, the resulting exergy efficiency is substantially improved compared to the value obtained when only the electricity generated is evaluated.

\section{Economic}

The main economic metrics are summarized in Table 53. Relative to the Adv. Unabated IGCC plant described in the previous section, the effect of $\mathrm{CO}_{2}$ capture with conventional precombustion technology results in a specific cost increase of $708,6 € / \mathrm{kW}(33,5 \%$ increase) while the LCOE rises by $25,4 € / \mathrm{MWh}(45,1 \%$ increase). On the other hand, given that the two plants employ the same GT size, the pre-combustion plant presents a fuel cost increase of 4,0 €/MWh (23,2\% increase) and capital cost increase of $11,5 € / \mathrm{MWh}(38,9 \%$ increase). Finally the variable costs experience a large increase given the $\mathrm{CO}_{2}$ transport and storage costs accounted for in the plant with CCS.

Table 53 Economic results for the Adv. Pre-combustion $\mathrm{CO}_{2}$ capture IGCC power plant

\begin{tabular}{|c|c|}
\hline Item & Value \\
\hline$S I(€ / \mathrm{kW})$ & 2826,5 \\
\hline$L C O E(€ / \mathrm{MWh})$ & 81,8 \\
\hline $\operatorname{COC} A\left(€ /\right.$ tonCO $\left._{2}\right)$ & 42,3 \\
\hline
\end{tabular}

The cost of $\mathrm{CO}_{2}$ avoided calculated for this plant uses the reference emissions and electricity cost of the Adv. Unabated IGCC power plant, i.e. $670,9 \mathrm{kgCO}_{2} / \mathrm{MWh}$ and 56,4 $€ / \mathrm{MWh}$ respectively. Finally, in Figure 97 the installed cost distribution for the precombustion plant is shown, which adds up to 1410,5 M€, while the different electricity cost contributions are reflected in Figure 98. 


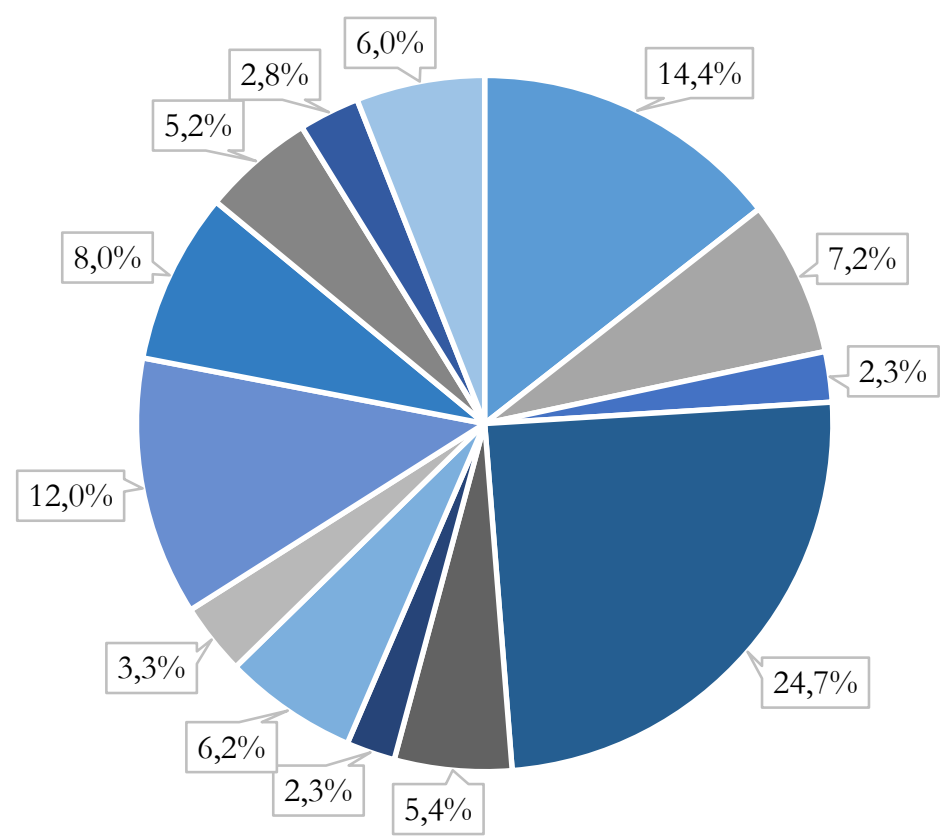

$\because \mathrm{ASU}$

- Coal handling

- Ash handling

- Gasifier

- HGCU

- WGS

- Selexol plant

- CO2 compression

- Gas Turbine

- Steam Turbine

- HRSG

- Heat exhangers

- Condenser

Figure 97 TIC distribution for the Adv. Pre-combustion $\mathrm{CO}_{2}$ capture IGCC power plant

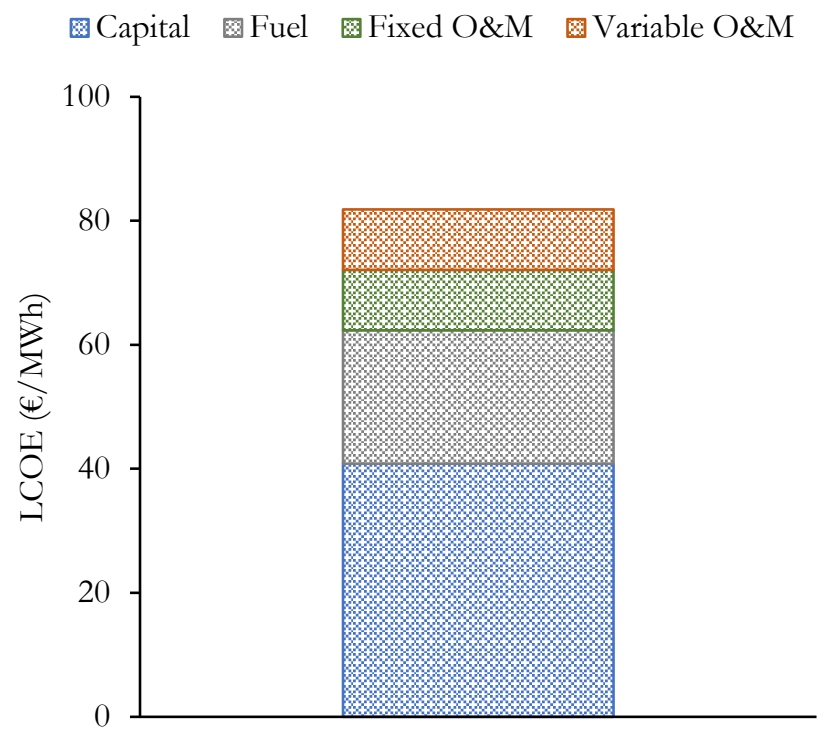

Figure 98 LCOE build-up for the Adv. Pre-combustion $\mathrm{CO}_{2}$ capture IGCC plant

\subsection{GSC Power Plants}

In this section the plants incorporating GSC are presented. The advanced plants also incorporate the MAWGS reactor to enhance the TIT and maximize thermal efficiency with modern $\mathrm{H}$-class turbines.

\subsubsection{Standalone GSC IGCC}

The GSC standalone IGCC power plant was designed based on [71] and has a similar gasification island as the pre-combustion $\mathrm{CO}_{2}$ capture benchmark. The scrubber unit is removed and cooling is done only to $\mathrm{HGCU}$ temperature $\left(400^{\circ} \mathrm{C}\right)$, incorporating the efficiency benefits of high temperature desulphurization. The hot syngas is routed then to the GSC reduction stage where it 
is fully combusted to water and $\mathrm{CO}_{2}$. After high temperature heat recovery in a dedicated exchanger, the pressurized reduction gases stream is further cooled to ambient, and routed to the $\mathrm{CO}_{2} \mathrm{CPU}$ where the required transport purity is reached, venting a small stream consisting of $\mathrm{CO}_{2}$ and mainly $\mathrm{N}_{2}$ which ingresses the reduction outlet during valve switching in the GSC, and due to the $\mathrm{N}_{2}$ present in the gasification oxidant stream. The oxidation reaction stage is operated with the $\mathrm{N}_{2}$ recycle strategy to maintain high average outlet temperature (up to $1181^{\circ} \mathrm{C}$ ) while minimizing the degree of undesired mixing. This requires the cooling to ambient temperatures of the exhaust gases after the HSRG and partial recirculation to the GT compressor (the changes in the GT operating point were neglected). Figure 99 shows a block flow diagram of the modelled concept. A detailed power plant schematic and stream summary are given in the Appendix in Figure 143 and Table 93 respectively.

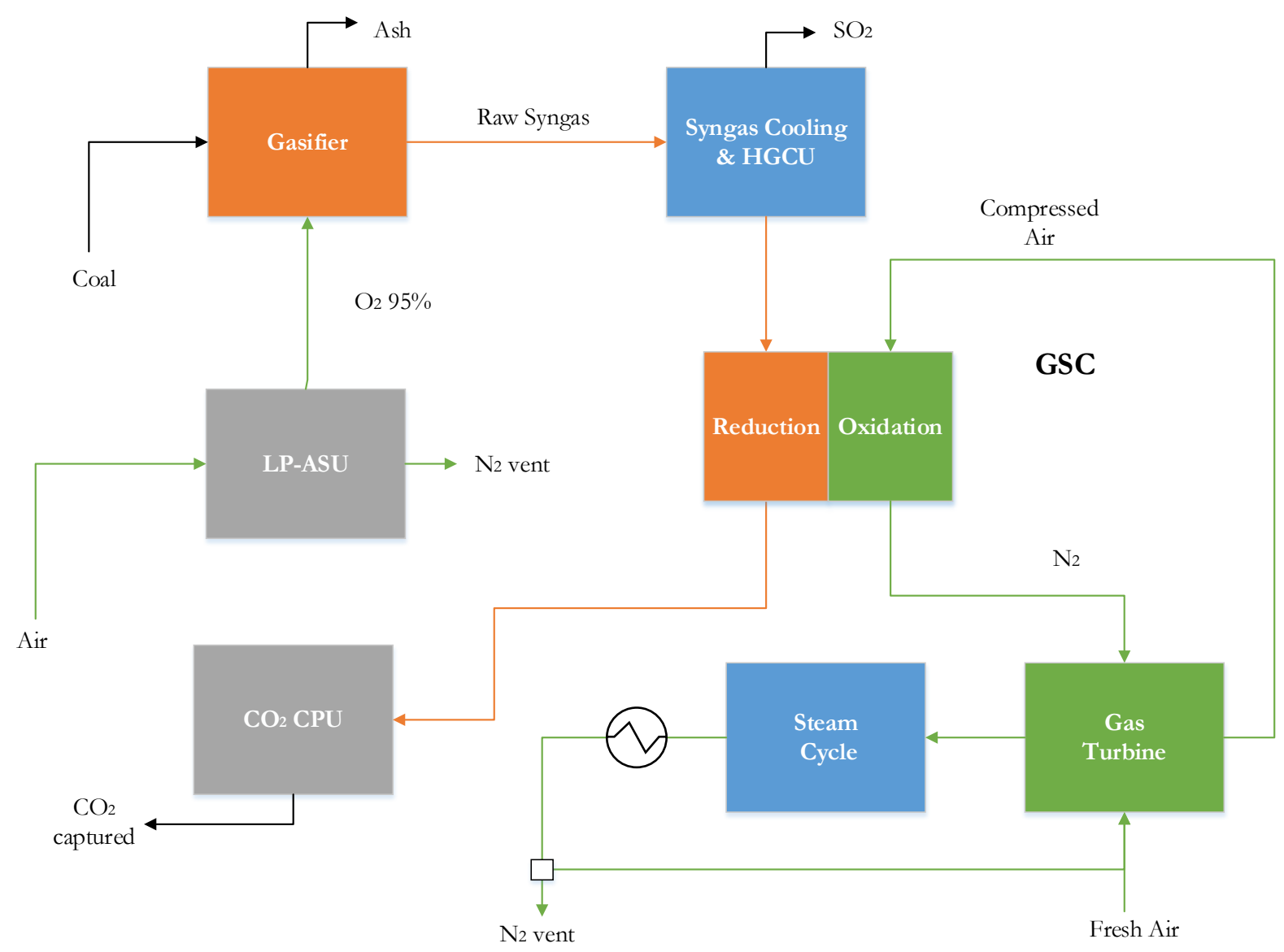

Figure 99 Block flow diagram of the Standalone GSC IGCC power plant

\section{Energy}

The energy breakdown of the Standalone GSC IGCC power plant is provided in Table 54. Due to the lower TIT, the power output shifts from the topping cycle to the bottoming cycle. The gross efficiency is therefore lower than the Unabated IGCC, but this configuration achieves a reduction of the energy penalty amounting to $5.6 \%$-points.

Table 54 Energy breakdown of the Standalone GSC IGCC power plant

Power \& heat balance

Coal heat input (MW) 854,0 


\begin{tabular}{|c|c|}
\hline Compressor (MW) & 328,7 \\
\hline Turbine (MW) & 533,8 \\
\hline GT net (MW) & 201,3 \\
\hline Steam cycle net (MW) & 234,0 \\
\hline Condenser (MW) & 320,8 \\
\hline N 2 cooling (MW) $^{\text {Power plant auxiliaries }}$ \\
\hline \multicolumn{2}{|c|}{ Po,1 } \\
\hline GT auxiliaries (MW) & 0,7 \\
\hline ASU (MW) & 36,8 \\
\hline Coal milling (MW) & 1,7 \\
\hline Ash handling (MW) & 0,5 \\
\hline Syngas treating (MW) & 1,0 \\
\hline Regeneration compander (MW) & 0,3 \\
\hline CO purification unit (MW) & 14,6 \\
\hline Water pumps (MW) & 3,2 \\
\hline Heat rejection (MW) & 3,9 \\
\hline Balance of plant (MW) & 1,3 \\
\hline Global balance \\
\hline Total auxiliaries (MW) & 63,9 \\
\hline Gross plant (MW) & 435,3 \\
\hline Net plant (MW) & 371,4 \\
\hline Total heat input (MW) & 854,0 \\
\hline Gross efficiency (\%LHV) & 51,0 \\
\hline Net efficiency (\%LHV) & 43,4 \\
\hline
\end{tabular}

The pressurized stream of $\mathrm{CO}_{2}$ obtained in the reduction outlet reduces the $\mathrm{CO}_{2}$ compression requirements. On the other hand, the larger steam cycle, which is a result of the lower thermodynamic temperatures reached in the topping cycle, results in higher auxiliary consumption of pumps and heat rejection (condenser) units. A detailed analysis of the GSC standalone plant is offered in [116], using Ilmenite as oxygen carrier.

\section{Environmental}

With regard to the $\mathrm{CO}_{2}$ emissions, the Standalone GSC IGCC power plant somewhat improves the performance of the pre-combustion capture plant, as observed in Table 55. It is reminded here that NOx emissions are not a concern due to the flameless combustion occurring in CLC, so there is no need for syngas dilution. Remaining H2S species after HGCU are safely retained in the reduction gases stream.

Table $55 \mathrm{CO}_{2}$ emissions performance of the Standalone GSC IGCC power plant

\begin{tabular}{|c|c|}
\hline Item & Value \\
\hline $\mathrm{CO}_{2}$ Emissions $(\mathrm{kgCO} / \mathrm{MWh})$ & 62,6 \\
\hline $\mathrm{CO}_{2}$ Capture $(\%)$ & 92,2 \\
\hline $\mathrm{CO}_{2}$ Avoidance $(\%)$ & 91,4 \\
\hline SPECCA $\left(\mathrm{MJ} / \mathrm{kgCO}_{2}\right)$ & 1,12 \\
\hline
\end{tabular}

An inspection of the $\mathrm{CO}_{2}$ emission sources across the plant (Figure 100) reveals that the lock hopper venting and emissions due to coal drying are the greatest contributor followed by the undesired mixing in the GSC cluster. 


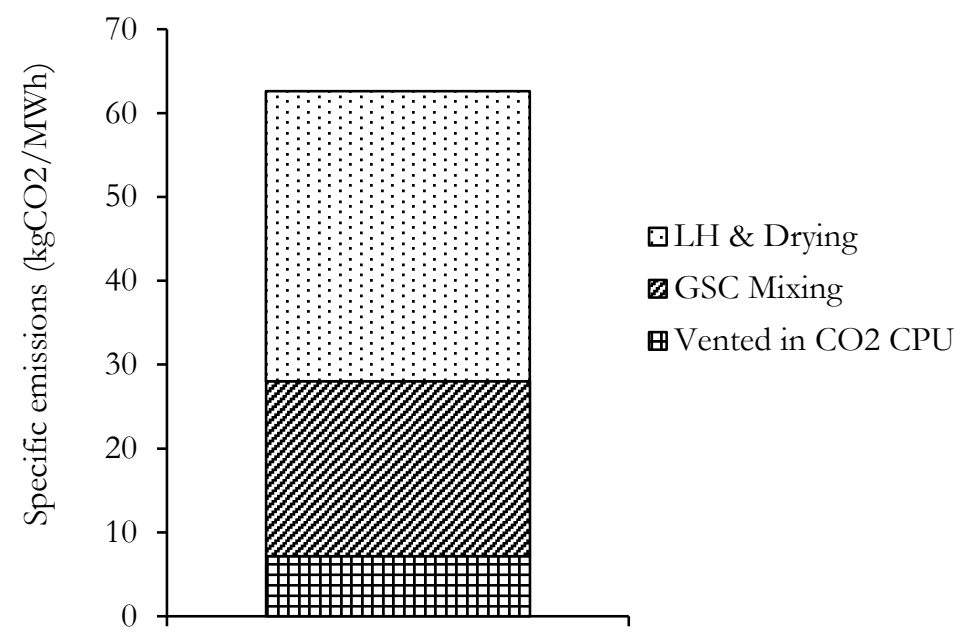

Figure $100 \mathrm{CO}_{2}$ emissions breakdown for the Standalone GSC IGCC power plant

\section{Exergy}

Exergy analysis for the Standalone GSC IGCC plant is summarized in Table 56 and Figure 101. The removal of the combustion chamber reduces signgicantly the exergy loss contribution of the GT. Instead, the GSC cluster takes up the exergy destruction due to the combustion of the fuel. On the other hand, the exergy destruction occurring during cooling and clean-up of syngas is greatly diminished due to HGCU, while the steam cycle now takes a bigger portion of the exergy losses. Since the exhaust gas from the HSRG is cooled down and recycled, there is a smaller overall exergy in the material streams leaving the boundary of the power plant.

Table 56 Total exergy breakdown for the Standalone GSC IGCC power plant

\begin{tabular}{|c|c|c|}
\hline Block & Item & Exergy (MW) \\
\hline \multirow{2}{*}{ Gasification island } & ASU & 23,5 \\
\hline & Gasifier & 130,5 \\
\hline \multirow{2}{*}{ Syngas cooling and treating } & SEC & 16,1 \\
\hline & HGCU & 9,3 \\
\hline GSC cluster & GSC & 156,5 \\
\hline \multirow{2}{*}{ Gas turbine } & Compressor & 27,1 \\
\hline & Turbine & 26,4 \\
\hline \multirow{5}{*}{ Steam cycle } & HSRG & 14,5 \\
\hline & Hot gases recovery unit & 18,4 \\
\hline & Condenser cooling \& pumps & 12,9 \\
\hline & $\mathrm{N}_{2}$ cooler & 7,7 \\
\hline & Steam turbine & 21,7 \\
\hline \multirow{2}{*}{$\mathrm{CO}_{2}$ purification \& compression } & Red. gases condenser & 4,6 \\
\hline & $\mathrm{CPU}$ & 7,2 \\
\hline \multirow{4}{*}{ Exergy out } & Slag & 5,3 \\
\hline & $\mathrm{CO}_{2}$ & 51,2 \\
\hline & Stack gases & 4,7 \\
\hline & Other (water etc.) & 5,6 \\
\hline Misc. & Misc. (BoP) & 1,3 \\
\hline Useful effect & Wnet & 370,5 \\
\hline
\end{tabular}




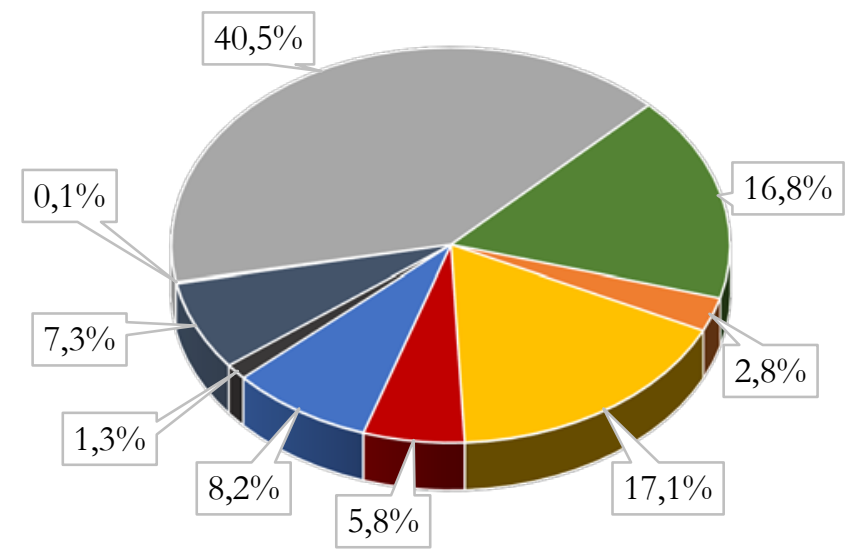

- Gasification island

- Syngas cooling and treating

- GSC cluster

- Gas turbine

- Steam cycle

- CO2 purification \& compression

- Exergy out

- Misc.

- Useful effect

Figure 101 Exergy distribution for the Standalone GSC IGCC power plant

An interesting visualization of the exergy flows occurring in the less-known IGCC plants with chemical looping technology was carried out: the Sankey flow diagram which is shown in Figure 102 for this power plant concept. A detailed exergy analysis discussion is presented in [117]

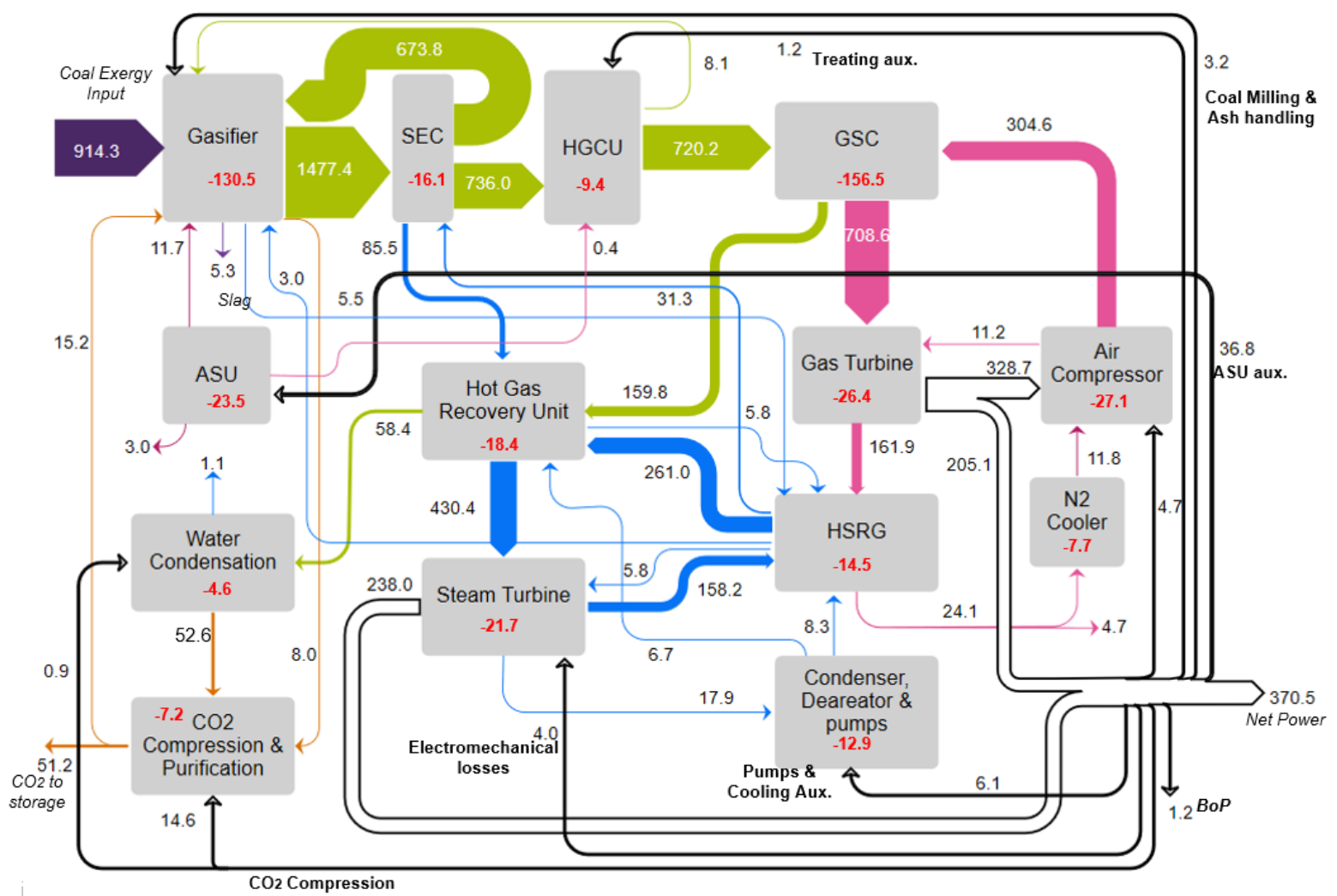

Figure 102 Exergy flow diagram of the Standalone GSC IGCC power plant. Values are in MW

Economic

For the economic assessment of the Standalone GSC plant, it was decided to lower the GSC oxidation outlet temperature in order to minimize the mixing and avoid the use of a $\mathrm{CO}_{2} \mathrm{CPU}$ unit, recurring only to a two stage compressor system. This implies a small efficiency penalty of 0,3\%-points and a 2,0\%-points higher capture rate. The main economic results are given in Table 57: 
Table 57 Economic results for the Standalone GSC IGCC power plant

\begin{tabular}{|c|c|}
\hline Item & Value \\
\hline$S I(€ / \mathrm{kW})$ & 3000,8 \\
\hline $\operatorname{LCOE}(€ / \mathrm{MWh})$ & 82,8 \\
\hline$C O C A_{I G C C}(€ /$ tonCO 2$)$ & 31,7 \\
\hline $\mathrm{COCA}_{S C P C}\left(€ /\right.$ tonCO $\left.\mathrm{C}_{2}\right)$ & 37,8 \\
\hline
\end{tabular}

The integration of a GSC cluster and HGCU treating technology achieves a reduction of the LCOE relative to the pre-combustion capture plant of $9,9 € / \mathrm{MWh}(10,7 \%$ reduction) while the specific investment dropped by $177,2 € / \mathrm{kW}$ (5,6\% reduction). Figure 103 shows the TIC cost distribution, which adds up to 732,9 M€, while Figure 104 reveals the LCOE build up considering different cost items.

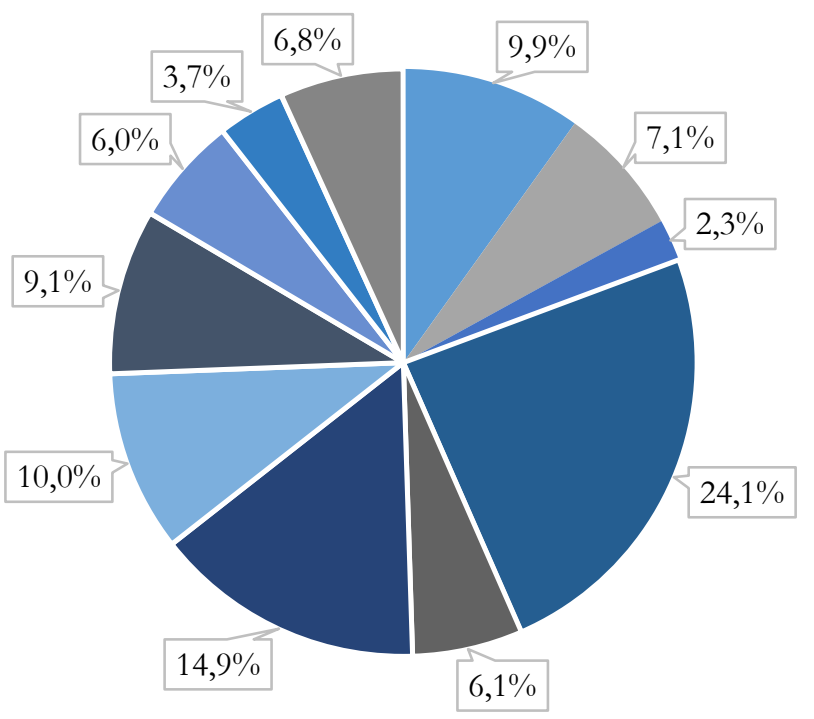

- ASU

- Coal handling

- Ash handling

- Gasifier

- HGCU

- Gas Switching Island

- Gas Turbine

- Steam Turbine

- HRSG

- Heat exhangers

- Condenser

Figure 103 TIC distribution for the Standalone GSC IGCC power plant

圈 Capital 图Fuel 圈Fixed O\&M 图 Variable O\&M

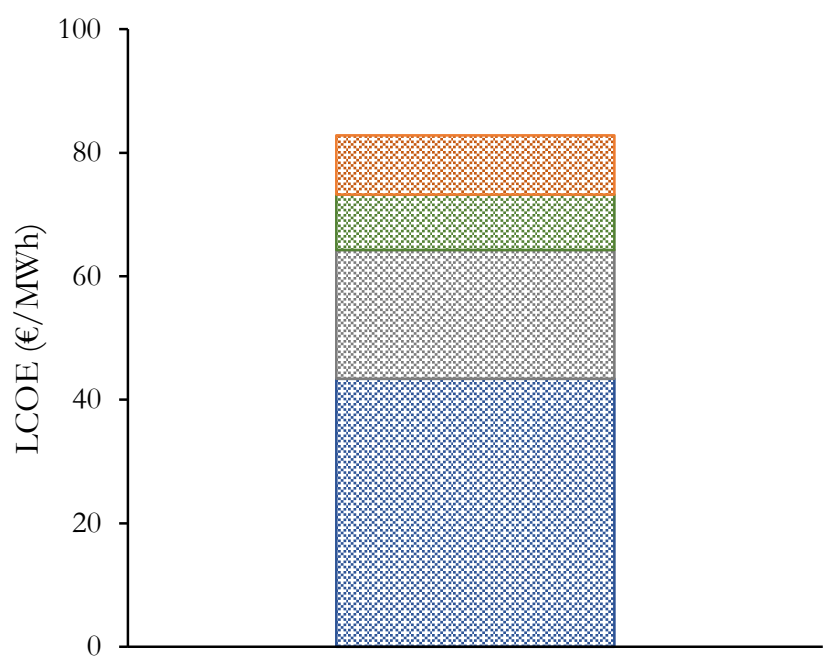

Figure 104 LCOE build up for the Standalone GSC IGCC power plant 


\subsubsection{GSC with Extra Firing IGCC}

An efficiency enhancement of the Standalone GSC IGCC concept consists of adding an extra firing chamber after the GSC cluster to boost the TIT to temperature levels of the reference Fclass turbine, using a natural gas fuel. Furthermore, the heat contained in the reduction gases after the cluster can be effectively transferred to the air stream, which is a more efficient solution than direct steam generation in the hot gases heat recovery unit, since the heat is transferred to the topping cycle. Steam superheat can be accomplished exclusively in the main HSRG since, due to the higher combustor temperatures, the TOT is consequently above than that in the Standalone GSC IGCC plant. The reduction gases after the recuperator have a smaller heat recovery unit with only HP evaporator and economizer. Since $\mathrm{O}_{2}$ is required after the GSC oxidation stage for the extra firing, the $\mathrm{N}_{2}$ recycle strategy to maintain high GSC temperature and minimize undesired mixing is not viable. Therefore the $\mathrm{O}_{2}$ slip strategy is used, which resulted in a very low level of mixing and prevented the need for a $\mathrm{CO}_{2}$ purification unit. Instead a two stage compressor and a pump were used to deliver the captured $\mathrm{CO}_{2}$ at 150 bar. A descriptive block flow diagram is given in Figure 105, while detailed schematics and stream summary are shown in Figure 144 and Table 94 in the Appendix.

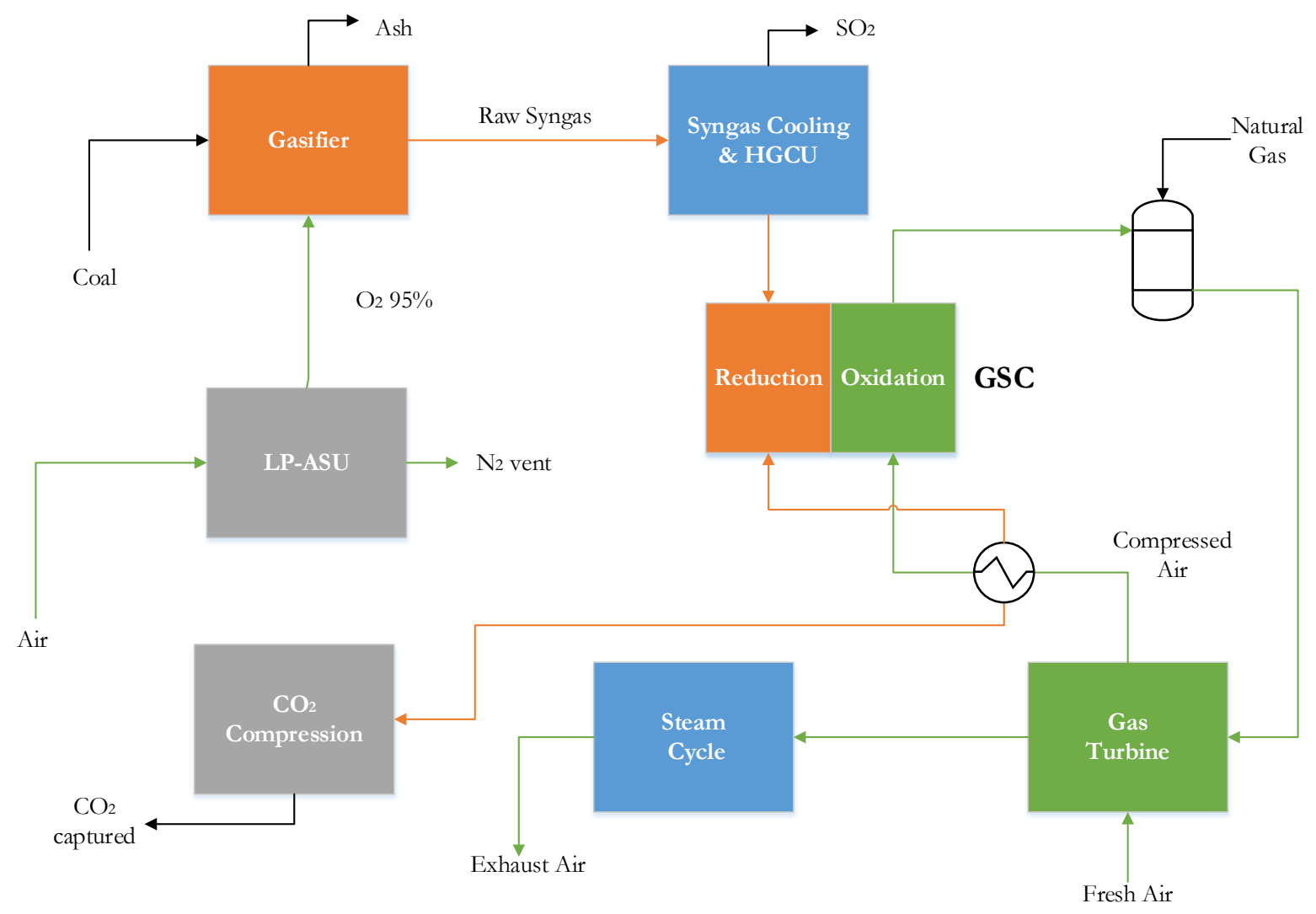

Figure 105 Block flow diagram of the GSC IGCC power plant with NG extra firing

\section{Energy}

The energy breakdown of the GSC with Extra Firing IGCC plant is provided in Table 58. The effect of natural gas firing to raise TIT results in a substantial increase of the gross efficiency. Furthermore, NG does not require clean up and gasification like coal, resulting in an overall net efficiency above the Unabated IGCC plant benchmark. 
Table 58 Energy breakdown of the GSC with Extra Firing IGCC power plant

\begin{tabular}{|c|c|}
\hline \multicolumn{2}{|c|}{ Power-heat breakdown } \\
\hline Coal input (MW) & 854,0 \\
\hline Natural gas input (MW) & 322,8 \\
\hline Compressor (MW) & 441,5 \\
\hline Turbine (MW) & 815,2 \\
\hline GT net (MW) & 368,3 \\
\hline Steam cycle net (MW) & 278,1 \\
\hline Condenser (MW) & 400,4 \\
\hline Power plant auxiliaries \\
\hline GT auxiliaries (MW) & 1,3 \\
\hline ASU (MW) & 36,8 \\
\hline Coal milling (MW) & 1,7 \\
\hline Ash handling (MW) & 0,5 \\
\hline Syngas recycle blower (MW) & 1,0 \\
\hline Syngas treating (MW) & 1,0 \\
\hline CO 2 compression(MW) & 13,3 \\
\hline Water pumps (MW) & 3,6 \\
\hline Heat rejection (MW) & 3,7 \\
\hline Balance of plant (MW) & 1,3 \\
\hline \multicolumn{2}{|c|}{ Global balance } \\
\hline Total auxiliaries (MW) & 64,0 \\
\hline Gross plant (MW) & 646,4 \\
\hline Net plant (MW) & 582,4 \\
\hline Total heat input (MW) & 1176,8 \\
\hline Gross efficiency (\%LHV) & 54,9 \\
\hline Net efficiency (\%LHV) & 49,5 \\
\hline \multicolumn{2}{|c}{} \\
\hline
\end{tabular}

Since part of the heat contained in the reduction gases is transferred into to the air compressor outlet and due to the higher thermodynamic cycle temperatures, the power output shifts again towards the topping cycle.

\section{Environmental}

The notorious efficiency improvement attained in this configuration comes at the cost of an increased degree of carbonaceous emissions and a lower capture rate, as detailed in Table 59. When looking at the emission distribution, it is clear that the natural gas firing contribution is the largest, as shown in Figure 106.

Table $59 \mathrm{CO}_{2}$ emissions performance of the GSC with Extra Firing IGCC power plant

\begin{tabular}{|c|c|}
\hline Item & Value \\
\hline $\mathrm{CO}_{2}$ Emissions (kgCO $\left./ \mathrm{MWh}\right)$ & 140,4 \\
\hline $\mathrm{CO}_{2}$ Capture $(\%)$ & 77,5 \\
\hline $\mathrm{CO}_{2}$ Avoidance $(\%)$ & 80,7 \\
\hline SPECCA $\left(\mathrm{MJ} / \mathrm{kgCO}_{2}\right)$ & $-0,482$ \\
\hline
\end{tabular}




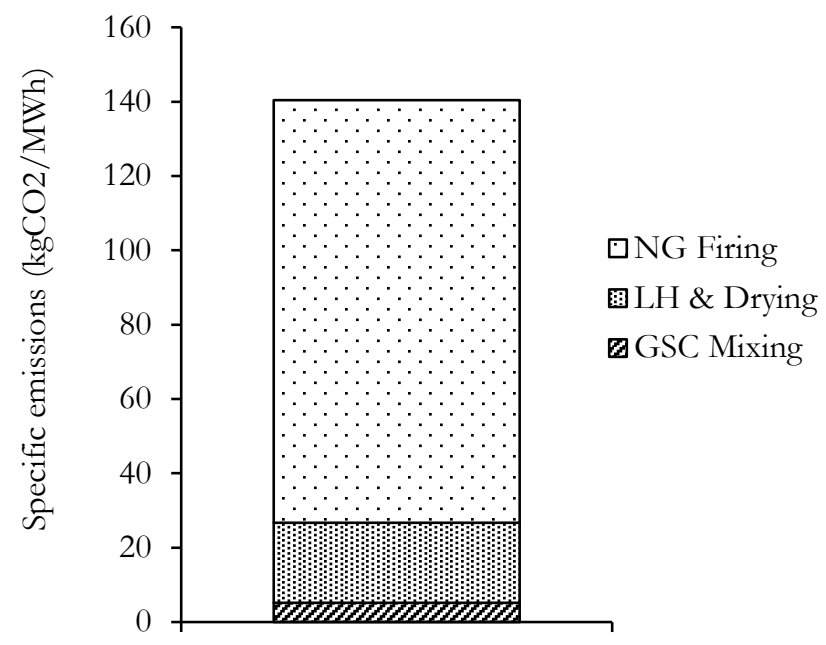

Figure $106 \mathrm{CO}_{2}$ emissions distribution for the GSC with Extra Firing IGCC power plant

The negative SPECCA value has no physical meaning other than the fact that the GSC with Extra Firing IGCC plant is actually more efficient than the Unabated IGCC benchmark, which also results in a $\mathrm{CO}_{2}$ avoidance value above the actual plant capture rate (also the lower carbon intensity of natural gas contributes to this). This is because natural gas fuel does not have to undergo the heating value losses that coal experiences due to gasification and contaminant removal (and associated auxiliary energy consumption needed to accomplish this).

\section{Exergy}

The total exergy breakdown and \% distribution is presented in Table 60 and Figure 107 respectively. In this case, the technology block topping cycle, refers to all the elements contained in the GT, including the recuperator exchanger. For this particular evaluation, the pressure drop exergy destruction from the gasifier pressure to the GSC was accounted for in the HGCU unit. The GSC contribution is presented separately.

Table 60 Exergy distribution for the GSC with Extra Firing IGCC power plant

\begin{tabular}{|c|c|c|}
\hline Block & Item & Exergy (MW) \\
\hline \multirow{2}{*}{ Gasification island } & ASU & 23,6 \\
\hline & Gasification & 128,6 \\
\hline \multirow{2}{*}{ Syngas cooling \& treating } & SEC & 15,4 \\
\hline & $\mathrm{HGCU}$ & 10,3 \\
\hline \multirow{4}{*}{ Topping cycle } & Recuperator & 11,7 \\
\hline & Firing chamber & 80,9 \\
\hline & Compressor & 29,3 \\
\hline & Turbine & 57,4 \\
\hline GSC cluster & GSC & 156,2 \\
\hline \multirow{4}{*}{ Bottoming cycle } & HSRG & 26,6 \\
\hline & Hot gases recovery & 2,9 \\
\hline & Condenser, pumps etc. & 14,5 \\
\hline & Steam turbine & 26,5 \\
\hline \multirow{2}{*}{$\mathrm{CO}_{2}$ compression } & Red. gases condenser & 3,8 \\
\hline & $\mathrm{CO}_{2}$ compression & 6,7 \\
\hline \multirow[b]{3}{*}{ Exergy out } & Exhaust gases & 14,4 \\
\hline & $\mathrm{CO}_{2}$ captured & 52,8 \\
\hline & $\mathrm{N}_{2}$ vent & 3,4 \\
\hline
\end{tabular}




\begin{tabular}{|c|c|c|}
\hline \multirow{2}{*}{ Misc. } & Slag & 5,3 \\
\cline { 2 - 3 } & Other (water, $\mathrm{CO}_{2}$ vent) & 2,7 \\
\hline Useful effect & BoP & 1,3 \\
\hline & $\mathrm{W}_{\text {net }}$ & 582,4 \\
\hline
\end{tabular}

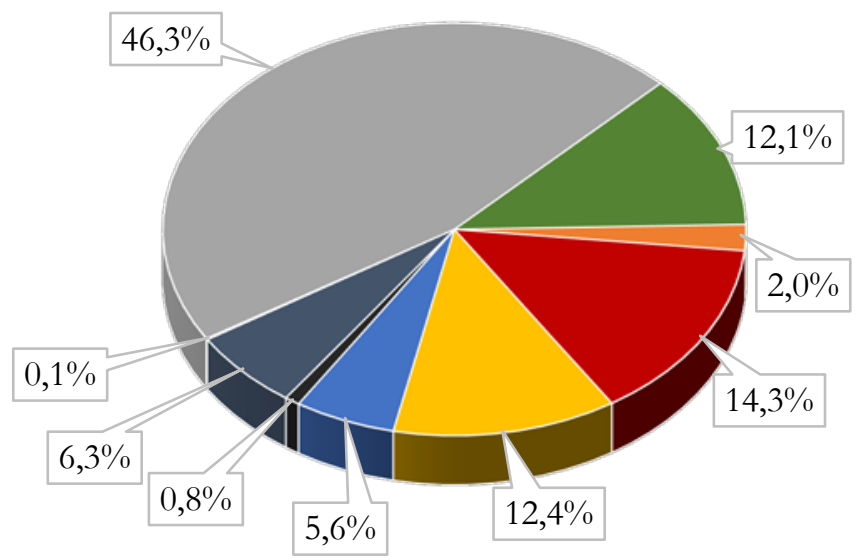

- Gasification

- Syngas cooling \& treating

- Topping cycle

- GSC cluster

- Bottoming cycle

- CO2 compression

- Exergy out

- Misc.

- Useful effect

Figure 107 Exergy distribution in \% of the GSC with Extra Firing IGCC power plant

Due to the addition of natural gas in the firing chamber, the topping cycle contribution is relatively bigger than for the Standalone GSC plant, while the rest of the component's contribution are similarly distributed.

\section{Economic}

The economic results for the GSC with Extra Firing IGCC power plant are presented in Table 61, while the installed cost distribution, with a total of 799,8 M€, is given in Figure 108. Finally, the cost contribution of capital and operating costs is shown in Figure 109.

Table 61 Economic results for the GSC with Extra Firing IGCC power plant

\begin{tabular}{|c|c|}
\hline Item & Value \\
\hline$S I(€ / \mathrm{kW})$ & 2067,7 \\
\hline $\operatorname{LCOE}(€ / \mathrm{MWh})$ & 69,8 \\
\hline$C O C A_{I G C C}\left(€ /\right.$ tonCO $\left.C_{2}\right)$ & 14,4 \\
\hline$C O C A_{S C P C}\left(€ /\right.$ tonCO $\left.C_{2}\right)$ & 22,4 \\
\hline
\end{tabular}

The GSC with Extra Firing IGCC plant achieves a reduction of the cost of electricity of 23,0 $€ /$ MWh $(24,8 \%$ reduction), while the specific investment falls by $1110,3 € / \mathrm{kW}$ (corresponding to $34,9 \%$ reduction). The large efficiency gain achieved with this configuration results in the lowest $\mathrm{CO}_{2}$ avoidance cost of the plants investigated. 


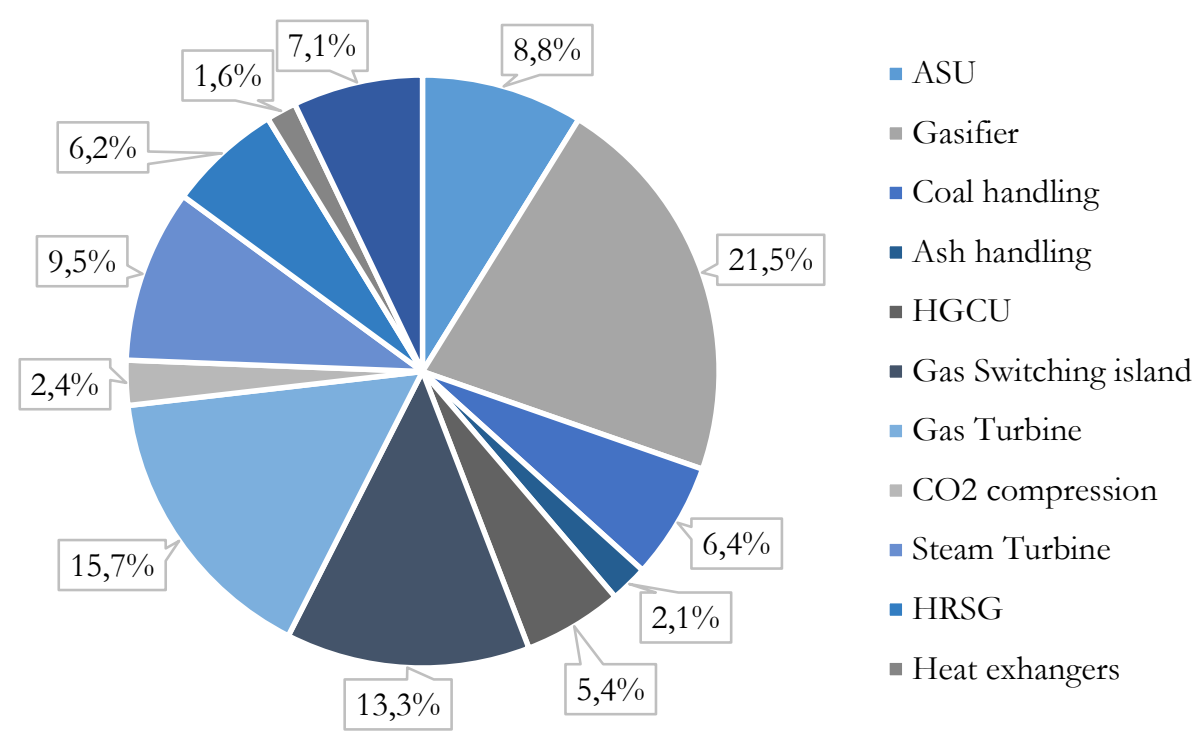

Figure 108 TIC distribution for the GSC with Extra Firing IGCC power plant

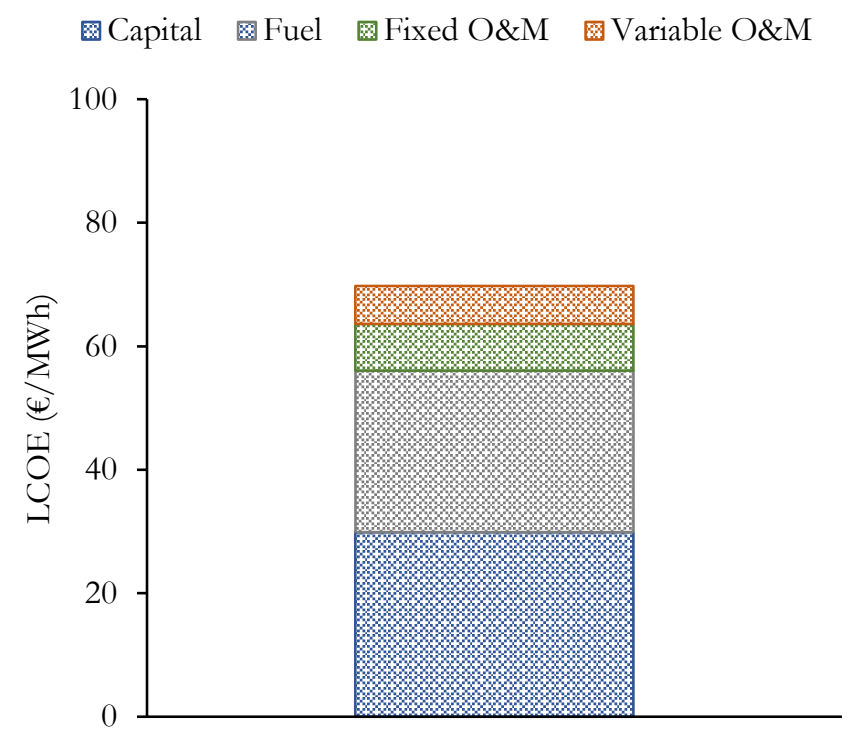

Figure 109 LCOE build up for the GSC with Extra Firing IGCC power plant

\subsubsection{Integrated Gasification GSC-HAT}

The Integrated Gasification GSC-HAT power plant concept arises with the need of increasing the flexibility of IGCC plants with traditionally inflexible units, long start up times, low capacity to operate discontinually or at partial loads. In an energy market with a high penetration of intermittent renewable sources, it becomes critical for thermal fossil fuel plant to adapt load upon demand $[118,119]$. In the GSC-HAT plant, air separation, gasification and gas clean operate at full capacity while the flexible humid air turbine cycle follows load depending on electricity demand. For this purpose, the GSC oxygen carrier behaves as an energy storage mechanism, with the reduction and oxidation sections of the plant completely decoupled and with the $\mathrm{N}_{2}$ recycle strategy to maintain the oxidation through the complete cycle length and avoid sharp changes in temperature. In that sense, the reduction section is electrically self-sufficient and is designed to maximize the flow rate across the reduction expansion path through a partial water quench cooling 
arrangement, similarly to the designs presented in [120]. In such an energy storage design, the capital intensive section of gasification and gas clean up can be downsized relatively to HAT power cycle, which is expected to bring savings in terms of capital expenditure compared to a combined cycle configuration. Due to the intercooling of the HAT compressor, the specific work is higher than in a normal GT with adiabatic compression. Therefore when operating at a pressure ratio of 10 , which is helpful in terms of reactor design for energy storage, the total reactor volume, (dependant of volumetric flow rates) is similar to the GSC Standalone IGCC plant. Since reduction gases expansion is carried out, the $\mathrm{n}^{\circ}$ of $\mathrm{CO}_{2}$ compression stages are increased to 5 in order to obtain reasonable duties. To ensure sufficient purity of the captured stream, the $\mathrm{O}_{2}$ purity from the ASU was raised to $98 \%$. Gasification is carried out with GE technology to minimize cost. A diagram of the Integrated Gasification GSC-HAT concept is presented in Figure 110, while a detailed schematic and corresponding stream summary are shown in Figure 145 \& Table 95.

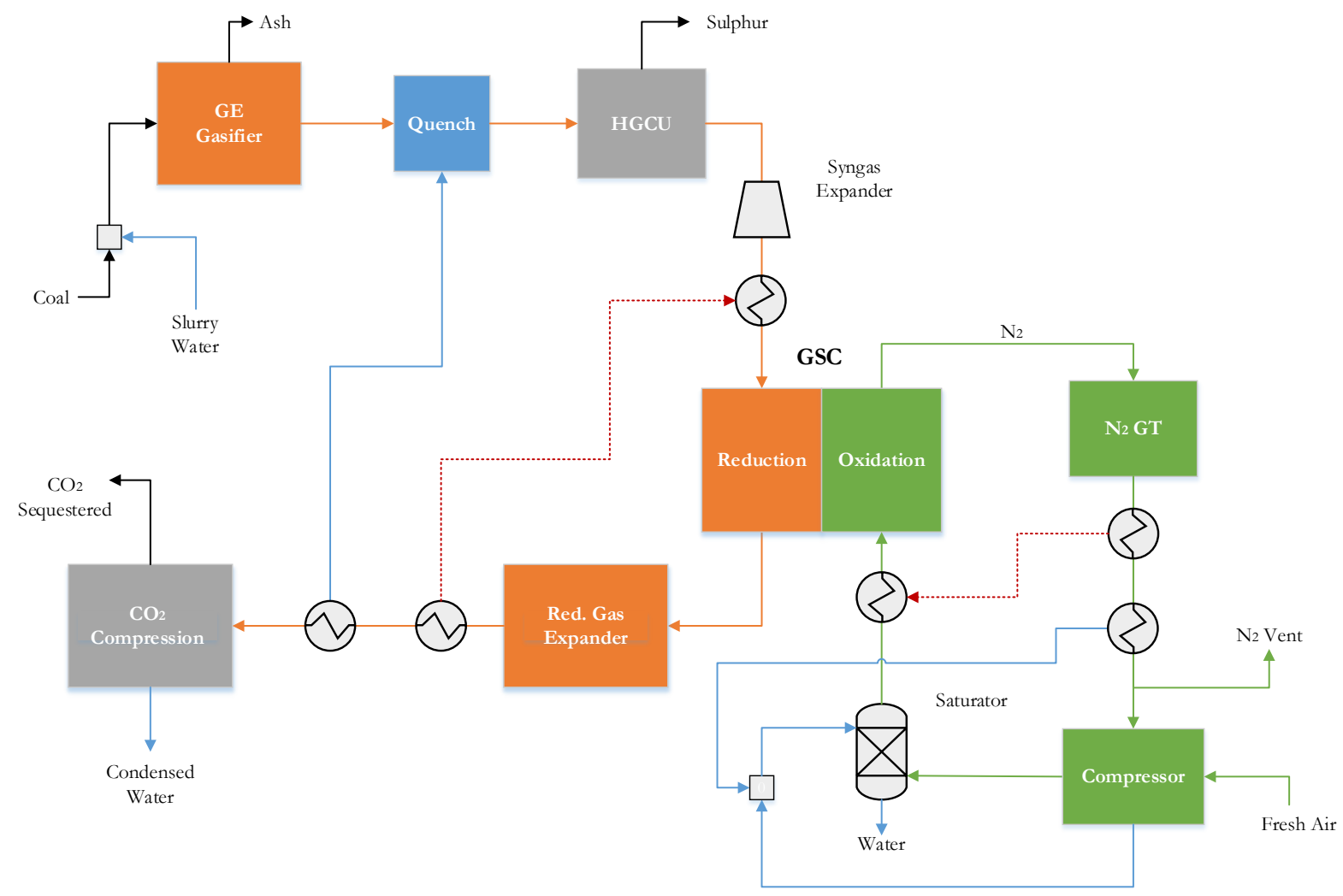

Figure 110 Block flow diagram of the Integrated Gasification GSC-HAT power plant

Energy

The energy breakdown for the Integrated Gasification GSC-HAT power plant is shown in Table 62. While still outcompeting the pre-combustion $\mathrm{CO}_{2}$ capture IGCC benchmark by approximately $3.8 \%$-points, there is an efficiency loss of 1.8\%-points compared to the Standalone GSC IGCC configuration.

Table 62 Energy breakdown of the Integrated Gasification GSC-HAT power plant

\begin{tabular}{|c|c|}
\hline \multicolumn{2}{|c|}{ Power-heat breakdown } \\
\hline Coal input (MW) & 854,0 \\
\hline Compressor (MW) & 195,9 \\
\hline Turbine (MW) & 470,0 \\
\hline GT net (MW) & 269,6 \\
\hline
\end{tabular}




\begin{tabular}{|c|c|}
\hline Reduction expander (MW) & 140,3 \\
\hline Red. gases condenser (MW) & 263,6 \\
\hline $\mathrm{N}_{2}$ cooling (MW) & 157,0 \\
\hline \multicolumn{2}{|c|}{ Power plant auxiliaries } \\
\hline GT auxiliaries (MW) & 0,9 \\
\hline ASU (MW) & 42,8 \\
\hline Coal milling (MW) & 1,7 \\
\hline Ash handling (MW) & 0,5 \\
\hline Syngas Treating (MW) & 1,0 \\
\hline CO 2 pump (MW) & 1,2 \\
\hline Water pumps (MW) & 1,4 \\
\hline Heat rejection (MW) & 3,7 \\
\hline Balance of plant (MW) & 1,3 \\
\hline Global balance & \\
\hline Total auxiliaries (MW) & 54,6 \\
\hline Gross plant (MW) & 409,9 \\
\hline Net plant (MW) & 355,3 \\
\hline Total heat input (MW) & 854,0 \\
\hline Gross efficiency (\%LHV) & 48,0 \\
\hline Net efficiency (\%LHV) & 41,6 \\
\hline CO ${ }_{2}$ Compression discounted from Reduction expander \\
\hline
\end{tabular}

An alternative configuration with a dry fed Shell gasification system and a bottom quench was evaluated with an efficiency improvement of approximately 1\%-point, but at the cost of around 4\%-points capture rate, due to $\mathrm{CO}_{2}$ venting in lock hoppers and syngas combustion for coal drying. Detailed analysis of the configuration and process line-up can be obtained in [121].

\section{Environmental}

The slurry-fed gasification system and low degree of mixing achieved through the $\mathrm{N}_{2}$ recycle strategy in the GSC cluster results in a very high capture rate, as depicted in Table 63:

Table $63 \mathrm{CO}_{2}$ emissions performance of the Integrated Gasification GSC-HAT power plant

\begin{tabular}{|c|c|}
\hline Item & Value \\
\hline $\mathrm{CO}_{2}$ emissions $(\mathrm{kgCO} / \mathrm{MWh})$ & 6,8 \\
\hline $\mathrm{CO}_{2}$ capture $(\%)$ & 99,2 \\
\hline $\mathrm{CO}_{2}$ avoidance $(\%)$ & 99,1 \\
\hline SPECCA $\left(\mathrm{MJ} / \mathrm{kgCO}_{2}\right)$ & 1,52 \\
\hline
\end{tabular}

The SPECCA index is on the other hand somewhat above the values obtained for the Standalone GSC IGCC power plant, highlighting the bigger weight of a larger energy penalty relative to an improved capture rate efficiency in this parameter.

\section{Exergy}

The exergy breakdown and relative contribution for the Integrated Gasification GSC-HAT plant is provided in Table 64 and Figure 111 respectively. A slightly different block categorization has been done for this power plant concept due to the large differences relative to the typical combined cycle setup. The main conclusions from the exergy study is that the turbomachinery and primarily GSC cluster exergy destruction reduction is offset by the larger losses occurring in heat exchange and gasification blocks. 
Table 64 Exergy breakdown for the Integrated Gasification GSC-HAT power plant

\begin{tabular}{|c|c|c|}
\hline Block & Item & Exergy (MW) \\
\hline \multirow{2}{*}{ Gasification island } & Gasifier and quench & 172,1 \\
\hline & ASU & 25,7 \\
\hline \multirow{10}{*}{$\begin{array}{l}\text { Heat recovery and } \\
\text { cooling }\end{array}$} & Syngas treating & 4,8 \\
\hline & Syngas recuperator & 7,9 \\
\hline & Reduction gases economizer & 10,9 \\
\hline & Reduction gases condenser & 28,1 \\
\hline & Intercooler & 8,4 \\
\hline & Aftercooler & 2,2 \\
\hline & $\mathrm{N}_{2}$ recuperator & 16,7 \\
\hline & Saturator & 6,9 \\
\hline & $\mathrm{N}_{2}$ economizer & 2,6 \\
\hline & $\mathrm{N}_{2}$ condenser & 13,0 \\
\hline GSC cluster & GSC cluster & 124,4 \\
\hline \multirow{5}{*}{ Turbomachinery } & Syngas expander & 4,8 \\
\hline & Reduction gases expander & 6,4 \\
\hline & Air compressor & 21,0 \\
\hline & $\mathrm{N}_{2}$ turbine & 23,8 \\
\hline & $\mathrm{CO}_{2}$ compressor & 10,6 \\
\hline Misc. & BoP, pumps & 1,7 \\
\hline \multirow{4}{*}{ Exergy out } & $\mathrm{N}_{2}$ vented & 6,2 \\
\hline & Slag & 5,9 \\
\hline & $\mathrm{CO}_{2}$ captured & 54,8 \\
\hline & Other (water etc.) & 0,2 \\
\hline Useful effect & $\mathrm{W}_{\text {net }}$ & 355,4 \\
\hline
\end{tabular}

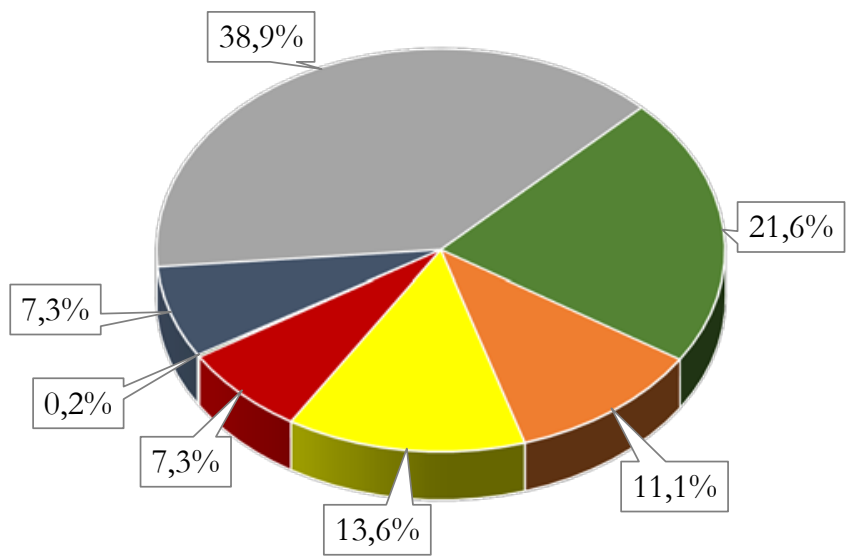

- Gasification island

- Heat recovery and cooling

GSC cluster

- Turbomachinery

- Misc.

- Exergy out

- Useful effect

Figure 111 Exergy distribution of the Integrated Gasification GSC-HAT power plant

The exergy flow diagram presented in Figure 112, was intentionally split between the reduction and oxidation section to highlight the decoupling between the syngas generation and $\mathrm{CO}_{2}$ capture with respect to the power cycle. 

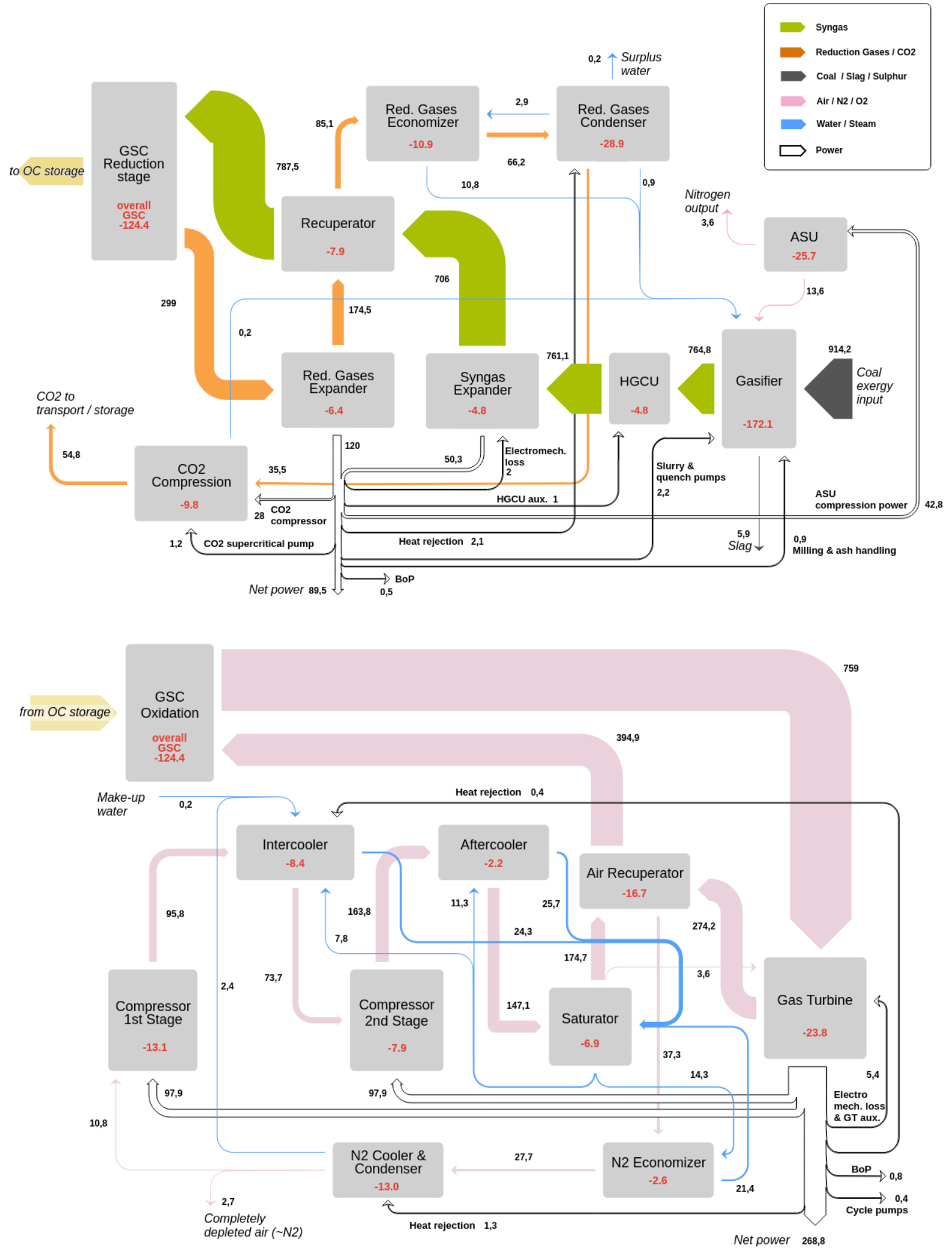

Figure 112 Exergy flow diagram of the reduction (above) and oxidation (below) sections of the Integrated Gasification GSC-HAT power plant 


\section{Economic}

No economic assessment of the Integrated Gasification GSC-HAT power plant was performed within the project timeframe. However, it can be mentioned that the avoidance of syngas effluent coolers and a cheaper gasification system can potentially outweigh the efficiency losses relatively to the inflexible GSC-IGCC configurations with more costly gasification and syngas cooling units [122].

\subsubsection{Adv. GSC-MAWGS IGCC with Shell Gasifier}

The exergy analysis performed to the "introductory" power plants confirm the efficiency advantages of 1) raising the TIT above the GSC reactor temperatures to values achievable by modern GTs 2) transferring heat from the reduction gases to the fuel or air inlets to the GSC cluster by means of a recuperator.

A possible pathway to generate a clean $\mathrm{H}_{2}$ fuel is the membrane $\mathrm{H}_{2}$ reactors (MAWGS) feeding syngas from a Shell gasifier, whereby the low grade syngas after the membrane can be used in the GSC and the hydrogen product can be fired in the extra firing chamber to raise the hot air stream from the GSC temperatures to the COT of the H-class turbine. Furthermore, this potential integration between GSC and MAWGS can allow to produce a $\mathrm{H}_{2}$ product as an energy vector from the plant in times of low electricity prices $\left(\mathrm{H}_{2}\right.$ mode). This flexible way of operation to modulate the power output will present important advantages to balance variable renewable energy (VRE) [123, 124]. The use of a recuperator is fairly straightforward given the performances shown in the GSC with Extra Firing IGCC power plant, but in this advanced plant configuration, it was implemented between GSC fuel input and output streams, in order to achieve a higher degree of decoupling between oxidation and reduction stages to enhance plant operational flexibility. On the other hand, the GSC is operated with the $\mathrm{O}_{2}$ slip strategy to minimize the amount of $\mathrm{H}_{2}$ required from the MAWGS (as this results in higher oxidation temperatures) while reducing significantly the degree of undesired mixing because of the longer reactor cycles. The GSC-MAWGS plant uses a LP-ASU with a specific power consumption of $325 \mathrm{kWh} /$ ton $\mathrm{O}_{2}$ to generate the oxidant stream to allow the plant to operate flexibly.

In power production mode, a portion of the syngas produced after HGCU is bypassed directly to the syngas expander, while only the required amount to generate sufficient $\mathrm{H}_{2}$ for extra firing is routed to the membrane reactor, after adequate steam addition from the HP stage steam turbine outlet. The permeate stream for the MAWGS is cooled in a recuperator and compressed to the required fuel pressure (35 bar) and combusted in the firing chamber with the GSC oxidation outlet. The bypassed syngas and retentate streams are fed to the GSC reduction stage. A schematic of this plant section is given in Figure 113 for a better understanding of the process. 


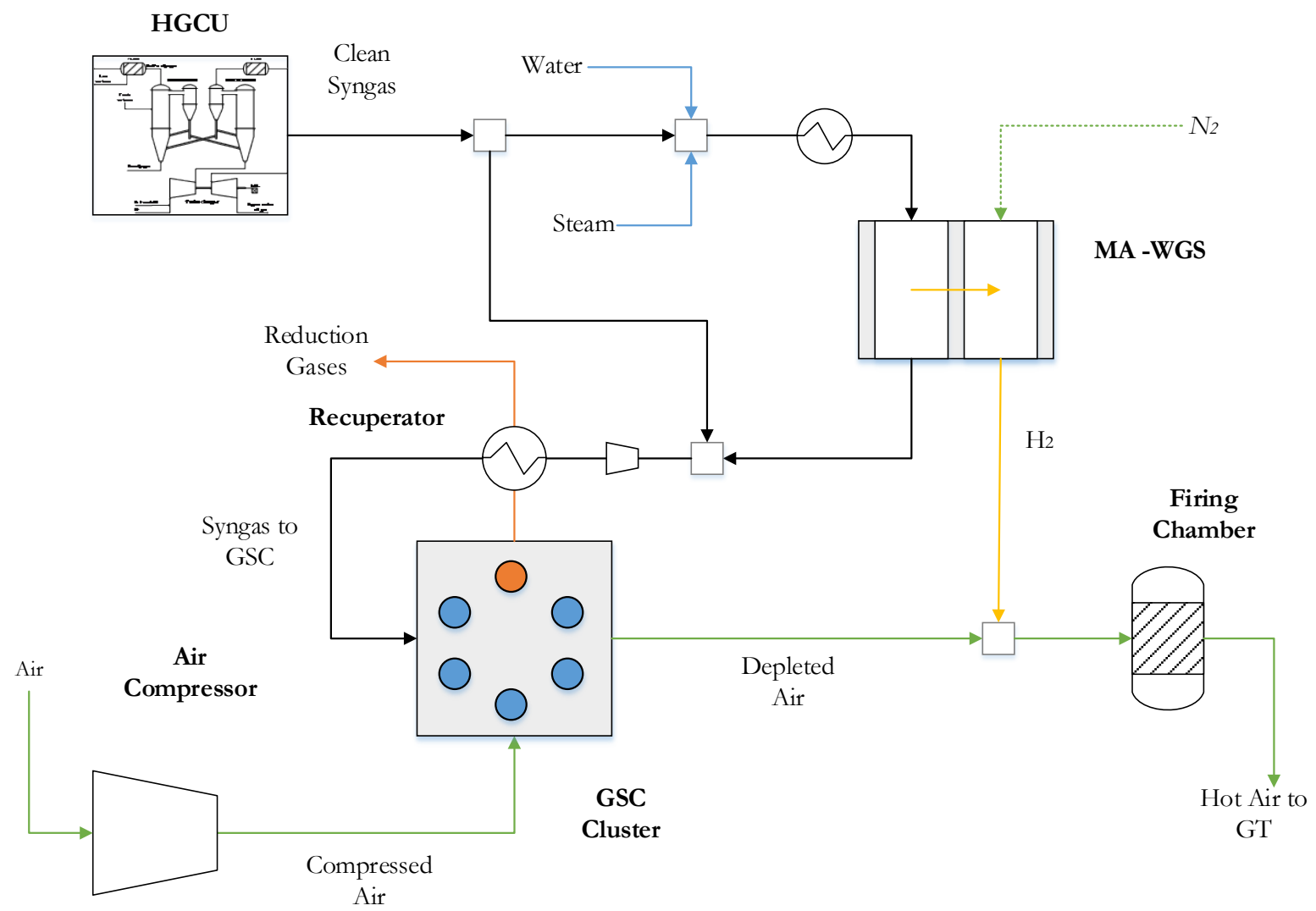

Figure 113 Integration of MAWGS, GSC and GT with a reduction gases recuperator

In $\mathrm{H}_{2}$ production mode, the $\mathrm{H}$-class turbines is shut down and the MAWGS extracts the maximum amount for $\mathrm{H}_{2}$ operating at a low permeate pressure (no sweep gas). The remaining low heating value syngas in the retentate is used in the reduction stage of the GSC. The air for the oxidation is provided by a small ad hoc GT operating at the oxidation outlet temperature.

A block flow diagram for the GSC-MAWGS plant with different gasification and integration pathways is presented in Figure 114, highlighting the different operation modes between power and $\mathrm{H}_{2}$ production. Detailed schematics and stream summary of the GSC-MAWGS IGCC with Shell gasifier are provided in Figure 146 and Table 96 in the Appendix. 


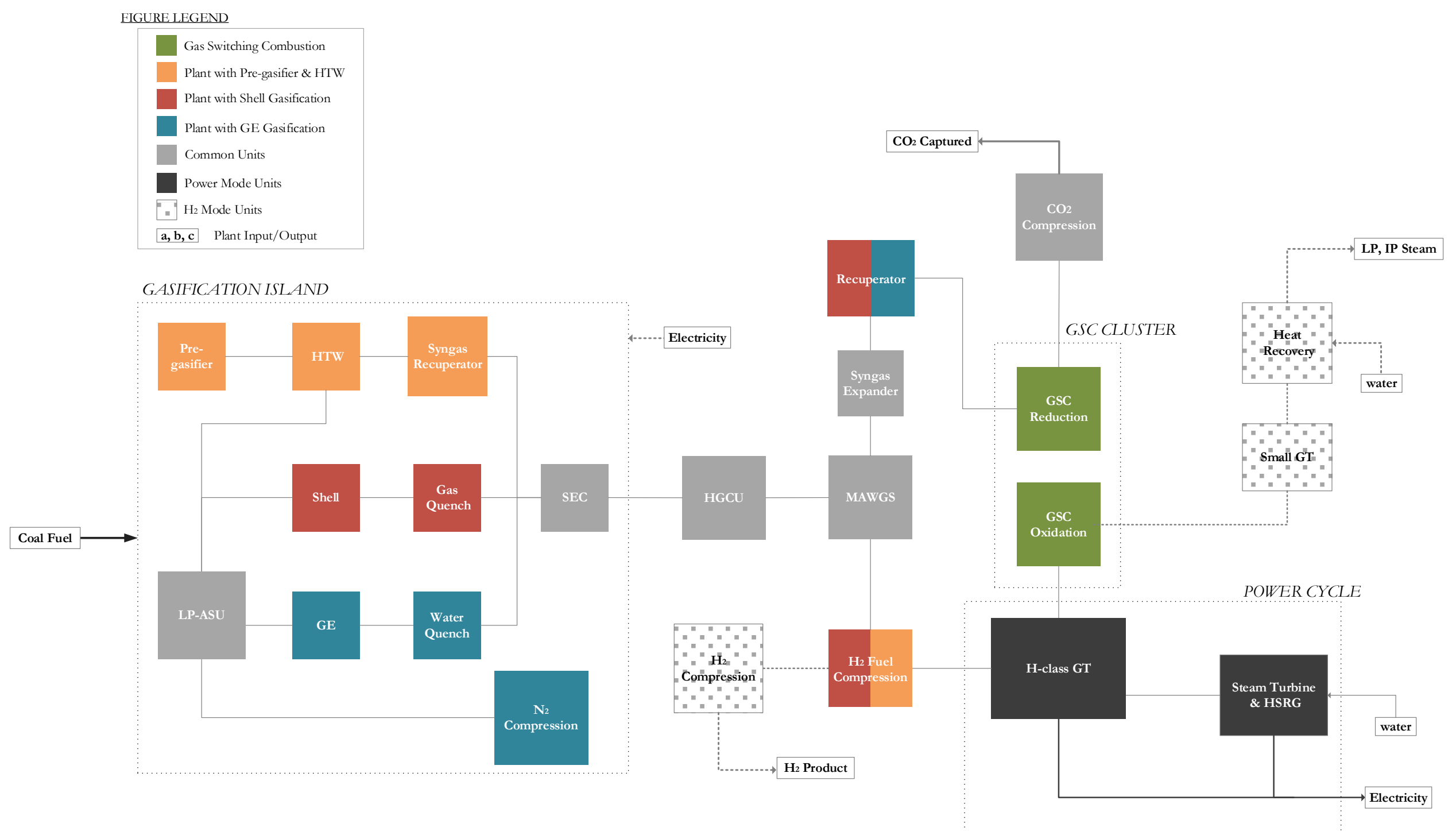

Figure 114 Block flow diagram of the GSC-MAWGS IGCC plant showing different configuration possibilities and Power/ $\mathrm{H}_{2}$ operating mode elements 
Energy

The GSC-MAWGS IGCC power plant with Shell gasification energy breakdown is provided in Table 65 for the different modes of operation. Two modes of $\mathrm{H}_{2}$ production are considered. A case where a small dedicated GT makes use of the retentate syngas (small GT), and a second one where the H-class GT is ramped down to $10 \%$ of its nominal power output (10\%GT). Since this latter mode of operation requires a minimum heat rate to the GSC, the $\mathrm{H}_{2}$ production efficiency is comparatively lower, although the plant is electrically self-sufficient. Since the GT operates at a very low load, the pressure ratio is $\sim 7$ with a low gross generator output (compared to a pressure ratio of $\sim 23$ in power mode) which causes a substantial change in the operating point of the syngas expander and downstream $\mathrm{CO}_{2}$ compressor (and thus such divergent duties). Furthermore, the steam turbine output is substantially below the nominal design output presented in power mode. The steam cycle is simulated with the same efficiency values as in power mode (which is an optimistic simplification) and the heat recovery units are specified so that they generate sufficient hot water to satisfy the syngas cooler demand. On the other hand, for the small GT case, the MAWGS can extract substantially higher amount of $\mathrm{H}_{2}$ (as there is not a minimum heat input required for the GT), but the high compression costs as well as the auxiliary consumption of other systems result in large electricity demand, which must be purchased outside of the plant battery limits. The steam cycle is shut down except for the HP stage of the steam turbine, which expands the HP steam generated in the SEC at approximately half of the nominal output. The IP and LP steam produced in the dedicated heat recovery units (small GT exhaust, permeate and reduction gases exchangers) are exported and sold.

Table 65 Energy breakdown for the GSC-MAWGS IGCC power plant with Shell Gasification

\begin{tabular}{|c|c|c|c|}
\hline Operation Mode & Power & $\mathrm{H}_{2}$ Small GT & $\mathrm{H}_{2} 10 \% \mathrm{GT}$ \\
\hline \multicolumn{4}{|c|}{ Gasification and treating } \\
\hline Coal (as received) $(\mathrm{kg} / \mathrm{s})$ & 59,1 & 59,1 & 59,1 \\
\hline Heat input (MW) & 1487,0 & 1487,0 & 1487,0 \\
\hline Coal milling (MW) & 3,0 & 3,0 & 3,0 \\
\hline Ash handling (MW) & 0,9 & 0,9 & 0,9 \\
\hline Syngas recycle compressor (MW) & 1,9 & 1,9 & 1,9 \\
\hline HGCU aux. (MW) & 1,7 & 1,7 & 1,7 \\
\hline HGCU compander (MW) & 0,4 & 0,4 & 0,4 \\
\hline ASU $(\mathrm{MW})$ & 58,6 & 58,6 & 58,6 \\
\hline \multicolumn{4}{|c|}{ Power cycle } \\
\hline GT net (MW) & 475,5 & 55,4 & 29,1 \\
\hline GT aux (MW) & 2,2 & 0,2 & 2,2 \\
\hline Steam net (MW) & 328,3 & 40,4 & 150,9 \\
\hline Pumps (MW) & 6,9 & 4,3 & 4,8 \\
\hline Heat rejection( (MW) & 3,8 & 0,6 & 2,7 \\
\hline $\mathrm{BoP}(\mathrm{MW})$ & 2,2 & 2,2 & 2,2 \\
\hline Syngas expander (MW) & 17,8 & 21,5 & 63,1 \\
\hline $\mathrm{H}_{2}$ compression $(\mathrm{MW})$ & 19,2 & 62,1 & 43,8 \\
\hline $\mathrm{CO}_{2}$ compression $(\mathrm{MW})$ & 18,7 & 19,2 & 35,6 \\
\hline \multicolumn{4}{|c|}{ Global balance } \\
\hline Heat input (MW) & 1487,0 & 1487,0 & 1487,0 \\
\hline Gross power (MW) & 821,6 & 117,3 & 243,0 \\
\hline Net power (MW) & 702,1 & $-37,8$ & 85,2 \\
\hline Total auxiliaries (MW) & 119,5 & 155,1 & 157,8 \\
\hline Gross efficiency $(\%)$ & 55,3 & 7,9 & 16,3 \\
\hline Net efficiency $(\%)$ & 47,2 & $-2,5$ & 5,7 \\
\hline
\end{tabular}




\begin{tabular}{|c|c|c|c|}
\hline $\mathrm{H}_{2}$ \& power efficiency $(\%)$ & - & 58,16 & 56,4 \\
\hline $\mathrm{H}_{2}$ efficiency $(\%)$ & - & 60,7 & 50,7 \\
\hline $\mathrm{H}_{2}$ eq. efficiency $(\%)$ & - & 57,9 & 57,0 \\
\hline $\mathrm{H}_{2}$ product $(\mathrm{kg} / \mathrm{s})$ & - & 7,52 & 6,28 \\
\hline
\end{tabular}

In this case, the $\mathrm{H}_{2}$ equivalent efficiency is calculated using the Advanced Unabated IGCC benchmark with as reference plant. It is noted that in $\mathrm{H}_{2}$ mode the gasification and gas clean up units operate at the design power mode point. The steam export characteristics of the plant in $\mathrm{H}_{2}$ mode with a small GT are presented in Table 66:

Table 66 Steam export in GSC-MAWGS IGCC plant with Shell gasifier in $\mathrm{H}_{2}$ mode with small GT

\begin{tabular}{|c|c|c|}
\hline Item & Mass flow (kg/s) & Duty (MW) (h-h $\left.\mathrm{h}_{\text {liq,sat }}\right)$ \\
\hline $\mathrm{LP}\left(165^{\circ} \mathrm{C} 5 \mathrm{bar}\right)$ & 29,6 & 63,2 \\
\hline IP $\left(350^{\circ} \mathrm{C} 40 \mathrm{bar}\right)(\mathrm{kg} / \mathrm{s})$ & 50,4 & 99,1 \\
\hline
\end{tabular}

\section{Environmental}

The $\mathrm{CO}_{2}$ emissions performance for this model is provided in Table 67. Given the long cycles achieved through the $\mathrm{O}_{2}$ slip heat management strategy in the GSC, the main source of emissions are the venting in the lock hoppers during coal loading, the emissions originating from coal drying and finally the $\mathrm{CO}_{2}$ which is entrained in the condensed water stream in the reduction gases cooler.

Table $67 \mathrm{CO}_{2}$ emissions performance of the GSC-MAWGS IGCC power plant with Shell gasifier

\begin{tabular}{|c|c|c|c|}
\hline Operation Mode & Power & $\mathrm{H}_{2}$ Small GT & $\mathrm{H}_{2} 10 \% \mathrm{GT}$ \\
\hline Specific Emissions $\left(\mathrm{kgCO}_{2} / \mathrm{MWh}\right)^{*}$ & 38,3 & 29,5 & 30,2 \\
\hline Capture Ratio (\%) & 94,8 & 94,8 & 95,6 \\
\hline $\mathrm{CO}_{2}$ Avoidance (\%) & 94,3 & - & - \\
\hline SPECCA $\left(\mathrm{MJ} / \mathrm{kgCO}_{2}\right)$ & 1,033 & - & - \\
\hline
\end{tabular}

The high thermal efficiency for the power mode results in a $\mathrm{CO}_{2}$ avoidance which is very close to the actual capture ratio.

\section{Exergy}

The exergy efficiency calculation performed to the flexible GSC-MAWGS IGCC power plant with Shell gasifier is summarized in Table 68. In case the plant imports electricity, the net duty is incorporated in the denominator of the exergy efficiency calculation, thus the total exergy input presented in the global balance given in Figure 115, is somewhat different from case to case. For the calculation of $\xi$, the exergy content of $\mathrm{H}_{2}$ product and electricity were considered, while for $\xi^{\prime}$ the steam export and $\mathrm{CO}_{2}$ captured exergy were added on top of that, following the approach described in 1.4.3.

Table 68 Exergy efficiency for the GSC-MAWGS IGCC power plant with Shell gasification

\begin{tabular}{|c|c|c|c|}
\hline Item /Mode & Power & $\mathbf{H}_{\mathbf{2}}$ Small GT & $\mathbf{H}_{\mathbf{2}} \mathbf{1 0} \% \mathbf{G T}$ \\
\hline$\xi(\%)$ & 44,1 & 58,5 & 55,4 \\
\hline$\xi^{\prime}(\%)$ & 49,9 & 69,3 & 61,2 \\
\hline
\end{tabular}

The high exergetic efficiencies in $\mathrm{H}_{2}$ operation modes are not surprising, as the original fuel has not been completely devaluated to electricity (as in power mode), and the chemical exergy is to a great extent preserved (discounting the losses of gasification and water gas shift). When steam and 
$\mathrm{CO}_{2}$ streams are considered in the exergy efficiency of the plants, a notorious improvement is observed, surpassing the values obtained for the Advanced Unabated IGCC power plant.

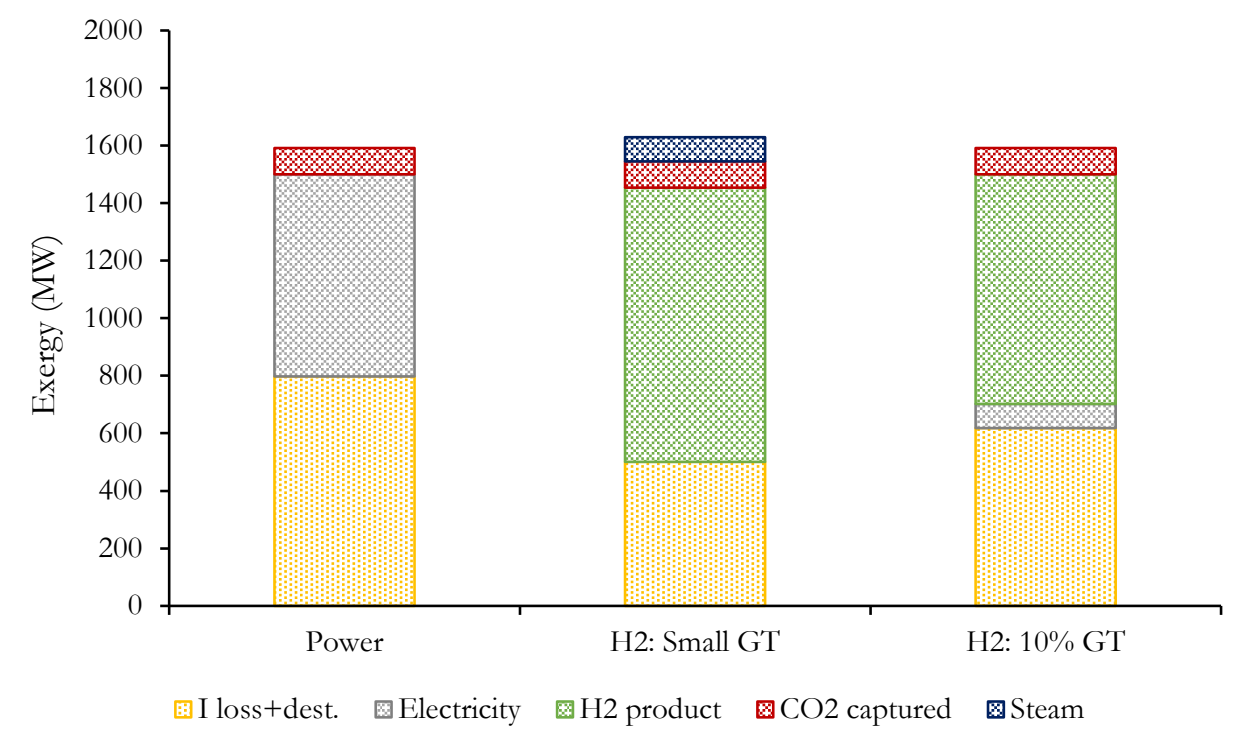

Figure 115 Total exergy distribution for the GSC-MAWGS IGCC power plant with Shell gasifier

\section{Economic}

The main economic parameters for the GSC-MAWGS IGCC plant with Shell gasification are summarized in Table 69.

Table 69 Economic results for the GSC-MAWGS IGCC plant with Shell gasification

\begin{tabular}{|c|c|}
\hline Item & Value \\
\hline$S I(€ / \mathrm{kW})$ & 2762,2 \\
\hline $\operatorname{LCOE}(€ / \mathrm{MWh})$ & 79,3 \\
\hline $\operatorname{COCA}(€ / \operatorname{tonCO} 2)$ & 36,2 \\
\hline
\end{tabular}

Relative to the advanced pre-combustion capture plant, the present configuration achieves specific investment reduction of $64,3 € / \mathrm{kW}(2,3 \%$ reduction) with a LCOE which is $2,5 € / \mathrm{MWh}$ lower (3,0\% reduction). The cost of $\mathrm{CO}_{2}$ avoidance falls by $6,1 € /$ tonCO $\mathrm{C}_{2}(14,4 \%$ less). In Figure 116 , the installed cost distribution which amounts to $1310,7 \mathrm{M} €$ is presented, while in Figure 117 the cost of electricity build up per item is provided.

The large efficiency gains shown in the energy and exergy evaluations are to a great extent eroded by the extra capital cost resulting from the membranes reactors and to a less extent the $\mathrm{H}_{2}$ fuel compressors. $\mathrm{N}_{2}$ compressor costs are not accounted for in the ASU block as there is no need for fuel dilution in this power plant concept. Variable operating and maintenance costs also slightly increase due to the costs of oxygen carrier material and membrane tubes of the GSC and MAWGS. It is highlighted again that the current results take into account only the power mode capability for the economic assessment. When the capacity for $\mathrm{H}_{2}$ generation at low electricity prices is considered, a substantial economic benefit for the GSC-MAWGS IGCC plants is expected. 


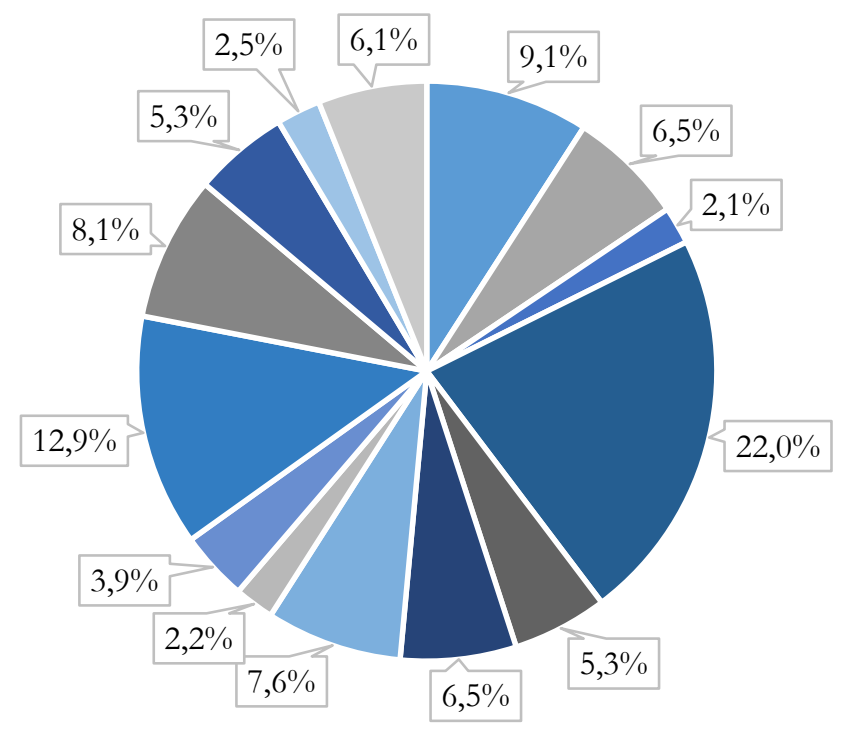

- ASU

- Coal handling

- Ash handling

- Gasifier

- HGCU

- MAWGS

- GSC reactors

- Hydrogen compression

- CO2 compression

- Gas Turbine

- Steam Turbine

- HRSG

- Heat exhangers

- Condenser

Figure 116 TIC cost distribution for the GSC-MAWGS IGCC power plant with Shell gasification

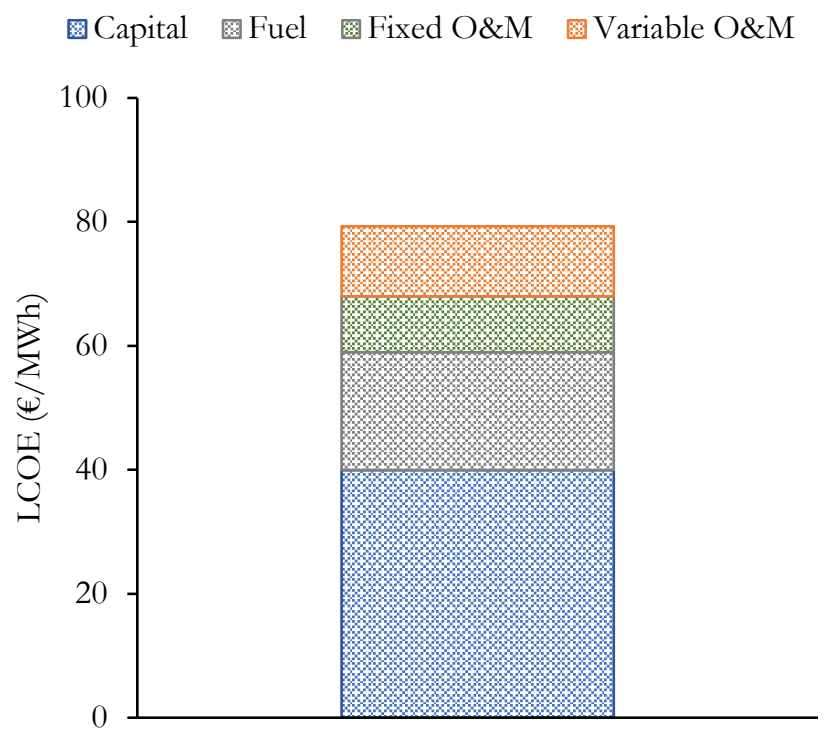

Figure 117 LCOE build-up for the GSC*MAWGS IGCC power plant with Shell gasification

\subsubsection{Adv. GSC-MAWGS IGCC with Pregasifier and HTW Gasifier}

The GSC-MAWGS IGCC plant with pregasifier and HTW unit eliminates the substantial energy penalty derived from syngas production by increasing the CGE of the gasification section. The hot gases from the reduction outlet of the GSC are used to preheat and pregasify a coal water slurry which devolatizes and is partially transformed to syngas. The residence time in the pregasification section must be sufficient to ensure that the endothermic gasification reactions occur, in such a way that the temperature pinch in the heat exchanger happens in the cold end, extracting the maximum amount of heat and transferring it to the slurry. The HTW which operates at low temperatures also has a lower $\mathrm{O}_{2}$ demand (as it is no longer required to heat up the reactants to $900^{\circ} \mathrm{C}$ ), thus reducing significantly the auxiliary consumption. A temperature profile for the power mode case of the pregasifier unit is provided in Figure 118, where the carbon conversion is determined at each point and the evaporation of the water in the slurry is seen. In the hot end of the unit, the cold stream temperature slope decreases (due to the endothermic reactions) while the 
hot stream temperature begins to condense at the cold end of the exchanger. To model this unit a series of gasifier blocks are used each receiving a proportional heat input from the reduction gases progressively being cooled.

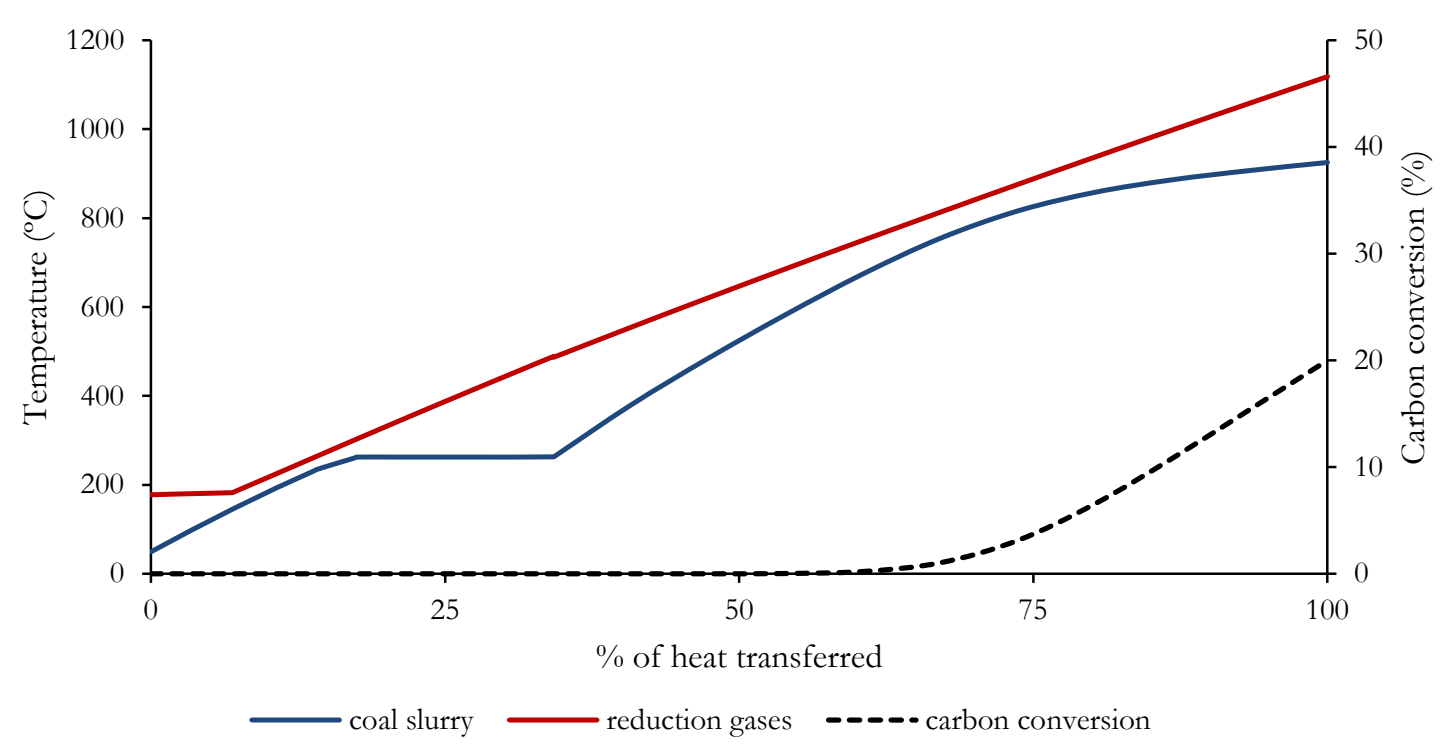

Figure 118 Temperature profile and carbon conversion in the pregasifier unit

The syngas from the gasifier at $900^{\circ} \mathrm{C}$ can be cooled down effectively by heating up the syngas stream that is routed to the GSC. A small syngas cooler sets the appropiate temperature before the HGCU unit. In power production mode, after desulphurization, a portion is routed to the MAWGS and the remaining is by passed to the GSC. The steam to carbon ratio prior to the membrane is adjusted to 1.9 using hot IP water and IP steam from the HP stage discharge. H2 produced at low pressure is compressed to $35 \mathrm{bar}$ and combusted in the firing chamber to raise the COT to the reference value of the H-class turbine. The reduction gases from the GSC are cooled in the pregasifier and further cooled in a LP evaporator + economizer. The block flow diagram of the plant is presented in Figure 114. A more detailed schematic of the GSC-MAWGS with pregasifier and HTW gasification is given in Figure 147 Fig in the Appendix, with the corresponding stream summary in Table 97.

In $\mathrm{H}_{2}$ mode, two modes of operation are shown, a case with a small GT where the minimum the permeate pressure in the MAWGS is set so that enough IP steam is produced to satisfy the demand of the membrane reactor, with dedicated heat recovery units ( $H_{2}:$ Small GT). Both the H-class GT and the steam cycle are completely shut down, and it is assumed that the small SEC can generate IP steam in $\mathrm{H}_{2}$ mode.

A second case which similarly to the plant with Shell gasification runs the GT at $10 \%$ of its nominal load and assumes that the steam cycle can be operated at a low part load $\left(H_{2}: 10 \% G T\right)$. The fact that a substantial IP extraction is needed for the WGS suggests that this assumption for the IP and LP stages is unlikely, but it is added here for completion. The part load strategy also has the problematic aspect of a very different operating point for the recuperator and syngas expander given the low pressure ratio. The electrical efficiency of the plant in $\mathrm{H}_{2}$ production mode is not critical from an economics perspective, given the fact that low electricity prices will be taken into account in these periods, and therefore the modelling simplifications made are assumable. 
Energy

The energy breakdown of the GSC-MAWGS with pregasifier and HTW gasification is provided in Table 70. It can be seen that the design items incorporated to this plant result in an efficiency gain of around 3\%-points. The CGE of the HTW gasifier is almost 100\% thanks to the high temperature feed that is delivered by the pregasifier. The ASU consumption is reduced to almost half of the previous configuration. Interestingly, the gross power generation is not much higher than the plant with Shell gasification, as the elimination of the SEC and the smaller reduction gases steam generator also reduced the bottoming cycle output substantially.

Table 70 Energy breakdown for the GSC-MAWGS IGCC power plant with Pregasifier and HTW gasification

\begin{tabular}{|c|c|c|c|}
\hline Operation Mode & Power & $\mathbf{H}_{2}:$ Small GT & $\mathrm{H}_{2}: 10 \% \mathrm{GT}$ \\
\hline \multicolumn{4}{|c|}{ Gasification and treating } \\
\hline Coal (as received) $(\mathrm{kg} / \mathrm{s})$ & 48,6 & 48,6 & 48,6 \\
\hline Heat input to plant (MW) & 1224,0 & 1224,0 & 1224,0 \\
\hline Coal milling (MW) & 2,4 & 2,4 & 2,4 \\
\hline Ash handling (MW) & 0,8 & 0,8 & 0,8 \\
\hline HGCU aux (MW) & 1,4 & 1,4 & 1,4 \\
\hline HGCU compander (MW) & 0,4 & 0,4 & 0,4 \\
\hline ASU $(M W)$ & 20,3 & 24,0 & 24,0 \\
\hline \multicolumn{4}{|c|}{ Power cycle } \\
\hline GT net (MW) & 466,0 & 92,9 & 22,3 \\
\hline GT aux. (MW) & 2,2 & 0,3 & 2,2 \\
\hline Steam met (MW) & 205,0 & 0,0 & 56,2 \\
\hline Pumps (MW) & 4,3 & 0,8 & 2,5 \\
\hline Heat rejection( (MW) & 2,8 & 0,7 & 1,4 \\
\hline BoP (MW) & 1,8 & 1,8 & 1,8 \\
\hline Syngas expander (MW) & 12,5 & 14,1 & 39,9 \\
\hline $\mathrm{H}_{2}$ compression $(\mathrm{MW})$ & 19,6 & 53,8 & 56,2 \\
\hline $\mathrm{CO}_{2}$ compression $(\mathrm{MW})$ & 11,6 & 11,9 & 23,5 \\
\hline \multicolumn{4}{|c|}{ Global balance } \\
\hline Heat input (MW) & 1224,0 & 1224,0 & 1224,0 \\
\hline Gross power (MW) & 683,5 & 105,8 & 118,4 \\
\hline Net power (MW) & 615,9 & 7,4 & 1,8 \\
\hline Total auxiliaries (MW) & 67,6 & 98,4 & 116,6 \\
\hline Gross efficiency (\%) & 55,8 & 8,6 & 9,7 \\
\hline Net efficiency $(\%)$ & 50,3 & 0,60 & 0,2 \\
\hline $\mathrm{H}_{2} \&$ power efficiency $(\%)$ & - & 66,9 & 62,4 \\
\hline $\mathrm{H}_{2}$ efficiency $(\%)$ & - & 66,2 & 62,4 \\
\hline $\mathrm{H}_{2}$ equivalent efficiency $(\%)$ & - & 67,0 & 62,4 \\
\hline $\mathrm{H}_{2}$ product $(\mathrm{kg} / \mathrm{s})$ & - & 6,76 & 6,37 \\
\hline
\end{tabular}

The higher $\mathrm{H}_{2}$ efficiency obtained relative to the Shell gasifier configuration is a result of the higher CGE, as a greater extent of the fuel heating value is not degraded to HP steam. Thus it can be effectively used to generate $\mathrm{H}_{2}$ in the membrane reactor. Nonetheless, due to the low gasification temperatures, a larger fraction of methane is formed (which cannot be converted to $\mathrm{H}_{2}$ in the MAWGS operating temperatures). The heating value of this component can only be retrieved in the form of electricity in the small GT and, coherently, the net power output of the small GT is around twice the value presented for the Shell gasification plant. 


\section{Environmental}

The $\mathrm{CO}_{2}$ emissions performance, with consistent GSC operation for the GSC-MAWGS IGCC power plant with Pregasifier and HTW gasification is summarize in Table 71. An increase in the capture ratios is observed relative to the plant with Shell gasification as venting during lock hopper operation and coal drying emissions are entirely avoided, due to the slurry type feed.

Table $71 \mathrm{CO}_{2}$ emissions performance of the GSC-MAWGS IGCC power plant with Pregasifier and HTW gasifier

\begin{tabular}{|c|c|c|c|}
\hline Operation Mode & Power & $\mathbf{H}_{2}:$ Small GT & $\mathbf{H}_{2}: \mathbf{1 0} \% \mathbf{G T}$ \\
\hline$*$ Specific emissions $\left(\mathrm{kgCO}_{2} / \mathrm{MWh}\right)$ & 13,2 & 7,6 & 2,5 \\
\hline Capture ratio $(\%)$ & 98,1 & 98,5 & 99,5 \\
\hline $\mathrm{CO}_{2}$ avoidance $(\%)$ & 98,0 & - & - \\
\hline SPECCA $\left(\mathrm{MJ} / \mathrm{kgCO}_{2}\right)$ & 0,28 & - & - \\
\hline
\end{tabular}

*either MWh electricity or LHV $\mathrm{H}_{2}$

\section{Exergy}

A similar global exergy balance was performed for the GSC-MAWGS IGCC power plant with Pregasifier and HTW gasification and is presented in Table 72 and Figure 119, following a consistent calculation to the results showed for the earlier model.

Table 72 Exergy efficiency for the GSC-MAWGS IGCC power plant with Pregasifier and HTW gasification

\begin{tabular}{|c|c|c|c|}
\hline Item /Mode & Power & $\mathbf{H}_{\mathbf{2}}$ Small GT & $\mathbf{H}_{\mathbf{2}} \mathbf{1 0} \% \mathbf{G T}$ \\
\hline$\xi(\%)$ & 47,0 & 63,2 & 59,2 \\
\hline$\xi^{\prime}(\%)$ & 52,8 & 70,1 & 65,0 \\
\hline
\end{tabular}

Since the case using a small GT does not have a minimum heat input to operate the power cycle (contrary to the case running the $\mathrm{H}$-class turbine at part load) it can be seen that for the former case the plant can extract more $\mathrm{H}_{2}$ from the available syngas.

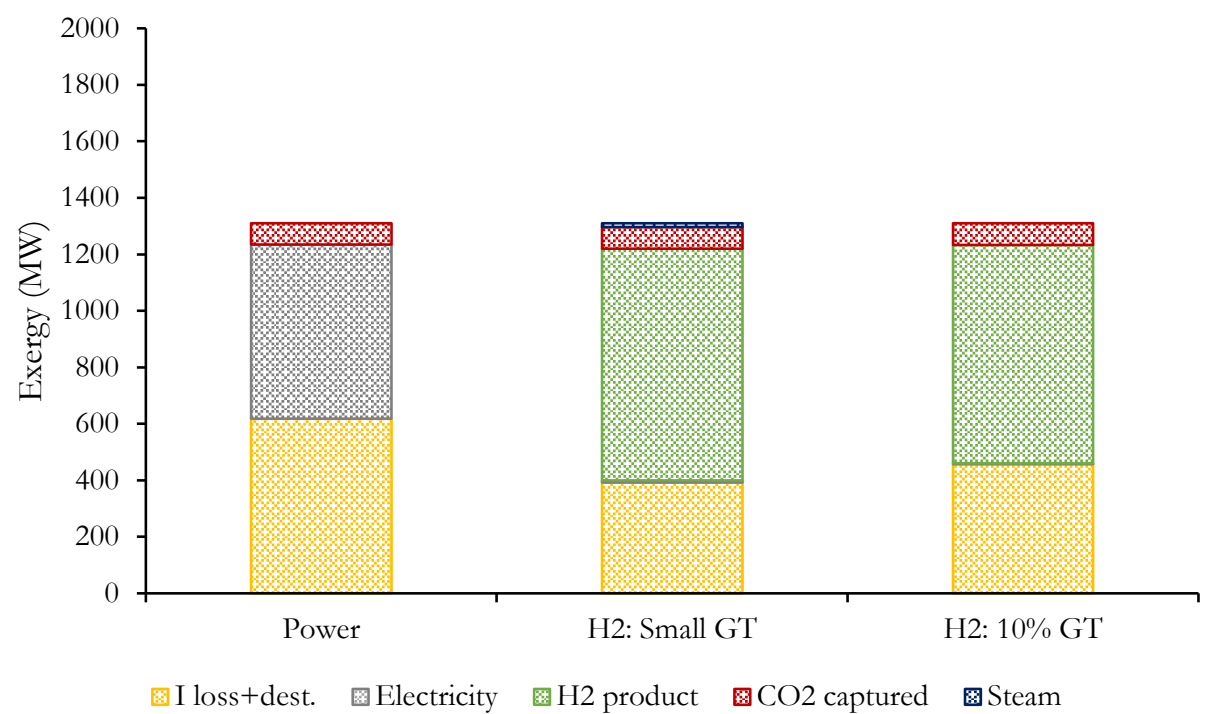

Figure 119 Total exergy distribution for the GSC-MAWGS IGCC power plant with Pregasifier and HTW gasification

\section{Economic}

The subsequent economic results are presented in Table 73: 
Table 73 Economic results for the GSC-MAWGS IGCC power plant with Pre-gasifier and HTW gasification

\begin{tabular}{|c|c|}
\hline Item & Value \\
\hline$S I(€ / \mathrm{kW})$ & 2452,5 \\
\hline $\operatorname{LCOE}(€ / \mathrm{MWh})$ & 73,2 \\
\hline $\mathrm{COCA}(€ / \operatorname{tonCO} 2)$ & 25,5 \\
\hline
\end{tabular}

Compared to the advanced plant with established capture technology, the present configuration achieves a reduction of the specific investment of $374,3 € / \mathrm{kW}(13,2 \%$ less) with a cost of electricity which is $8,6 € / \mathrm{MWh}$ lower $(10,5 \%$ reduction). Due to the high efficiency of this concept, the cost of $\mathrm{CO} 2$ avoidance is as much as $16,8 € /$ tonCO $\mathrm{C}_{2}$ lower (39,6\% reduction). On the other hand, the installed cost distribution, which amounted to $1020,9 \mathrm{M} €$ for this plant, is presented in Figure 120

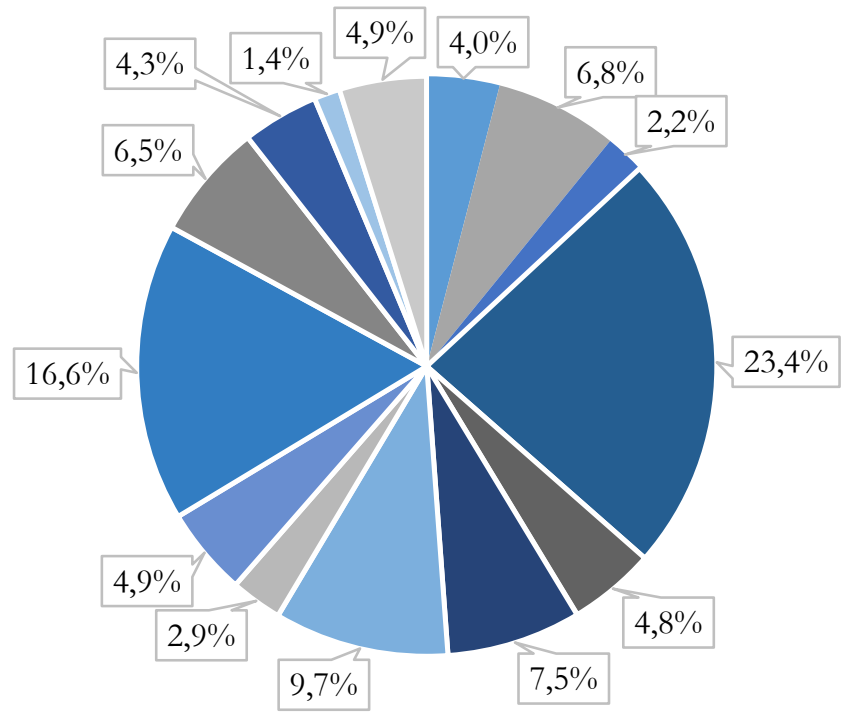

- ASU

- Coal handling

- Ash handling

- Gasifier

- HGCU

- MAWGS

- GSC reactors

- Hydrogen compression

- CO2 compression

- Gas Turbine

- Steam Turbine

- HRSG

Heat exhangers

- Condenser

Figure 120 TIC distribution of the GSC-MAWGS IGCC power plant with Pre-gasifier and HTW gasification

The LCOE build up per item is provided in Figure 121, where substantial reductions in the capital and fuel component costs are observed relative to the precombustion plant. A large reduction in the contribution of the ASU to the total cost is observed due to the smaller size and the lack of $\mathrm{N}_{2}$ compressors, while the cost of the slurry pregasifier is lumped with that of the HTW gasifier. The cost of this item has been assumed to be comparable to the equivalent cost of the entrained flow Shell gasification system. 


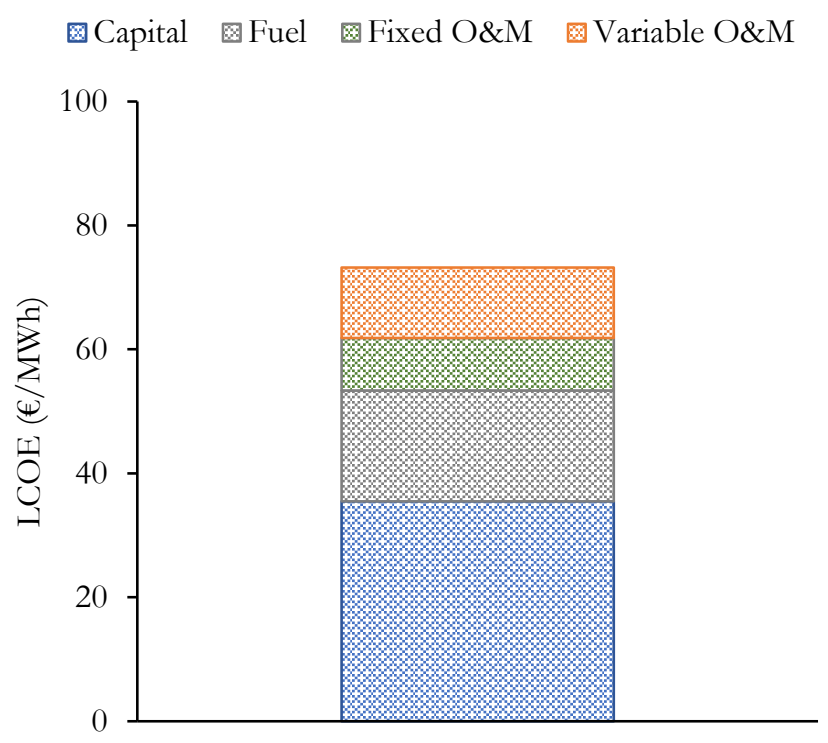

Figure 121 LCOE build-up for the GSC-MAWGS IGCC power plant with Pregasifier\& HTW gasification

\subsubsection{Adv. GSC-MAWGS IGCC with GE Gasifier}

Finally, the power plant configuration which is described in Figure 114, employs a GE gasifier with a slurry feed in order to evaluate the plant performance when a high pressure syngas (around 70 bar) is obtained after HGCU. The syngas cooling is performed with an initial partial water quench to around $700^{\circ} \mathrm{C}$ followed by a syngas effluent cooler. In this way, the required steam to carbon ratio required in the MAWGS is reached, without the need of extracting IP steam from the bottoming cycle. The driving force across the reactor membrane is higher and comparatively to the earlier cases, less membrane surface must be used to generate sufficient $\mathrm{H}_{2}$ to reach the COT and the $\mathrm{N}_{2}$ available from the ASU can be used to sweep the permeate at pressurized conditions (using an intercooled $\mathrm{N}_{2}$ compressor) to deliver a fuel mixture at 35 bar to the combustor. This operation avoids the significantly high auxiliary consumption of the $\mathrm{H}_{2}$ fuel compressor, given the fact that the $\mathrm{N}_{2}$ compression duty is outweighed by a similar duty reduction in the GT compressor.

In $\mathrm{H}_{2}$ mode, two operation strategies were investigated, both using a small GT with the H-class turbine completely shut down. Only the HP stage from the steam turbine was operative to expand the HP steam generated in the SEC to the IP level. In the first mode of operation $\left(\mathrm{H}_{2} \mathrm{Small}\right.$ GT), all IP (\& LP) steam production from the dedicated heat recovery units of permeate, reduction gases and small GT exhaust is exported from the plant battery limits. The MAWGS is operated with a low permeate pressure to maximize $\mathrm{H}_{2}$ extraction. In the second mode of operation $\left(\mathrm{H}_{2}\right.$ Small GT IP sweep), IP steam generation is maximized to use it as sweep gas in the MAWGS reactors, obtaining a $\mathrm{H}_{2} /$ steam permeate at around 40 bar which, after heat recovery and water condensation, is compressed to 150 bar. In this case the $\mathrm{H}_{2}$ auxiliary consumption and compressor costs are much lower. The condensation of the permeate stream allows to generate a substantial amount of LP steam which is exported. A more detailed schematic of the plant is presented in the Appendix in Figure 148 with a stream summary in Table 98.

\section{Energy}

The energy breakdown for the GSC-MAWGS IGCC power plant with GE gasification is provided in Table 74. It can be seen that the energy savings due to the avoidance of the $\mathrm{H}_{2}$ fuel compressor are outweighed by a somewhat higher ASU consumption and the resulting lower CGE. The loss 
in efficiency due to a less effective heat recovery with HP steam generation resulting from the water quench in the syngas cooling section is also compensated by the avoidance of IP steam extraction from the bottoming cycle to the MAWGS reactor. The flow of $\mathrm{N}_{2}$ to sweep the membrane reactor was selected to be the minimum possible to minimize the $\mathrm{N}_{2}$ compression costs, in such a way that there was sufficient driving force across the membrane to generate a fuel stream at 35 bar which reached the COT upon combustion with the GSC outlet. In this way, by increasing the fuel flow rate and compensating from the oxygen removal in the GSC cluster, the operating point of the gas turbine resembles the nominal design operating point for the natural gas fired case, resulting in a higher generator output compared to the earlier plants.

Table 74 Energy breakdown for the GSC-MAWGS IGCC power plant with GE gasifier

\begin{tabular}{|c|c|c|c|}
\hline Operation mode & Power & $\mathbf{H}_{2}:$ Small GT & $\underset{\text { sweep }}{\mathrm{H}_{2}: \text { Small GT IP }}$ \\
\hline \multicolumn{4}{|c|}{ Gasification and treating } \\
\hline Coal (as received) $(\mathrm{kg} / \mathrm{s})$ & 62,4 & 63,4 & 62,4 \\
\hline Heat input (MW) & 1569,3 & 1569,3 & 1569,3 \\
\hline Coal milling (MW) & 3,1 & 3,1 & 3,1 \\
\hline Ash handling (MW) & 0,9 & 0,9 & 0,9 \\
\hline HGCU aux (MW) & 1,8 & 1,8 & 1,8 \\
\hline HGCU compander (MW) & 0,8 & 0,8 & 0,8 \\
\hline ASU (MW) & 69,6 & 69,6 & 69,6 \\
\hline $\mathrm{N}_{2}$ compression (MW) & 34,3 & 0,0 & 0,0 \\
\hline \multicolumn{4}{|c|}{ Power cycle } \\
\hline GT Net (MW) & 525,2 & 18,3 & 40,2 \\
\hline GT Aux (MW) & 2,2 & 0,1 & 0,1 \\
\hline Steam Net (MW) & 311,7 & 23,6 & 22,4 \\
\hline Pumps (MW) & 6,6 & 2,7 & 4,1 \\
\hline Heat rejection( (MW) & 4,2 & 0,8 & 1,3 \\
\hline $\mathrm{BoP}(\mathrm{MW})$ & 2,4 & 2,4 & 2,4 \\
\hline Syngas expander (MW) & 41,5 & 37,3 & 31,4 \\
\hline $\mathrm{H}_{2}$ compression (MW) & 0,0 & 73,2 & 18,4 \\
\hline $\mathrm{CO}_{2}$ compression $(\mathrm{MW})$ & 15,2 & 14,9 & 14,8 \\
\hline \multicolumn{4}{|c|}{ Global balance } \\
\hline Heat input (MW) & 1569,3 & 1569,3 & 1569,3 \\
\hline Gross power (MW) & 879,2 & 80,0 & 94,5 \\
\hline Net power (MW) & 738,9 & $-90,6$ & $-22,0$ \\
\hline Total auxiliaries (MW) & 140,3 & 170,6 & 116,6 \\
\hline Gross efficiency $(\%)$ & 56,0 & 5,1 & 6,022 \\
\hline Net efficiency (\%) & 47,1 & $-5,8$ & $-1,4$ \\
\hline $\mathrm{H}_{2}$ \& power efficiency $(\%)$ & - & 61,2 & 62,1 \\
\hline $\mathrm{H}_{2}$ efficiency $(\%)$ & - & 67,0 & 63,5 \\
\hline $\mathrm{H}_{2}$ equivalent efficiency (\%) & - & 60,3 & 61,8 \\
\hline $\mathrm{H}_{2}$ product $(\mathrm{kg} / \mathrm{s})$ & - & 8,76 & 8,31 \\
\hline
\end{tabular}

The lower driving force resulting from a pressurized operation with the IP steam sweep gas results in a lower $\mathrm{H}_{2}$ extraction comparatively which consequently leads to a bigger size of the small GT and thus, the hydrogen efficiency decreases while the electricity import is lower for this case. In terms of excess steam generated by the plant, Table 75 provides a summary for each $\mathrm{H}_{2}$ operating mode: 
Table 75 Steam export stream for the GSC-MAWGS IGCC power plant with GE gasification in $\mathrm{H}_{2}$ operation mode

\begin{tabular}{|c|c|c|}
\hline Steam Export & $\mathbf{H}_{2}$ : Small GT & $\begin{array}{c}\mathbf{H}_{2}: \text { Small GT } \\
\text { IP sweep }\end{array}$ \\
\hline LP $\left(160^{\circ} \mathrm{C} 5\right.$ bar $)(\mathrm{kg} / \mathrm{s})$ & 1,2 & 92,6 \\
\hline LP Duty $(\mathrm{MW})\left(\mathrm{h}-\mathrm{h}_{\text {liq,sat }}\right)$ & 2,6 & 196,9 \\
\hline IP $\left(350^{\circ} \mathrm{C} 40 \mathrm{bar}\right)(\mathrm{kg} / \mathrm{s})$ & 87,6 & - \\
\hline IP Duty $(\mathrm{MW})\left(\mathrm{h}-\mathrm{h}_{\text {liq,sat }}\right)$ & 169,9 & - \\
\hline
\end{tabular}

Steam export for the Shell and GE plants using the GSC-MAWGS integration may be challenging due to the intermittent delivery of such steam. A possibility to eliminate this issue could be to generate LP superheated steam at around $300^{\circ} \mathrm{C}$ and utilize the LP stage steam turbine, bypassing the IP stage as there is not sufficient temperature for adequate superheating when operating in $\mathrm{H}_{2}$ mode (the exhaust air from the small GT is relatively small and due to the lower TIT and high pressure ratio it is available only at around $450^{\circ} \mathrm{C}$ ). In such disposition, the extra electricity generated would reduce to some extent the power import. However, given the fact that this import will occur at very low electricity prices, the overall effect on the plant economics would be relatively small. In any case, no revenue was considered for the steam exported.

\section{Environmental}

The use of a slurry fed gasification system and the long GSC cycles result in very low $\mathrm{CO}_{2}$ emissions, as shown in Table 76.

Table $76 \mathrm{CO}_{2}$ emissions performance for the GSC-MAWGS IGCC power plant with GE gasification

\begin{tabular}{|c|c|c|c|}
\hline Operation mode & Power & $\begin{array}{c}\mathbf{H}_{2} \text { : Small } \\
\text { GT }\end{array}$ & $\begin{array}{c}\mathbf{H}_{2} \text { : Small GT } \\
\text { IP sweep }\end{array}$ \\
\hline Specific emissions $\left(\mathrm{kgCO}_{2} / \mathrm{MWh}\right)$ & 11,6 & 4,0 & 4.9 \\
\hline Capture ratio $(\%)$ & 98,4 & 99,2 & 99,1 \\
\hline $\mathrm{CO}_{2}$ avoidance $(\%)$ & 98,3 & - & - \\
\hline $\mathrm{SPECCA}\left(\mathrm{MJ} / \mathrm{kgCO}_{2}\right)$ & 1,02 & - & - \\
\hline
\end{tabular}

*either MWh electricity or LHV $\mathrm{H}_{2}$

\section{Exergy}

Following the same approach as for the earlier models, the exergy efficiencies for this power plant are presented in Table 77:

Table 77 Exergy efficiency of the GSC-MAWGS IGCC with GE gasifier power plant

\begin{tabular}{|c|c|c|c|}
\hline Item /Mode & Power & $\mathbf{H}_{2}$ Small GT & $\begin{array}{c}\mathbf{H}_{2} \text { Small GT } \\
\text { IP sweep }\end{array}$ \\
\hline$\xi(\%)$ & 44,0 & 59,8 & 61,1 \\
\hline$\xi^{\prime}(\%)$ & 50,0 & 71,4 & 71,6 \\
\hline
\end{tabular}

The results indicate again the high efficiency gain when the $\mathrm{CO}_{2}$ and steam streams are accounted for. Utilization of the steam exergy could be achieved with little extra capital expenditure if the steam cycle items were adapted to run at low steam flow rates attained in $\mathrm{H}_{2}$ mode. 


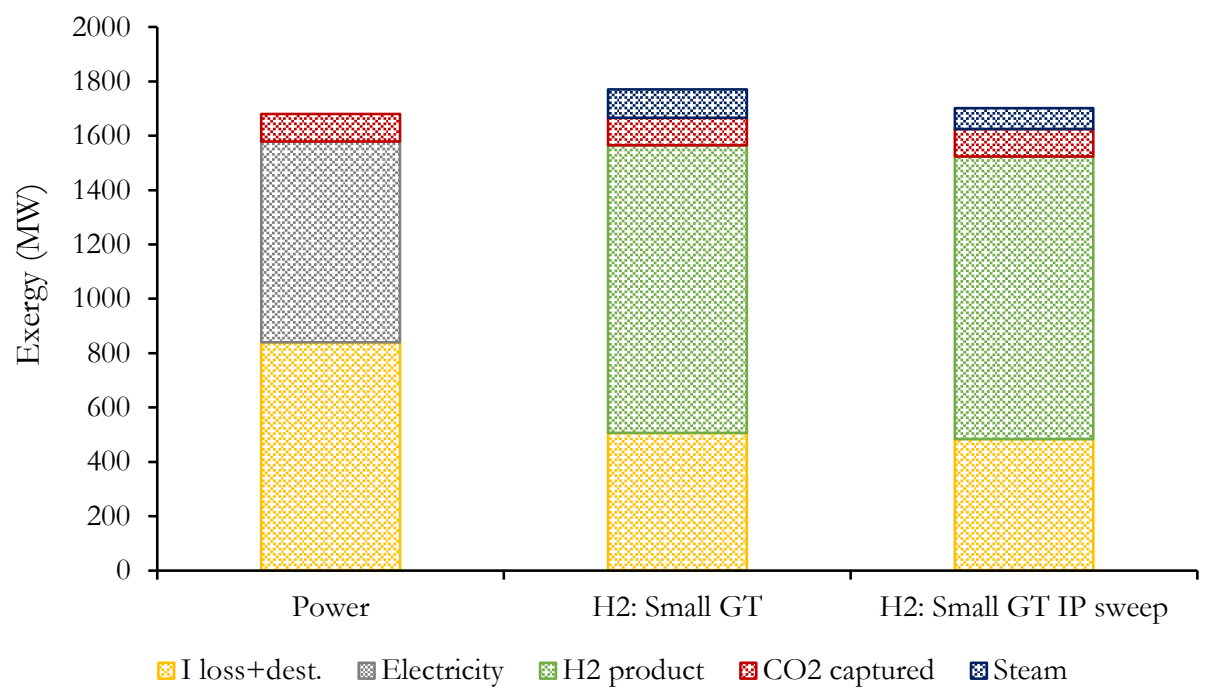

Figure 122 Total exergy distribution for the GSC-MAWGS IGCC power plant with GE gasification

By employing IP sweep gas, the exergy that is exported as steam is decreased, as well as the electricity import.

\section{Economic}

Lastly, the economic performance of the GSC-MAWGS IGCC power plant with GE gasification is summarized in Table 78:

Table 78 Economic results for the GSC-MAWGS IGCC power plant with GE gasification

\begin{tabular}{|c|c|}
\hline Item & Value \\
\hline$S I(€ / \mathrm{kW})$ & 2610,9 \\
\hline$L C O E(€ / \mathrm{MWh})$ & 77,4 \\
\hline $\operatorname{COC} A\left(€ /\right.$ tonCO $\left._{2}\right)$ & 31,9 \\
\hline
\end{tabular}

Compared to the precombustion benchmark, the flexible power plant with GE gasification attains a specific investment cost reduction of $215,6 € / \mathrm{kW}(7,6 \%$ less) while the cost of electricity drop by $4,4 € / \mathrm{MWh}$ (5,3\% reduction). The cost of $\mathrm{CO}_{2}$ avoidance cost falls by $10,4 € /$ ton (corresponding to a $24,6 \%$ reduction). In terms of capital cost distribution, fig shows the lower contribution taken by the gasifier (compared to Shell cases) while a larger proportion to the installed cost is observed by the ASU units. Again, the capital and variable fuel cost contributions to the total are slightly reduced for the plant with GS technology, but are offset to an extent by the higher variable operating costs. 


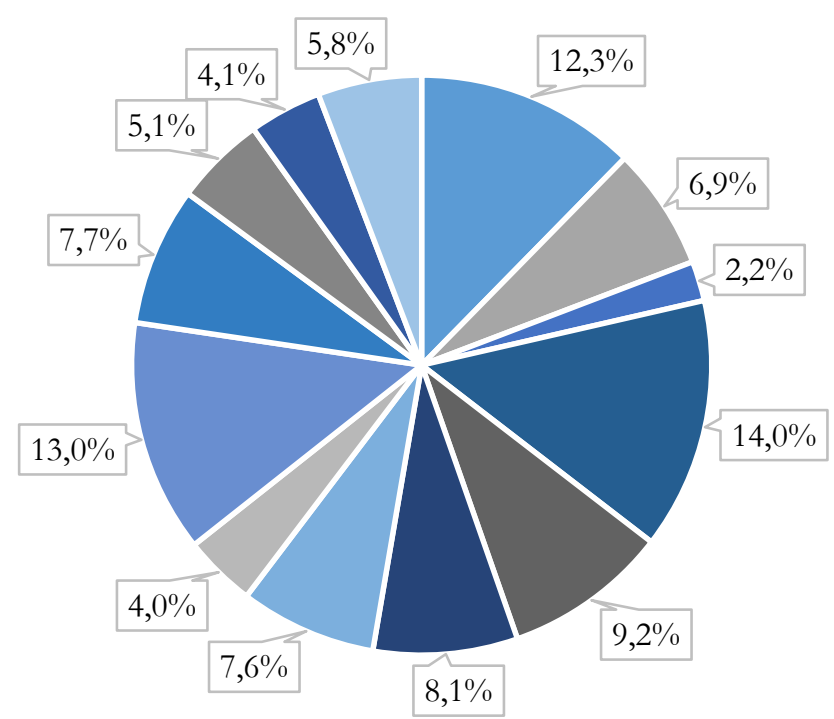

$\because \mathrm{ASU}$

- Coal handling

- Ash handling

- Gasifier

- HGCU

- MAWGS

- GSC reactors

- CO2 compression

- Gas Turbine

- Steam Turbine

- HRSG

- Heat exhangers

- Condenser

Figure 123 TIC distribution for the GSC-MAWGS IGCC power plant with GE gasification

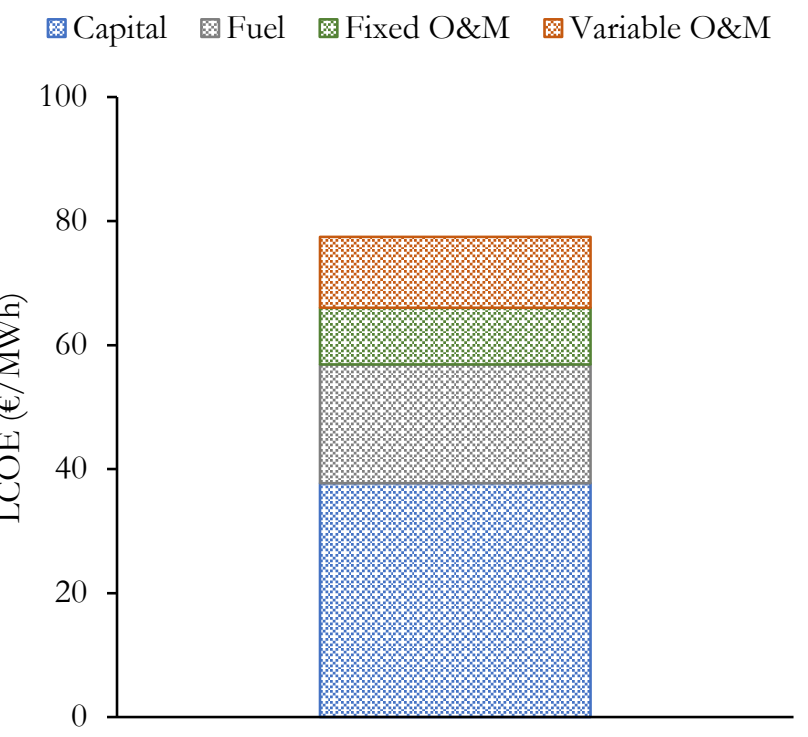

Figure 124 LCOE build-up for the GSC-MAWGS IGCC power plant with GE gasification

\subsection{GSOP Power Plants}

A brief assessment on the possibility of integrating GSOP clusters in IGCC plants to circumvent the energy penalty imposed by the ASU was carried out at an initial phase of the project. By assuming a hypothetical reactor performance in terms of $\mathrm{O}_{2}$ production, which is detailed in section 2.3.1, the power plant performance can be determined. It is noted that due to the low feasibility to synthesize the GSOP oxygen carrier, this phase was neglected at an intermediate stage of the project and the focus on GSC integration for power production prevailed.

\subsubsection{Oxygen Production Pre-Combustion (OPPC) IGCC}

The oxygen production pre-combustion (OPPC) IGCC power plant features several advantages compared to the Standalone GSC IGCC power plant. The concept uses the compressed air stream from the GT to separate a fraction of $\mathrm{O}_{2}$ in the GSOP needed for gasification in a HTW unit. An extra addition of air or steam must take place to close the energy balance of the gasifier (which 
operates adiabatically). The fluidized bed gasification option must be used because high operating temperatures of the entrained flow units would result in low efficiencies. A portion of the produced syngas is fed to the GSOP, while the remaining is shifted in a WGS unit. An absorption based technology is employed to remove converted $\mathrm{CO}_{2}$. The purified $\mathrm{H}_{2}$ stream is fired with the GSOP oxidation outlet, reaching TIT levels of the F-class machine. Due to the high air temperature, it was considered that $\mathrm{H}_{2}$ dilution with steam $\left(\mathrm{N}_{2}\right.$ from an ASU is not available) was not necessary to limit NOx emissions because the flame can be maintained with higher than stoichiometric air feeds (resembling a premixed combustor). A conventional steam cycle produces more electricity from the remnant heat of combustion in the GT exhaust stream. The key advantage of the OPPC concept is that despite the oxygen production carrier is more challenging to manufacture, the operating temperature is significantly below that of the GSC, avoiding consequent issues of both the oxygen carrier and downstream filters and valves. Plus, there is no need for a dedicated heat recovery unit for the reduction gases, while the technology blocks in charge of $\mathrm{CO}_{2}$ removal and sequestration are currently commercially available. A schematic of the OPPC IGCC power plant is shown in Figure 125, while detailed process flow diagram and stream summary are provided in Figure 149 and Table 99 respectively in the Appendix.

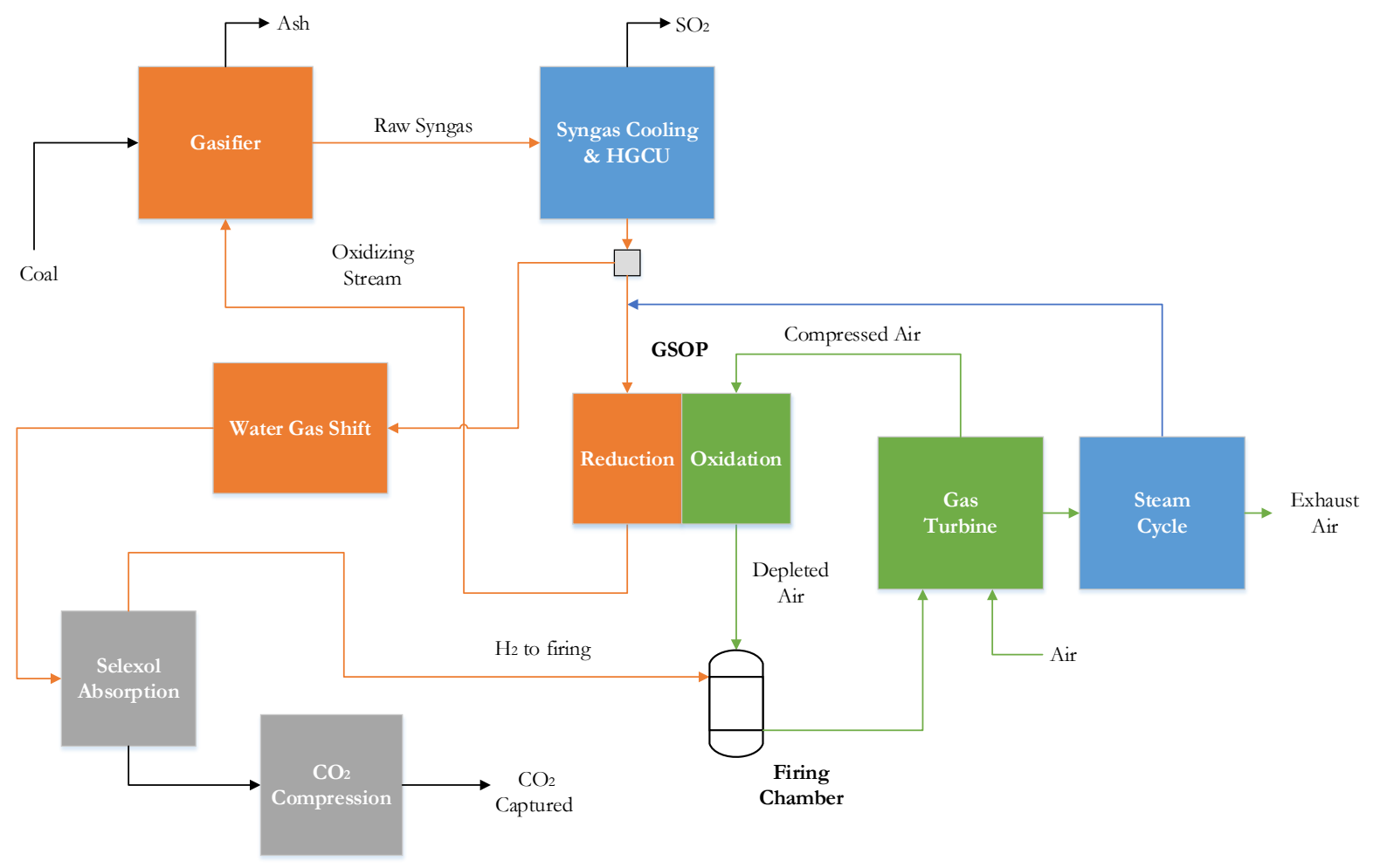

Figure 125 Block flow diagram of the OPPC IGCC power plant

Different $\mathrm{CO}_{2}$ removal technologies and GSOP operating temperatures are presented in [125]. The case shown here corresponds to a GSOP operating temperature of $900^{\circ} \mathrm{C}$ using a Selexol unit for absorption and steam addition to the GSOP syngas feed to satisfy the gasifier energy balance.

Energy

The energy breakdown of the OPPC IGCC power plant is presented in Table 79. The combined benefits of the higher TIT, higher CGE and HGCU result in attractive efficiency numbers, with a very low overall auxiliary consumption, thanks to the avoidance of the ASU unit. 
Table 79 Energy breakdown of the OPPC IGCC power plant

\begin{tabular}{|c|c|}
\hline \multicolumn{2}{|c|}{ Power-heat breakdown } \\
\hline Coal input (MW) & 854,0 \\
\hline Compressor (MW) & 278,5 \\
\hline Turbine (MW) & 599,3 \\
\hline GT net (MW) & 244,0 \\
\hline Steam cycle net (MW) & 193,8 \\
\hline Condenser (MW) & 263,0 \\
\hline Power plant auxiliaries \\
\hline GT auxiliaries (MW) & 0,9 \\
\hline Fuel/Syngas booster (MW) & 5,4 \\
\hline Coal milling (MW) & 1,4 \\
\hline Ash handling (MW) & 1,1 \\
\hline Selexol plant (AGRU) (MW) & 4,6 \\
\hline Syngas treating (MW) & 1,3 \\
\hline CO Compression (MW) & 21,1 \\
\hline Water pumps (MW) & 3,0 \\
\hline Heat rejection (MW) & 2,4 \\
\hline Balance of plant (MW) & 1,3 \\
\hline Global balance \\
\hline Total auxiliaries (MW) & 42,4 \\
\hline Gross plant (MW) & 437,8 \\
\hline Net plant (MW) & 395,4 \\
\hline Total heat input (MW) & 854,0 \\
\hline Net efficiency (\%LHV) & 51,3 \\
\hline & 46,3 \\
\hline
\end{tabular}

An interesting metric for this plant is the fact that around $40.2 \%$ of the total heating value of the original fuel is invested in the GSOP process to generate the oxidant stream. However this set-up synergistically heats up to a great extent $\left(900^{\circ} \mathrm{C}\right)$ the air flow rate of the GT, whilst providing a high temperature oxidant stream which coincidentally enhances CGE in the gasification, as less full combustion reactions must take place to reach the required operating temperature. In that sense, $\mathrm{O}_{2}$ generation incurs at most in a "thermal efficiency penalty" as opposed to a traditional line-up with an ASU where the auxiliary duty is in the form of electricity, with a comparatively higher exergy content.

\section{Environmental}

The pitfall of the OPPC concept is that capture rate (particularly when Selexol is used as absorption technology) is substantially lower than the GSC power plant counterpart. Although the use of HTW gasifier avoids coal drying emissions and a lower $\mathrm{CO}_{2}$ venting in the lock hoppers (less transport gas is needed for coal loading due to the lower gasification pressure), as substantial amount of methane is formed due to the low operating temperatures. This high heating value component which enhances CGE is not removed in the absorption process and contributes significantly to the emission levels. Furthermore, the absorption unit operates at relatively low pressures, which results in a significant $\mathrm{CO}_{2}$ slip and, finally, incomplete $\mathrm{CO}$ conversion in the upstream WGS also generates $\mathrm{CO}_{2}$ upon combustion in the extra firing chamber. Lastly, the GSOP mixing also presents an important fraction of the overall emissions, due to the fact that the only optimization strategy that can be implemented in this GS technology is the delayed switch. Table 80 summarizes the $\mathrm{CO}_{2}$ emission metrics for this plant while Figure 126 provides the build-up of specific emissions depending on the source where they originate. 
Table $80 \mathrm{CO}_{2}$ emissions performance of the OPPC IGCC power plant

\begin{tabular}{|c|c|}
\hline Items & Value \\
\hline $\mathrm{CO}_{2}$ Emissions $(\mathrm{kgCO} / \mathrm{MWh})$ & 123,3 \\
\hline $\mathrm{CO}_{2}$ Capture $(\%)$ & 83,2 \\
\hline $\mathrm{CO}_{2}$ Avoidance $(\%)$ & 83,0 \\
\hline SPECCA $\left(\mathrm{MJ} / \mathrm{kgCO}_{2}\right)$ & 0,361 \\
\hline
\end{tabular}

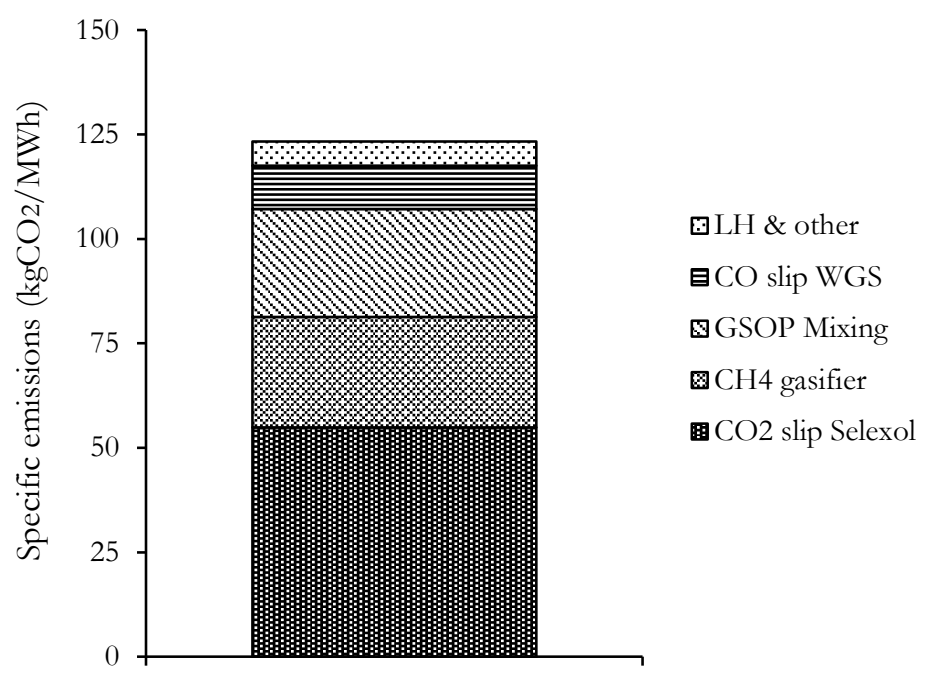

Figure $126 \mathrm{CO}_{2}$ Emissions breakdown for the OPPC IGCC power plant

Exergy

The exergy analysis performed to the OPPC IGCC plant is summarized in Table 81 and Figure 127 , where total and \% values respectively of exergy distribution are presented, based on technology blocks and process units.

Table 81 Total exergy breakdown for the OPPC IGCC power plant

\begin{tabular}{|c|c|c|}
\hline Block & Item & Exergy (MW) \\
\hline Gasification island & Gasification & 77,5 \\
\hline \multirow{4}{*}{ Syngas cooling \& treating } & Slag HX & 2,7 \\
\cline { 2 - 3 } & SEC & 16,4 \\
\cline { 2 - 3 } & HGCU & 4,5 \\
\cline { 2 - 3 } & WGS & 25,2 \\
\cline { 2 - 3 } & Fuel, syngas booster & 10,8 \\
\hline \multirow{3}{*}{ Topping cycle } & Firing chamber & 1,1 \\
\cline { 2 - 3 } & Compressor & 90,5 \\
\cline { 2 - 3 } & Turbine & 21,9 \\
\hline GSOP cluster & GSOP cluster & 33,6 \\
\hline \multirow{3}{*}{ Bottoming cycle } & HSRG & 100,0 \\
\hline & Condenser, pumps etc. & 15,0 \\
\hline & Steam turbine & 18,2 \\
\hline CO $_{2}$ compression & $\mathrm{CO}_{2}$ compression & 4,5 \\
\hline \multirow{3}{*}{ Exergy out } & Exhaust gases & 11,0 \\
\hline & $\mathrm{CO}_{2}$ captured & 45,3 \\
\hline & Slag & 28,7 \\
\hline
\end{tabular}




\begin{tabular}{|c|c|c|}
\hline & Other (water, $\mathrm{CO}_{2}$ vent) & 1,8 \\
\hline Misc. & BoP & 1,3 \\
\hline Useful effect & Wnet & 395,5 \\
\hline
\end{tabular}

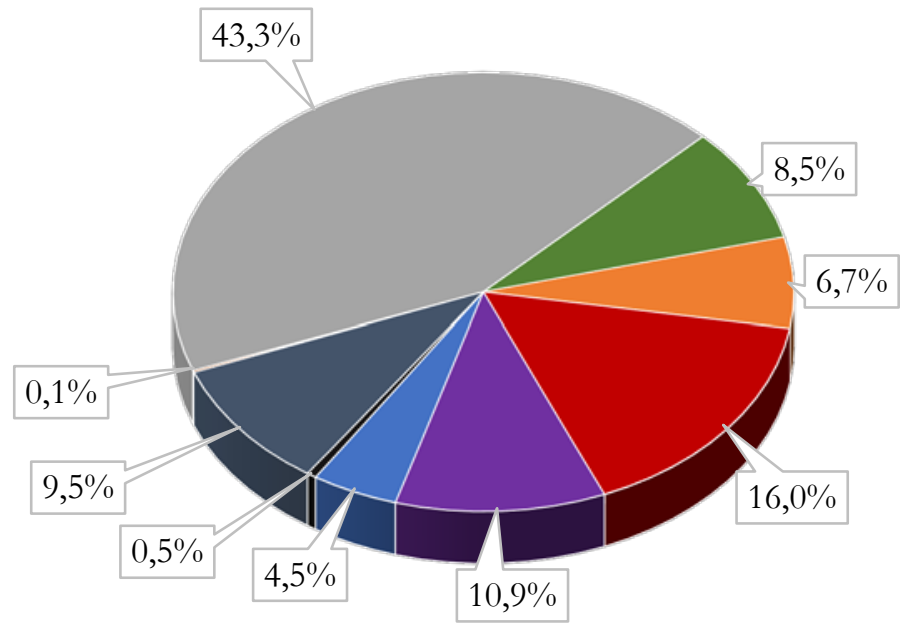

- Gasification island

- Syngas cooling \& treating

- Topping cycle

- GSOP cluster

- Bottoming cycle

- CO2 compression

- Exergy out

- Misc.

- Useful effect

Figure 127 Exergy distribution in \% for the OPPC IGCC power plant

A large contribution to the exergy that exists the plant boundary occurs in the slag, due to the limited carbon conversion in the HTW gasification system relative to the entrained flow gasifiers. On the other hand, a drastic reduction in the exergy loss fraction of the gasification section is shown, given the high temperature oxidizing agent and the low gasification temperature. The elements where a chemical combustion of the syngas fuel take place, i.e. GSOP cluster and extra firing chamber also present large exergy destruction, while the WGS section reveals comparatively lower overall losses than in the benchmark pre-combustion $\mathrm{CO}_{2}$ capture power plant, since less $\mathrm{CO}$ is required to be shifted (as this species can be combusted safely in the GSOP free of emissions)

\section{Economic}

The economic assessment results for the OPPC IGCC power plant are summarized in Table 82. Figure 128 shows the distribution of the TIC, with a total of 776,7 M€, while Figure 129 provides the LCOE cost build up.

Table 82 Economic results for the OPPC IGCC power plant

\begin{tabular}{|c|c|}
\hline Item & Value \\
\hline$S I(€ / \mathrm{kW})$ & 2958,9 \\
\hline $\operatorname{LCOE}(€ / \mathrm{MWh})$ & 79,7 \\
\hline$C O C A_{I G C C}(€ /$ tonCO 2$)$ & 30,6 \\
\hline $\mathrm{COCA}_{S C P C}\left(€ /\right.$ tonCO $\left.\mathrm{C}_{2}\right)$ & 37,5 \\
\hline
\end{tabular}

With respect to the pre-combustion benchmark, the OPPC plant achieves a reduction in the LCOE of $13,1 € / M W h(14,1 \%$ reduction) while the specific investment drops by $219,1 € / \mathrm{kW}$ $(6,9 \%$ less). The larger syngas flow rate resulting from the oxidizing stream results in a large cost contribution for this item. Nonetheless, the economic study reveals the competitiveness $(3,1$ $€ / M W h$ lower electricity cost) of the OPPC concept with respect to the Standalone IGCC power 
plant, provided that the technical uncertainty of the high temperature operation is traded off with the oxygen carrier development requirement for $\mathrm{O}_{2}$ production.

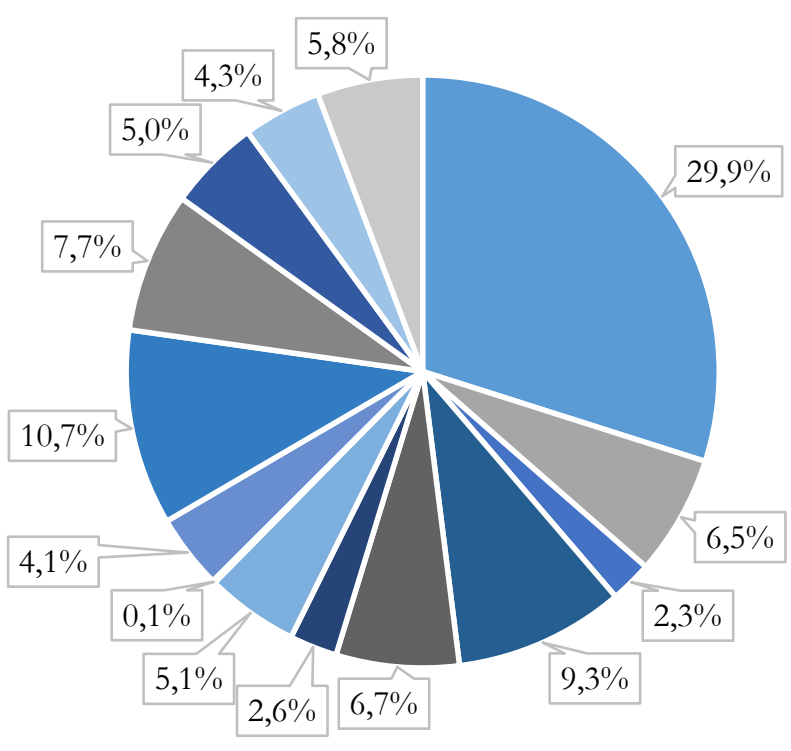

- Gasifier

- Coal handling

- Ash handling

- HGCU

- GSOP

- WGS

- Selexol plant

- Booster

- $\mathrm{CO} 2$ compression

- Gas Turbine

- Steam Turbine

Figure 128 TIC distribution of the OPPC IGCC power plant

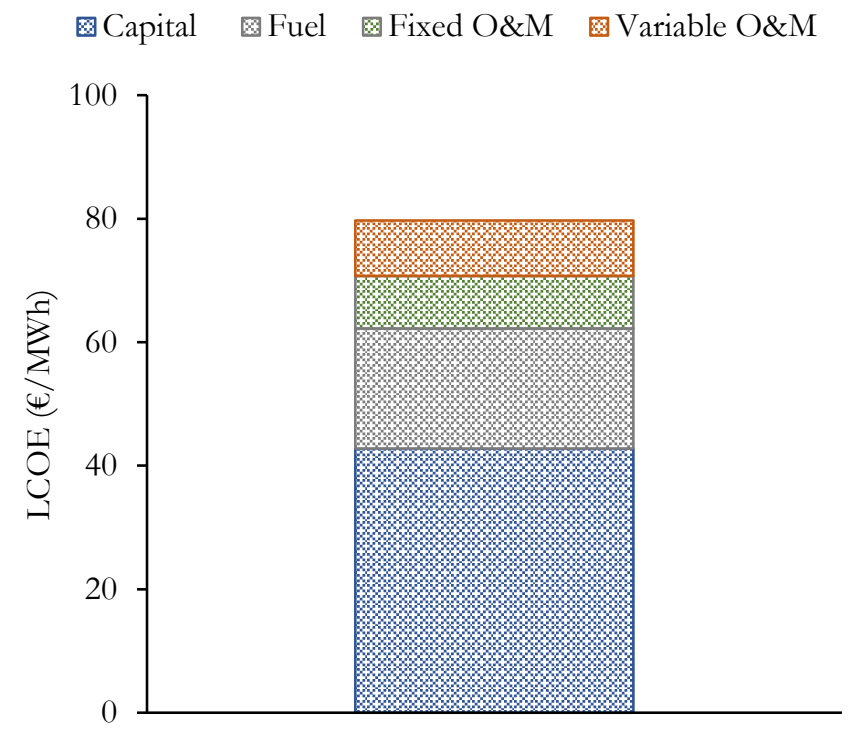

Figure 129 LCOE build up for the OPPC IGCC power plant

\subsubsection{Composite: GSOP-GSC IGCC}

The Composite process [56] consists in a two way coupling of the GSOP and GSC clusters, in such a way that the energy penalty of ASU is eliminated by the oxygen production cluster, while the remaining air heating to approximately $1200^{\circ} \mathrm{C}$ is carried out in the GSC, thereby achieving inherent capture of $\mathrm{CO}_{2}$ in a pressurized condition. The gasification system is analogous to the OPPC concept, while a hot gases recovery unit and a purification system are still present. The lower temperatures attainable in the GSC relative to the $\mathrm{H}_{2}$ firing in OPPC, results in a shift of the net power output towards the bottoming cycle, similarly to what takes place in the standalone GSC IGCC power plant. The block flow diagram for the Composite process is provided in Figure 130. Analogously to the OPPC plant, a sweep stream must be introduced in the reduction stage feed 
of the GSOP to generate sufficient $\mathrm{O}_{2}$ in the outlet stream, so as to achieve an adiabatic operation in the gasifier. A detailed schematic and corresponding stream summary are given in Figure 150 and Table 99 in the Appendix.

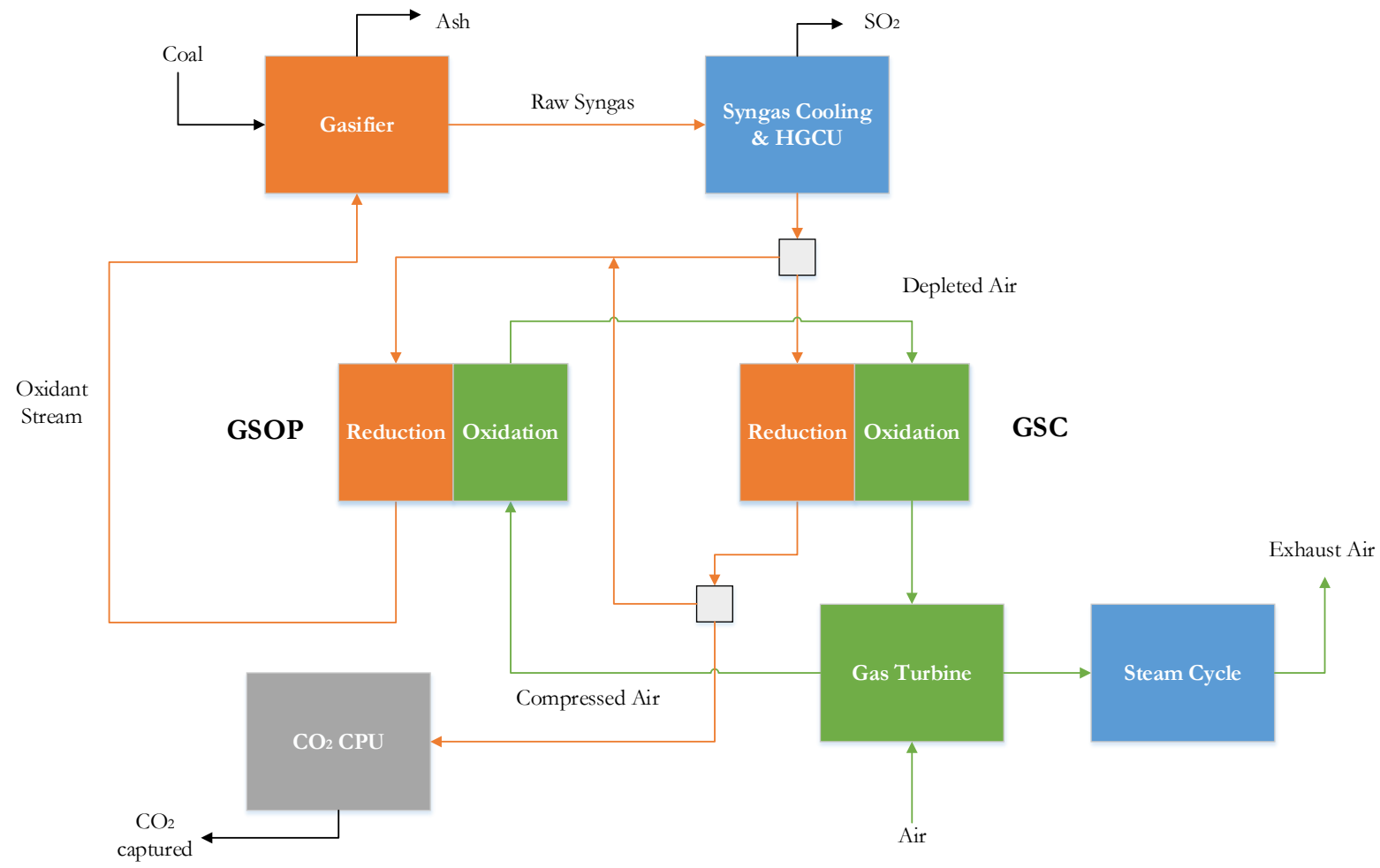

Figure 130 Block flow diagram of the Composite: GSOP-GSC IGCC power plant

An important concern regarding the feasibility of this concept is the challenging simultaneous operation of two GS clusters, and their integration with the gasification and gas turbine system allows for a relatively low degree of flexibility, which would require high plant capacity factors to present attractive economics. Although the scope of the work is to present the potential energy penalty reductions, these considerations should be noted in future developments. A positive aspect of the GSOP based concepts is that the HTW gasification system employed is more flexible to operate at different loads relative to the entrained flow concepts.

\section{Energy}

The energy breakdown of the Composite IGCC power plant is provided in Table 83. For the plant presented here, the GSOP operating temperature was fixed to approximately $700^{\circ} \mathrm{C}$, which results in a $32 \%$ fraction of the syngas heating value in the GSOP cluster to maintain that temperature (the remaining is used in the GSC) while around $20 \%$ of the reduction gases are recirculated as sweep gas to close the energy balance in the gasifier.

Table 83 Energy breakdown for the Composite IGCC power plant

\begin{tabular}{|c|c|}
\hline \multicolumn{2}{|c|}{ Power/heat breakdown } \\
\hline Coal input (MW) & 854,0 \\
\hline Compressor (MW) & 345,8 \\
\hline Turbine (MW) & 552,3 \\
\hline GT net (MW) & 203,5 \\
\hline Steam cycle net (MW) & 222,7 \\
\hline Condenser (MW) & 314,2 \\
\hline
\end{tabular}




\begin{tabular}{|c|c|}
\hline \multicolumn{2}{|c|}{ Plant auxiliaries } \\
\hline GT auxiliaries (MW) & 0,7 \\
\hline Fuel/Syngas booster (MW) & 8,1 \\
\hline Coal milling (MW) & 1,4 \\
\hline Ash handling (MW) & 1,1 \\
\hline Syngas treating (MW) & 1,2 \\
\hline CO $_{2}$ purification unit (MW) & 11,4 \\
\hline Water pumps (MW) & 2,9 \\
\hline Heat rejection (MW) & 3,0 \\
\hline Balance of plant (MW) & 1,3 \\
\hline \multicolumn{2}{|c|}{ Global balance } \\
\hline Total auxiliaries (MW) & 31,0 \\
\hline Gross plant (MW) & 426,2 \\
\hline Net plant (MW) & 395,2 \\
\hline Total heat input (MW) & 854,0 \\
\hline Gross efficiency (\%LHV) & 49,9 \\
\hline Net efficiency (\%LHV) & 46,3 \\
\hline
\end{tabular}

Compared to the results shown in [56] using packed beds for the GS clusters and GSOP operating temperature of $800^{\circ} \mathrm{C}$, the present study shows a substantial improvement in efficiency of $0.8 \%$ points. This can be due to the improved performance in the GSOP cluster due to the fluidization operation; the good mixing properties allow a greater $\mathrm{O}_{2}$ concentration difference between the stage outlet streams, reducing the overall flow rate through the loop gasifier-GSOP and related energy penalty of cooling (only to produce steam for the bottoming cycle) and reheating. It must be said, the efficiency values obtained in this study correspond to a fixed carbon conversion of $95.5 \%$ in the HTW, as opposed to the value of $97 \%$ for the OPPC case. The most advanced circulating fluidized bed gasifiers can achieve the latter value of conversion [76], but the former value used to present a consistent comparison with [56]. In relation to the OPPC plant, the Composite plant would result between 0.1-0.2\%-points more efficient, if the same fixed carbon conversion was assumed.

\section{Environmental}

The attractive efficiency benefits relative to the packed bed configuration has the drawback of an increased mixing of GS cluster outlet streams and reduced capture ratio, as shown in Table 58:

Table $84 \mathrm{CO}_{2}$ emissions performance of the Composite IGCC power plant

\begin{tabular}{|c|c|}
\hline Item & Value \\
\hline $\mathrm{CO}_{2}$ Emissions $(\mathrm{kgCO} / \mathrm{MWh})$ & 116,4 \\
\hline $\mathrm{CO}_{2}$ Capture $(\%)$ & 83,9 \\
\hline $\mathrm{CO}_{2}$ Avoidance $(\%)$ & 84,0 \\
\hline SPECCA $\left(\mathrm{MJ} / \mathrm{kgCO}_{2}\right)$ & 0,362 \\
\hline
\end{tabular}

Due to the low fixed carbon conversion compared to the benchmark plant, it is noticeable that the avoided $\mathrm{CO}_{2}$ is slightly higher than the capture ratio. Finally the emission distribution from the different sources is illustrated in Figure 103: 


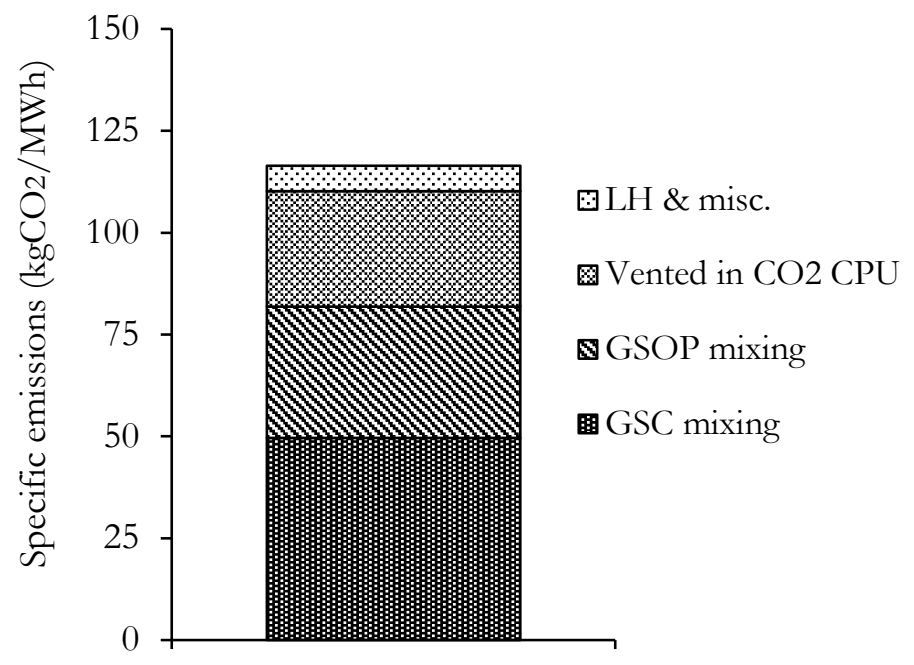

Figure $131 \mathrm{CO}_{2}$ emissions distribution for the Composite IGCC power plant

\section{Exergy}

The exergy analysis is presented in Figure 132 and Table 85. The GSOP and GSC clusters are shown separately.

Table 85 Total exergy distribution for the Composite IGCC power plant

\begin{tabular}{|c|c|c|}
\hline Block & Item & Exergy (MW) \\
\hline Gasification island & Winkler Gasifier & 95,1 \\
\hline \multirow{3}{*}{ Syngas cooling \& treating } & Slag HX & 3,4 \\
\hline & SEC & 14,7 \\
\hline & HGCU + Booster & 6,8 \\
\hline GSOP cluster & GSOP & 80,0 \\
\hline GSC cluster & GSC & 108,3 \\
\hline \multirow{2}{*}{ Gas turbine } & Compressor & 21,5 \\
\hline & Turbine & 29,2 \\
\hline \multirow{4}{*}{ Steam cycle } & HSRG & 14,8 \\
\hline & Hot gases recovery unit & 12,7 \\
\hline & Condenser \& pumps & 11,2 \\
\hline & Steam turbine & 21,4 \\
\hline \multirow{2}{*}{$\mathrm{CO}_{2}$ purification \& compression } & Red. gases condenser & 5,8 \\
\hline & $\mathrm{CPU}$ & 8,1 \\
\hline \multirow{4}{*}{ Exergy out } & Slag & 28,7 \\
\hline & $\mathrm{CO}_{2}$ captured & 44,9 \\
\hline & Stack gases & 10,6 \\
\hline & Other (water etc.) & 0,7 \\
\hline Misc. & $\mathrm{BoP}$ & 1,3 \\
\hline Useful effect & Wnet & 395,2 \\
\hline
\end{tabular}




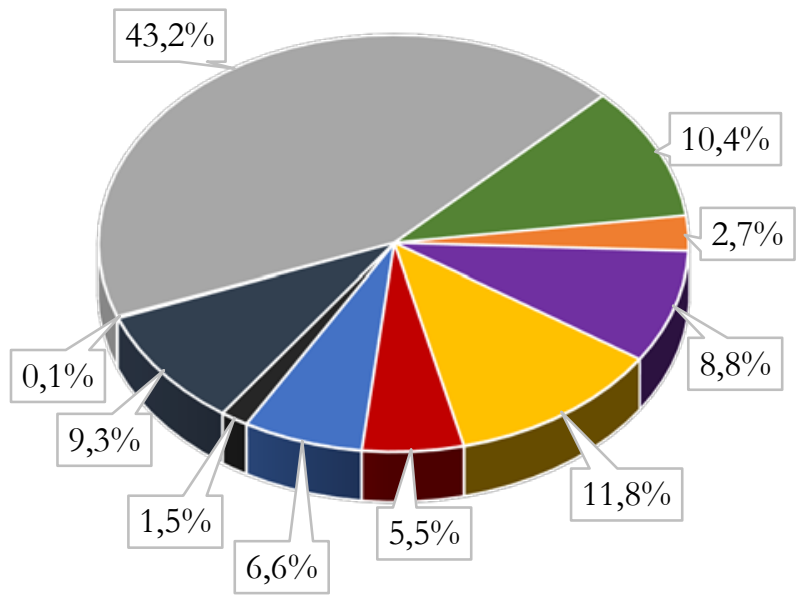

- Gasification island

- Syngas cooling \& treating

- GSOP cluster

- GSC cluster

- Gas turbine

- Steam cycle

- CO2 purification \& compression

- Exergy out

- Misc.

- Useful effect

Figure 132 Exergy distribution in \% for the Composite IGCC power plant

It can be seen that the highest losses are distributed evenly between gasification and GS clusters. Again, due to the larger net power output contribution of the bottoming cycle, the exergy losses in these units is bigger. Somewhat higher losses are present in the GSC (extra firing) and gasifier relative to the OPPC concept because the operating temperature of the GSOP is $200^{\circ} \mathrm{C}$ lower in this case. Finally, an exergy flow diagram of the Composite IGCC power plant is presented in Figure 133.

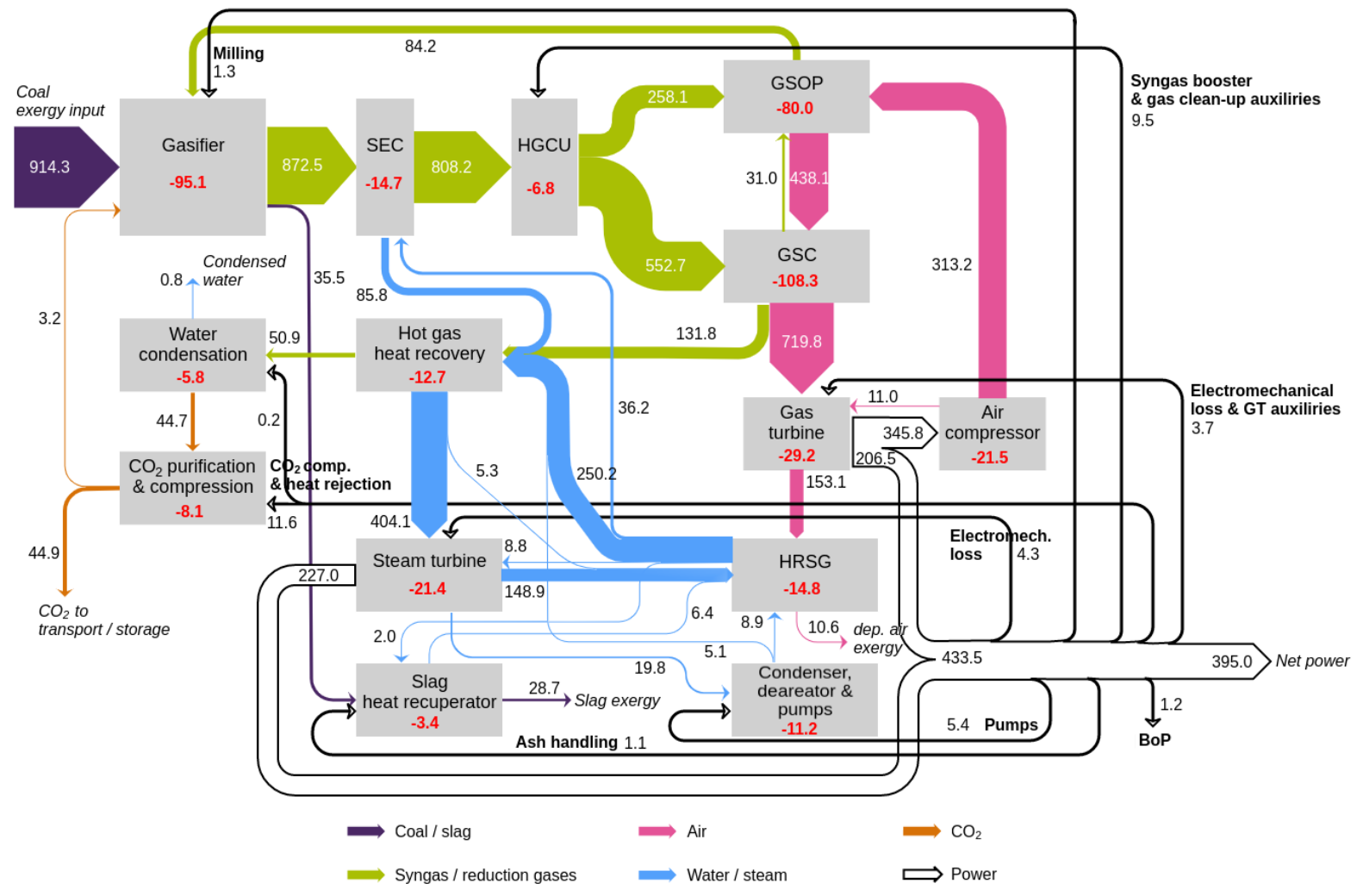

Figure 133 Exergy flow diagram for the Composite IGCC power plant

\section{Economic}

No economic assessment was carried out in the GasTech project. An economic evaluation of using an integration of packed bed oxygen production and combustion reactors proved marginal 
economic benefits relative to the standalone packed bed CLC configuration [126]. Thus, the increased complexity leading to higher thermal efficiencies for this process is not beneficial from an economic point of view. It is likely that the efficiency gain when using fluidized gas switching reactors does not outweigh the $\mathrm{CO}_{2}$ capture losses, particularly when the emission costs considered are high. 


\section{Chapter 5}

\section{Conclusions}

In this chapter the main outcomes of the power plants synthesized in the previous chapters are provided. A summary of the key performance indicators is given for the introductory and advanced plants. A qualitative assessment of the key advantages and technology gaps is also presented. Finally several concluding remarks and recommendations for future work are given.

\subsection{Summary of Results}

In this research work the performance of several novel technologies based on the gas switching chemical looping concepts has been evaluated. The modelling of the gas switching technology was presented in Chapter 2, with significant simplifications to the complex nature of the heterogenous reactions taking place with the solid particles in a heterogenous regime. Total reactivity of the carrier was a plausible assumption, to highlight the ex ante nature of the present assessment. The process models were built using standardized technology blocks using performance values consistent with other literature studies.

\subsection{1 "Introductory" Power Plants}

A summary of the results obtained for the "introductory" power plant models is presented in Table 86, attending to the key performance indicators described at the beginning of section 1.4. Additionally, Table 87 gives a qualitative description of the main design advantages and disadvantages of the proposed process concepts and lists the key technology gaps which need to be developed in order to realize the schemes. The key economic findings and appropiate sensitivity analysis and comparison with renewable and non-renewable energy sources can be found in [127].

The pre-combustion $\mathrm{CO}_{2}$ capture benchmark incurs in an energy penalty which is around 9,8\%points relative to the IGCC Unabated case. The plant is designed to capture approximately $90 \%$ of the $\mathrm{CO}_{2}$ generated. The exergy efficiencies showed lower absolute values for all of the plants given that the exergy correlation for coal predicted a chemical exergy substantially above the lower heating value of the fuel. When the exergy of the captured $\mathrm{CO}_{2}$ was accounted for in the exergy efficiency, the result increased notoriously for the plants with CCS. A detailed exergy analysis of the benchmark plants, the GSC IGCC model and the Composite GSOP-GSC plant is presented in [117]. The subsequent economic assessment revealed that the increase in the cost of electricity when implementing conventional pre-combustion CCS technology amounted to 31,5 €/MWh, which yielded a $\mathrm{CO}_{2}$ avoidance cost of $54,7 € /$ ton.

The standard IGCC design incorporating hot gas clean up technology and GSC cluster instead of a combustion chamber resulted in an efficiency penalty reduction to only 4,2\%-points, with a slightly higher capture rate, resulting in approximately 3\%-points higher capture avoidance and a corresponding decrease in specific emissions. To further boost the plant efficiency, and extrafiring chamber using natural gas and the GSC oxidation stage outlet was assessed, surpassing the efficiency of the Unabated IGCC model (6.1\%-points above the standalone GSC concept) but incurring in an increased emissions rate (due to $\mathrm{CO}_{2}$ formation upon combustion of natural gas) . The standalone IGCC concept achieved a LCOE reduction with respect to the pre-combustion 
capture plant of $9,9 € / \mathrm{MWh}$. When the extra firing with natural gas case was assessed, the LCOE reduction amounted to $22,9 € / \mathrm{MWh}$. The costs of $\mathrm{CO}_{2}$ avoidance where reduced by $16,9 € /$ ton and $32,3 € /$ ton respectively. A detailed study involving different cluster heat management strategies and efficiency enhancement pathways is given in [116].

An alternative option employing a less efficient, less costly gasification system (GE gasifier) was evaluated by integrating the GSC cluster into a Humid Air Turbine (HAT) power cycle. The energy penalty was 1,8\%-points above that of the GSC standalone concept, but the scheme has the potential to operate flexibly using the oxygen carrier as an energy storage mechanism, analogously to a battery. This concept is thoroughly studied in [121].

Finally, two process concepts employing GSOP clusters were evaluated. The OPPC IGCC plant replaces the GSC cluster with the oxygen production technology, which is effectively coupled to the gasification system. The GSOP oxidation outlet is further heated by combusting a $\mathrm{H}_{2}$ rich fuel, which is produced by shifting a portion of the clean syngas. The remaining is fed to the GSOP reduction stage. Relative to the standalone GSC model, the OPPC plant achieves a reduction of the energy penalty of 2,9\%-points, avoiding the temperature limitations associated to the clusters of the reactors, the gas switching valves and the filters. Also the heat recovery section for the reduction gases is avoided. Instead, existing well-known $\mathrm{CO}_{2}$ capture technology must be employed. It should be mentioned that the efficiency gains also arises from the use of a more efficient gasification system, which recovers to a higher degree the heating value of the solid fuel in the syngas produced, and which has not been applied up to date in large scale power production IGCC plants. The less effective $\mathrm{CO}_{2}$ capture in this section and the increased $\mathrm{n}^{\circ}$ of $\mathrm{CO}_{2}$ emissions (methane slip, lack of $\mathrm{CO}$ full conversion) results in a $\mathrm{CO}_{2}$ capture reduction of 9,0\%-points and similarly lower avoidance but, due to the high efficiency of the OPPC concept, the SPECCA Index results $0,76 \mathrm{MJ} / \mathrm{kg} \mathrm{CO}$ lower. Due to the high degree of uncertainty regarding the GSOP oxygen carrier, in [125] a detailed assessment with a sensitivity analysis to the cluster operating temperature and an evaluation of different capture technologies was performed. The economic assessment for this plant using Selexol absorption technology revealed a LCOE reduction relative to the precombustion CCS plant of 13,0 €/MWh, with a cost of $\mathrm{CO}_{2}$ avoided which was $17,2 € /$ ton lower.

Finally, an assessment of the Composite concept, integrating a GSOP and a GSC cluster was studied, revealing an attractive efficiency result with an energy penalty with respect to the Unabated plant of only 1,3\%-points. However, due to the large amount of mixing taking place in both clusters operating in fluidization mode the capture ratio dropped by $8,3 \%$-points, relative to the standalone GSC IGCC power plant. The gasification technology employed is the same as the one used for the OPPC concept, which definitely contributes to the efficiency gains because of the low gasification temperatures and additionally the high oxidant stream temperature. The complex integration of the gasifier, GSOP and GSC suggests that it is a challenging plant to operate in reality, which lessens the feasibility potential of the configuration. Furthermore, economic studies of this concept external to the GasTech project based on this line-up using packed bed reactors in the clusters indicate the low attractiveness of the addition of the GSOP cluster (relative to the standalone GSC process), despite the auxiliary consumption savings and elimination of the process units in the ASU for the generation of an oxidant stream. For this reason, the present study only provides an exergy analysis of this plant [117]. 
Table 86 KPI summary of the "Introductory" power plants

\begin{tabular}{|c|c|c|c|c|c|c|c|}
\hline \multirow{2}{*}{$\begin{array}{c}\text { Power Plant Type } \\
\text { Concept/ KPI }\end{array}$} & \multicolumn{2}{|c|}{ Benchmarks } & \multicolumn{3}{|c|}{$\underline{\text { GSC }}$} & \multicolumn{2}{|c|}{ GSOP } \\
\hline & $\begin{array}{c}\text { Unabated } \\
\text { IGCC }\end{array}$ & $\begin{array}{c}\text { Pre-combustion } \\
\mathrm{CO}_{2} \text { capture } \\
\text { IGCC }\end{array}$ & $\begin{array}{l}\text { Standalone } \\
\text { GSC IGCC }\end{array}$ & $\begin{array}{c}G S C \text { with Extra } \\
\text { Firing IGCC }\end{array}$ & $\begin{array}{l}\text { Integrated } \\
\text { Gasification } \\
G S C-H A T\end{array}$ & $\begin{array}{c}\text { Oxygen } \\
\text { Production Pre- } \\
\text { combustion } \\
\text { (OPPC) IGCC }\end{array}$ & $\begin{array}{l}\text { Composite: } \\
\text { GSOP-GSC } \\
\text { IGCC }\end{array}$ \\
\hline \multicolumn{8}{|c|}{ Energy } \\
\hline$\eta_{t}^{W}(\%)$ & 47,6 & 37,8 & 43,4 & 49,5 & 41,6 & 46,3 & 46,3 \\
\hline \multicolumn{8}{|c|}{ Environmental } \\
\hline$E_{\mathrm{CO}_{2}}\left(\mathrm{kgCO}_{2} / \mathrm{MWh}\right)$ & 726,8 & 86,4 & 62,6 & 140,4 & 6,8 & 123,3 & 116,4 \\
\hline$C_{\mathrm{CO}_{2}}(\%)$ & 0,0 & 90,6 & 92,2 & 77,5 & 99,2 & 83,2 & 83,9 \\
\hline $\mathrm{A}_{\mathrm{CO}_{2}}(\%)$ & 0,0 & 88,1 & 91,4 & 80,7 & 99,1 & 83,0 & 84 \\
\hline$S P E C C A\left(\mathrm{MJ} / \mathrm{kgCO}_{2}\right)$ & - & 3,08 & 1,12 & - & 1,52 & 0,36 & 0,36 \\
\hline \multicolumn{8}{|c|}{ Exergy } \\
\hline$\xi(\%)$ & 44,5 & 35,2 & 40,5 & 46,3 & 38,9 & 43,3 & 43,2 \\
\hline$\xi^{\prime}(\%)$ & 44,5 & 40,9 & 46,1 & 50,5 & 44,6 & 48,2 & 48,1 \\
\hline \multicolumn{8}{|c|}{ Economic } \\
\hline$S I(€ / \mathrm{kW})$ & 2244,7 & 3178,0 & 3000,8 & 2067,7 & - & 2958,9 & - \\
\hline$L C O E(€ / \mathrm{MWh})$ & 61,2 & 92,7 & 82,8 & 69,8 & - & 79,7 & - \\
\hline $\mathrm{COCA}_{S C P C}\left(€ /\right.$ tonCO $\left.\mathrm{CO}_{2}\right)$ & - & 54,7 & 37,8 & 22,4 & - & 37,5 & - \\
\hline
\end{tabular}


Table 87 Qualitative assessment of the "Introductory" power plants

\begin{tabular}{|c|c|c|c|c|c|c|c|}
\hline \multirow{2}{*}{$\begin{array}{c}\begin{array}{c}\text { Power Plant } \\
\text { Type }\end{array} \\
\text { Concept/ KPI }\end{array}$} & \multicolumn{2}{|c|}{$\underline{\text { Benchmarks }}$} & \multicolumn{3}{|c|}{$\underline{\text { GSC }}$} & \multicolumn{2}{|c|}{ GSOP } \\
\hline & $\begin{array}{c}\text { Unabated } \\
\text { IGCC }\end{array}$ & $\begin{array}{c}\text { Pre-combustion } \\
\mathrm{CO}_{2} \text { capture } \\
\text { IGCC }\end{array}$ & $\begin{array}{c}\text { Standalone GSC } \\
I G C C\end{array}$ & $\begin{array}{c}\text { GSC with Extra } \\
\text { Firing IGCC }\end{array}$ & $\begin{array}{c}\text { Integrated } \\
\text { Gasification GSC- } \\
H A T\end{array}$ & $\begin{array}{c}\text { Oxygen Production } \\
\text { Pre-combustion } \\
\text { (OPPC) IGCC }\end{array}$ & $\begin{array}{l}\text { Composite: GSOP- } \\
\text { GSC IGCC }\end{array}$ \\
\hline $\begin{array}{c}\text { Key } \\
\text { Advantages }\end{array}$ & $\begin{array}{l}\text { Inherently } \\
\text { more efficient } \\
\text { than PC boilers }\end{array}$ & $\begin{array}{l}\text { Effective removal } \\
\text { of } \mathrm{CO}_{2} \text { before fuel } \\
\text { combustion }\end{array}$ & $\begin{array}{l}\text { Inherent } \mathrm{CO}_{2} \\
\text { capture. Low } \\
\text { energy penalty and } \\
\text { avoidance of } \mathrm{NOx} \\
\text { due to flameless } \\
\text { combustion }\end{array}$ & $\begin{array}{l}\text { Temperature can be } \\
\text { raised to actual GT } \\
\text { technology leading to } \\
\text { higher efficiencies. } \\
\text { Costly gasification } \\
\text { island can be } \\
\text { downsized relative to } \\
\text { the power cycle }\end{array}$ & $\begin{array}{l}\text { Possibility to operate } \\
\text { flexibly decoupling } \\
\text { reduction \& oxidation } \\
\text { sections to balance } \\
\text { VRE. Reduction } \\
\text { section can be } \\
\text { downsized with } \\
\text { reduced cost prospects. }\end{array}$ & $\begin{array}{l}\text { Ability to raise TIT } \\
\text { through carbon free } \\
\text { fuel in an extra firing } \\
\text { stage, and } \\
\text { consequently } \\
\text { thermodynamic } \\
\text { efficiency }\end{array}$ & $\begin{array}{l}\text { Inherent carbon } \\
\text { capture and avoidance } \\
\text { of ASU, which results } \\
\text { in high efficiency }\end{array}$ \\
\hline $\begin{array}{c}\text { Key } \\
\text { Drawbacks }\end{array}$ & $\begin{array}{l}\mathrm{No} \mathrm{CO}_{2} \\
\text { capture. High } \\
\text { capital } \\
\text { expenditure }\end{array}$ & $\begin{array}{l}\text { Large energy } \\
\text { penalty and } \\
\text { associated cost }\end{array}$ & $\begin{array}{l}\text { Limited reactor } \\
\text { temperature } \\
\text { reduces cycle } \\
\text { thermodynamic } \\
\text { efficiency }\end{array}$ & $\begin{array}{l}\text { Carbonaceous } \\
\text { emissions arise from } \\
\text { extra firing }\end{array}$ & $\begin{array}{l}\text { Low reactor } \\
\text { temperature results in } \\
\text { low efficiency. Quench } \\
\text { design for syngas } \\
\text { cooling and HAT cycle } \\
\text { have lower efficiency } \\
\text { relative to an integrated } \\
\text { CC. }\end{array}$ & $\begin{array}{l}\text { Lower capture rate due } \\
\text { to methane slip. Lower } \\
\text { performance of the } \\
\text { Selexol plant due to } \\
\text { lower operating } \\
\text { pressures. }\end{array}$ & $\begin{array}{l}\text { Complex integration } \\
\text { of two GS cluster for } \\
\text { an inflexible scheme. } \\
\text { Low attainable } \\
\text { temperature in GSC } \\
\text { limits thermodynamic } \\
\text { efficiency. } \\
\text { High level of mixing } \\
\text { in the } 2 \text { clusters } \\
\text { lowers capture rate }\end{array}$ \\
\hline $\begin{array}{l}\text { Technology } \\
\text { Gaps }\end{array}$ & $\begin{array}{l}\text { GT adapted to } \\
\text { syngas fuel }\end{array}$ & $\begin{array}{l}\text { GT must be } \\
\text { adapted to use } \\
\mathrm{H}_{2} / \mathrm{N}_{2} \text { mixture as } \\
\text { fuel }\end{array}$ & $\begin{array}{l}\text { HGCU must be } \\
\text { demonstrated. } \\
\text { High temperature } \\
\text { valves and filters } \\
\text { and oxygen carrier } \\
\text { material }\end{array}$ & $\begin{array}{l}\text { High temperature } \\
\text { valves and filters and } \\
\text { oxygen carrier } \\
\text { material. Heat } \\
\text { management to } \\
\text { ensure low mixing } \\
\text { must be } \\
\text { demonstrated at large } \\
\text { scale. HGCU must } \\
\text { be demonstrated }\end{array}$ & $\begin{array}{l}\text { HAT cycle is not yet } \\
\text { commercial. Coupling } \\
\text { the reduction section } \\
\text { turbomachinery can be } \\
\text { challenging HGCU } \\
\text { must be demonstrated. } \\
\text { High temperature } \\
\text { valves and filters and } \\
\text { oxygen carrier material }\end{array}$ & $\begin{array}{l}\text { Oxygen carrier is at a } \\
\text { very early stage of } \\
\text { development and must } \\
\text { be demonstrated at lab } \\
\text { scale. } \mathrm{H}_{2} \text { firing might } \\
\text { require dillution and } \\
\text { diffusive flame } \\
\text { combustion to limit } \\
\text { NOx. Gasification } \\
\text { technology not } \\
\text { implemented in large } \\
\text { scale IGCC. HGCU } \\
\text { must be demonstrated }\end{array}$ & $\begin{array}{l}\text { High temperature } \\
\text { valves and filters, } \\
\text { oxygen carrier } \\
\text { material development } \\
\text { for GSOP. } \\
\text { Gasification } \\
\text { technology not } \\
\text { implemented in large } \\
\text { scale IGCC. HGCU } \\
\text { must be demonstrated }\end{array}$ \\
\hline
\end{tabular}




\subsection{2 "Advanced" Power Plants}

A second set of power plant models referred to as "Advanced" power plants was developed in order to tackle the problematic integration of Variable Renewable Energy (VRE) in the grid. These configurations make use of $\mathrm{H}$-class turbines and assume also that hot gas desulphurization technology is available for the benchmark plants. To properly compare these flexible plants, two benchmark IGCC technologies with and without CCS were developed using H-class GT and HGCU and designed as base-load power producers.

The flexible $\mathrm{H}_{2}$-power plants are based on the integration of a GSC cluster with MAWGS reactor and have two modes of operation. In power production mode, only sufficient $\mathrm{H}_{2}$ is generated in the membrane reactor to reach the COT of the H-class turbine after the oxidation stage of the GSC. In $\mathrm{H}_{2}$ mode during low electricity prices, most of the syngas is routed to the membrane reactor to maximize $\mathrm{H}_{2}$ production. The permeate stream is cooled down and compressed to delivery pressure. The heating value of the syngas which cannot be extracted as $\mathrm{H}_{2}$ is converted to either steam or electricity. In some cases, electricity import is required to satisfy the plant energy consumption. The cases described in Table 88 correspond to the use of a small GT fuelled by the retentate stream of the MAWGS and, for the case of the GE gasification, additionally employing an IP steam sweep to avoid excessively large $\mathrm{H}_{2}$ compression systems. Several gasification technologies and component integration strategies were investigated in the creation of the flexible plants. The Shell gasification with reduction gases recuperator was the reference model for the GSC-MAWGS IGCC configurations. It achieved a reduction of the energy penalty of 5,3\%-points, with respect to the Advanced Pre-combustion $\mathrm{CO}_{2}$ capture IGCC model, with an energy penalty amounting to 4,4\%-points relative to the Advanced Unabated IGCC power plant, while attaining attractive $\mathrm{H}_{2}$ production efficiencies. On the other hand, a concept using the heat contained in the reduction gases from the GSC to preheat the slurry feed to a HTW gasifier was evaluated. The improvement in CGE of the gasification system and reduction of the ASU auxiliary consumption resulted in an energy penalty of only 1,3\%-points. Finally, a GE gasification plant producing a syngas stream at elevated pressure allowed a different operation of the membrane reactors: using $\mathrm{N}_{2}$ from the ASU as sweep gas and avoiding the need of $\mathrm{H}_{2}$ compression to the combustor. Furthermore, a quench cooling design prevented the need of steam extraction from the bottoming cycle to reach the required steam to carbon ratio prior to the WGS. Due to the higher auxiliary consumption of the ASU and somewhat lower CGE, the resulting efficiency was similar to the Shell gasification case, but presented higher $\mathrm{H}_{2}$ efficiencies due to higher permeability of $\mathrm{H}_{2}$, which is a consequence of the high operating pressures in the retentate side of the membrane reactor. Because of the advanced heat management strategy assumed for GSC cluster operation, the degree of mixing was relatively small leading to low $\mathrm{CO}_{2}$ emissions for all the plants. A detailed study of the first two configurations is provided in [128], with a $\mathrm{H}_{2}$ production mode which assumed part load operation of the H-class GT.

The economic performance evaluation of the advanced plants is an ongoing work and will be presented assessing flexibility benefits before the end of the GasTech project. Both the Advanced Unabated IGCC and the Pre-combustion $\mathrm{CO}_{2}$ capture IGCC power plants are assessed only as base-load power producers. In the results presented in this thesis for the GSC-MAWGS IGCC flexible plants, only the power mode components were taken into account in the initial economic assessment, reflecting a lower cost reduction relative to the corresponding pre-combustion benchmark, than that reflected in the Introductory plants, particularly for the case with natural gas extra firing. The addition of membrane reactors and $\mathrm{H}_{2}$ fuel compression contribute to the increase of the installed cost of the advanced plants with gas switching technology. 
Table 88 KPI Summary of the "Advanced" power plants

\begin{tabular}{|c|c|c|c|c|c|c|c|c|}
\hline Power Plant Type & \multicolumn{2}{|c|}{$\underline{\text { Benchmarks }}$} & \multicolumn{6}{|c|}{ GSC-MAWGS } \\
\hline \multirow[t]{2}{*}{ Concept/ KPI } & \multirow{2}{*}{$\begin{array}{l}\text { Unabated } \\
\text { IGCC }\end{array}$} & \multirow{2}{*}{$\begin{array}{c}\text { Pre-combustion } \\
\mathrm{CO}_{2} \text { capture IGCC }\end{array}$} & \multicolumn{2}{|c|}{ Shell gasifier } & \multicolumn{2}{|c|}{$\begin{array}{c}\text { Pregasifier \& } H T W \\
\text { gasifier }\end{array}$} & \multicolumn{2}{|c|}{ GE gasifier } \\
\hline & & & Power & $\mathrm{H}_{2}$ & Power & $\mathrm{H}_{2}$ & Power & $\mathrm{H}_{2}$ \\
\hline \multicolumn{9}{|c|}{ Energy } \\
\hline$\eta_{t}^{w}(\%)$ & 51,6 & 41,9 & 47,2 & $-2,5$ & 50,3 & 0,6 & 47,1 & $-1,4$ \\
\hline$\eta_{t}^{H_{2}}(\%)$ & - & - & - & 60,7 & - & 66,2 & - & 63,5 \\
\hline$\eta_{t, e q}^{H_{2}}(\%)$ & - & - & - & 57,9 & - & 67,0 & - & 61,8 \\
\hline \multicolumn{9}{|c|}{ Environmental } \\
\hline$E_{\mathrm{CO}_{2}}(\mathrm{kgCO} 2 / \mathrm{MWh})$ & 670,9 & 70,6 & 38,3 & 29,5 & 13,2 & 7,6 & 11,6 & 4,9 \\
\hline$C_{\mathrm{CO}_{2}}(\%)$ & 0 & 91,5 & 94,8 & 94,8 & 98,1 & 98,5 & 98,4 & 99,1 \\
\hline$A_{\mathrm{CO}_{2}}(\%)$ & 0 & 89,5 & 94,3 & - & 98,0 & - & 98,3 & - \\
\hline SPECCA $(\mathrm{MJ} / \mathrm{kgCO})_{2}$ & - & 2,7 & 1,03 & - & 0,28 & - & 1,02 & - \\
\hline \multicolumn{9}{|c|}{ Exergy } \\
\hline$\xi(\%)$ & 48,2 & 39,1 & 44,1 & 58,5 & 47,0 & 63,2 & 47,0 & 61,1 \\
\hline$\xi^{\prime}(\%)$ & 48,2 & 44,7 & 49,9 & 69,3 & 52,8 & 70,1 & 52,8 & 71,6 \\
\hline \multicolumn{9}{|c|}{ Economic } \\
\hline$S I(€ / \mathrm{kW})$ & 2117,9 & 2826,5 & 2762,2 & - & 2452,5 & - & 2610,9 & - \\
\hline$L C O E(€ / \mathrm{MWh})$ & 56,4 & 81,8 & 79,3 & - & 73,2 & - & 77,4 & - \\
\hline $\operatorname{COCA}(€ / \operatorname{tonCO} 2)$ & - & 42,3 & 36,2 & - & 25,4 & - & 31,9 & - \\
\hline
\end{tabular}




\subsection{Conclusions \& Future Work}

In this Thesis the potential of gas switching technology using the chemical looping concept to eliminate the energy penalty of $\mathrm{CO}_{2}$ capture was assessed. The use of gas switching units instead of traditional interconnected fluidized beds was justified because of the higher potential of the former to be scaled up at pressurized conditions [129], avoiding external circulation of solids and permitting a high load flexibility. Operation in fluidization mode avoids several operational challenges related to fuel slip, carbon deposition, kinetic limitations due to larger solid particles and less mechanical stability issues resulting from temperature gradients. The good mixing achieved in fluidized bed operation which lead to homogenous reactor conditions and the possibility of continuous replenishment of spent material are outweighed by the higher degree of outlet stream mixing which simultaneously reduce the capture rate and purity of the $\mathrm{CO}_{2}$ stream. The clusters were designed to deliver a stable flow rate to the gas turbine power island. The high reactivity of the oxygen carrier led to the assumption of complete conversion in the models developed [130].

Considering the consistent assumptions taken for the performance of the different power plant units and sections, together with the ideal performance and technological availability of GS clusters operating in a fluidization regime, it has been shown that such technology has a substantial potential to reduce the energy penalty of $\mathrm{CO}_{2}$ capture when integrated in IGCC power plants, relative to the most efficient and currently deployable CCS technology: pre-combustion $\mathrm{CO}_{2}$ capture, even when ideal gas turbine operation is considered for the reference plants. In a carbon constrained energy market, second generation CCS technologies are likely to be implemented by the year 2040. IGCC technologies which employ solid fuels (largest contributor to $\mathrm{CO}_{2}$ emissions from fossil fuels) have experienced several decades of slow progress and demonstration at a large scale, but promise higher efficiencies and lower emissions compared to widespread pulverized coal boilers. Even more so when novel and more competitive CCS technologies relative to postcombustion capture with absorbents are developed and implemented. As a drawback, the large capital expenditure and cost overrun experienced in the past IGCC projects can be a deterrent for future investment.

An initial power plant assessment was carried out using the commercially established F-class gas turbine technology's performance as a baseline, assuming that such machine had conveniently been engineered to cope with a syngas or alternatively $\mathrm{H}_{2}$ rich fuels in terms of compressor-turbine matching and blade cooling requirements. Together with hot gas treating processes, which avoids the energy penalty of cooling and reheating the gaseous fuel, the integration of a gas switching combustion cluster (GSC) results in significantly lower energy penalty, which is evidenced by the attractive reductions in the LCOE, relative to conventional capture technologies mentioned in the previous section. The efficiency of the concepts incorporating chemical looping technology is severely hampered by the maximum allowable temperature achievable in the reactors. In this assessment, an optimistic value of $1200^{\circ} \mathrm{C}$ was employed consistently to previous literature studies. To avoid this thermodynamic efficiency constraint, extra firing with natural gas of the oxidation outlet was carried out, allowing a notable efficiency increase but reducing significantly the capture rate. The economic assessment suggests that this hybrid plant could be an attractive energy solution with reasonable carbon mitigation capacity. Alternatively to NG, hydrogen could also be used as fuel to reach higher capture rates depending on the relative costs of this fuel and the carbon emission taxes. The possibility of using the oxygen carrier as an energy storage mechanism was assessed by integrating this cluster to a flexible humid air turbine cycle, allowing a complete decoupling of reduction and oxidation sections. This concept is particularly attractive in a scenario 
of high renewable penetration, in which this thermal plant can be used to balance variable renewables by storing chemical energy in the reactors, since it presents reasonable efficiencies with low minimum thermal load. However, the flexible power cycle based on a humid air turbine has not reached yet successful commercialization.

With regards to concepts integrating oxygen production chemical looping technologies, the low level of material development at the current project phase led the modelling work to focus on hypothetical reactor performance based on a simplified kinetic law to determine $\mathrm{O}_{2}$ release in the reduction stage, acknowledging that suitable carriers should be developed to operate at the specified reactor temperatures. The concepts employing a GSOP cluster require the use of fluidized bed gasification technologies (which have not been demonstrated in large scale IGCC and with lower $\mathrm{O}_{2}$ demand) with limited carbon conversion and high amount of methane in the syngas, relative to established entrained flow gasification systems. However, the OPPC concept which uses extra firing with process-generated $\mathrm{H}_{2}$ after the oxidation stage eliminates the technology uncertainties related to the high temperature limits of the oxygen carrier, valves and filters appearing in full combustion chemical looping, while being able to reach temperatures of modern gas turbines, resulting in a very low energy penalty and ultimately more economically competitive than the standalone GSC plant. The $\mathrm{CO}_{2}$ avoidance is on the other hand partially diminished due to a lower capture efficiency of the process. Finally, the plant assessment of the concept integrating two clusters: GSOP-GSC showed high efficiency prospects but limited feasibility due to the complex integration between subsystems of the plant, and therefore the study was limited to the conceptual attractiveness of the complex system, with interesting exergy analysis decomposition.

In terms of future work for these initial power plant designs it is recommended to carry out a more thorough evaluation of the GSC-HAT concept, potentially incorporating extra firing with natural gas and a pertinent economic assessment. On the other hand, OPPC design has room for improvement: a booster compressor prior to the Selexol unit can increase the capture rate of the plant at a small efficiency cost. Alternatively, Sorption Enhanced Water Gas Shift Units (SEWGS) is an upcoming technology that could further boost plant efficiency, eliminating the losses associated to cooling of the syngas stream prior to the Selexol plant, and subsequent reheating of the fuel. There is a large uncertainty regarding the performance of the GSOP cluster, but results show that higher operating temperatures $\left(900^{\circ} \mathrm{C}\right)$ have a positive impact in plant performance, while maximizing the $\mathrm{O}_{2}$ concentration difference between reduction and oxidation outlets contributes to minimize the losses taking place in the cooling and reheating of the loop gasifierGSOP. Hot air combustion with pure $\mathrm{H}_{2}$ should be further investigated in order to reap the efficiency gains of fuel dilution avoidance, while minimizing NOx formation [131].

Because of the criticality of next generation thermal power plants with CCS to integrate power from intermittent renewable sources in order to remain competitive, and additional assessment of flexible power plants with $\mathrm{H}_{2}$-power coproduction integrating gas switching combustion (GSC) and membrane assisted water gas shift reactors (MAWGS) was carried out, using modern H-class gas turbines as baseline. The key design feature is that the substantially inflexible section of the plant (Gasification, air separation and syngas treating) operates at nominal load, while the power cycle (gas Turbine and steam cycle) are ramped up upon demand. Figure 134 represents the concept of flexible $\mathrm{H}_{2}$-power coproduction for these advanced plants. Consistent benchmarks of an Unabated and a Pre-combustion $\mathrm{CO}_{2}$ capture IGCC power plants were modelled, incorporating HGCU for syngas desulphurization and designed for base load electricity production. 


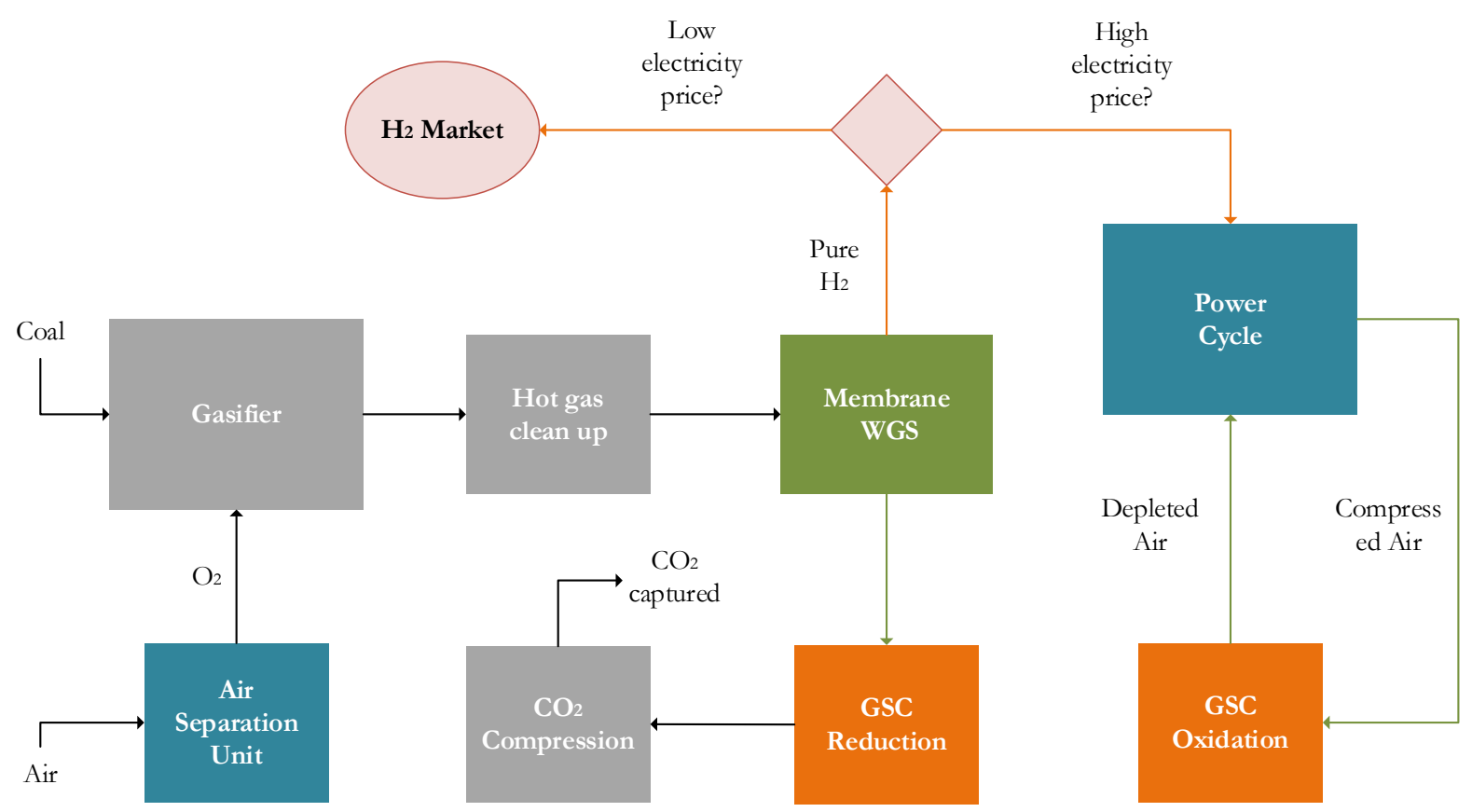

Figure 134 GSC-MAWGS flexible power plant concept

The basic principle of operation in power production mode of the flexible GSC-MAWGS concepts is to partially convert the clean syngas to $\mathrm{H}_{2}$ which permeates the membrane reactor, obtaining a carbon free fuel stream. The resulting low grade syngas is combusted in the GSC reduction stage, heating up air from the compressor in the oxidation stage. The $\mathrm{H}_{2}$ is cooled, compressed and reheated before being fired in a combustion chamber to further raise the depleted air temperature to the values achievable by the GT. Shell gasification was used as a baseline comparison with the benchmark plants employing the same gasification technology. Alternatively, a concept which utilized the heat contained in the reduction stage outlet of the GSC to preheat a water coal slurry feed to an HTW gasification systems was studied, with a relevant efficiency penalty reduction. Finally, a slurry fed entrained flow gasification system (GE) with partial water quench for syngas cooling operating at elevated pressures was studied. The case with pregasifier yielded both a higher electrical and $\mathrm{H}_{2}$ production performance, thanks to the large improvement of the CGE of the gasification system. On the other hand the case with GE gasification resulted in similar electrical efficiencies as the Shell case, but led to higher $\mathrm{H}_{2}$ efficiencies given the large driving force in the membrane reactors for $\mathrm{H}_{2}$ permeation, with a foreseeable lower capital expenditure thanks to the decreased costs of $\mathrm{H}_{2}$ compression and of the gasification island. In $\mathrm{H}_{2}$ operation mode, a dedicated small GT was employed was used to convert the remaining heating value of the retentate stream of the MAWGS to useful electricity with dedicated heat recovery units. Because of the cooling requirements of the syngas leaving the gasifier for the Shell and GE cases, HP steam was generated and expanded to IP level in the steam turbine HP stage. The LP/IP steam produced in the plant was exported but, given the intermittent nature of the $\mathrm{H}_{2}$ operation mode, it is not likely that a customer for that steam is available and consequently, no revenue should be attributed to those streams. A suggested improvement would be to redesign the heat recovery network to raise LP superheated steam which can be expanded in the last stage of the turbine. IP steam expansion would not be possible given the fact that the hot streams have too low temperature to superheat the steam. Nevertheless, expanding the LP steam would imply an operation which is around $50 \%$ of the nominal load reached in power mode, avoiding to a large extent some of the electricity imports that are required in $\mathrm{H}_{2}$ mode operation. Further work should 
aim at completely decoupling the syngas cooling system from the steam turbine operation to maximize flexibility and avoid issues concerning part load operation of the turbomachinery in the bottom cycle. Future research endeavours will aim to maximize the advantages presented with the GE and pregasification system, investigating two stage gasifiers which can simultaneously decrease the ASU consumption, increase CGE and carry out the syngas cooling through chemical quench and subsequent partial water quench for optimal operation of the MWGS reactor. The modelling assumptions regarding the pregasification with the GSC reduction gases should be further validated, although several experimental results show that it is possible to vaporize a coal water slurry without particle agglomeration [132]. More detailed analysis on the constraints of the reactor should be carried out, in order to potentially minimize the steam to carbon ratio in case a large portion of IP steam is subtracted from the steam cycle. From a flexible operation perspective, avoiding the integration between the syngas coolers in the gasification island and the steam cycle would be advantageous. Therefor future designs should aim to achieve this decoupling with minimal efficiency sacrifice.

Within the scope of future work and ongoing research activities on chemical looping within the Energy Department at UPM, the research conducted with gas switching combustion technology can be easily extended to NGCC power plants. This task was not carried out within the project scope as it was being already investigated with conventional interconnected fluidized beds by the project partners from SINTEF [133], but it would be straightforward to implement in the current models developed during this Thesis. In fact suitable benchmarks employing calibrated GT models of the F-class and $\mathrm{H}$-class machines are already developed. The main challenge with respect to conventional CLC operation will be to ensure adequate fluidization velocities in the reduction stage, given the lower flow rates of natural gas with respect to syngas (due to the higher energy density of the former), avoiding an exceedingly large number of reactors in the cluster. A practical solution to avoid this is the partial recirculation of reduction gases to the fuel input in order to increase the flow rate (and consequently fluidization velocity) for a fixed reactor diameter. Given the fact that the GSC reactor can operate up to $1200^{\circ} \mathrm{C}$, it will be illustrating to determine the trade-off between carbon avoidance and efficiency gain when extra firing with natural gas to reach the achievable gas turbine TIT is performed, with economic indicators at several carbon tax levels. An alternative pathway to mitigate the increased emissions occurring due to extra firing is again to employ a $\mathrm{H}_{2}$ fuel, withstanding that a comparatively higher fuel cost will be taken into account.

In parallel to this this, a gas switching technology involving an oxygen carrier which can partially oxidize a natural gas stream (Gas Switching Partial Oxidation, GSPOX) will be investigated and integrated in a $\mathrm{H}_{2}$-power coproduction plant, alongside previously developed within the GasTech team Gas Switching Reforming (GSR) models for $\mathrm{H}_{2}$ and/or power production in combined cycles [41, 134], which will be used as benchmarks and will be further optimized. In the partial oxidation reaction, a mole of methane is partially combusted to produce 2 moles of $\mathrm{H}_{2}$ and 1 of $\mathrm{CO}$, as opposed to reforming which delivers 3 moles of $\mathrm{H}_{2}$ per mol of $\mathrm{CO}$. The initial assessments carried out assume an ideal performance of the oxygen carrier with respect to kinetics and operational flexibility, which are helpful to showcase the potential benefit from a process perspective in order to optimize efforts on material development at laboratory scale, but which nonetheless currently suggest that the equilibrium conversion limitations of steam methane reforming present in the GSR models can be avoided. This GSPOX cluster delivers several output streams: A syngas stream with a $\mathrm{H}_{2} / \mathrm{CO}$ ratio of 2 from the partial oxidation stage, a $\mathrm{H}_{2}$ stream with some $\mathrm{H}_{2} \mathrm{O}$ from a sweep stage (steam can re-oxidize the metallic carrier), an $\mathrm{O}_{2}$ depleted air stream (which can be integrated in a power cycle) in the oxidation and finally, a reduction gases 
stream (where low grade syngas is used as fuel) required to provide sufficient heat to the reactor to reach authothermal operation. In this final stage full combustion to $\mathrm{CO}_{2}$ and $\mathrm{H}_{2} \mathrm{O}$ of the fuel occurs. While the syngas from the partial oxidation stage can be further shifted to $\mathrm{H}_{2}$ and purified in a PSA unit to produce more $\mathrm{H}_{2}$, the $\mathrm{H}_{2}$ stream from the sweep stage can be effectively employed to combust the hot oxidation outlet in order to reach COT values of F-class or (potentially) $\mathrm{H}$ class GT, thereby minimizing the energy penalty imposed by limited reactor temperature operation when using GSC clusters. An alternative option to GSR or GSPOX cluster integration with conventional power systems based on Brayton \& Rankine cycles are Solid Oxide Fuels Cells (SOFC), which have the potential to surpass Carnot efficiency limitations and reach thermal efficiencies beyond $70 \%$ [113].

Finally, within a broader scope of GS technology applicability, it is recommended to evaluate the $\mathrm{H}_{2}$ generation capability and foreseen improved efficiencies of GSR and GSPOX clusters when integrated with chemical processes for commodity production such as Methanol or Ammonia (both currently employing tailored $\mathrm{H}_{2}$ production systems based on conventional steam reforming or authothermal reforming upstream the chemical synthesis loop). The optimal $\mathrm{H}_{2} / \mathrm{CO}$ of each process can be tailored by using different oxygen carriers in the reactors. This new study of great academic and industrial interest would constitute a novel value proposition for chemical looping technology beyond energy production and CCS (either based on interconnected fluidized beds or gas switching clusters), which would trigger renewed interest and funding willingness from research institutions and industry partners, if the ex-ante process evaluations of the integrated concepts reveal attractive results. 


\section{Appendix 1: GST Model Scilab Codes}

The dynamic cluster code is presented in the following sections:

\section{A1.1 Mainscript.}

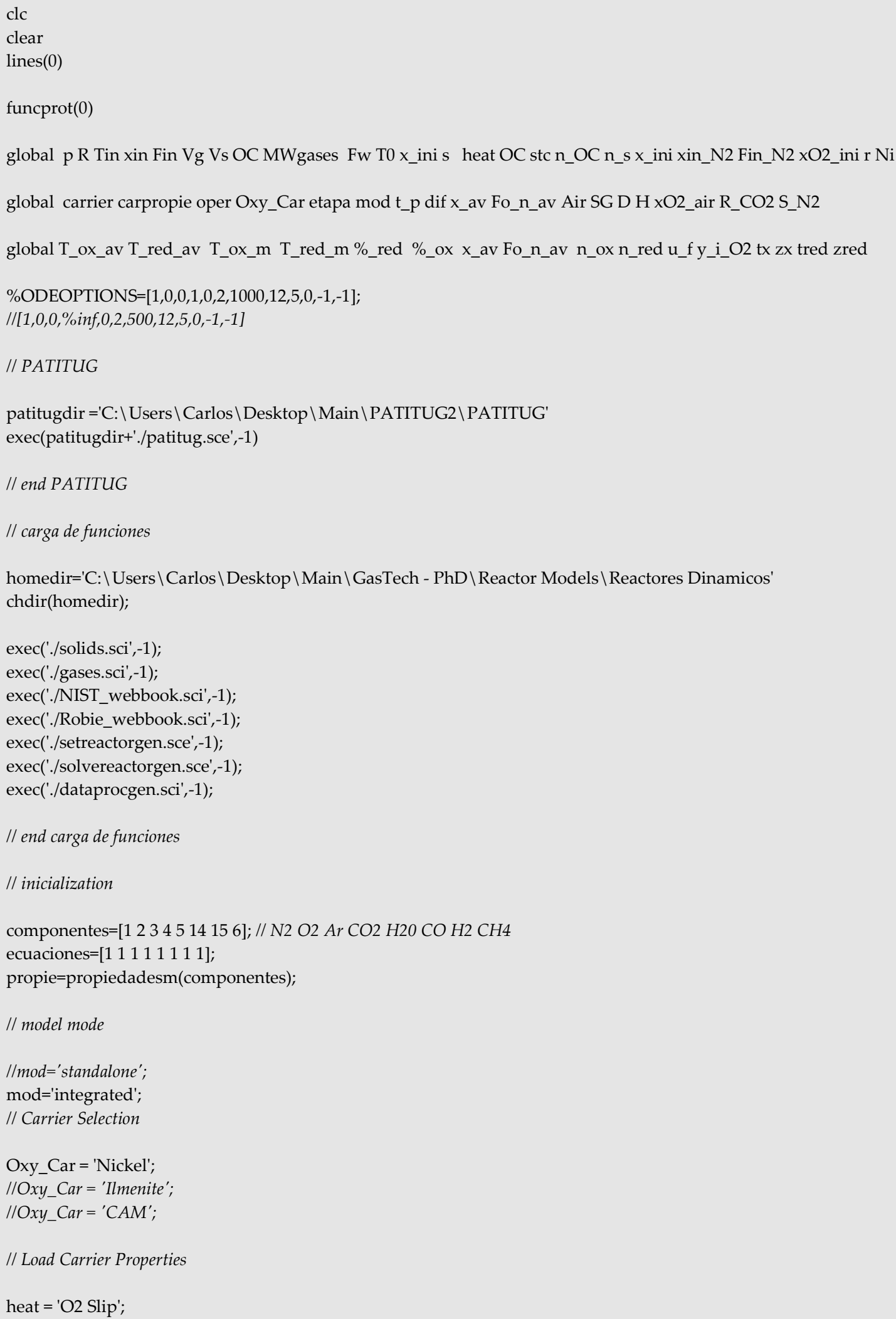


Appendix

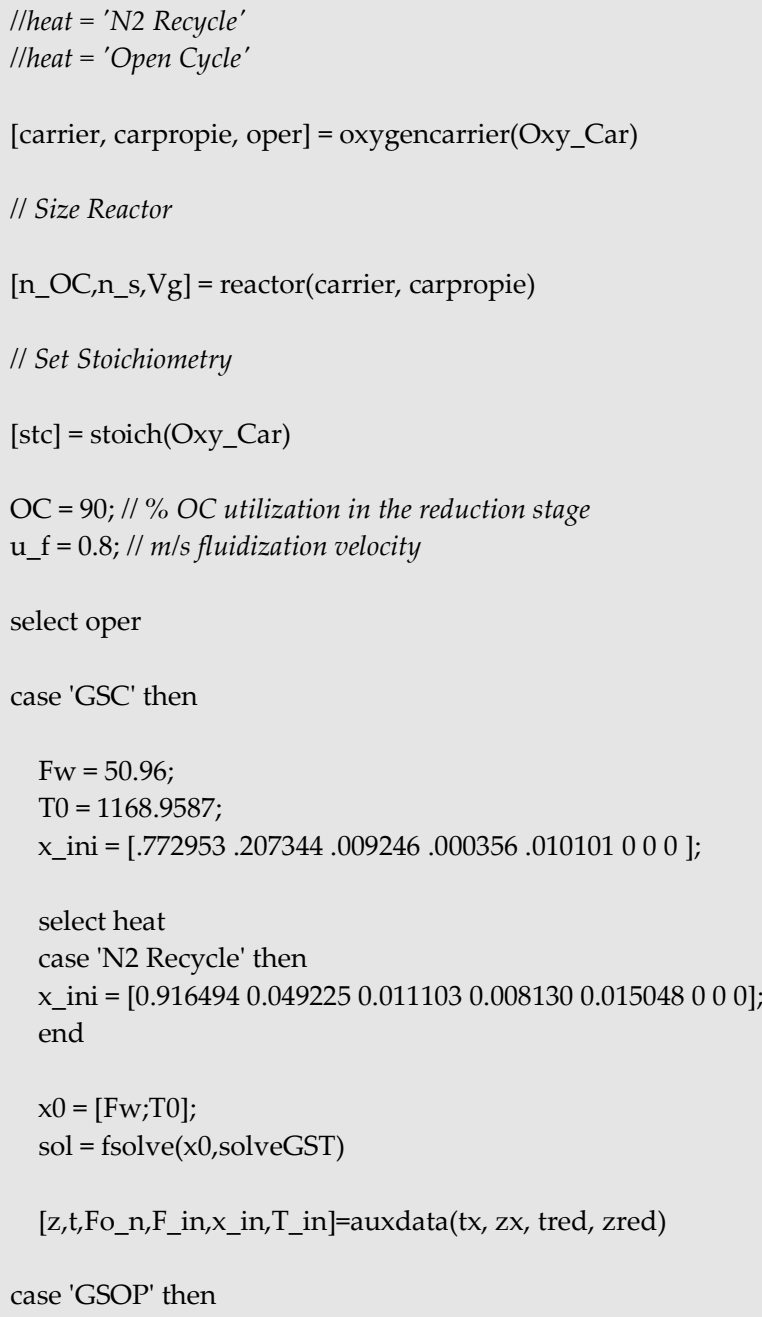


Appendix

x_av $=$ abs $\left(x \_a v\right)$;

disp('iter correct')

I/plotfun (t,z, T_ox_av,T_red_av, T_ox_m, T_red_m, \%_red, \%_ox)

\section{A1.2 Set Reactor}

function [carrier, carpropie, oper] $=\underline{\text { oxygencarrier(Oxy_Car) }}$

global oper carrier carpropie

// OC properties [ Oxidized, Reduced, Support, weight\%, total density] //

select Oxy_Car

case 'Nickel' then

carrier $=[$ 'NiO', 'Ni','Al2O3'];

carpropie $=[74.6928 / 1000,58.6934 / 1000,101.9613 / 1000,40 / 100,3446]$;

oper = 'GSC';

case 'Ilmenite' then

carrier $=[$ 'Fe2O3', 'FeO', 'TiO2'];

carpropie $=[159.6887 / 1000,71.844 / 1000,79.866 / 1000,33 / 100,4000]$;

oper $=$ 'GSC'

case 'CAM' then

carrier $=[$ 'CAMox', 'CAMred','CAMred' ];

carpropie $=[242.0705 / 1000,250.070083 / 1000,250.070083 / 1000,75 / 100,3000] ;$

oper ='GSOP';

case 'OX' then

carrier $=\left[\mathrm{XO}^{\prime}, \mathrm{X}^{\prime}, \mathrm{Al} 2 \mathrm{O} \mathrm{3}^{\prime}, \mathrm{C}^{\prime}\right]$;

carpropie $=[227 / 1000,205.4 / 1000,101.9613 / 1000,40 / 100,2000]$;

end

endfunction

function [n_OC, n_s, Vg] $=\underline{\text { reactor(carrier, carpropie) }}$

global n_cluster p R Vg Vs MWgases n_red n_ox D H

// reactor dato

$\mathrm{H}=12$;

$\mathrm{D}=6$;

n_red $=3$;

n_ox $=1$;

n_cluster $=$ n_red + n_ox;

eps $=0.65$;

ps $=$ carpropie(5);

carw = carpropie $(4)$;

select mod

case 'integrated' then

$\mathrm{p}=\operatorname{Air}(1) / 10^{\wedge} 5$;

case 'standalone' then

$\mathrm{p}=18.1$; 
Appendix

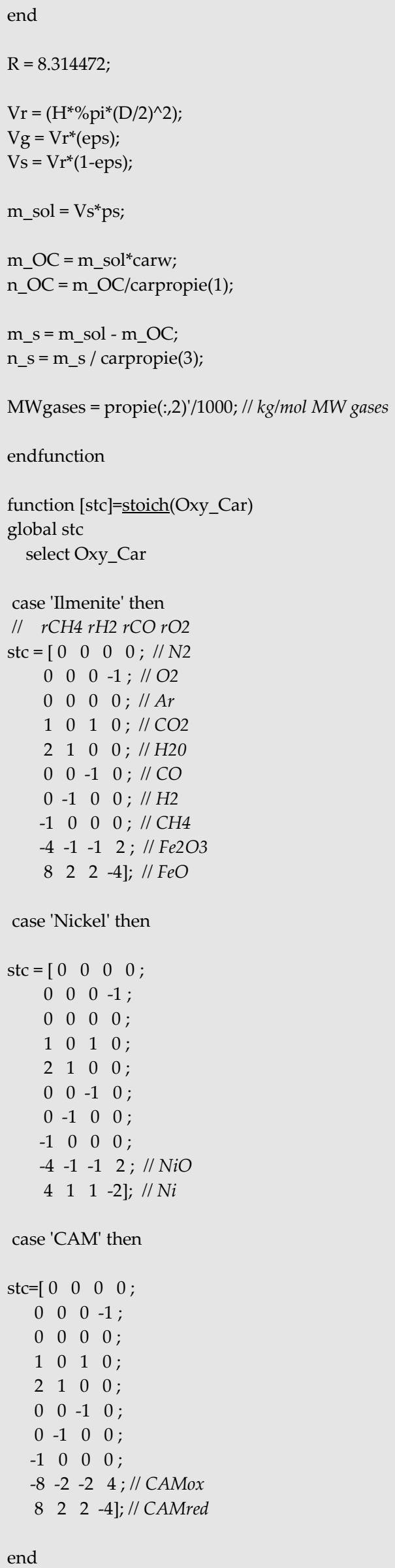

case 'Nickel' then

$\mathrm{stc}=\left[\begin{array}{llll}0 & 0 & 0 & 0\end{array}\right]$

$\begin{array}{llll}0 & 0 & 0 & -1 ;\end{array}$

$\begin{array}{llll}0 & 0 & 0 & 0 \text {; }\end{array}$

$\begin{array}{llll}1 & 0 & 1 & 0 \text {; }\end{array}$

$\begin{array}{llll}2 & 1 & 0 & 0\end{array}$

$\begin{array}{lllll}0 & 0 & -1 & 0 \text {; }\end{array}$

$\begin{array}{llll}0 & -1 & 0 & 0\end{array}$

$\begin{array}{llll}-1 & 0 & 0 & 0\end{array}$

$\begin{array}{llll}-4 & -1 & -1 & 2 ; / / N i O\end{array}$

$\left.\begin{array}{llll}4 & 1 & 1 & -2\end{array}\right] ; / / / N i$

case 'CAM' then

end 
Appendix

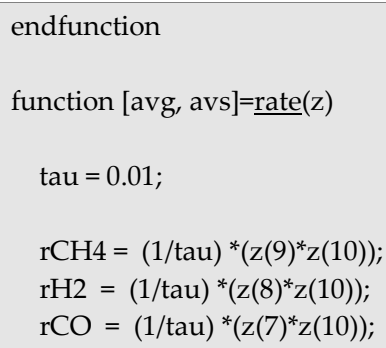


Appendix

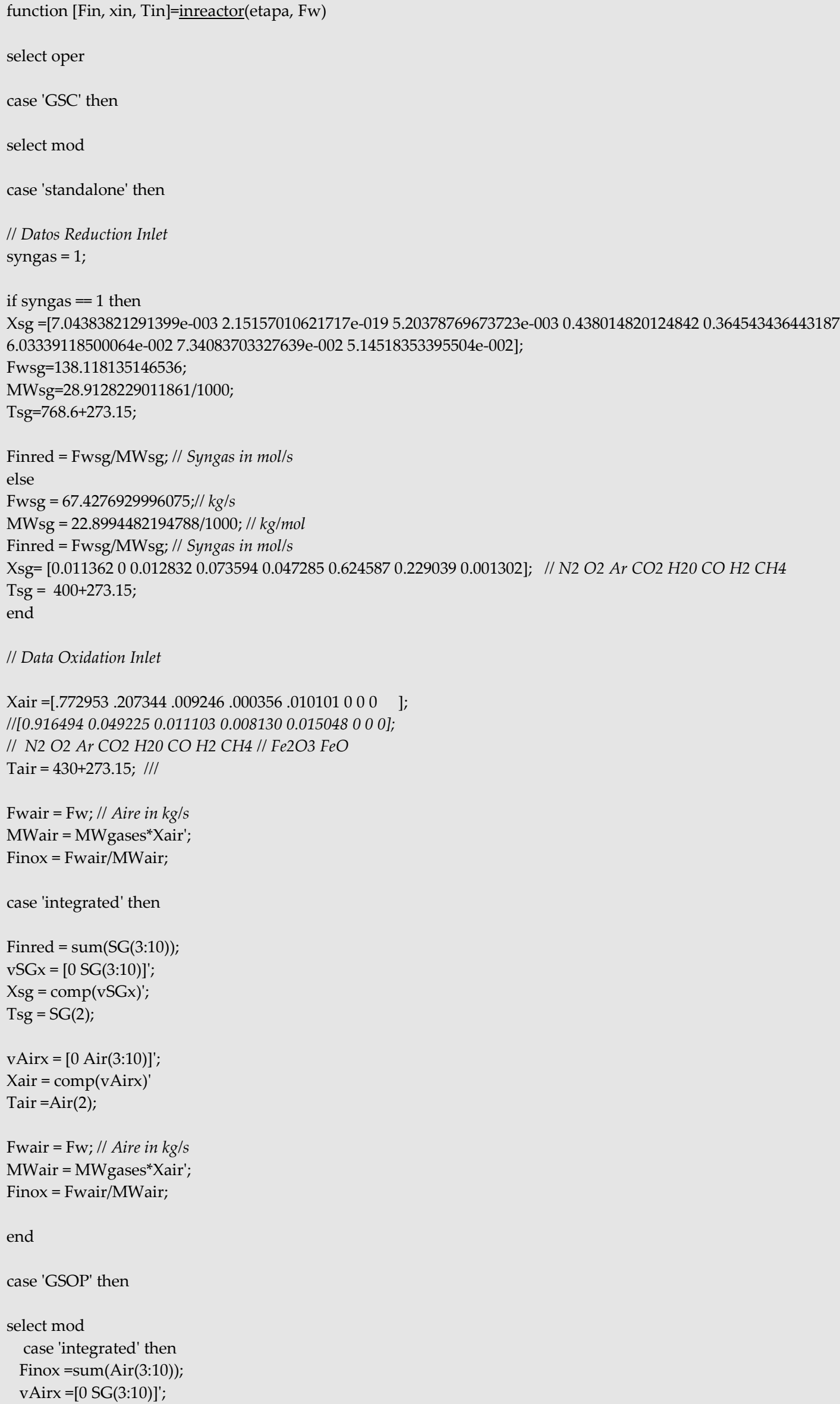




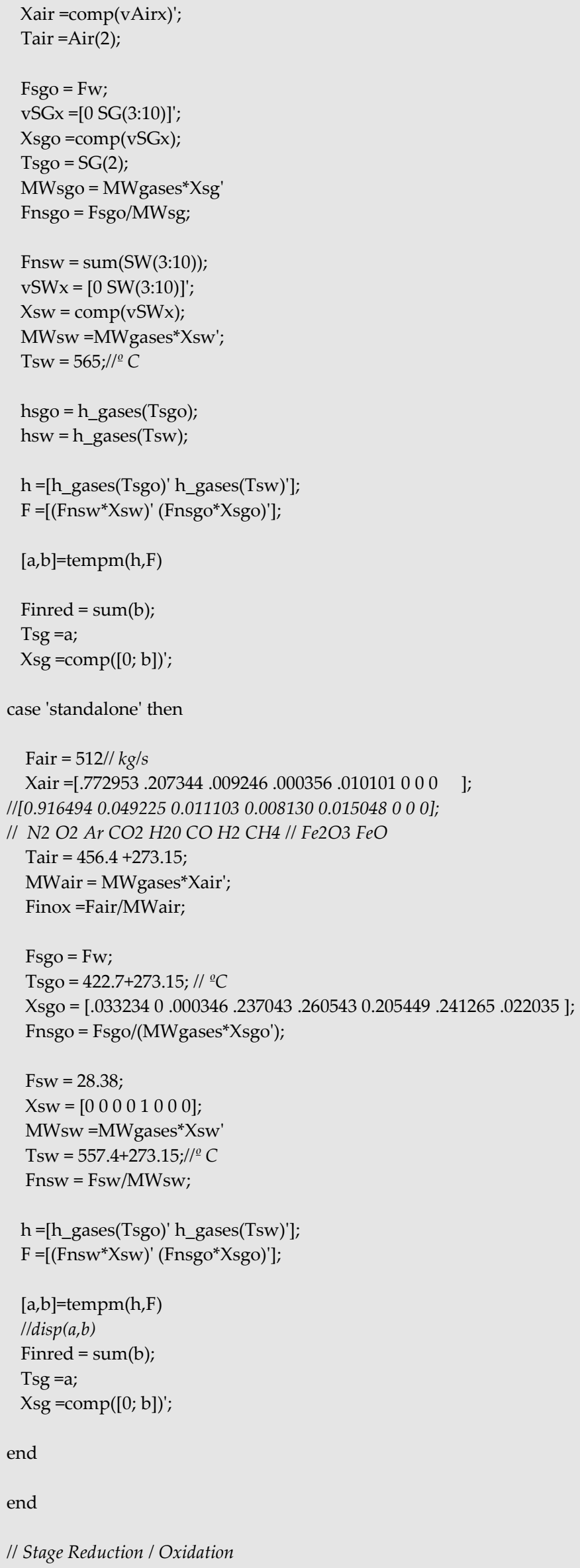


Appendix

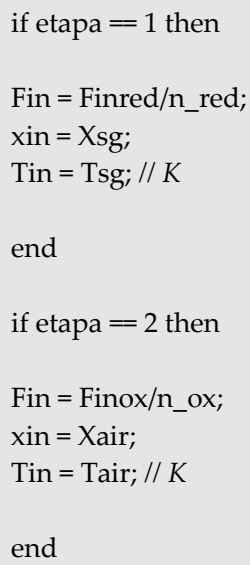

\section{A1.3 Solve Reactor}

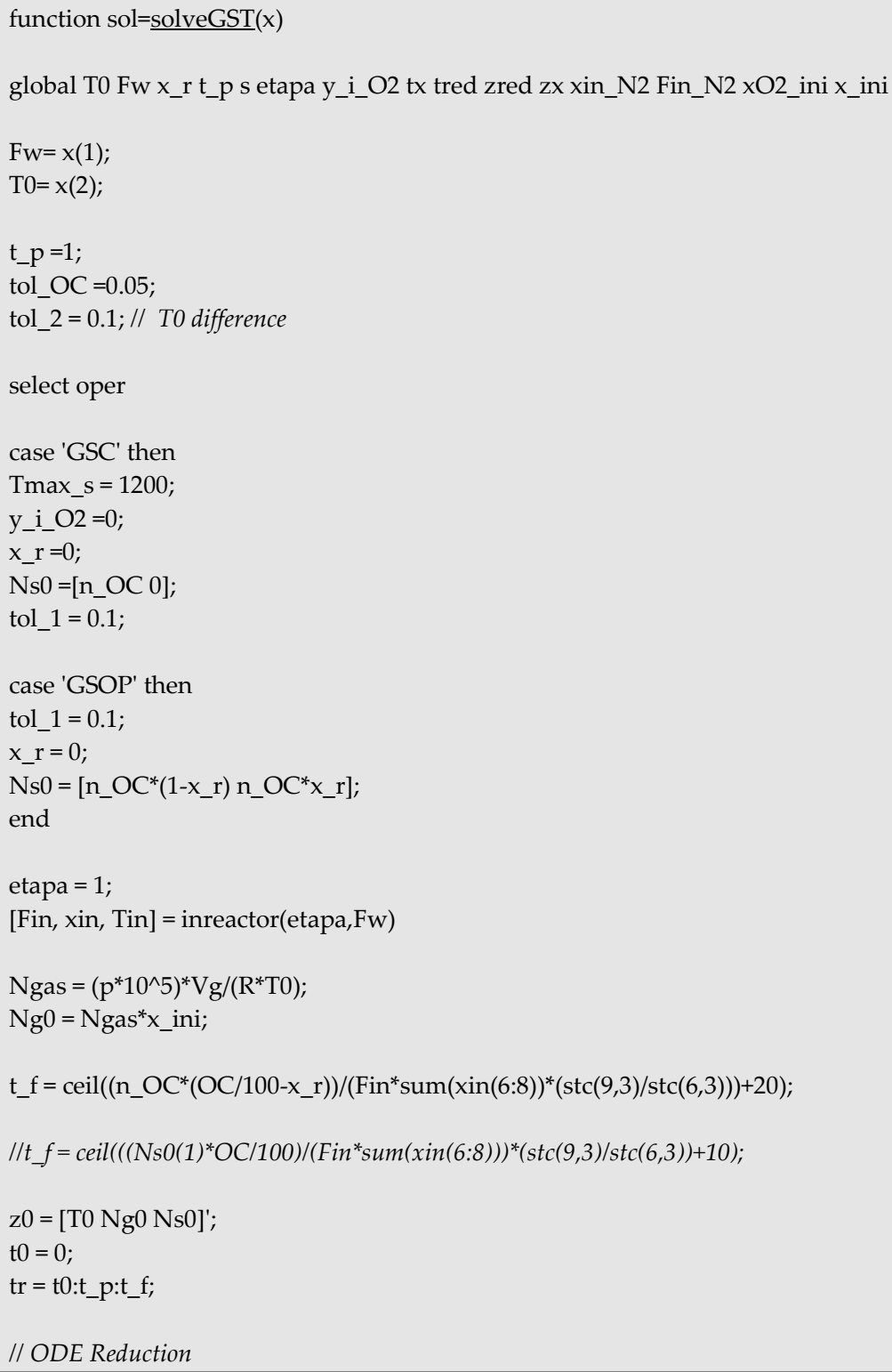


Appendix

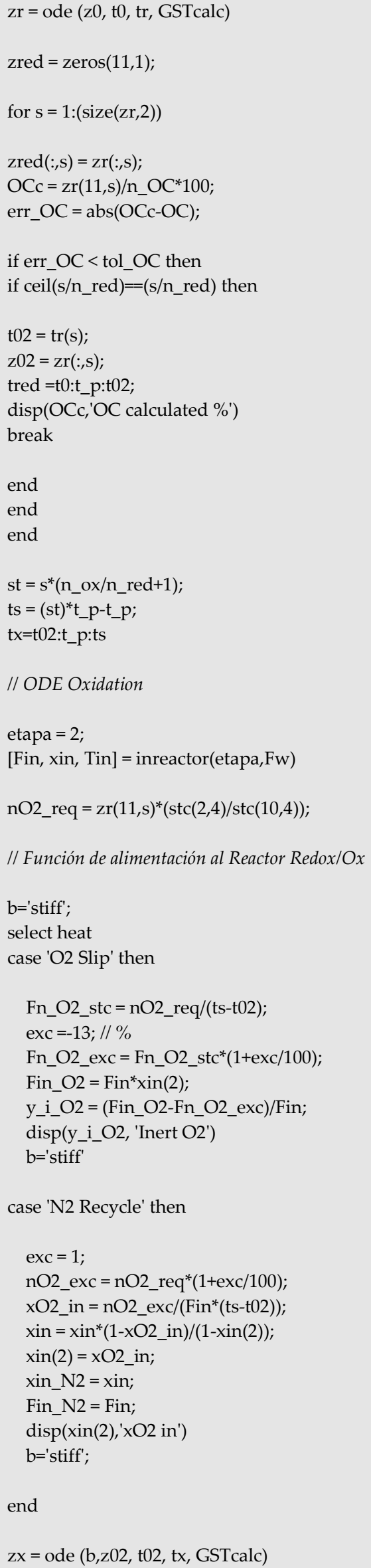


Appendix

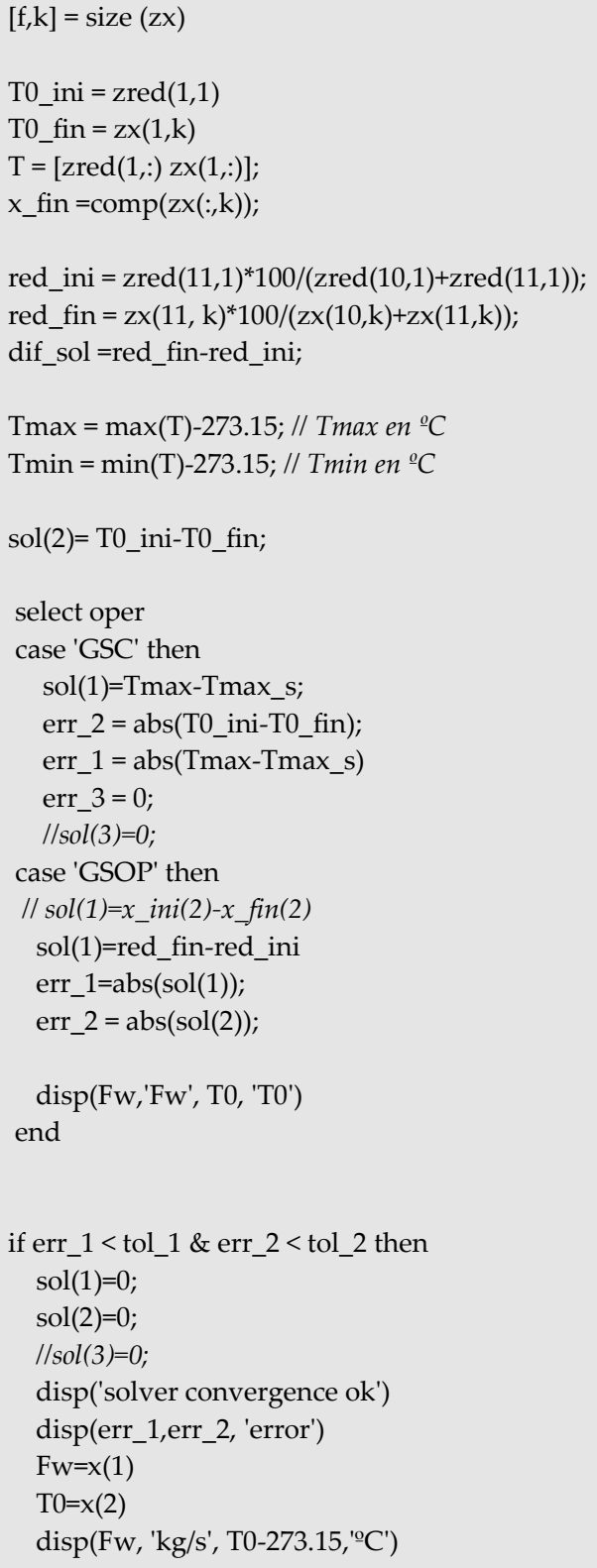


Appendix

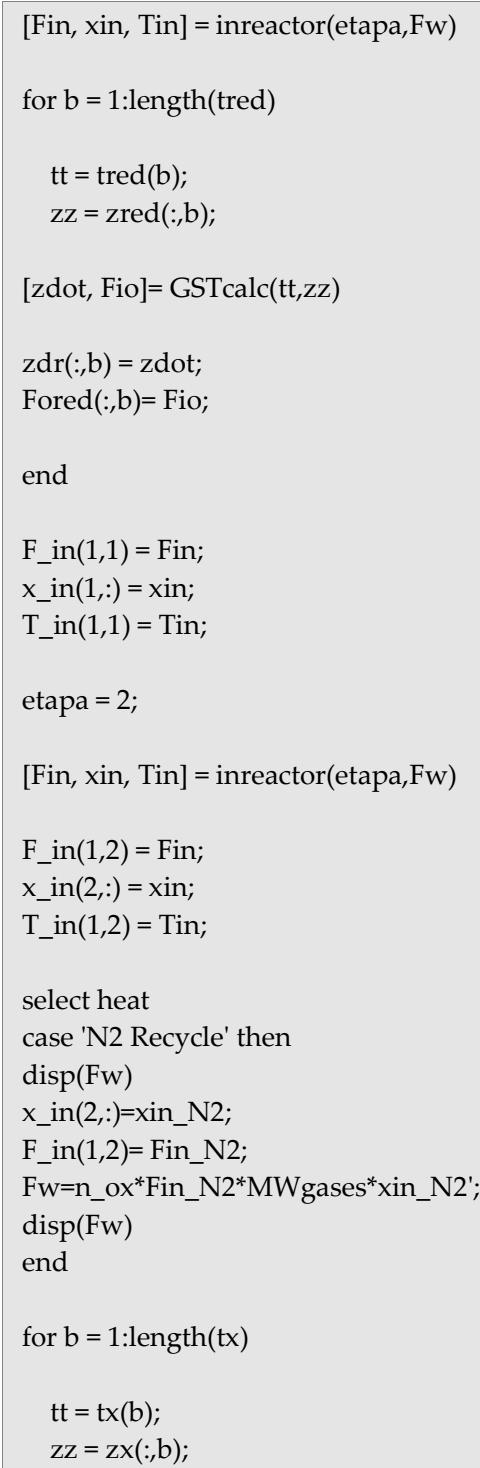

[zdot, Fio] $=$ GSTcalc $(\mathrm{tt}, \mathrm{zz})$

zdo(:,b) = zdot;

Foo(:,b)= Fio;

end

$\mathrm{qq}=\operatorname{size}(\mathrm{zx})$

for $g=1:(q q(2)-1)$

$\operatorname{zox}(:, \mathrm{g})=\mathrm{zx}(:, \mathrm{g}+1)$;

tox $(\mathrm{g})=\mathrm{tx}(\mathrm{g}+1)$;

Foox $(:, g)=F o o(:, g+1)$

end

tox = tox';

$\mathrm{z}=[$ zred zox $]$

$\mathrm{t}=$ [tred tox $]$;

Fo_n $=[$ Fored Foox $]$;

disp(s, 's_red',t(s),'tred')

disp(length(t)-s, 's_ox', (t(length(t))-t(s)),'tox')

endfunction 
Appendix

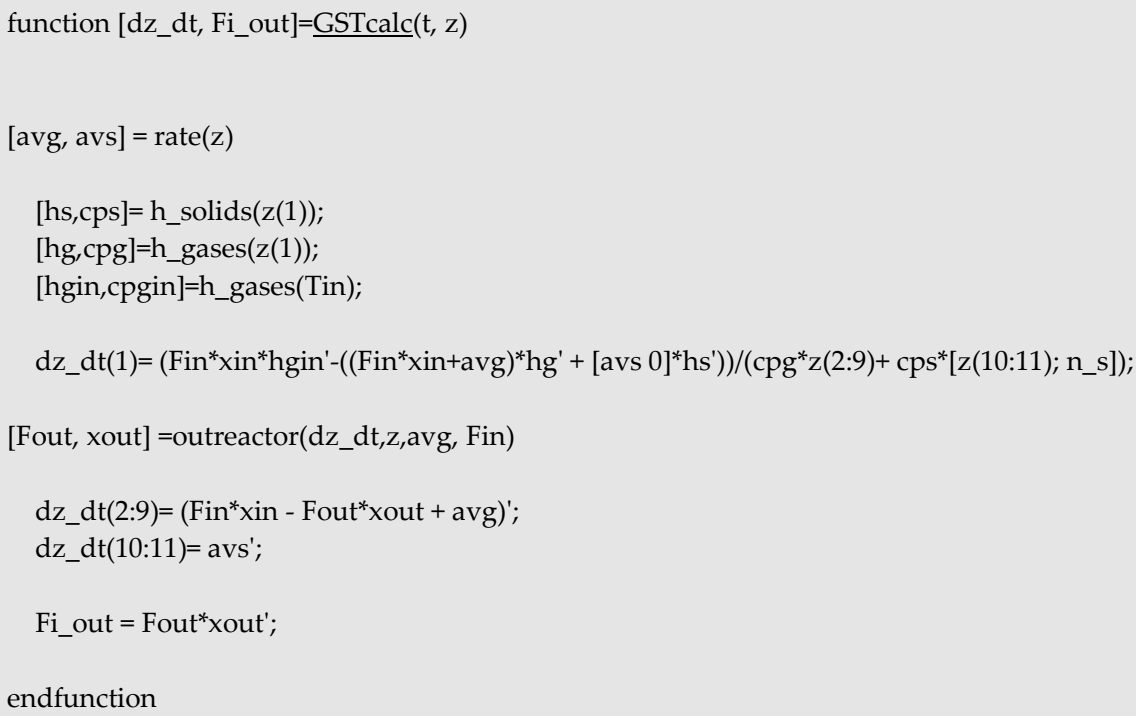

\section{A1.4 Solve Cluster}

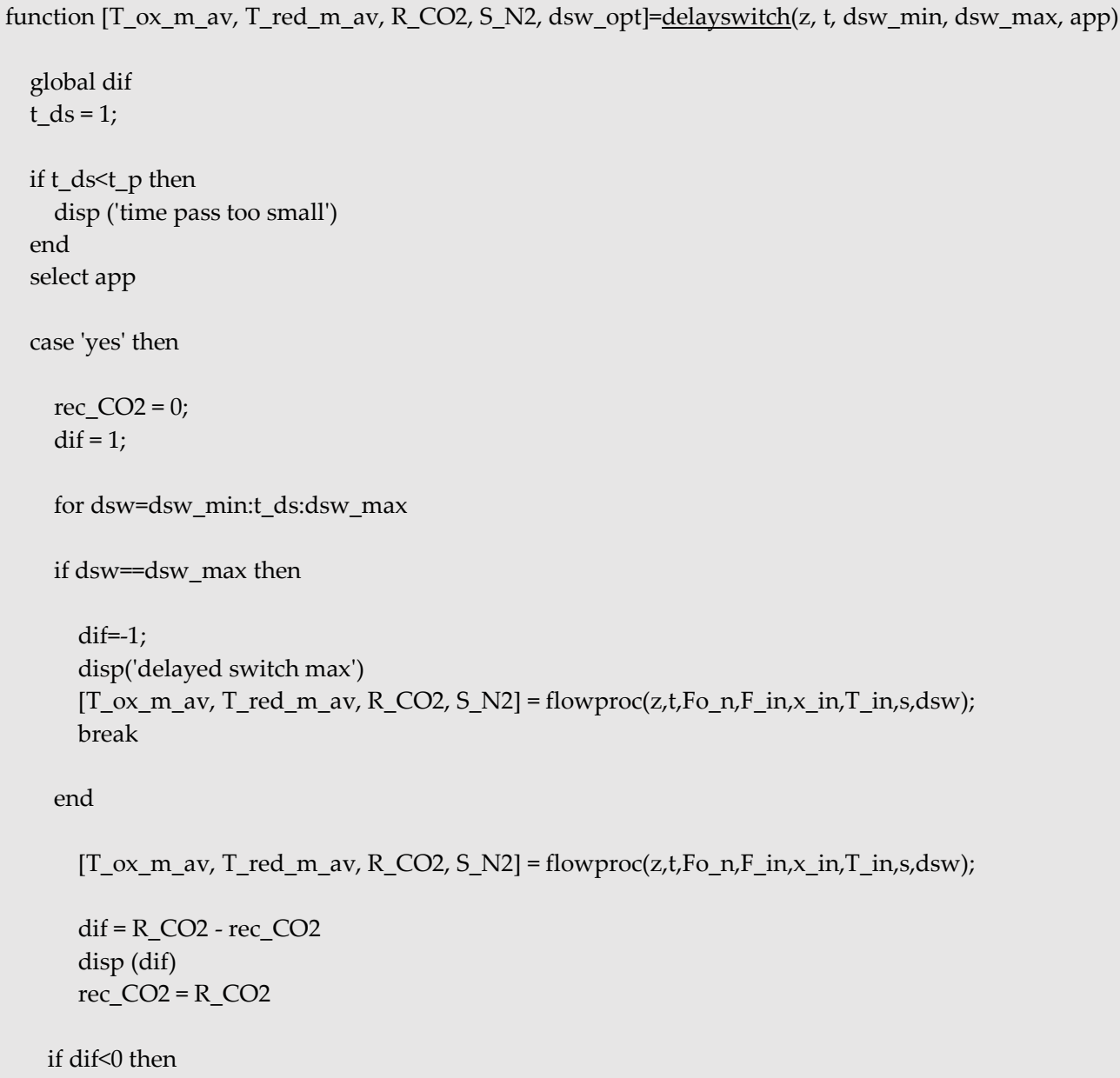


Appendix

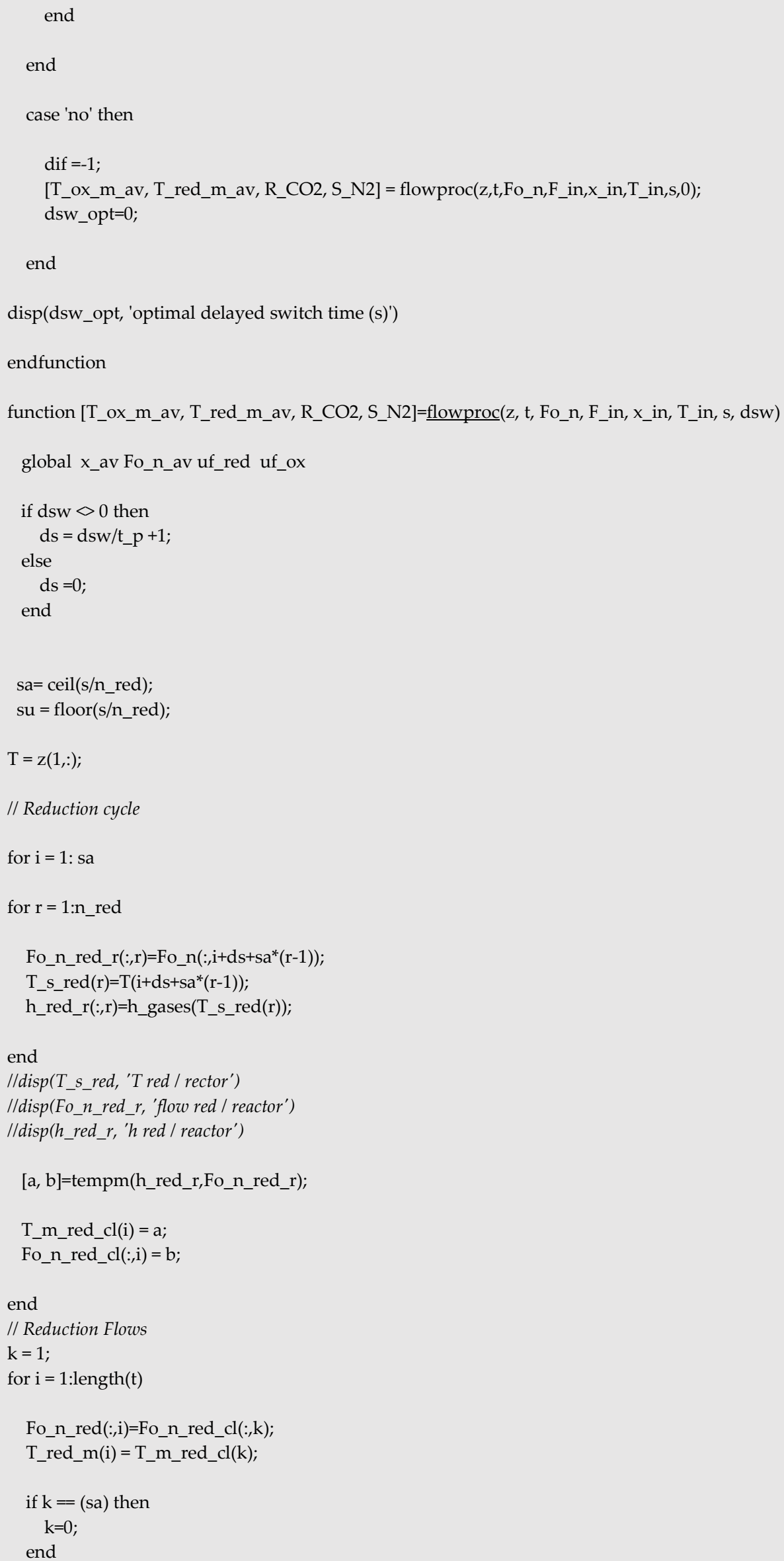


Appendix

\section{$\mathrm{k}=\mathrm{k}+1$;}

end

T_red_m = T_red_m';

// Oxydation Cycle

for $\mathrm{i}=1$ : sa

for $r=$ n_red:(n_ox+n_red-1)

if $\mathrm{i}+(\mathrm{sa})^{*} \mathrm{r}+\mathrm{ds}>$ length $(\mathrm{t})$

Fo_n_ox_r(:,r-(n_red-1)) $=$ Fo_n(:,i+(sa) $\left.{ }^{*} r+d s-l e n g t h(t)\right)$;

T_s_ox $\left(r-\left(n \_r e d-1\right)\right)=T\left(i+(s a)^{*} r+d s-l e n g t h(t)\right)$;

else

Fo_n_ox_r(:,r-(n_red-1)) $=$ Fo_n(:,i+(sa) $\left.{ }^{*} \mathrm{r}+\mathrm{ds}\right)$;

T_s_ox $\left(\mathrm{r}-\left(\mathrm{n} \_\right.\right.$red-1 $\left.)\right)=\mathrm{T}\left(\mathrm{i}+(\mathrm{sa})^{*} \mathrm{r}+\mathrm{ds}\right)$;

I/disp (Fo_n_ox_r)

end

h_ox_r(:,r-(n_red-1))=h_gases(T_s_ox(r-(n_red-1)));

end

//disp(T_s_ox, 'T ox / rector')

//disp (Fo_n_ox_r, 'flow ox / reactor')

//disp (h_ox_r, 'hox / reactor')

[a, b]=tempm(h_ox_r,Fo_n_ox_r);

T_m_ox_cl(i) = a;

Fo_n_ox_cl(:,i) $=$;

end

// Flujos Etapa oxidación

$\mathrm{k}=1$;

for $\mathrm{q}=1$ :length $(\mathrm{t})$

Fo_n_ox $(:, \mathrm{q})=$ Fo_n_ox_cl(:,k);

T_ox_m(q)=T_m_ox_cl(k);

if $\mathrm{k}==(\mathrm{sa})$ then

$\mathrm{k}=0$;

end

$\mathrm{k}=\mathrm{k}+1$;

end

T_ox_m = T_ox_m';

// Average values

T_red_m_av $=0$;

T_ox_m_av $=0$;

Fo_n_ox_av $=$ zeros $(8,1)$;

Fo_n_red_av $=$ zeros $(8,1)$;

kk = length(Fo_n_ox_av);

for $\mathrm{q}=1$ :(length ( $\mathrm{t})-1)$

T_red_m_av $=$ T_red_m_av $+\left(\mathrm{T} \_r e d \_m(q)+T \_r e d \_m(q+1)\right)^{*}(\mathrm{t}(\mathrm{q}+1)-\mathrm{t}(\mathrm{q})) /\left(2^{*}(\mathrm{t}(\right.$ length $\left.(\mathrm{t}))-\mathrm{t}(1))\right)$; 
Appendix

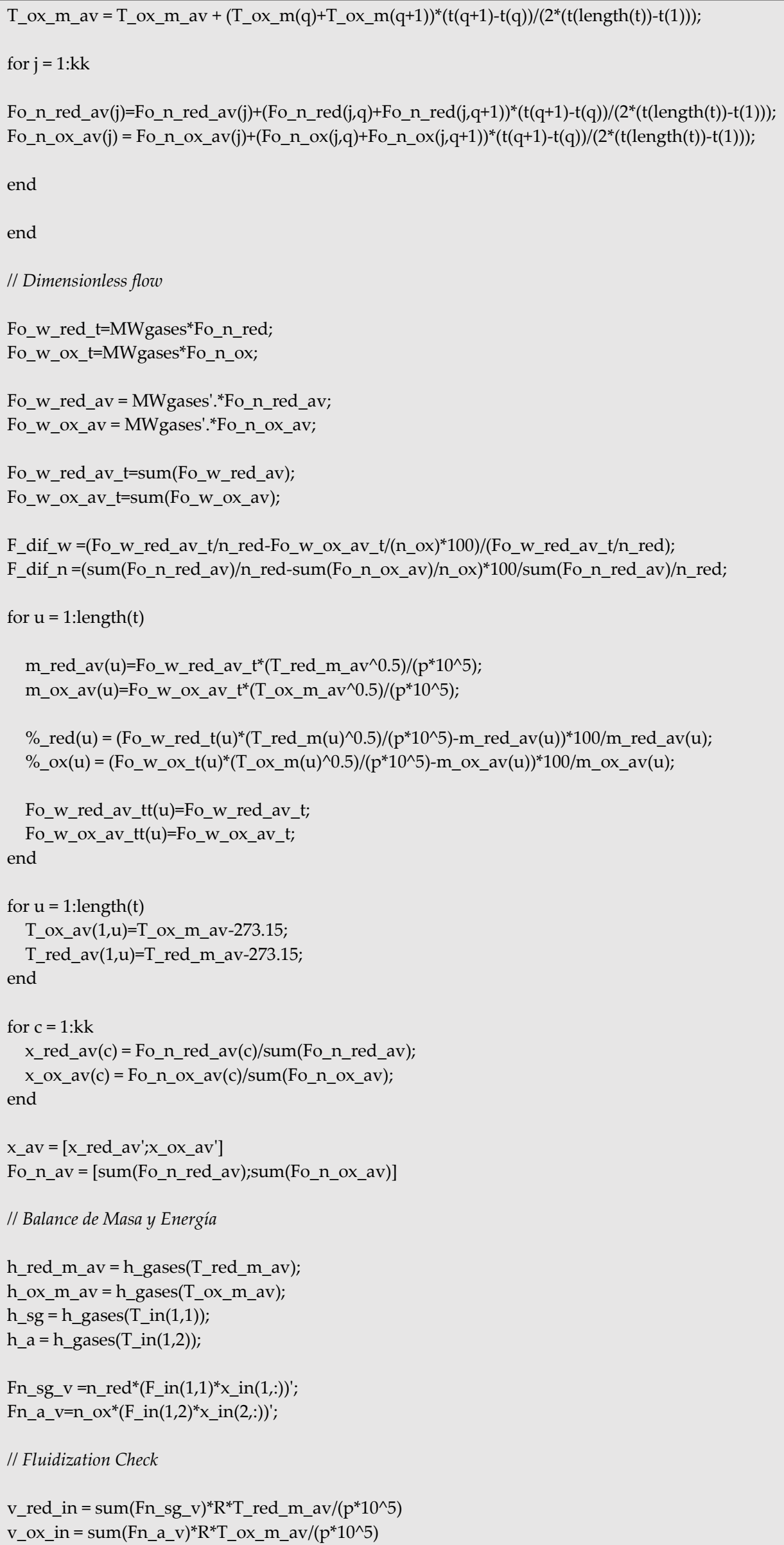




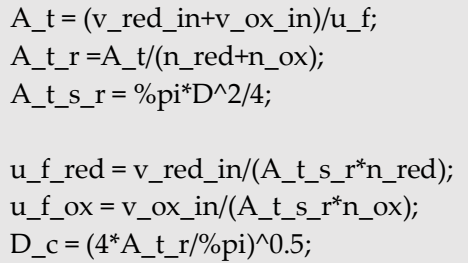


Appendix

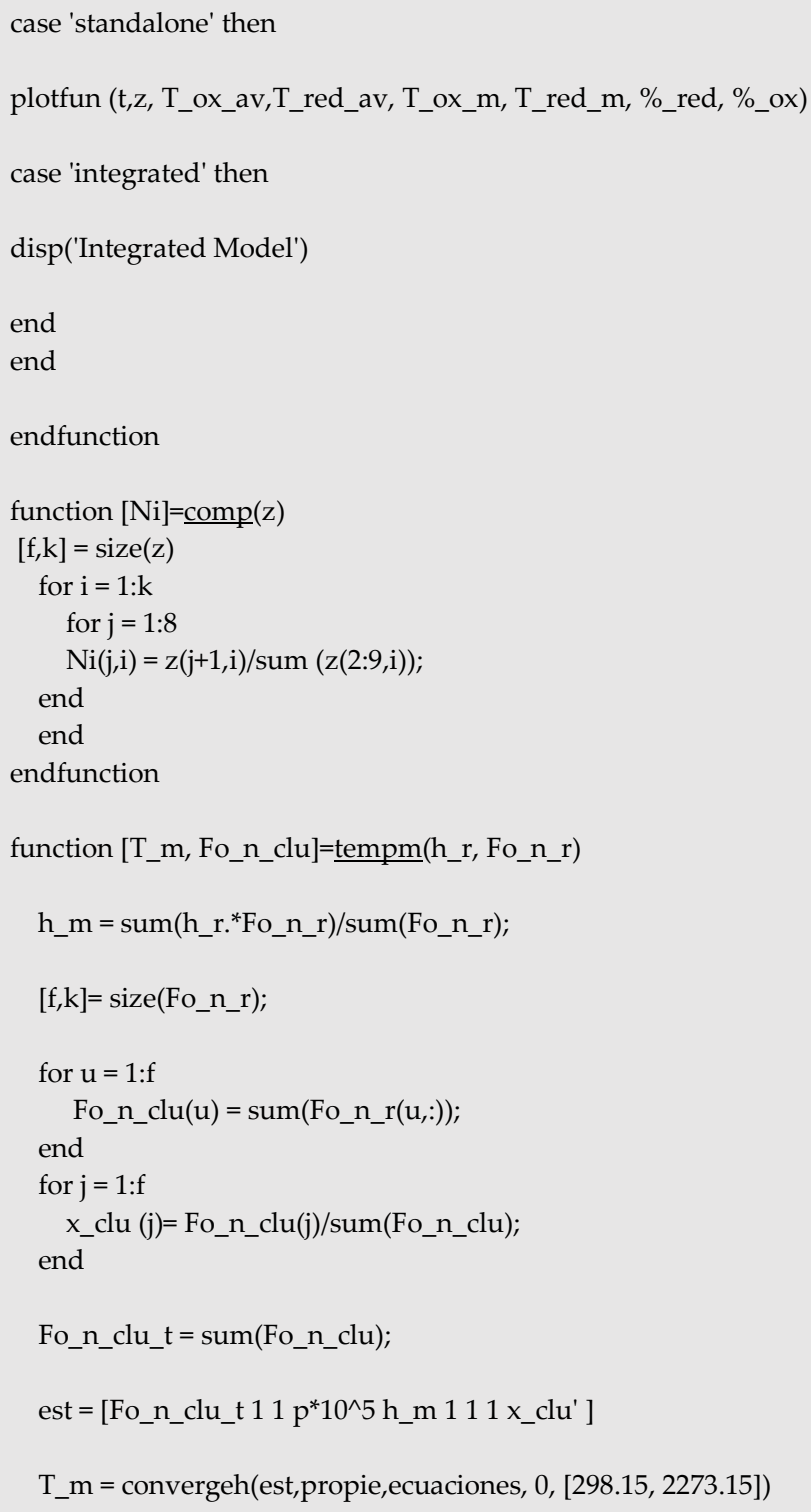




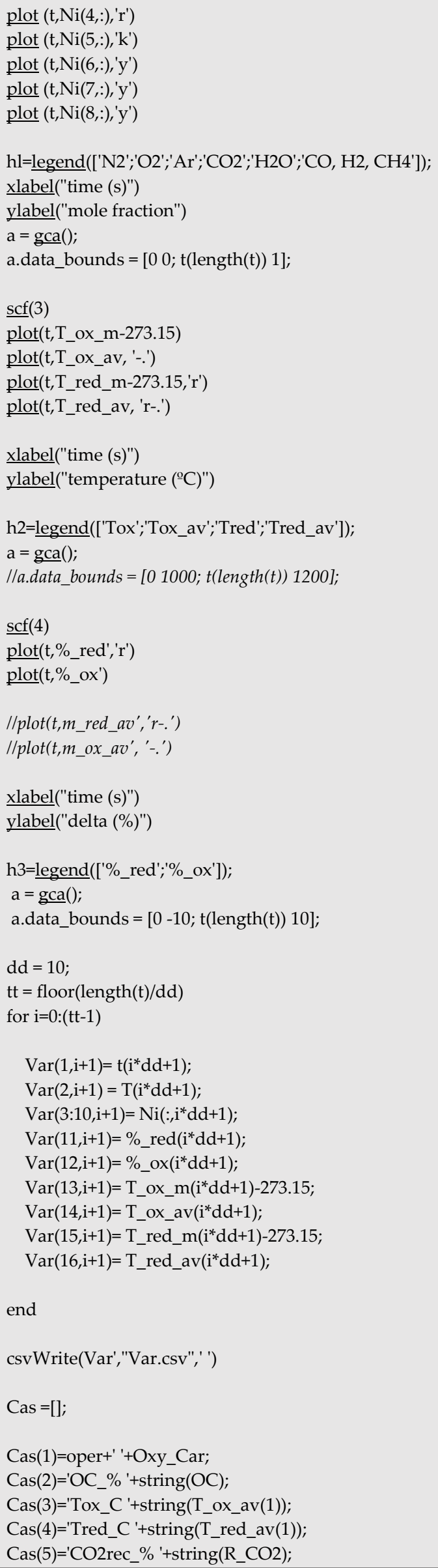


Appendix

Cas(6)='N2slip_\% '+string(S_N2);

$\operatorname{Cas}(7)=$ 'Air_kg/s '+string(Fw);

Cas(8)='red-oxi '+string(n_red)+'-'+string(n_ox);

Cas(9)='uf_ox_m/s '+string(uf_ox);

Cas(10)='uf_red_m/s '+string(uf_red);

Cas(11)='ox_flow_kg/s '+string(sum(Fo_w_ox_av));

Cas $(12)=$ 'red_flow_kg/s '+string(sum(Fo_w_red_av $))$;

csvWrite(Cas,"Cas.csv")

endfunction 


\section{Appendix 2: MAWGS Model \& Auxiliary Scilab Codes}

The MAWGS code and auxiliary tools for property estimation are presented in the following pages:

\section{A2.1 WGS_Main}

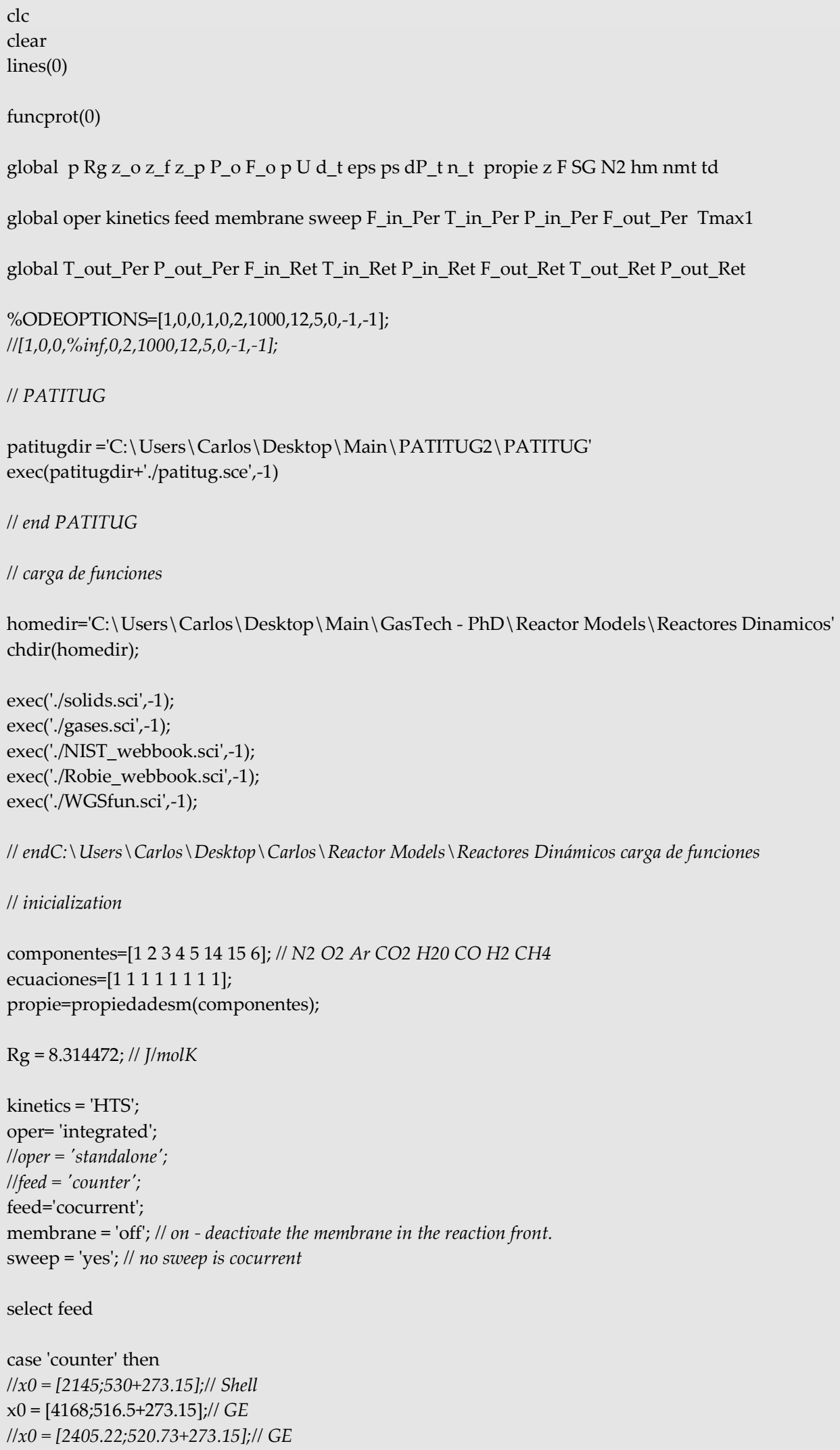


Appendix

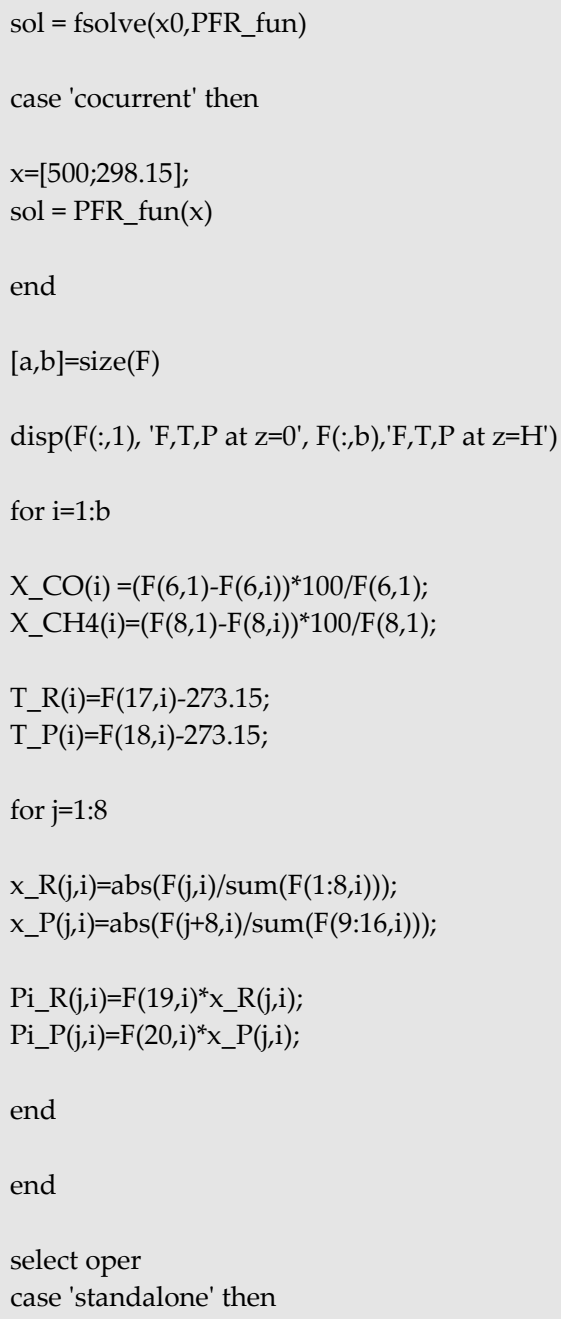


Appendix

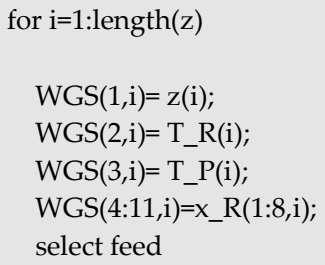

case 'cocurrent'

F_in_Per $=F(9: 16,1)^{*}$ _ $t$;

T_in_Per $=\mathrm{F}(18,1)$;

P_in_Per $=F(20,1)$; 


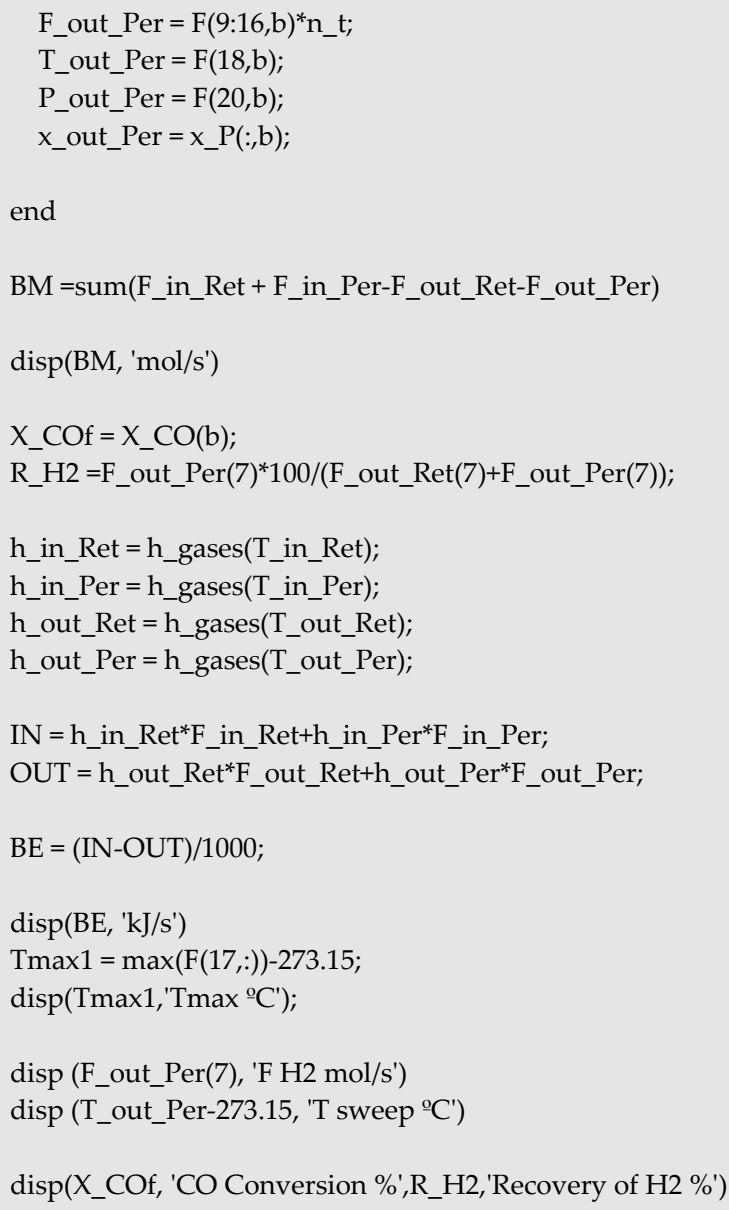

\section{A2.2 PFR_Fun}

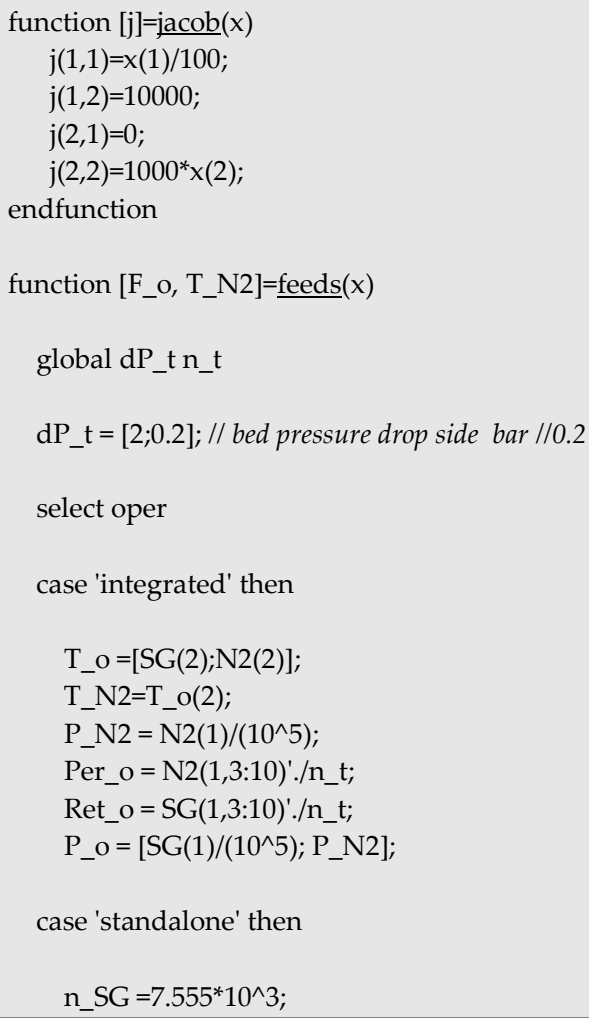




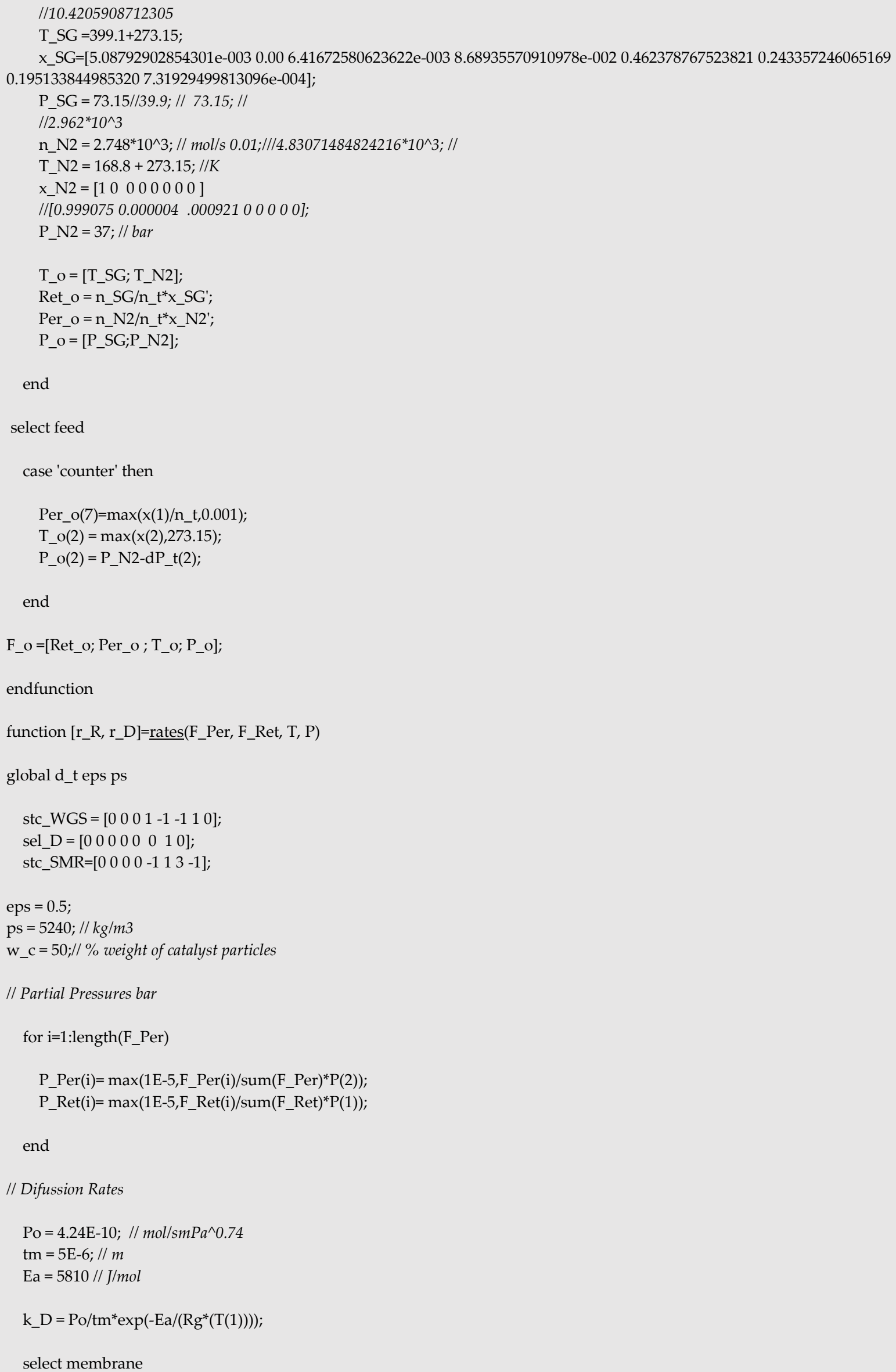


case 'on'then

R_D $=\%$ pi $^{*}$ d_t ${ }^{*}{ }_{-} \_D^{*}\left(\left(P_{-} \operatorname{Ret}(7)^{*} 10^{\wedge} 5\right)^{\wedge} 0.74-\left(\left(P_{-} \operatorname{Per}(7)^{*} 10^{\wedge} 5\right)^{\wedge} 0.74\right)\right) ; / / m o l / m s$

case 'off' then

R_D $=\%$ pi ${ }^{*}$ __t ${ }^{*}{ }_{-} \_D^{*}\left(\left(P \_R e t(7)^{*} 10^{\wedge} 5\right)^{\wedge} 0.74-\left(\left(P \_P e r(7)^{*} 10^{\wedge} 5\right)^{\wedge} 0.74\right)\right) ; / / m o l / m s$

if $R_{-} D<0$ then

R_D $=0$;

end

end

// Reaction Rates

// N2 O2 Ar CO2 H2O CO H2 CH4

K_eq_WGS $=\exp (4577.8 / \mathrm{T}(1)-4.33)$;

K_eq_SMR $=\exp (-26830 / \mathrm{T}(1)+30.114) ; / / b^{\prime} r^{\wedge} 2$

P_eq_CH4 $=\left(\right.$ P_Ret $\left.(6)^{*}\left(P_{-} \_\operatorname{Ret}(7)^{\wedge} 3\right)\right) /\left(\right.$ P_Ret $(5)^{*}$ K_eq_SMR $)$;

Beta $=$ P_Ret $(4)^{*} P_{-} \operatorname{Ret}(7) /\left(K_{-}\right.$eq_WGS*P_Ret $(6)^{*}$ P_Ret(5));

if Beta $<1 \mathrm{e}-6$ then

Beta $=1 \mathrm{e}-6$

//disp(Beta,'Beta')

end

Alfa $=\left(P_{-} \operatorname{Ret}(6)^{*}\left(P_{-} \operatorname{Ret}(7)^{\wedge} 3\right)\right) /\left(P_{-} \operatorname{Ret}(5)^{*} P_{-} \operatorname{Ret}(8)\right)$;

select kinetics

case 'LTS' then

k_K $=(1.85 \mathrm{E}-5)^{*} \exp (12.88-1855.5 / \mathrm{T}(1))$;

R_R $=\% \mathrm{pi}^{*}\left(\mathrm{~d}_{-} \mathrm{t}^{\wedge} 2\right) / 4^{*} \mathrm{ps}^{*} \mathrm{w}_{-} \mathrm{c} / 100^{*}(1-\mathrm{eps})^{*} \mathrm{k}_{-} \mathrm{K}^{*}(1-\mathrm{Beta})^{*}\left(10^{\wedge} 3\right) / 60^{*} \mathrm{P} \_\operatorname{Ret}(6)^{*} \mathrm{P}_{-} \operatorname{Ret}(5) ; / / \mathrm{mol} / \mathrm{ms}$

case 'HTS' then

tau $=0.01$;

k_K $=\left(10^{\wedge} 2.845\right)^{*} \exp \left(-111^{*} 10^{\wedge} 3 /\left(\operatorname{Rg}^{*} \mathrm{~T}(1)\right)\right)$;

$\mathrm{a}=1 ; / / \mathrm{CO}$

$\mathrm{b}=-0.36 ; / / \mathrm{CO} 2$

$\mathrm{c}=-0.09 ; / / \mathrm{H} 2$

$\mathrm{d}=0 ; / / \mathrm{H} 2 \mathrm{O}$

R_WGS $=\% \mathrm{pi}^{*}\left(\mathrm{~d} \_\mathrm{t}^{\wedge} 2\right) / 4^{*} \mathrm{ps}^{*} \mathrm{w}_{-} \mathrm{c} / 100^{*}\left(10^{\wedge} 3\right)^{*}(1-\mathrm{eps})^{*} \mathrm{k} \_\mathrm{K}^{*}(1-$

$\operatorname{Beta})^{*}\left(\left(P_{-} \operatorname{Ret}(6)^{*} 10^{\wedge} 2\right)^{\wedge} \mathrm{a}\right)^{*}\left(\left(\mathrm{P} \_\operatorname{Ret}(4)^{*} 10^{\wedge} 2\right)^{\wedge} \mathrm{b}\right)^{*}\left(\left(\mathrm{P}_{-} \operatorname{Ret}(7)^{*} 10^{\wedge} 2\right)^{\wedge} \mathrm{c}\right)^{*}\left(\left(\mathrm{P} \_\operatorname{Ret}(5)^{*} 10^{\wedge} 2\right)^{\wedge} \mathrm{d}\right) ; / / \mathrm{mol} / \mathrm{ms}$

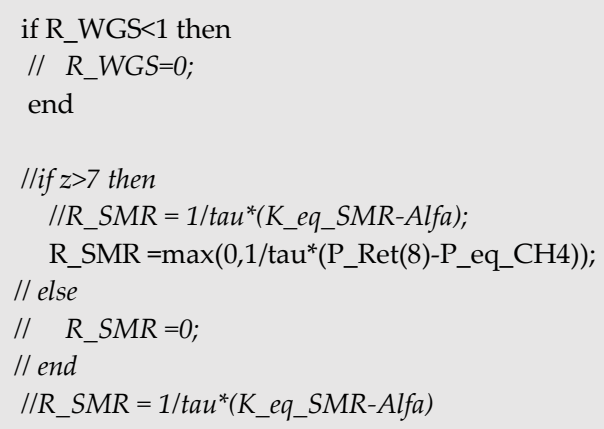


Appendix

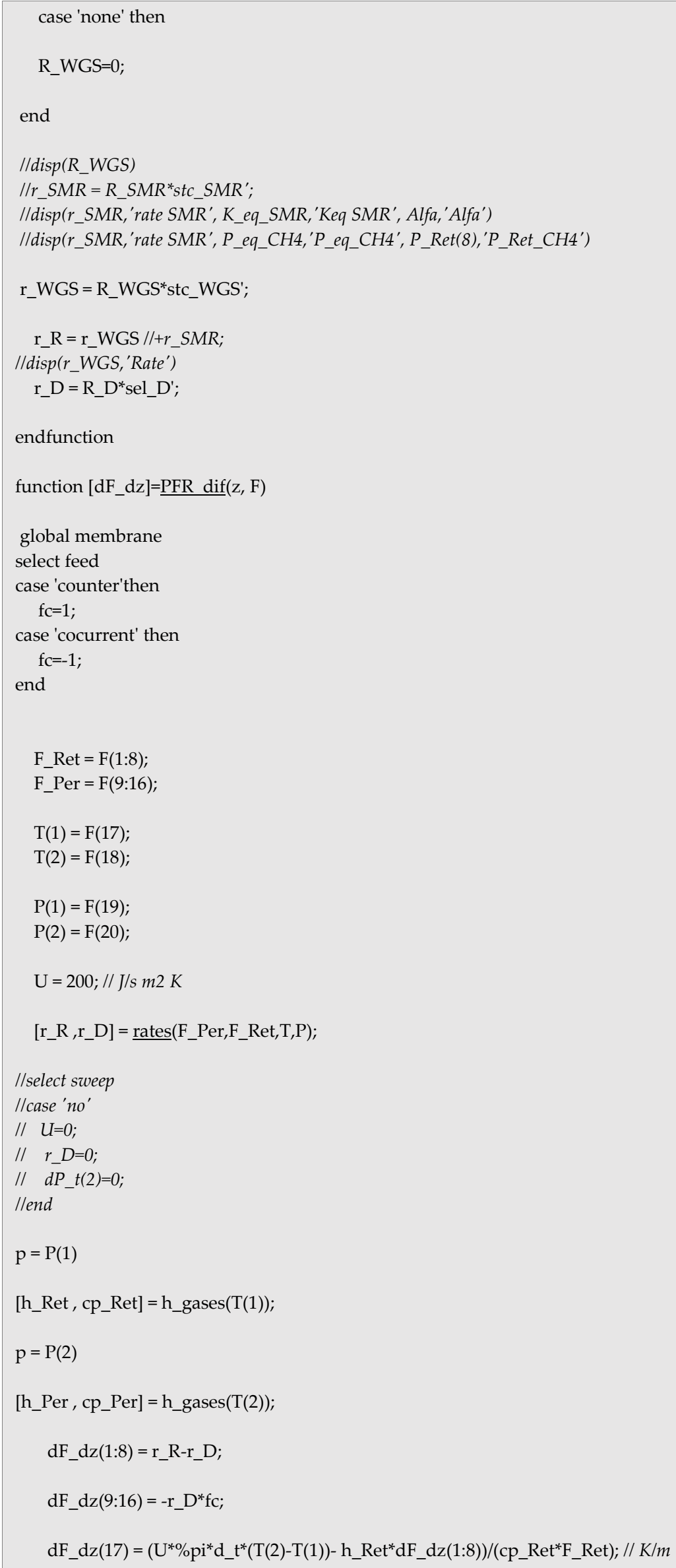


Appendix

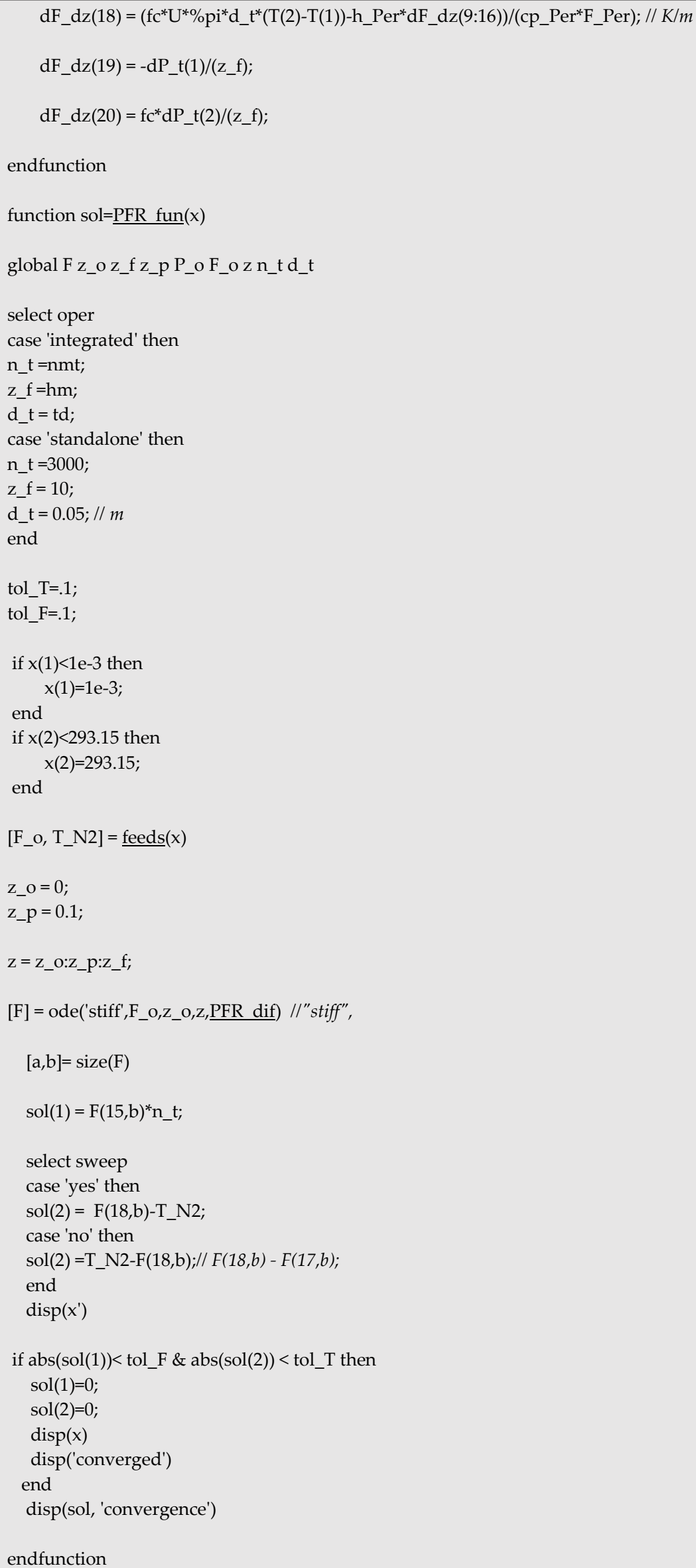




\section{A2.3 Shomate Data Fit Code}

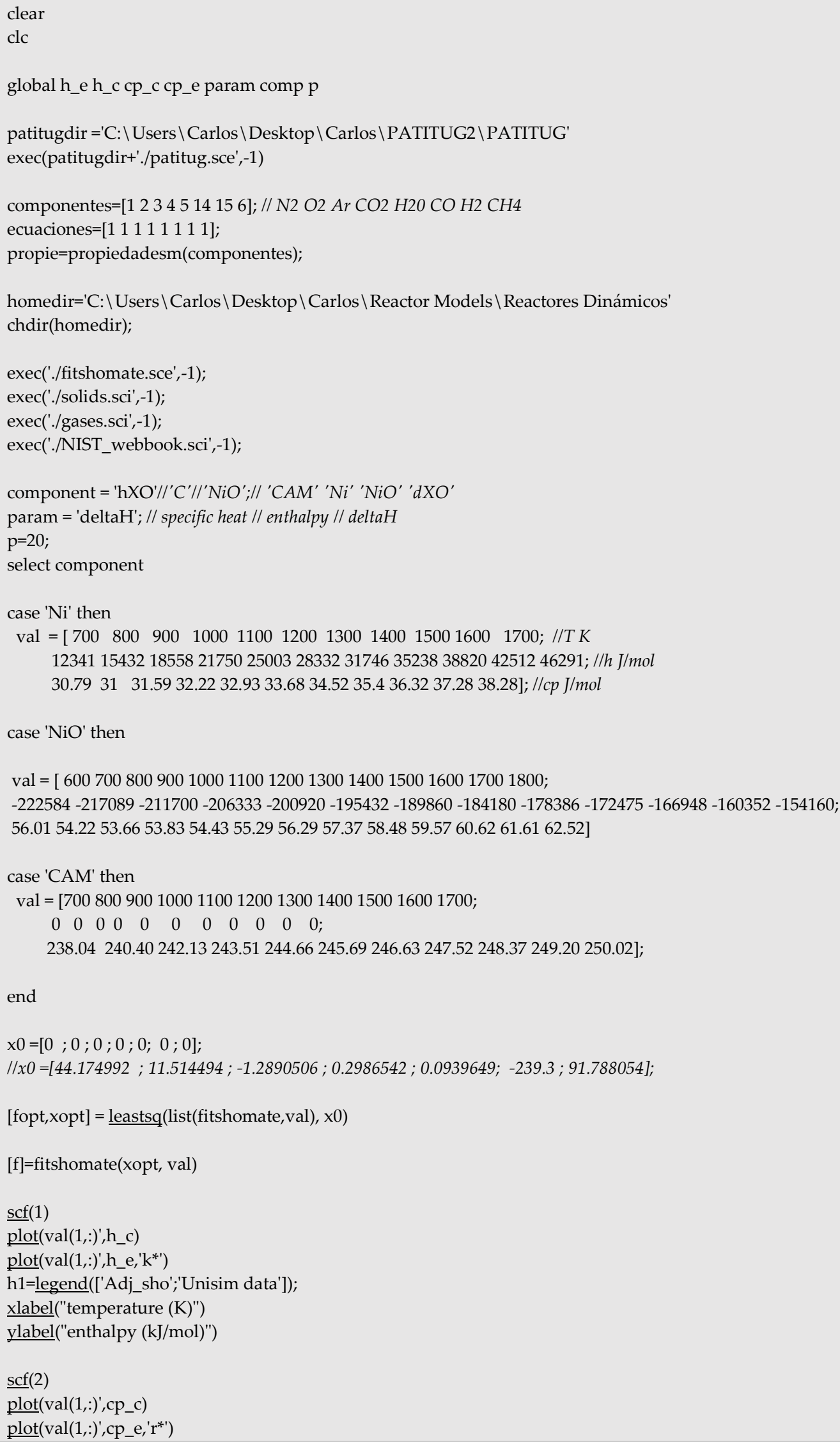


Appendix

h2=legend(['Adj_sho';'Unisim data']);

xlabel("temperature (K)")

ylabel("specific heat $(\mathrm{J} / \mathrm{molK}) ")$

st = ['A' 'B' 'C' 'D' 'E' 'F' 'G'];

$\operatorname{disp}($ xopt, st)

function $v=$ fitshomate $(x, v a l)$

global h_e h_c cp_c cp_e
$A=x(1)$
$B=x(2)$;
$C=x(3)$;
$\mathrm{D}=\mathrm{x}(4)$;
$\mathrm{E}=\mathrm{x}(5)$;
$\mathrm{F}=\mathrm{x}(6)$;
$\mathrm{G}=\mathrm{x}(7)$;

$[\mathrm{f}, \mathrm{k}]=\operatorname{size}(\mathrm{val})$

for $\mathrm{i}=1: \mathrm{k}$

$\mathrm{t}(\mathrm{i})=\operatorname{val}(1, \mathrm{i}) / 1000$;

h_e(i) $=\operatorname{val}(2, \mathrm{i}) / 1000$;

cp_e $(\mathrm{i})=\mathrm{val}(3, \mathrm{i})$;

$\mathrm{cp}_{-} \mathrm{c}(\mathrm{i})=\mathrm{A}+\mathrm{B}^{*} \mathrm{t}(\mathrm{i})+\mathrm{C}^{*} \mathrm{t}(\mathrm{i})^{\wedge} 2+\mathrm{D}^{*} \mathrm{t}(\mathrm{i})^{\wedge} 3+\mathrm{E} /\left(\mathrm{t}(\mathrm{i})^{\wedge} 2\right)$

$h_{-} \mathrm{c}(\mathrm{i})=\mathrm{A}^{*} \mathrm{t}(\mathrm{i})+\mathrm{B}^{*} \mathrm{t}(\mathrm{i})^{\wedge} 2 / 2+\mathrm{C}^{*} \mathrm{t}(\mathrm{i})^{\wedge} 3 / 3+\mathrm{D}^{*} \mathrm{t}(\mathrm{i})^{\wedge} 4 / 4-\mathrm{E} / \mathrm{t}(\mathrm{i})+\mathrm{F}$;

h_g $(:, i)=h \_g a s e s(\operatorname{val}(1, i))$;

$\mathrm{dH}(\mathrm{i})=\mathrm{h} \_\mathrm{g}(6, \mathrm{i})+2^{*} \mathrm{~h} \_\mathrm{g}(7, \mathrm{i})-0.74^{*} \mathrm{~h} \_\mathrm{c}(\mathrm{i})-\mathrm{h} \_\mathrm{g}(8, \mathrm{i})$;

end

select param

case 'enthalpy' then

$\mathrm{v}=\left(\mathrm{h} \_\mathrm{c}-\mathrm{h} \_\mathrm{e}\right)$;

disp('hola')

case 'specific heat' then

$\mathrm{v}=($ cp_c-cp_e $)$;

case'deltaH' then

$\mathrm{v}=\mathrm{dH}-\mathrm{h} \mathrm{e}$;

end

$\operatorname{disp}(v)$

endfunction 


\section{Appendix 3: Power Plant}

\section{A3.1 Data Sheets for Stationary Operating Points of GSC and GSOP}

GSC Input

\begin{tabular}{|c|c|c|c|c|}
\hline \multicolumn{5}{|c|}{ Gas Switching Combustion Input Sheet } \\
\hline Stream Data Date & $\underline{26 / 07 / 2018}$ & Comments: & \multicolumn{2}{|c|}{$\begin{array}{l}\text { Master Sheet for correlations. Input streams of air and syngas to Matlab O-D model } \\
\text { to return correlations of GSC operation depending on Heat Management Strategy }\end{array}$} \\
\hline \multicolumn{3}{|c|}{ Syngas Inlet Stream } & \multicolumn{2}{|c|}{ Air Inlet Stream } \\
\hline \multicolumn{3}{|c|}{ Syngas Production } & \multicolumn{2}{|c|}{ Air Compression } \\
\hline Gasifier & \multicolumn{2}{|c|}{ Entrained Flow } & Gas Turbine Pressure Ratio & 20 \\
\hline Technology & \multicolumn{2}{|c|}{ Shell } & Extra Firing \& Recovery & No \\
\hline \multicolumn{3}{|c|}{ Syngas Treating } & \multicolumn{2}{|c|}{ GSC Heat Mangement Strategy } \\
\hline Technology & \multicolumn{2}{|c|}{$\mathrm{HGCU}$} & \multicolumn{2}{|c|}{\begin{tabular}{l|l}
$\mathrm{N}_{2}$ recycle & Yes \\
\end{tabular}} \\
\hline Treating Temperature & \multicolumn{2}{|c|}{400} & Steam Purge & Yes \\
\hline Syngas Preheating & & & $\mathrm{O}_{2}$ Slip & Yes \\
\hline \multicolumn{3}{|c|}{ Syngas Conditions \& Composition } & \multicolumn{2}{|c|}{ Syngas Conditions \& Composition } \\
\hline Component & \multicolumn{2}{|c|}{ mol fraction } & Component & mol fraction \\
\hline $\mathrm{N}_{2}$ & \multicolumn{2}{|c|}{0,0104} & $\mathrm{~N}_{2}$ & 0,7730 \\
\hline $\mathrm{O}_{2}$ & \multicolumn{2}{|c|}{0,0001} & $\mathrm{O}_{2}$ & 0,2073 \\
\hline Ar & \multicolumn{2}{|c|}{0,0140} & Ar & 0,0092 \\
\hline $\mathrm{CO}_{2}$ & \multicolumn{2}{|c|}{0,0933} & $\mathrm{CO}_{2}$ & 0,0004 \\
\hline $\mathrm{H}_{2} \mathrm{O}$ & \multicolumn{2}{|c|}{0,0659} & $\mathrm{H}_{2} \mathrm{O}$ & 0,0101 \\
\hline CO & \multicolumn{2}{|c|}{0,6083} & CO & 0,0000 \\
\hline $\mathrm{H}_{2}$ & \multicolumn{2}{|c|}{0,2070} & $\mathrm{H}_{2}$ & 0,0000 \\
\hline $\mathrm{CH}_{4}$ & \multicolumn{2}{|c|}{0,0010} & $\mathrm{CH}_{4}$ & 0,0000 \\
\hline $\mathrm{H}_{2} \mathrm{~S}$ & \multicolumn{2}{|c|}{0,0000} & $\mathrm{H}_{2} \mathrm{~S}$ & 0,0000 \\
\hline mass flow $(\mathrm{kg} / \mathrm{s})$ & \multicolumn{2}{|c|}{69,12} & mass flow $(\mathrm{kg} / \mathrm{s})$ & 703,10 \\
\hline molar flow $(\mathrm{kmol} / \mathrm{s})$ & \multicolumn{2}{|c|}{2,93} & molar flow $(\mathrm{kmol} / \mathrm{s})$ & 24,37 \\
\hline Temperature $\left({ }^{\circ} \mathrm{C}\right)$ & \multicolumn{2}{|c|}{400} & Temperature $\left({ }^{\circ} \mathrm{C}\right)$ & 447 \\
\hline Pressure (bar) & \multicolumn{2}{|c|}{20,1} & Pressure (bar) & 20,1 \\
\hline
\end{tabular}

Figure 135 Screenshot of GSC input spreadsheet

GSC Output

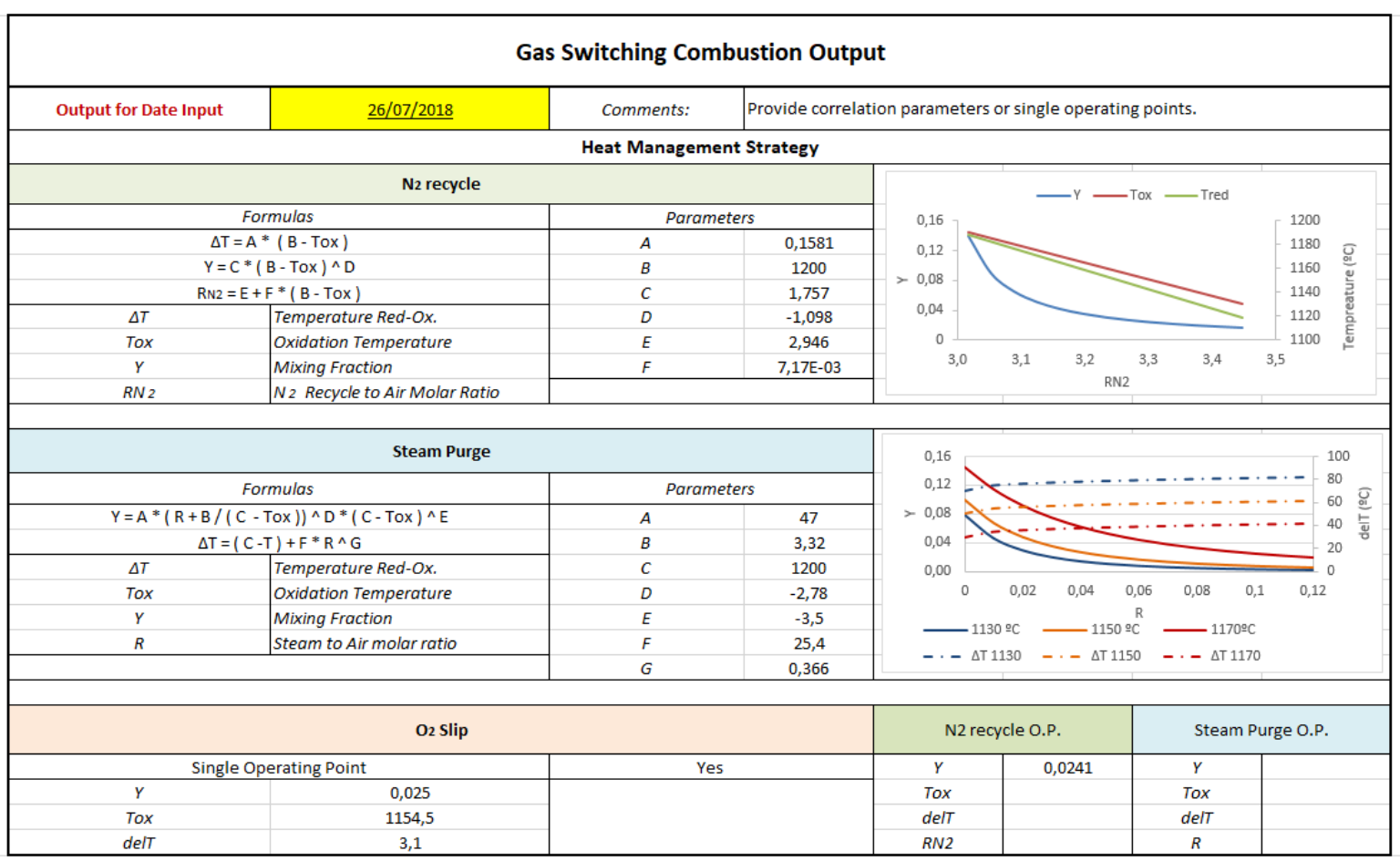

Figure 136 Screenshot of GSC output spreadsheet 
GSOP Input

\begin{tabular}{|c|c|c|c|c|}
\hline \multicolumn{5}{|c|}{ Gas Switching Oxygen Production Stream Inlet } \\
\hline Stream Data Date & $\underline{30 / 07 / 2018}$ & Comments: & \begin{tabular}{|l|} 
Master Sheet for correlations. Inp \\
to return correlations of GSOP ope
\end{tabular} & $\begin{array}{l}\text { rand syngas to Matlab O-D model } \\
\text { g on Heat Management Strategy }\end{array}$ \\
\hline \multicolumn{3}{|c|}{ Syngas Inlet Stream } & \multicolumn{2}{|c|}{ Air Inlet Stream } \\
\hline \multicolumn{3}{|c|}{ Syngas Production } & \multicolumn{2}{|c|}{ Air Compression } \\
\hline Gasifier & \multicolumn{2}{|c|}{ Fluidized Bed } & Gas Turbine Pressure Ratio & 17 \\
\hline Technology & \multicolumn{2}{|c|}{ HTW } & Extra Firing \& Recovery & No \\
\hline \multicolumn{3}{|c|}{ Syngas Treating } & \multicolumn{2}{|c|}{ GSC Heat Mangement Strategy } \\
\hline Technology & \multicolumn{2}{|c|}{$\mathrm{HGCU}$} & $\mathrm{N}_{2}$ recycle & Not Possible \\
\hline Treating Temperature & \multicolumn{2}{|c|}{400} & Steam Purge & Yes \\
\hline Syngas Preheating & \multicolumn{2}{|c|}{ No } & Delayed Switching & Yes \\
\hline \multicolumn{3}{|c|}{ Syngas \& Sweepgas Conditions and Composition } & \multicolumn{2}{|c|}{ Syngas Conditions \& Composition } \\
\hline Component & Syngas mol frac. & Sweep Gas mol frac. & Component & mol fraction \\
\hline $\mathrm{N}_{2}$ & 0,0257 & 0,0385 & $\mathrm{~N}_{2}$ & 0,7730 \\
\hline $\mathrm{O}_{2}$ & 0,0000 & 0,0027 & $\mathrm{O}_{2}$ & 0,2073 \\
\hline $\operatorname{Ar}$ & 0,0004 & 0,0004 & $\operatorname{Ar}$ & 0,0092 \\
\hline $\mathrm{CO}_{2}$ & 0,2979 & 0,5734 & $\mathrm{CO}_{2}$ & 0,0004 \\
\hline $\mathrm{H}_{2} \mathrm{O}$ & 0,1535 & 0,3850 & $\mathrm{H}_{2} \mathrm{O}$ & 0,0101 \\
\hline $\mathrm{CO}$ & 0,3370 & 0,0000 & $\mathrm{CO}$ & 0,0000 \\
\hline $\mathrm{H}_{2}$ & 0,1853 & 0,0000 & $\mathrm{H}_{2}$ & 0,0000 \\
\hline $\mathrm{CH}_{4}$ & 0,0003 & 0,0000 & $\mathrm{CH}_{4}$ & 0,0000 \\
\hline $\mathrm{H}_{2} \mathrm{~S}$ & 0,0000 & 0,0000 & $\mathrm{H}_{2} \mathrm{~S}$ & 0,0000 \\
\hline mass flow $(\mathrm{kg} / \mathrm{s})$ & 44,91 & 16,46 & mass flow $(\mathrm{kg} / \mathrm{s})$ & 703,10 \\
\hline molar flow (kmol/s) & 1,70 & 0,49 & molar flow (kmol/s) & 24,37 \\
\hline Temperature $\left({ }^{\circ} \mathrm{C}\right)$ & 438 & 1086 & Temperature $\left({ }^{\circ} \mathrm{C}\right)$ & 447 \\
\hline Pressure (bar) & 17,0 & 17,0 & Pressure (bar) & 20,1 \\
\hline
\end{tabular}

Figure 137 Screenshot of GSOP inlet spreadsheet

GSOP Output

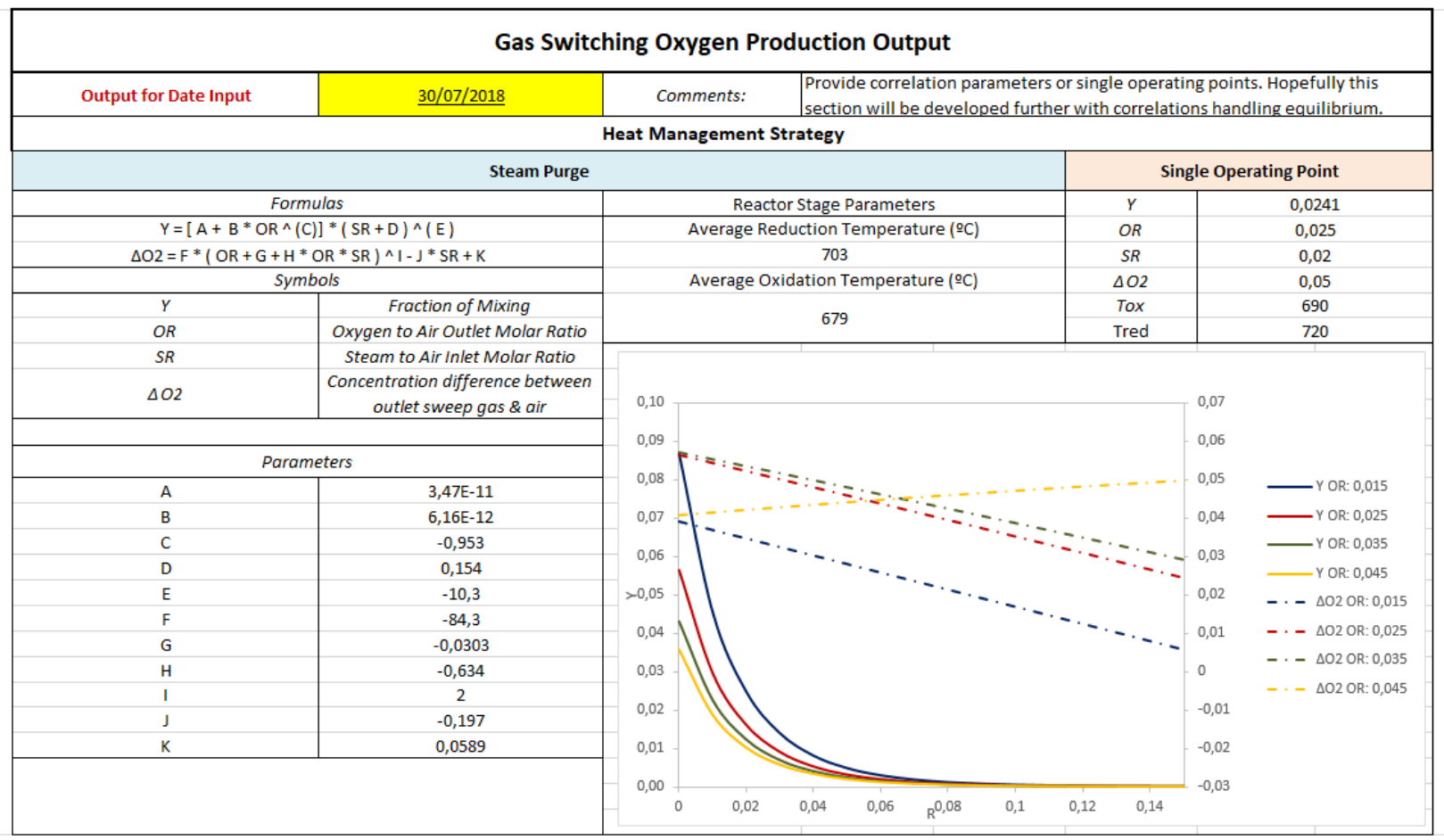

Figure 138 Screenshot with GSOP outlet spreadsheet 
A3.2 Stream Data \& Detailed Schemes for Power Plant Concepts

Benchmark Power Plants

Unabated IGCC

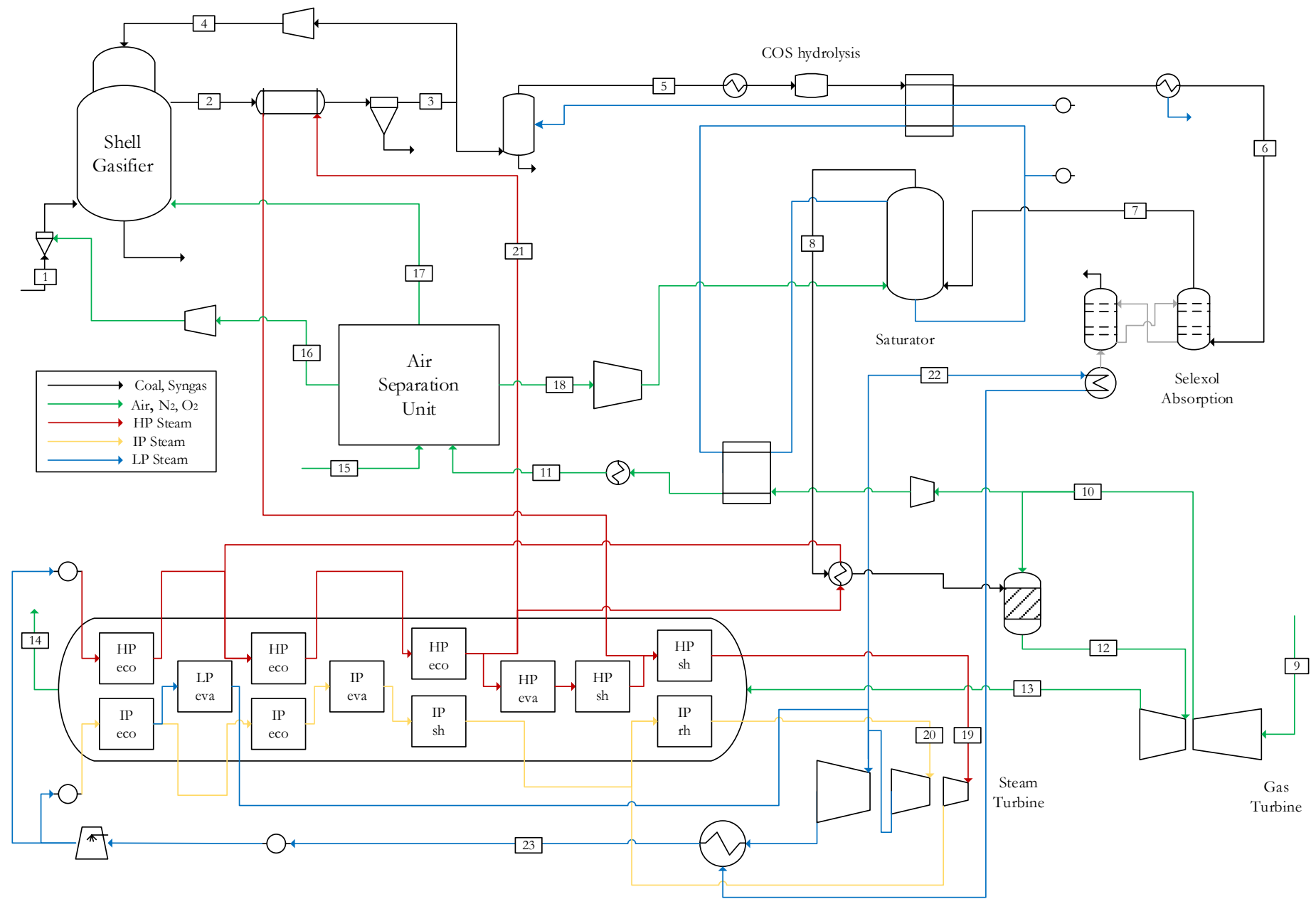

Figure 139 Detailed schematic of the Unabated IGCC power plant 
Table 89 Stream summary of the Unabated IGCC power plant

\begin{tabular}{|c|c|c|c|c|c|c|c|c|c|c|c|c|}
\hline \multicolumn{4}{|c|}{ Property } & \multicolumn{9}{|c|}{ Composition ( $\% \mathrm{~mol})$} \\
\hline Stream $n^{\circ}$ & $\mathrm{P}$ (bar) & $\mathrm{T}\left({ }^{\circ} \mathrm{C}\right)$ & $\mathrm{m}(\mathrm{kg} / \mathrm{s})$ & $\mathrm{N}_{2}$ & $\mathrm{O}_{2}$ & $\mathrm{Ar}$ & $\mathrm{CO}_{2}$ & $\mathrm{H}_{2} \mathrm{O}$ & $\mathrm{CO}$ & $\mathrm{H}_{2}$ & $\mathrm{CH}_{4}$ & $\mathrm{H}_{2} \mathrm{~S}$ \\
\hline 1 & 1,0 & 25,0 & 33,9 & \multicolumn{9}{|c|}{ Douglas Premium Coal } \\
\hline 2 & 44,0 & 900,3 & 125,8 & 5,0 & 0,0 & 0,9 & 2,4 & 5,6 & 60,8 & 25,0 & 0,2 & 0,2 \\
\hline 3 & 42,0 & 297,5 & 127,7 & 6,0 & 0,0 & 0,9 & 2,4 & 5,5 & 60,1 & 24,7 & 0,2 & 0,2 \\
\hline 4 & 44,0 & 269,7 & 65,1 & 5,8 & 0,0 & 0,9 & 2,3 & 8,3 & 58,3 & 24,0 & 0,2 & 0,2 \\
\hline 5 & 41,5 & 160,1 & 70,5 & 5,4 & 0,0 & 0,8 & 2,1 & 15,6 & 53,7 & 22,1 & 0,2 & 0,2 \\
\hline 6 & 41,2 & 30,0 & 61,2 & 6,4 & 0,0 & 0,9 & 2,5 & 0,2 & 63,5 & 26,1 & 0,2 & 0,2 \\
\hline 7 & 41,2 & 30,0 & 60,3 & 6,4 & 0,0 & 0,9 & 2,5 & 0,2 & 63,6 & 26,2 & 0,2 & 0,0 \\
\hline 8 & 23,0 & 113,4 & 157,7 & 50,4 & 0,9 & 0,6 & 1,1 & 7,9 & 27,6 & 11,3 & 0,1 & 0,0 \\
\hline 9 & 1,0 & 15 & 514,8 & 77,3 & 20,7 & 0,9 & 0,0 & 1,0 & 0,0 & 0,0 & 0,0 & 0,0 \\
\hline 10 & 18,2 & 426,6 & 348,0 & 77,3 & 20,7 & 0,9 & 0,0 & 1,0 & 0,0 & 0,0 & 0,0 & 0,0 \\
\hline 11 & 9,9 & 25,0 & 63,4 & 77,3 & 20,7 & 0,9 & 0,0 & 1,0 & 0,0 & 0,0 & 0,0 & 0,0 \\
\hline 12 & 17,6 & 1440 & 505,7 & 72,9 & 7,6 & 0,9 & 10,7 & 7,9 & 0,0 & 0,0 & 0,0 & 0,0 \\
\hline 13 & 1,0 & 619,8 & 605,2 & 73,6 & 9,8 & 0,9 & 9,0 & 6,8 & 0,0 & 0,0 & 0,0 & 0,0 \\
\hline 14 & 1,0 & 92,7 & 605,2 & 73,6 & 9,8 & 0,9 & 9,0 & 6,8 & 0,0 & 0,0 & 0,0 & 0,0 \\
\hline 15 & 1,0 & 15 & 63,4 & 77,3 & 20,7 & 0,9 & 0,0 & 1,0 & 0,0 & 0,0 & 0,0 & 0,0 \\
\hline 16 & 88,0 & 80,0 & 8,9 & 99,9 & 0,0 & 0,1 & 0,0 & 0,0 & 0,0 & 0,0 & 0,0 & 0,0 \\
\hline 17 & 48,0 & 22,2 & 28,8 & 2,1 & 95,0 & 2,9 & 0,0 & 0,0 & 0,0 & 0,0 & 0,0 & 0,0 \\
\hline 18 & 2,7 & 22,2 & 88,3 & 97,6 & 2,0 & 0,4 & 0,0 & 0,0 & 0,0 & 0,0 & 0,0 & 0,0 \\
\hline 19 & 144,0 & 565,0 & 115,7 & 0,0 & 0,0 & 0,0 & 0,0 & 100,0 & 0,0 & 0,0 & 0,0 & 0,0 \\
\hline 20 & 36,0 & 565,0 & 122,2 & 0,0 & 0,0 & 0,0 & 0,0 & 100,0 & 0,0 & 0,0 & 0,0 & 0,0 \\
\hline 21 & 151,6 & 450,0 & 67,3 & 0,0 & 0,0 & 0,0 & 0,0 & 100,0 & 0,0 & 0,0 & 0,0 & 0,0 \\
\hline 22 & 4,0 & 253,6 & 5,6 & 0,0 & 0,0 & 0,0 & 0,0 & 100,0 & 0,0 & 0,0 & 0,0 & 0,0 \\
\hline 23 & 0,048 & 32,2 & 111,4 & 0,0 & 0,0 & 0,0 & 0,0 & 100,0 & 0,0 & 0,0 & 0,0 & 0,0 \\
\hline
\end{tabular}


Pre-combustion $\mathrm{CO}_{2}$ capture IGCC

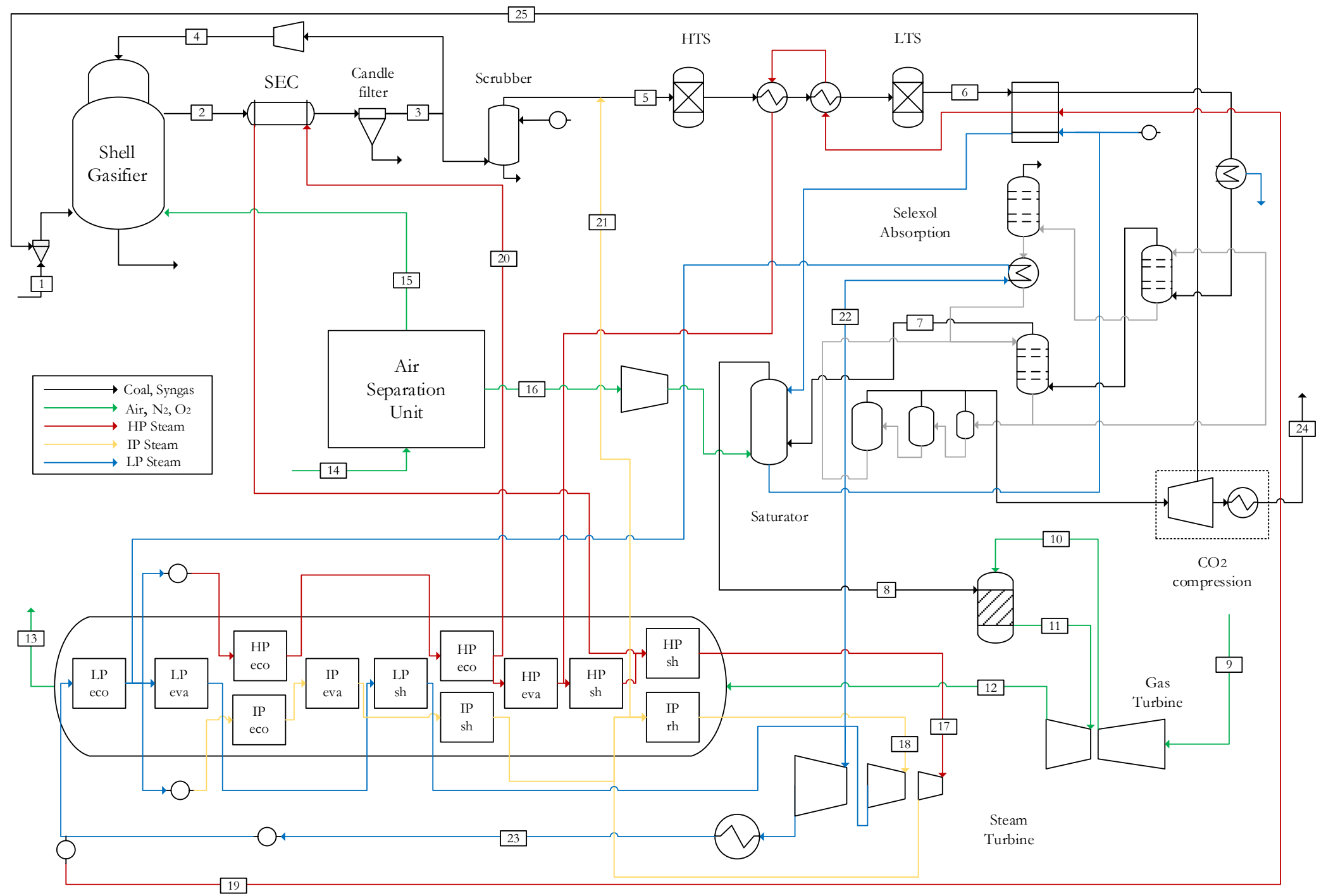

Figure 140 Detailed schematic of the Pre-combustion $\mathrm{CO}_{2}$ capture IGCC power plant 
Table 90 Stream summary of the Pre-combustion $\mathrm{CO}_{2}$ capture IGCC power plant

\begin{tabular}{|c|c|c|c|c|c|c|c|c|c|c|c|c|}
\hline \multicolumn{4}{|c|}{ Property } & \multicolumn{9}{|c|}{ Composition ( $\% \mathrm{~mol}$ ) } \\
\hline Stream $\mathrm{n}^{\circ}$ & $\mathrm{P}$ (bar) & $\mathrm{T}\left({ }^{\circ} \mathrm{C}\right)$ & $\mathrm{m}(\mathrm{kg} / \mathrm{s})$ & $\mathrm{N}_{2}$ & $\mathrm{O}_{2}$ & Ar & $\mathrm{CO}_{2}$ & $\mathrm{H}_{2} \mathrm{O}$ & $\mathrm{CO}$ & $\mathrm{H}_{2}$ & $\mathrm{CH}_{4}$ & $\mathrm{H}_{2} \mathrm{~S}$ \\
\hline 1 & 1,0 & 25,0 & 33,9 & \multicolumn{9}{|c|}{ Douglas Premium Coal } \\
\hline 2 & 44,0 & 899,7 & 125,3 & 1,0 & 0,0 & 1,2 & 6,4 & 6,0 & 62,4 & 22,8 & 0,1 & 0,2 \\
\hline 3 & 41,5 & 295,8 & 127,9 & 1,0 & 0,0 & 1,2 & 7,4 & 5,9 & 61,7 & 22,6 & 0,1 & 0,2 \\
\hline 4 & 44,0 & 288,4 & 59,7 & 1,0 & 0,0 & 1,1 & 7,3 & 7,4 & 60,7 & 22,2 & 0,1 & 0,2 \\
\hline 5 & 41,0 & 261,9 & 129,5 & 0,5 & 0,0 & 0,5 & 3,5 & 55,4 & 29,2 & 10,7 & 0,0 & 0,0 \\
\hline 6 & 37,0 & 248,5 & 129,5 & 0,5 & 0,0 & 0,5 & 32,2 & 26,8 & 0,5 & 39,4 & 0,1 & 0,1 \\
\hline 7 & 36,0 & 25,0 & 11,8 & 1,1 & 0,0 & 1,3 & 3,2 & 0,0 & 1,2 & 93,1 & 0,1 & 0,0 \\
\hline 8 & 25,0 & 200,0 & 79,3 & 41,0 & 0,0 & 0,7 & 1,6 & 8,7 & 0,6 & 47,3 & 0,1 & 0,0 \\
\hline 9 & 1,0 & 15,0 & 443,4 & 77,3 & 20,7 & 0,9 & 0,0 & 1,0 & 0,0 & 0,0 & 0,0 & 0,0 \\
\hline 10 & 18,2 & 426,6 & 352,0 & 77,3 & 20,7 & 0,9 & 0,0 & 1,0 & 0,0 & 0,0 & 0,0 & 0,0 \\
\hline 11 & 17,6 & 1440 & 431,3 & 71,6 & 7,9 & 0,9 & 0,8 & 18,9 & 0,0 & 0,0 & 0,0 & 0,0 \\
\hline 12 & 1,0 & 607,2 & 519,4 & 72,5 & 9,9 & 0,9 & 0,7 & 16,1 & 0,0 & 0,0 & 0,0 & 0,0 \\
\hline 13 & 1,0 & 126,3 & 519,4 & 72,5 & 9,9 & 0,9 & 0,7 & 16,1 & 0,0 & 0,0 & 0,0 & 0,0 \\
\hline 14 & 1,0 & 15,0 & 117,8 & 77,3 & 20,7 & 0,9 & 0,0 & 1,0 & 0,0 & 0,0 & 0,0 & 0,0 \\
\hline 15 & 48,0 & 22,0 & 28,8 & 1,1 & 95,0 & 3,9 & 0,0 & 0,0 & 0,0 & 0,0 & 0,0 & 0,0 \\
\hline 16 & 1,2 & 22,0 & 59,3 & 99,9 & 0,0 & 0,1 & 0,0 & 0,0 & 0,0 & 0,0 & 0,0 & 0,0 \\
\hline 17 & 144,0 & 565,0 & 134,4 & 0,0 & 0,0 & 0,0 & 0,0 & 100,0 & 0,0 & 0,0 & 0,0 & 0,0 \\
\hline 18 & 40,6 & 565,0 & 93,1 & 0,0 & 0,0 & 0,0 & 0,0 & 100,0 & 0,0 & 0,0 & 0,0 & 0,0 \\
\hline 19 & 166,1 & 60,0 & 88,4 & 0,0 & 0,0 & 0,0 & 0,0 & 100,0 & 0,0 & 0,0 & 0,0 & 0,0 \\
\hline 20 & 151,6 & 450,0 & 65,0 & 0,0 & 0,0 & 0,0 & 0,0 & 100,0 & 0,0 & 0,0 & 0,0 & 0,0 \\
\hline 21 & 42,7 & 366,7 & 53,8 & 0,0 & 0,0 & 0,0 & 0,0 & 100,0 & 0,0 & 0,0 & 0,0 & 0,0 \\
\hline 22 & 6,5 & 289,4 & 7,0 & 0,0 & 0,0 & 0,0 & 0,0 & 100,0 & 0,0 & 0,0 & 0,0 & 0,0 \\
\hline 23 & 0,048 & 32,2 & 83,7 & 0,0 & 0,0 & 0,0 & 0,0 & 100,0 & 0,0 & 0,0 & 0,0 & 0,0 \\
\hline 24 & 150,0 & 25,0 & 74,51 & 0,0 & 0,0 & 0,0 & 100,0 & 0,0 & 0,0 & 0,0 & 0,0 & 0,0 \\
\hline 25 & 54,0 & 80,0 & 23,7 & 0,0 & 0,0 & 0,0 & 100,0 & 0,0 & 0,0 & 0,0 & 0,0 & 0,0 \\
\hline
\end{tabular}


Adv. Unabated IGCC

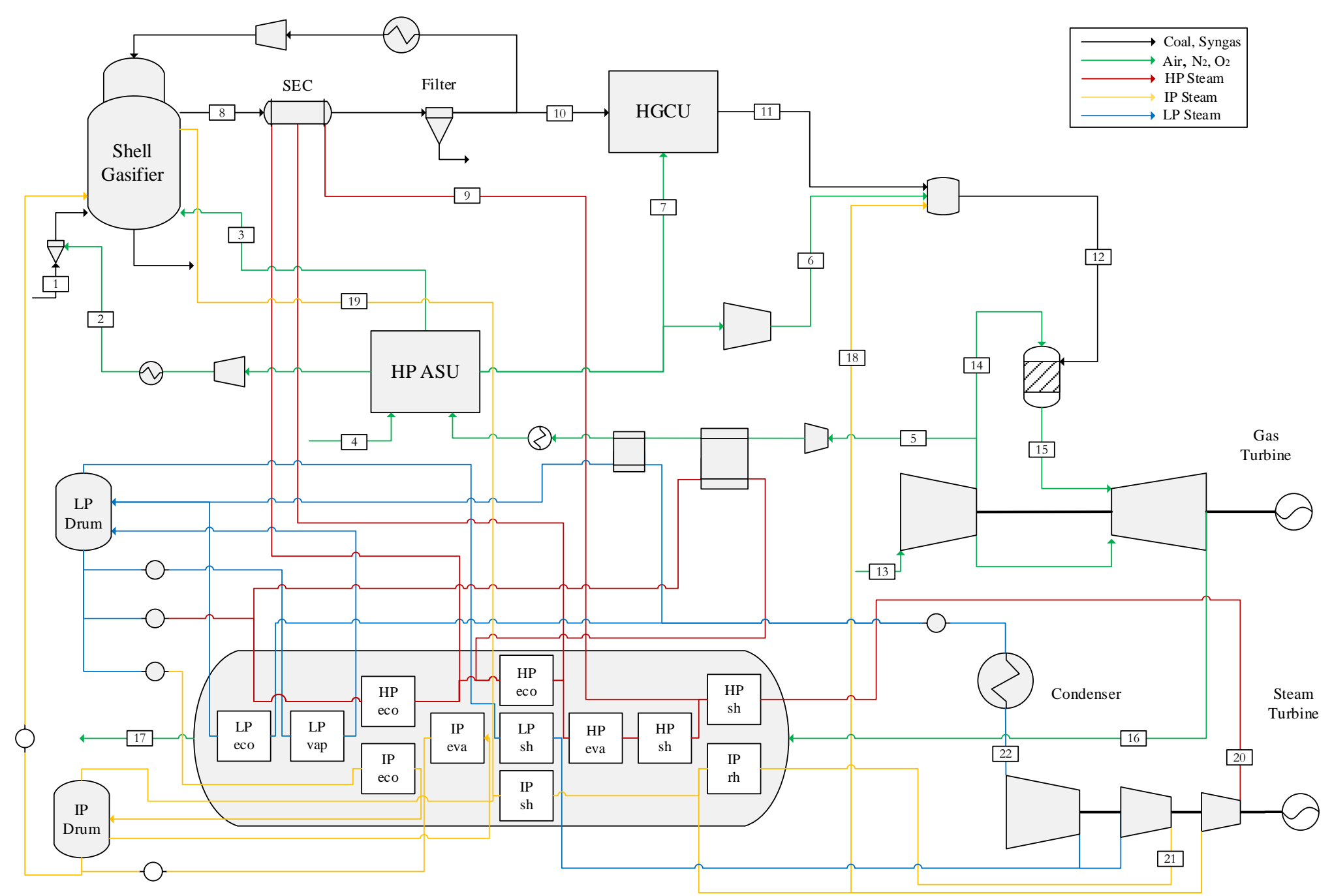

Figure 141 Detailed schematic of the Advanced Unabated IGCC power plant 
Table 91 Stream summary of the Advance Unabated IGCC power plant

\begin{tabular}{|c|c|c|c|c|c|c|c|c|c|c|c|c|}
\hline \multicolumn{4}{|c|}{ Property } & \multicolumn{9}{|c|}{ Composition $(\% \mathrm{~mol})$} \\
\hline Stream $n^{\circ}$ & $\mathrm{P}$ (bar) & $\mathrm{T}\left({ }^{\circ} \mathrm{C}\right)$ & $\mathrm{m}(\mathrm{kg} / \mathrm{s})$ & $\mathrm{N}_{2}$ & $\mathrm{O}_{2}$ & $\mathrm{Ar}$ & $\mathrm{CO}_{2}$ & $\mathrm{H}_{2} \mathrm{O}$ & $\mathrm{CO}$ & $\mathrm{H}_{2}$ & $\mathrm{CH}_{4}$ & $\mathrm{H}_{2} \mathrm{~S}$ \\
\hline 1 & 1,0 & 25,0 & 61,0 & \multicolumn{9}{|c|}{ Douglas Premium Coal } \\
\hline 2 & 88,0 & 25,0 & 16,0 & 99,9 & 0,0 & 0,1 & 0,0 & 0,0 & 0,0 & 0,0 & 0,0 & 0,0 \\
\hline 3 & 48,0 & 180,0 & 51,7 & 2,1 & 95,0 & 2,9 & 0,0 & 0,0 & 0,0 & 0,0 & 0,0 & 0,0 \\
\hline 4 & 1,0 & 15,0 & 114,0 & 77,3 & 20,7 & 0,9 & 0,0 & 1,0 & 0,0 & 0,0 & 0,0 & 0,0 \\
\hline 5 & 23,9 & 455,8 & 114,0 & 77,3 & 20,7 & 0,9 & 0,0 & 1,0 & 0,0 & 0,0 & 0,0 & 0,0 \\
\hline 6 & 35,0 & 187,4 & 137,9 & 97,6 & 2,0 & 0,5 & 0,0 & 0,0 & 0,0 & 0,0 & 0,0 & 0,0 \\
\hline 7 & 35,0 & 187,4 & 137,9 & 97,6 & 2,0 & 0,5 & 0,0 & 0,0 & 0,0 & 0,0 & 0,0 & 0,0 \\
\hline 8 & 44,0 & 900,0 & 237,0 & 5,2 & 0,0 & 0,9 & 2,5 & 2,7 & 62,6 & 25,8 & 0,2 & 0,2 \\
\hline 9 & 148,0 & 450,0 & 132,5 & 0,0 & 0,0 & 0,0 & 0,0 & 100,0 & 0,0 & 0,0 & 0,0 & 0,0 \\
\hline 10 & 42,0 & 356,4 & 112,3 & 6,2 & 0,0 & 0,9 & 2,5 & 2,6 & 61,9 & 25,5 & 0,2 & 0,2 \\
\hline 11 & 39,9 & 400,0 & 112,2 & 6,2 & 0,0 & 0,9 & 2,5 & 2,8 & 61,9 & 25,5 & 0,2 & 0,0 \\
\hline 12 & 35,0 & 312,2 & 277,5 & 43,8 & 0,8 & 0,6 & 1,1 & 14,9 & 27,4 & 11,3 & 0,1 & 0,0 \\
\hline 13 & 1,0 & 9,0 & 833,6 & 77,3 & 20,7 & 0,9 & 0,0 & 1,0 & 0,0 & 0,0 & 0,0 & 0,0 \\
\hline 14 & 23,7 & 455,8 & 530,9 & 77,3 & 20,7 & 0,9 & 0,0 & 1,0 & 0,0 & 0,0 & 0,0 & 0,0 \\
\hline 15 & 23,0 & 1577,8 & 808,5 & 69,6 & 6,0 & 0,9 & 12,0 & 11,7 & 0,0 & 0,0 & 0,0 & 0,0 \\
\hline 16 & 1,0 & 641,0 & 997,3 & 71,1 & 8,7 & 0,9 & 9,7 & 9,5 & 0,0 & 0,0 & 0,0 & 0,0 \\
\hline 17 & 1,0 & 641,0 & 997,3 & 71,1 & 8,7 & 0,9 & 9,7 & 9,5 & 0,0 & 0,0 & 0,0 & 0,0 \\
\hline 18 & 41,9 & 405,1 & 28,7 & 0,0 & 0,0 & 0,0 & 0,0 & 100,0 & 0,0 & 0,0 & 0,0 & 0,0 \\
\hline 19 & 51,8 & 300,0 & 7,1 & 0,0 & 0,0 & 0,0 & 0,0 & 100,0 & 0,0 & 0,0 & 0,0 & 0,0 \\
\hline 20 & 141,8 & 600,0 & 219,0 & 0,0 & 0,0 & 0,0 & 0,0 & 100,0 & 0,0 & 0,0 & 0,0 & 0,0 \\
\hline 21 & 39,6 & 600,0 & 197,4 & 0,0 & 0,0 & 0,0 & 0,0 & 100,0 & 0,0 & 0,0 & 0,0 & 0,0 \\
\hline 22 & 0,04 & 29,0 & 199,5 & 0,0 & 0,0 & 0,0 & 0,0 & 100,0 & 0,0 & 0,0 & 0,0 & 0,0 \\
\hline
\end{tabular}


Adv. Pre-combustion $\mathrm{CO}_{2}$ capture IGCC

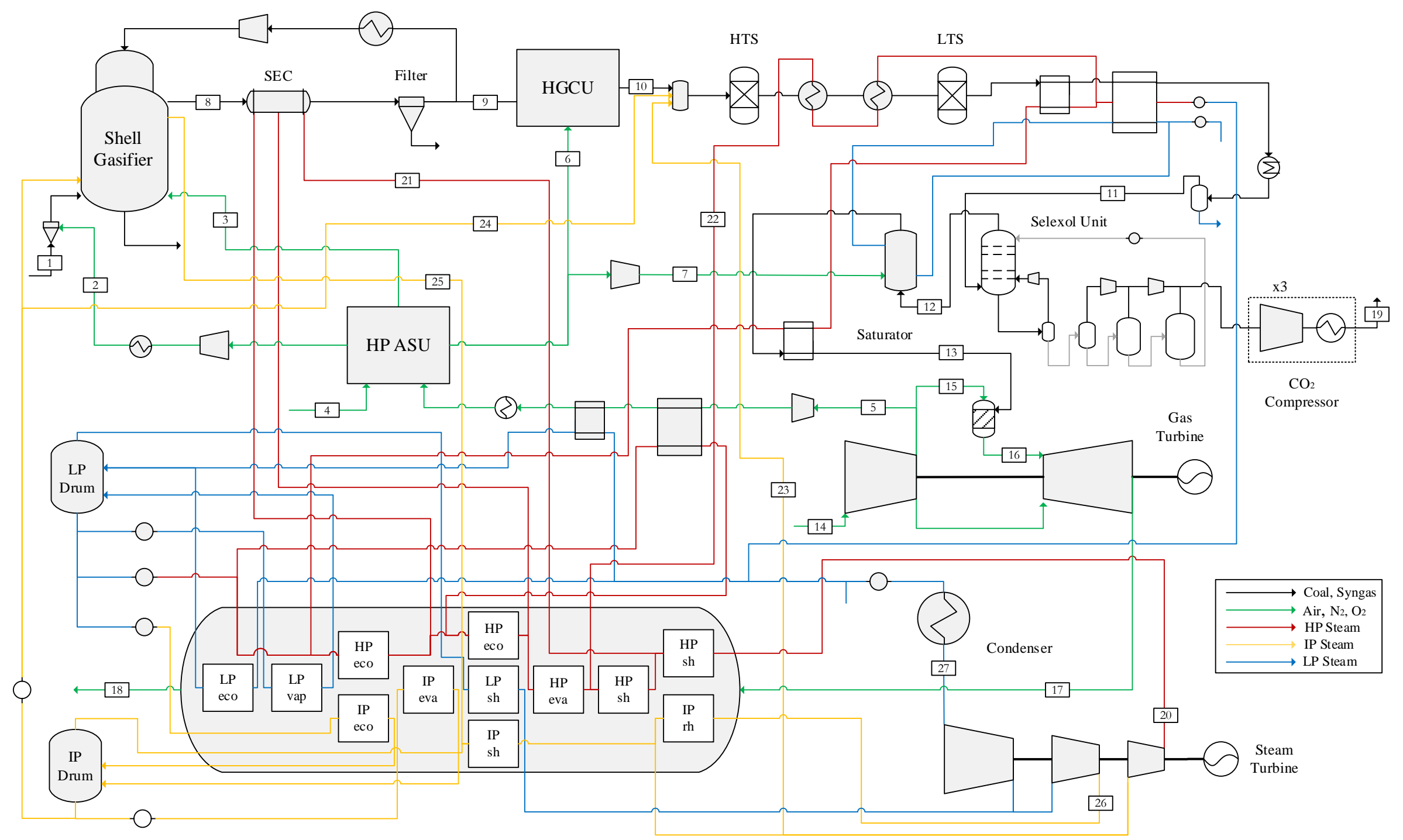

Figure 142 Detailed schematic of the Advanced Pre-combustion $\mathrm{CO}_{2}$ capture IGCC power plant 
Table 92 Stream summary of the Pre-combustion $\mathrm{CO}_{2}$ capture IGCC power plant

\begin{tabular}{|c|c|c|c|c|c|c|c|c|c|c|c|c|}
\hline \multicolumn{4}{|c|}{ Property } & \multicolumn{9}{|c|}{ Composition ( $\% \mathrm{~mol})$} \\
\hline Stream n ${ }^{\circ}$ & $\mathrm{P}$ (bar) & $\mathrm{T}\left({ }^{\circ} \mathrm{C}\right)$ & $\mathrm{m}(\mathrm{kg} / \mathrm{s})$ & $\mathrm{N}_{2}$ & $\mathrm{O}_{2}$ & Ar & $\mathrm{CO}_{2}$ & $\mathrm{H}_{2} \mathrm{O}$ & $\mathrm{CO}$ & $\mathrm{H}_{2}$ & $\mathrm{CH}_{4}$ & $\mathrm{H}_{2} \mathrm{~S}$ \\
\hline 1 & 1,0 & 25,0 & 71,3 & \multicolumn{9}{|c|}{ Douglas Premium Coal } \\
\hline 2 & 88,0 & 80,0 & 18,7 & 99,9 & 0,0 & 0,1 & 0,0 & 0,0 & 0,0 & 0,0 & 0,0 & 0,0 \\
\hline 3 & 48,0 & 22,0 & 604,5 & 2,2 & 95,1 & 2,9 & 0,0 & 0,0 & 0,0 & 0,0 & 0,0 & 0,0 \\
\hline 4 & 1,0 & 15,0 & 133,6 & 77,3 & 20,7 & 0,9 & 0,0 & 1,0 & 0,0 & 0,0 & 0,0 & 0,0 \\
\hline 5 & 23,9 & 455,8 & 133,6 & 77,3 & 20,7 & 0,9 & 0,0 & 1,0 & 0,0 & 0,0 & 0,0 & 0,0 \\
\hline 6 & 2,7 & 22,2 & 24,3 & 97,5 & 2,0 & 0,5 & 0,0 & 0,0 & 0,0 & 0,0 & 0,0 & 0,0 \\
\hline 7 & 35,0 & 187,4 & 161,9 & 97,5 & 2,0 & 0,5 & 0,0 & 0,0 & 0,0 & 0,0 & 0,0 & 0,0 \\
\hline 8 & 44,0 & 900,0 & 278,1 & 5,2 & 0,0 & 0,9 & 2,5 & 2,7 & 62,6 & 25,7 & 0,2 & 0,2 \\
\hline 9 & 42,0 & 356,8 & 131,4 & 6,2 & 0,0 & 0,9 & 2,5 & 2,7 & 61,9 & 25,5 & 0,2 & 0,2 \\
\hline 10 & 39,9 & 400,0 & 131,2 & 6,2 & 0,0 & 0,9 & 2,5 & 2,9 & 61,9 & 25,5 & 0,2 & 0,0 \\
\hline 11 & 37,5 & 25,0 & 193,9 & 3,9 & 0,0 & 0,6 & 39,9 & 0,1 & 0,7 & 54,7 & 0,1 & 0,0 \\
\hline 12 & 36,5 & 25,0 & 35,2 & 6,3 & 0,0 & 0,9 & 3,9 & 0,0 & 1,2 & 87,5 & 0,2 & 0,0 \\
\hline 13 & 35,0 & 220,0 & 224,0 & 45,5 & 0,9 & 0,6 & 1,7 & 11,4 & 0,5 & 39,3 & 0,1 & 0,0 \\
\hline 14 & 1,0 & 9,0 & 837,5 & 77,3 & 20,7 & 0,9 & 0,0 & 1,0 & 0,0 & 0,0 & 0,0 & 0,0 \\
\hline 15 & 23,7 & 455,8 & 481,9 & 77,3 & 20,7 & 0,9 & 0,0 & 1,0 & 0,0 & 0,0 & 0,0 & 0,0 \\
\hline 16 & 23,0 & 1650,7 & 705,8 & 69,4 & 3,4 & 0,9 & 1,2 & 25,1 & 0,0 & 0,0 & 0,0 & 0,0 \\
\hline 17 & 1,0 & 641,0 & 928,7 & 71,1 & 7,3 & 0,9 & 0,9 & 19,8 & 0,0 & 0,0 & 0,0 & 0,0 \\
\hline 18 & 1,0 & 98,4 & 928,7 & 71,1 & 7,3 & 0,9 & 0,9 & 19,8 & 0,0 & 0,0 & 0,0 & 0,0 \\
\hline 19 & 150,0 & 25,0 & 158,2 & 0,2 & 0,0 & 0,0 & 99,7 & 0,0 & 0,0 & 0,2 & 0,0 & 0,0 \\
\hline 20 & 141,8 & 600,0 & 277,5 & 0,0 & 0,0 & 0,0 & 0,0 & 100,0 & 0,0 & 0,0 & 0,0 & 0,0 \\
\hline 21 & 148,1 & 450,0 & 155,5 & 0,0 & 0,0 & 0,0 & 0,0 & 100,0 & 0,0 & 0,0 & 0,0 & 0,0 \\
\hline 22 & 154,9 & 351,5 & 82,9 & 0,0 & 0,0 & 0,0 & 0,0 & 100,0 & 0,0 & 0,0 & 0,0 & 0,0 \\
\hline 23 & 41,9 & 405,1 & 103,5 & 0,0 & 0,0 & 0,0 & 0,0 & 100,0 & 0,0 & 0,0 & 0,0 & 0,0 \\
\hline 24 & 43,0 & 255,7 & 22,2 & 0,0 & 0,0 & 0,0 & 0,0 & 100,0 & 0,0 & 0,0 & 0,0 & 0,0 \\
\hline 25 & 51,8 & 300,0 & 8,3 & 0,0 & 0,0 & 0,0 & 0,0 & 100,0 & 0,0 & 0,0 & 0,0 & 0,0 \\
\hline 26 & 39,6 & 600,0 & 182,3 & 0,0 & 0,0 & 0,0 & 0,0 & 100,0 & 0,0 & 0,0 & 0,0 & 0,0 \\
\hline 27 & 0,04 & 29,0 & 203,9 & 0,0 & 0,0 & 0,0 & 0,0 & 100,0 & 0,0 & 0,0 & 0,0 & 0,0 \\
\hline
\end{tabular}


GSC Power Plants

Standalone GSC IGCC

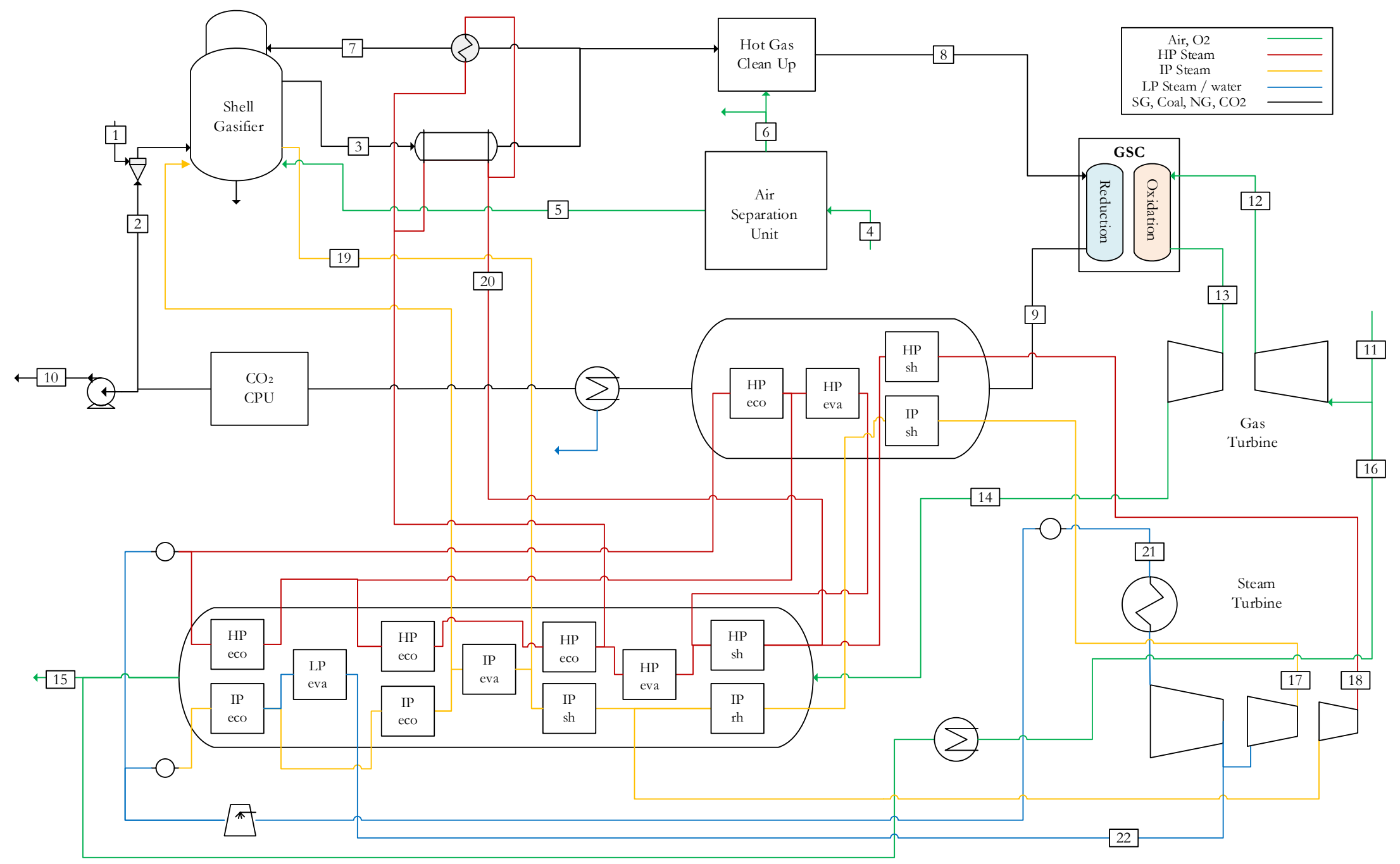

Figure 143 Detailed schematic of the Standalone GSC IGCC power plant 
Table 93 Stream summary of Standalone GSC IGCC power plant

\begin{tabular}{|c|c|c|c|c|c|c|c|c|c|c|c|c|}
\hline \multicolumn{4}{|c|}{ Property } & \multicolumn{9}{|c|}{ Composition $(\% \mathrm{~mol})$} \\
\hline Stream $n^{\circ}$ & $\mathrm{P}$ (bar) & $\mathrm{T}\left({ }^{\circ} \mathrm{C}\right)$ & $\mathrm{m}(\mathrm{kg} / \mathrm{s})$ & $\mathrm{N}_{2}$ & $\mathrm{O}_{2}$ & $\mathrm{Ar}$ & $\mathrm{CO}_{2}$ & $\mathrm{H}_{2} \mathrm{O}$ & $\mathrm{CO}$ & $\mathrm{H}_{2}$ & $\mathrm{CH}_{4}$ & $\mathrm{H}_{2} \mathrm{~S}$ \\
\hline 1 & 1,0 & 25,0 & 33,9 & \multicolumn{9}{|c|}{ Douglas Premium Coal } \\
\hline 2 & 56,0 & 80,0 & 23,7 & 2,5 & 0,0 & 1,5 & 96,0 & 0,0 & 0,0 & 0,0 & 0,0 & 0,0 \\
\hline 3 & 44,0 & 900,3 & 128,2 & 1,1 & 0,0 & 1,3 & 6,4 & 4,6 & 0,0 & 0,0 & 0,0 & 0,0 \\
\hline 4 & 1,0 & 15,0 & 117,8 & 77,3 & 20,7 & 0,9 & 0,0 & 1,0 & 0,0 & 0,0 & 0,0 & 0,0 \\
\hline 5 & 48,0 & 22,0 & 28,8 & 1,1 & 95,0 & 3,9 & 0,0 & 0,0 & 0,0 & 0,0 & 0,0 & 0,0 \\
\hline 6 & 1,2 & 22,0 & 88,3 & 99,9 & 0,0 & 0,1 & 0,0 & 0,0 & 0,0 & 0,0 & 0,0 & 0,0 \\
\hline 7 & 44,0 & 309,9 & 62,6 & 1,1 & 0,0 & 1,3 & 7,4 & 4,5 & 62,5 & 22,9 & 0,1 & 0,2 \\
\hline 8 & 18,2 & 399,8 & 67,4 & 1,1 & 0,0 & 1,3 & 7,4 & 4,7 & 62,5 & 22,9 & 0,1 & 0,0 \\
\hline 9 & 17,5 & 1175,0 & 107,3 & 3,4 & 0,0 & 1,3 & 68,1 & 27,2 & 0,0 & 0,0 & 0,0 & 0,0 \\
\hline 10 & 150,0 & 25,0 & 78,0 & 2,7 & 0,0 & 1,3 & 96,0 & 0,0 & 0,0 & 0,0 & 0,0 & 0,0 \\
\hline 11 & 1,0 & 15,0 & 179,0 & 77,3 & 20,7 & 0,9 & 0,0 & 1,0 & 0,0 & 0,0 & 0,0 & 0,0 \\
\hline 12 & 18,2 & 442,6 & 704,4 & 77,3 & 20,7 & 0,9 & 0,0 & 1,0 & 0,0 & 0,0 & 0,0 & 0,0 \\
\hline 13 & 17,5 & 1181,0 & 664,5 & 96,1 & 0,1 & 1,2 & 1,0 & 1,6 & 0,0 & 0,0 & 0,0 & 0,0 \\
\hline 14 & 1,1 & 500,5 & 690,5 & 95,9 & 0,2 & 1,2 & 1,1 & 1,7 & 0,0 & 0,0 & 0,0 & 0,0 \\
\hline 15 & 1,0 & 115,8 & 133,6 & 95,9 & 0,2 & 1,2 & 1,1 & 1,7 & 0,0 & 0,0 & 0,0 & 0,0 \\
\hline 16 & 1,0 & 3,0 & 556,8 & 95,9 & 0,2 & 1,2 & 1,1 & 1,7 & 0,0 & 0,0 & 0,0 & 0,0 \\
\hline 17 & 36,0 & 565,0 & 148,6 & 0,0 & 0,0 & 0,0 & 0,0 & 100,0 & 0,0 & 0,0 & 0,0 & 0,0 \\
\hline 18 & 144,0 & 565,0 & 130,7 & 0,0 & 0,0 & 0,0 & 0,0 & 100,0 & 0,0 & 0,0 & 0,0 & 0,0 \\
\hline 19 & 51,8 & 300,0 & 4,8 & 0,0 & 0,0 & 0,0 & 0,0 & 100,0 & 0,0 & 0,0 & 0,0 & 0,0 \\
\hline 20 & 148,6 & 450,0 & 60,9 & 0,0 & 0,0 & 0,0 & 0,0 & 100,0 & 0,0 & 0,0 & 0,0 & 0,0 \\
\hline 21 & 0,048 & 32,2 & 146,6 & 0,0 & 0,0 & 0,0 & 0,0 & 100,0 & 0,0 & 0,0 & 0,0 & 0,0 \\
\hline 22 & 4,0 & 143,6 & 7,7 & 0,0 & 0,0 & 0,0 & 0,0 & 100,0 & 0,0 & 0,0 & 0,0 & 0,0 \\
\hline
\end{tabular}


GSC with Extra Firing IGCC

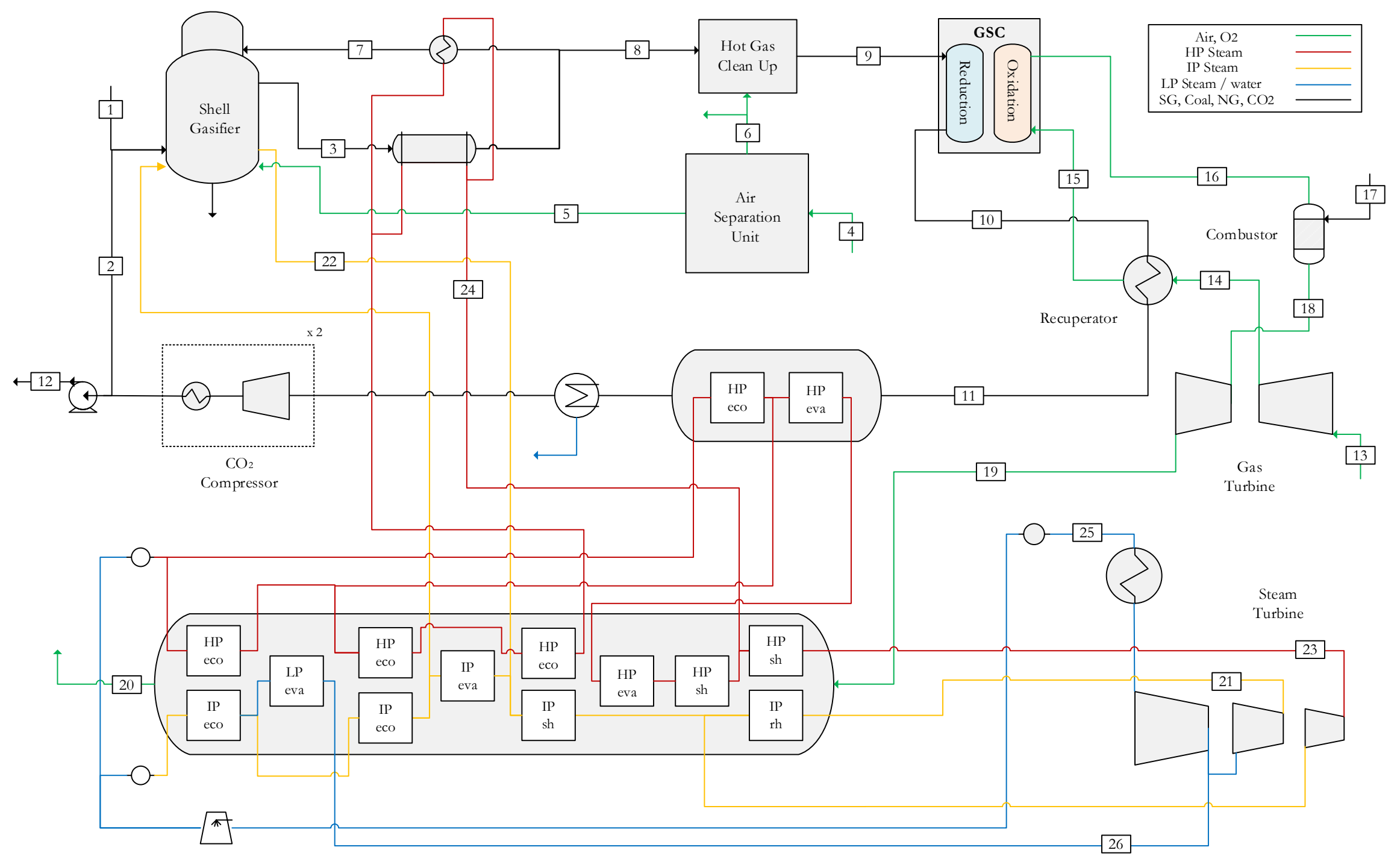

Figure 144 Detailed schematic of the GSC with Extra Firing IGCC power plant 
Table 94 Stream summary of the GSC with Extra Firing IGCC power plant

\begin{tabular}{|c|c|c|c|c|c|c|c|c|c|c|c|c|}
\hline \multicolumn{4}{|c|}{ Property } & \multicolumn{9}{|c|}{ Composition (\% mol) } \\
\hline Stream $n^{\circ}$ & $\mathrm{P}$ (bar) & $\mathrm{T}\left({ }^{\circ} \mathrm{C}\right)$ & $\mathrm{m}(\mathrm{kg} / \mathrm{s})$ & $\mathrm{N}_{2}$ & $\mathrm{O}_{2}$ & $\mathrm{Ar}$ & $\mathrm{CO}_{2}$ & $\mathrm{H}_{2} \mathrm{O}$ & $\mathrm{CO}$ & $\mathrm{H}_{2}$ & $\mathrm{CH}_{4}$ & $\mathrm{H}_{2} \mathrm{~S}$ \\
\hline 1 & 1,0 & 25,0 & 33,9 & \multicolumn{9}{|c|}{ Douglas Premium Coal } \\
\hline 2 & 56,0 & 80,0 & 26,7 & 2,2 & 0,2 & 1,6 & 96,0 & 0,0 & 0,0 & 0,0 & 0,0 & 0,0 \\
\hline 3 & 44,0 & 899,6 & 128,8 & 1,1 & 0,0 & 1,2 & 6,4 & 4,6 & 63,1 & 23,1 & 0,1 & 0,2 \\
\hline 4 & 1,0 & 15,0 & 117,9 & 77,3 & 20,7 & 0,9 & 0,0 & 1,0 & 0,0 & 0,0 & 0,0 & 0,0 \\
\hline 5 & 48,0 & 22,0 & 28,8 & 1,2 & 95,0 & 3,8 & 0,0 & 0,0 & 0,0 & 0,0 & 0,0 & 0,0 \\
\hline 6 & 1,2 & 22,0 & 88,2 & 99,9 & 0,0 & 0,1 & 0,0 & 0,0 & 0,0 & 0,0 & 0,0 & 0,0 \\
\hline 7 & 44,0 & 309,9 & 63,1 & 1,2 & 0,0 & 1,2 & 7,4 & 4,6 & 62,4 & 22,9 & 0,1 & 0,2 \\
\hline 8 & 42,2 & 394,5 & 68,3 & 1,2 & 0,0 & 1,2 & 7,4 & 4,6 & 62,4 & 22,9 & 0,1 & 0,2 \\
\hline 9 & 18,0 & 394,3 & 67,4 & 1,2 & 0,0 & 1,2 & 7,4 & 4,6 & 62,6 & 22,9 & 0,1 & 0,0 \\
\hline 10 & 17,2 & 1129,0 & 107,6 & 1,9 & 0,2 & 1,2 & 69,2 & 27,4 & 0,0 & 0,0 & 0,0 & 0,0 \\
\hline 11 & 17,0 & 436,6 & 107,6 & 1,9 & 0,2 & 1,2 & 69,2 & 27,4 & 0,0 & 0,0 & 0,0 & 0,0 \\
\hline 12 & 150,0 & 25,0 & 80,1 & 2,2 & 0,2 & 1,6 & 96,0 & 0,0 & 0,0 & 0,0 & 0,0 & 0,0 \\
\hline 13 & 1,0 & 15,0 & 1020,0 & 77,3 & 20,7 & 0,9 & 0,0 & 1,0 & 0,0 & 0,0 & 0,0 & 0,0 \\
\hline 14 & 18,2 & 426,6 & 855,6 & 77,3 & 20,7 & 0,9 & 0,0 & 1,0 & 0,0 & 0,0 & 0,0 & 0,0 \\
\hline 15 & 18,0 & 534,9 & 855,6 & 77,3 & 20,7 & 0,9 & 0,0 & 1,0 & 0,0 & 0,0 & 0,0 & 0,0 \\
\hline 16 & 17,2 & 1155,0 & 815,3 & 80,7 & 17,2 & 1,0 & 0,1 & 1,1 & 0,0 & 0,0 & 0,0 & 0,0 \\
\hline 17 & 70,0 & 200,0 & 6,9 & \multicolumn{9}{|c|}{ Natural Gas } \\
\hline 18 & 17,0 & 1440,0 & 822,3 & 79,5 & 14,2 & 1,0 & 1,6 & 3,8 & 0,0 & 0,0 & 0,0 & 0,0 \\
\hline 19 & 1,0 & 594,6 & 979,0 & 79,2 & 15,2 & 0,9 & 1,3 & 3,3 & 0,0 & 0,0 & 0,0 & 0,0 \\
\hline 20 & 1,0 & 110,0 & 979,0 & 79,2 & 15,2 & 0,9 & 1,3 & 3,3 & 0,0 & 0,0 & 0,0 & 0,0 \\
\hline 21 & 36,0 & 565,0 & 171,8 & 0,0 & 0,0 & 0,0 & 0,0 & 100,0 & 0,0 & 0,0 & 0,0 & 0,0 \\
\hline 22 & 51,8 & 300 & 4,9 & 0,0 & 0,0 & 0,0 & 0,0 & 100,0 & 0,0 & 0,0 & 0,0 & 0,0 \\
\hline 23 & 144,0 & 565,0 & 149,2 & 0,0 & 0,0 & 0,0 & 0,0 & 100,0 & 0,0 & 0,0 & 0,0 & 0,0 \\
\hline 24 & 151,5 & 450,0 & 60,8 & 0,0 & 0,0 & 0,0 & 0,0 & 100,0 & 0,0 & 0,0 & 0,0 & 0,0 \\
\hline 25 & 0,048 & 32,2 & 183,5 & 0,0 & 0,0 & 0,0 & 0,0 & 100,0 & 0,0 & 0,0 & 0,0 & 0,0 \\
\hline 26 & 4,0 & 143,6 & 23,7 & 0,0 & 0,0 & 0,0 & 0,0 & 100,0 & 0,0 & 0,0 & 0,0 & 0,0 \\
\hline
\end{tabular}


Appendix

Integrated Gasification GSC-HAT
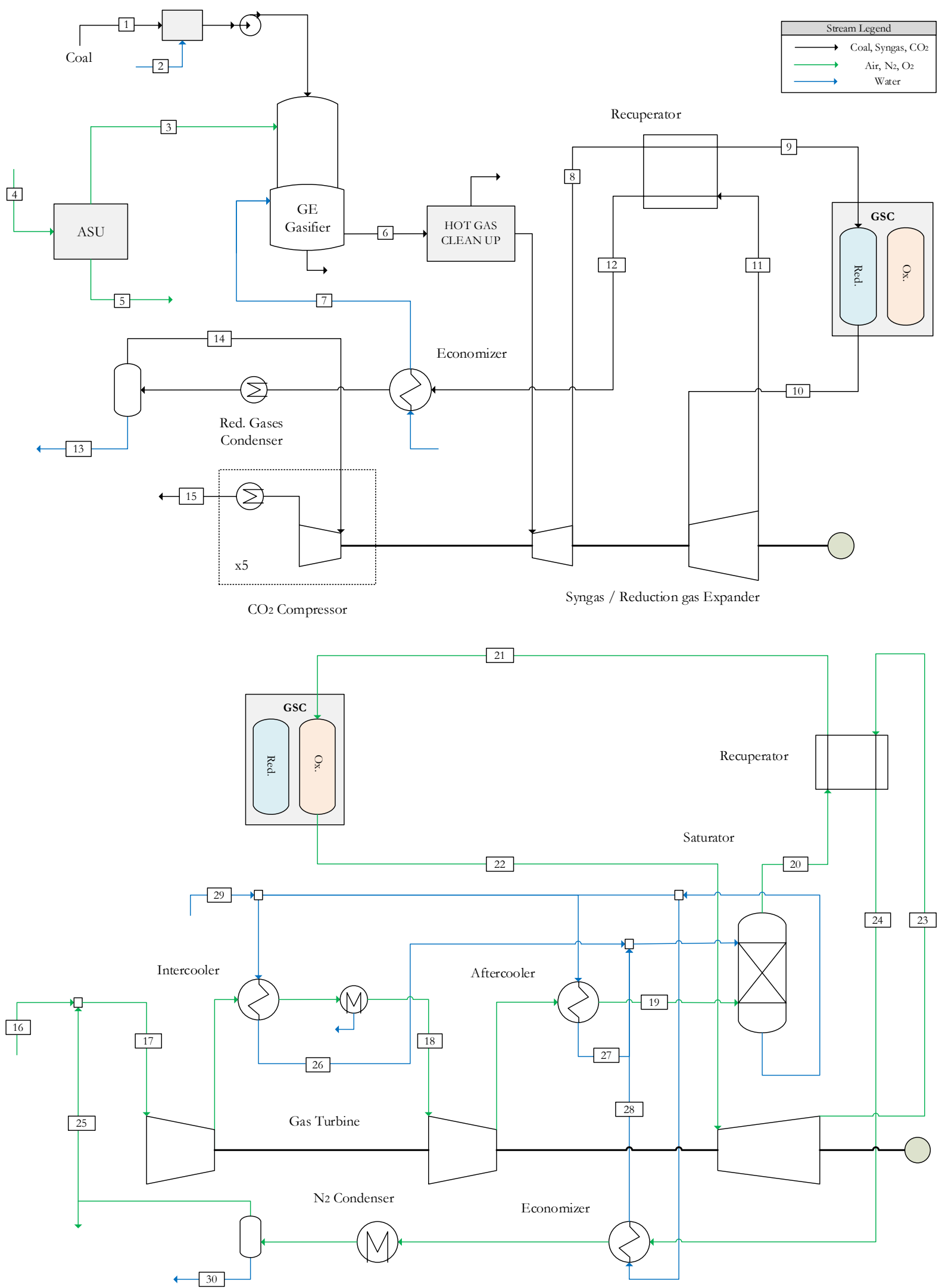

Figure 145 Detailed schematic of the Integrated Gasification GSC-HAT power plant. Reduction section (above) and Oxidation section (below) 
Table 95 Stream summary of the Integrated Gasification GSC-HAT power plant

\begin{tabular}{|c|c|c|c|c|c|c|c|c|c|c|c|c|}
\hline \multicolumn{4}{|c|}{ Property } & \multicolumn{9}{|c|}{ Composition (\%mol) } \\
\hline Steam & $\mathrm{m}(\mathrm{kg} / \mathrm{s})$ & $\mathrm{P}$ (bar) & $\mathrm{T}\left({ }^{\circ} \mathrm{C}\right)$ & $\mathrm{N}_{2}$ & $\mathrm{O}_{2}$ & $\mathrm{Ar}$ & $\mathrm{CO}$ & $\mathrm{CO}_{2}$ & $\mathrm{CH}_{4}$ & $\mathrm{H}_{2}$ & $\mathrm{H}_{2} \mathrm{O}$ & $\mathrm{H}_{2} \mathrm{~S}$ \\
\hline 1 & 33,9 & 1,0 & 25,0 & \multicolumn{9}{|c|}{ South African Douglas Premium Coal } \\
\hline 2 & 18,3 & 1,0 & 60,0 & 0,0 & 0,0 & 0,0 & 0,0 & 0,0 & 0,0 & 0,0 & 100,0 & 0,0 \\
\hline 3 & 30,0 & 82,0 & 23,1 & 0,0 & 98,0 & 2,0 & 0,0 & 0,0 & 0,0 & 0,0 & 0,0 & 0,0 \\
\hline 4 & 128,0 & 1,0 & 15,0 & 77,3 & 20,7 & 0,9 & 0,0 & 0,0 & 0,0 & 0,0 & 0,0 & 0,0 \\
\hline 5 & 97,2 & 1,2 & 23,1 & 99,2 & 0,2 & 0,7 & 0,0 & 0,0 & 0,0 & 0,0 & 0,0 & 0,0 \\
\hline 6 & 128,1 & 80,0 & 400,0 & 0,3 & 0,0 & 0,3 & 20,3 & 8,2 & 0,1 & 16,5 & 54,2 & 0,1 \\
\hline 7 & 50,9 & 82,0 & 177,8 & 0,0 & 0,0 & 0,0 & 0,0 & 0,0 & 0,0 & 0,0 & 100,0 & 0,0 \\
\hline 8 & 127,9 & 9,7 & 155,4 & 0,3 & 0,0 & 0,3 & 20,3 & 8,3 & 0,1 & 16,5 & 54,3 & 0,0 \\
\hline 9 & 127,9 & 9,6 & 757,4 & 0,3 & 0,0 & 0,3 & 20,3 & 8,3 & 0,1 & 16,5 & 54,3 & 0,0 \\
\hline 10 & 166,5 & 8,9 & 1167,0 & 0,9 & 0,0 & 0,3 & 0,0 & 28,4 & 0,0 & 0,0 & 70,4 & 0,0 \\
\hline 11 & 166,5 & 1,1 & 777,4 & 0,9 & 0,0 & 0,3 & 0,0 & 28,4 & 0,0 & 0,0 & 70,4 & 0,0 \\
\hline 12 & 166,5 & 1,0 & 249,4 & 0,9 & 0,0 & 0,3 & 0,0 & 28,4 & 0,0 & 0,0 & 70,4 & 0,0 \\
\hline 13 & 81,7 & 1,0 & 30,0 & 0,0 & 0,0 & 0,0 & 0,0 & 0,0 & 0,0 & 0,0 & 100,0 & 0,0 \\
\hline 14 & 84,9 & 1,0 & 30,0 & 2,9 & 0,0 & 1,0 & 0,0 & 93,0 & 0,0 & 0,0 & 3,1 & 0,0 \\
\hline 15 & 83,7 & 150,0 & 30,0 & 3,0 & 0,0 & 1,0 & 0,0 & 96,0 & 0,0 & 0,0 & 0,0 & 0,0 \\
\hline 16 & 168,9 & 1,0 & 15,0 & 77,3 & 20,7 & 0,9 & 0,0 & 0,0 & 0,0 & 0,0 & 0,0 & 0,0 \\
\hline 17 & 701,6 & 1,0 & 26,6 & 90,3 & 5,0 & 1,1 & 0,0 & 0,3 & 0,0 & 0,0 & 3,4 & 0,0 \\
\hline 18 & 692,4 & 3,5 & 30,0 & 92,2 & 5,1 & 1,1 & 0,0 & 0,3 & 0,0 & 0,0 & 1,4 & 0,0 \\
\hline 19 & 692,4 & 9,9 & 73,5 & 92,2 & 5,1 & 1,1 & 0,0 & 0,3 & 0,0 & 0,0 & 1,4 & 0,0 \\
\hline 20 & 753,6 & 9,7 & 105,6 & 80,9 & 4,5 & 1,0 & 0,0 & 0,2 & 0,0 & 0,0 & 13,4 & 0,0 \\
\hline 21 & 738,4 & 9,6 & 606,9 & 80,9 & 4,5 & 1,0 & 0,0 & 0,2 & 0,0 & 0,0 & 13,4 & 0,0 \\
\hline 22 & 699,8 & 8,9 & 1173,0 & 84,5 & 0,0 & 1,0 & 0,0 & 0,3 & 0,0 & 0,0 & 14,1 & 0,0 \\
\hline 23 & 715,0 & 1,1 & 643,8 & 84,4 & 0,1 & 1,0 & 0,0 & 0,3 & 0,0 & 0,0 & 14,1 & 0,0 \\
\hline 24 & 715,0 & 1,0 & 125,6 & 84,4 & 0,1 & 1,0 & 0,0 & 0,3 & 0,0 & 0,0 & 14,1 & 0,0 \\
\hline 25 & 532,7 & 1,0 & 30,0 & 94,2 & 0,2 & 1,1 & 0,0 & 0,3 & 0,0 & 0,0 & 4,2 & 0,0 \\
\hline 26 & 192,9 & 12,9 & 136,6 & 0,0 & 0,0 & 0,0 & 0,0 & 0,0 & 0,0 & 0,0 & 100,0 & 0,0 \\
\hline 27 & 190,4 & 12,9 & 143,5 & 0,0 & 0,0 & 0,0 & 0,0 & 0,0 & 0,0 & 0,0 & 100,0 & 0,0 \\
\hline 28 & 241,1 & 12,9 & 103,5 & 0,0 & 0,0 & 0,0 & 0,0 & 0,0 & 0,0 & 0,0 & 100,0 & 0,0 \\
\hline 29 & 61,3 & 12,9 & 25,0 & 0,0 & 0,0 & 0,0 & 0,0 & 0,0 & 0,0 & 0,0 & 100,0 & 0,0 \\
\hline 30 & 50,0 & 1,0 & 30,0 & 0,0 & 0,0 & 0,0 & 0,0 & 0,0 & 0,0 & 0,0 & 100,0 & 0,0 \\
\hline
\end{tabular}


Adv. GSC-MAWGS IGCC with Shell Gasifier

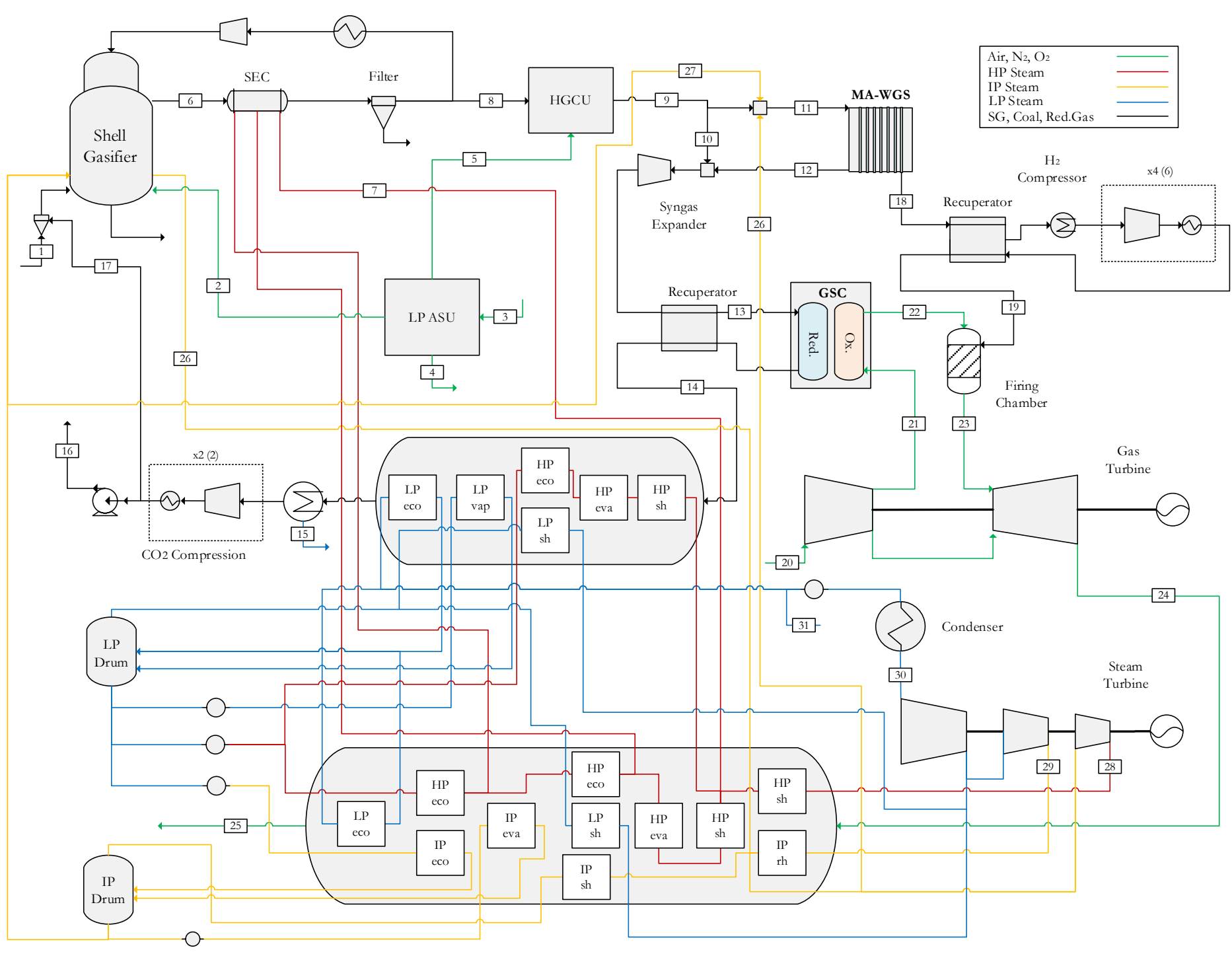

Figure 146 Detailed schematic of the GSC-MAWGS IGCC power plant with Shell gasification 
Table 96 Stream summary for the GSC-MAWGS IGCC power plant with Shell gasification

\begin{tabular}{|c|c|c|c|c|c|c|c|c|c|c|c|c|}
\hline \multicolumn{4}{|c|}{ Property } & \multicolumn{9}{|c|}{ Composition $(\% \mathrm{~mol})$} \\
\hline Stream $n^{\circ}$ & $\mathrm{P}$ (bar) & $\mathrm{T}\left({ }^{\circ} \mathrm{C}\right)$ & $\mathrm{m}(\mathrm{kg} / \mathrm{s})$ & $\mathrm{N}_{2}$ & $\mathrm{O}_{2}$ & $\mathrm{Ar}$ & $\mathrm{CO}_{2}$ & $\mathrm{H}_{2} \mathrm{O}$ & $\mathrm{CO}$ & $\mathrm{H}_{2}$ & $\mathrm{CH}_{4}$ & $\mathrm{H}_{2} \mathrm{~S}$ \\
\hline 1 & 1,0 & 25,0 & 59,1 & \multicolumn{9}{|c|}{ Douglas Premium Coal } \\
\hline 2 & 48,0 & 22,1 & 50,1 & 1,1 & 95,0 & 3,9 & 0,0 & 0,0 & 0,0 & 0,0 & 0,0 & 0,0 \\
\hline 3 & 1,0 & 15,0 & 205,1 & 77,3 & 20,7 & 0,9 & 0,0 & 1,0 & 0,0 & 0,0 & 0,0 & 0,0 \\
\hline 4 & 1,2 & 22,1 & 135,4 & 99,9 & 0,0 & 0,1 & 0,0 & 0,0 & 0,0 & 0,0 & 0,0 & 0,0 \\
\hline 5 & 1,2 & 22,1 & 18,2 & 99,9 & 0,0 & 0,1 & 0,0 & 0,0 & 0,0 & 0,0 & 0,0 & 0,0 \\
\hline 6 & 44,0 & 900,0 & 224,0 & 1,1 & 0,0 & 1,3 & 6,4 & 4,6 & 63,1 & 23,1 & 0,1 & 0,2 \\
\hline 7 & 154,1 & 450,0 & 119,9 & 0,0 & 0,0 & 0,0 & 0,0 & 100,0 & 0,0 & 0,0 & 0,0 & 0,0 \\
\hline 8 & 42,0 & 388,5 & 118,9 & 1,1 & 0,0 & 1,3 & 7,3 & 4,5 & 62,4 & 22,9 & 0,1 & 0,2 \\
\hline 9 & 39,9 & 400,0 & 117,4 & 1,1 & 0,0 & 1,3 & 7,3 & 4,7 & 62,4 & 22,9 & 0,1 & 0,0 \\
\hline 10 & 39,9 & 400,0 & 48,1 & 1,1 & 0,0 & 1,3 & 7,3 & 4,7 & 62,4 & 22,9 & 0,1 & 0,0 \\
\hline 11 & 39,9 & 323,0 & 131,5 & 0,5 & 0,0 & 0,6 & 3,4 & 55,5 & 29,2 & 10,7 & 0,1 & 0,0 \\
\hline 12 & 37,9 & 599,9 & 127,2 & 0,8 & 0,0 & 0,9 & 45,6 & 42,3 & 3,1 & 7,1 & 0,1 & 0,0 \\
\hline 13 & 23,1 & 1102,0 & 175,2 & 0,9 & 0,0 & 1,0 & 1,0 & 33,1 & 30,1 & 22,5 & 12,3 & 0,0 \\
\hline 14 & 22,4 & 592,8 & 212,2 & 1,6 & 0,1 & 1,0 & 55,1 & 42,1 & 0,0 & 0,0 & 0,0 & 0,0 \\
\hline 15 & 22,1 & 25,0 & 50,2 & 0,0 & 0,0 & 0,0 & 1,0 & 99,0 & 0,0 & 0,0 & 0,0 & 0,0 \\
\hline 16 & 150,0 & 25,0 & 140,8 & 2,7 & 0,2 & 1,8 & 95,3 & 0,0 & 0,0 & 0,0 & 0,0 & 0,0 \\
\hline 17 & 88,0 & 80,0 & 41,2 & 2,7 & 0,2 & 1,8 & 95,3 & 0,0 & 0,0 & 0,0 & 0,0 & 0,0 \\
\hline 18 & 2,6 & 598,6 & 4,3 & 0,0 & 0,0 & 0,0 & 0,0 & 0,0 & 0,0 & 100,0 & 0,0 & 0,0 \\
\hline 19 & 35,0 & 578,6 & 4,3 & 0,0 & 0,0 & 0,0 & 0,0 & 0,0 & 0,0 & 100,0 & 0,0 & 0,0 \\
\hline 20 & 1,0 & 9,0 & 947,6 & 77,3 & 20,7 & 0,9 & 0,0 & 1,0 & 0,0 & 0,0 & 0,0 & 0,0 \\
\hline 21 & 23,1 & 450,3 & 765,4 & 77,3 & 20,7 & 0,9 & 0,0 & 1,0 & 0,0 & 0,0 & 0,0 & 0,0 \\
\hline 22 & 22,6 & 1130,0 & 728,4 & 80,7 & 17,2 & 1,0 & 0,1 & 1,1 & 0,0 & 0,0 & 0,0 & 0,0 \\
\hline 23 & 21,9 & 1648,2 & 732,8 & 77,4 & 12,4 & 0,9 & 0,1 & 9,1 & 0,0 & 0,0 & 0,0 & 0,0 \\
\hline 24 & 1,0 & 630,7 & 915,1 & 77,4 & 14,0 & 0,9 & 0,1 & 7,6 & 0,0 & 0,0 & 0,0 & 0,0 \\
\hline 25 & 1,0 & 126,7 & 915,1 & 77,4 & 14,0 & 0,9 & 0,1 & 7,6 & 0,0 & 0,0 & 0,0 & 0,0 \\
\hline 26 & 41,9 & 405,1 & 53,6 & 0,0 & 0,0 & 0,0 & 0,0 & 100,0 & 0,0 & 0,0 & 0,0 & 0,0 \\
\hline 27 & 43,0 & 255,7 & 8,6 & 0,0 & 0,0 & 0,0 & 0,0 & 100,0 & 0,0 & 0,0 & 0,0 & 0,0 \\
\hline 28 & 141,8 & 600,0 & 227,0 & 0,0 & 0,0 & 0,0 & 0,0 & 100,0 & 0,0 & 0,0 & 0,0 & 0,0 \\
\hline 29 & 39,6 & 600,0 & 182,1 & 0,0 & 0,0 & 0,0 & 0,0 & 100,0 & 0,0 & 0,0 & 0,0 & 0,0 \\
\hline 30 & 0,04 & 29,0 & 197,0 & 0,0 & 0,0 & 0,0 & 0,0 & 100,0 & 0,0 & 0,0 & 0,0 & 0,0 \\
\hline
\end{tabular}


Adv. GSC-MAWGS IGCC with Pre-gasifier and HTW Gasifier

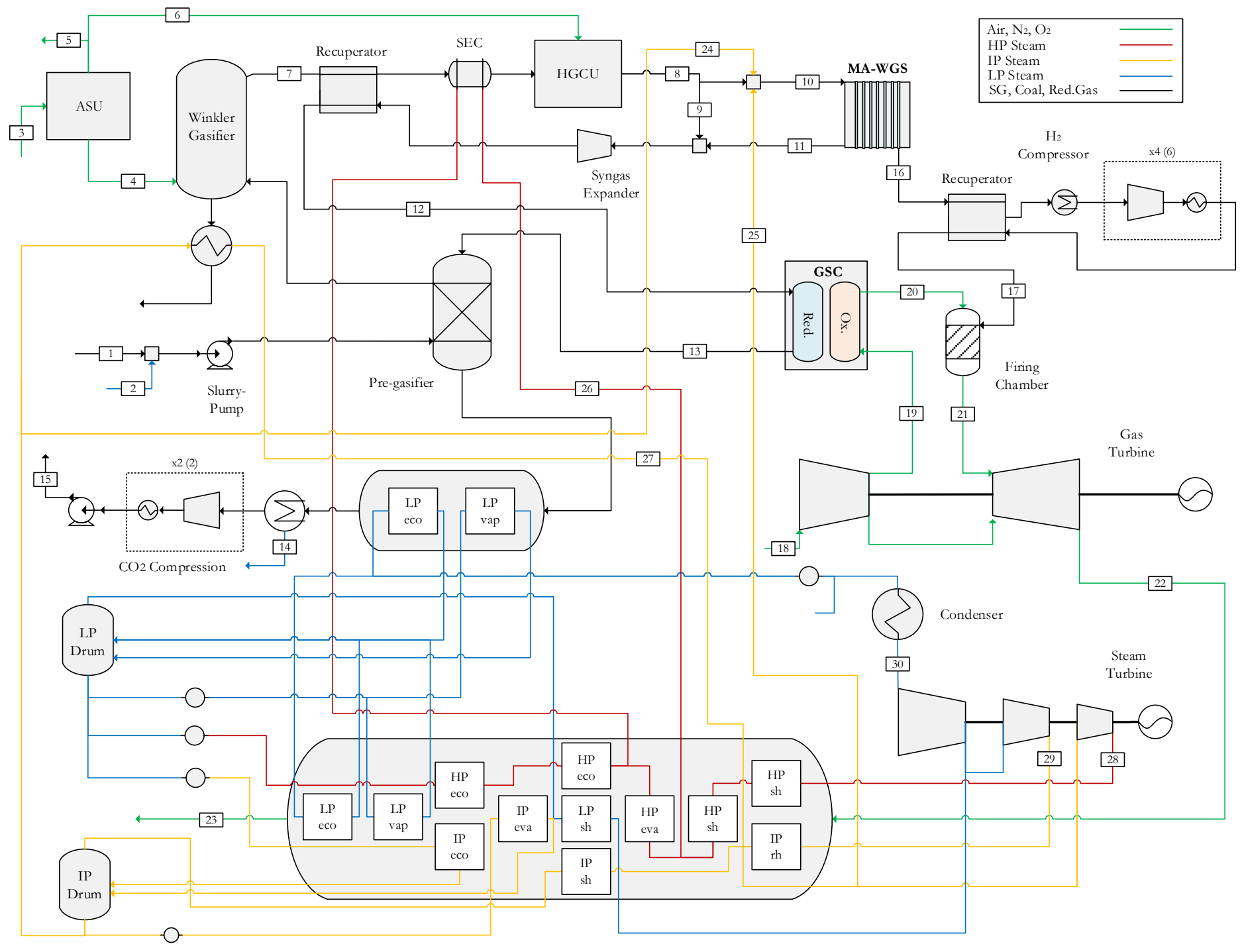

Figure 147 Detailed schematic of the GSC-MAWGS IGCC power plant with Pregasifier and HTW gasification 
Table 97 Stream summary of the GSC-MAWGS IGCC power plant with Pre-gasifier and HTW gasification

\begin{tabular}{|c|c|c|c|c|c|c|c|c|c|c|c|c|}
\hline \multicolumn{4}{|c|}{ Property } & \multicolumn{9}{|c|}{ Composition ( $\% \mathrm{~mol})$} \\
\hline Stream $n^{\circ}$ & $\mathrm{P}$ (bar) & $\mathrm{T}\left({ }^{\circ} \mathrm{C}\right)$ & $\mathrm{m}(\mathrm{kg} / \mathrm{s})$ & $\mathrm{N}_{2}$ & $\mathrm{O}_{2}$ & Ar & $\mathrm{CO}_{2}$ & $\mathrm{H}_{2} \mathrm{O}$ & $\mathrm{CO}$ & $\mathrm{H}_{2}$ & $\mathrm{CH}_{4}$ & $\mathrm{H}_{2} \mathrm{~S}$ \\
\hline 1 & 1,0 & 25,0 & 48,6 & \multicolumn{9}{|c|}{ Douglas Premium Coal } \\
\hline 2 & 1,0 & 60,0 & 26,2 & 0,0 & 0,0 & 0,0 & 0,0 & 100,0 & 0,0 & 0,0 & 0,0 & 0,0 \\
\hline 3 & 1,0 & 15,0 & 71,0 & 77,3 & 20,7 & 0,9 & 0,0 & 1,0 & 0,0 & 0,0 & 0,0 & 0,0 \\
\hline 4 & 48,0 & 22,1 & 17,3 & 1,1 & 95,0 & 3,9 & 0,0 & 0,0 & 0,0 & 0,0 & 0,0 & 0,0 \\
\hline 5 & 1,2 & 22,1 & 38,2 & 99,9 & 0,0 & 0,1 & 0,0 & 0,0 & 0,0 & 0,0 & 0,0 & 0,0 \\
\hline 6 & 1,2 & 22,1 & 14,9 & 99,9 & 0,0 & 0,1 & 0,0 & 0,0 & 0,0 & 0,0 & 0,0 & 0,0 \\
\hline 7 & 44,0 & 900,0 & 84,5 & 0,7 & 0,0 & 0,5 & 6,9 & 5,4 & 43,0 & 36,0 & 7,3 & 0,2 \\
\hline 8 & 39,9 & 400,0 & 84,3 & 0,7 & 0,0 & 0,5 & 6,9 & 5,6 & 43,0 & 36,0 & 7,3 & 0,0 \\
\hline 9 & 39,9 & 400,0 & 31,1 & 0,7 & 0,0 & 0,5 & 6,9 & 5,6 & 43,0 & 36,0 & 7,3 & 0,0 \\
\hline 10 & 39,9 & 372,0 & 92,9 & 0,4 & 0,0 & 0,3 & 3,9 & 46,4 & 24,4 & 20,4 & 4,2 & 0,0 \\
\hline 11 & 37,9 & 599,8 & 88,8 & 0,7 & 0,0 & 0,4 & 44,4 & 39,1 & 2,6 & 5,8 & 6,9 & 0,0 \\
\hline 12 & 22,9 & 797,0 & 119,9 & 0,7 & 0,0 & 0,4 & 31,1 & 27,2 & 17,0 & 16,5 & 7,0 & 0,0 \\
\hline 13 & 22,4 & 1118,0 & 166,7 & 1,3 & 0,1 & 0,4 & 47,9 & 50,3 & 0,0 & 0,0 & 0,0 & 0,0 \\
\hline 14 & 22,0 & 25,0 & 50,3 & 0,0 & 0,0 & 0,0 & 1,0 & 99,0 & 0,0 & 0,0 & 0,0 & 0,0 \\
\hline 15 & 150,0 & 25,0 & 116,3 & 2,5 & 0,3 & 0,8 & 96,4 & 0,0 & 0,0 & 0,0 & 0,0 & 0,0 \\
\hline 16 & 2,2 & 599,6 & 4,1 & 0,0 & 0,0 & 0,0 & 0,0 & 0,0 & 0,0 & 100,0 & 0,0 & 0,0 \\
\hline 17 & 2,2 & 579,6 & 4,1 & 0,0 & 0,0 & 0,0 & 0,0 & 0,0 & 0,0 & 100,0 & 0,0 & 0,0 \\
\hline 18 & 1,0 & 9,0 & 947,6 & 77,3 & 20,7 & 0,9 & 0,0 & 1,0 & 0,0 & 0,0 & 0,0 & 0,0 \\
\hline 19 & 22,9 & 447,9 & 767,5 & 77,3 & 20,7 & 0,9 & 0,0 & 1,0 & 0,0 & 0,0 & 0,0 & 0,0 \\
\hline 20 & 22,4 & 1153,0 & 720,8 & 81,7 & 16,1 & 1,0 & 0,1 & 1,2 & 0,0 & 0,0 & 0,0 & 0,0 \\
\hline 21 & 21,7 & 1647,8 & 724,9 & 78,5 & 11,6 & 0,9 & 0,1 & 8,9 & 0,0 & 0,0 & 0,0 & 0,0 \\
\hline 22 & 1,0 & 632,2 & 906,1 & 78,3 & 13,3 & 0,9 & 0,1 & 7,4 & 0,0 & 0,0 & 0,0 & 0,0 \\
\hline 23 & 1,0 & 127,7 & 906,1 & 78,3 & 13,3 & 0,9 & 0,1 & 7,4 & 0,0 & 0,0 & 0,0 & 0,0 \\
\hline 24 & 43,0 & 255,7 & 2,3 & 0,0 & 0,0 & 0,0 & 0,0 & 100,0 & 0,0 & 0,0 & 0,0 & 0,0 \\
\hline 25 & 41,9 & 405,1 & 37,4 & 0,0 & 0,0 & 0,0 & 0,0 & 100,0 & 0,0 & 0,0 & 0,0 & 0,0 \\
\hline 26 & 148,0 & 450,0 & 13,1 & 0,0 & 0,0 & 0,0 & 0,0 & 100,0 & 0,0 & 0,0 & 0,0 & 0,0 \\
\hline 27 & 43,0 & 360,0 & 7,1 & 0,0 & 0,0 & 0,0 & 0,0 & 100,0 & 0,0 & 0,0 & 0,0 & 0,0 \\
\hline 28 & 141,8 & 600,0 & 133,9 & 0,0 & 0,0 & 0,0 & 0,0 & 100,0 & 0,0 & 0,0 & 0,0 & 0,0 \\
\hline 29 & 39,6 & 600,0 & 103,5 & 0,0 & 0,0 & 0,0 & 0,0 & 100,0 & 0,0 & 0,0 & 0,0 & 0,0 \\
\hline 30 & 0,0 & 29,0 & 136,0 & 0,0 & 0,0 & 0,0 & 0,0 & 100,0 & 0,0 & 0,0 & 0,0 & 0,0 \\
\hline
\end{tabular}


Adv. GSC-MAWGS IGCC with GE Gasifier

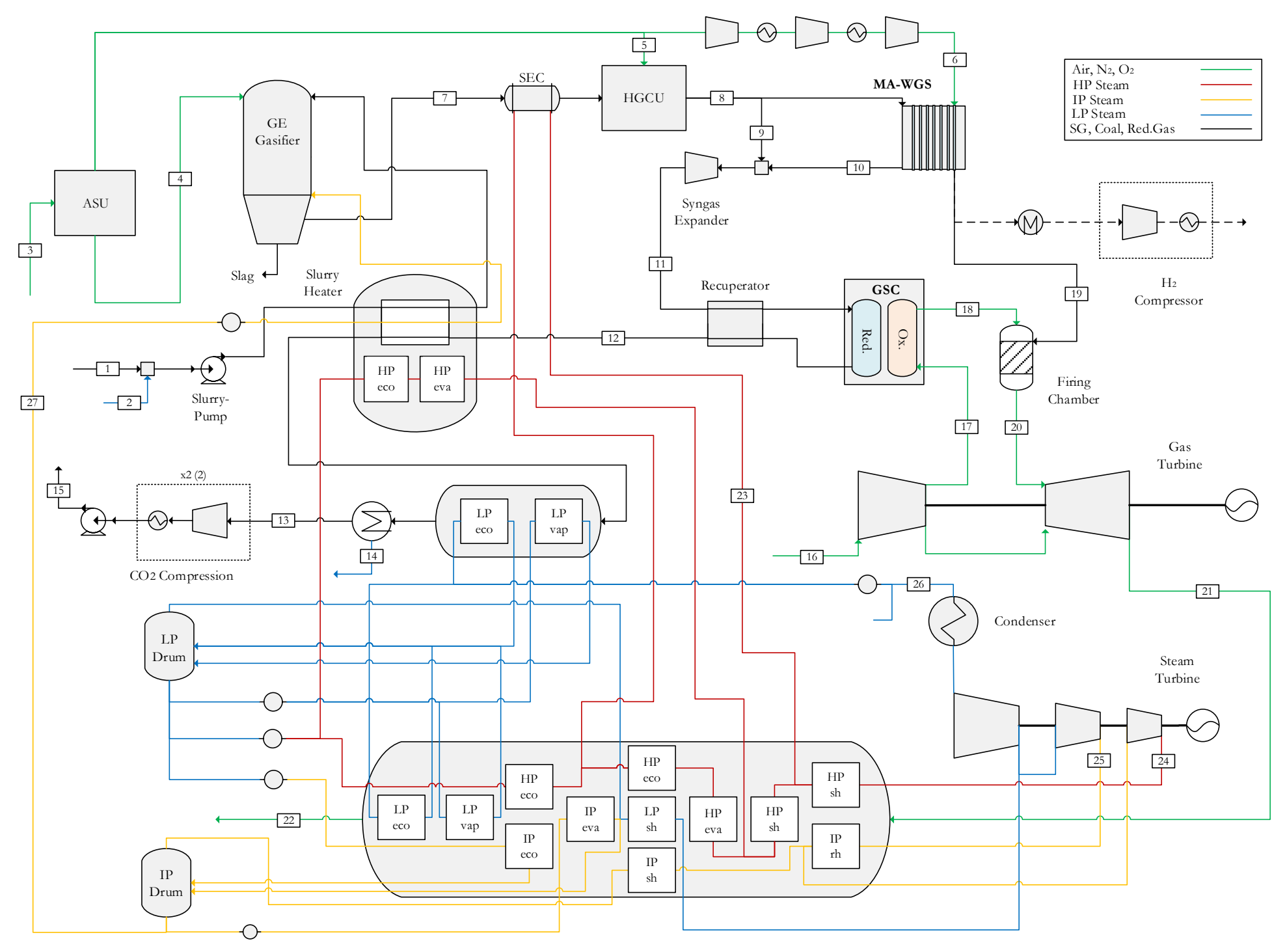

Figure 148 Detailed schematic of the GSC-MAWGS IGCC power plant with GE gasification 
Table 98 Stream summary of the GSC-MAWGS IGCC power plant with GE gasification

\begin{tabular}{|c|c|c|c|c|c|c|c|c|c|c|c|c|}
\hline \multicolumn{4}{|c|}{ Property } & \multicolumn{9}{|c|}{ Composition $(\% \mathrm{~mol})$} \\
\hline Stream $\mathrm{n}^{\circ}$ & $\mathrm{P}$ (bar) & $\mathrm{T}\left({ }^{\circ} \mathrm{C}\right)$ & $\mathrm{m}(\mathrm{kg} / \mathrm{s})$ & $\mathrm{N}_{2}$ & $\mathrm{O}_{2}$ & $\mathrm{Ar}$ & $\mathrm{CO}_{2}$ & $\mathrm{H}_{2} \mathrm{O}$ & $\mathrm{CO}$ & $\mathrm{H}_{2}$ & $\mathrm{CH}_{4}$ & $\mathrm{H}_{2} \mathrm{~S}$ \\
\hline 1 & 1,0 & 25,0 & 62,4 & \multicolumn{9}{|c|}{ Douglas Premium Coal } \\
\hline 2 & 1,0 & 60,0 & 33,6 & 0,0 & 0,0 & 0,0 & 0,0 & 100,0 & 0,0 & 0,0 & 0,0 & 0,0 \\
\hline 3 & 1,0 & 15,0 & 224,6 & 77,3 & 20,7 & 0,9 & 0,0 & 1,0 & 0,0 & 0,0 & 0,0 & 0,0 \\
\hline 4 & 82,0 & 23,2 & 54,8 & 1,1 & 95,0 & 3,9 & 0,0 & 0,0 & 0,0 & 0,0 & 0,0 & 0,0 \\
\hline 5 & 1,2 & 23,2 & 19,3 & 99,9 & 0,0 & 0,1 & 0,0 & 0,0 & 0,0 & 0,0 & 0,0 & 0,0 \\
\hline 6 & 37,0 & 168,8 & 75,5 & 99,9 & 0,0 & 0,1 & 0,0 & 0,0 & 0,0 & 0,0 & 0,0 & 0,0 \\
\hline 7 & 80,0 & 662,7 & 204,8 & 0,5 & 0,0 & 0,6 & 8,7 & 46,1 & 24,3 & 19,5 & 0,1 & 0,1 \\
\hline 8 & 73,2 & 399,1 & 204,6 & 0,5 & 0,0 & 0,6 & 8,7 & 46,2 & 24,3 & 19,5 & 0,1 & 0,0 \\
\hline 9 & 73,2 & 399,1 & 56,3 & 0,5 & 0,0 & 0,6 & 8,7 & 46,2 & 24,3 & 19,5 & 0,1 & 0,0 \\
\hline 10 & 71,2 & 514,5 & 143,5 & 0,7 & 0,0 & 0,9 & 44,6 & 36,3 & 4,0 & 13,3 & 0,1 & 0,0 \\
\hline 11 & 23,9 & 334,9 & 199,7 & 0,7 & 0,0 & 0,8 & 31,7 & 39,8 & 11,3 & 15,5 & 0,1 & 0,0 \\
\hline 12 & 23,2 & 441,5 & 234,8 & 1,1 & 0,1 & 0,8 & 42,8 & 55,1 & 0,0 & 0,0 & 0,0 & 0,0 \\
\hline 13 & 22,5 & 25,0 & 153,8 & 2,5 & 0,2 & 1,9 & 95,2 & 0,2 & 0,0 & 0,0 & 0,0 & 0,0 \\
\hline 14 & 22,5 & 25,0 & 81,0 & 0,0 & 0,0 & 0,0 & 1,0 & 99,0 & 0,0 & 0,0 & 0,0 & 0,0 \\
\hline 15 & 150,0 & 25,0 & 153,7 & 2,5 & 0,2 & 1,9 & 95,4 & 0,0 & 0,0 & 0,0 & 0,0 & 0,0 \\
\hline 16 & 1,0 & 15,0 & 888,9 & 77,3 & 20,7 & 0,9 & 0,0 & 1,0 & 0,0 & 0,0 & 0,0 & 0,0 \\
\hline 17 & 23,7 & 455,8 & 700,8 & 77,3 & 20,7 & 0,9 & 0,0 & 1,0 & 0,0 & 0,0 & 0,0 & 0,0 \\
\hline 18 & 23,4 & 1142,0 & 665,7 & 80,8 & 17,0 & 1,0 & 0,1 & 1,1 & 0,0 & 0,0 & 0,0 & 0,0 \\
\hline 19 & 35,0 & 520,6 & 81,4 & 52,8 & 0,0 & 0,0 & 0,0 & 0,0 & 0,0 & 47,2 & 0,0 & 0,0 \\
\hline 20 & 22,5 & 1648,0 & 746,0 & 79,1 & 10,1 & 0,8 & 0,1 & 9,8 & 0,0 & 0,0 & 0,0 & 0,0 \\
\hline 21 & 1,0 & 626,9 & 934,8 & 78,8 & 12,2 & 0,8 & 0,1 & 8,1 & 0,0 & 0,0 & 0,0 & 0,0 \\
\hline 22 & 1,0 & 153,0 & 934,8 & 78,8 & 12,2 & 0,8 & 0,1 & 8,1 & 0,0 & 0,0 & 0,0 & 0,0 \\
\hline 23 & 155,0 & 450,0 & 77,7 & 0,0 & 0,0 & 0,0 & 0,0 & 100,0 & 0,0 & 0,0 & 0,0 & 0,0 \\
\hline 24 & 141,8 & 600,0 & 178,8 & 0,0 & 0,0 & 0,0 & 0,0 & 100,0 & 0,0 & 0,0 & 0,0 & 0,0 \\
\hline 25 & 39,6 & 600,0 & 178,8 & 0,0 & 0,0 & 0,0 & 0,0 & 100,0 & 0,0 & 0,0 & 0,0 & 0,0 \\
\hline 26 & 0,04 & 29,0 & 200,8 & 0,0 & 0,0 & 0,0 & 0,0 & 100,0 & 0,0 & 0,0 & 0,0 & 0,0 \\
\hline 27 & 43,0 & 254,7 & 63,2 & 0,0 & 0,0 & 0,0 & 0,0 & 100,0 & 0,0 & 0,0 & 0,0 & 0,0 \\
\hline
\end{tabular}


GSOP Power Plants

Oxygen Production Pre-combustion (OPPC) IGCC

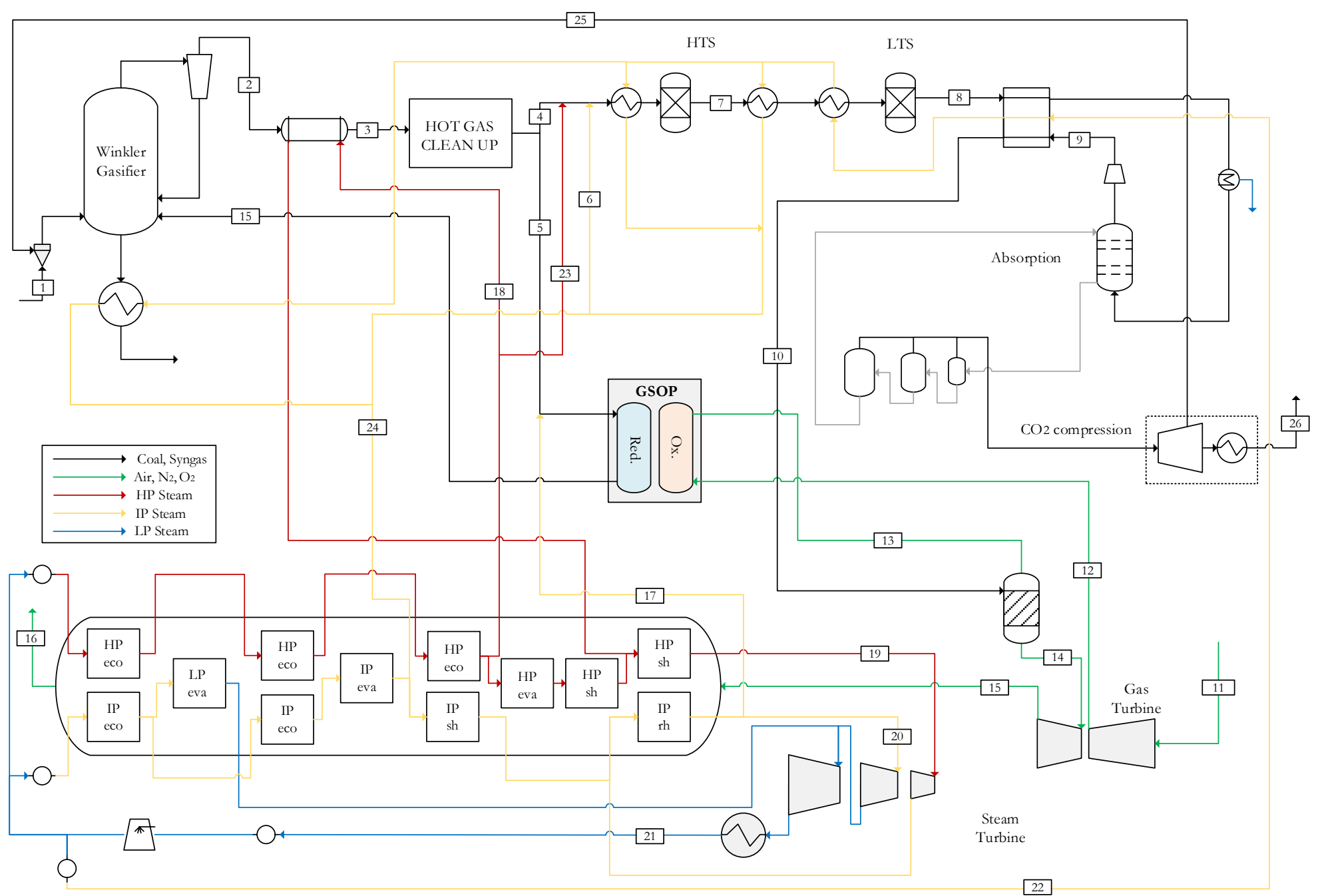

Figure 149 Detailed schematic of the Oxygen Production Pre-combustion (OPPC) IGCC power plant 
Table 99 Stream summary for the Oxygen Production Pre-combustion (OPPC) IGCC power plant

\begin{tabular}{|c|c|c|c|c|c|c|c|c|c|c|c|c|}
\hline \multicolumn{4}{|c|}{ Property } & \multicolumn{9}{|c|}{ Composition ( $\% \mathrm{~mol})$} \\
\hline Stream $n^{\circ}$ & $\mathrm{P}$ (bar) & $\mathrm{T}\left({ }^{\circ} \mathrm{C}\right)$ & $\mathrm{m}(\mathrm{kg} / \mathrm{s})$ & $\mathrm{N}_{2}$ & $\mathrm{O}_{2}$ & Ar & $\mathrm{CO}_{2}$ & $\mathrm{H}_{2} \mathrm{O}$ & $\mathrm{CO}$ & $\mathrm{H}_{2}$ & $\mathrm{CH}_{4}$ & $\mathrm{H}_{2} \mathrm{~S}$ \\
\hline 1 & 1,0 & 25,0 & 33,9 & \multicolumn{9}{|c|}{ Douglas Premium Coal } \\
\hline 2 & 17,5 & 899,3 & 144,5 & 4,6 & 0,0 & 0,0 & 30,6 & 16,1 & 29,7 & 16,7 & 2,2 & 0,1 \\
\hline 3 & 17,0 & 400,0 & 144,5 & 4,6 & 0,0 & 0,0 & 30,6 & 16,1 & 29,7 & 16,7 & 2,2 & 0,1 \\
\hline 4 & 16,1 & 399,9 & 79,89 & 4,6 & 0,0 & 0,0 & 30,6 & 16,1 & 29,8 & 16,6 & 2,2 & 0,0 \\
\hline 5 & 18,2 & 421,2 & 64,6 & 4,6 & 0,0 & 0,0 & 30,7 & 16,1 & 29,7 & 16,6 & 2,2 & 0,0 \\
\hline 6 & 41,6 & 325,0 & 7,1 & 0,0 & 0,0 & 0,0 & 0,0 & 100,0 & 0,0 & 0,0 & 0,0 & 0,0 \\
\hline 7 & 15,6 & 423,6 & 101,5 & 3,3 & 0,0 & 0,0 & 38,9 & 23,2 & 4,1 & 28,9 & 0,2 & 0,0 \\
\hline 8 & 14,9 & 237,6 & 101,5 & 3,3 & 0,0 & 0,0 & 42,4 & 19,7 & 0,6 & 32,4 & 0,2 & 0,0 \\
\hline 9 & 24,5 & 84,3 & 14,5 & 7,9 & 0,0 & 0,1 & 7,9 & 0,1 & 0,1 & 78,7 & 3,8 & 0,0 \\
\hline 10 & 24,0 & 200,0 & 14,5 & 7,9 & 0,0 & 0,1 & 7,9 & 0,1 & 0,1 & 78,7 & 3,8 & 0,0 \\
\hline 11 & 1,0 & 15,0 & 643,5 & 77,3 & 20,7 & 0,9 & 0,0 & 1,0 & 0,0 & 0,0 & 0,0 & 0,0 \\
\hline 12 & 18,2 & 426,6 & 540,3 & 77,3 & 20,7 & 0,9 & 0,0 & 1,0 & 0,0 & 0,0 & 0,0 & 0,0 \\
\hline 13 & 17,5 & 899,8 & 500,3 & 82,2 & 15,0 & 1,0 & 0,4 & 1,4 & 0,0 & 0,0 & 0,0 & 0,0 \\
\hline 14 & 17,1 & 1440,0 & 514,8 & 78,4 & 9,7 & 0,9 & 1,6 & 9,4 & 0,0 & 0,0 & 0,0 & 0,0 \\
\hline 15 & 1,0 & 602,7 & 613,1 & 78,2 & 11,4 & 0,9 & 1,4 & 8,1 & 0,0 & 0,0 & 0,0 & 0,0 \\
\hline 16 & 1,0 & 95,2 & 613,1 & 78,2 & 11,4 & 0,9 & 1,4 & 8,1 & 0,0 & 0,0 & 0,0 & 0,0 \\
\hline 17 & 36,0 & 565,0 & 6,9 & 0,0 & 0,0 & 0,0 & 0,0 & 100,0 & 0,0 & 0,0 & 0,0 & 0,0 \\
\hline 18 & 157,9 & 343,6 & 70,7 & 0,0 & 0,0 & 0,0 & 0,0 & 100,0 & 0,0 & 0,0 & 0,0 & 0,0 \\
\hline 19 & 144,0 & 565,0 & 114,3 & 0,0 & 0,0 & 0,0 & 0,0 & 100,0 & 0,0 & 0,0 & 0,0 & 0,0 \\
\hline 20 & 36,0 & 565,0 & 119,1 & 0,0 & 0,0 & 0,0 & 0,0 & 100,0 & 0,0 & 0,0 & 0,0 & 0,0 \\
\hline 21 & 0,048 & 32,2 & 120,3 & 0,0 & 0,0 & 0,0 & 0,0 & 100,0 & 0,0 & 0,0 & 0,0 & 0,0 \\
\hline 22 & 42,4 & 60,4 & 38,9 & 0,0 & 0,0 & 0,0 & 0,0 & 100,0 & 0,0 & 0,0 & 0,0 & 0,0 \\
\hline 23 & 157,9 & 343,6 & 14,6 & 0,0 & 0,0 & 0,0 & 0,0 & 100,0 & 0,0 & 0,0 & 0,0 & 0,0 \\
\hline 24 & 41,6 & 330,1 & 11,6 & 0,0 & 0,0 & 0,0 & 0,0 & 100,0 & 0,0 & 0,0 & 0,0 & 0,0 \\
\hline 25 & 42,0 & 50,0 & 5,1 & 0,1 & 0,0 & 0,0 & 99,9 & 0,0 & 0,0 & 0,0 & 0,0 & 0,0 \\
\hline 26 & 150,0 & 25,0 & 67,0 & 0,1 & 0,0 & 0,0 & 99,9 & 0,0 & 0,0 & 0,0 & 0,0 & 0,0 \\
\hline
\end{tabular}


Composite: GSOP-GSC IGCC

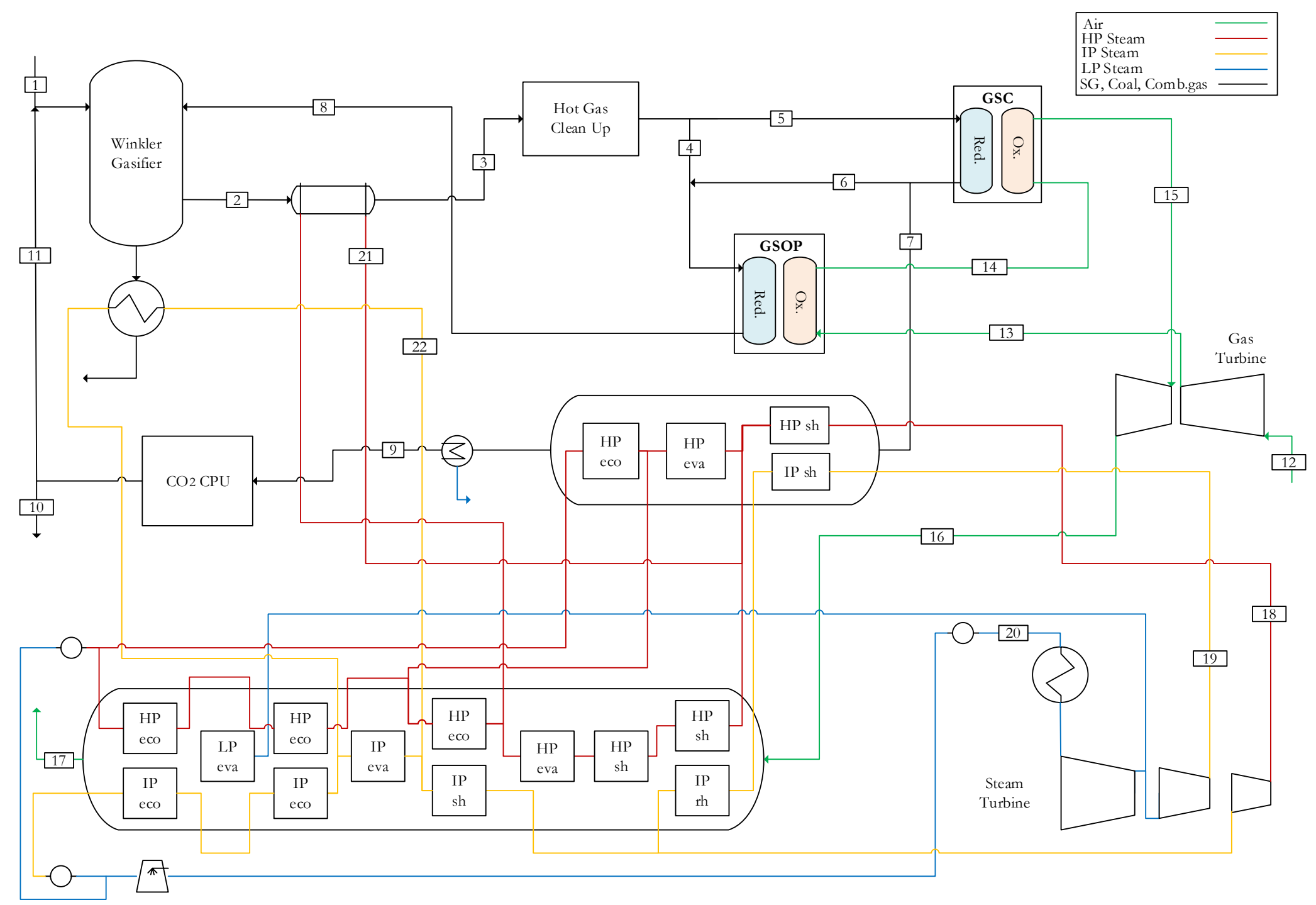

Figure 150 Detailed schematic of the Composite: GSOP-GSC IGCC power plant 
Table 100 Stream summary for the Composite: GSOP-GSC IGCC power plant

\begin{tabular}{|c|c|c|c|c|c|c|c|c|c|c|c|c|}
\hline \multicolumn{4}{|c|}{ Property } & \multicolumn{9}{|c|}{ Composition $(\% \mathrm{~mol})$} \\
\hline Stream $n^{\circ}$ & $\mathrm{P}$ (bar) & $\mathrm{T}\left({ }^{\circ} \mathrm{C}\right)$ & $\mathrm{m}(\mathrm{kg} / \mathrm{s})$ & $\mathrm{N}_{2}$ & $\mathrm{O}_{2}$ & $\mathrm{Ar}$ & $\mathrm{CO}_{2}$ & $\mathrm{H}_{2} \mathrm{O}$ & $\mathrm{CO}$ & $\mathrm{H}_{2}$ & $\mathrm{CH}_{4}$ & $\mathrm{H}_{2} \mathrm{~S}$ \\
\hline 1 & 1,0 & 25,0 & 33,9 & \multicolumn{9}{|c|}{ Douglas Premium Coal } \\
\hline 2 & 15,7 & 900,0 & 131,9 & 6,6 & 0,0 & 0,1 & 30,6 & 10,3 & 36,2 & 13,1 & 2,5 & 0,1 \\
\hline 3 & 15,2 & 393,0 & 131,9 & 6,6 & 0,0 & 0,1 & 30,6 & 10,3 & 36,2 & 13,1 & 2,5 & 0,1 \\
\hline 4 & 18,1 & 443,6 & 59,8 & 6,6 & 0,0 & 0,1 & 30,6 & 10,4 & 36,7 & 13,1 & 2,5 & 0,0 \\
\hline 5 & 18,1 & 443,6 & 42,0 & 6,6 & 0,0 & 0,1 & 30,6 & 10,4 & 36,7 & 13,1 & 2,5 & 0,0 \\
\hline 6 & 17,4 & 1097,0 & 17,4 & 10,6 & 0,8 & 0,1 & 62,8 & 25,7 & 0,0 & 0,0 & 0,0 & 0,0 \\
\hline 7 & 17,4 & 1097,0 & 96,4 & 10,6 & 0,8 & 0,1 & 62,8 & 25,7 & 0,0 & 0,0 & 0,0 & 0,0 \\
\hline 8 & 16,7 & 702,8 & 99,3 & 10,0 & 23,1 & 0,1 & 47,4 & 19,4 & 0,0 & 0,0 & 0,0 & 0,0 \\
\hline 9 & 16,3 & 25,0 & 83,7 & 14,2 & 1,1 & 0,1 & 84,3 & 2,5 & 0,0 & 0,0 & 0,0 & 0,0 \\
\hline 10 & 150,0 & 25,0 & 68,5 & 3,6 & 0,3 & 0,1 & 96,0 & 0,0 & 0,0 & 0,0 & 0,0 & 0,0 \\
\hline 11 & 42,0 & 80,0 & 5,1 & 3,6 & 0,3 & 0,1 & 96,0 & 0,0 & 0,0 & 0,0 & 0,0 & 0,0 \\
\hline 12 & 1,0 & 15,0 & 818,7 & 77,3 & 20,7 & 0,9 & 0,0 & 1,0 & 0,0 & 0,0 & 0,0 & 0,0 \\
\hline 13 & 18,2 & 417,1 & 784,9 & 77,3 & 20,7 & 0,9 & 0,0 & 1,0 & 0,0 & 0,0 & 0,0 & 0,0 \\
\hline 14 & 17,4 & 679,1 & 750,3 & 80,1 & 17,4 & 1,0 & 0,3 & 1,1 & 0,0 & 0,0 & 0,0 & 0,0 \\
\hline 15 & 16,7 & 1149,0 & 721,1 & 82,6 & 14,1 & 1,0 & 0,9 & 1,4 & 0,0 & 0,0 & 0,0 & 0,0 \\
\hline 16 & 1,0 & 490,3 & 748,7 & 82,4 & 14,4 & 1,0 & 0,8 & 1,4 & 0,0 & 0,0 & 0,0 & 0,0 \\
\hline 17 & 1,0 & 114,0 & 748,7 & 82,4 & 14,4 & 1,0 & 0,8 & 1,4 & 0,0 & 0,0 & 0,0 & 0,0 \\
\hline 18 & 144,0 & 565,0 & 122,9 & 0,0 & 0,0 & 0,0 & 0,0 & 100,0 & 0,0 & 0,0 & 0,0 & 0,0 \\
\hline 19 & 36,0 & 565,0 & 139,1 & 0,0 & 0,0 & 0,0 & 0,0 & 100,0 & 0,0 & 0,0 & 0,0 & 0,0 \\
\hline 20 & 0,048 & 32,2 & 143,3 & 0,0 & 0,0 & 0,0 & 0,0 & 100,0 & 0,0 & 0,0 & 0,0 & 0,0 \\
\hline 21 & 144,0 & 450,0 & 61,0 & 0,0 & 0,0 & 0,0 & 0,0 & 100,0 & 0,0 & 0,0 & 0,0 & 0,0 \\
\hline 22 & 39,9 & 300,0 & 6,0 & 0,0 & 0,0 & 0,0 & 0,0 & 100,0 & 0,0 & 0,0 & 0,0 & 0,0 \\
\hline
\end{tabular}




\section{A3.3 Parameters for Economic Evaluation}

Table 101 Reference capacities, scaling exponents (Introductory/Advanced) and costs for the Unabated IGCC power plants for the year 2011 [6]

\begin{tabular}{|c|c|c|c|c|}
\hline Equipment & Scaling parameter & $\begin{array}{c}\text { Reference } \\
\text { cost (M€) }\end{array}$ & $\begin{array}{c}\text { Reference } \\
\text { capacity }\end{array}$ & $\begin{array}{c}\text { Scaling } \\
\text { exponent }\end{array}$ \\
\hline ASU & Oxygen produced $(\mathrm{kg} / \mathrm{s})$ & 64,48 & 26,54 & $0,67 / 1$ \\
\hline Coal handling & Coal input $(\mathrm{kg} / \mathrm{s})$ & 49,50 & 32,90 & $0,67 / 1$ \\
\hline Ash handling & Ash flowrate $(\mathrm{kg} / \mathrm{s})$ & 16,00 & 4,65 & $0,60 / 1$ \\
\hline HRSG & ST gross power (MW) & 35,46 & 182,36 & $0,67 / 1$ \\
\hline Gas turbine (Intro.) & Net power output (MW) & 88,60 & 254,42 & $1 /-$ \\
\hline Gas turbine (Adv.) & Net power output (MW) & 159,43 & 520,0 & $-/ 0$ \\
\hline Steam turbine & ST gross power (MW) & 55,00 & 182,36 & $0,67 / 1$ \\
\hline Condenser & ST gross power (MW) & 40,56 & 182,36 & $0,67 / 1$ \\
\hline Gasifier & Coal thermal input (MW) & 162,00 & 828,02 & $0,67 / 1$ \\
\hline Gas clean-up & Syngas flowrate (kg/s) & 58,03 & 75,26 & $0,67 /-$ \\
\hline Hot gas clean-up & Syngas flowrate (kg/s) & 46,12 & 89,21 & $-/ 1$ \\
\hline
\end{tabular}

Table 102 Reference capacities, scaling exponents (Introductory/Advanced) and for the power plants with $\mathrm{CO}_{2}$ capture for the year 2011 [6]

\begin{tabular}{|c|c|c|c|c|}
\hline Equipment & Scaling parameter & $\begin{array}{c}\text { Reference } \\
\text { cost (M€) }\end{array}$ & $\begin{array}{c}\text { Reference } \\
\text { capacity }\end{array}$ & $\begin{array}{c}\text { Scaling } \\
\text { exponent }\end{array}$ \\
\hline ASU & Oxygen produced $(\mathrm{kg} / \mathrm{s})$ & 72,80 & 31,45 & $0,67 / 1$ \\
\hline Coal handling & Coal input $(\mathrm{kg} / \mathrm{s})$ & 53,89 & 38,72 & $0,67 / 1$ \\
\hline Ash handling & Ash flowrate $(\mathrm{kg} / \mathrm{s})$ & 17,42 & 5,48 & $0,67 / 1$ \\
\hline HRSG & ST gross power $(\mathrm{MW})$ & 34,10 & 168,46 & $0,67 / 1$ \\
\hline Gas turbine (Intro.) & Net power output $(\mathrm{MW})$ & 93,32 & 282,87 & $1 /-$ \\
\hline Gas turbine (Adv.) & Net power output $(\mathrm{MW})$ & 159,43 & 520,0 & $-/ 0$ \\
\hline Steam turbine & ST gross power $(\mathrm{MW})$ & 52,00 & 168,46 & $0,67 / 1$ \\
\hline Condenser & ST gross power $(\mathrm{MW})$ & 39,00 & 168,46 & $0,67 / 1$ \\
\hline Shell Gasifier & Thermal input $(\mathrm{MW})$ & 180,00 & 954,08 & $0,67 / 1$ \\
\hline GE Gasifier & Thermal Input $(\mathrm{MW})$ & $60 \%$ Shell & 954,08 & $-/ 1$ \\
\hline HTW Gasifier & Raw syngas flowrate $(\mathrm{kg} / \mathrm{s})$ & 167,1 & 65,60 & $0,67 / 1$ \\
\hline Gas clean-up & Syngas flowrate $(\mathrm{kg} / \mathrm{s})$ & 61,49 & 89,21 & $0,67 / 1$ \\
\hline Hot gas clean-up & Syngas flowrate $(\mathrm{kg} / \mathrm{s})$ & 46,12 & 89,21 & $0,67 / 1$ \\
\hline SelexolTM CO 2 capture unit & Shifted syngas flowrate $(\mathrm{kg} / \mathrm{s})$ & 45,00 & 111,04 & $0,67 / 1$ \\
\hline WGS unit $[135]$ & Syngas flowrate $(\mathrm{kg} / \mathrm{s})$ & 21,12 & 89,21 & $0,67 / 1$ \\
\hline CO compression & Compressor power $(\mathrm{MW})$ & 30,00 & 20,69 & $1 / 1$ \\
\hline Membrane & Membrane surface area $\left(\mathrm{m}{ }^{2}\right)$ & 0,006 & 1 & $-/ 1$ \\
\hline
\end{tabular}




\section{Publications \& Conferences}

The research outcome of this Thesis has resulted in the following publications:

1. C. Arnaiz del Pozo, S. Cloete, J.H. Cloete, Á Jiménez Álvaro and S. Amini, "The potential of chemical looping combustion using the gas switching concept to eliminate the energy penalty of $\mathrm{CO}_{2}$ capture" International Journal of Greenhouse Gas Control. 2019, vol. 83, pp. 265-281. https://doi.org/10.1016/i.ijggc.2019.01.018.

2. C. Arnaiz del Pozo, S. Cloete, J.H Cloete, Á. Jiménez Álvaro and S. Amini, "The oxygen production pre-combustion (OPPC) IGCC plant for efficient power production with $\mathrm{CO}_{2}$ capture" Energy Conversion and Management. 2019, vol. 201, pp. 112109. https://doi.org/10.1016/i.enconman.2019.112109

3. C. Arnaiz del Pozo, A. Jiménez Álvaro, J.H Cloete, S. Cloete and S. Amini, "Exergy Analysis of Gas Switching Chemical Looping IGCC Plants" Energies. 2020, vol. 13, no. 3, pp. 544. https://doi.org/10.3390/en13030544

4. C. Arnaiz del Pozo, J.H. Cloete, S. Cloete, Á Jiménez Álvaro and S. Amini, "Integration of gas switching combustion in a humid air turbine cycle for flexible power production from solid fuels with near-zero emissions of $\mathrm{CO}_{2}$ and other pollutants" International Journal of Energy Research. 2020, https://doi.org/10.1002/er.5443

5. C. Arnaiz del Pozo, S. Cloete, P. Chiesa, Á. Jiménez Álvaro and S. Amini, "Integration of gas switching combustion and membrane reactors for exceeding 50\% efficiency in flexible IGCC power plants with near-zero $\mathrm{CO}_{2}$ emissions" Energy Conversion and Management. 2020, In press. https://doi.org/10.1016/j.ecmx.2020.100050

6. S. Szima, C. Arnaiz del Pozo, S. Cloete, S. Fogarasi, Á Jiménez Álvaro, A. Cormos, C. Cormos and S. Amini, "Techno-economic assessment of IGCC power plants using gas switching technology to minimize the energy penalty of $\mathrm{CO}_{2}$ capture" Sustainable Energy Technologies and Assessments. Under Review.

The conferences and poster sessions that were attended to during the course of the project are listed below:

1. C. Arnaiz del Pozo, A. Jiménez Álvaro, J. Rodríguez Martín, S. Sánchez Orgaz, I. López Paniagua. C. González Fernández. R. Nieto Carlier. Exergy Calculation Modelling Tool for Mixtures in Power Generation: Application to WGS and ASU units of an IGCC Power Plant with Pre-combustion $\mathrm{CO}_{2}$ Capture. XI Congreso Nacional y II Internacional de Ingeniería Termodinámica. 2019. No ISBN: 978-84-09-11635-5.

2. C. Arnaiz del Pozo, A. Jiménez Álvaro, J. Rodríguez Martín, S. Sánchez Orgaz, I. López Paniagua. C. González Fernández. R. Nieto Carlier. Design and Simulation of a $\mathrm{CO}_{2}$ purification unit for inherent carbon capture in IGCC power plants. XI Congreso Nacional y II Internacional de Ingeniería Termodinámica. 2019. No ISBN: 978-84-09-11635-5.

3. C. Arnaiz del Pozo, A. Jiménez Álvaro, J.H. Cloete, S. Cloete, S. Amini. Integration of Gas Switching Chemical Looping Technology in IGCC plants for Inherent $\mathrm{CO}_{2}$ Capture. 14th Conference on Sustainable Development of Energy Water and Environment Systems-SDEWES. 2019. N ISBN: 1847-7186.

4. S. Szima, C. Arnaiz del Pozo, S. Cloete, AM. Cormos, Á. Jiménez Álvaro, S. Amini, CC. Cormos. Techno-Economic Analysis of the new Gas Switching Combustion Technology in a Coal-Fired Power Plant. 21st Romanian International Conference on Chemistry and Chemical Engineering (RICCCE 21), 2019. Constanta-Mamaia, Rumanía. 
5. S. Szima, C. Arnaiz del Pozo, S. Cloete, AM. Cormos, Á. Jiménez Álvaro, S. Amini, CC. Cormos. Techno-Economic Analysis and Comparison of the new Gas Switching Combustion Technology. 12th International Conference Processes In Isotopes And Molecules (PIM). 2019 ClujNapoca, Rumanía. 


\section{References}

[1] https://climate.nasa.gov/vital-signs/global-temperature/ 2020.

[2] Anonymous "European Geosciences Union's Reaction to IPCC Report on Global Warming of 1.5 Degrees Celsius" Targeted News Service. 2018.

[3] IEA (2019), World Energy Outlook 2019, IEA, Paris https://www.iea.org/reports/worldenergy-outlook-2019.

[4] https://energypost.eu/developing-world-cashflow-analysis-shows-gas-coal-far-moreprofitable-than-clean-energy/ 2020.

[5] https://energypost.eu/an-independent-global-energy-forecast-to-2050-part-4-of-5-nuclearbiomass-and-ccs/2020.

[6] R. Anantharaman, O. Bolland, N. Booth, E. Van Dorst, E. Sanchez Fernandez, F. Franco, E. Macchi, G. Manzolini, D. Nikolic, A. Pfeffer, M. Prins, S. Rezvani and L. Robinson, "Cesar Deliverable D2.4.3. European Best Practice Guidelines For Assessment Of Co2 Capture Technologies" 2018.

[7] D. Jansen, M. Gazzani, G. Manzolini, E.v. Dijk and M. Carbo, "Pre-combustion CO2 capture" International Journal of Greenbouse Gas Control. 2015, vol. 40, pp. 167-187.

[8] R. Chein and C. Yu, "Thermodynamic equilibrium analysis of water-gas shift reaction using syngases-effect of CO2 and H2S contents" Energy. 2017, vol. 141, pp. 1004-1018.

[9] Fluor, "Electricity Production and CO2 Capture via Partial Oxididation of Natural Gas" 2000.

[10] https://www.mhps.com/catalogue/pdf/mhps hydrogen en.pdf 2020.

[11] G. Pipitone and O. Bolland, "Power generation with CO2 capture: Technology for CO2 purification" International Journal of Greenbouse Gas Control. 2009, vol. 3, no. 5, pp. 528-534.

[12] Luca Mancuso, Noemi Ferrari, Paolo Chiesa, Emanuele Maartelli and Matteo Romano, "IEAGHG: Oxy-Combustion turbine power plants" 2015.

[13] G. Lozza, M. Romano and A. Giuffrida, "Thermodynamic performance of IGCC with oxycombustion CO2 capture" 2009.

[14] Ishida, M., Zheng, D., Akehata, T., "Evaluation of a chemical-looping-combustion powergeneration system by graphic exergy analysis. " Energy. 1987, pp. 12, 147-154.

[15] F. Zerobin and T. Pröll, "Potential and limitations of power generation via chemical looping combustion of gaseous fuels" International Journal of Greenhouse Gas Control. 2017, vol. 64, pp. 174182. 
[16] S. Wang, G. Wang, F. Jiang, M. Luo and H. Li, "Chemical looping combustion of coke oven gas by using $\mathrm{Fe} 2 \mathrm{O} 3 / \mathrm{CuO}$ with $\mathrm{MgAl} 2 \mathrm{O} 4$ as oxygen carrier" Energy Environ.Sci. 2010, vol. 3, no.

9, pp. 1353-1360.

[17] M.M. Yazdanpanah, "Investigation of a Chemical Looping Combustion (CLC)

Configuration with Gas Feed" 2011.

[18] T. Mattisson, M. Keller, C. Linderholm, P. Moldenhauer, M. Rydén, H. Leion and A. Lyngfelt, "Chemical-looping technologies using circulating fluidized bed systems: Status of development" Fuel Process Technol. 2018, vol. 172, pp. 1-12.

[19] C. Ekström, F. Schwendig, O. Biede, F. Franco, G. Haupt, G. de Koeijer, C. Papapavlou and P.E. Røkke, "Techno-economic evaluations and benchmarking of pre-combustion CO2 capture and oxy-fuel processes developed in the European ENCAP project" Energy Procedia. 2009, vol. 1, no. 1, pp. 4233-4240.

[20] T. Proll, P. Kolbitsch, J. BolhÃ r-Nordenkampf and H. Hofbauer, "Chemical looping pilot plant results using a nickel-based oxygen carrier" Oil \& Gas Science and Technologyâ€ "Revue dâ€ ${ }^{\mathrm{TM}} I F P$ Energies nouvelles. 2011, vol. 66, no. 2, pp. 173-180.

[21] A. Zaabout, S. Cloete, S.T. Johansen, S.A. Van, F. Gallucci and S. Amini, "Experimental demonstration of a novel gas switching combustion reactor for power production with integrated CO 2 capture" Industrial and Engineering Chemistry Research. 2013, vol. 52, no. 39, pp. 14241-14250.

[22] T. Chmielniak and M. Sciazko, "Co-gasification of biomass and coal for methanol synthesis" Applied Energy. 2003, vol. 74, no. 3, pp. 393-403.

[23] D.C.C. Habgood, A.F.A. Hoadley and L. Zhang, "Techno-economic analysis of gasification routes for ammonia production from Victorian brown coal" Chemical Engineering Research and Design. 2015, vol. 102, pp. 57-68.

[24] H.C. Mantripragada and E.S. Rubin, "Techno-economic evaluation of coal-to-liquids (CTL) plants with carbon capture and sequestration" Energy Policy. 2011, vol. 39, no. 5, pp. 2808-2816.

[25] https://www.netl.doe.gov/research/Coal/energy-systems/gasification/gasifipedia/elcogas 2020.

[26] A. Giuffrida, M. Romano and G. Lozza, "Thermodynamic Assessment of IGCC Plants with Hot Gas Desulphurization" Applied energy. 2010, vol. 87, no. 11, pp. 3374-3383.

[27] K. Atsonios, K.D. Panopoulos, A. Doukelis, A.K. Koumanakos, E. Kakaras, T.A. Peters and Y.C. van Delft, "1 - Introduction to palladium membrane technology" Palladium Membrane Technology for Hydrogen Production, Carbon Capture and Other Applications. 2015, pp. 1-21.

[28] S.C. Gülen, "Gas Turbines for Electric Power Generation", 2019.

[29] R. Nieto Carlier, C. González Fernández, I. López Paniagua, A. Jiménez Álvaro and J. Rodríguez Marín, "Termodinámica" Madrid: Dextra Editorial SI. 2014. 
[30] Sadi Carnot, "Sadi Carnot, Réflexions sur la puissance motrice du feu, éd. Robert Fox" Revue d'histoire des sciences. 1980, vol. 33, no. 2, pp. 181-183.

[31] L. Pogliani and M. Berberan-Santos, "Constantin Carathéodory and the axiomatic thermodynamics" Journal of Mathematical Chemistry. 2000, vol. 28, no. 1, pp. 313-324.

[32] R.K. Srivastava, W. Jozewicz and C. Singer, "SO 2 scrubbing technologies: A review" Environ.Prog. 2001, vol. 20, no. 4, pp. 219-228.

[33] S.K. Gangwal, R. Gupta and W.J. McMichael, "Hot-gas cleanup-sulfur recovery technical, environmental, and economic issues" Heat Recovery Systems and CHP. 1995, vol. 15, no. 2, pp. 205214.

[34] P. Chiesa, G. Lozza and L. Mazzocchi, "Using Hydrogen as Gas Turbine Fuel" Journal of Engineering for Gas Turbines and Power (Transactions of the ASME). 2005, vol. 127, no. 1, pp. 73-80.

[35] A. Battista and D.M. Todd, "Demonstrated Applicability of Hydrogen Fuel for Gas Turbines" 2000, vol. 4.

[36] A. Zoelle, D. Keairns, M.J. Turner, M. Woods, N. Kuehn, V. Shah, V. Chou, L.L. Pinkerton and T. Fout, "Cost and Performance Baseline for Fossil Energy Plants" Cost and Performance Baseline for Fossil Energy Plants Volume 1b: Bituminous Coal (IGCC) to Electricity Revision 2b-Year Dollar Update. 2015.

[37] F. García-Labiano, L.F. de Diego, A. Cabello, P. Gayán, A. Abad, J. Adánez and G. Sprachmann, "Sulphuric acid production via Chemical Looping Combustion of elemental sulphur" Applied Energy. 2016, vol. 178, pp. 736-745.

[38] T.J. Kotas, "The exergy method of thermal plant analysis", 1985.

[39] Plant Cost Index Archives - Chemical Engineeringhttp://www.chemengonline.com 2018.

[40] I. Nexant, "Preliminary feasibility analysis of RTI warm gas cleanup (WGCU) technology" 2007.

[41] S. Szima, S.M. Nazir, S. Cloete, S. Amini, S. Fogarasi, A. Cormos and C. Cormos, "Gas switching reforming for flexible power and hydrogen production to balance variable renewables" Renewable and Sustainable Energy Reviews. 2019, vol. 110, pp. 207-219.

[42] H.T. Bi and J.R. Grace, "Flow regime diagrams for gas-solid fluidization and upward transport" Int.J.Multiphase Flow. 1995, vol. 21, no. 6, pp. 1229-1236.

[43] R. Turton, R.C. Bailie, W.B. Whiting and J.A. Shaeiwitz, "Analysis, synthesis and design of chemical processes", 2008.

[44] H.P. Hamers, M.C. Romano, V. Spallina, P. Chiesa, F. Gallucci and M.v.S. Annaland, "Comparison on process efficiency for CLC of syngas operated in packed bed and fluidized bed reactors" International Journal of Greenhouse Gas Control. 2014, vol. 28, pp. 65-78.

[45] https://www.aspentech.com/en/products/engineering/aspen-plus 2020. 
[46] Anonymous "https://sw.aveva.com/engineer-procure-construct/process-engineering-andsimulation/pro-ii-process-engineering" 2020.

[47] Anonymous "https://www.chemstations.com/CHEMCAD/" 2020.

[48] Anonymous "https://www.honeywellprocess.com/en-US/online campaigns/unisimdesign/Pages/index.html" 2020.

[49] Scilab, "https://www.scilab.org/".

[50] S. Noorman, F. Gallucci, M. van Sint Annaland and J. Kuipers, "Experimental investigation of chemical-looping combustion in packed beds: a parametric study" Ind Eng Chem Res. 2011, vol. 50, no. 4, pp. 1968-1980.

[51] V. Spallina, F. Gallucci, M.C. Romano, P. Chiesa, G. Lozza and M. van Sint Annaland, "Investigation of heat management for CLC of syngas in packed bed reactors" Chem.Eng.J. 2013, vol. 225, pp. 174-191.

[52] S. Gonzalez, N. Brown and J.J. Brown, "High temperature ceramic particulate filter" High temperature ceramic particulate filter. 1992.

[53] D.F. Ciliberti and T.E. Lippert, "Filter unit for use at high temperatures" Filter unit for use at high temperatures. 1988.

[54] https://www.trilliumflow.com/products/industries/og-midstream/batley-valve-bv-32000refractory-lined/ 2020.

[55] S.M. Nazir, J.H. Cloete, S. Cloete and S. Amini, "Techno-economic Comparison Of Combined Cycle Power Plants With Pre-combustion CO2 Capture Via Two Different Reforming Methods: Chemical Looping Reforming And Gas Switching Reforming" 2018, pp. 21-26.

[56] S. Cloete, A. Giuffrida, M. Romano, P. Chiesa, M. Pishahang and Y. Larring, "Integration of chemical looping oxygen production and chemical looping combustion in integrated gasification combined cycles" Fuel. 2018, vol. 220, pp. 725-743.

[57] H.F. Scott, "Elements of chemical reaction engineering", 2016.

[58] R. Kuusik, A. Trikkel, A. Lyngfelt and T. Mattisson, "High temperature behavior of NiObased oxygen carriers for Chemical Looping Combustion" Energy Procedia. 2009, vol. 1, no. 1, pp. 3885-3892.

[59] B. Moghtaderi, "Application of Chemical Looping Concept for Air Separation at High Temperatures" Energy Fuels. 2010, vol. 24, no. 1, pp. 190-198.

[60] A. Abad, J. Adánez, F. García-Labiano, L. de Diego F., P. Gayán and J. Celaya, "Mapping of the range of operational conditions for $\mathrm{Cu}-, \mathrm{Fe}-$, and Ni-based oxygen carriers in chemicallooping combustion" Chemical Engineering Science. 2007, vol. 62, no. 1-2, pp. 533-549.

[61] P.J. Linstrom and W.G. Mallard, "NIST Chemistry WebBook, NIST Standard Reference Database Number 69", 2020. 
[62] R.A. Robie and B.S. Hemingway, "Thermodynamic properties of minerals and related substances at $298.15 \mathrm{~K}$ and 1 bar (105 Pascals) pressure and at higher temperatures", 1995.

[63] S. Cloete, M.C. Romano, P. Chiesa, G. Lozza and S. Amini, "Integration of a Gas Switching Combustion (GSC) system in integrated gasification combined cycles" International Journal of Greenhouse Gas Control. 2015, vol. 42, pp. 340-356.

[64] T.E. Daubert and R.L. Danner, "Physical and thermodynamic properties of pure chemicals: data compilation" 1989.

[65] S. Cloete, A. Zaabout, M.C. Romano, P. Chiesa, G. Lozza, F. Gallucci, S.A. van and S. Amini, "Optimization of a Gas Switching Combustion process through advanced heat management strategies" Appl.Energy. 2017, vol. 185, pp. 1459-1470.

[66] R. Morales-Rodríguez, R. Gani, S. Déchelotte, A. Vacher and O. Baudouin, "Use of CAPEOPEN standards in the interoperability between modelling tools (MoT) and process simulators (Simulis ${ }^{\circledR}$ Thermodynamics and ProSimPlus)" Chem.Eng.Res.Design. 2008, vol. 86, no. 7, pp. 823833.

[67] J.S. Lopez-Echeverry, S. Reif-Acherman and E. Araujo-Lopez, "Peng-Robinson equation of state: 40 years through cubics" Fluid Phase Equilib. 2017, vol. 447, pp. 39-71.

[68] A.H. Harvey, A.P. Peskin and S.A. Klein, "NIST/ASME steam properties" 1997.

[69] Z. Kapetaki, S. Brandani, P. Brandani and H. Ahn, "Process simulation of a dual-stage Selexol process for $95 \%$ carbon capture efficiency at an integrated gasification combined cycle power plant" International Journal of Greenhouse Gas Control. 2015, vol. 39, pp. 17-26.

[70] L. Van Der Ham, "Improving the Second law efficiency of a cryogenic air separation unit" 2011.

[71] V. Spallina, M.C. Romano, P. Chiesa, F. Gallucci, S.A. van and G. Lozza, "Integration of coal gasification and packed bed CLC for high efficiency and near-zero emission power generation" International Journal of Greenhouse Gas Control. 2014, vol. 27.

[72] D.J. Dillon, R.S. Panesar, R.A. Wall, R.J. Allam, V. White, J. Gibbins and M.R. Haines, "Oxy-combustion processes for CO2 capture from advanced supercritical PF and NGCC power plant" Greenhouse Gas Control Technologies 7. 2005, pp. 211-220.

[73] R.J. Allam, "Improved oxygen production technologies" Energy Procedia. 2009, vol. 1, no. 1, pp. 461-470.

[74] Y.S. Kim, J.J. Lee, T.S. Kim and J.L. Sohn, "Effects of syngas type on the operation and performance of a gas turbine in integrated gasification combined cycle" Energy Conversion and Management. 2011, vol. 52, no. 5, pp. 2262-2271.

[75] D. Jones, D. Bhattacharyya, R. Turton and S.E. Zitney, "Optimal design and integration of an air separation unit (ASU) for an integrated gasification combined cycle (IGCC) power plant with CO 2 capture" Fuel Process Technol. 2011, vol. 92, no. 9, pp. 1685-1695.

[76] C. Higman, "Gasification" 2nd ed., 2008. 
[77] R. Breault, "Gasification Processes Old and New: A Basic Review of the Major Technologies" Energies. 2010, vol. 3, no. 2, pp. 216-240.

[78] M. Mansouri Majoumerd, H. Raas, S. De and M. Assadi, "Estimation of performance variation of future generation IGCC with coal quality and gasification process - Simulation results of EU H2-IGCC project" Appl.Energy. 2014, vol. 113, pp. 452-462.

[79] D. Toporov and R. Abraham, "Gasification of low-rank coal in the High-Temperature Winkler (HTW) process" Journal of the Southern African Institute of Mining and Metallurgy. 2015, vol. 115, no. 7 , pp. 589-597.

[80] N. Holt, "Gasification Process Selection - Trade offs and Ironies" 2004.

[81] Quian Zhu, "High Temperature Syngas Coolers, CCC/257" IE A Clean Coal Centre. 2015.

[82] K. Uebel, U. Guenther, F. Hannemann, U. Schiffers, H. Yilmaz and B. Meyer, "Development and engineering of a synthetic gas cooler concept integrated in a Siemens gasifier design" Fuel. 2014, vol. 116, pp. 879-888.

[83] J. Zhang, K. Boddington and D.J. Young, "Oxidation, carburisation and metal dusting of 304 stainless steel in CO/CO 2 and CO/H 2/H $2 \mathrm{O}$ gas mixtures" Corros.Sci. 2008, vol. 50, no. 11, pp. 3107-3115.

[84] Y. Ohtsuka, N. Tsubouchi, T. Kikuchi and H. Hashimoto, "Recent progress in Japan on hot gas cleanup of hydrogen chloride, hydrogen sulfide and ammonia in coal-derived fuel gas" Powder Technol. 2009, vol. 190, no. 3, pp. 340-347.

[85] D. Liu, Q. Wang, J. Wu and Y. Liu, "A review of sorbents for high-temperature hydrogen sulfide removal from hot coal gas" Environmental Chemistry Letters. 2019, vol. 17, no. 1, pp. 259276.

[86] S. Uemiya, N. Sato, H. Ando and E. Kikuchi, "The water gas shift reaction assisted by a palladium membrane reactor" Ind Eng Chem Res. 1991, vol. 30, no. 3, pp. 585-589.

[87] S.A. Wassie, S. Cloete, V. Spallina, F. Gallucci, S. Amini and M. van Sint Annaland, "Techno-economic assessment of membrane-assisted gas switching reforming for pure $\mathrm{H} 2$ production with CO2 capture" International Journal of Greenhouse Gas Control. 2018, vol. 72, pp. 163174.

[88] F. Gallucci, E. Fernandez, P. Corengia and M. van Sint Annaland, "Recent advances on membranes and membrane reactors for hydrogen production" Chemical Engineering Science. 2013, vol. 92, pp. 40-66.

[89] S.S. Hla, D. Park, G.J. Duffy, J.H. Edwards, D.G. Roberts, A. Ilyushechkin, L.D. Morpeth and T. Nguyen, "Kinetics of high-temperature water-gas shift reaction over two iron-based commercial catalysts using simulated coal-derived syngases" Chem.Eng.J. 2009, vol. 146, no. 1, pp. 148-154.

[90] B.S. RJ, M. Loganathan and M.S. Shantha, "A review of the water gas shift reaction kinetics" International Journal of Chemical Reactor Engineering. 2010, vol. 8, no. 1. 
[91] Y. Wang and A.E. Rodrigues, "Hydrogen production from steam methane reforming coupled with in situ CO2 capture: conceptual parametric study" Fuel. 2005, vol. 84, no. 14-15, pp. 1778-1789.

[92] M.C. Romano, P. Chiesa and G. Lozza, "Pre-combustion CO2 capture from natural gas power plants, with ATR and MDEA processes" International Journal of Greenhouse Gas Control. 2010, vol. 4, no. 5, pp. 785-797.

[93] S. Moioli, A. Giuffrida, M.C. Romano, L.A. Pellegrini and G. Lozza, "Assessment of MDEA absorption process for sequential H2S removal and CO2 capture in air-blown IGCC plants" Applied Energy. 2016, vol. 183, pp. 1452-1470.

[94] X. Zhang, H. Keramati, M. Arie, F. Singer, R. Tiwari, A. Shooshtari and M. Ohadi, "Recent developments in high temperature heat exchangers: A review" Frontiers in Heat and Mass Transfer. 2018, vol. 11, pp. .

[95] M. Jonsson, O. Bolland, D. Bücker and M. Rost, "Gas turbine cooling model for evaluation of novel cycles" 2005.

[96] J.H. Horlock, "Chapter 4 - CYCLE EFFICIENCY WITH TURBINE COOLING (COOLING FLOW RATES SPECIFIED)" Advanced Gas Turbine Cycles. 2003, pp. 47-69.

[97] E. Jeffs, "Thermoflow integrates-THERMOFLEX and ST PRO with PEACE" Turbomach.Int. 2003, vol. 44, no. 4, pp. 20-23.

[98] P. Chiesa and E. Macchi, "A Thermodynamic Analysis of Different Options to Break 60\% Electric Efficiency in Combined Cycle Power Plants" Journal of Engineering for Gas Turbines and Power (Transactions of the ASME). 2004, vol. 126, no. 4, pp. 770-785.

[99] M. Gazzani, P. Chiesa, E. Martelli, S. Sigali and I. Brunetti, "Using Hydrogen as Gas Turbine Fuel: Premixed Versus Diffusive Flame Combustors" Journal of Engineering for Gas Turbines and Power. Transactions of the ASME. 2014, vol. 136, no. 5, pp. np.

[100] M. Gazzani, E. Macchi and G. Manzolini, "CO2 capture in integrated gasification combined cycle with SEWGS a Part A: Thermodynamic performances" Fuel. 2013, vol. 105, pp. 206-219.

[101] U. - Desideri and F. - Di Maria, "- Humid Air Turbine Cycles With Water Recovery: How to Dispose Heat in an Efficient Way" 1998, vol. -, no. - 78644, pp. V003T08A008.

[102] P. Orts-Gonzalez, P.K. Zachos and G.D. Brighenti, "Techno-economic analysis of a reheated humid air turbine" Appl.Therm.Eng. 2018, vol. 137, pp. 545-554.

[103] P. Breeze, "Power Generation Technologies, 3rd Edition" 3, 2019.

[104] P. Orts-Gonzalez, P.K. Zachos and G.D. Brighenti, "The impact of heat exchanger degradation on the performance of a humid air turbine system for power generation" Appl.Therm.Eng. 2019, vol. 149, pp. 1492-1502.

[105] H. Zhao, P. Yue and L. Cao, "Analysis of Humid Air Turbine Cycle with Low- or MediumTemperature Solar Energy" International Journal of Photoenergy. 2009, vol. 2009. 
[106] M.T. Mansouri, P. Ahmadi, A.G. Kaviri and M.N.M. Jaafar, "Exergetic and economic evaluation of the effect of HRSG configurations on the performance of combined cycle power plants" Energy Conversion and Management. 2012, vol. 58, pp. 47-58.

[107] J. Kotowicz and M. BrzÄ ${ }^{\mathbf{T M}_{\text {Czek, }}}$ "Analysis of increasing efficiency of modern combined cycle power plant: A case study" Energy. 2018, vol. 153, pp. 90-99.

[108] S. Sabugal García and F. Gómez Moñux, "Centrales térmicas de ciclo combinado: teoría y proyecto", 2006.

[109] R. Kehlhofer, "Combined-cycle gas \& steam turbine power plants", 2009.

[110] S. Cho, M.S. Kim, S. Baik, Y. Ahn and J. Lee, "Investigation of the Bottoming Cycle for High Efficiency Combined Cycle Gas Turbine System With Supercritical Carbon Dioxide Power Cycle", 2015.

[111] P. Huck, S. Freund, M. Lehar and M. Peter, "Performance comparison of supercritical CO2 versus steam bottoming cycles for gas turbine combined cycle applications" 2016.

[112] M. Sankir and N. Demirci Sankir, "Hydrogen production technologies", 2017.

[113] S. Campanari, L. Mastropasqua, M. Gazzani, P. Chiesa and M.C. Romano, "Predicting the ultimate potential of natural gas SOFC power cycles with CO2 capture - Part B: Applications" J.Power Sources. 2016, vol. 325, pp. 194-208.

[114] S. Posch and M. Haider, "Optimization of CO2 compression and purification units (CO2CPU) for CCS power plants" Fuel. 2012, vol. 101, pp. 254-263.

[115] A. Giuffrida, M.C. Romano and G. Lozza, "Thermodynamic analysis of air-blown gasification for IGCC applications" Appl.Energy. 2011, vol. 88, no. 11, pp. 3949-3958.

[116] C. Arnaiz del Pozo, S. Cloete, J.H. Cloete, Á Jiménez Álvaro and S. Amini, "The potential of chemical looping combustion using the gas switching concept to eliminate the energy penalty of CO2 capture" International Journal of Greenhouse Gas Control. 2019, vol. 83, pp. 265-281.

[117] C. Arnaiz del Pozo, A. Jiménez Álvaro, J.H. Cloete, S. Cloete and S. Amini, "Exergy Analysis of Gas Switching Chemical Looping IGCC Plants" Energies. 2020, vol. 13, no. 3, pp. 544.

[118] J. Hentschel, Ugljes a Babić and H. Spliethoff, "A parametric approach for the valuation of power plant flexibility options" Energy Reports. 2016, vol. 2, pp. 40-47.

[119] R. Domenichini, L. Mancuso, N. Ferrari and J. Davison, "Operating Flexibility of Power Plants with Carbon Capture and Storage (CCS)" Energy Procedia. 2013, vol. 37, pp. 2727-2737.

[120] Van Den Berg, Robert Erwin, F.G. Van Dongen, T.P. Von Kossak-Glowczewski, Van Der Ploeg, Henrik Jan and P.L. Zuideveld, "Method and system for producing synthesis gas, gasification reactor, and gasification system" Method and system for producing synthesis gas, gasification reactor, and gasification system. 2014. 
[121] C. Arnaiz del Pozo, J.H. Cloete, S. Cloete, Á Jiménez Álvaro and S. Amini, "Integration of gas switching combustion in a humid air turbine cycle for flexible power production from solid fuels with near-zero emissions of CO2 and other pollutants" Int.J.Energy Res. 2020, vol. n/a.

[122] E. Martelli, T. Kreutz and S. Consonni, "Comparison of coal IGCC with and without CO2 capture and storage: Shell gasification with standard vs. partial water quench" Energy Procedia. 2009, vol. 1, no. 1, pp. 607-614.

[123] J. Davison, "Electricity systems with near-zero emissions of CO 2 based on wind energy and coal gasification with CCS and hydrogen storage" International Journal of Greenhouse Gas Control. 2009, vol. 3, no. 6, pp. 683-692.

[124] S. Cloete and L. Hirth, "Flexible power and hydrogen production: Finding synergy between CCS and variable renewables" Energy. 2020, vol. 192.

[125] C. Arnaiz del Pozo, S. Cloete, J. Hendrik Cloete, Á Jiménez Álvaro and S. Amini, "The oxygen production pre-combustion (OPPC) IGCC plant for efficient power production with CO2 capture" Energy Conversion and Management. 2019, vol. 201, pp. 112109.

[126] S. Cloete, A. Tobiesen, J. Morud, M. Romano, P. Chiesa, A. Giuffrida and Y. Larring, "Economic assessment of chemical looping oxygen production and chemical looping combustion in integrated gasification combined cycles" International Journal of Greenhouse Gas Control. 2018, vol. 78, pp. 354-363.

[127] S. Szima, C. Arnaiz del Pozo, S. Cloete, S. Fogarasi, Á Jiménez Álvaro, A. Cormos, C. Cormos and S. Amini, "Techno-economic assessment of IGCC power plants using gas switching technology to minimize the energy penalty of CO2 capture" Sustainable Energy Technologies and Assessments. , pp. Under Review.

[128] C. Arnaiz del Pozo, S. Cloete, P. Chiesa, Á Jiménez Álvaro and S. Amini, "Integration of gas switching combustion and membrane reactors for exceeding $50 \%$ efficiency in flexible IGCC plants with near-zero CO2 emissions" Energy Conversion and Management. 2020.

[129] A. Zaabout, S. Cloete, J.R. Tolchard and S. Amini, "A pressurized Gas Switching Combustion reactor: Autothermal operation with a CaMnO3 $\hat{a}^{\wedge}$ ' $\hat{\mathrm{I}}^{\prime}$-based oxygen carrier" Chem.Eng.Res.Design. 2018, vol. 137, pp. 20-32.

[130] A. Zaabout, S. Cloete and S. Amini, "Autothermal operation of a pressurized Gas Switching Combustion with ilmenite ore" International Journal of Greenhouse Gas Control. 2017, vol. 63, pp. 175-183.

[131] H. Tsuji, A.K. Gupta, T. Hasegawa, M. Katsuki, K. Kishimoto and M. Morita, "High temperature air combustion: from energy conservation to pollution reduction", 2002.

[132] K. Aiuchi, R. Moriyama, S. Takeda, S. Kitada, M. Onozaki and Y. Katayama, "A preheating vaporization technology of coal-water-slurry for the gasification process" Fuel Processing Technology. 2007, vol. 88, no. 4, pp. 325-331.

[133] M.N. Khan, S. Cloete and S. Amini, "Efficiency Improvement of Chemical Looping Combustion Combined Cycle Power Plants" Energy Technology. 2019, vol. 7, no. 11, pp. 1900567. 
[134] S.M. Nazir, J.H. Cloete, S. Cloete and S. Amini, "Efficient hydrogen production with CO2 capture using gas switching reforming" Energy. 2019, vol. 185, pp. 372-385.

[135] V. Spallina, D. Pandolfo, A. Battistella, M.C. Romano, M. Van Sint Annaland and F. Gallucci, "Techno-economic assessment of membrane assisted fluidized bed reactors for pure H2 production with CO2 capture" Energy Conversion and Management. 2016, vol. 120, pp. 257-273. 


\section{Abbreviations}

ACF Annual Cash Flow

ASU Air Separation Unit

AGRU Acid Gas Removal Unit

ASC Advanced Supercritical

BAC Booster Air Compressor

CAPE Computer-Aided Process Engineering

CAPEX Capital Expenditure

CCS Carbon Capture Utilization \& Storage

CGE Cold Gas Efficiency

CLC Chemical Looping Combustion

COCA Cost of $\mathrm{CO}_{2}$ Avoided

COT Combustor Outlet Temperature

CPU $\quad\left(\mathrm{CO}_{2}\right)$ Cryogenic Purification Unit

CSTR Continuous Stirred Tank Reactor

DEA Diethanoleamine

EPCC Engineering Procurement \& Construction Costs

GE General Electric

GHG Greenhouse Gas Emissions

GSC Gas Switching Combustion

GSOP Gas Switching Oxygen Production

GSR Gas Switching Reforming

GSWS Gas Switching Water Splitting

GT Gas Turbine

HAT Humid Air Turbine

HGCU Hot Gas Clean Up

HHV High Heating Value

HP High Pressure

HPC High Pressure Column

HSRG Heat Recovery Steam Generator 
HTW High Temperature Winkler

IGCC Integrated Gasification Combined Cycle

IGV Inlet Guide Vanes

IP Intermediate Pressure

ITM Ion Transport Membranes

LCOE Levelized Cost of Electricity

LHV Lower Heating Value

LP Low Pressure

LPC Low Pressure Column

MAC Main Air Compressor

MAWGS Membrane Assisted Water Gas Shift

MCHE Main Cryogenic Heat Exchanger

MEA Methyl-ethanolamine

MDEA Methyl-diethanoleamine

MITA Minimum Temperature Approach

NG Natural Gas

NGCC Natural Gas Combined Cycle

NPV Net Present Value

OPPC Oxygen Production Pre-combustion

O\&M Operating \& Maintenance

PCB Pulverized Coal Boilers

PFR Plug Flow Reactor

PS Process Contingency

PT Project Contingency

RH Relative Humidity

SEC Syngas Effluent Cooler

SI Specific Investment

SOFC Solid Oxide Fuel Cell

SPECCA Specific Primary Energy Consumption of $\mathrm{CO}_{2}$ Avoided

ST Steam Turbine

TIC Total Installed Cost 
TOT Turbine Outlet Temperature

TOC Total Overnight Cost

TPC Total Plant Costs

VGV Variable Guide Vane

VRE Variable Renewable Energy

WGDU Wet Gas Desulphurization Unit

WGS Water Gas Shift

\section{List of Symbols}

$\mathrm{A}_{\mathrm{CO}_{2}} \quad \mathrm{CO}_{2}$ Avoided (\%)

$B^{\prime} \quad$ Exergy $(J)$

$c_{p} \quad$ Specific heat capacity $(\mathrm{J} / \mathrm{molK})$

$D_{R} \quad$ Reactor Diameter (m)

$d_{t} \quad$ Membrane tube diameter $(\mathrm{m})$

$e \quad$ Specific Flow Exergy $(\mathrm{J} / \mathrm{mol})$

$E_{a} \quad$ Activation Energy $(\mathrm{J} / \mathrm{mol})$

$E_{\mathrm{CO}_{2}} \quad$ Specific Emissions (kg/MWh)

$\Delta G_{r}^{o} \quad$ Standard Gibbs Free Energy of Reaction $(\mathrm{J} / \mathrm{mol})$

$h \quad$ Specific enthalpy $(\mathrm{J} / \mathrm{mol})$

$H \quad$ Enthalpy (J)

$\Delta H_{r}^{\circ} \quad$ Standard Enthalpy of Reaction $(\mathrm{J} / \mathrm{mol})$

I $\quad$ Exergy Destruction (J)

K Cooling fraction proportionality constant (-)

$k \quad$ Pressure drop constant (-)

$n \quad$ Total moles (mol)

$f \quad$ Species molar flow $(\mathrm{mol} / \mathrm{s})$

$F \quad$ Total flow $(\mathrm{mol} / \mathrm{s})$

$K_{e q} \quad$ Equilibrium constant (-)

$P \quad$ Pressure (bar)

$\Delta P \quad$ Pressure Drop (bar) 


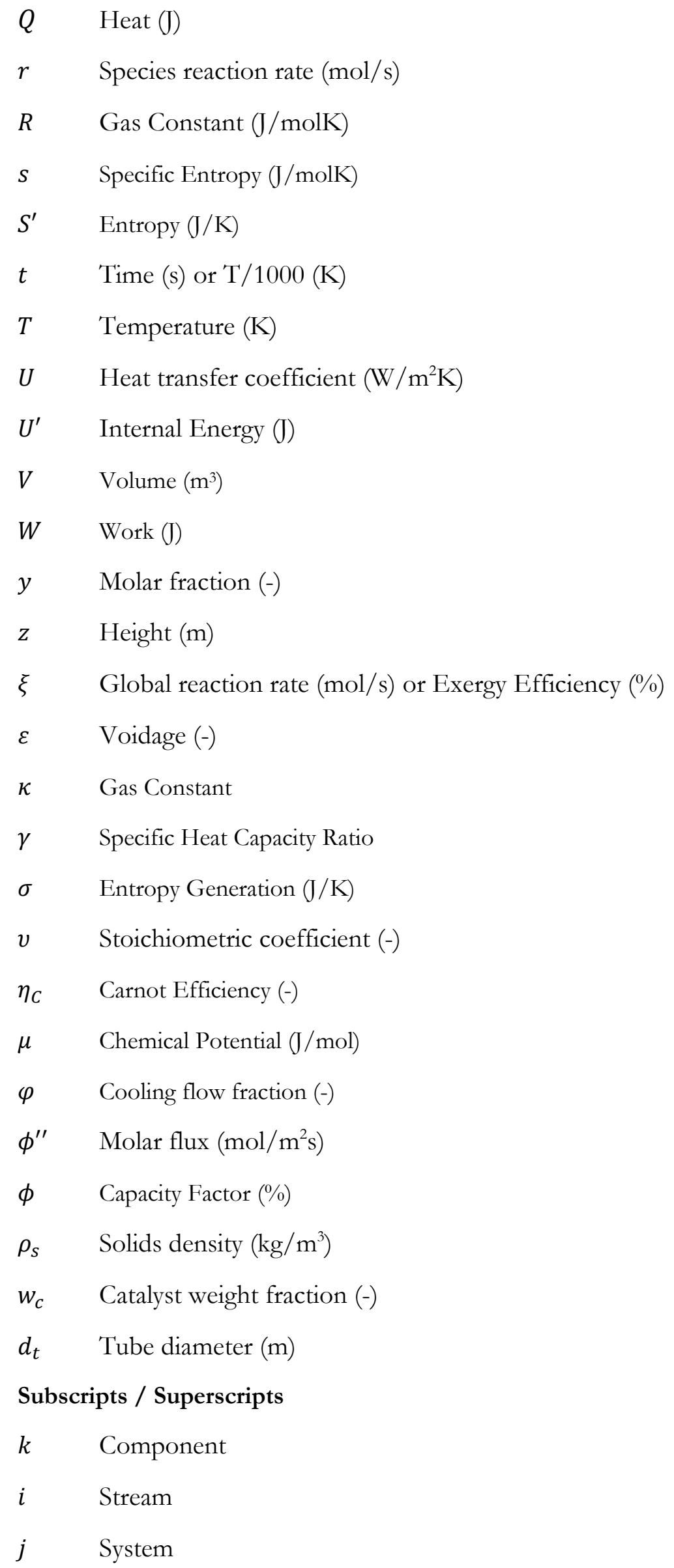




\begin{tabular}{|c|c|}
\hline$r$ & Reaction / Rotor \\
\hline$s$ & Stator \\
\hline$g$ & Hot gas \\
\hline o & Ambient/reference conditions \\
\hline$\cdot$ & Per unit of time \\
\hline$\square$ & Pure component \\
\hline$R$ & Retentate \\
\hline$P$ & Permeate \\
\hline el & Electricity \\
\hline th & Thermal \\
\hline$b l$ & Blade \\
\hline in & Inlet \\
\hline out & Outlet \\
\hline red & Reduction \\
\hline$o x$ & Oxidation \\
\hline $\operatorname{mix}$ & Mixture \\
\hline ref & Reference value \\
\hline ch & Chemical \\
\hline$p h$ & Physical \\
\hline$c$ & Kinetic \\
\hline$p$ & Potential \\
\hline
\end{tabular}




\section{List of Figures}

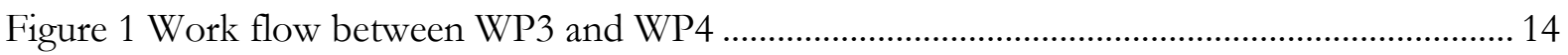

Figure 2 Global surface (land-ocean) temperature relative to 1951-1980 average values [1] ........ 15

Figure 3 Global greenhouse gas emissions by gas in 2010 [2] ........................................................ 15

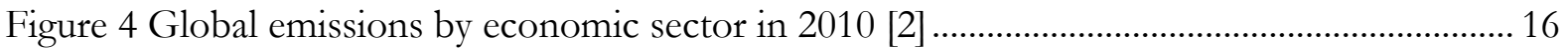

Figure 5 Carbon intensity of different sources for electricity generation [2] .................................. 17

Figure 6 Block flow diagram of post-combustion $\mathrm{CO}_{2}$ capture plants for solid and gaseous fuels

Figure 7 Absorption-desorption process for post-combustion $\mathrm{CO}_{2}$ capture.................................. 19

Figure 8 Block flow diagram of pre-combustion $\mathrm{CO}_{2}$ capture plants for gaseous and solid fuels21

Figure 9 Block flow diagram of an oxy-combustion $\mathrm{CO}_{2}$ capture IGCC plant .............................. 22

Figure 10 Basic gas-fuelled CLC layout with interconnected fluidized beds ................................... 23

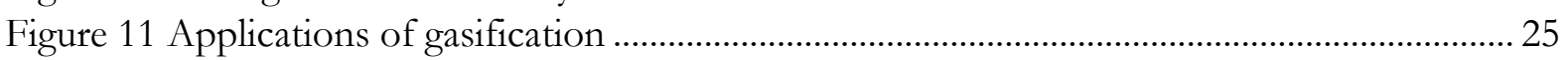

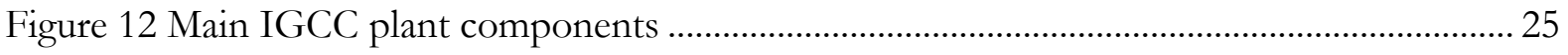

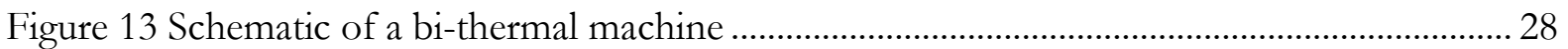

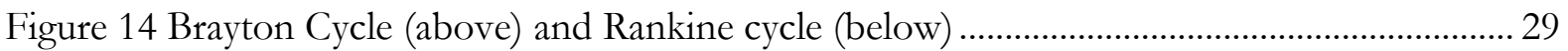

Figure 15 T-s diagram of a Brayton (topping) and Rankine (bottoming) combined cycle and

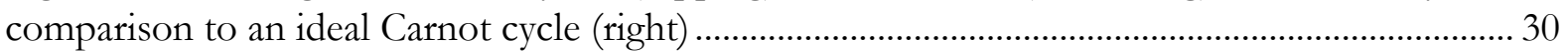

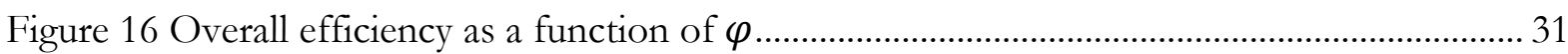

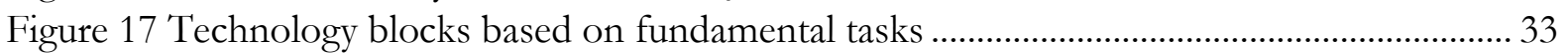

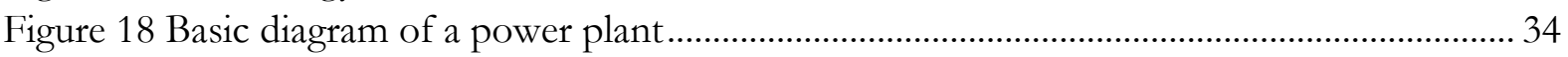

Figure 19 Average emissions: sulphur dioxide $\left(\mathrm{SO}_{2}\right)$, nitrogen oxides $(\mathrm{NOx})$ and particulate matter

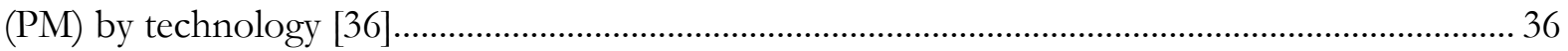

Figure 20 Schematic comparison of $\mathrm{CO}_{2}$ emissions for power plants with and without CCS ..... 37

Figure 21 Carnot efficiency as a function of hot temperature $(T)$ for heat rejection temperature T0 $=300 \mathrm{~K}$ (left) and heat rejection temperature $\left(\mathrm{T}_{0}\right)$ for different hot temperature $(\mathrm{T})$ values (right)

38

Figure 22 Closed system interacting only with an environment at $\mathrm{P}_{0}$ and $\mathrm{T}_{0} \ldots \ldots \ldots \ldots \ldots \ldots \ldots \ldots \ldots \ldots \ldots . . . . . . . . . . . . . . . .39$

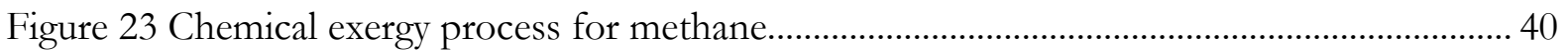

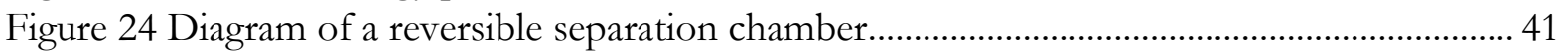

Figure 25 Modelling tool diagram for the determination of the total exergy flow of a mixture... 42

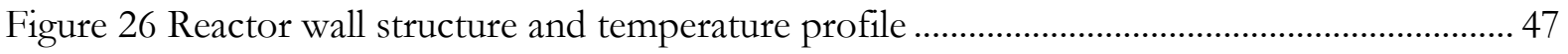

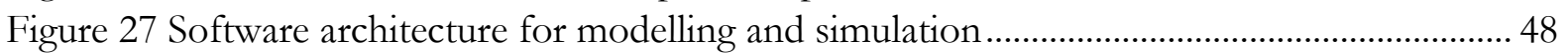

Figure 28 CLC system with interconnected fluidized beds vs. gas switching concept................... 49

Figure 29 Illustration of the gas switching cluster operation concept .............................................. 50

Figure 30 Different chemical looping concepts: combustion (top left) reforming (top right), water

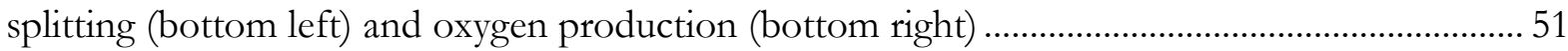

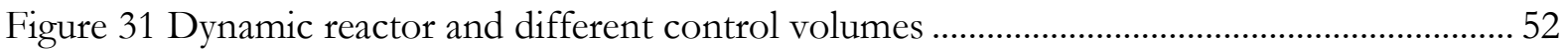

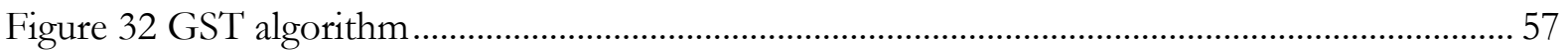

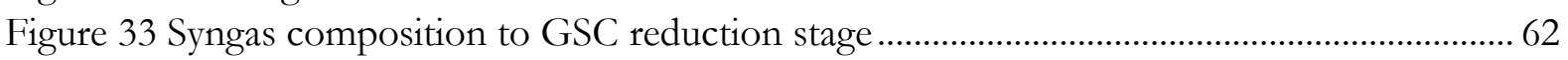

Figure 34 Time averaged outlet reduction (left) and oxidation (right) compositions of GSC cluster

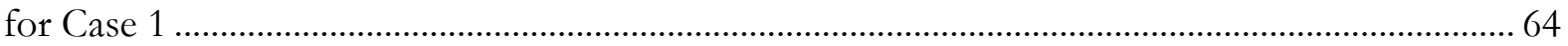

Figure 35 Temperature profile of a reactor cycle for Case 1 (dashed line) \& Case 2 (solid line).. 65

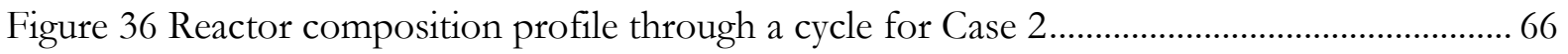

Figure 37 Blended and average temperature of the oxidation stage outlet for Case 2 .................. 67

Figure 38 Dimensionless mass flow variation of the oxidation stage outlet with respect to average

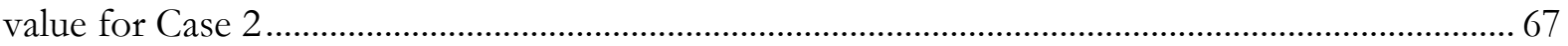


Figure 39 Temperature profile of a reactor cycle for Case 2 (solid line) and Case 3 (dashed line)

Figure $40 \mathrm{CO}_{2}$ capture performance of Nickel and Ilmenite for the same oxidation stage

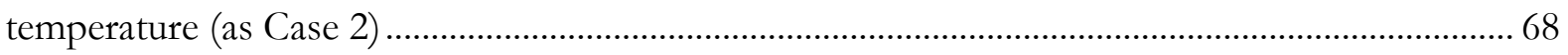

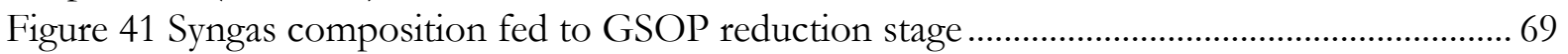

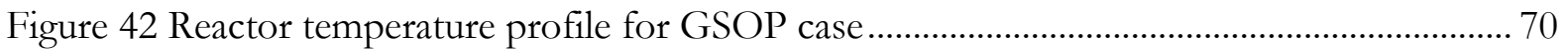

Figure 43 Reaction composition profile for GSOP case ................................................................. 70

Figure 44 Delayed switch for Case 2 with feed valve switch (at 0 s and 82.6s) and product valve

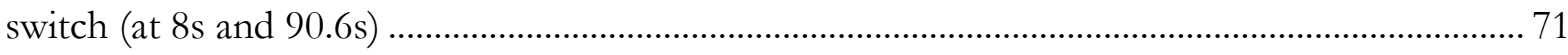

Figure $45 \mathrm{CO}_{2}$ Recovery and $\mathrm{N}_{2}$ Slip in \% for different delayed switch times for Case 2............ 72

Figure 46 Reactor temperature profile for Case 4 (black line) and Case 5 (grey line) with $\mathrm{N}_{2}$ recycle

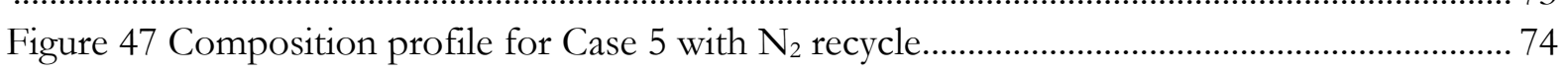

Figure 48 Reactor temperature profile for Case 6 and Case 7 with $\mathrm{O}_{2}$ slip .................................... 75

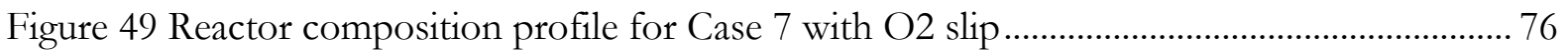

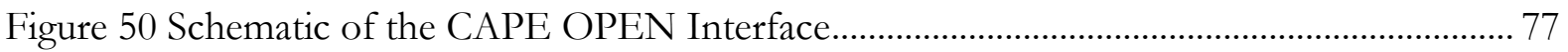

Figure 51 Simplified cluster model for the stationary flowsheet ......................................................... 77

Figure 52 Schematic of parameter and material transfer between Scilab and Unisim simulation

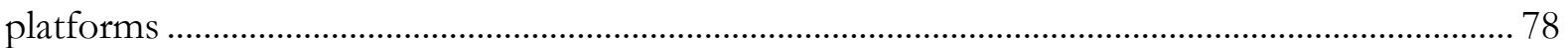

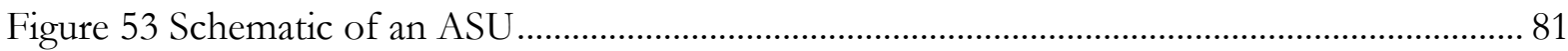

Figure 54 Temperature profile in the MCHE (left) and condenser reboiler (right)........................ 82

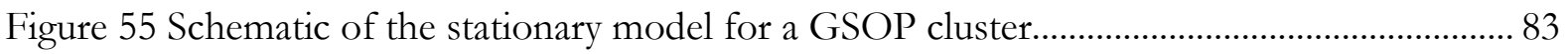

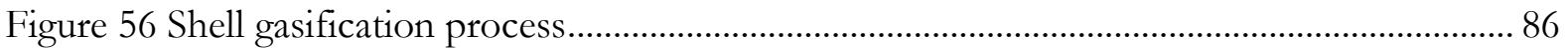

Figure $57 \mathrm{GE}$ gasification system with full water quench and syngas scrubber.............................. 87

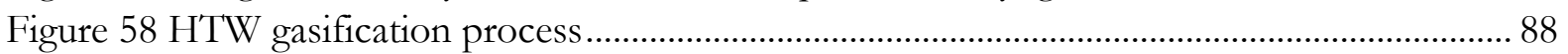

Figure 59 Temperature profile of a syngas effluent cooler (SEC) .................................................. 90

Figure 60 Syngas cooling designs. Temperature values are approximate ......................................... 90

Figure 61 LTHR section with $\mathrm{H}_{2} \mathrm{~S}$ removal and syngas saturator .................................................. 91

Figure 62 Schematic of HGCU process with sorbent regeneration................................................ 93

Figure $63 \mathrm{HGCU}$ with off gas recirculation to the regenerator....................................................... 94

Figure 64 Schematic of the WGS unit with saturator and heat recovery units ................................ 95

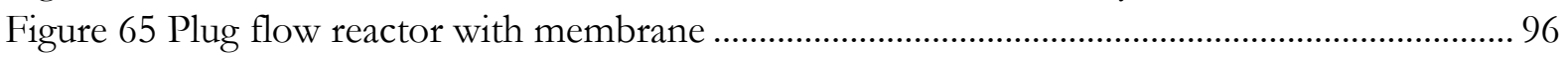

Figure 66 MAWGS reactor temperature and pressure profile for Case A..................................... 100

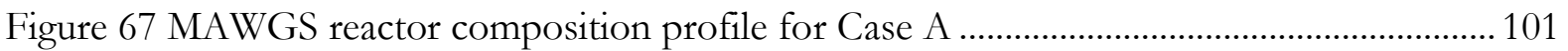

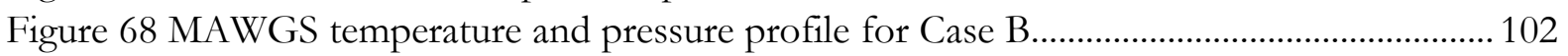

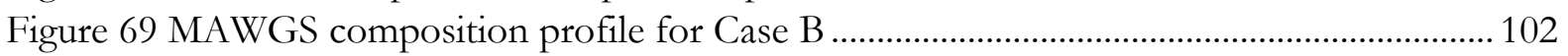

Figure $70 \mathrm{CO}$ conversion and $\mathrm{H}_{2}$ Recovery of the MAWGS for Case A and Case B ................. 103

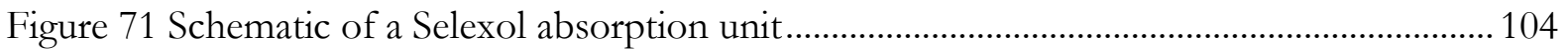

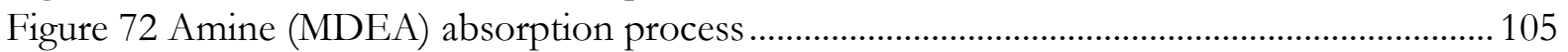

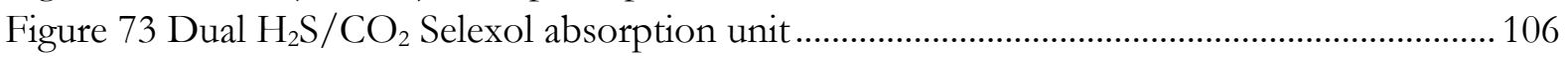

Figure 74 GSC with reduction gases heat recovery and/or extra firing chamber......................... 107

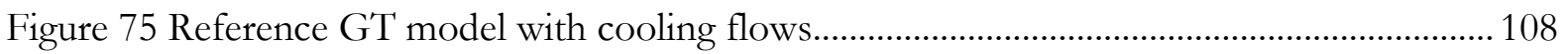

Figure 76 Compressor operating curve with efficiency and pressure ratio changes at different inlet

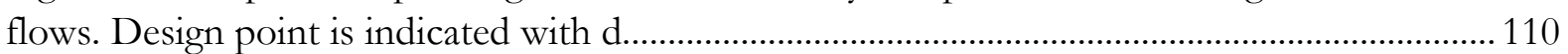

Figure 77 GT model integrated with GSC cluster .......................................................................... 111

Figure 78 Block flow diagram of the Syngas $/ \mathrm{H}_{2}$ fired gas turbine. Blue lines indicate water/steam streams. Dotted lines indicate potential integration options. 
Figure 79 HAT cycle configuration. Blue lines indicate water streams ......................................... 114

Figure 80 Heat temperature profile of a NGCC base case......................................................... 117

Figure 81 Steam cycle configuration for advanced power plants ................................................... 117

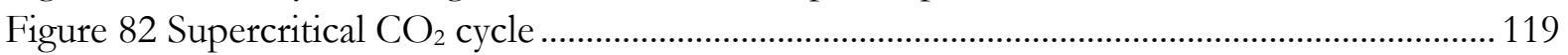

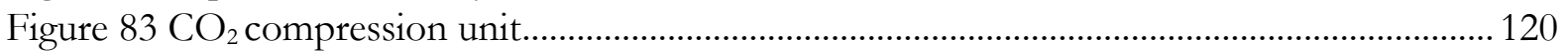

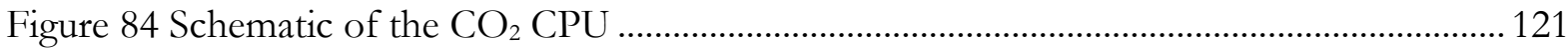

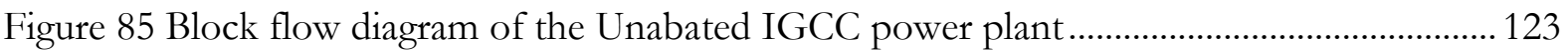

Figure 86 Exergy breakdown in \% for the Unabated IGCC power plant ...................................... 125

Figure 87 TIC distribution for the Unabated IGCC power plant .................................................... 126

Figure 88 LCOE build-up for the Unabated IGCC power plant ..................................................126

Figure 89 Block flow diagram of the Pre-combustion $\mathrm{CO}_{2}$ capture IGCC plant..........................127

Figure 90 Exergy breakdown in \% of the pre-combustion $\mathrm{CO}_{2}$ capture IGCC power plant..... 129

Figure 91 TIC distribution for the Pre-combustion $\mathrm{CO}_{2}$ capture IGCC power plant.................. 130

Figure $92 \mathrm{LCOE}$ build up for the Pre-combustion $\mathrm{CO}_{2}$ capture IGCC power plant................... 130

Figure 93 Block flow diagram of the Advanced Unabated and Pre-combustion $\mathrm{CO}_{2}$ capture IGCC

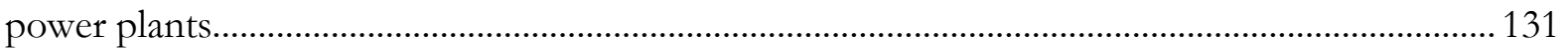

Figure 94 Specific emissions and efficiency comparison between Unabated IGCC benchmarks

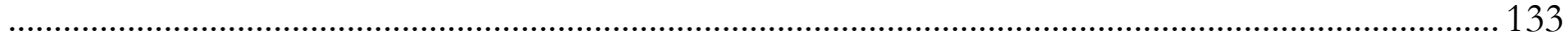

Figure 95 TIC distribution of the Adv. Unabated IGCC power plant ........................................... 134

Figure 96 LCOE build-up for the Adv. Unabated IGCC power plant ........................................ 134

Figure 97 TIC distribution for the Adv. Pre-combustion $\mathrm{CO}_{2}$ capture IGCC power plant ........ 137

Figure 98 LCOE build-up for the Adv. Pre-combustion $\mathrm{CO}_{2}$ capture IGCC plant ..................... 137

Figure 99 Block flow diagram of the Standalone GSC IGCC power plant ....................................138

Figure $100 \mathrm{CO}_{2}$ emissions breakdown for the Standalone GSC IGCC power plant .................... 140

Figure 101 Exergy distribution for the Standalone GSC IGCC power plant.................................. 141

Figure 102 Exergy flow diagram of the Standalone GSC IGCC power plant. Values are in MW

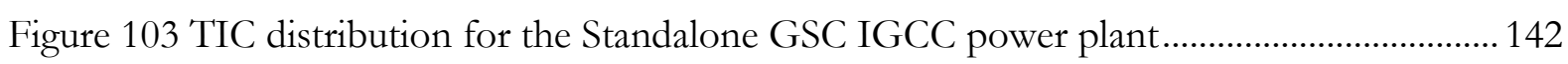

Figure 104 LCOE build up for the Standalone GSC IGCC power plant....................................... 142

Figure 105 Block flow diagram of the GSC IGCC power plant with NG extra firing ................ 143

Figure $106 \mathrm{CO}_{2}$ emissions distribution for the GSC with Extra Firing IGCC power plant ........ 145

Figure 107 Exergy distribution in \% of the GSC with Extra Firing IGCC power plant ............. 146

Figure 108 TIC distribution for the GSC with Extra Firing IGCC power plant .............................147

Figure 109 LCOE build up for the GSC with Extra Firing IGCC power plant ...........................147

Figure 110 Block flow diagram of the Integrated Gasification GSC-HAT power plant.............. 148

Figure 111 Exergy distribution of the Integrated Gasification GSC-HAT power plant ............. 150

Figure 112 Exergy flow diagram of the reduction (above) and oxidation (below) sections of the

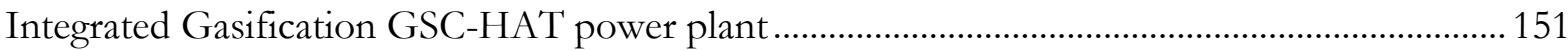

Figure 113 Integration of MAWGS, GSC and GT with a reduction gases recuperator ...............153

Figure 114 Block flow diagram of the GSC-MAWGS IGCC plant showing different configuration

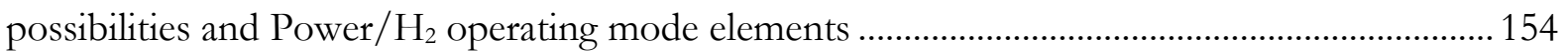

Figure 115 Total exergy distribution for the GSC-MAWGS IGCC power plant with Shell gasifier 157

Figure 116 TIC cost distribution for the GSC-MAWGS IGCC power plant with Shell gasification 158

Figure 117 LCOE build-up for the GSC*MAWGS IGCC power plant with Shell gasification 158 Figure 118 Temperature profile and carbon conversion in the pregasifier unit. 159 
Figure 119 Total exergy distribution for the GSC-MAWGS IGCC power plant with Pregasifier and HTW gasification

Figure 120 TIC distribution of the GSC-MAWGS IGCC power plant with Pre-gasifier and HTW gasification

Figure 121 LCOE build-up for the GSC-MAWGS IGCC power plant with Pregasifier\& HTW gasification

Figure 122 Total exergy distribution for the GSC-MAWGS IGCC power plant with GE gasification

Figure 123 TIC distribution for the GSC-MAWGS IGCC power plant with GE gasification.. 167

Figure 124 LCOE build-up for the GSC-MAWGS IGCC power plant with GE gasification... 167

Figure 125 Block flow diagram of the OPPC IGCC power plant ................................................. 168

Figure $126 \mathrm{CO}_{2}$ Emissions breakdown for the OPPC IGCC power plant .................................... 170

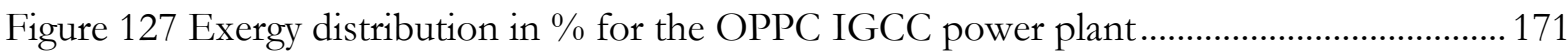

Figure 128 TIC distribution of the OPPC IGCC power plant ....................................................... 172

Figure 129 LCOE build up for the OPPC IGCC power plant......................................................... 172

Figure 130 Block flow diagram of the Composite: GSOP-GSC IGCC power plant.................... 173

Figure $131 \mathrm{CO}_{2}$ emissions distribution for the Composite IGCC power plant ............................. 175

Figure 132 Exergy distribution in \% for the Composite IGCC power plant ................................. 176

Figure 133 Exergy flow diagram for the Composite IGCC power plant ....................................... 176

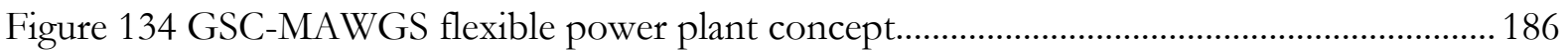

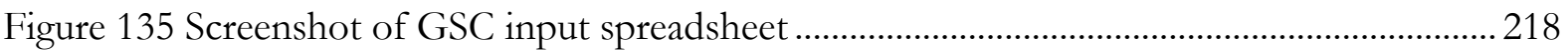

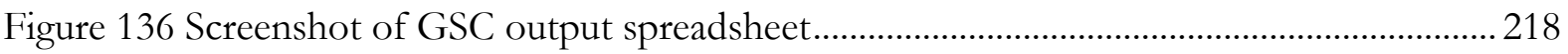

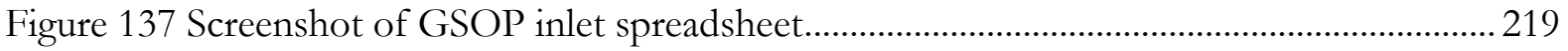

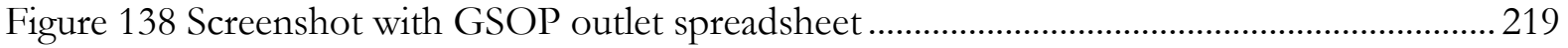

Figure 139 Detailed schematic of the Unabated IGCC power plant .............................................220

Figure 140 Detailed schematic of the Pre-combustion $\mathrm{CO}_{2}$ capture IGCC power plant............. 222

Figure 141 Detailed schematic of the Advanced Unabated IGCC power plant ........................... 224

Figure 142 Detailed schematic of the Advanced Pre-combustion $\mathrm{CO}_{2}$ capture IGCC power plant

226

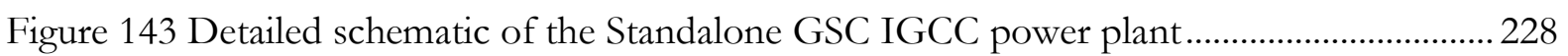

Figure 144 Detailed schematic of the GSC with Extra Firing IGCC power plant ........................ 230

Figure 145 Detailed schematic of the Integrated Gasification GSC-HAT power plant. Reduction

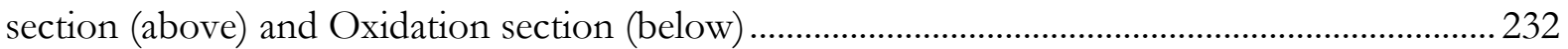

Figure 146 Detailed schematic of the GSC-MAWGS IGCC power plant with Shell gasification

Figure 147 Detailed schematic of the GSC-MAWGS IGCC power plant with Pregasifier and HTW

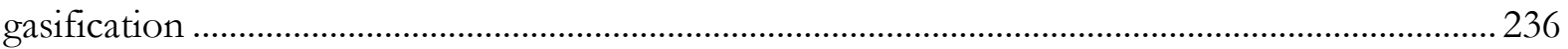

Figure 148 Detailed schematic of the GSC-MAWGS IGCC power plant with GE gasification238 Figure 149 Detailed schematic of the Oxygen Production Pre-combustion (OPPC) IGCC power

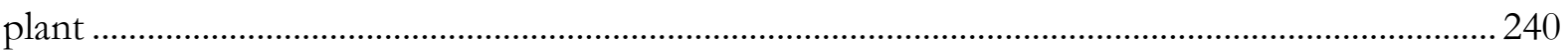

Figure 150 Detailed schematic of the Composite: GSOP-GSC IGCC power plant.....................242 


\section{List of Tables}

Table 1 Gas'Tech work distribution

Table 2 Thermal efficiencies for power plants without capture and post-combustion $\mathrm{CO}_{2}$ capture with MEA [6]

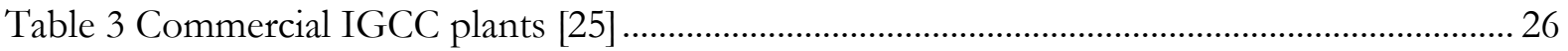

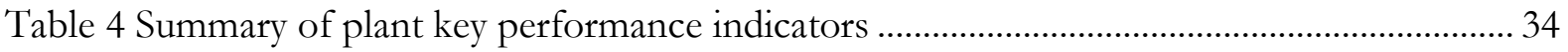

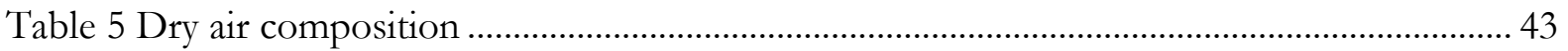

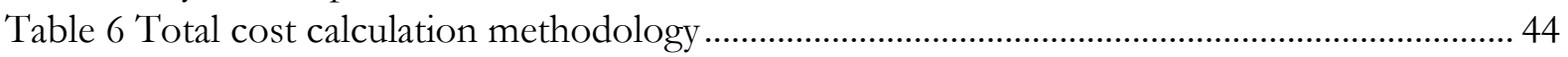

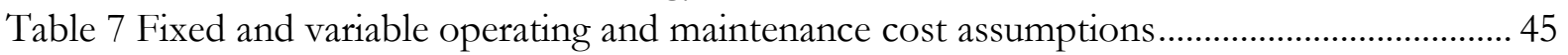

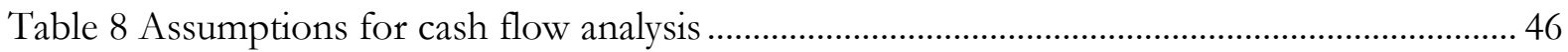

Table 9 Heterogeneous reactions and kinetic rates for Ilmenite oxygen carrier ............................. 59

Table 10 Heterogeneous reactions and kinetic rates for Nickel Oxide oxygen carrier .................. 59

Table 11 Heterogeneous reactions and kinetic rates for CAM oxygen carrier ................................. 59

Table 12 Property summary of the different oxygen carriers employed ............................................ 60

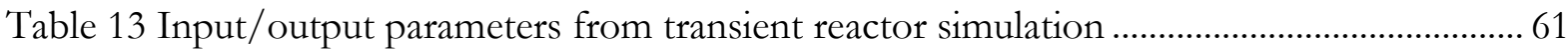

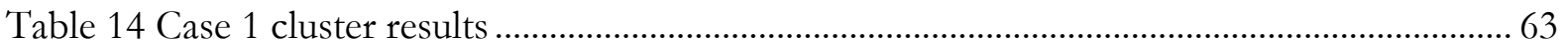

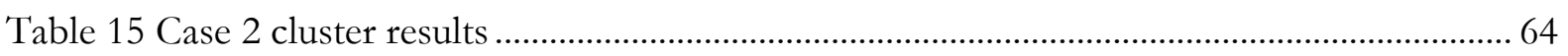

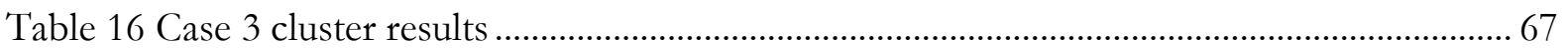

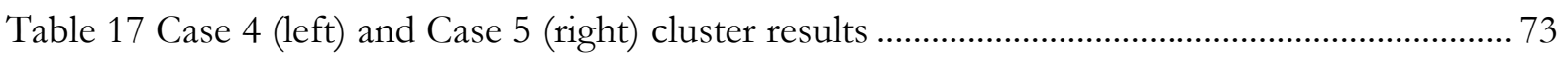

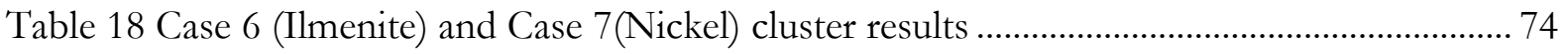

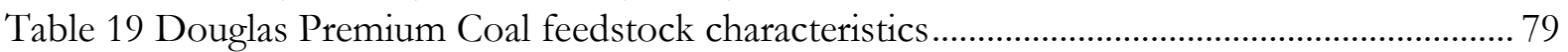

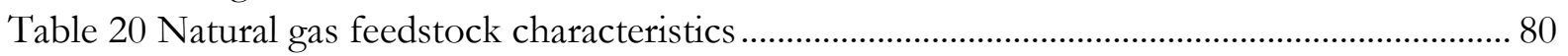

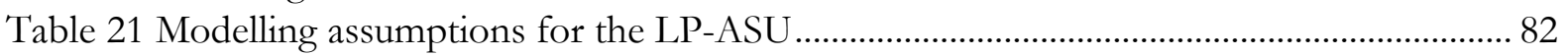

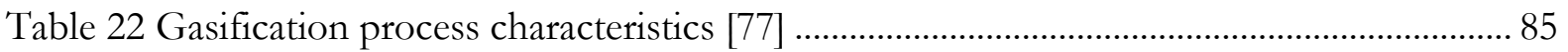

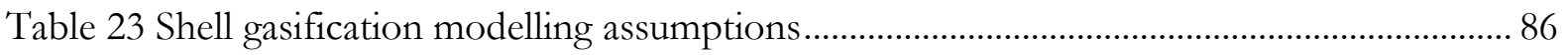

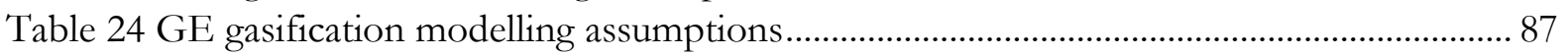

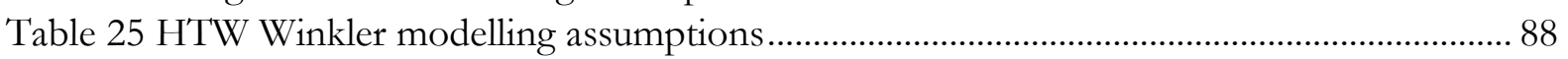

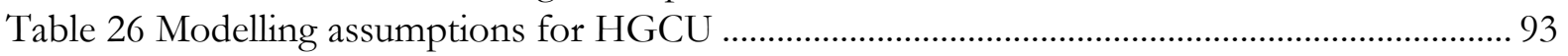

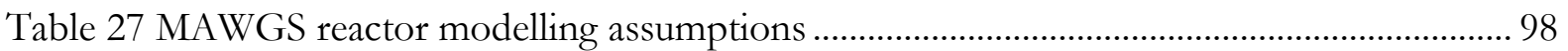

Table 28 Henry's Constant parameters for different components................................................... 104

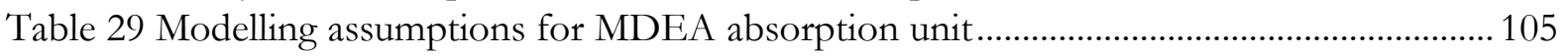

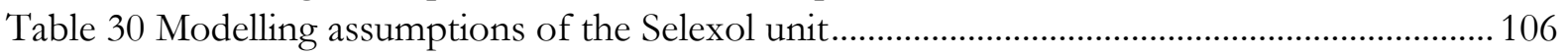

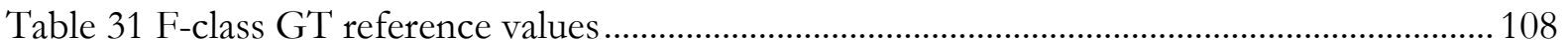

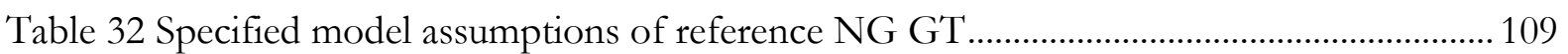

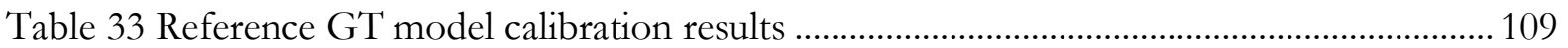

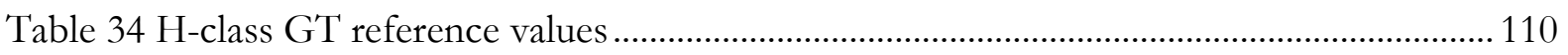

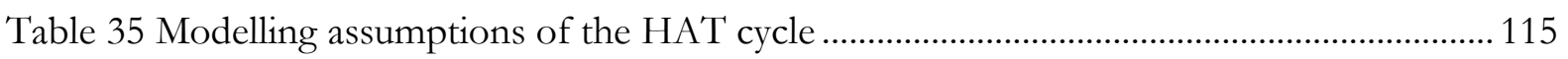

Table 36 Steam cycle modelling assumptions for introductory and advanced plants ...................116

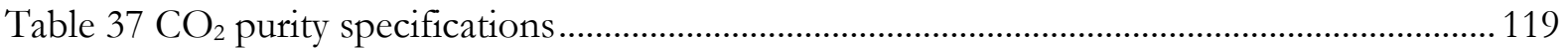

Table 38 Modelling assumptions of a $\mathrm{CO}_{2} / \mathrm{H}_{2}$ compression unit................................................. 120

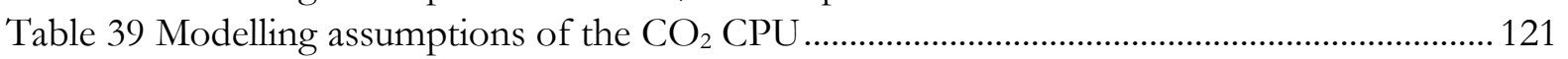

Table 40 Energy breakdown of the Unabated IGCC plant............................................................... 123

Table 41 Total exergy breakdown per system of the Unabated IGCC plant...................................124

Table 42 Economic results for the Unabated IGCC power plant.................................................. 125

Table 43 Energy breakdown of the Pre-combustion $\mathrm{CO}_{2}$ capture IGCC power plant ................ 127

Table $44 \mathrm{CO}_{2}$ emissions performance of the pre-combustion $\mathrm{CO}_{2}$ capture IGCC power plant 128

Table 45 Total exergy breakdown for the Pre-combustion $\mathrm{CO}_{2}$ capture IGCC power plant..... 128 
Table 46 Economic results for the Pre-combustion $\mathrm{CO}_{2}$ capture IGCC power plant ................. 129

Table 47 Energy breakdown for the Advanced Unabated IGCC power plant .............................. 132

Table 48 Exergy results for the Advanced Unabated IGCC power plant....................................... 133

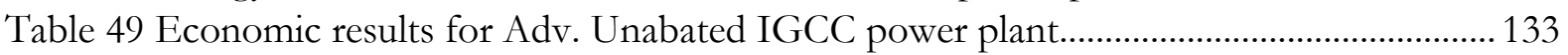

Table 50 Energy breakdown for the Advance Pre-combustion $\mathrm{CO}_{2}$ capture IGCC power plant 135

Table $51 \mathrm{CO}_{2}$ emissions performance of the Advanced Pre-combustion $\mathrm{CO}_{2}$ capture IGCC power

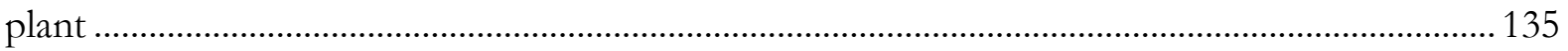

Table 52 Exergy balance for the Advance Pre-combustion $\mathrm{CO}_{2}$ capture IGCC power plant.... 136 Table 53 Economic results for the Adv. Pre-combustion $\mathrm{CO}_{2}$ capture IGCC power plant....... 136 Table 54 Energy breakdown of the Standalone GSC IGCC power plant ...................................... 138

Table $55 \mathrm{CO}_{2}$ emissions performance of the Standalone GSC IGCC power plant ...................... 139

Table 56 Total exergy breakdown for the Standalone GSC IGCC power plant............................ 140

Table 57 Economic results for the Standalone GSC IGCC power plant......................................... 142

Table 58 Energy breakdown of the GSC with Extra Firing IGCC power plant ........................... 144

Table $59 \mathrm{CO}_{2}$ emissions performance of the GSC with Extra Firing IGCC power plant .......... 144

Table 60 Exergy distribution for the GSC with Extra Firing IGCC power plant ......................... 145

Table 61 Economic results for the GSC with Extra Firing IGCC power plant..............................146

Table 62 Energy breakdown of the Integrated Gasification GSC-HAT power plant................... 148

Table $63 \mathrm{CO}_{2}$ emissions performance of the Integrated Gasification GSC-HAT power plant 149

Table 64 Exergy breakdown for the Integrated Gasification GSC-HAT power plant ................. 150

Table 65 Energy breakdown for the GSC-MAWGS IGCC power plant with Shell Gasification 155

Table 66 Steam export in GSC-MAWGS IGCC plant with Shell gasifier in $\mathrm{H}_{2}$ mode with small GT

Table $67 \mathrm{CO}_{2}$ emissions performance of the GSC-MAWGS IGCC power plant with Shell gasifier

Table 68 Exergy efficiency for the GSC-MAWGS IGCC power plant with Shell gasification.. 156 Table 69 Economic results for the GSC-MAWGS IGCC plant with Shell gasification.............. 157 Table 70 Energy breakdown for the GSC-MAWGS IGCC power plant with Pregasifier and HTW gasification ...

Table $71 \mathrm{CO}_{2}$ emissions performance of the GSC-MAWGS IGCC power plant with Pregasifier and HTW gasifier.

Table 72 Exergy efficiency for the GSC-MAWGS IGCC power plant with Pregasifier and HTW gasification

Table 73 Economic results for the GSC-MAWGS IGCC power plant with Pre-gasifier and HTW gasification 162

Table 74 Energy breakdown for the GSC-MAWGS IGCC power plant with GE gasifier ........ 164 Table 75 Steam export stream for the GSC-MAWGS IGCC power plant with GE gasification in $\mathrm{H}_{2}$ operation mode

Table $76 \mathrm{CO}_{2}$ emissions performance for the GSC-MAWGS IGCC power plant with GE

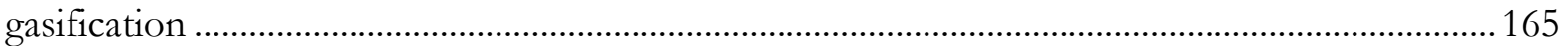

Table 77 Exergy efficiency of the GSC-MAWGS IGCC with GE gasifier power plant............. 165

Table 78 Economic results for the GSC-MAWGS IGCC power plant with GE gasification.... 166

Table 79 Energy breakdown of the OPPC IGCC power plant......................................................... 169

Table $80 \mathrm{CO}_{2}$ emissions performance of the OPPC IGCC power plant............................................170

Table 81 Total exergy breakdown for the OPPC IGCC power plant ...........................................170 
Table 82 Economic results for the OPPC IGCC power plant

Table 83 Energy breakdown for the Composite IGCC power plant.............................................. 173

Table $84 \mathrm{CO}_{2}$ emissions performance of the Composite IGCC power plant ................................. 174

Table 85 Total exergy distribution for the Composite IGCC power plant..................................... 175

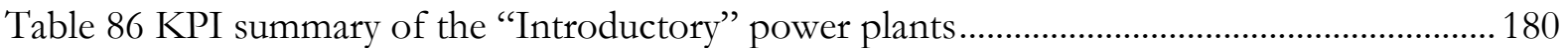

Table 87 Qualitative assessment of the "Introductory" power plants ............................................... 181

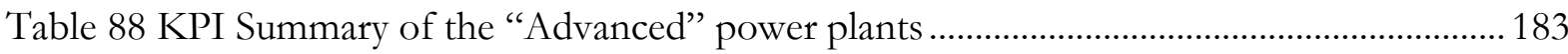

Table 89 Stream summary of the Unabated IGCC power plant ........................................................221

Table 90 Stream summary of the Pre-combustion $\mathrm{CO}_{2}$ capture IGCC power plant ....................223

Table 91 Stream summary of the Advance Unabated IGCC power plant.....................................225

Table 92 Stream summary of the Pre-combustion $\mathrm{CO}_{2}$ capture IGCC power plant.................... 227

Table 93 Stream summary of Standalone GSC IGCC power plant..................................................229

Table 94 Stream summary of the GSC with Extra Firing IGCC power plant .............................. 231

Table 95 Stream summary of the Integrated Gasification GSC-HAT power plant .......................233

Table 96 Stream summary for the GSC-MAWGS IGCC power plant with Shell gasification... 235 Table 97 Stream summary of the GSC-MAWGS IGCC power plant with Pre-gasifier and HTW

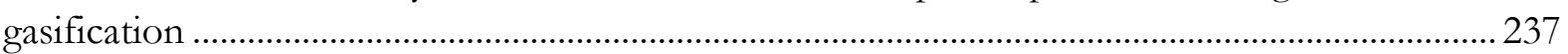

Table 98 Stream summary of the GSC-MAWGS IGCC power plant with GE gasification ...... 239 Table 99 Stream summary for the Oxygen Production Pre-combustion (OPPC) IGCC power plant

Table 100 Stream summary for the Composite: GSOP-GSC IGCC power plant ........................ 243

Table 101 Reference capacities, scaling exponents (Introductory/Advanced) and costs for the Unabated IGCC power plants for the year 2011 [6].

Table 102 Reference capacities, scaling exponents (Introductory/Advanced) and for the power plants with $\mathrm{CO}_{2}$ capture for the year 2011 [6]. 